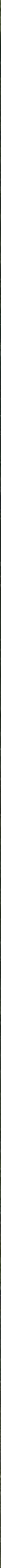




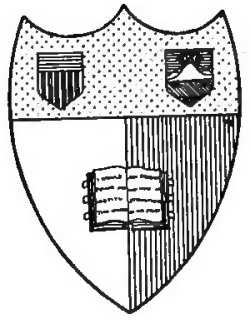

2Naw 糸ark

State Cுallege of Agrirulture

- At Gnernell Hniuergity

武thaca, 站.

\section{Jithrary}




\section{Cornell University Library}

QL 49.56471910

The world of animal life,

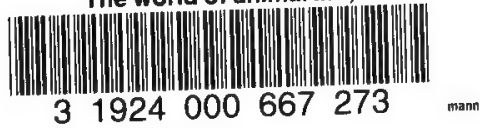




\section{Cornell University Library}

The original of this book is in the Cornell University Library.

There are no known copyright restrictions in the United States on the use of the text.

http://www.archive.org/details/cu31924000667273 
The World of Animal Life 




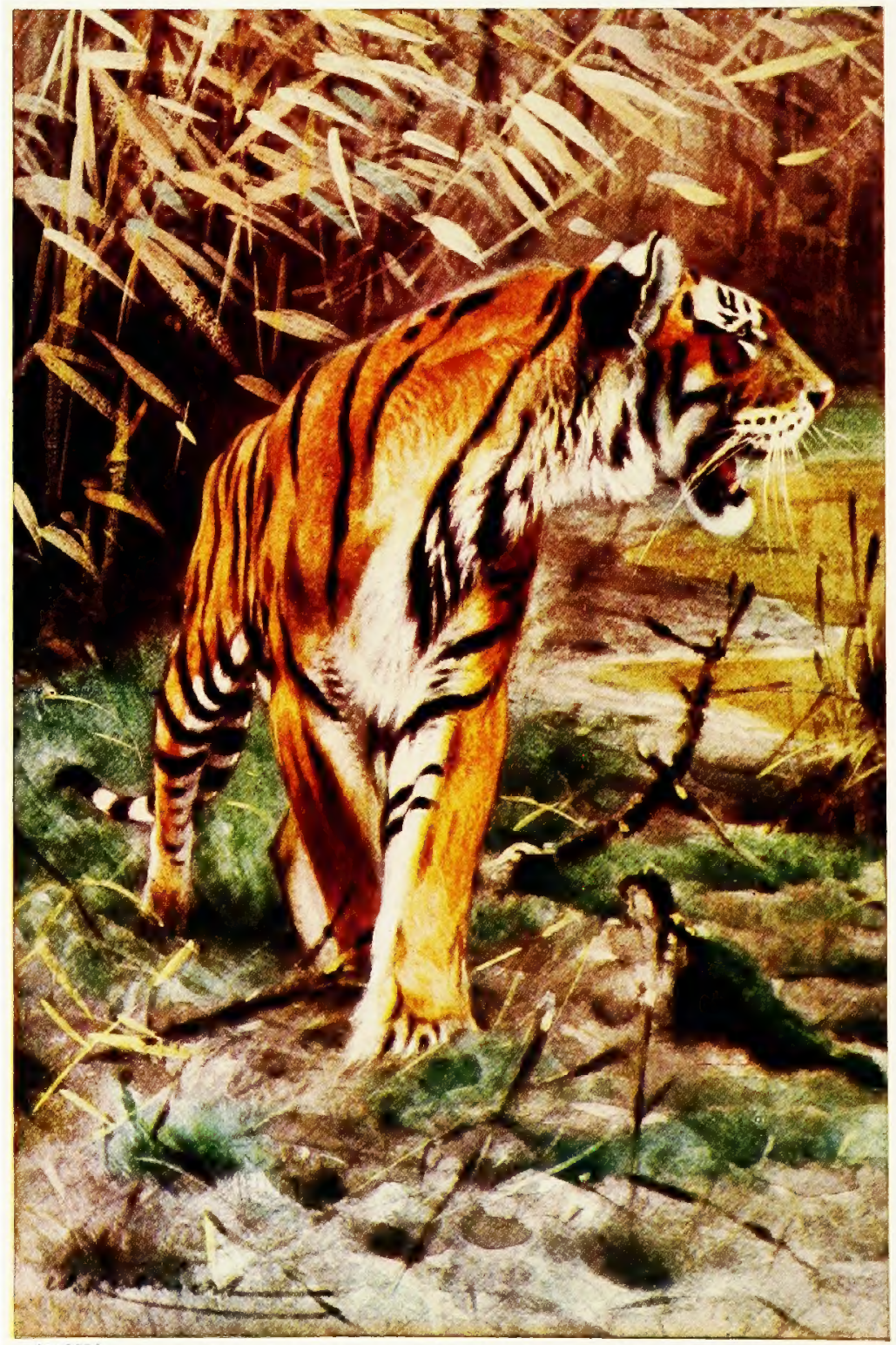

( 31568 )

TIIE IFENGAL TIGER 


\title{
THE WORLD OF
}

\section{ANIMAL LIFE}

\author{
EDITED BY \\ FRED SMITH \\ Author of "The Boyhood of a Naturalist" \\ "The Animal Book"
}

With Eight Coloured Plates and 216 Illustrations

NEW EDITION

BLACKIE AND SON LIMITED LONDON GLASGOW DUBLIN BOMBAY 



\title{
CONTENTS
}

How Animals are Classified

\section{THE VERTEBRATES}

\author{
MAMMALS \\ General Description and Classification \\ The Primates. The Gorilla-The Chimpanzee-The Orang-Utan- \\ Gibbons-Spider Monkeys-Baboons-Lemurs \\ HAND-WINGED ANIMALS, OR BATS \\ InSECT-EATERS. The Hedgehog-The Mole-Shrews \\ Carnivores, OR Flesh-EATERs. The Lion-The Tiger-The Leopard \\ - The Hunting Leopard-The Jaguar-The Puma-Hyænas-The \\ Collie Dog-The Wolf-The Jackal-The Fox-The Polar Bear- \\ The Brown Bear-The Sloth Bear-The Weasel-The Badger-- \\ The Otter-Seals
}

Ungulates, OR HOOFED Animals. The Ox-The Sheep-The Goat-

The Antelopes-The Giraffe - The Deer-The Reindeer-The Camel

- The Horse-The Ass - The Zebra-The Elephant-The Tapir-The

Rhinoceros-The Pig-The Hippopotamus -

Cetacea. The Whale-The Porpoise

Rodents. The Squirrel-The Beaver-The Rat-The Harvest Mouse--

The Porcupine-The Hare-The Rabbit

Edentates. The Sloth-The Armadillo- The Ant-eater

Marsupials. The Kangaroo-The Opossum

MONOTREMES. Ornithorhynchus

\section{BIRDS}

GeNERAL DESCRIPTION

Classification of BiRds. Orders of Birds

PASSERES. The Crows-The Rook-The Raven and Carrion-crow-The Birds of Paradise-The Starlings-Finches-The Sparrow-The Skylark-Titmice-Thrushes-The Song Thrush-The Redbreast-The Nightingale-The Wrens-The Common Wren-The Swallow

PICARIE. The Woodpeckers-The Cuckoo-Humming-birds-The Nightjar-The Kingfisher 
PSITTACI. The Parrot

STRIges. The Barn-owl

Accipitres. The Kestrel Hawk-The Eagle-Vultures

Herodiones. The Herons - The Stork

Odontoglosser. The Flamingoes

ANSERES. The Duck

Columbe. The Pigeon

Gallinæe. The Partridge--The Pheasant--Pea-fowl

FULICARIÆ. The Coot

Gavies. The Guils 266

Impennes. The Penguins 269

Ratite. The Ostrich

REPTILES

General Description and Classification

Crocodilia. The Crocodiles

Chelonia. The Tortoises-Turtles - 280

Squamata. Lizards-The Iguana The Blind-worm-The Chameleons-

The Snakes - Pythons, Boas, Anacondas-The Cobras-Cobra-di-

Capello-Vipers

AMPHIBIANS OR BATRACHIANS

General Description and Classification

ECAUdATA. The Frogs-The Toads

Caudata. Newts and Salamanders

\section{FISHES}

General Description and Classification

Teleostomi. The Sword-fish-Flying-fish-The Cod-Flat-fish-Eels-

The Pike--The Herring-The Salmon

ELASMOBRANCHII. Sharks

\section{THE INVERTEBRATES}

Classification

INSECTS

General Description and Classification

Hymenoptera. Ants-Wasps-Ichneumon Flies-The Hive Bee 
DIPTERA. Gnats-The Daddy-long-legs

LePidoptera. The Peacock Butterfly-Looper Caterpillars

COLEOPTERA. The Great Water-beetle-Wire-worms-The Glow-worm-

Lady-birds

NEURoptera. Caddis-flies

Orthoptera. The Dragon-fly--The Earwig 370

Rhynchota. The Aphis $37 \mathrm{I}$

MYRIOPODA

Centipedes and Millipedes -

ARACHNIDA

General Description

ARANEE. The Garden Spiders-The Trap-door Spiders-The Hunting Spider-The Water Spider

CRUSTACEA

General Description. The Lobster

ECHINODERMATA

STONE-Lilies, StaR-FISHES, AND SEA-URChins

MOLLUSCA

General Description and Classification 393

CEPHalopoda. Cuttle-fishes 394

Gasteropoda. Snails-Whelks

Pelecypoda. The Piddock or Pholas--The Ship-worm or Teredo

VERMES

ANNELIDA. The Earthworm

COELENTERATA

JELLY-FISH AND SEA-ANEMONES

PORIFERA

THE SPONGES

PROTOZOA

General Description 


\section{LIST OF COLOURED PLATES}

The Bengal Tiger

Frontispiece

LION SEIZING PREY

facing page 46

FAMILY OF COMMON SQUiRRELS

,$\quad 158$

British Perching Birds

" , 202

KINGFISHERS

" $\quad 230$

The Coral Snake (S. America and IV. Indies)

292

SALMON

$, \quad, \quad 326$

A Tidal Pool with Familiar Marine Animals , " 402 vili 


\section{THE \\ WORLD OF ANIMAL LIFE}

\section{HOW ANIMALS ARE CLASSIFIED}

In this opening chapter we shall learn something about the Classification of Animals; or, in other words, about the way in which animals are arranged by men of science.

Now, perhaps you will think that this is a very dull and dry subject, and that it cannot be of interest to those who know nothing about it. But in reality it is not dull at all. Indeed, it is almost as interesting to find out how different animals are related to one another, as it is to learn about their ways and habits; for in doing so we are led to examine their bodily frames, and to notice how wonderfully every part is suited to the life which the animals have to lead.

Some of us may think that it cannot be necessary to know anything about this subject, and that anyone who is really fond of animals can study them quite well, without understanding their natural arrangement. But this, as we shall presently see, is a great mistake.

Suppose that a general were placed in command of a large army, and found that his men, instead of being divided into "brigades", and "regiments", and "companies", were dressed in all kinds of uniforms, and mingled together in one great crowd, without any order or division into smaller bodies. In this condition he would be unable to lead them to battle; and the very first necessity would be to reduce this vast body of men to order 
and arrangement. Until this had been done they could not even be instructed in their different duties.

We may compare a naturalist to such a general; for all the many animals in the world form, as it were, a huge army. His first task, then, must be to arrange these animals in some way, so that he may be able, not only to study them more easily himself, but to inform others of his discoveries.

How is he to do this?

We may answer that question by remembering what the general would do with his soldiers.

Would he not look at their uniforms? Some of his men might have green facings on their tunics; he would put these together in orie regiment. Others might have yellow facings; he would put these together into another regiment; and so on. And so he would arrange them in classes, as it were, according to their uniforms.

We may do exactly the same with animals, if we consider their bodily characteristics as their uniforms. That is, we may put together in a "class" all those which are formed alike.

We have not, indeed, to arrange them for ourselves at all. We have only to find out how Nature has arranged them already, and to put together in different classes such animals as she has made to resemble one another.

Now, how would our general set to work, when he began to arrange his army? Clearly, he would first of all separate it into two or three great groups, such groups, in fact, as those which we call divisions. He might, for instance, put into one division all the soldiers who wore red uniforms, into a second all those who wore blue, and into a third all those who wore gray or green. After he had done this, he would separate these large divisions into a number of brigades, and those again into regiments. And he would be guided throughout by the uniforms which the soldiers wore.

The naturalist, remembering that the bodily characteristics of animals are their uniforms, proceeds upon exactly the same plan. He very quickly finds that all animals may be placed in two great groups. One of these contains all those that possess bones, while the other includes all those that do not. And so we have, as it were, the divisions in our animal army. 
Of all the bone-structures in the body, the most important is the spine, or backbone. This is in part hollow, and through it run the nerves connected with all the lower parts of the body. If you were to break your spine, you would no longer be able to walk or stand, or use your limbs at all. And you would lose all sense of feeling in them too, so that they might be wounded, or burned, or even cut off, without paining you in the least.

The spine is not a single bonc, but is made up of a number of little bones, which are fastened to one another in such a manner that the whole can be curved or bent. In your own spine there are thirty-three of these little bones, which are called "vertebræ".

As every animal which possesses bones must have a spine, or spinal or vertebral column, as it is called, and as the spine is always made up of these little vertebra, those animals that have bones are called VERTEBRATES, while those that have not are called INVERTEBRATES.

These two divisions are separated into smaller groups, which we call classes. The classes, therefore, correspond with the brigades in an army.

In the VERTEBRATES there are five of these classes, namely:

(I) Mammals. These suckle their young, and have hearts containing four chambers.

(2) Birds. These are covered with feathers, and do not suckle their young, which they rear from eggs.

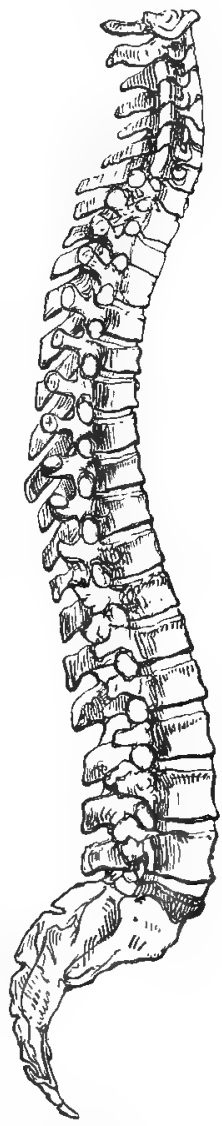

Human Spine or Backbone

(3) Reptiles. These are cold-blooded, and possess hearts with only three chambers.

(4) Batrachians. These resemble reptiles, but pass through a tadpole stage before attaining to their perfect form; and

(5) Fishes. These live in the water, breathe by means of gills, and have only two chambers in their hearts. 
The InVertebrates are also divided into classes, such as:

(I) Molluscs, whose bodies are soft and enclosed in a membrane called the "mantle".

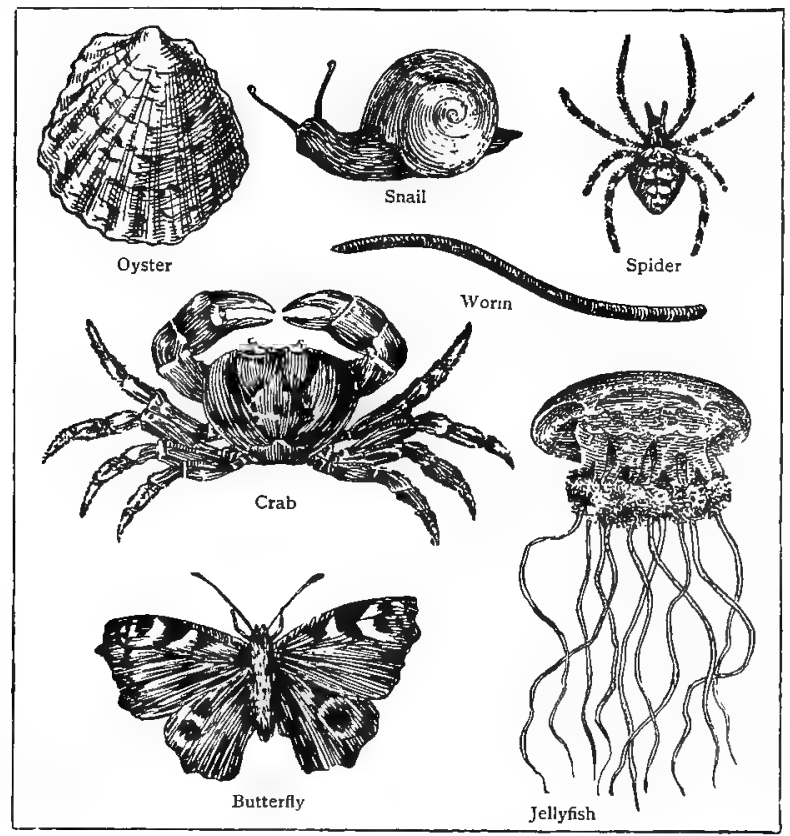

Some Animals without Backbones

(2) Insects, which possess six legs and two or four wings, and whose bodies are made up of a number of segments or articulations.

(3) Crustaceans, which are covered with a hard shelly armour: besides other classes.

The common snail is a good example of the first of these, the butterfly of the second, and the crab of the third.

We have now seen how animals are grouped, first into divisions, and then into classes. But there is still a great deal to be done, for each of these classes contains a very great number of animals, which cannot all be closely related to one another. We find. 
therefore, that each class is divided into smaller groups, which we call orders, and which are distinguished by some feature in their bodily structure of less importance than that which forms the mark of the class.

In the class of the Mammals, for example, we have the order of the Beasts of Prey. We may know these by the character of their teeth, which are formed, not so much for chewing the flesh of their victims, as for tearing it from their bones. In the class of Insects, again, we have the order of the Beetles, whose upper

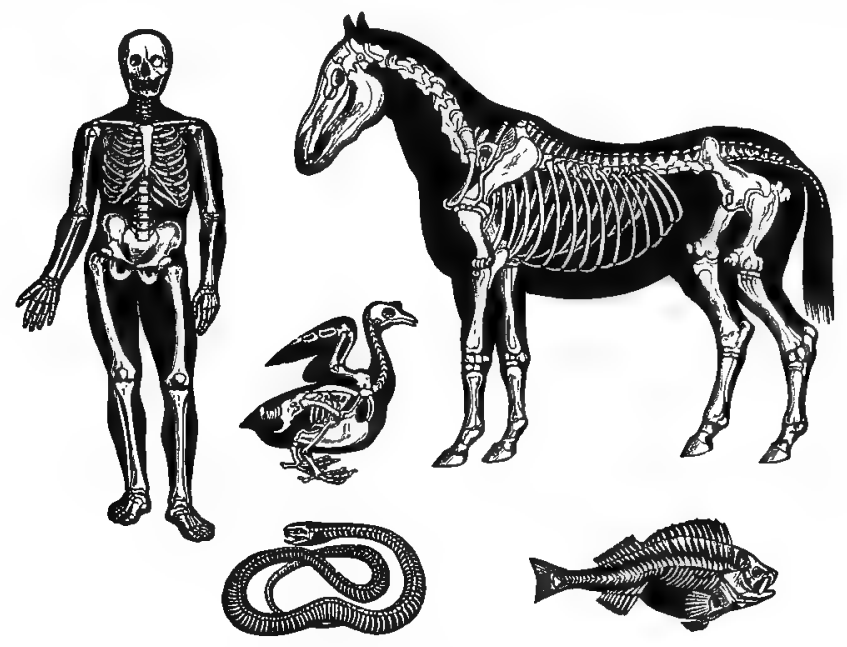

Some Backboned Animals

wings are hard and horny, and are only used to protect the lower pair when not in use.

An order, in fact, is a small class, and a class is a small division. And as a class of animals answers to the brigade of an army, so an order answers to a regiment.

But even this is not enough, for there are a great many beasts of prey, for instance, that differ from one another in many important respects. Thus, a hyæna is very different from a lion, and a seal is very different from a wolf, and a bear from a panther.

So we find that each order is naturally divided into smaller 
groups still, which we call families. Thus, in the order of the Beasts of Prey we have the families of the Cats, the Dogs, the Bears, and the Seals; in the order of the Beetles we have the families of the Water-beetles, the Long-horned beetles; and so on. And these families answer, as it were, to the companies of a regiment.

If we were required to describe a lion, we could do so by saying, "It belongs to the family of the Cats, to the order of the Beasts of Prey, to the class of the Mammals, and to the great division of the VERTEBRATES".

In the same way, if we were asked to describe that pretty green beetle which we sometimes find on willow trees, and which smells so sweetly that it is called the "musk" beetle, we could say, "It belongs to the family of the Long-horns, to the order of the Beetles, to the class of the Insects, and to the division of the INVERTEBRATES".

But in order to complete our natural arrangement, we must carry out our simile of the ammy a little further. An army is made up, as we have seen, of larger or smaller groups of men which have certain distinguishing characteristics. But some are more characterized than others. Some in cach greater division are "colonels", or "captains", or "sergeants". Now colonels, captains, sergeants, or any specified officers, being smaller groups than "families" of soldiers, might be described as genera; a genus being the group of colonels, or the group of captains, or of sergeants; i.e. all colonels are of one genus, all captains of another, and so on. But then, of course, a colonel or captain might be of this or that company of "foot", or "mounted", or otherwise, and here we come to the end of our classification, for a captain of the "foot" would be an indizidual of this or that kind; and a colonel or captain of this or that kind would be a species; a species is an individual kind of any genus.

And so we have exactly carried out the plan of our imaginary general. For all these dizisions, and classes, and orders, and families, and genera, and species, are marked by some feature in the uniform; that is, in the bodily characteristics of the different beings represented. 
And, just as a general can tell to what company, regiment, brigade, and division a soldier belongs, by looking at his uniform, so a naturalist can tell to what genus, family, order, class, and division an animal belongs, by looking at its bodily characteristics.

\section{THE VERTEBRATES}

\section{MAMMALS}

The animal army, as we have seen, is divided by naturalists into two great halves-the Vertebrates and Invertebrates. The principal difference between these two divisions is, that every Vertebrate possesses bones and a spinal column of some kind or other, while the Invertebrates have no inside skeleton at all. In the Invertebrates the hard parts are, when they exist, usually placed outside the body; as, for instance the shell of the crab or lobster or snail, or the horny covering of beetles or other insects. Another difference is, that the Vertebrates have never more than four limbs, while the Invertebrates may possess a large numberin some cases amounting to hundreds. Lastly, every vertebrate animal possesses a distinct heart, which in many of the Invertebrates is absent. There are other differences between these two great divisions with which we need not trouble ourselves at present.

Mammals are the highest of the five classes that form the Vertebrate division. By highest we mean that the bodies of the Mammals contain as a rule a larger number of parts, each intended for a special use, than those of the other four classesbirds, reptiles, batrachians, and fishes.

The Mammals vary greatly in size and shape, from the tiny mouse to the huge whale, which, as we shall see later on, is not a fish, but a Mammal living in the water. But whatever their differences, all Mammals have certain points of resemblance to one another. In the first place, they suckle their young; secondly, 


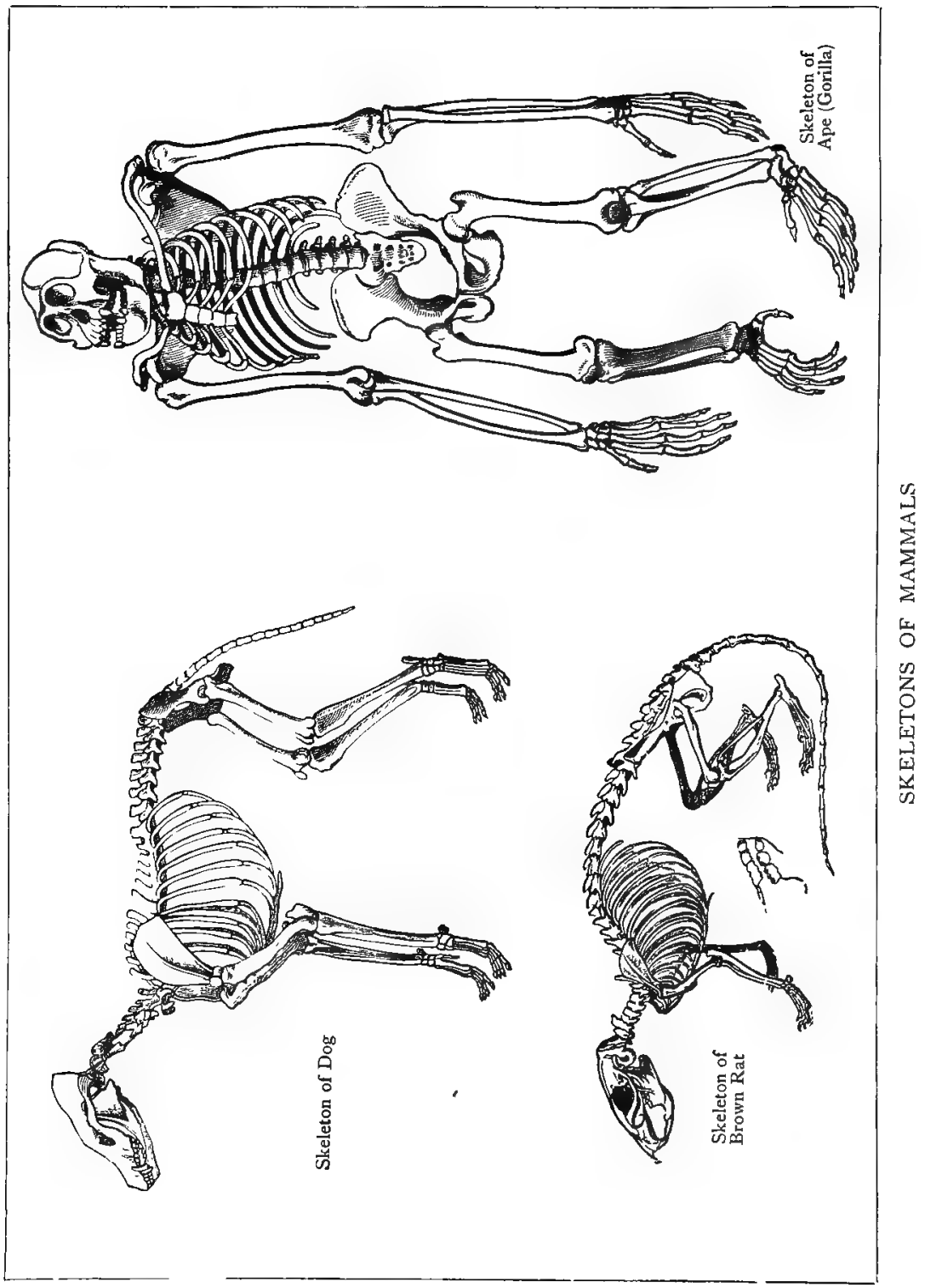


they have warm blood which circulates through their bodies from a four-chambered heart; thirdly, they breathe air by means of lungs.

The Mammals are usually divided into eleven orders:

(I.) Primates (such as the ape, monkey, and lemur).

(2.) Chiroptera, or hand-winged animals (bats).

(3.) Insectivores, or insect-eaters (such as the mole and hedgehog).

(4.) Carnivores, or flesh-eaters (such as the lion, tiger, cat, dog, and bear).

(5.) Ungulates, or hoofed animals (such as the horse, rhinoceros, sheep, pig, and ox).

(6.) Sirenia (such as the sea-cow and dugong).

(7.) Cetacea (such as the whale, dolphin, and porpoise).

(8.) Rodents, or gnawers (such as the rat, mouse, beaver, porcupine, and rabbit).

(9.) Edentates, or toothless animals (such as the sloth, armadillo, and ant-eater).

(IO.) Marsupials, or pouched animals (such as the kangaroo and opossum).

(I I.) Monotremes, or egg-laying animals (such as the ornithorhynchus).

\section{THE PRIMATES \\ THE GORILLA}

The Primates form that order of the class of Mammals that approaches most nearly to Man. In fact, if we consider only his bodily structure, and take no account of his intellect, Man himself must be included among the Primates. To the Primates belong all the members of the ape tribe, the monkeys, and the lemurs. Their home is, as a rule, in the dense forests of tropical countries, very few being found in the colder regions of the earth.

The most important of all the Primates is the great ape which we call the Gorilla. It is the largest and fiercest of all the apes, 
and lives in the depths of the thick, dark forests of Central Africa, where the footstep of man is seldom heard. A fully-grown gorilla, when standing upright, is a little more than six feet in height. As its body is so stout and broad, and its great hairy arms so long and powerful, it is even larger than Man himself; that is, it is the largest of the Primates.

But a gorilla cannot, without aid, stand quite upright. Its feet are not made like ours, with soles that can rest flat upon the ground, but are like huge hands, with thumbs instead of great toes. Like nearly all other apes, it lives principally in trees, and has feet which can firmly grasp the branches.

For climbing, its thumbed fect are very useful, and can be employed just like a second pair of hands. But when the gorilla walks upon the ground, it can only tread on the sides of its feet, and hobbles along as awkwardly as if it were lame.

We do not know much about the habits of the gorilla, for the forests in which it lives are so thick, that it is not easy to watch it. It is such a savage animal, too, that, even if we could do so, it would not be safe to approach it. The natives of the countries in which it lives are very much afraid of it, and say that it is more to be dreaded than even a lion. And it is so active and so strong, that a fully-grown gorilla has never been taken alive.

Young gorillas have, however, often been captured, and several have been brought to England. One of these, called "Gena", lived for nearly three weeks in the Crystal Palace. She was quite a timid little animal, only about two years old, and lived in a large cage with a chimpanzee, which was her companion and playmate.

When "Gena" was alarmed, she always tried to hide herself behind the chimpanzee, who took great care of her, and would not allow anyone to interfere with her. And at night the two animals used to sleep curled up together.

For some time it was hoped that "Gena" might live to grow up; for she ate well, and seemed to thrive in her warm cage. But one chilly day she caught a bad cold, which settled upon her chest; and in a very few days poor "Gena" was no more. This has been the invariable fate of some half a dozen young gorillas that have been brought to Europe. 


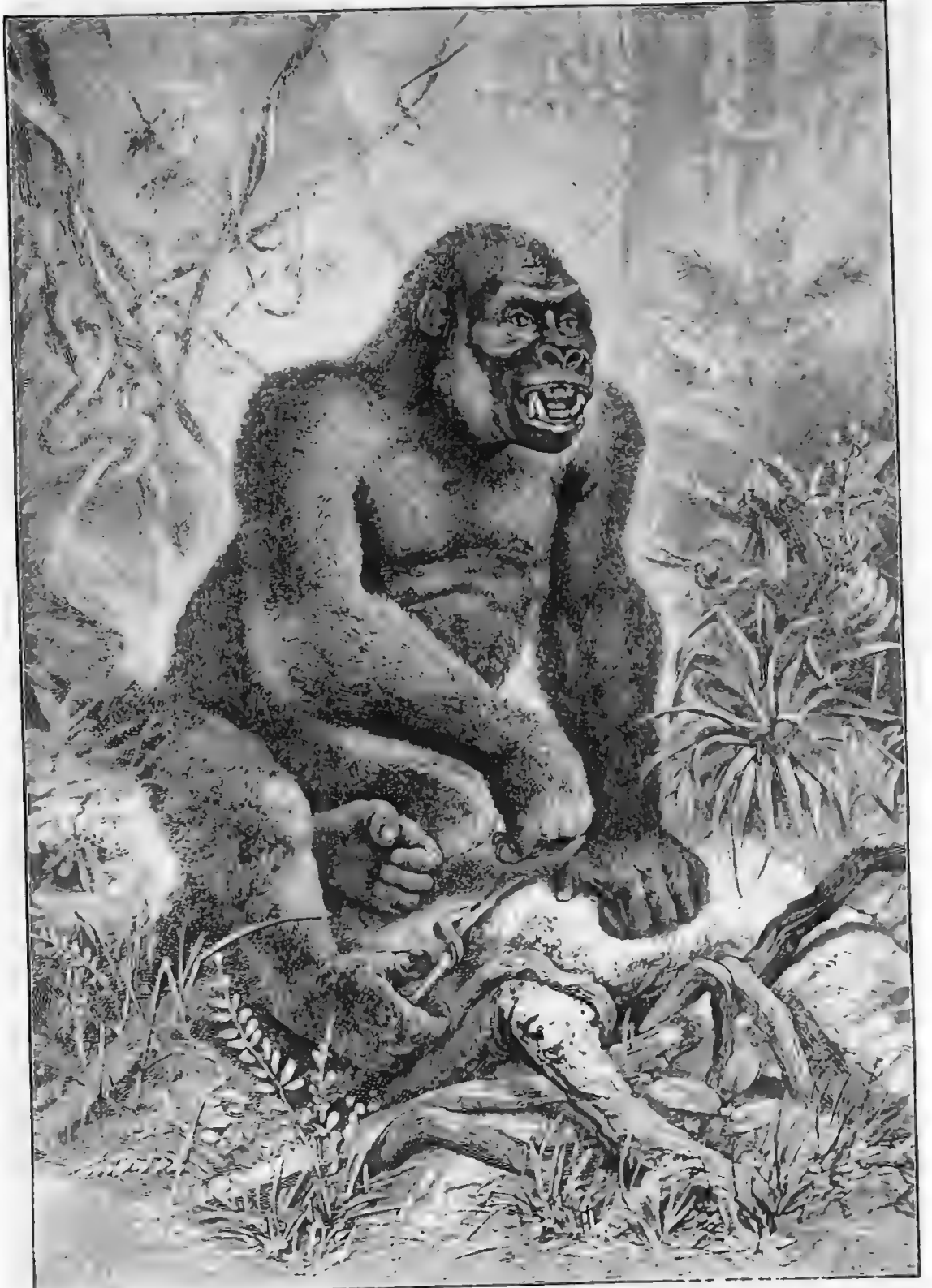


The gorilla makes a kind of home for itself, in its native forests, by twisting a number of branches into a rough platform, on which it sleeps. It is abroad during the day in search of fruits, which are its principal article of food. In the adult state it is no doubt the fiercest among the apes, but it has probably been caught oftener than was supposed, for it is now known that as far back as I 860 a common showman was exhibiting one in England.

\section{THE CHIMPANZEE}

The Chimpanzee is very closely related to the gorilla, and inhabits the same dense forests of Central Africa. For a long time some of the best naturalists thought that the words gorilla and chimpanzee were simply two names for the same animal, and it is only within the past fifty years that we have learned to distinguish between them. The country in which they live was one of the last to be explored by white men, and both of these fierce forest dwellers are so difficult to approach that it is not surprising that travellers were long in obtaining exact particulars of their appearance and habits.

The chimpanzee is shorter than the gorilla, is far less ugly, and is on the whole of a more amiable disposition. In its native forests it is at times quite playful, and when caught young may become exceedingly tame. In general appearance and structure it has a closer likeness to mankind than the gorilla, and we read that some of the earliest travellers in Africa mistook it for a "wild man of the woods".

One traveller gives us a very good description of a young chimpanzee which he bought on the coast of Africa, and brought home to the Zoological Gardens in London. The mother of the little captive had been shot a few months before, when the baby was caught because he refused to leave his wounded parent.

On being purchased by the traveller, the little chimpanzee was placed in the care of a black boy, of whom he became so fond 
that, if parted from him, he would scream and throw himself into the most violent passion. He showed also a strange liking for clothes, never losing a chance of stealing any kind of garment that came in his way.

On obtaining any article of dress, he would seat himself upon it

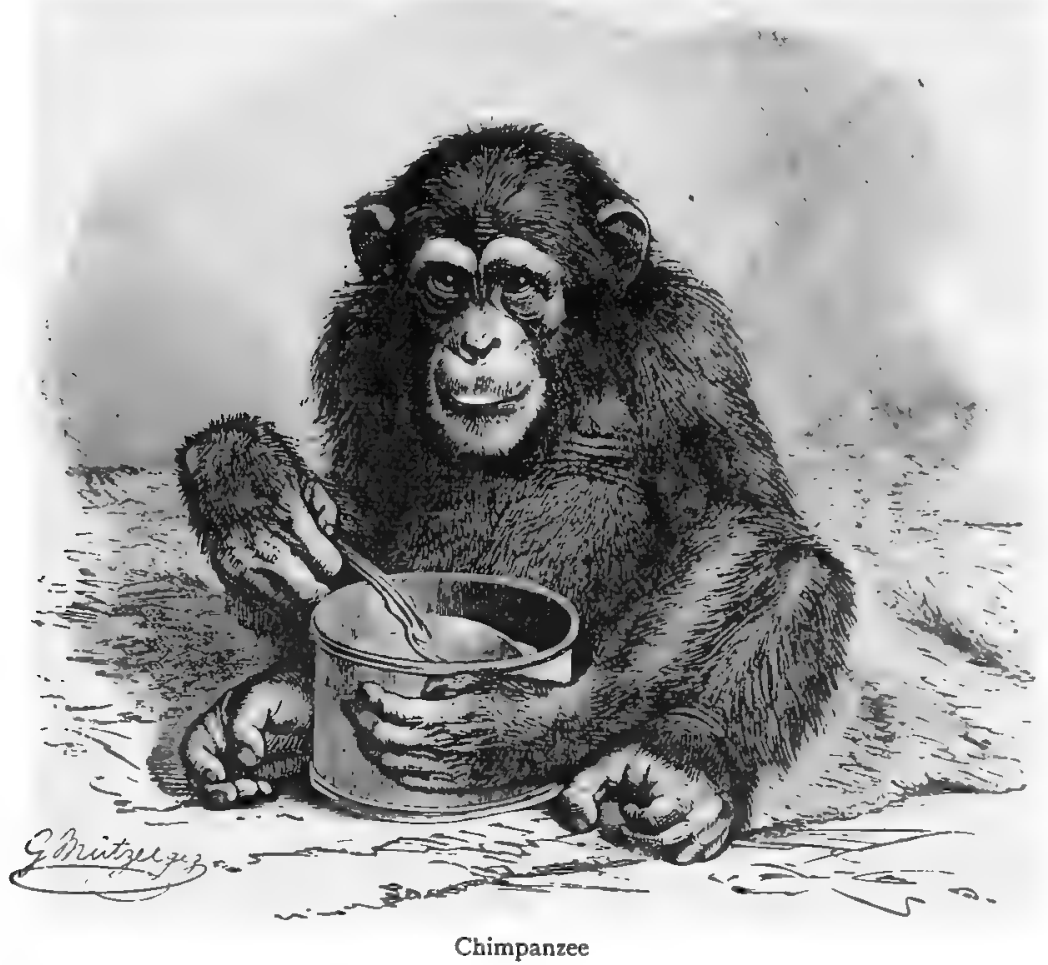

with a self-satisfied grunt, and would refuse to give it up without a hard fight. The traveller, observing this strange fancy, provided the little chimpanzee with a small piece of cotton cloth, which he carried about wherever he went, refusing to leave it even for a moment.

Bamboo, as he was called, behaved very much like a spoilt child. He was amiable and good-tempered so long as he was 
allowed to have his own way; if his will was opposed, he would throw himself into the most violent passion. But although he would scream, and dash his head against the wall until he obtained what he wanted, he never attempted to bite.

The natives of Central Africa give remarkable accounts of the strength of the chimpanzee. They have seen these apes strip off boughs with the greatest ease, which the united strength of two men could scarcely bend.

The chimpanzee lives in small family groups, but will occasionally invade in a larger body unprotected cultivated fruit areas. It is exceedingly watchful, and the first one that discovers the approach of a stranger warns the others by uttering a mournful cry, like that of a human being in distress.

The home of the chimpanzee is Central and West tropical Africa. That it builds a sort of nest high up in trees seems to be established; but it does not, as has been asserted, erect roofs to keep the rain off. Though well able to defend itself when at bay, it does not readily attack man. It is tractable and intelligent in captivity, feeding itself with a spoon or drinking from a cup or glass, and has even been taught to count up to five well, and up to ten more uncertainly.

\section{THE ORANG-UTAN}

The Orang-utan is the third of the great man-like apes. $\mathrm{He}$ is not, however, an inhabitant of Central or Western tropical Africa, but his native home is limited to the islands of Sumatra and Borneo in the Malay Archipelago and in the same tropical zone as his African cousins.

The Orang-utan (which is a Malay word meaning "Man of the (Woods") is really the historical ape of that designation. Under that name he was known to the naturalist Linnæus as far back as 1766 . In 1776 , William, Prince of Orange, had one in his private menagerie. But for long this and the two apes of which we have treated were greatly confused and mixed up together, both in scientific and popular opinion. Now, however, the three 


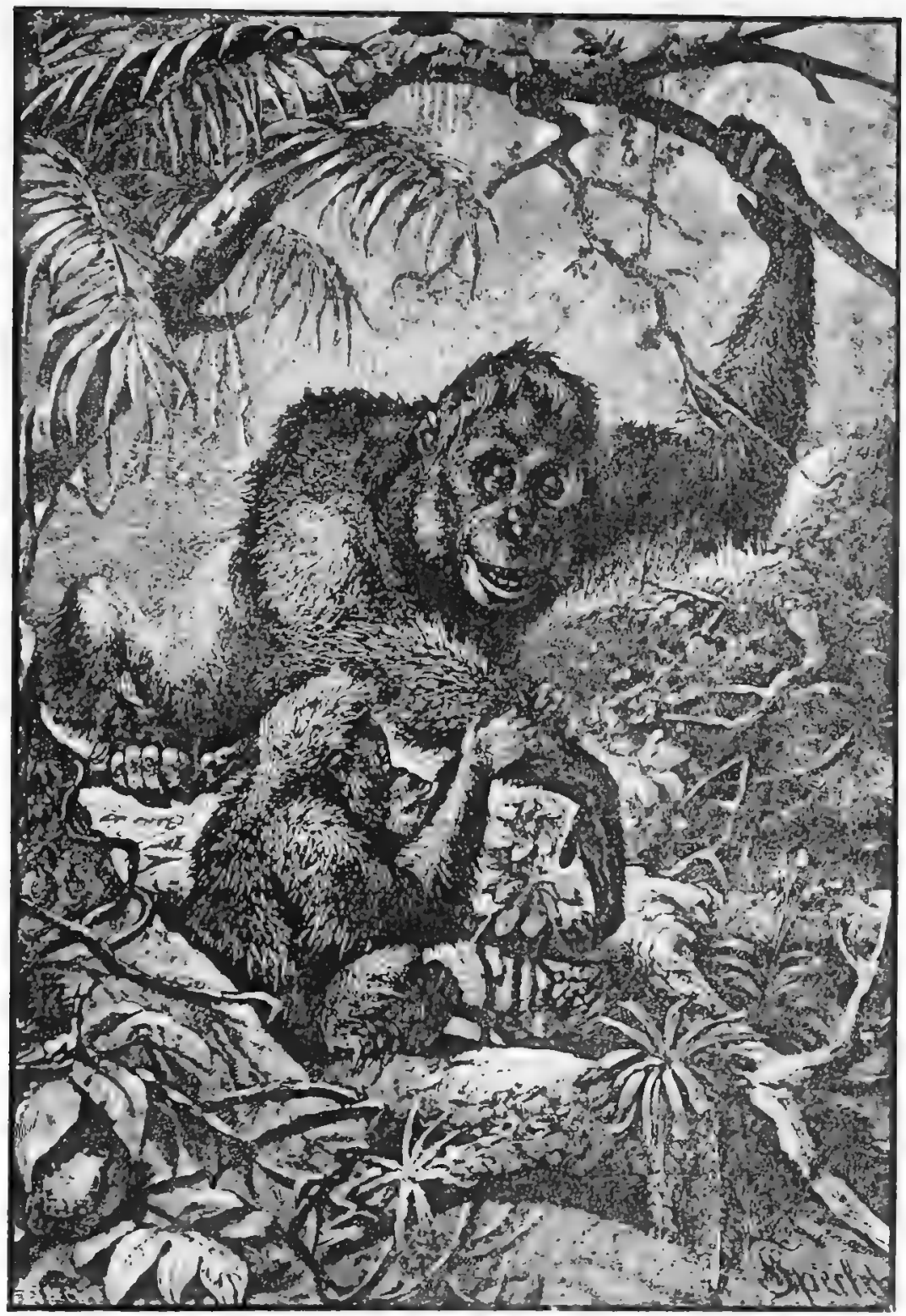

THE ORANG.UTAN 
are well known from each other by certain striking characteristics. Thus-

While the gorilla is the greatest of the three he is not so near to man in his physical structure as is the chimpanzee. Their comparative sizes are as follows:-

Height of full-grown male gorilla, over $6 \mathrm{ft}$. Height of full-grown male chimpanzee, not over $5 \mathrm{ft}$. Height of full-grown male orang-utan, $4 \mathrm{ft} .4 \mathrm{in}$.

Stature is about the only feature in which the gorilla is more man-like than the other two. When we come to other features, from which we select the length of the arms by way of illustration, the gorilla is second and the orang-utan third. Thus-

When the chimpanzee stands upright, the ends of its fingers reach only a little below its knees, but even then its arms are much longer than those of a man. The gorilla's arms, when he is upright, reach a good bit nearer to its ankles; while the orangutan's arms in the upright attitude reach to the ankles, i.e. almost touch the ground.

The orang-utan, like the chimpanzee and gorilla, also makes a kind of nest in a tree. It goes in family parties, that is to say, a mother and sire with three or four younger ones as the case may be. They are mainly, if not entirely, fruit and vegetable feeders. With their long arms they travel swiftly and cleverly through their native forests. They will rather avoid than attack man, although they can defend themselves fiercely and bravely when put to it.

\section{Monkey Acrobats}

\section{GIBBONS}

With but very few exceptions, the members of the Ape Tribe are inhabitants of trees. Possessing great strength of limb, and aided by the hand-like structure of the hinder paws, they can ascend the trunks, scamper along the branches, and swing them- 
selves from one bough to another, far more easily and rapidly than they can travel along the ground. But one group of the tribe is distinguished above all the rest by the marvellous activity of its members, which has won for them the title of the "acrobats of the monkey race".

These are the Gibbons, the last of the family of manlike apes, without tails, which are principally found on the mainland of India, chiefly in the Malay Peninsula, in Sumatra, Borneo, and some of the neighbouring islands. They seem generally to live in small companies of from fifty to one hundred individuals; but very little is known about their habits

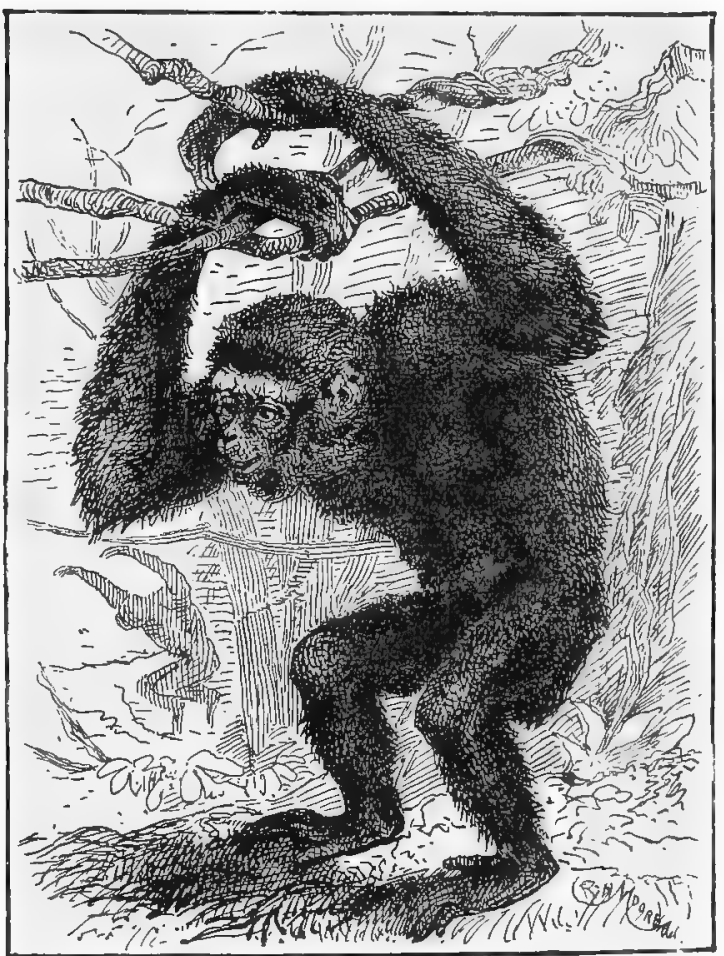

The Hoolock, one of the Gibbons when in a state of freedom, for they are so cautious and wary that it is almost impossible for an observer to approach them.

When a gibbon is alarmed, it runs up to one of the topmost branches of a lofty tree, swings for a moment or two to gain an impetus, and then launches itself into the air towards a distant branch. Just touching this, it passes on to another, and from that to a third; and so on until, in a very few moments, it is out of sight. 
These animals utter a loud and piercing cry at morning and evening; and when they are leaping from branch to branch, and flinging themselves fearlessly from one tree to another, it is quite difficult to realize that they are not so many great birds. In fact, in a state of nature the movements of some of these gibbons is so rapid that they take small birds on the wing, which they devour. They are much more omnivorous in their feeding than the preceding apes, since they devour insects, eggs, and callow birds, as well, no doubt, as fruit.

Even in captivity a gibbon is so active that the eye can scarcely follow its movements. If an apple or banana is shown to it, the animal will dash round and round the cage in its excitement, leaping from floor to roof and from roof to floor, and scarcely touching the bars and branches as it passes along. Yet its movements are so easy and graceful that it does not seem to be exerting itself in the least.

The gibbon walks more easily than any of the apes, and that upon two feet, which it places flatly and firmly on the ground, and either balances its enormous arms like a comical figure $T$, or throws them round the back of its neck. So long are its arms, that when the animal stands upright the tips of the fingers reach to the ground. The arms of a man, standing in the same position, reach only to half-way between the hip and the knee.

In like manner, the spread of a man's arms, when stretched out upon either side of the body, measured from the tips of the fingers of the one hand to those of the other, is just about equal to his height. But in the gibbon the spread of the arms is rather more than twice the height of the body.

Although the thumb of the hinder foot of a gibbon is unusually $\operatorname{large}$, that of the fore-foot, or hand, is very tiny, and, moreover, is set side by side with the fingers. A gibbon, in consequence, cannot pick up a small object between its finger and thumb, as we ourselves are able to do. The human thumb is of very little use in climbing, as we may easily see by watching a gymnast. We shall quickly notice that he does not employ his thumb at all when he hangs from a bar, but simply hooks his fingers over it. Indeed were he to grasp the bar, the strain upon his muscles 
would be so great that fatigue would soon oblige him to relinquish his hold.

The thumb of a gibbon's hand, being useful neither for grasping nor for climbing, is therefore quite small and unimportant. That of the hinder foot, however, is very large and powerful, for in it great strength of grasp is required. If our own feet were formed like our hands we should be able to climb very much better than we can now, although we could not walk so well upon level ground. But the bodily frame of every animal is always most wonderfully suited to the life which it has to lead; and as the gibbon lives almost entirely in the trees, its feet are more formed for climbing among the branches than for walking upon the ground, though it walks more upright than any of the other apes.

The gibbons are the smallest of these man-like apes, the largest gibbons being barely over three feet, while most of them are under two-and-a-half feet.

\section{SPIDER MONKEYS}

None of the gibbons inhabit any part of the American continent; but their place in the New World is taken by another very interesting group of "monkey acrobats". These are usually known as Spider Monkeys, because their long, slender limbs and hairy bodies give them very much the appearance of overgrown spiders. Unlike the gibbons, all the members of this group are furnished with long preluensile tails-that is, tails that can be twisted tightly round a branch or other object, and employed as a sort of additional hand.

When a spider monkey is climbing about in a tree, he never seems to feel quite secure unless the tip of his tail is firmly grasping a branch. Occasionally, of course, he finds it necessary to walk along a bough which has no smaller branches growing from it, so that this "fifth hand", as it has often been styled, can find no hold. Even in this case, however, it is not permitted to remain idle, but is held over the back, curled into the shape of the letter 
$\mathbf{S}$, in order that it may serve as a balancing-pole; just as a pole balances a tight-rope walker.

But this useful member can be employed for other purposes as well. Its muscular strength is very considerable, for it will sustain the whole weight of the animal for any length of time that may be required. A spider monkey will suspend himself by his tail from

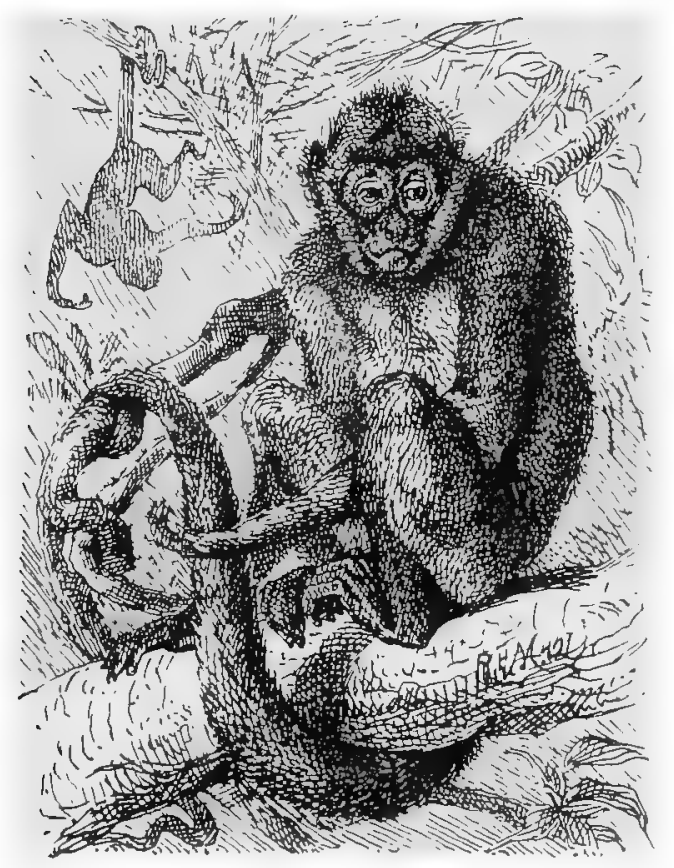

Spider Monkey a branch, in order to obtain a bunch of fruit which would otherwise be out of his reach. In passing from one tree to another, he will sometimes hang by his tail alone, and swing himself through the air to a distant bough.

There is said to be still another use for the tail. All the spider monkeys are very fond of birds' eggs; and sometimes they find a nest in a hole with an opening sosmall that even their narrow paws cannot enter it. But the tip of the tail, which has almost as much delicacy of touch as our own fingers, is easily inserted, and the eggs are dexterously hooked out one after another.

You will recollect, no doubt, that the thumb of the gibbon is very small, and is set side by side with the fingers. Most of the spider monkeys, however, have no thumbs at all, and their hands consist simply of the four fingers and the palm.

Perhaps the most curious of the American monkeys are the Howlers, so called from the hideous cries which they utter almost 
incessantly during the night. "Nothing", says a well-known traveller, "can sound more dreadful than their nocturnal howlings. While lying in your hammock in these gloomy and immeasurable wilds, you hear them howling at intervals from eleven o'clock at night till daybreak. You would suppose that half the wild beasts

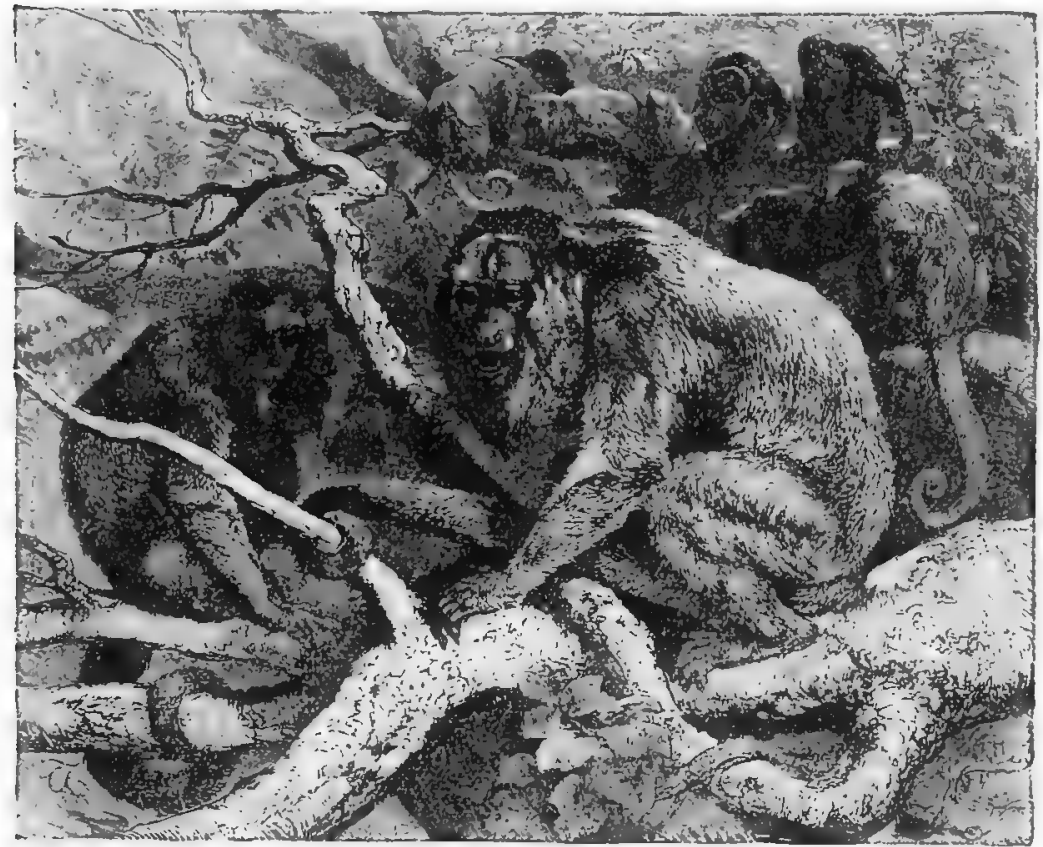

Red Howling Monkeys

of the forest were collecting for the work of carnage. Now it is the tremendous roar of the jaguar as he springs on his prey; now it changes to his deep-toned growlings as he is pressed on all sides by superior force; and now you hear his last dying moan beneath a mortal wound."

It is said that these strange cries can be plainly heard at a distance of more than two miles. They are uttered principally by the male animals, which are provided with special sound arrangements at the base of the tongue and in the throat. 
Howler monkeys are social in their habits, and sometimes congregate together in enormous numbers. Humboldt, the great traveller, estimated that on one occasion at least two thousand had assembled within the space of a square league. Their nocturnal concerts are generally led by a single animal, the rest joining in chorus.

Spider monkeys are sometimes captured alive in a rather singular manner. A large nut is hollowed out through a narrow orifice, partly filled with sugar, and laid upon the ground near the trees which the howlers are known to frequent. Before very long a monkey notices the nut, and, with the usual curiosity of his race, comes down from the trees to examine it. A moment later he has discovered the nature of the contents, thrust his paw through the opening, and grasped a large handful of the sugar.

As soon as he clenches his paw, however, he finds that he can no longer withdraw it. In vain he pulls and twists the nut about, and beats it upon the ground in the hope of breaking it. The hunters, who have been keeping watch from a place of concealment close by, now rush out; the monkey, not having sense to let go the sugar, vainly endeavours to reach the nearest tree, with his paw still imprisoned within the nut. And in a minute or two the chase is over, and the captive, bound and helpless, repents of his foolishness too late.

\section{BABOONS}

In the preceding chapters we have read about two families of the primates, namely, Apes and Monkeys, the members of which are all very agile in trees, but extremely awkward and ungainly upon level ground. Now we come to a third group of these animals, which are excellent climbers, but are very active upon the ground as well.

These are the Baboons, of which about twelve different kinds are known, almost all being natives of Africa. We may distinguish them at a glance from all other monkeys, both by their dog-like 
form, and by their long, blunt muzzles, at the extremity of which the nostrils are situated. They run, too, upon all-fours, and seldom even attempt to stand upright. The jaws are immensely powerful, and the long canine teeth are so sharply edged that they cut almost like razors.

Of this fact the baboon often takes advantage when pursued by dogs. Knowing that if a number of these animals attack him simultaneously he will certainly be killed, he gallops away at full speed until one of his pursuers has outstripped the rest. Then he suddenly turns, springs upon the astonished dog, seizes it with his powerful arms, and buries his teeth in its neck. Ex-

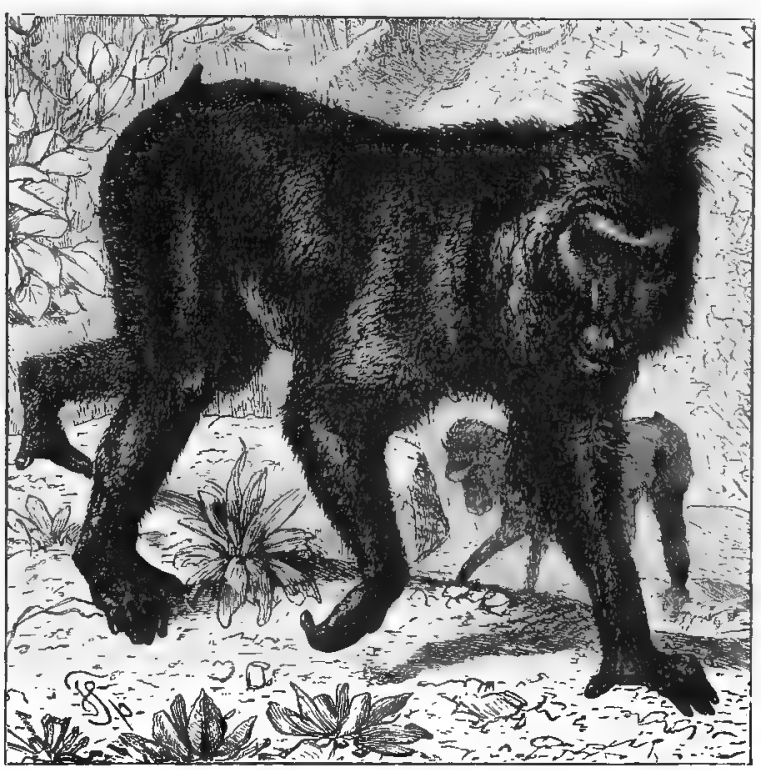

The "Drill" Baboon erting all his strength, and with his jaws still clenched, he then forces away the body of his victim, so that the terrible teeth tear their way through the great blood-vessels of the neck. A moment later the bleeding dog is flung dying upon the ground, and the baboon is galloping on as before.

Baboons as a rule take up their abode in rocky ground, over which they can gallop with perfect ease, while their enemies find it very difficult to follow them. They live in large companies, under the leadership of an old and experienced animal, which has won his position by fighting all his rivals. 
Such a band of baboons is very disagreeable in the neighbourhood of the South African colonists, for they are most accomplished robbers, and make constant raids upon the corn-fields and orchards. These expeditions are generally conducted by night, and the animals are so stealthy and cautious in their movements, that very often their presence is not suspected even by the dogs which have been set to watch.

When the baboons intend to rob an orchard, they wait for a dark night, and then set off for the scene of operations. Arrived at the spot, a number of sentinels are told off to keep watch, while a few of the older animals scale the fence, climb the trees, and gather the fruit. The rest of the band do not enter the orchard, but form themselves into a long line outside. As soon as the baboons within the orchard have filled their cheek-pouches, they hand down the fruit to their companions below, who fill their own pouches in like manner, and pass on what they cannot carry to others. In this way the whole band is soon supplied, and the thieves, laden with spoil, make their way homewards as silently as they came.

The traveller Alfred Brehm, in his book From North Pole to Equator, tells a little story that illustrates both the intelligence of the baboon and its affection for its young. While passing through a rocky valley, the traveller, who was accompanied by a number of dogs, came across a band of baboons that were crossing from one side to the other. The dogs at once gave chase, but only the females of the band took to flight. "The males", says Herr Brehm, "turned to face the dogs, growled, beat the ground fiercely with their hands, opened their mouths wide and showed their glittering teeth, and looked at their adversaries so furiously and maliciously that the hounds, unusually bold and battle-hardened, shrank back discomfited, and almost timidly sought safety beside us. Before we had succeeded in stirring them up to show fight, the position of the monkeys had changed considerably, and when the dogs charged a second time nearly all the herd were in safety.

"But one little monkey about half a year old had been left behind. It shrieked loudly as the dogs rushed towards it, but succeeded in gaining the top of a rock before they had arrived. 


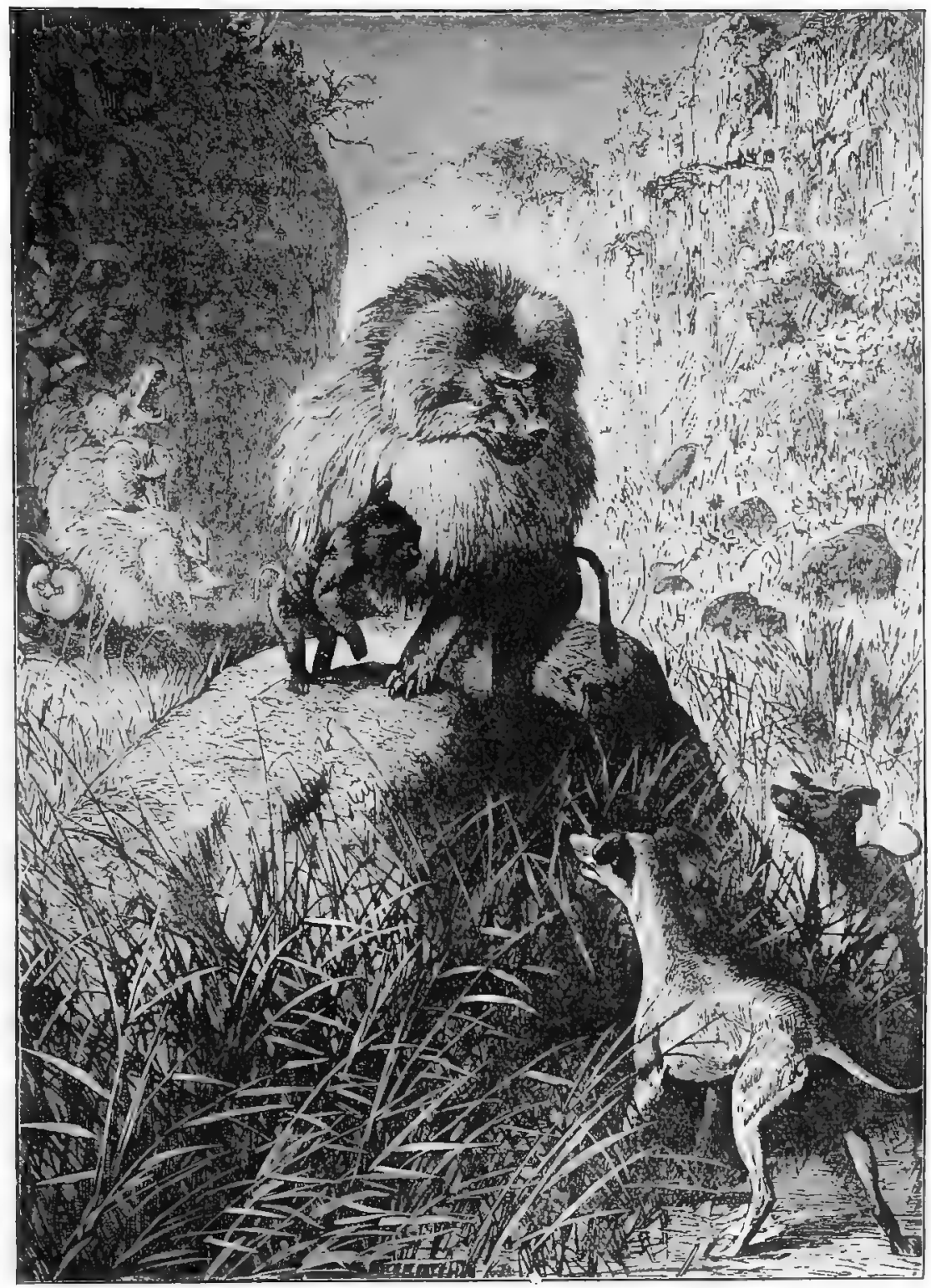


Our dogs placed themselves cleverly, so as to cut off its retreat, and we hoped that we might be able to catch it. But that was not to be. Proudly and with dignity, without hurrying in the least, or paying any heed to us, an old male stepped down from the security of the rocks towards the hard-pressed little one, walked towards the dogs without betraying the slightest fear, held them in check with glances, gestures, and quite intelligible sounds, slowly climbed the rock, picked up the baby-monkey, and retreated with it, before we could reach the spot, and without the visibly disconcerted dogs making the slightest attempt to prevent him.

"While the patriarch of the troop performed this brave and self-sacrificing deed, the other members, densely crowded on the cliff, uttered sounds which I had never before heard from baboons. Old and young, males and females, roared, screeched, snarled, and bellowed all together, so that one would have thought they were struggling with leopards or other dangerous beasts. I learned later that this was the monkeys' battle-cry: it was intended obviously to intimidate us and the dogs, possibly also to encourage the brave old giant, who was running into such evident danger before their cyes."

A baboon called the Chacma is sometimes employed by the African natives for a very curious purpose. When on the march, in seasons of drought, a whole tribe is sometimes in no little danger of perishing from thirst. Knowing, however, that the chacma has a marvellous faculty for discovering the presence of water, they capture one of these animals, keep him without liquid for two or three days, and feed him only with victuals highly seasoned with salt. The poor thirsty creature is then secured by a long cord, and allowed to wander where he will.

Before long he begins to sniff about and smell the ground. Then he darts off in a new direction, pulling eagerly at his rope. Now he pulls up a tuft of herbage, and examines its roots; now he darts off again, more eagerly than before. Ere long, guided by his wonderful instinct, he is almost sure to discover some stream or spring, at which both he and his captors are able to quench their thirst.

A chacma was once kept at the Crystal Palace, in a large cage 
which also contained a number of smaller monkeys. Being of a very quarrelsome disposition, he was confined to a corner of the cage by a strong chain, which was fastened to a belt round his body. The other monkeys all knew the exact length of his chain, and would sit and eat nuts an inch or two beyond his reach. This always made him furiously angry, and, after chattering and screaming with passion for a few moments, he would gather up a quantity of straw, and hurl it furiously with both arms at his tormentors.

All the baboons are savage animals, and but slightly sensible to kindness. They are sometimes tamed, it is true, when quite young, and will learn to know their master, and follow him about like a dog. But as they grow older they become more and more ferocious in disposition, until at last it is dangerous to allow them to remain at large; for even a small baboon is more than a match for an unarmed man, who would be helpless against its powerful arms and its terrible, sharp-edged teeth.

\section{LEMURS}

The great island of Madagascar is the home of the third group of Primates, known as the Lemuroids, or lemur-like animals. Ages ago, the vast forests that used at one time to exist in Britain were inhabited by animals closely resembling the lemurs which are now to be found in Madagascar, but they have long since disappeared; at the present day we must go to the sunny south if we wish to visit the lemur at home.

There are over fifty lemurs of various kinds, and the differences between them are almost as great as between the many varieties of monkeys. The true lemur is found only in Madagascar and the neighbouring islands, but he has relations more or less closely resembling him in various parts of Africa and Asia.

His brain is of a far lower order than that of the monkey, and this no doubt is why his small foxy face has less expression than that of his relative. But he is very interesting nevertheless, and if kindly treated is harmless and even affectionate. 
Unlike the monkey, the lemur works by night and sleeps during the day. He is not dainty in his food, eating almost anything he

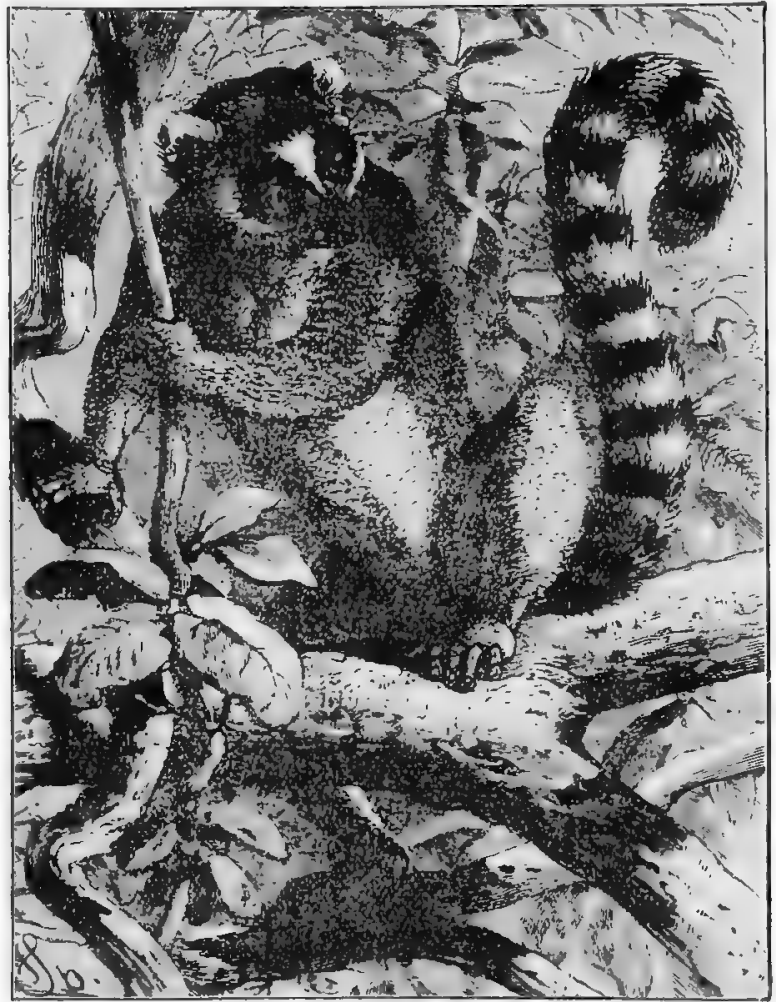

Ring-tailed Lemur

comes across, from fruit, vegetables, and leaves, to birds, and even snakes.

One of the prettiest members of the lemur tribe is the little creature with the ringed tail that is often to be seen in zoological gardens. It is about the size of an ordinary tabby cat, and with its long fluffy tail, gray furry body, and its peculiar habit of arching the back, it has so close a resemblance to pussy that it is frequently called the cat-like lemur. Most members of the lemur group rarely leave the trees, but the ring-tailed variety is quite at home in rocky country.

Another interesting family is that of the mouse lemurs, tiny creatures smaller in size than the rat, which have the curious habit of sleeping, that is, hibernating, during the hottest and driest season of the year. There are many animals, as we shall presently see, in the colder parts of the earth, which sleep during the winter, 
when food is scarce and the ground is covered with snow. But it is rare to find an animal which chooses the hottest part cf the summer for its long yearly nap. Perhaps the reason is the same in both cases: the mouse lemur finding it more difficult to pick up a living when the ground is parched with heat, than in the colder and wetter seasons of the year.

During its long sleep this little animal, strange though it may seem, lives upon its tail. Even while asleep it requires of course a certain amount of food to keep it alive, and it obtains this supply from its tail, which is thick and massive with fat when it goes to sleep, and thin and limp when it awakes some months later.

One of the strangest of the lemur-like animals is the Aye-aye. In appearance he is a mixture of the fox, the monkey, the lemur, and the squirrel, and his body is so curiously constructed that naturalists have had great difficulty in making up their minds in what group he should be placed. They have now decided, owing to the nature of his teeth, that he is most closely related to the lemurs.

The most striking peculiarity in the aye-aye is the shape of his second finger, which is extremely long and slender, resembling a piece of bent wire, and is evidently intended to assist him in his search for grubs and insects.

A well-known naturalist several years ago described the manner in which the aye-aye goes to work in using this remarkable claw. He obtained an aye-aye, shut him up in a large cage, with a number of thick branches from a tree attacked by a large and destructive grub. At sunset the aye-aye awoke from his daily nap, and began to examine his surroundings. When he came to one of the worm-eaten branches he stopped and inspected it carefully, and, bending forward his ears and applying his nose to the bark, rapidly tapped the surface with his curious second finger. At last he came to a part of the branch that evidently gave out an interesting sound, for he began to tear it with his strong teeth, stripped off the bark, cut into the wood, and exposed the nest of a grub, which he daintily fished out with his slender tapping finger, and ate with evident pleasure.

The aye-aye is indeed a marvellous example of the way in 


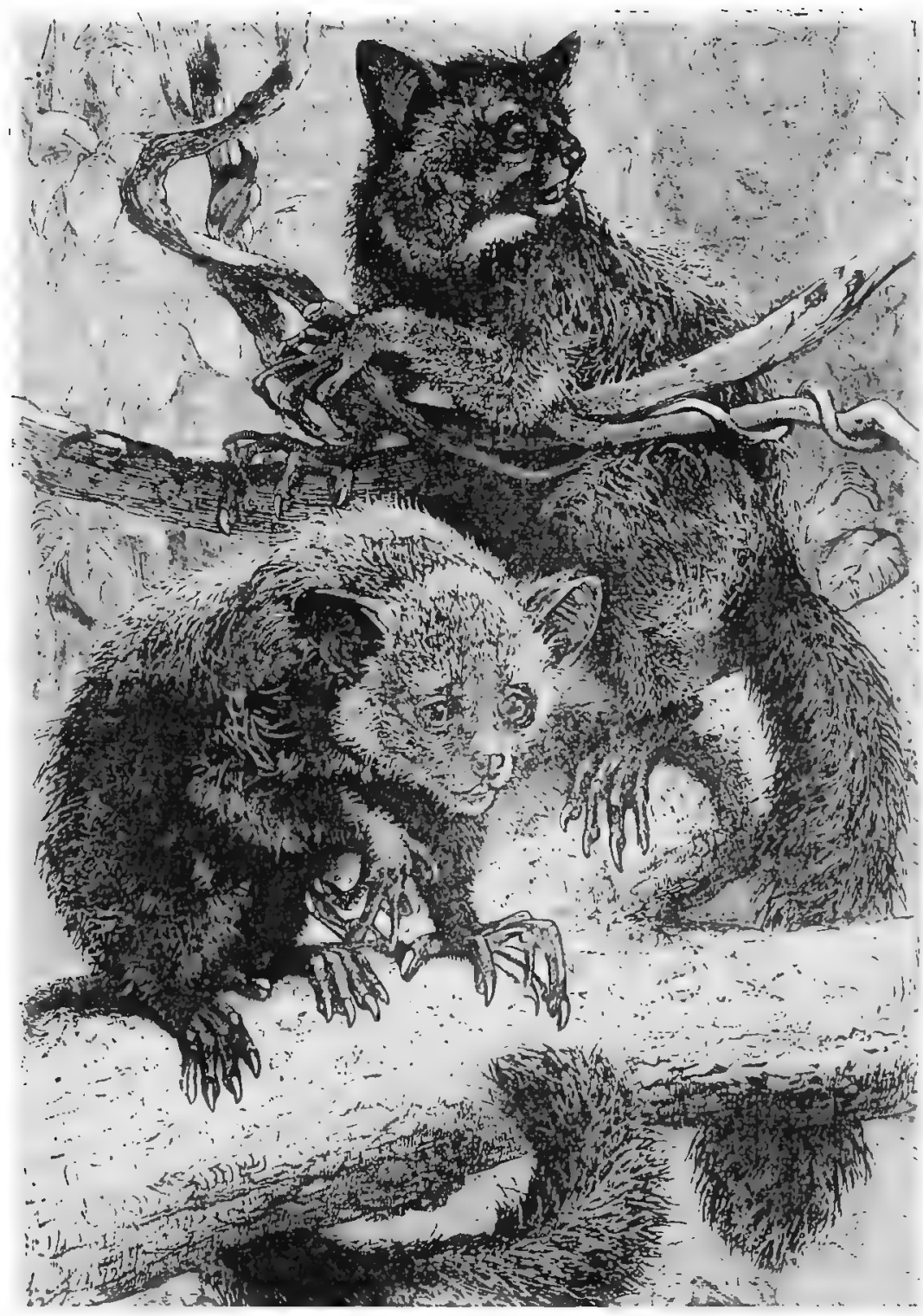


which animals are provided by nature with the means of earning their living. As the naturalist just quoted points out, he has acute hearing, enabling him to distinguish the different tones given out by the wood by his gentle tapping, he has evidently a keen sense of smell to aid him in the search, his strong limbs support him firmly on the slender branches to which he clings, his sharp teeth permit him to tear through the tough wood, and lastly, he uses his extraordinary second finger as a tapping instrument, as a probe, and as a scoop.

\section{HAND-WINGED ANIMALS OR BATS}

The Bats have some habits in common with the lemurs, although in appearance there is very little similarity between them.

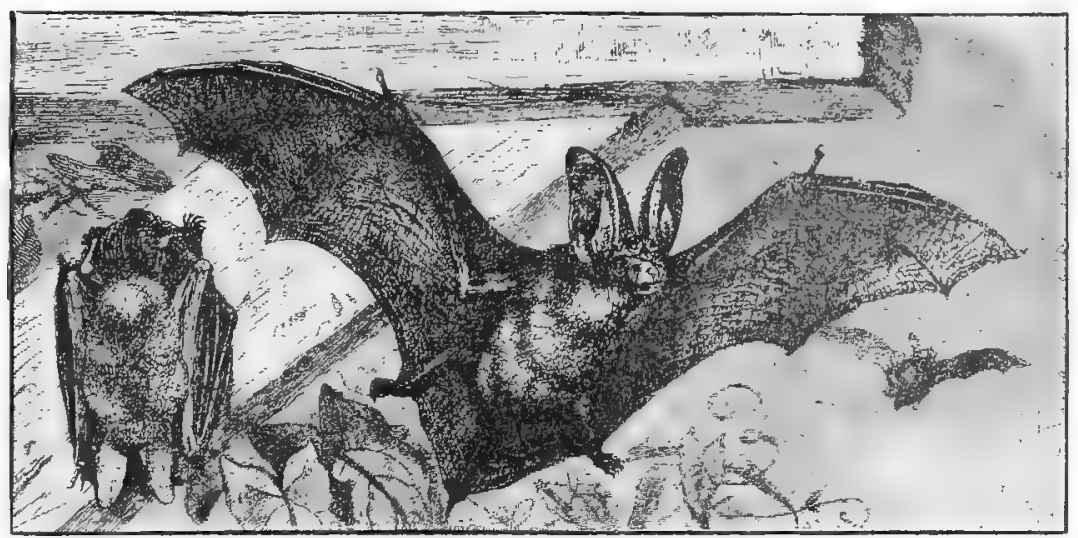

Long-eared Bat

Both live on insects, fruit, and small animals of various kinds, and do their hunting by night, though, owing to their curious flitting movements, the former are looked upon with a certain amount of fear by the more ignorant of their human neighbours. Like the lemurs, the bat is also, as a rule, a very harmless animal, and it 
is only in South America that we find a few mombers of this interesting family which deserve the very hard things that are said about the bat tribe.

In this country, on any warm evening in spring or summer we may see Bats flying swiftly to and fro; and we may hear them, too, for occasionally they utter a very shrill squeak, somewhat like that of a mouse.

They are then hunting for beetles, flies, moths, and other

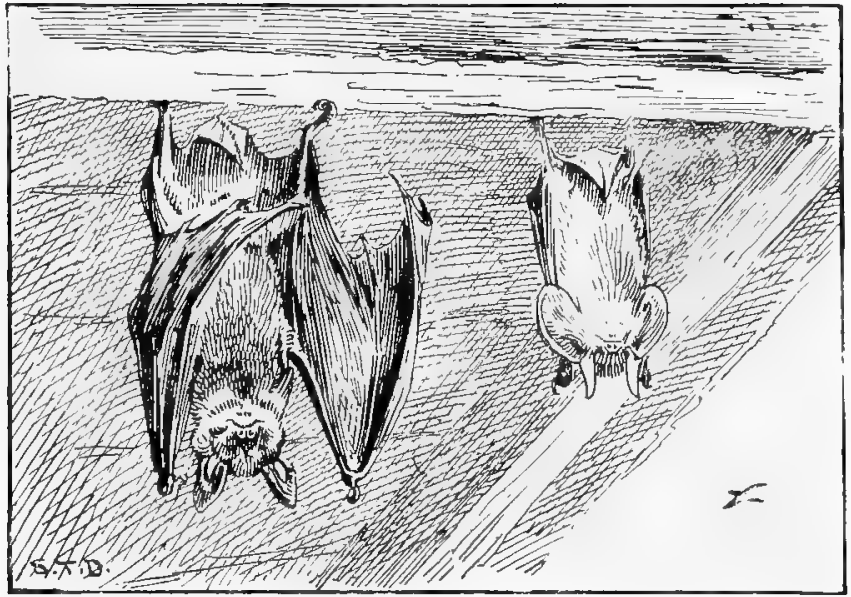

Bats asleep

insects which only come out after the sun has set. Like the swallow, they catch and devour their prey on the wing; and all night long they are busily engaged in the chase.

Once I kept a pet bat for some little time. He had been wounded in one of his wings, and could not fly; so I put him under a large glass bell, and fed him with big blue-bottle flies. And how many do you think he used to eat every day? No fewer than seventy! No doubt, if he had been able to fly about and take exercise, he would have required a great many more.

The legs and wings of these flies were not at all to his taste, so he carefully bit them off before eating the bodies.

He used to catch his victims in a very curious way. He would 
creep up to a fly very quietly and carefully, and would suddenly spring upon it, and cover it over with one of his wings. Then he would tuck his head down underneath the wing; and a few seconds later we could hear him biting off the wings and legs, and crunching up the body.

Bats do not like the daylight, and always hide themselves away in some dark corner before sunrise. They resort to hollow trees and old ruins. As many as thirty or forty bats have been found in such a retreat, all fast asleep together.

They do not lie down to rest like other animals, but hang

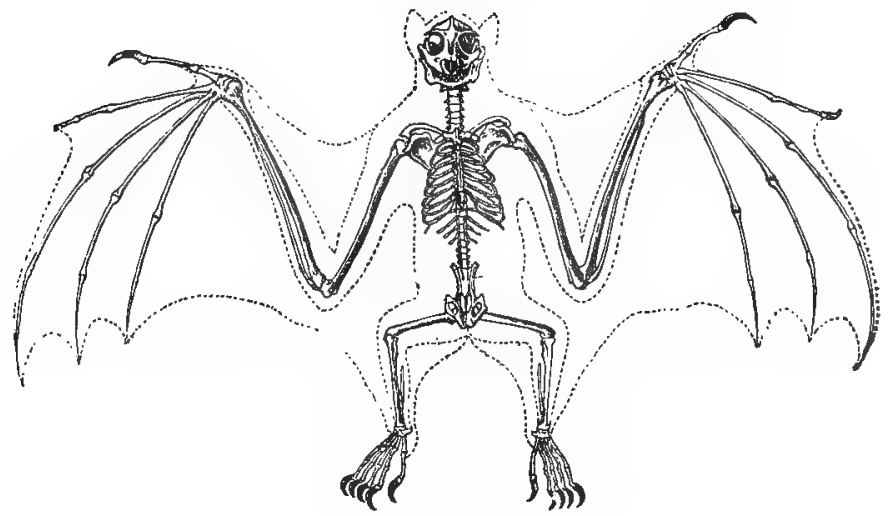

Skeleton of Bat

themselves up by the sharp little claws of their hind feet, with their heads downwards. If they should be alarmed, all they have to do is to loose their hold, fall into the air, and fly away.

Bats hibernate in the winter time, when there are no longer any moths or flies for them to eat. They go to sleep until the spring, and do not need any food at all. On a mild evening, it is true, they will sometimes come out for an hour or two, and catch some of the winter gnats which are enjoying the warmth. But they can live for three or four months with nothing to eat, while they almost cease to breathe, and their blood scarcely flows through their bodies.

As soon as the warm nights of spring come round, however, (M. 868) 
the bat wakes up, and goes out to hunt for insects as before. And it catches and eats them in such numbers, that it soon makes up for its long fast.

Let us cxamine the construction of the bat's wings. For a very long time people thought that the bat was a kind of bird, because it can fly through the air. But if you catch one and look at it, you will see at once that it is not like a bird at all.

It has no feathers, for instance, as all birds have; and its wings are quite different from those of a bird, and remind one very much of a boy's kite. They consist of a light framework of bone, upon which is stretched a thin but strong membrane, which answers to the linen of the kite.

This framework, strange to say, is made of the bones of the bat's hand or fore-paw! If we carefully strip the skin away from one of the wings, we shall find that the bones of the fore-limbs are light and slender, but nevertheless very strong. Those of the fingers, however, are drawn out, as it were, to such a length, that a bat's middle finger is sometimes longer than its whole body! These long and slender bones form the framework of the wing, just as the thin cross-laths make the framework of the kite.

The membrane that is spread upon them is really the skin of its body very much stretched out, so as to form large, broad wings. If you look at a picture of a bat's skeleton, you will see that this skin stretches over not only the fore-legs, but the hinder-legs as well; and that it even runs on behind these and joins the tail.

When a bat is not using its wings it can fold them up, just as a lady folds up her fan. It packs them closely against its sides when they are at rest.

On each wing, if you look closely, you will see a tiny hook-like claw. This is really the claw, or nail, of the thumb; and the bat uses it to drag itself along, when it is crawling upon the ground.

The bat guides its course by means of its tail, which serves as a kind of rudder. Every boat has at its stern a flat piece of wood, which can be turned to one side or the other in the water, and which causes the boat to turn also. That is the rudder. The tail of a bat, like that of a bird, is an air-rudder, and can be turned to either side in just the same way. 
If you watch a bird with a large tail, such as a pigeon or a swallow, when it is flying, you will see that it turns its tail from side to side just as often as it changes the direction of its flight. And if you watch a bat while flying, you will see that it uses its tail in exactly the same way.

In this country bats render good service to the farmer and fruitgrower, by eating up vast quantities of moths and other insects that prey upon the crops. In some parts of the world, however, they are not always so useful, and in South America there are one or two kinds of bats which may be by no means pleasant neighbours. The Vampire bat, for instance, is not content with insects and fruit, but varies this diet at times by sucking blood from the larger animals, and even from man himself.

\section{INSECT-EATERS}

We next come to the small group of INSECTIVORES, or insecteating mammals. There are very few animals in this group, in fact its only well-known members are the hedgehogs, the moles, and the shrew-mice.

\section{THE HEDGEHOG}

Perhaps the oddest little animal we have in Great Britain is the Hedgehog, with its thick coat of sharp spines. It is somewhat like a small porcupine in appearance, although it is not very nearly related to that animal. It can roll itself up into a ball so tightly as to be quite safe from the attacks of almost any enemy except man himself.

The spines which cover the hedgehog so closely are shaped like bent pins. If you were to strip off the skin from a dead hedgehog, you would find that these bristles were pinned, as it were, through the skin, and that each was kept in its place by a kind of round head. 
These sharp spines take some little time to grow, and a young hedgehog, until it is several weeks old, has only soft quills, and looks almost like a young bird.

Sometimes a hedgehog uses its spines in a very curious way. It seems to know how wonderfully elastic they are, and, if it should come to a very steep bank, it simply curls itself into a ball, and rolls down to the bottom.

A hedgehog has been known to throw itself in this way from

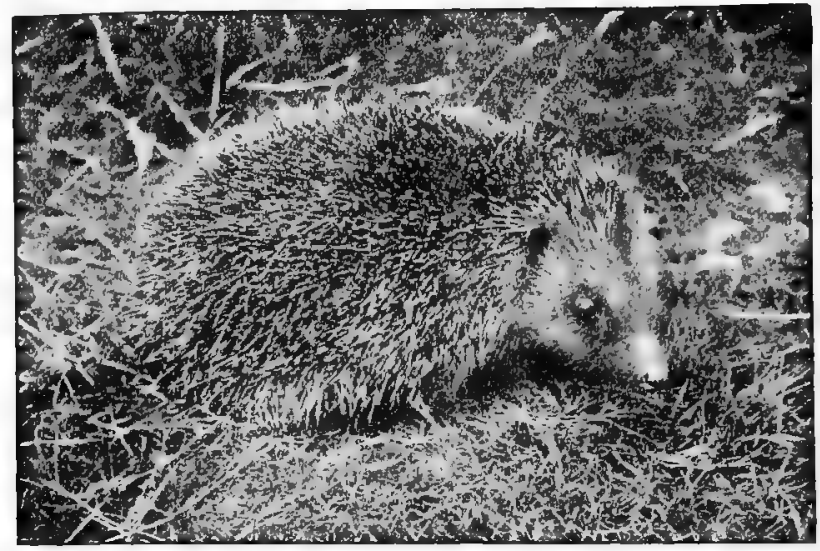

Hedgehog. (From a Photograph by Cherry Kearton)

off a wall ten feet high, pick itself up at once, and trot away quite unhurt.

A hedgehog kept in a house used to climb upstairs, and then, assuming the ball shape, roll itself down again, apparently for fun.

Although the hedgchog belongs to the great group of the Insect-eaters, and is the largest British specimen of that group, it feeds on worms, snails, and even on small animals, as well as on insects. At evening, as soon as the darkness has fallen, it sallies out from its hiding-place, and begins to hunt for victims.

Hedgehogs have very large appetites, and never seem to be satisfied. A hedgehog kept as a pet would eat as many worms or as much other food every night as would nearly fill a jam-pot.

The hedgehog is said to kill snakes by biting them two or 
three times across the back. It eats them by beginning at the tail, and making its way slowly towards the head.

If it should happen to attack an adder, and receive a bite from the poison-bearing fangs, it is not in the least hurt, for the poison has no effect upon it.

The flesh of the hedgehog is edible, and gipsies are very fond

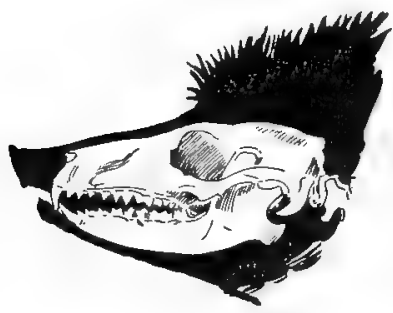

Skull of Hedgehog-showing Teeth (Natural Size)

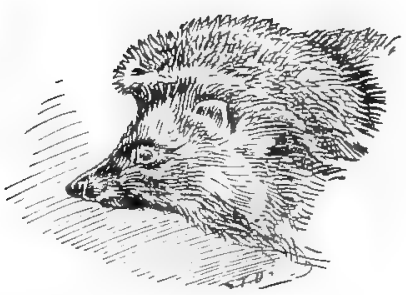

Head of Hedgehog

of it. In gipsy encampments hedgehogs may be seen tied up by long strings until they are required for use.

The manner in which they are cooked by the gipsies is very curious. They are simply rolled up in a ball of clay and put into the fire. When the ball cracks the hedgehog is baked. The clay is then broken away, bringing the spines and skin with it; and the flesh is ready to be eaten. Those who have tasted baked hedgehog say that it is very delicate and tender.

\section{THE MOLE}

People who do not know any better often pity the Mole. They think that it must be such an unhappy animal, because it is compelled to spend its life in cold, dark tunnels underground, and hardly ever comes out into the bright sunshine and fresh air above. But they forget that the mole is carefully formed for the life which it leads, and that it would be just as unnatural for it to live above-ground as it would be for a squirrel or a bird to dwell in a burrow. The mole is just as happy in its own way as the 
skylark, although its manner of life may perhaps seem a strange one to us.

Now I want you to notice how very much the mole is assisted

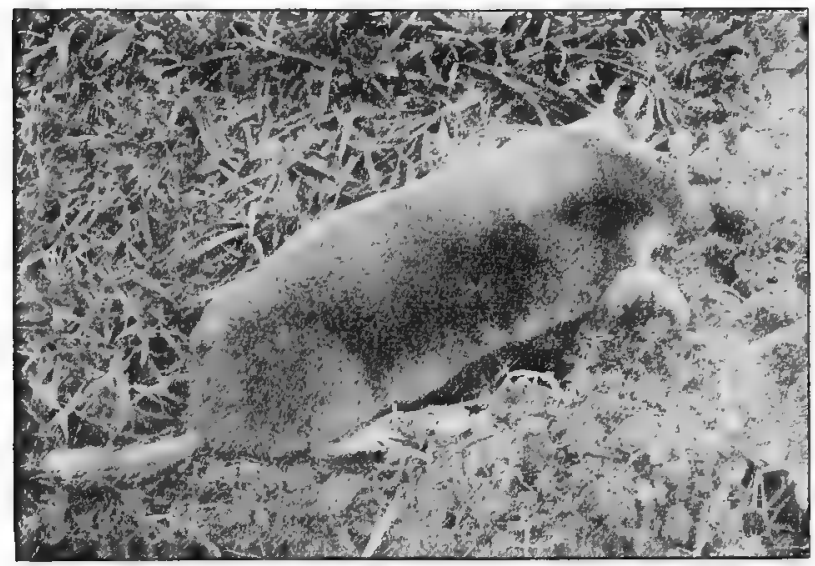

Mole. (From a Photograph by Cherry Kearton)

in digging by the manner in which its body is formed. Let us suppose that we have a dead mole lying before us. What shall we see?

First, that its front paws are very curiously made. The legs,

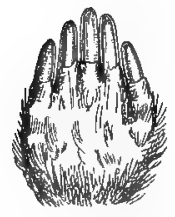

Upper or outer

Surface

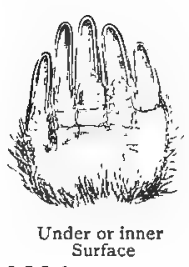

Fore-feet of Mole we notice, are quite short, but the paws are very large and broad, and are covered with a tough, horny slin, while the claws are immensely strong and sharp.

These paws are the tools with which the mole digs. The strong, curved claws enable it to scrape away the earth, while with the broad palm of the paw it can shovel the loosened soil out of its burrow. The tough, hard skin that we noticed prevents the paw from being cut by any little fragment of sharp stone.

Then we shall see that the body is bottle-shaped, while the 
head is long and pointed. Now this is the very best form that an animal can have, which has to bore its way through the earth.

Next we shall notice that the soft, warm fur does not lie flat, as it does in most animals, but stands straight out from the body. This is to allow the mole to travel through its narrow tunnel either forwards or backwards.

If a cat, for instance, were to try to crawl backwards through a burrow only just large enough for her body to pass, she would find it very difficult. Her fur would stand up and
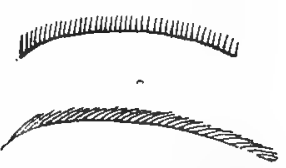

Set of Fur (I) in the Mole (2) in ordinary Animals hinder her, just as it hinders your hand if you stroke her from the tail towards the head. But the mole's fur, which is set differently, does not hinder it at all, and lies flat upon its back, in whatever direction the animal is moving.

Where are the mole's eyes? Press the fur on its face aside and you will see them, but they arc very small. The mole does not want to use them in its dark, underground tunnels, so they are always covered by the fur, which prevents any little fragment of earth or stone from finding its way into them.

In spite of its small size, the mole is said to be a very savage animal. If it should happen to meet with another mole it is always ready to fight, and will not cease from the combat until either the one or the other is killed. And it makes its attack with such ferocity that it has been said that, if a mole could be increased to the size of a tiger, it would be by far the fiercer and more dangerous animal of the two.

It is also said to be a very voracious animal. Those who make mole-catching their business say that it cannot go without food for more than a very few hours at a time. It is asserted that the mole feeds regularly and at stated times, namely, that at 8 and $\mathrm{I} 2$ a.m., and at 4 p.m., it may be detected burrowing for its food. It sleeps between these times.

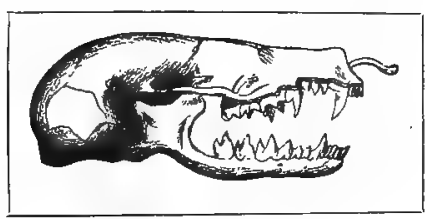

Skull of Mole

In one way there can be no doubt that the mole is very useful 
to us, for it preys upon such mischievous grubs as the wire-worm and the "leather-jacket", which feed upon the roots of cultivated plants. Whenever you see a chain of mole-hills running across a field, you may be quite sure that many a hurtful grub has been destroyed there, and that the mole has been helping the farmer by killing some of his very worst enemies.

It helps us, too, even by making these hillocks of earth. They look very unsightly, it is true; and if they should happen to be in a field of corn or hay, they blunt the edges of the cutting-machines. But then the earth of which they are made is fresh, good earth, brought up from below. All that we have to do is to spread it over the field, when it makes a good "top-dressing", as the farmers call it, and strengthens the crops.

Once more, the burrows which the mole makes help to drain the fields; so that in at least three different ways the animal is useful to us.

Why, you may ask, does the mole burrow in the ground?

This question is very easily answered. The grubs and worms upon which it feeds live underground; and of course it must go underground, too, if it wishes to catch them.

Besides the long tunnels which it drives in all directions, the mole makes a kind of dwelling-place, or "fortress", as we mostly

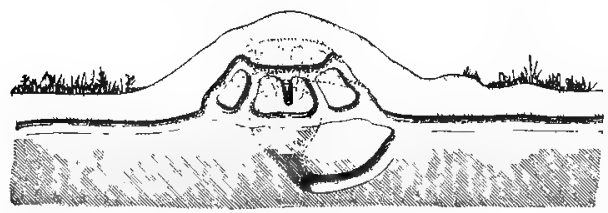

A Mole's Dwelling call it, underneath the roots of a bush or tree. In the middle is a large chamber or sleeping-place, with a warm bed made of dry grass and moss; and all round it and over it run tunnels, leading both into the nest and into each other. So, if a weasel should follow a mole along its tunnel, it is nearly sure to miss its way and lose itself when it comes to the fortress.

It is an odd thing that neither the mole nor the shrew, its near relative, is found in Ireland. 


\section{SHREWS}

Towards the beginning of autumn we may find lying dead upon a country pathway, or by the roadside, a little grayishbrown animal, which at first sight bears a strong resemblance to a mouse. Upon a closer examination, however, we find that in three important respects it is very different from a mouse. In the first place, it has a long projecting snout; in the second, it possesses no "rodent" or gnawing teeth in the front of the jaws; and in the third, its tail is short, blunt, and four-sided, the tip being almost square.

This little animal is a Shrew, and is related, not to the mice and rats, but to the hedgehog and the mole. It belongs, in fact, to the great family of the Insect-eaters, and is always searching about for worms, snails, slugs, and insects, and other small creatures which may serve it for food.

But it does not feed upon these alone. If it should happen to find the dead body of a small animal or bird, it will feast heartily upon the carcass. Sad to say, too, it is a very quarrelsome little creature, and a dreadful cannibal. If two shrews meet one another they frequently fight, and the one which proves the conqueror, kills its vanquished foe, and then devours it!

On one occasion, as a well-known naturalist tells us, a steel trap was set for a rat. In the morning, when the gardener who had set the trap came to look at it, he found a dead rat in its iron jaws, and sitting upon its body was a small dark object, which proved to be a shrew. On looking closer, the gardener found that the voracious little animal had actually eaten a hole in the side of the rat, and was so absorbed in its repast that it allowed the gardener to capture it.

Several different kinds of shrews are found in Great Britain, the most interesting of which is perhaps the Water-shrew. This little animal makes its burrows in the banks of streams and ponds, and may be found almost everywhere in such places by anybody who can sit quietly and watch for it.

Among the shrews is found the smallest of all mammals, 
one species averaging only $2 \mathrm{I} / 2$ inches in length, including the tail.

It is a very pretty sight to see a number of these little creatures at play. They scamper to and fro, run races, tumble over one another, and pretend to fight, all the time giving utterance to tiny squeaks, which are very much like the shrill cry of a bat.

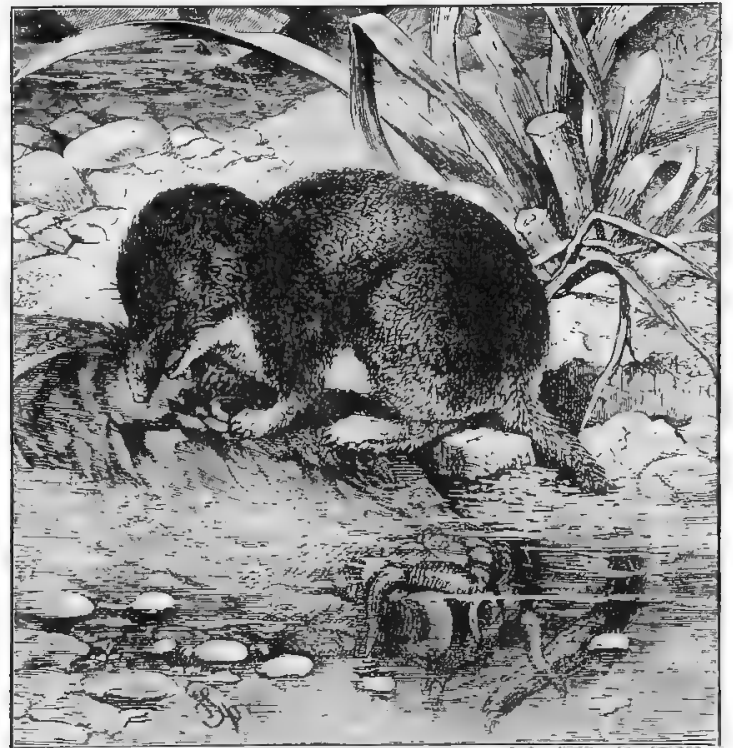

The Water-shrew Suddenly one of them will plunge into the stream, and swim along under water. While submerged, it looks almost like a ball of silver, for in its fur are entangled a great number of bubbles of air. Suddenly it vanishes into the bank; for its burrow always has two openings, one above the surface of the water, and the other beneath.

It swims by means of a fringe of stiff white bristles which encircle its hinder paws. With these it paddles its way along, using its feet alternately, and consequently travelling in rather a zigzag manner. Round its tail is another fringe of similar bristles, and this member serves as a rudder, and enables it to steer its course.

We might even see one of these water-shrews dive under water, overturn a stone, and poke about in the mud with its long snout. It is searching for water-shrimps, or the grubs of water insects, which it captures and devours in great numbers. It has also been known to feed upon frogs.

There is a curious resemblance between the ears of the seal 
and those of the shrew. On diving beneath the sea, the ears of the seal are immediately closed by the pressure of the water upon them, so that not even the tiniest drop can find admission to the delicate organs within. The ears of the water-shrew are formed in almost exactly the same way, so that not a drop of water can enter them when the animal is diving.

In olden days, country people had very curious superstitions concerning these harmless little animals. One of these was, that a cow over which a shrew had run would sufferfrom terrible swellings in the body, and at last die from a kind of consumption. Such cattle were said to be "shrew-struck". It was thought, too, that the only way to save their lives was to burn the body of a shrew, and apply the ashes to the wound.

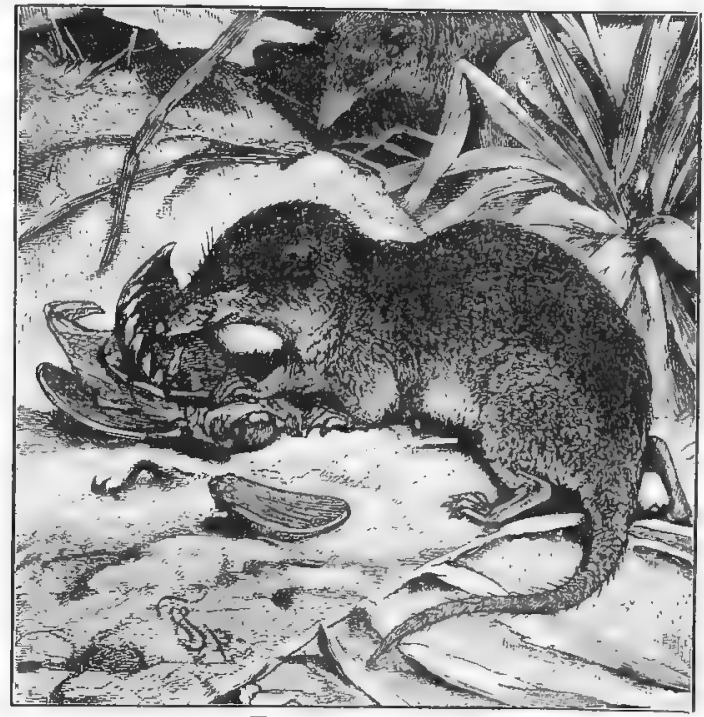

The Garden-shrew

Sometimes, hoivever, a shrew could not be obtained. But it was said that the branch of an ash-tree in which one of these animals had been buried alive would answer quite as well. Accordingly, it was not uncommon to have an ash-tree ready for such an emergency, and it was prepared in this wise. A hole was bored in the trunk, a shrew introduced, and the hole closed by a wooden plug, the unfortunate prisoner being left to perish from starvation. For "shrew-struck" animals a branch of this tree was thought to be an unfailing specific! 


\section{CARNIVORES, OR FLESH-EATERS.}

The order of Flesh-Eaters, or Beasts of Prey, is one of the largest and certainly one of the most interesting of the eleven groups into which we have divided the class of mammals. There would be very little for the sportsman to do if the Carnivores were to vanish off the face of the earth, for they include most of the animals whose pursuit is attended with danger, without which hunting would be a very tame amusement. Moreover, our zoological gardens would lose their principal attractions without these fierce inmates, which may be regarded as the lords of the animal world. What would become of our menageries if there were no lions or tigers, no leopards or panthers, wolves, hyænas, or bears?

There are, of course, numbers of other orders, the members of which are quite as fierce and dangerous as any of the carnivora, but there is no other that comprises so many terrible families.

Wide differences exist between the various families that make up the flesh-eating group. For instance, there is little resemblance between the tiger and the seal, or the walrus and the fox; but, as their name implies, the carnivora all agree in this, that they prey upon other animals which are weaker, less active, or less cunning than themselves.

Although the order is known by the general name of flesheaters, it must not be supposed that the carnivora eat no other food; nor, again, must we assume that because an animal is not included among the carnivora it never indulges in a flesh diet. Some of the carnivora, as, for instance, the bears, are to a great extent vegetarians, while outside the flesh-eating order are to be found such animals as the lemur, which, as we have just seen, will at times vary its ordinary bill of fare by catching and eating small birds and beasts. But with a few exceptions the general rule is, that the carnivora are flesh-eating mammals, while the other classes live on the vegetable produce of field and forest.

Carnivora are to be found in all parts of the world, except 
Australia and New Zealand. In the coldest regions of the earth they are represented by the bear, the seal, and the walrus, but it is in the burning tropics that we find the grandest and most terrible members of the order-the lion, the tiger, and other scarcely less formidable princes of the forest and plain.

\section{The Cat Tribe.}

Of all the families that make up the order of carnivora that of the Cats is by far the most important. The household puss herself

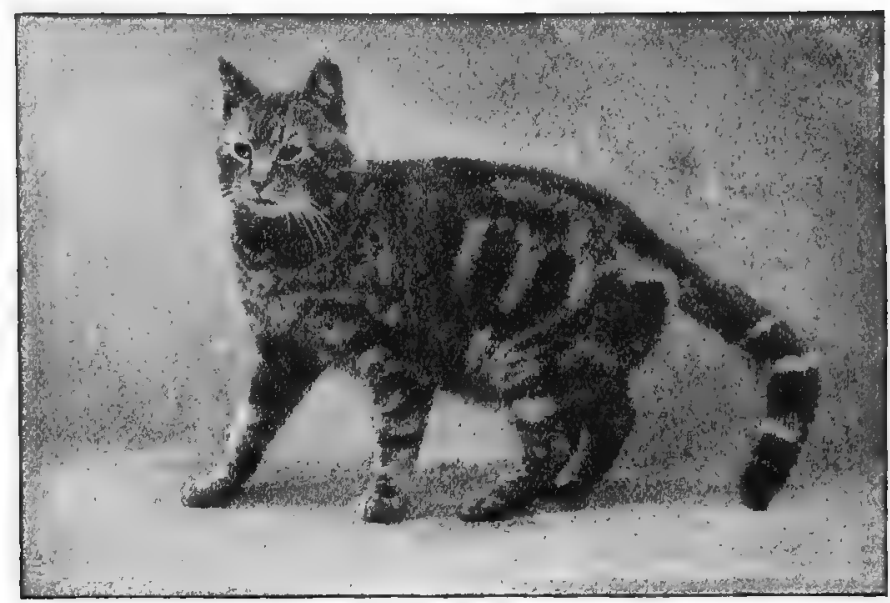

Common Domestic Cat. (From a Photograph by Thomas Fall.)

is a very small and insignificant member of the cat tribe, which includes the lion, the tiger, the leopard, the panther, the jaguar, the puma, the lynx, and others.

\section{THE LION.}

The largest of all the cat tribe is the Lion. Although so big and strong, the lion is similar in structure to our domestic cat. And if we take a cat and examine her body very carefully, we 
shall have a very good idea of the way in which the lion's body is formed.

In the first place, the lion has claws of just the same kind, only they are a great deal larger and stronger. The lion feeds upon living animals, and requires some kind of weapons with which to capture them; and such weapons he has in his claws.

As these claws must always be kept sharp, there is a sheath

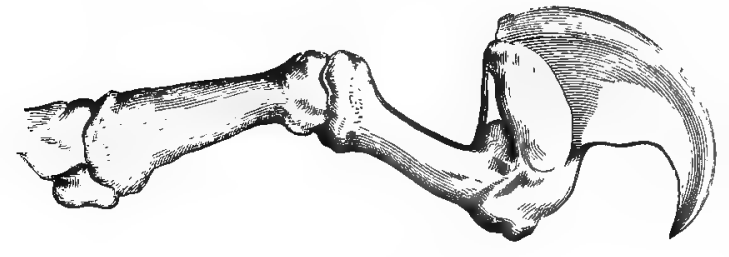

Claw of the Lion into which each of them can be drawn when it is not being used. In this way the points are preserved from being worn away by rubbing against the ground. A dog does not possess such sheaths, and so his claws are always blunt. But no matter how much a lion or cat may run about, the points of the claws never touch the ground.

Then the lion must be able to creep quietly up to his prey, so that he may leap upon it suddenly; for many of the animals upon which a lion feeds are so much more swift of foot than himself, that he could not possibly overtake them in fair chase.

Underneath a lion's foot, therefore, there are soft fleshy pads,
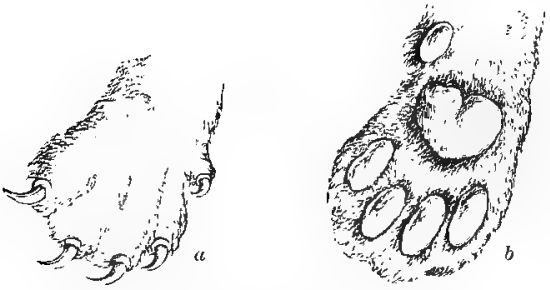

Cat's Foot: $a$, with claws unsheathed; $b$, showing cushions or pads just like those which we may notice on a cat's paw. You know how silently a cat can walk along, and how often it is impossible to hear its footstep. Although the lion is a much larger and heavier animal, he can move quite as noiselessly, and can creep up to his victims without alarming them by the slightest sound.

A lion has whiskers, too, like the cat, and they are used for just the same purpose. 


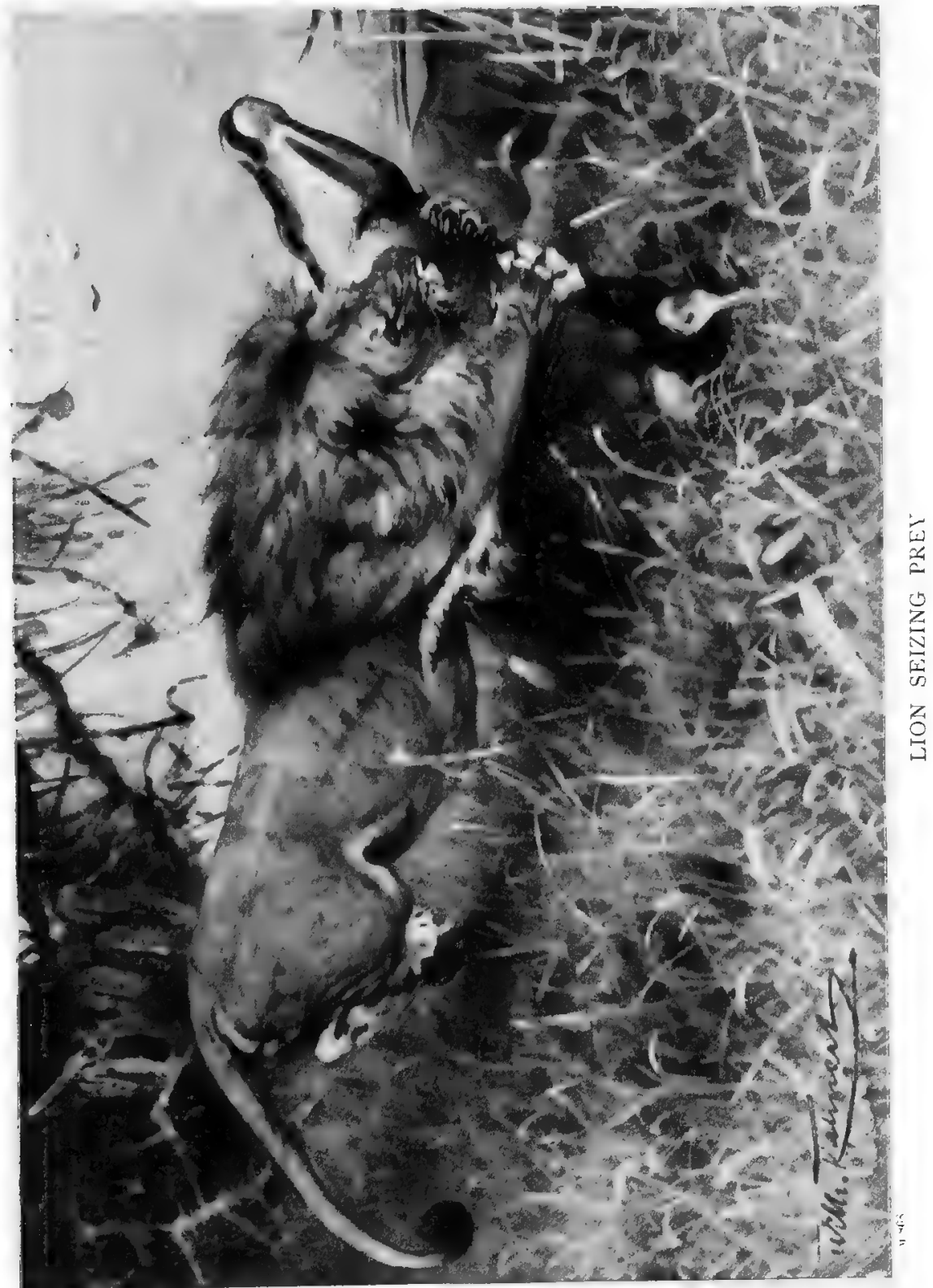



If you look at a cat's whiskers, you will see that they are just as wide as her body. At the root of each hair is a very delicate nerve, so placed that the cat can tell at once if the tip of the whiskers is touched. It is easy to understand how useful these whiskers may be to the cat when she is hunting for food.

Suppose she catches sight of a bird or a mouse, and is trying to creep up to it through some bushes. She must keep her eyes fixed

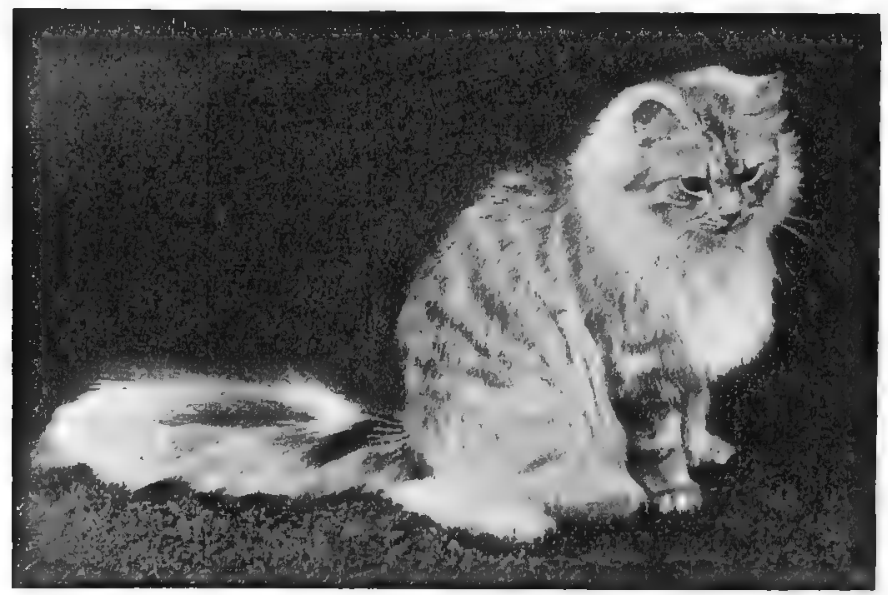

Persian Cat. (From a Photograph by Thomas Fall.)

on her victim, and cannot use them to see where she is going. And so she might try to crawl through some opening where there was not sufficient room for her body to pass. But her whiskers at once tell her that the passage is too narrow; and she is able to draw back her head without making any sound to alarm her victim.

The lion's eyes, also, are like those of the cat, and are just as useful upon a dark night. Of course, neither a lion nor a cat can see when it is perfectly dark. But the eyes of both are formed in such a manner that they can see well when there is so little light that we could not use our eyes at all.

Let us try to understand how this is. You know, perhaps, thai it is the round dark spot in the middle of our eyes through which we really see. We call this the "pupil" of the eye. Now the 
larger this "pupil" is, the more light it can take in; and even in our own eyes the pupil is larger at some times than at others.

What happens if we walk from a dark room into a well-lighted one? We are dazzled, as we say, for some moments. The fact is, that in the dark the pupils of our eyes expand, so as to take in more light, and when we walk into a light room, they take in more light than we want, until the pupils have had time to decrease to their usual size.

The pupils of a cat's eyes increase in the dark far more than

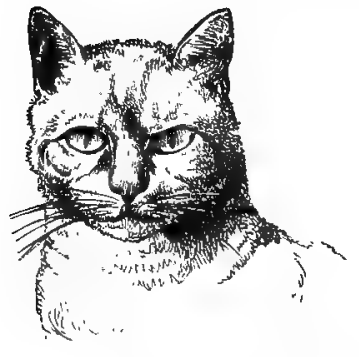

Cat's Head, showing Pupils closed and opened

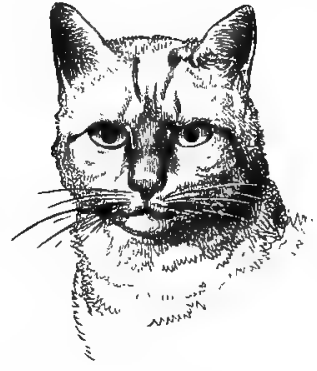


way, and are very useful in tearing the flesh of its victims. They are so very sharp, that they cut almost like so many knives.

We have now learned that a lion resembles a cat in the character of his claws, the pads upon his feet, his whiskers, his eyes, and his teeth. But there is still another part of the body in which the two animals are very much alike, and that is the tongue.
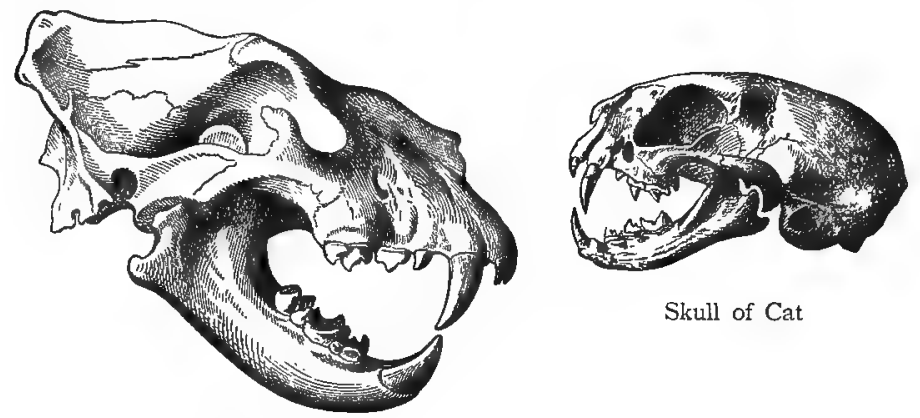

Skull of Cat

Skull of Lion

You know that if a dog licks your hand, the tongue feels soft and wet; while, if a cat does so, the tongue feels rough and dry. If you look at a cat's tongue carefully, you will find that it is covered all over with sharp, hard points, somewhat like the teeth upon a file, and all directed backwards. It is the scraping of these against your skin that you feel when a cat licks your hand.

A cat or a lion cannot crush and eat the bones of its victims, as a dog can. But, by licking them with its rough tongue it can scrape all the flesh from off them.

Of course the points upon a lion's tongue are much rougher and stronger than those upon the tongue of a cat; and if a lion were to lick your hand, it would quickly scrape away the skin.

Once a gentleman very nearly lost his life in this way. He had a tame lion cub, which was a great pet, and used to sleep in his room. On one occasion, when he was lying in bed, the animal came up, and, to show his affection for his master, began to lick his hand. In a very few seconds his rough tongue drew blood; now, when a lion has once tasted human blood it never afterwards loses the desire for it, and becomes what is known as a "man(in 868) 
eater". The gentleman knew this; and, when the animal growled as he tried to draw his hand away, he felt at once that his pet must die. So with his right hand he drew a heavy pistol from under his pillow, and shot the lion through the head.

The lion can also lap water with his tongue, just as a cat laps milk. For the tongue of a cat can be turned up at the edges, so as to make a kind of scoop, or spoon. The tongue of a lion is formed in just the same way, so that he can use it for drinking, as well as for scraping the flesh from the bones of his prey.

Thus, in the character of his paws, his claws, his eyes, his whiskers, his teeth, and his tongue, the lion is exactly like a very big and strong cat.

Now let us learn something of the habits of the lion.

We should guess, from the way in which his eyes are made, that he must be abroad chiefly by night, and that he would be likely to sleep during the day in some dark retreat. And this is exactly what he does. All day long, unless he is very hungry, he lies hidden in the thickest parts of the forest, where even the most skilful hunter cannot follow him, and sleeps securely in his lair. But when night falls he wakes up, and sallies forth in search of food.

By the aid of his sharp eyes, or his keen scent, he soon detects his prey. Then he creeps up slowly and silently, just as a cat creeps up to a mouse or a bird, and with a mighty spring and a loud roar he leaps upon it, and bears it down to the ground.

Having done this, he first drinks the blood, and then feeds upon the flesh of his victim till he is satisfied; then he seeks his lair, to spend the day in sleep.

Meanwhile, a number of the smaller carnivora, such as jackals and hyænas, have sat quietly waiting until he had finished his meal, when they make their repast.

The lion is very much afraid of fire, and therefore hunters and travellers, when they are camping for the night, always light a large fire, and tether their horses and oxen around it.

But the lion is said to adopt a way of capturing one of the animals without coming near the fire at all. Putting his mouth close against the ground, he roars as loudly as he can. The 


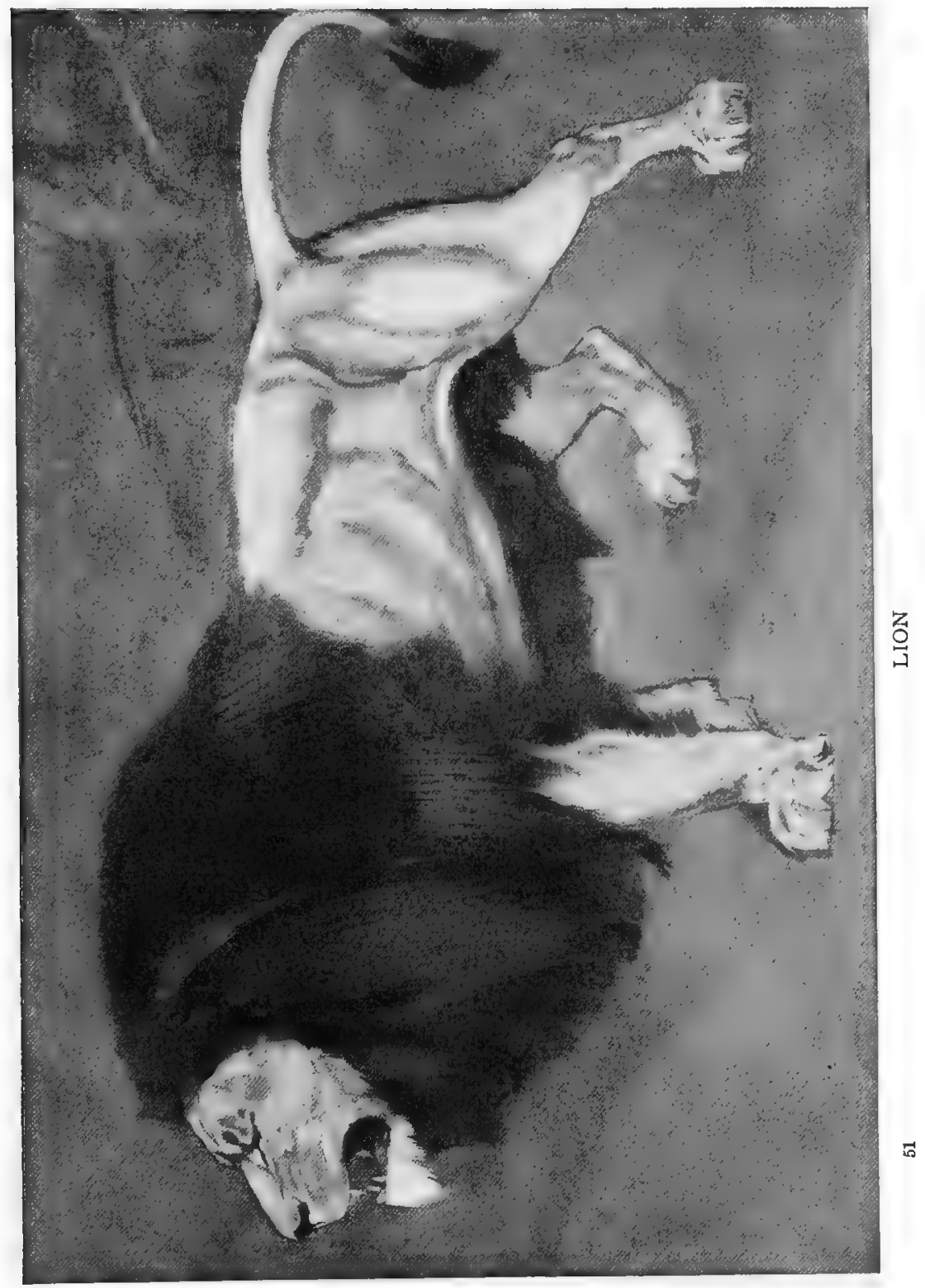


frightened animals often succeed in breaking away, and then the lion springs upon one of them, and carries it off under cover of the darkness.

The cubs of the lion are three or four in number, and are just as playful as so many kittens. When they are a day or two old, each is about as big as a fully-grown cat.

\section{THE TIGER}

Like the lion, the jaguar, the leopard, and the panther, the Tiger belongs to the important family of the Cats. It has the same muscular limbs as our own domestic cat, the same sharp curved claws, with sheaths to protect them when not in use; the same soft pads upon the feet; the same sharp teeth, so suitable for tearing the prey; the same rasp-like tongue; the same curious eyes, so wonderfully adapted for use upon the darkest night; and the same long whiskers, with delicate nerves at their roots, to warn their owner when the path taken is too narrow for the body to pass through. Indeed, if a cat could be magnified to the size of a tiger, there would be very little difference between the two animals.

The colour, of course, would not be the same, for that of a tiger is tawny yellow, with a number of blackish-brown stripes running transversely round the body and the limbs. One would think that this bright colouring would render the animal very conspicuous. Yet those who have met with the tiger in its native jungles say that it is hardly visible, since its hues harmonize most perfectly with those of the surrounding vegetation.

The natives of India divide tigers into three classes. The first of these they call Hunting Tigers, the second Cattle-eaters, and the third Man-eaters.

The Hunting Tigers are the young animals, which are full of health and energy, and prey almost entirely upon the deer and other wild animals which they capture in the jungle. These tigers are rarely destroyed, as they serve to keep down the herds of antelopes, which are often very mischievous in the corn-fields. 


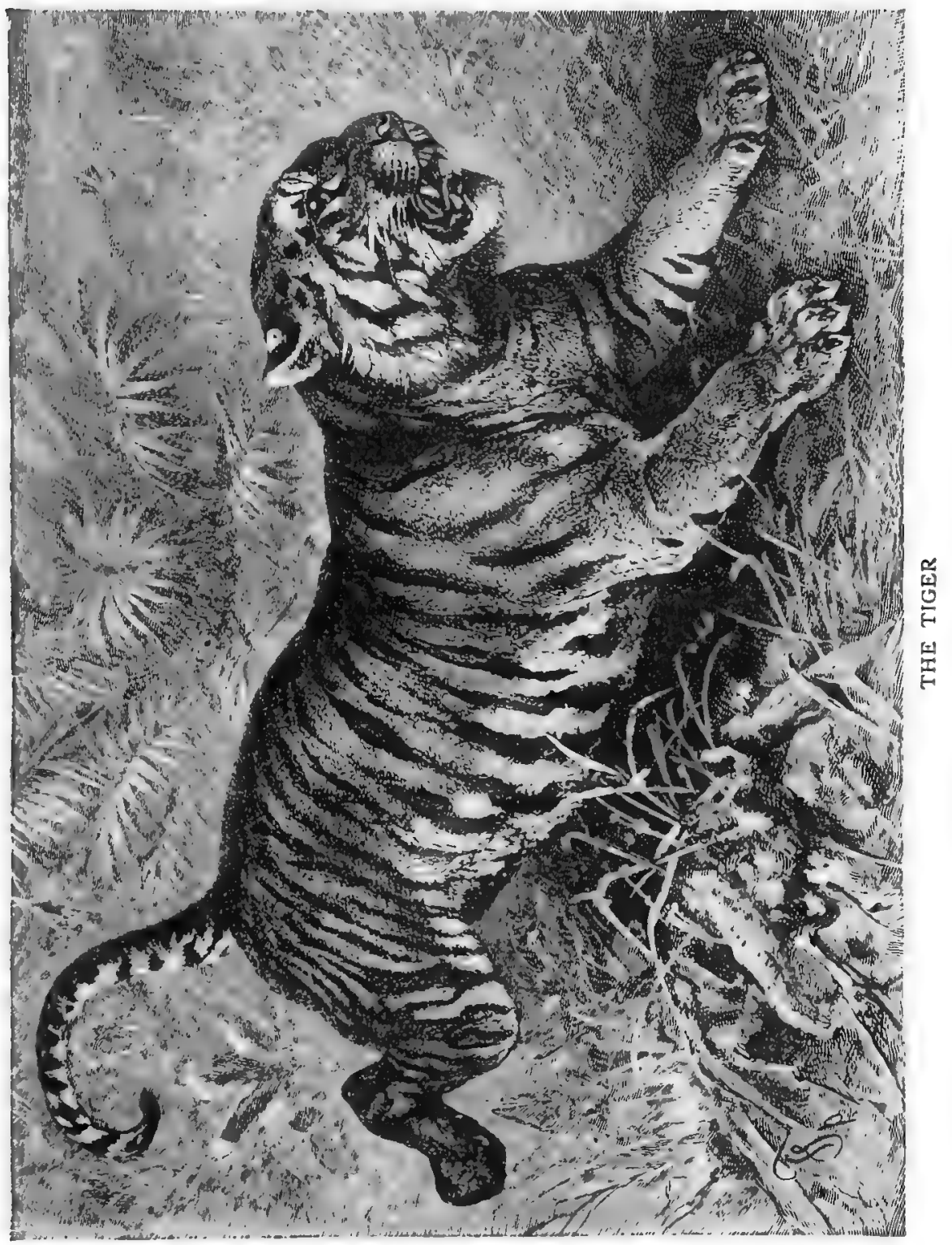


The Cattle-eaters are the older animals, which have lost something of their strength and activity, and prefer to prowl about the villages in the hope of pouncing upon stray cattle. These tigers are often very troublesome, for they carry off cattle night after night, first breaking the necks of their victims, and then dragging them away to their lairs. In this way a single tiger has been known to destroy no fewer than seventy cattle in less than twelve months.

More dangerous still, however, are the Man-eaters; for after a tiger has once tasted human flesh he always prefers it to any other food. A man-eater is nearly always an old animal, which, owing to wounds or other infirmities, is unable to procure his ordinary food. He usually makes his lair by the side of a road, and then lies in wait, hidden among the bushes on the opposite side. He will seldom attack men even if they are unarmed, but if a woman or child passes he springs out, strikes down his victim, and drags away the body to devour at his leisure. A single man-eater has been known to kill more than a hundred human beings in the course of a year.

Tigers are generally hunted with the help of elephants. A kind of wooden or basket-work carriage, called a "howdah", is fastened upon the elephant's back, and in this the hunters are seated. A suitable position is taken up at the part of the jungle where a tiger is supposed to be lying. A long line of "beaters" then come from the opposite direction, forcing their way through the jungle towards the hunters, shouting, yelling, beating drums, letting off fireworks-making, in short, as much din as possible as they press forward. The tiger, hoping to escape unnoticed, steals away before them, only to find that there are enemics to the front as well.

Sometimes he is shot down without much trouble, but often he makes a hard fight for his life. With open jaws and flaming eyes, and uttering terrible roars, he dashes furiously at the elephant, which, even after the most careful training, frequently turns and flees before his determined onslaught. A bullet, however, soon ends his career, and then the elephant, if he be not checked, will trample the carcass into a shapeless mass. 
Another way of hunting tigers is to build a small platform or machan in the branches of a tree by the side of a path along which these animals are accustomed to pass. On this the hunter takes up his post at nightfall, and remains watching until daybreak in the hope of obtaining a shot. Sometimes this machan is constructed near the body of an animal which the tiger has killed and only partly devoured. The sportsman knows that "Mr. Stripes" is almost certain to return to his feast. In other cases a goat or buffalo is tied up near the machan to serve as a bait for the tiger.

In the dense jungles of Mysore, through which it is impossible for the beaters to make their way, the tiger is usually destroyed by means of stout netting, wherewith the thicket in which the animal has taken up its abode is carefully inclosed. The tiger is then driven from his retreat by means of rockets, and attempts to dash through the netting, in the meshes of which he soon becomes entangled, and is then easily killed.

A fourth way of destroying this animal is much more singular. A number of large broad leaves are smeared with bird-lime and scattered in the animal's path. When the tiger comes to the spot, he treads upon one of these leaves, and, finding that it adheres to his foot, tries to rub it off against his head. The only result of this proceeding, of course, is to cover his ears, eyes, nose, and mouth with the glutinous substance. Meanwhile he has trodden upon more leaves, of which he tries to rid himself in the same manner. And before very long the poor animal, blinded and bewildered, is entirely at the mercy of his enemies. This method of destroying the tiger is mentioned in old books, but does not seem to have been employed during recent years.

\section{THE LEOPARD}

The Leopard or Panther is inferior to the Tiger in size and in brute strength, but it is quite as cunning and far more active, and probably does even more damage. Like the tiger and the lion, the leopard resembles a huge cat, and it shares with them and the rest 
of the cat tribe the peculiarities that have already been noticed in the character of the claws, the pads upon the feet, the eyes, whisliers, and teeth.

The general colour of the leopard is as a rule a yellowish fawn, the sides being somewhat paler than the back, while the under part of the body is lighter still, and may at times be white. On the head, neck, back, and limbs the leopard is marked with black spots, while on the sides it has larger ring-shaped markings of the same colour.

At one time it was thought that the leopard and the panther were different animals, but they are now looked upon as belonging to exactly the same family, although they may vary greatly in size. The leopard may be described as a small panther, while the panther is nothing more than a large leopard.

The leopards are distributed over a greater part of the world's surface than almost any other members of the cat tribe. They are to be found in all parts of Africa, and all but the coldest parts of Asia, and wherever they are met with they are the most destructive of all the wild animals that prey upon the shepherd's flocks.

In one respect the leopard has a great advantage over both the lion and the tiger, for it is a clever climber, and can run easily up the smoothest and most slippery trees. A hunter perched high up in a mackan is fairly safe against the tiger, so long as he is above springing distance, but he is by no means beyond the reach of the leopard, which, if wounded, will climb up to the platform and endeavour to drag him down. It is not often, however, that the leopard will allow himself to be shot at from a machan. The tiger, which is not accustomed to climb, seldom raises its eyes to the upper branches of the trees around, and therefore walks unsuspectingly underneath the hunter's perch. The leopard, on the other hand, is almost as much at home in the tree-tops as on the ground, and is accustomed in his stealthy prowl through the forest to examine all his surroundings with equal keenness.

One of the most curious facts about the leopard is its fondness for dog-flesh. It is not as a rule a courageous animai, although it will fight with the greatest determination when wounded, but to capture a dog it will run the most extraordinary risks. In some 


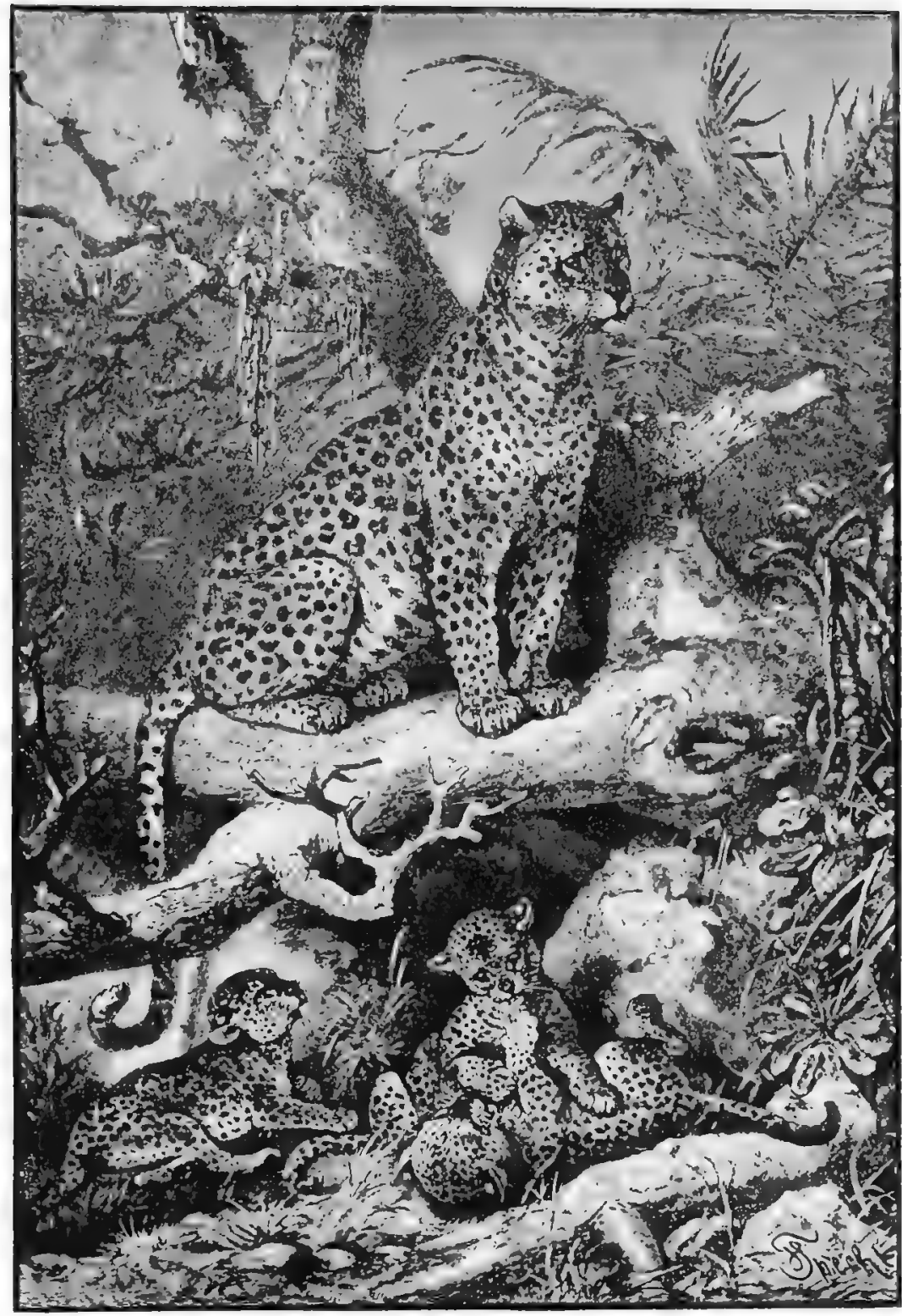


villages of India, around which leopards are plentiful, it is almost impossible to protect dogs from the attacks of these fierce and cunning foes.

\section{THE HUNTING LEOPARD}

Imagine a cat's head on a dog's body, and you will have a fairly good idea of the appearance of the Cheetah, or Hunting Leopard. This remarkable animal differs from the other members of the cat tribe in the fact that the claws are not completely

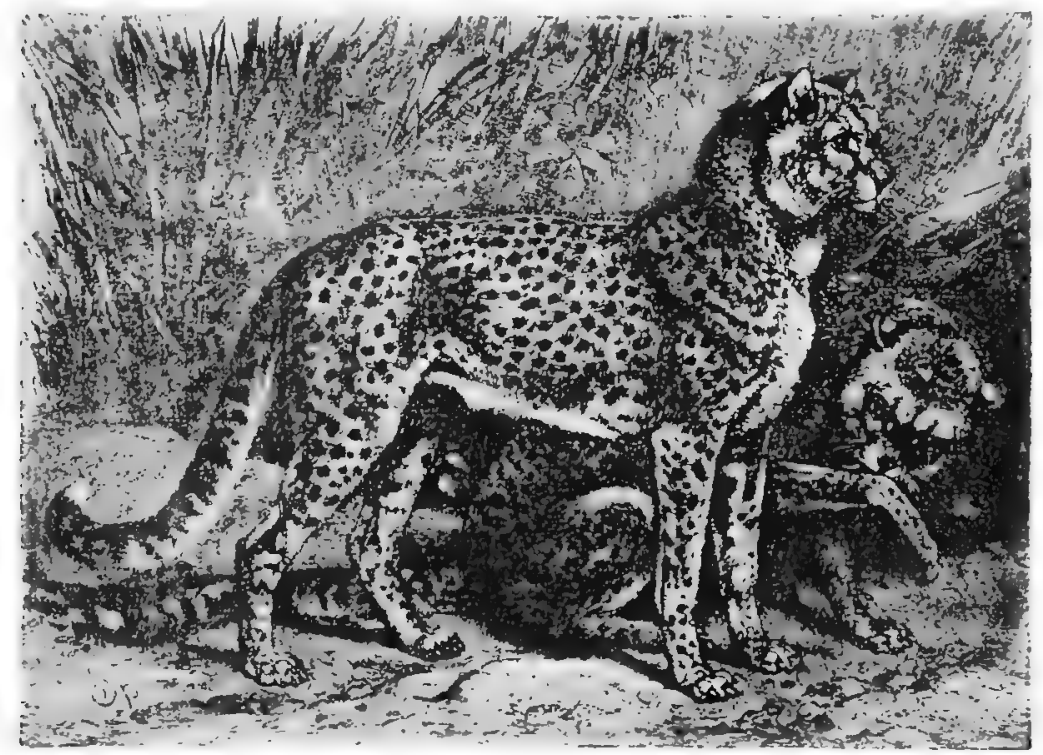

Cheetah or Hunting Leopard

covered by the protecting sheaths, and the nature of its teeth is also so peculiar that it has been placed by itself as a separate genus or family.

We find the cheetah in most parts of Africa and throughout almost the whole of Eastern Asia, but it is principally in India that it has been tamed and used for hunting purposes. It is believed 
that over a short distance the cheetah is the fleetest animal on the face of the earth. Even the greyhound and the race-horse are slow by comparison. But the cheetah cannot run far without resting, and if he fails to catch his prey at the first attempt, he makes no effort to follow it up. Sir Samuel Baker gives an account of a hunt with the cheetah. The animal was taken to the scene of the hunt in a cage. When the game was sighted the cheetah was loosed and crept cautiously towards its prey. Sir Samuel Baker says: "We followed quietly upon horseback, and in a few seconds we saw the two bucks about a hundred and twenty yards distant, standing with their attention fixed upon us. At the same instant the cheetah dashed forward with an extraordinary rush. The two bucks, at the sight of their dreaded enemy, bounded away at their usual speed, with the cheetah following, until all the animals were lost to view in the scattered bushes. We galloped forward in the direction they had taken, and in less than three hundred yards arrived at the spot where the cheetah had pinned the buck. This was lying upon its back without a struggle, while the firm jaws of its pursuer gripped it by the throat. The cheetah did not attempt to shake or tear the prey, but simply retained its hold, thus strangling the victim, which had ceased all resistance.

"The keeper now arranged the hood upon the cheetah's head, thus masking the eyes, which were gleaming with wild excitement, but it in no way relaxed its grip. Taking a strong cord, the keeper now passed it several times around the neck of the buck, while it was still held in the jaws of the cheetah, and, drawing the cord tight, he carefully cut the throat close to the jaws of the tenacious animal. As the blood spurted from the wound it was caught in a large but shallow wooden bowl or ladle, furnished with a handle. When this was nearly full, the mask was taken off the cheetah, and, upon seeing the bowl full of blood it relaxed its grasp, and immediately began to lap the blood from the wellknown vessel. When the meal was finished, the mask or hood was replaced, and the cheetah was once more confined within its cage, as it would not run again during that day."

Another traveller tells us that if the cheetah fails to strike his prey at the first rush he walks about for a few minutes in a tower- 
ing passion, after which he again submits to be helped on to the cart. Many hunting leopards become exceedingly tame and show the greatest affection for their keepers.

\section{THE JAGUAR.}

The Jaguar is to the New World what the tiger and the leopard are to the old. It is somewhat larger than the leopard and smaller than the tiger, and in appearance at least is fiercer than either. Throughout the greater part of South and Central America it reigns as undisputed King of the Forest, and in some cases is almost as dangerous to man as the Bengal Tiger himself. It can climb as well as the leopard, is as clever a hunter, and is, in addition, an accomplished fisherman.

The jaguar fishes, like the cat, with its paw, and frequently makes a meal of the turtle, which it dexterously turns on its back. It is said that it does not hesitate at times to attack even the crocodile and the alligator. On dry land the jaguar may be victorious, but in the water its enemy, crocodile or alligator, has an immense advantage, and after a time will probably pull it into mid-stream and hold it under water until it is drowned.

Another animal with which the jaguar frequently comes into conflict is the peccary, a hog of very small size, but one of the fiercest of its tribe. The jaguar is very fond of peccary, but as it is usually to be found in herds and is absolutely fearless in attacking any enemy, even man himself, and inflicting terrible wounds with its short sharp tusks, the peccary is not an animal that can be easily caught. The jaguar, however, falls back upon its skill as a climber, seizes a straggler from the herd, and bounds into a tree. The peccaries will surround the tree and keep the jaguar a close prisoner for hours, but it sits patiently out of their reach and waits until they are driven by hunger to disperse.

The advantage is not always, however, with the jaguar. In one case, after seizing a peccary in this way the assailant chose a tree that was too low, its savage little enemies stormed its position and literally ripped it to pieces with their tusks. 


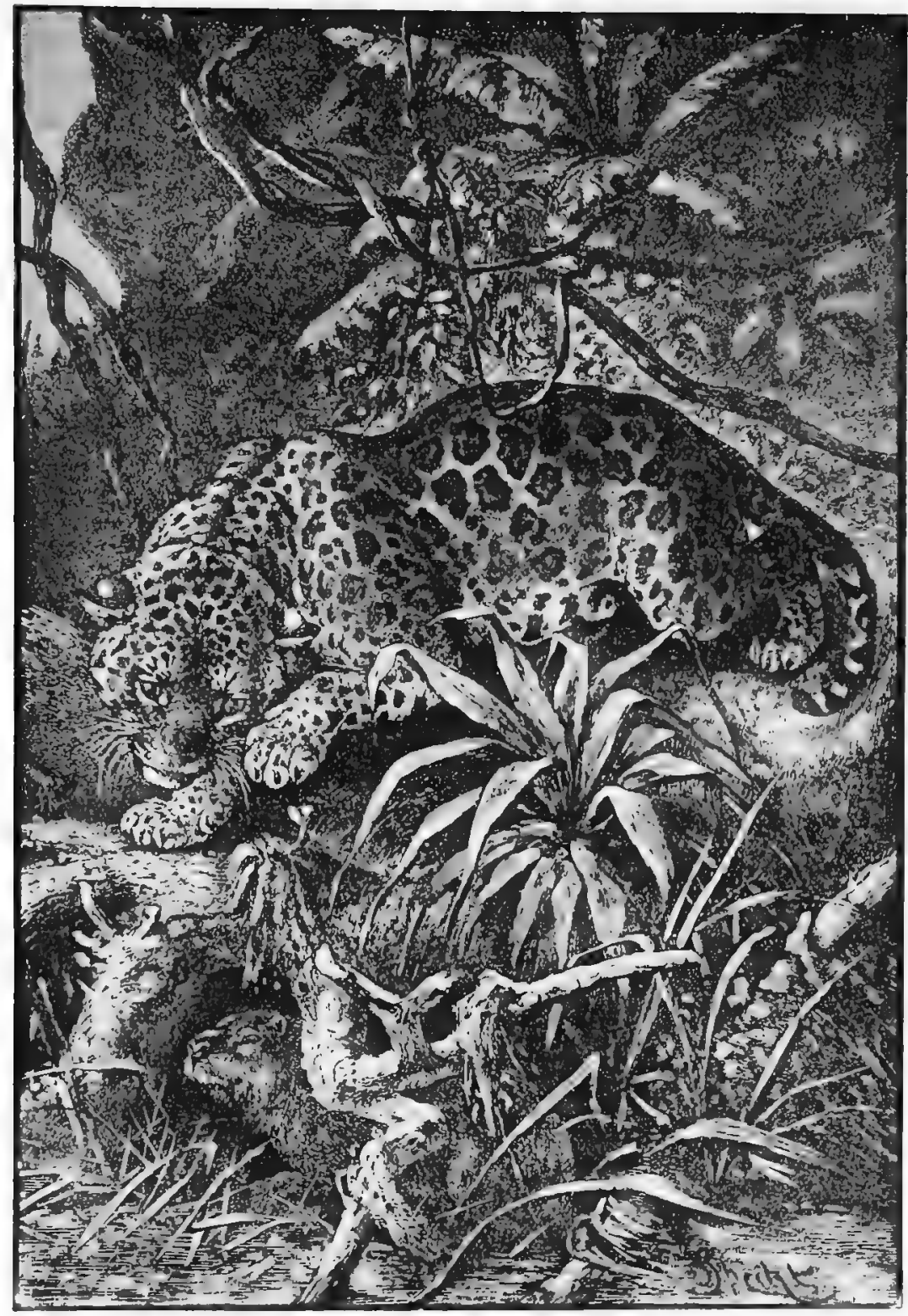




\section{THE PUMA}

Next to the jaguar, the Puma, or Cougar, as it is sometimes called, is the largest member of the cat tribe to be found in America. It extends over a far greater area than the jaguar, ranging from British Columbia in the north to Patagonia in the far south. In this enormous tract of country, extending over 6000 miles in length, there are, of course, great differences of climate, and the puma adapts itself in the most wonderful manner to the peculiarities of the country in which its lot happens to be cast. It is equally at home in the snow-clad mountains of North and South America, in the tropical forests of Brazil, or on the grassy plains of the Argentine.

In appearance the puma more nearly resembles the lion than the tiger, but it has not the enormous mane to which the lion owes so much of its beauty, and in comparison to its size, which is considerably less than that of the lion, it has a longer body and a shorter head. It is often said that the puma is a cowardly animal, but those who know it best tell extraordinary stories of its courage and ferocity. The mistake has probably arisen from the fact that in South America the puma will scarcely ever venture to attack man. Indeed, so great is its fear of mankind that it makes little or no attempt even to defend itself against the hunter. It is indecd said that the South American puma has been known to guard human beings against the attacks of other animals.

In North America, on the other hand, the puma is by no means friendly. At times he will venture to attack children, and when wounded will fight desperately with the hunter. But, as a rule, he prefers, if possible, to slink away.

Very different, on the other hand, is his behaviour towards the various wild animals that compete with him for a living in his native forests, mountains, or plains. There is no animal in America so universally dreaded as the puma. Even the lordly jaguar is not safe from its attacks. A traveller in South America writes that "it is well known that where the two species inhabit the same 
district they are at enmity, the puma being the persistent persecutor of the jaguar, following and harassing it as a tyrant-bird harasses a hawk, moving about it with such rapidity as to confuse it, and,

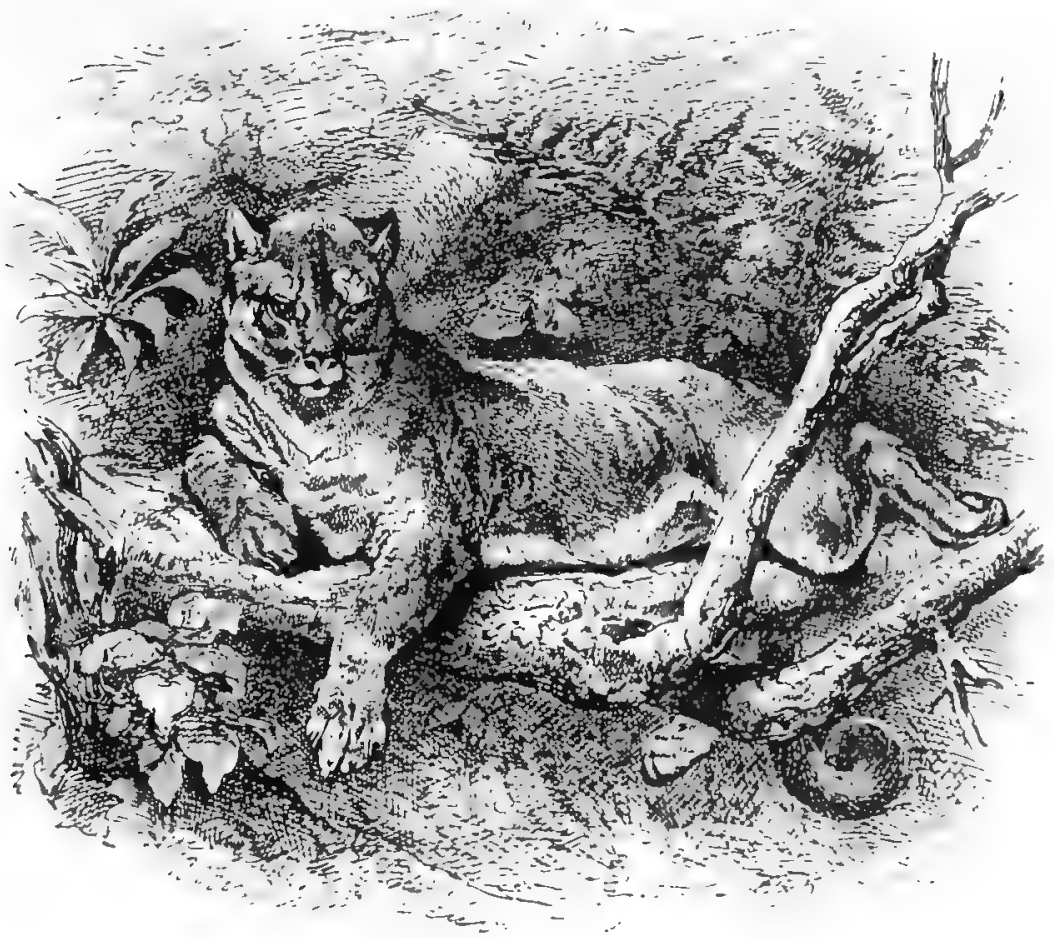

Puma

when an opportunity occurs, springing upon its back, and inflicting terrible wounds with teeth and claws. Jaguars with scarred backs are frequently killed, and others, not long escaped from their tormentors, have been easily overcome by the hunters."

Great battles also occur in North America between the puma and the grizzly bear, and it is believed the latter usually comes off second best in the struggle. 


\section{HYÆNAS}

The Cat family, as we have seen, includes a very large number of animals differing widely from each other, but all having certain qualities in common. The next important family is that of the Dogs, but there are several animals with a certain resemblance both to the Cat and the Dog tribe that cannot properly be classed in either family. Of these the Hyæna is perhaps the most important.

The Hyæna, which is rather larger than a collie, somewhat resembles a rough-haired $\operatorname{dog}$ in general appearance. On the neck, however, is a mane of bristly hairs, and the body slopes from the shoulders almost to the tail. This is due to the fact that almost the whole muscular strength of a hyæna is concentrated into the fore parts of its body.

The jaws are so immensely powerful that they will crack and splinter the thigh-bone of an ox; and the fore-legs, which are employed for digging, are also very large and strong. But the hind-legs, which are not so used, are quite short and small in comparison; and to this fact the animal owes its slinking appearance, and its curious shambling gait.

Like the jackal, the hyæna is very much averse to seeking prey for itself, and much prefers to feast upon the carcasses of animals which have been killed by beasts of prey, or have died a natural death. When pressed by hunger, however, it will sometimes attack cattle, and has a curious way of suddenly springing up just beneath their eyes, in the hope of startling them, and causing them to take to flight. If the frightened animal does so, the hyæna leaps upon its flanks, and tries to tear it to the ground.

But the hyæna is a sad coward, and will never attack any animal which faces it. For this reason it often happens that the strong and vigorous cattle fall victims to it, while those that are weakly escape; for the former attempt to run away, while the latter, being unable to do so, are compelled to stand their ground. 


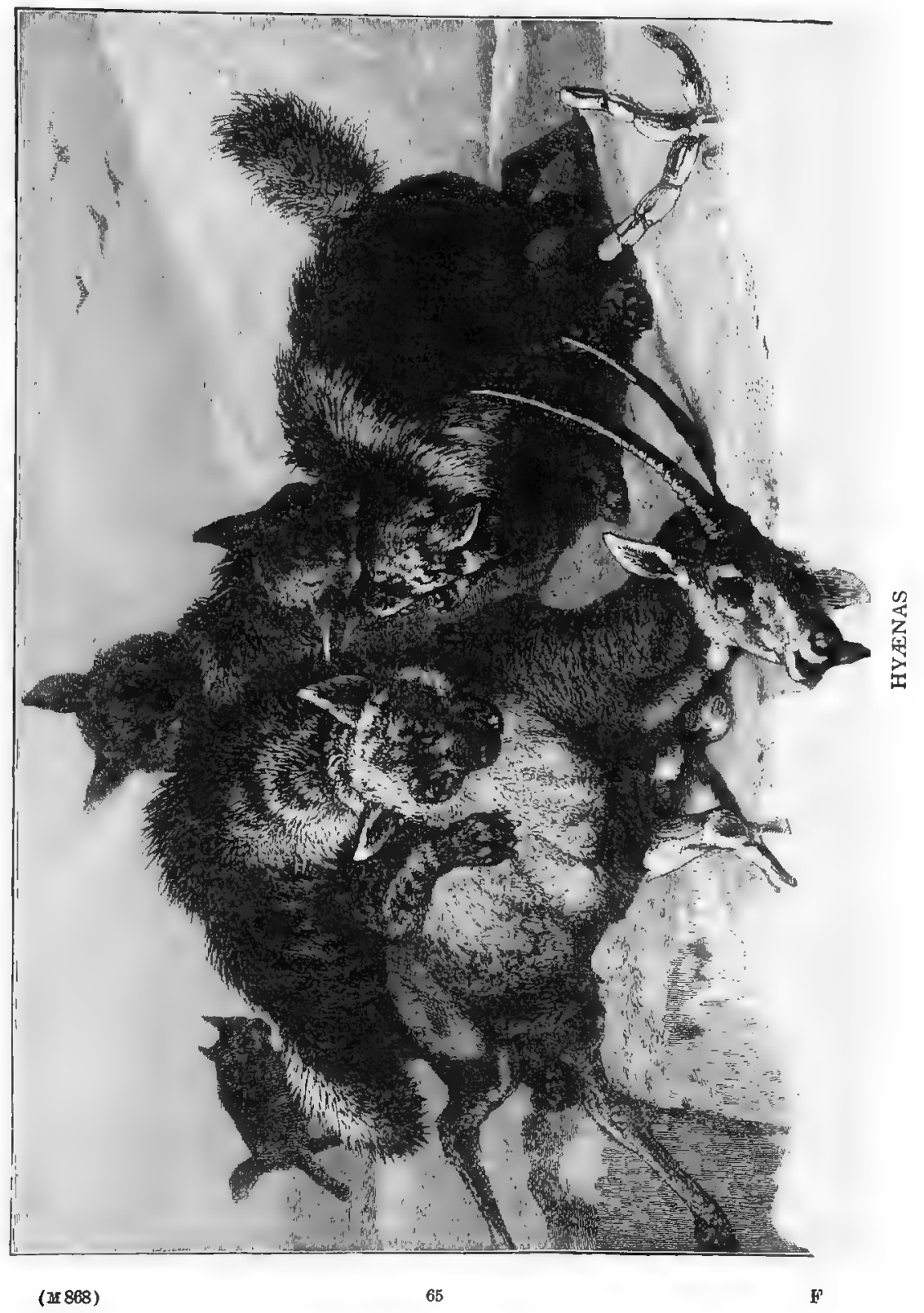


Owing to the cowardice of the hyæna, the Arabs entertain a great contempt for the animal, and think that it is beneath the dignity of a man to kill it. When they find a hyæna in its burrow, they fling a handful of wet mud in its face, drag out the bewildered animal before it has recovered from its surprise,

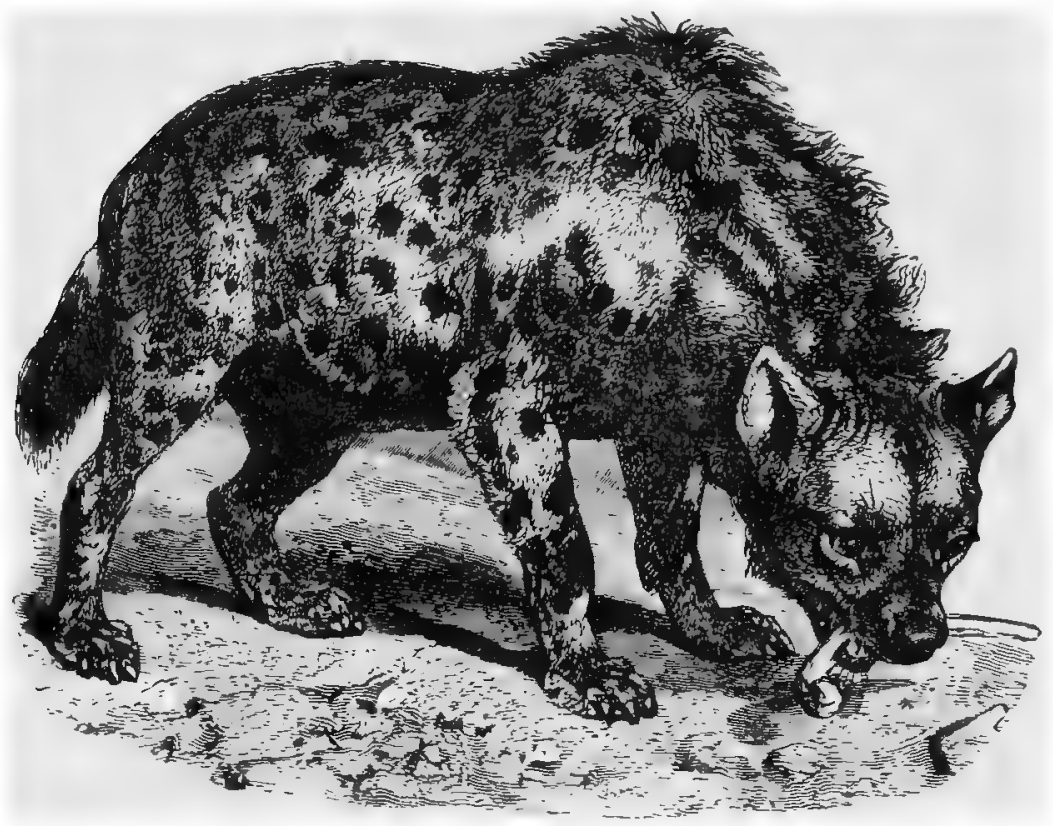

Spotted or Laughing Hyæna

bind its limbs, and then give it to the women and children to be stoned to death. Even a spear or gun which has been employed to kill a hyæna is considered as defiled and unfit for further use.

The jackals, as we shall see, act as scavengers in the towns of India and Ceylon, roaming in large bands through the streets by night, and devouring all the offal which has been thrown out from the houses. The hyænas behave in just the same manner in the African villages. But they are more enterprising than the jackals, and the inhabitants are obliged to close their doors at 
night, lest a hyæna should enter and carry off one of the smaller sieepers.

So cautious and cunning are these animals, that they have been known to take an infant from its mother's arms without awakening her; and a prowling hyæna has been known to crush in the skull of a man sleeping with a party of others, and drag his body away, without disturbing his companions.

One of these animals, known as the Spotted or Laughing Hyæna, is remarkable for the extraordinary cries to which it gives vent when excited. At such times it behaves in a most singular manner, standing upon its hind-legs, turning round and round, dancing up and down, bowing its head towards the ground, and performing all manner of ungainly antics, uttering meanwhile its hideous laughing cry, which can be heard for a very considerable distance.

In olden days it was thought that when the animal "laughed" in this manner it was endeavouring to imitate the cries of a human being in distress, in order to allure some passer-by to a spot from whence it might spring upon him.

The African settlers destroy this hyæna in a very simple but ingenious manner. Fastening a spring-gun in position, they fix a piece of meat upon the muzzle, and connect it by a cord, or the stem of some creeping plant, with the trigger. As soon as the hyæna attempts to pull away the meat, the gun is discharged, and the animal falls dead with a bullet through its brain.

\section{The Dog Family}

The dogs that we know in everyday life have, like the cats, a large number of wild relations which endeavour as a rule to keep as far as possible from the haunts of men. The Canidæ, as the whole of the Dog tribe are called, include, in addition to the many kinds of dogs which we all know by sight, the wolf, the fox, the jackal, and a number of other inhabitants of field and forest. 
There are, of course, great differences in the appearance of these members of the same family, but there are some features that are common to all, and enable us to see at a glance that, however unlike they may otherwise be, they are more or less closely related. All the dog tribe, whether wild or tame, have long pointed muzzles, while those of the cat family are always short; they have far more teeth than the cats; their tails are comparatively long, and the claws of their feet cannot, like those of the cats, be withdrawn, when not in use, into a protecting sheath.

Another important difference between the dog and the cat tribe is the fact that while cats usually hunt alone or in pairs, dogs, being less able to protect themselves, prefer, as a rule, to seek their prey in packs. By this means they make up in numbers for what they lack in strength.

\section{THE COLLIE DOG}

Although our domestic Dogs are of many different breeds, we can only talk about one, and that one shall be the Collie.

What a shepherd would do without his faithful collie it is not easy to guess. For the dog is not merely his pet, his friend; it is also his clever and willing servant. It does work for him which he could not possibly do for himself. It is ever ready to obey his lightest word, or even a simple gesture of his hand. It guides the sheep, it prevents them from straying, and it gathers and keeps them together. And if a sheep or a lamb should be lost, it sets off in search of it, and does not rest until it has found the wanderer and brought it back.

The clever dog even knows its master's sheep from others; and if some of them should happen to be mingled with another flock, it will pick them all out without making a mistake. Indeed, if his dog were to be taken away, the shepherd would be quite at a loss, and would be, in many places, unable to manage his flock.

The sheep very soon discover that the collie does not mean to hurt them; and although they move away when it runs up to them and barks, that is only because they know what it wants them to 
do. If any danger should appear, they will all crowd round it, seeming to know that, like the shepherd himself, it is their true friend.

The cleverness of a collie was once shown in a remarkable way. Just as it was growing dark, a large flock of lambs suddenly took

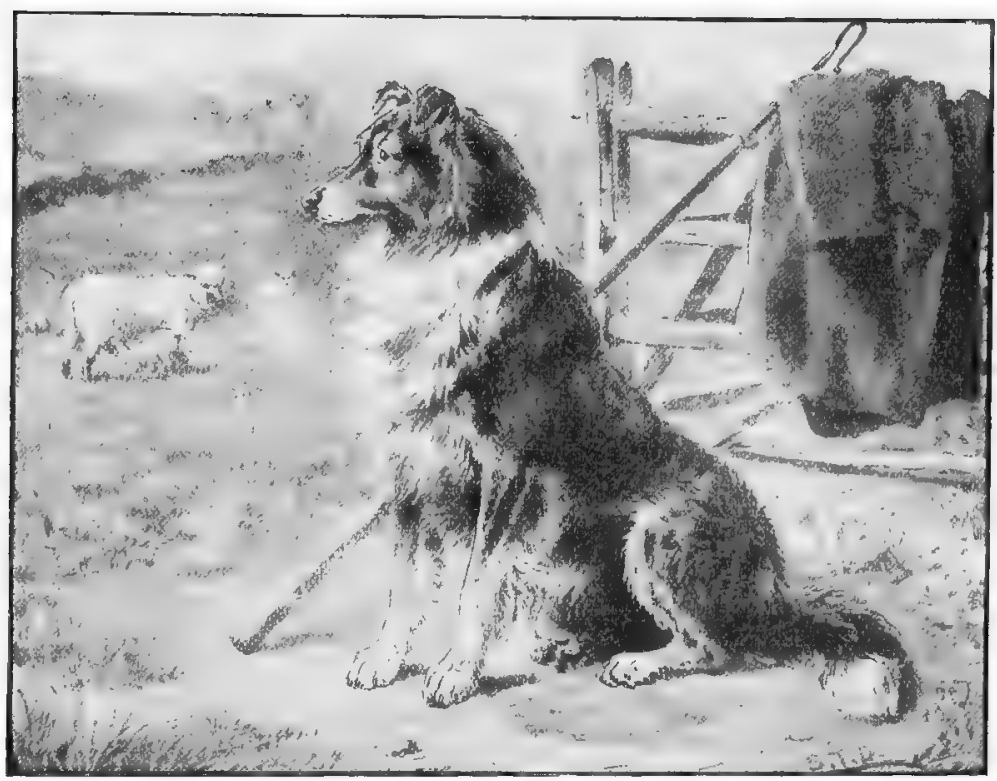

Collie Dog

fright and scattered in three different directions. The shepherd, after trying in vain to bring them together, sent his collie to look for them in one direction, while he himself started off in another.

All night long the shepherd walked without finding any of the wanderers, and at break of day he came sadly back again to tell his master of his loss. When he drew near the place from which he had started, what was his surprise to see his faithful collie standing guard over a flock of lambs! And what his delight when he found that all three bands were there, and that not a single lamb was missing' 
The clever dog had found them all, and brought them all together.

If you look at a collie you will see how well suited it is for a hardy, outdoor life. The long, thick coat of hair keeps it warm even on the coldest night; the bushy tail covers its paws and nose when it lies down to sleep; while its limbs are very strong. It is indeed a wonderful dog in every way, and is one of the most useful four-footed servants that man has.

\section{THE WOLF}

Just as the lion is a kind of cat, so the Wolf is a kind of dog. If, for example, you could examine the legs of a wolf, you would find that they were exactly like those of a dog; slender, and yet very strong, with just the same kind of stout but blunt claws.

For a wolf does not use its claws as a lion does, in tearing down its prey. The way in which a wolf kills its victims is by springing up at them as they are running along, and snapping over and over again at their throats, so as to tear their flesh, and weaken them by loss of blood.

Its claws, therefore, are not sharp, like those of the cat, neither are they drawn back into sheaths while not in use. The consequence is, that as fast as they grow they are worn away by rubbing against the ground.

If the wolf finds the body of some animal that has already been killed, it will not take the trouble to hunt for prey, but will eat such as it finds.

Wolves as a rule are not courageous, and will not attack even an unarmed man unless they are very hungry But in the winter, when food is scarce, they become very savage and desperate, and lose all sense of fear.

How timid the wolf is at other times is shown by the simple manner in which hunters prevent it from stealing their game. All that they have to do is to plant a short stick in the ground, beside the body of the dead animal, and to tie a narrow strip of calico or linen to the top. This flutters about in the wind, and so frightens the wolf that it will not even approach it. 


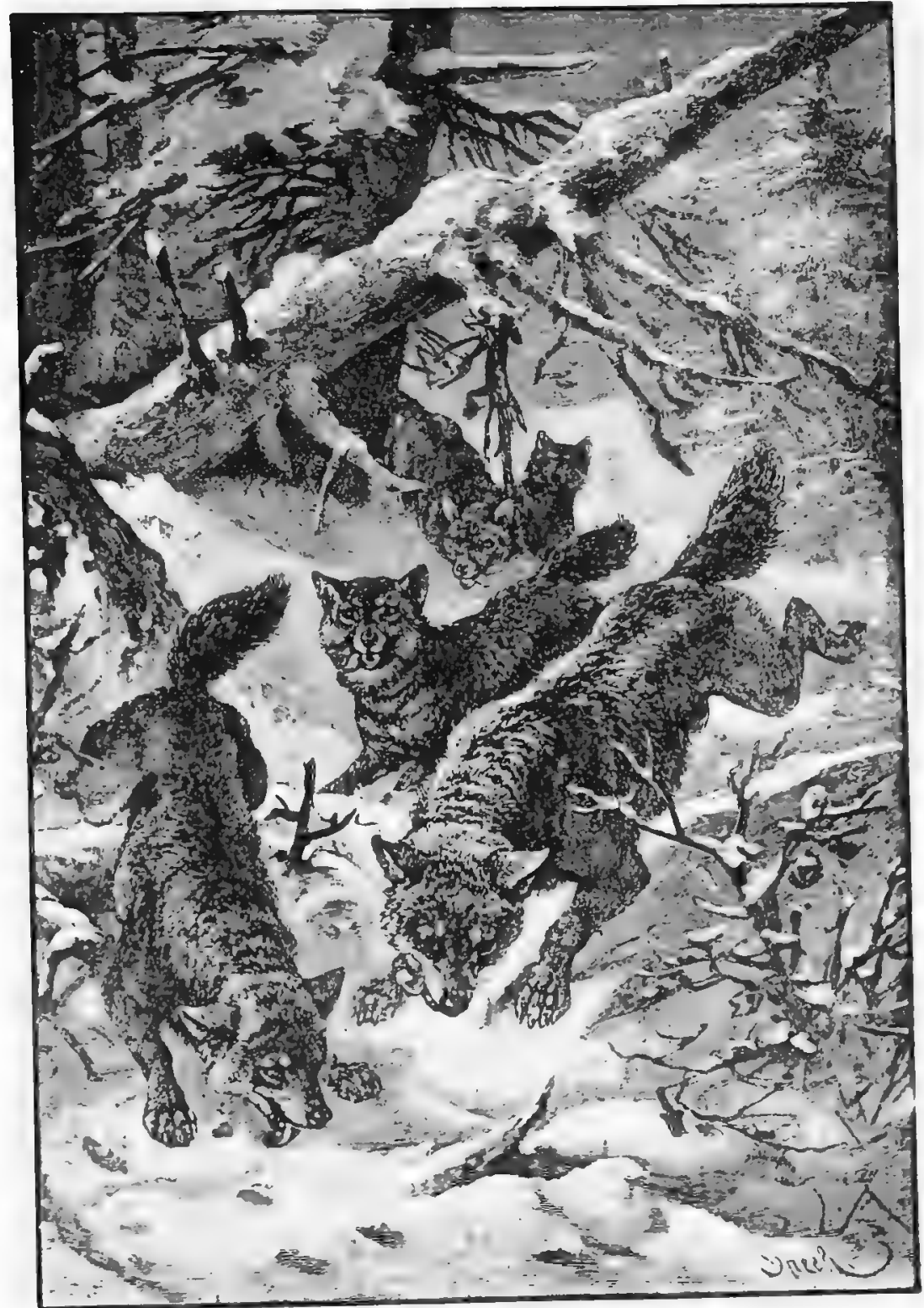

PACK OF WOLVES 
Like most members of the dog tribe they have an extremely keen sense of smell, and this enables them to track their prey over vast distances.

When a party of travellers has been pursued by a pack of wolves, they have sometimes saved their lives by throwing out various objects, such as coats and cloaks, from their carriage. As each was thrown out, the wolves stopped for a time to cautiously examine it; and in this way they were kept at a distance until a village was reached.

It has been found, too, that in Norway the wolves are so much afraid of the telegraph wires, that they have never been known to pass underneath them.

Wolves prefer as a rule to hunt in packs, particularly in the winter, when they are forced to run great risks in order to obtain food. It is said that when combined in this way they conduct their hunting on a definite plan, each member of the pack having a certain duty to perform. This combination is, however, purely selfish, for they have no feeling of affection towards one another. If a wolf be wounded, his companions will tear him to pieces and eat him on the spot.

While the wolf is still young it is easily tamed, and will soon learn to follow its master like a dog. It is said that in such a case it loses all desire for a wild life, and will never even try to rejoin its companions, even if it should be permitted to wander about as it pleases. But it can never be taught that it must not go into the poultry-yard and kill the chickens; and therefore it is not very often caught and kept as a pet.

\section{THE JACKAL}

When a lion has slaughtered a large animal, such as a buffalo or a deer, he is seldom able to make more than one hearty meal upon the carcass of his victim, for, even while he is eating, a number of hungry jackals are almost sure to assemble, and anxiously await their opportunity to seize upon the remnants of the feast. And as soon as he has finished his repast and retired into the 
nearest thicket, they rush hastily down to the remains of the carcass, and are soon snarling and quarrelling over it.

Jackals have sometimes been called the "lion's providers". It would be more accurate, however, to style the lion the "jackal's provider", since these animals so frequently obtain a meal from the remains of the victims which he has killed. They seldom hunt prey for themselves, for they are rather cowardly animals, and have been known torun away from even a small child armed with a stick.

In appearance they are very much like rather large foxes, with long, narrow muzzles and big, bushytails. They live, as a rule, in large packs, which hide away during the daytime

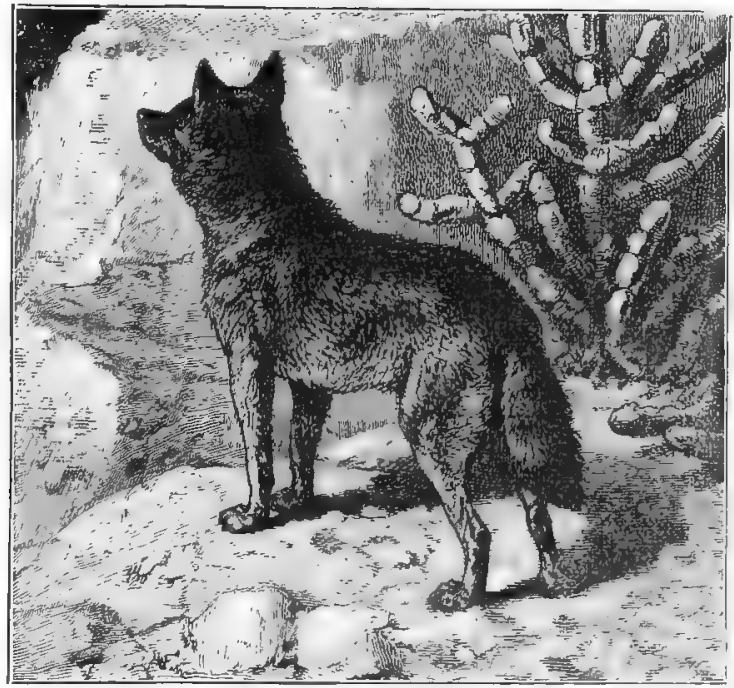

Jackal among bushes or in holes, and come out at night to scour the country in search of food.

Sometimes, however, a jackal will live all by himself, generally choosing the neighbourhood of a village for his habitation. In such a case he soon becomes very troublesome to the inhabitants, carrying off pigs, lambs, kids, and poultry with such caution that it is very difficult to shoot or trap him.

If a pack of jackals should happen to meet with a wounded animal they will follow it for days, seeming to know that it is certain to fall a victim to them at last. But so wanting in courage are they, that they will not dare to attack it until it sinks to the ground under the faintness of approaching death. 
Yet if these animals should be driven to bay they will fight with great determination and ferocity. Their teeth are long and sharp, and they deliver a succession of snapping bites, after the manner of the wolf, so as to lacerate the flesh of their antagonist, and weaken him by loss of blood. In one instance a pack of hounds were attacked by a number of jackals, which fought so furiously that they were with difficulty driven off.

Sometimes a jackal, perceiving that it has no chance against its pursuers, will escape by feigning to be dead. By this artifice one of these animals has been known to deceive quite a number of dogs, which, after biting and worrying it for some time, left it upon the ground as lifeless. No sooner had they abandoned it, hovever, than it cautiously raised its head, gave a quick glance round, and then ran away with all speed, apparently not much hurt.

The Common Jackal, or Kholah as it is termed by the natives, is a very useful animal in the towns of India and Ceylon, as it scours the streets by night, and devours the offal that has been thrown out. This offal, if it were allowed to remain even until the next day, would putrefy and poison the air, so that the jackals do good service in removing it. While engaged in their nocturnal task they fill the air with hideous yells; but the inhabitants are so accustomed to their outcry that it does not disturb their rest in the least.

In consequence of their usefulness, kholahs are protected in many parts of India, and allowed to roam at will. Under ordinary circumstances they seldom or never attack a human being. Occasionally, however, one is seized with madness, akin to that terrible canine disease which we call "hydrophobia"; and then it will run through the streets, even in broad daylight, snapping at every human being and animal that it meets.

Jackals have often been domesticated, and kept for many years in captivity, learning to obey the word of command, and to follow their master about just like pet dogs. In order to render them perfectly tame, however, it is essential that they should either be born in captivity, or else be captured while quite young; for if they have once enjoyed the freedom of a wild life, they have acquired a treacherous and revengeful disposition, which they never afterwards lose. 


\section{THE FOX}

The Fox has always been regarded as one of the most cunning and intelligent of all four-footed creatures, and there is no doubt

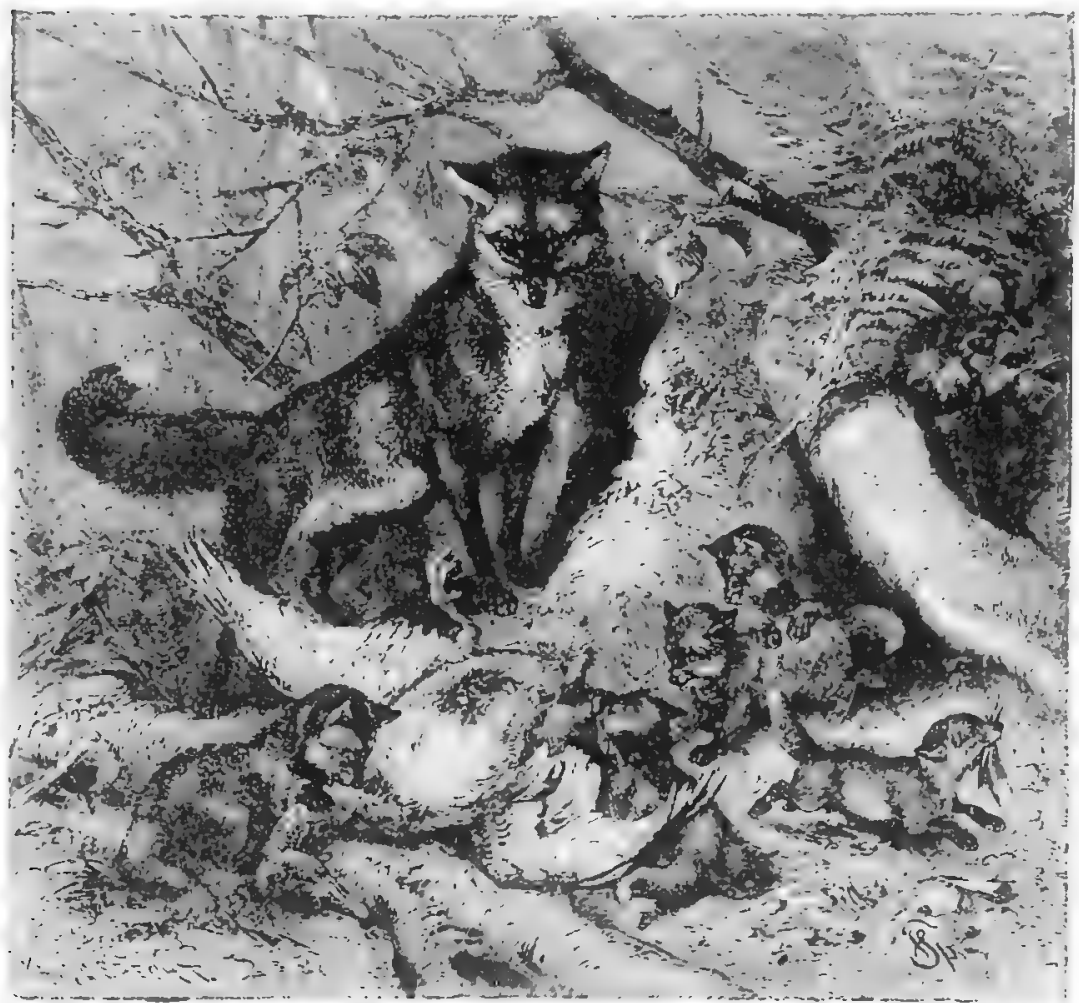

Fox and Cubs

that it well deserves its reputation. In appearance it differs widely from the dog, the wolf, and even the jackal, so widely indeed, that some naturalists regard it as a separate genus. It has a much sharper muzzle than the rest of the Dog tribe, its legs are shorter 
in proportion to its body, its tail longer and bushier, and its ears more erect. But the principal difference lies in the nature of its eyes, the pupils of which contract like those of the Cats in daylight, and expand at night.

Unlike the wolf and the jackal, the fox is a solitary animal. The members of a single family may hunt together, assisting one another in the most remarkable manner, but we do not find foxes associated in packs for mutual help.

The fox makes its lair, or "earth" as it is called, underground, in holes dug out by itself or stolen from some other burrowing animal. These holes are skilfully arranged to afford the fox as many means of escape as possible. As the character of its eyes might lead us to suppose, most of its hunting is done by night. A remarkable power of scent, together with acute hearing and eyesight, enable it to discover signs of danger with marvellous quickness. Its stealthiness of movement, quickness of eye, and great cunning, render it the most formidable of all the poaching tribe that prey on poultry and game; while its speed, and extraordinary skill in baffling pursuit, make its capture or destruction exceedingly difficult. It seldom ventures out of its lair by day, unless pressed by hunger.

Some remarkable stories are told of the cunning displayed by foxes when pursued by hounds and huntsmen. On one occasion we read, a fox, run hard by the hounds and "finding himself in great danger of being taken, made for a high wall at a short distance, and, springing over it, crept close under the other side. The hounds followed, but no sooner had they leaped the wall, than he sprang back again over it, and by this cunning device gave them the slip, and got safe away from his pursuers."

A curious instance of mutual help on the part of two foxes is given by a well-known naturalist. A sportsman was stationed one evening near a gully on a hillside when he observed two foxes playing together a short distance away. After a time, one of the foxes concealed itself under a large stone or rock at the bottom of the channel, while the other disappeared up the hill. The latter, however, soon returned, chasing a hare before it. As the hare was passing the stone where the first fox lay in wait, Reynard tried to 
seize her by a sudden spring, but missed its aim and the prey escaped. The chasing fox then came up, and finding that its prey had got away through its associate's want of skill, it fell upon its companion, and they both fought with so much fury that the person who had been watching them came up and destroyed them both.

We must find room for one other story of a fox's intelligence. A farmer, we are told, was looking out of his window one summer's morning about three o'clock, when he saw a fox crossing a field, carrying a large duck which he had captured. On coming to a stone dyke, about four feet high, on the side of the field, Reynard made an effort to leap over it with his prey, but failed, and fell back into the field. After making three attempts, with the same result, he sat down, and viewed the dyke for a few minutes. Then, apparently satisfying himself, he caught the duck by the head, and, standing up against the dyke with his fore-paws as high as he could reach, he placed the bill of the duck in a crevice in the wall; then, springing upon the top, he reached down, and, pulling up the duck, dropped it upon the other side, leaped down, and, picking it up, went on his way.

\section{The Bears}

The Bear family is in appearance so unlike any other that its members can be recognized at a glance. They are all heavy, awkward animals, with a peculiar shuffing gait, thick and clumsy body, short tail, and ragged fur. In walking they put the soles of the feet flat upon the ground, and the track of a bear has, therefore, some resemblance to that of a man. As they live partly upon flesh and partly upon vegetable diet, their teeth are specially adapted not only for tearing and cutting their food as in the dog, but for grinding and chewing, as in the purely vcgetarian animals, which we shall shortly discuss.

The bear family is widely distributed over the face of the earth. Its members are found in the frozen regions around the Poles, in North and South America, the greater part of Europe and Asia, 
and in certain districts of Northern Africa. As a rule, however, it avoids the hotter regions, and where it exists in the tropics it makes its home on the sides of hills and mountains considerably above the level of the sea, where it is cooler than in the surrounding and lower districts.

Most members of the bear family belong to what is known as the genus Ursus. This genus includes among others the polar and the brown bear. We shall notice, however, in addition, the sloth bear, a very interesting animal differing widely from these species.

\section{THE POLAR BEAR}

It seems strange that a warm-blooded animal, such as a bear, can live far away in the Arctic regions, where the ice and snow sometimes do not melt all the year round. But the Polar Bear, or "Nennook" as the Eskimos call it, is specially formed for such a life, and has such a warm coat of thick close fur that it never feels the cold.

There is another way, too, in which the polar bear is suited to the life it has to lead. It is often obliged to travel over the ice, especially when it wants to catch one of the seals which are to be found resting upon it.

Any other bear would be sure to slide about on the slippery surface, and would so alarm its intended victim. But the Nennook, unlike other bears, has the soles of its feet closely covered with stout bristles, so that it can always obtain a firm footing even upon the ice.

The feet of the polar bear, besides being very long and heavy, are furnished with a set of huge claws, with which it seizes and destroys its prey. It is a capital swimmer, and can even overtake and catch fish. Sometimes, too, it attacks the walrus, which is a kind of large seal, and kills it in a way so curious as to be worth description.

The walrus, like the seals, frequently leaves the water, and sleeps near the edge of a sheet of ice, or "floe" as it is often called, so that it may quickly dive into the sea if it should be 


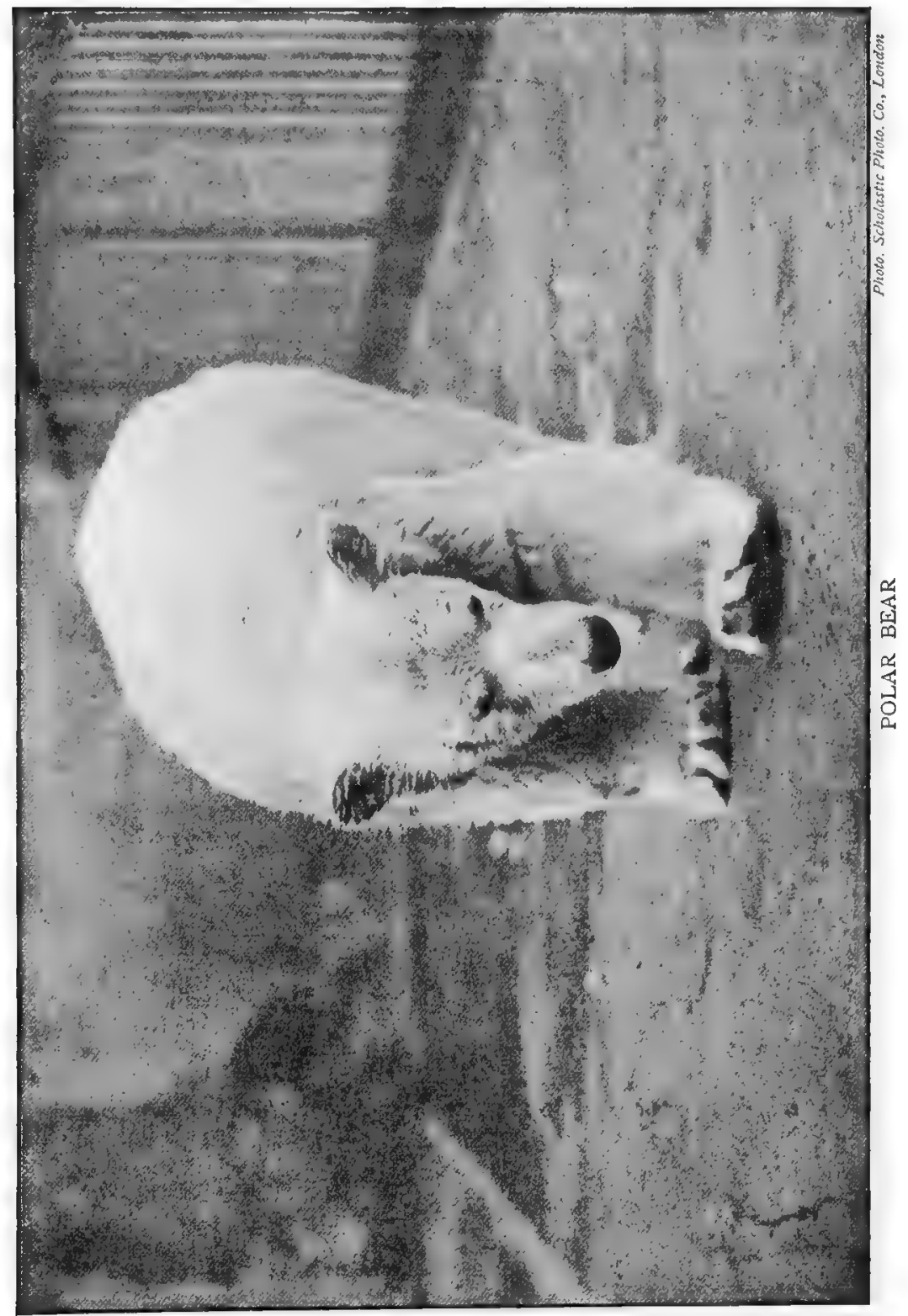


alarmed. But the polar bear creeps up so quietly that the walrus does not hear it coming. Springing upon it, he imprisons it by his powerful claws, and ends its life by crushing in its skull.

It was believed that bears tried to hug their enemies, and that they were able in their embrace to crush the breath out of their bodies. This was a popular delusion. But the polar bear bites; and its teeth are so large and strong, and its jaws so powerful, that it can inflict terrible wounds.

The polar bear is not nearly so courageous an animal as is often imagined; for if it is attacked it will nearly always run away. If it is brought to bay, howerer, it will fight most fiercely, and is then a very dangerous antagonist.

\section{THE BROWN BEAR}

The Brown Bear is more frequently met with than any other member of its family. Although, of course, the bear, like all other wild animals, is gradually disappearing in most civilized countries, it is still to be found in almost all the colder districts of the Old World, from Western Europe to Eastern Asia, and in the Atlas Mountains of Northern Africa. At one time it was common in this country, but the last bear found in a wild state in Britain is said to have been killed about the time of William the Conqueror.

The brown bear has a shorter muzzle, a larger head, and a shorter neck than his cousin at the Pole. Although, as his name indicates, his colour is usually brown, it varies considerably in shade according to the character of the country in which he lives. In the Himalayas, for instance, where the lower slopes are thickly wooded with silver birch, and where in winter the snow lies much longer on the ground than in the mountains of Europe, the brown bear is much lighter in colour than his relations in the west. This of course helps to make him less visible to his prey and his enemies -another example of the manner in which animals are adapted to meet the conditions under which they happen to live.

The brown bear eats as great a variety of food as almost any animal under the sun. It will eat vegetables and fruit, insects, fish, 
and flesh, but it prefers, as a rule, a vegetable diet. It is only when this fails that it preys upon other animals.

In the colder districts the brown bear, when winter approaches, creeps into a cave or hollow tree, and sleeps until the approach of spring. During this long nap it is kept alive by the thick layer:

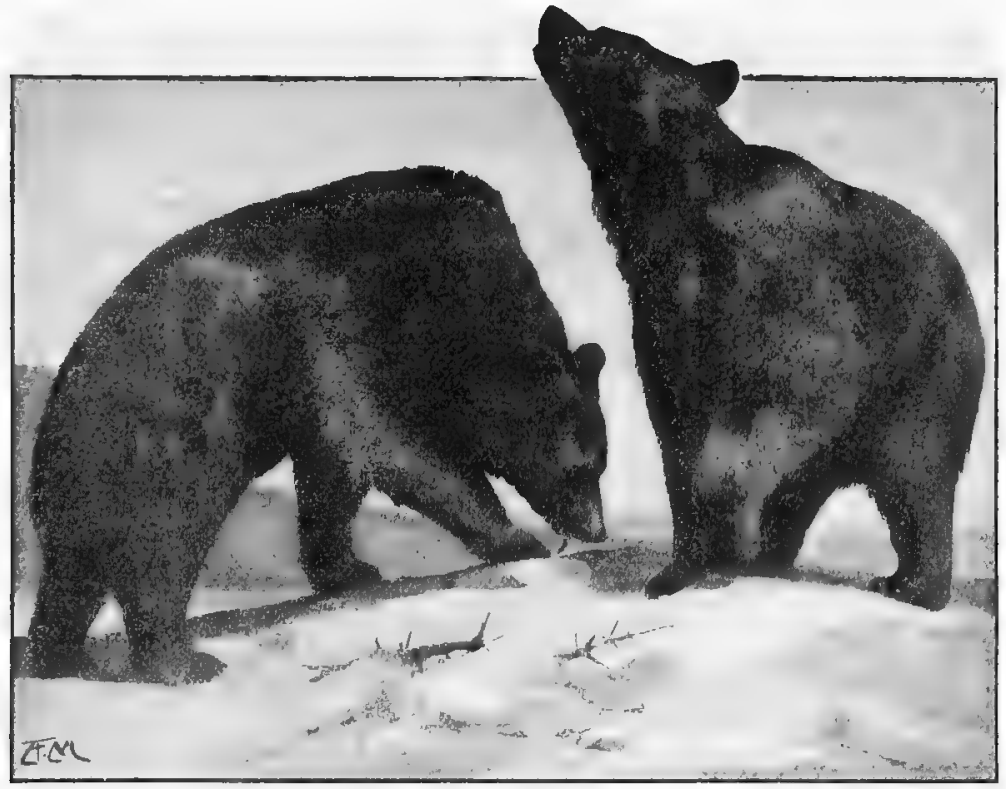

Brown Bears. (From a Photograph)

of fat that have accumulated upon its body during the summer months. This fat is gradually exhausted until, when the bear awakes and creeps forth from his den, he is a scraggy, pitiable object, as compared with the plump beast that settled down for its winter nap some months before. This habit of hibernating, as it is called, enables the bear to tide over the winter when it might otherwise starve for lack of its ordinary food.

The brown bear can be easily tamed, and as it possesses a iarge share of intelligence, can be taught to dance and perform tricks.

The great naturalist Herr Brehm, in his book Wild Life and (ar 868) 
Scenes, tells us how the Siberians whom he visited are accustomed to hunt the bear. During the summer the bear is seldom long in the same place, and is therefore very difficult to track. But in the

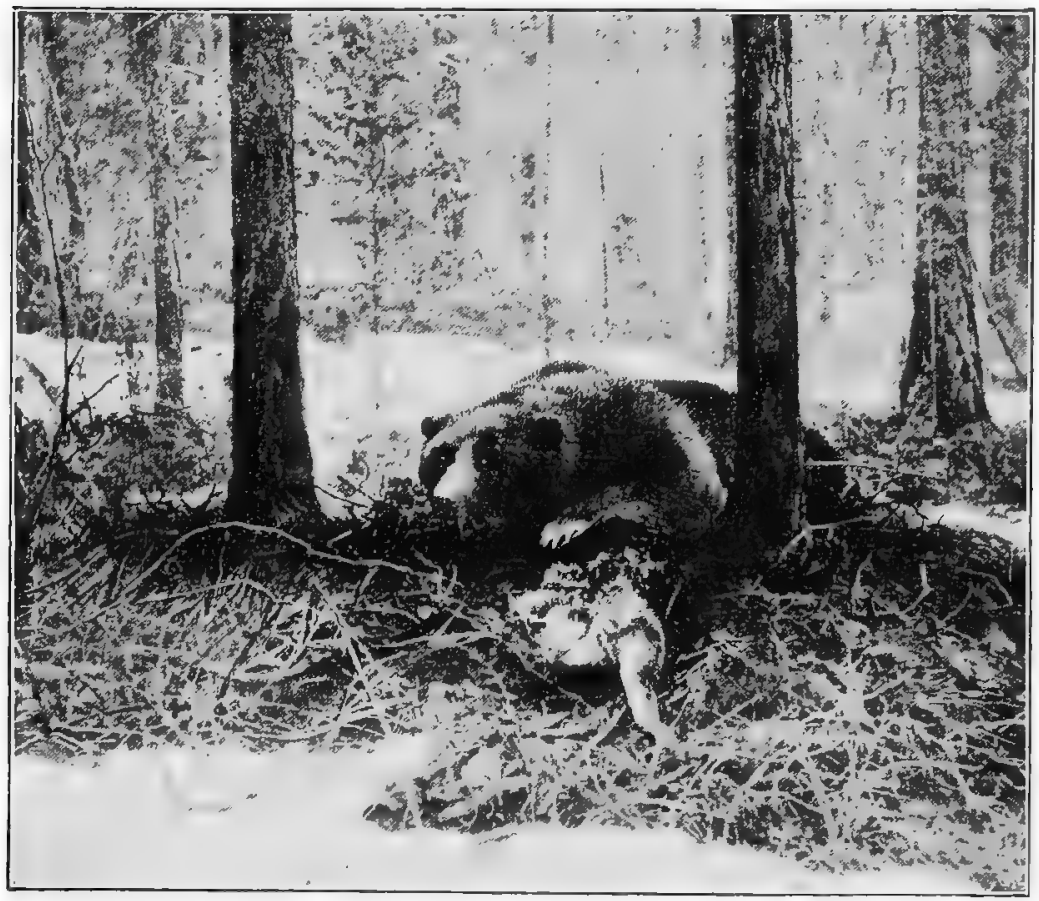

Large Grizzly, guarding the carcass of a deer, which he has covered with rubbish

winter he is often discovered asleep in his lair, and the peasant who finds him sells the secret of his hiding-place to some well-to-do sportsman. The latter collects a party of hunters, who surround poor Bruin in his hiding-place. "It is thus", says Herr Brehm, "that the great majority of the bears are secured, and to good shots there is little danger. In summer and autumn they track the bear with small dogs, and while these bait him on all sides, the sportsman seizes a good opportunity for a telling shot. Or he may use the bear-spear, as the bold Ostiaks do, and charge the animal. Or else he may wind birch-bark several times round his left arm, 
and, holding this as a shield against the angry bear, may plunge a long, broad knife into his heart as he snaps at the bark. In these modes of attack accidents do, indeed, often happen; but in the course of time some hunters become so expert and cold-blooded that they prefer the spear or knife to any other weapon. Indeed, a peasant girl in the village of Morschowa is famous all over West Siberia for having killed more than thirty bears with the knife."

In the Rocky Mountains of North America, extending some thousands of miles from Alaska to Mexico, lives the Grizzly, the fiercest and most dreaded of all the bear family. He is closely related to the brown bear of Europe. With the exception, perhaps, of the jaguar, there is no animal in the Western World which hunters are so cautious in attacking as this huge unwieldy animal, with its enormous strength, and its terrible equipment of tooth and claw.

The grizzly is considerably larger than the brown bear, measuring as much as nine feet in length, and weighing from 800 to 1000 lbs. Some years ago, before the Western territories of the United States were occupied by settlers, a species of grizzly, weighing when full-grown from 1000 to 1800 lbs., existed in the Sierra Nevada range. They proved, however, so destructive to the flocks and herds of the early settlers that the shepherds were forced to destroy them by poison, and few or none of these giants of the bear family now exist. The smaller grizzlies are still to be found in the more out-of-the-way districts, but even they are gradually disappearing.

\section{THE SLOTH BEAR}

The Sloth Bear differs widely from the other members of the bear family. It has short hind-legs, a very thick furry coat, and its snout and lower lip are unusually long. Altogether, it is certainly the ugliest and most ungainly of the bear tribe.

The curious shape of its snout and lower lip is evidently adapted to the sloth bear's manner of picking up a living. It exists almost 


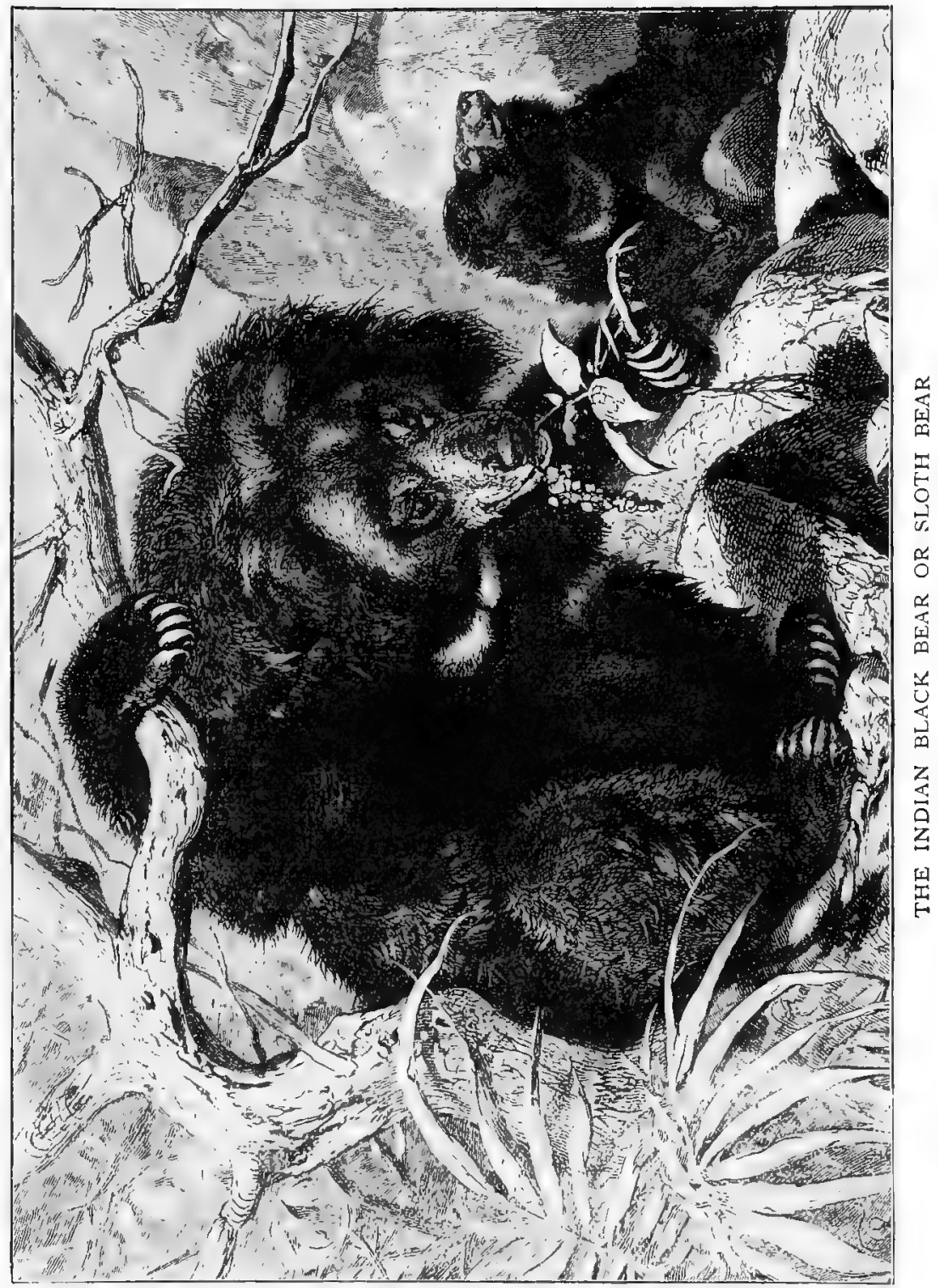


entirely on fruit and insects, and its long easily movable lips are of the greatest value in collecting its food.

The sloth bear lives in the hills and jungles of India, where it is one of the commonest of all wild animals. But it is rarely to be seen by day, for most of its hunting is done between sunset and sunrise. In diet it is by no means hard to please, but its favourite food is a dish of termites or white ants.

The manner in which it procures these tiny victims has been described in a very interesting way by a well-known naturalist. In the sloth bear, he says, "the power of suction, as well as of propelling wind from its mouth, is very great. It is by this means it is enabled to procure its common food of white ants and larvæ with ease. On arriving at an ant-hill, the bear scrapes away with the fore-feet until he reaches the large combs at the bottom of the galleries. He then with violent puffs dissipates the dust and crumbled particles of the nest, and sucks out the inhabitants of the comb by such forcible inhalations as to be heard at two hundred yards' distance or more. Large larvæ are in this way sucked out from great depths under the soil."

Except when provoked, the sloth bear seldom attacks man. But when wounded or driven into a corner it becomes an exceedingly dangerous foe, and can inflict terrible injuries with its powerful claws.

\section{The Weasel Family}

The Weasel family include not only the active little poacher from which they take their name, but various kinds of polecats, the badger, the otter, and a host of other animals. Members of the family are to be found in every part of the world except Australia and Madagascar, and, although they vary greatly in appearance, most of them have long, thin bodies and short legs. They are as a rule small in size, but very active and extremely skilful hunters. In pursuing their prey, which consists largely of 
burrowing animals, they are, of course, greatly assisted by the shape of their bodies, which allows them to make their way into the narrowest of holes.

The weasel is one of the most interesting of the small flesh-eat-

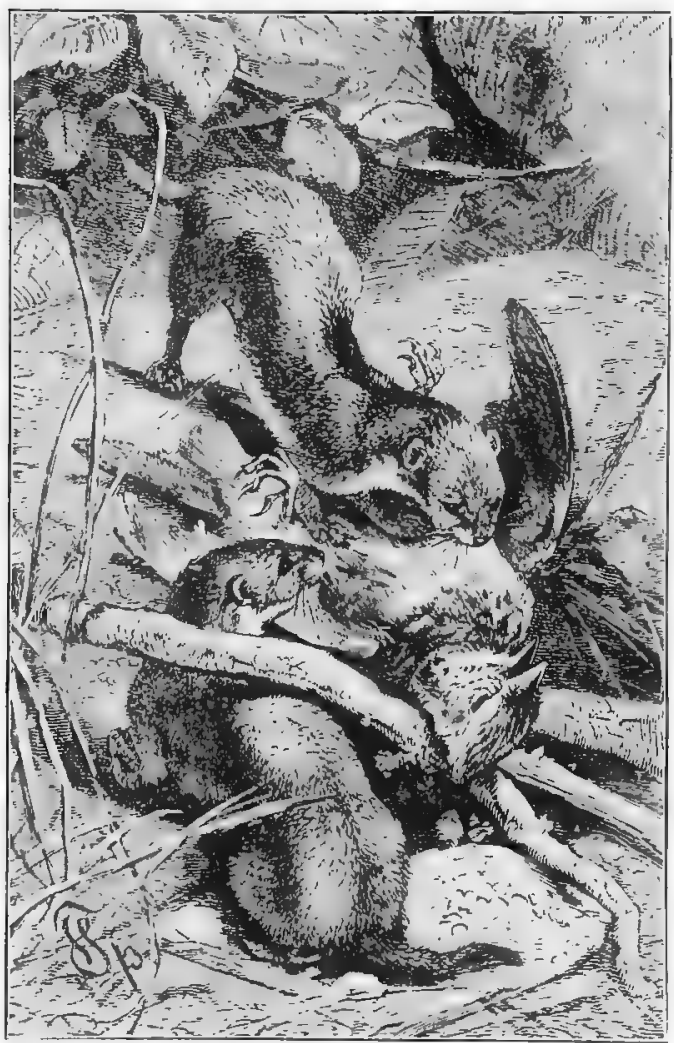

The Weasel ing mammals. It has two great qualitiesintelligence and courage, and, taken together, they enable it to triumph over animals far larger and stronger than itself. There is no doubt that weasels do a great deal of mischief among poultry and game, and they are especially destructive to hares and rabbits. But some naturalists believe that the harm they do to the farmer is more than balanced by their assistance in killing mice, rats, and voles.

The weasel is extraordinarily active in following up its prey. It can track almost as surely by scent as by sight, can climb trees as well as burrow into the earth, and when within springing distance its attack is unerring. Weasels are not only very courageous, but often combine for offence and defence. It is recorded that a peasant in Dumfriesshire, while working in a field, was attaclied by six weasels, which pursued him until he fortunately found a broken 
branch of a tree, and after killing three put the rest to flight. On another occasion a labourer, having struck a weasel and caused him to squeak, was attacked by over a dozen and severely bitten. He would probably have fared badly had not a passer-by come to his assistance.

The weasel is always full of courage, but its conduct often rises to heroism in defending its young. A pretty story is told of a weasel that was intercepted by a labourer while carrying one of her young ones in her mouth. The labourer kicked her, causing her to drop the little one, and she took refuge for the moment in a hedge. Wishing to learn how the mother would act, he stood over the little one flourishing a stick. The weasel made several attempts to get her charge, but was again and again driven back. At last, rendered desperate by her failures, she advanced boldly, and, dodging the stick, carried away the little one in triumph.

Weasels are occasionally attacked by incautious birds of prey, and the latter usually come off second best in the struggle. In one case a kite was observed to pounce upon a weasel, which it carried off in its talons. In a few moments, however, the kite began to show signs of great uneasiness, rising rapidly in the air, or as quickly falling, and wheeling irregularly round, while it was evidently endeavouring to free some obnoxious thing from it with its feet. After a short but sharp contest the kite suddenly fell to earth, and on the observer approaching, the weasel ran away apparently unhurt. The kite was dead, with a hole eaten through the skin under the wing.

\section{THE BADGER}

The Badger is, like many other animals, very quiet and inoffensive so long as it is not interfered with, but it is extremely dangerous to handle when roused. It has a rather long head, narrowing to a snout like that of the pig, small ears and eyes, a thick-set, clumsy body, short and thick legs, and long, curved claws which on the fore-paws are, as in all burrowing animals, sharp and broad. In many respects, as may be seen, the badger 
is not unlike the pig; but it is provided, like several members of the weasel family, with a stink gland that serves as a defence against its enemies.

The badger is found both in the Old and New Worlds, and in all varieties of climate, from the intense heat of Central Africa to the equally extreme cold of Siberia.

The common badger makes its home in a hole dug on the

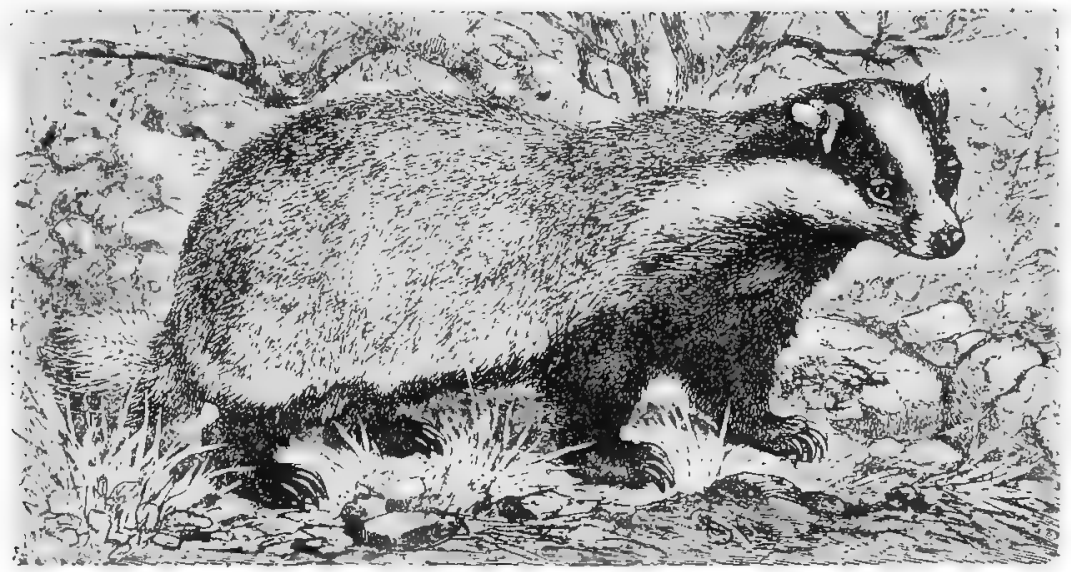

Badger

sunny side of lonely wooded hills. Passages of eight to ten yards in length, and sometimes as many as ten in number, lead from the surface above into a large underground chamber, which is made snug and warm with moss and dried leaves. Only two or three of these passages serve as everyday passage-ways to the outside; the others are intended for ventilation, or for flight in case of urgent danger.

In this cosy den the badger spends the day, and it ventures out only with great caution when night begins to fall. It is said that the fox sometimes visits the badger without an invitation, and stays longer than its host desires. It makes itself quite at home in the badger's housc, forcing the owner to retire into the deepest part of its dwelling.

In sunny lands the badger remains active the whole year round, 
but in the far north, where the winters are long and severe, it sleeps, like the bears, for months together. When spring arrives it wakes up, much leaner and more hungry than when it went to sleep, and begins to hunt for mice, rats, moles, and nests of ants and humblebees, going about grunting like a pig, and turning up the earth with its snout.

It is by no means dainty in its appetite, for in addition to the objects first mentioned its bill of fare may include young hares or partridges, lizards, serpents, toads, underground fungi, and various kinds of roots, grapes, currants, and other fruits. To the stings of ants and humble-bees it pays little heed.

When driven into a corner the badger defends itself with great courage. Lying on its back, it assails its foe with teeth and claws, and it is only when attacked by several enemies at once that it can be forced to leave its den.

\section{THE OTTER}

The Otter, like the badger, is found in most parts of the Old and New Worlds. It may be regarded as a water weasel, its diet consisting of fish instead of the many small animals that form the food of its relations on dry land. Its body is long, stout, and shaped like a cylinder, its legs, like those of the weasel, are short, the tail is long and flat, and the feet are webbed, as in all animals that spend a great part of their life in the water.

The otter is perhaps the most expert of all swimming and diving animals. It swims easily against the strongest currents, and is in no way inferior to the trout and pike in rapidity of movement. The holes on the banks of streams in which the otter makes its home are, as a rule, very cunningly concealed. The passage to the outside generally opens at a certain depth below the surface of the water, while one or more passages leading to the ground above serve for ventilation.

Although fish and crayfish are the favourite food of the otter, it also eats small mammals, frogs, and in short everything that lives in or near the water. It is so destructive to fish that great efforts are made to capture and kill it, but there is probably no 
animal more difficult to approach. Its scent is infinitely delicate and its hearing exceptionally keen, and it is so intelligent that

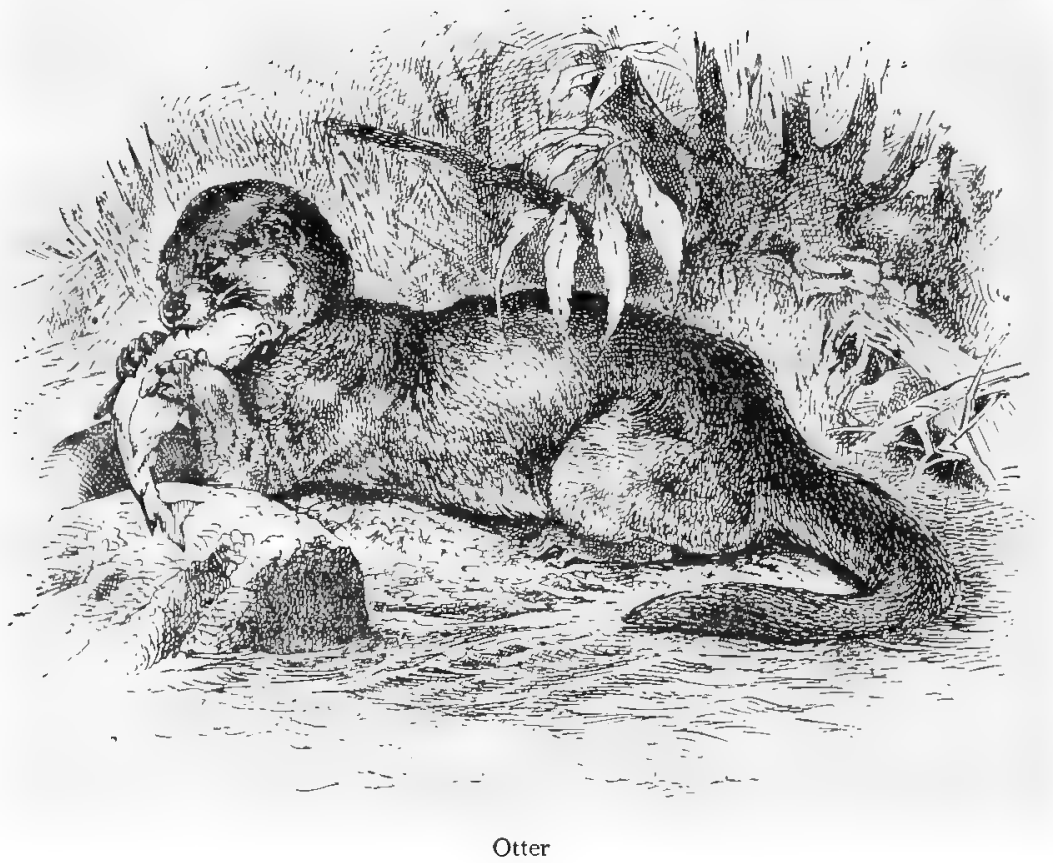

it seldom allows itself to be caught in a trap. When caught young, however, the otter can be easily tamed. It then becomes much attached to its master, following him like a dog, and will even allow itself to be trained to catch fish.

\section{The Seals}

The last of the flesh-eating families with which we shall deal are the seals and walruses. They differ widely from all other carnivora, their bodies bcing adapted solely for life in the water. 


\section{SEALS}

Few animals are so curious and interesting as the Seals. Although they are mammals and not fish, they live almost entirely

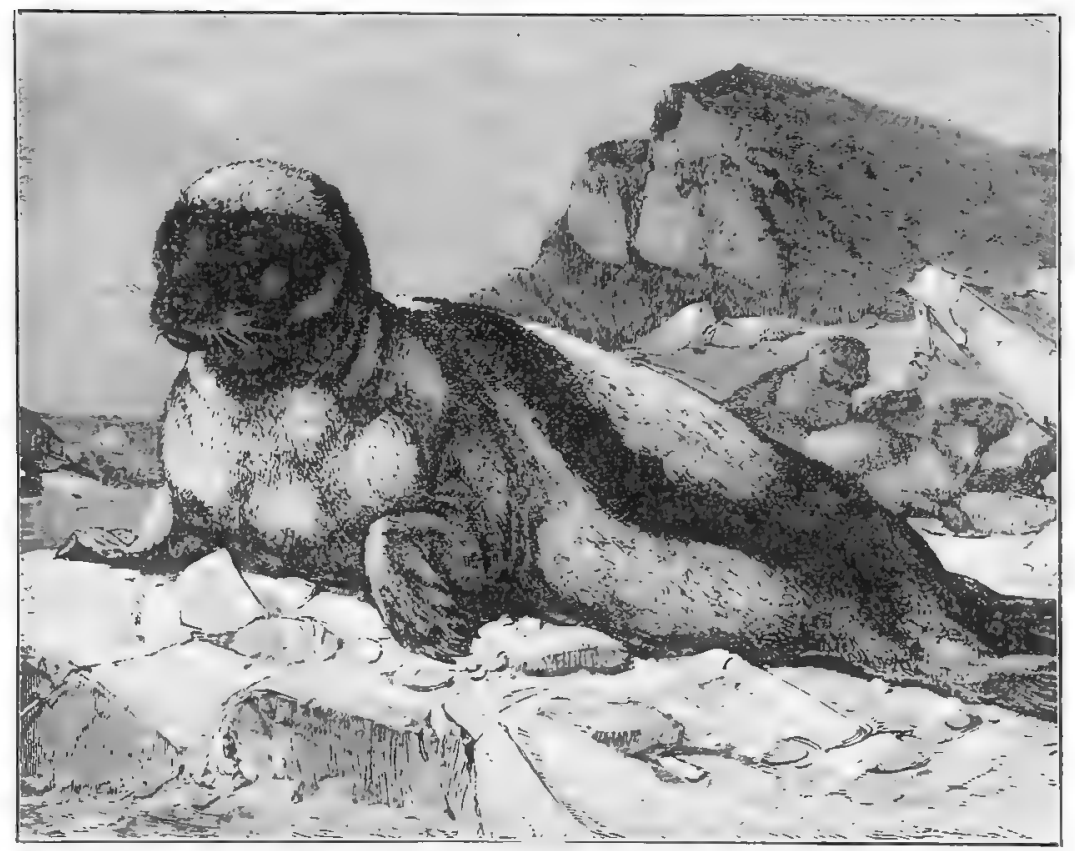

The Greenland Seal

in the water; although they are creatures of prey, they have no talons with which to tear their victims; and although they are warm-blooded animals, they are almost entirely confined to the icy seas of the Arctic and Antarctic regions.

Let us briefly examine their structure, and see how it is adapted to the peculiar life which they are destined to lead.

In the first place, then, we find that seals are protected from the extreme cold of the frozen seas in which they live by a threefold outer garment, if we may use the expression. First comes a 
thick layer of stiff, stout bristles. We do not see these in the "seal-skin" of a lady's cloak, because they are carefully removed in one of the processes by which the skin is prepared for use. But in the living animal they are easily noticeable, and as they are continually lubricated by a kind of oil, which is secreted by a number of tiny glands in the skin, they form, as it were, a kind of waterproof greatcoat.

Beneath this is another layer of much softer and finer hairs, which lie closely against the skin, and form, when thoroughly cleansed and prepared, the ordinary "seal-skin" of commerce. These, too, are lubricated by the natural oil, so that the icy water in which these animals spend so much of their lives can never come into actual contact with the skin.

The skin itself, too, is considerably madified, for it is from two to three inches thick, and contains a great number of cells filled with oil, like the well-known "blubber" of the whale. Now, oil is an excellent non-conductor of heat; that is, it will not allow heat to pass freely through it. Thus, the seal is protected from the icy chill of the water in which it swims, first, by the outer layer of thick, stiff bristles; secondly, by the inner layer of soft, warm fur; and thirdly, by the thick, blubber-like skin.

How do seals swim? If we look at one of them as it glides through the water, we cannot detect its method of propulsion. It does not paddle itself along with its flippers, but seems to move in any direction at will, without putting forth any kind of exertion.

But if we look a little more closely, we shall see that the two flattened hinder feet are pressed closely side by side together, so as to form a single broad oar. By means of this oar the animal swims. It is well known that a boat can be propelled by a single oar, worked to and fro in the water from the stern. Now, if we look upon the body of a seal as a boat, we shall see that the animal propels itself along by simply turning its natural oar from side to side in the water.

The form of a seal's body, too, is well adapted for swimming, for it is that of a pointed cylinder; and this shape, which offcrs the least possible amount of resistance, is common to all creatures which fly through the air, tunnel through wood, burrow 
in the ground, or swim through the water. Birds, wood-boring beetles, moles, and fishes all have bodies shaped like pointed cylinders.

We adopt the same shape, too, for our bullets, which are to fiy through the air; our gimlets and augers, which bore holes in wood; our well-sinking tools, which bore holes in the ground; and our torpedoes, those terrible explosive weapons which are designed to attack a ship below the water-line.

The structure of a seal's skeleton, again, helps it greatly in

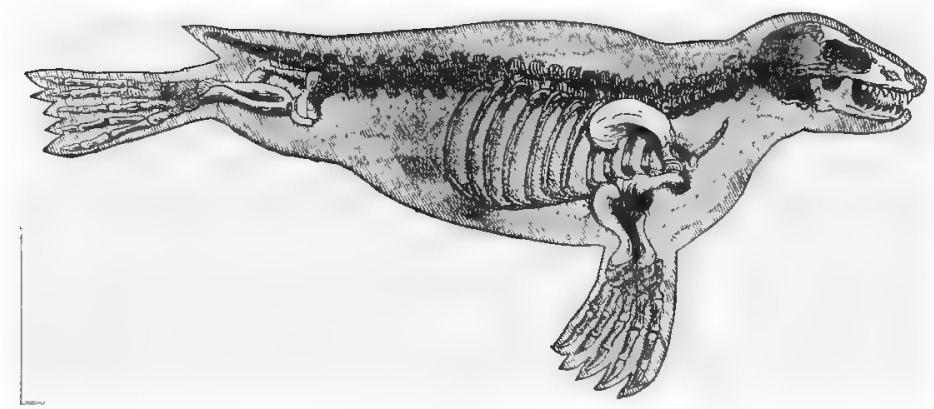

Skeleton of Seal

swimming, for the vertebræ, or small bones of the spine, are not fastened so closely together as in many other animals, but are more widely.separated from one another by a cushion of cartilage or gristle. This is very elastic, so that the spine can be bent and curved in all directions, and the animal is enabled to twist and turn in the water with the most perfect ease and activity.

So proficient, indeed, are seals in the arts of swimming and diving, that they can overtake and capture fish in their own element. Their teeth, too, are studded with a great number of sharp jagged points, which points enter the body, and prevent the lithe, slippery creature from breaking away.

The ears of the seal are so formed that they are immediately closed by the pressure of water upon them. They are constructed, in fact, upon precisely the same principle as "flood-gates" The greater the pressure upon these gates, the more securely they 
are closed. So it is with the ears of the seal, which close as soon as the animal dives, and prevent the admission of even a single drop of water.

If we were to dissect a seal, we should find that the outward ear is situated at some little distance from the internal organs of hearing, with which it communicates by means of a narrow tubular passage. The reason for this peculiar structure is evident.

If a human swimmer dives under water, he at once becomes perfectly deaf to sounds in the air above. He cannot hear the loudest shouting, or even the explosion caused by the discharge of a gun. But he can hear sounds in the water very distinctly. He can distinguish, for instance, the beating of the oars in a boat at a considerable distance away. And if a heavy blow were to be struck upon the surface of the water exactly above him, he would be almost stunned by the shock.

Of this fact the North American Indians take advantage when they are engaged in hunting the beaver. As they walk over the glassy, frozen surface of a river, they catch sight of one of these animals swimming below. One of the hunters then raises his club, and strikes a heavy blow upon the ice. The beaver is stunned by the shock, floats motionless to the surface, and is extracted through a hastily-cut hole before it can recover its senses.

The nostrils of the seal are formed upon somewhat the same principles as the ears, for they, too, close tightly when the animal dives, and effectually prevent the admission of water.

Even yet we have not exhausted the interesting features of a seal's structure. How, for instance, does it contrive to remain so long under water? Between the moment at which it disappears beneath the surface and that at which it rises again to breathe, twenty minutes or half an hour are said to elapse. How is this? The seal is a warm-blooded animal, and therefore its blood must be incessantly purified. And we know that a human swimmer cannot remain submerged for more than two minutes at a time.

The seal, however, is remarkable for a singular development of the veins near the liver, which are dilated in such a manner 
as to form chambers, or reservoirs, of considerable size. In these it seems that the blood is stored up for a while, after it has passed through the arteries, instead of being immediately sent on to be purified in the lungs. Thus the animal is enabled to remain without breathing beneath the water for much longer than would otherwise be possible.

So, we see, the entire frame of these remarkable animals is most wonderfully adapted to the peculiar conditions of their life.

Seals are found in many parts of the world, but are most plentiful in the Arctic and Antarctic regions. We may perhaps wonder how they contrive to live in those frostbound latitudes, where even the sea, during the greater part of the year, is frozen over. It would seem that the seals must remain either upon the ice, in which case they could procure no food, or beneath it, when they could obtain no air.

But during the winter

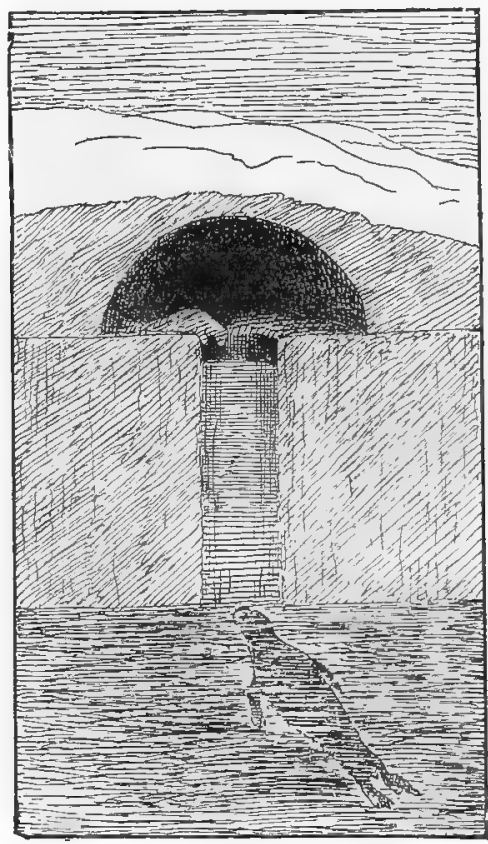

Igloo, or Seal's House (shown in section) months these animals always keep a number of passages open through the ice by the simple act of continually passing through it. Upon the ice, of course, is a layer of snow, often many feet in thickness. The seals scoop this away just above their airholes, and so hollow out a large chamber, which is called by the Esquimaux the seal's "igloo", or house.

Upon a ledge of ice inside this "igloo" the baby seals are usually kept. These are very odd little creatures, and at first are nearly white, becoming darker by degrees. Their mothers take great care of them, and, if danger should threaten, tuck their 
little ones under their flippers and swim hurriedly away with them. These little seals spend the first few weeks of their lives upon dry land, upon which their parents live for some little time before the young are born.

Graceful as a seal is in the water, it is very clumsy and awkward upon the shore, and crawls along in a most ungainly manner, by the help of its flippers. Those who have seen a herd of seals in their native homes say that when they are upon land they look very much like a number of enormous caterpillars.

Clumsy though it is, however, the seal can travel over the ground, if necessary, with some rapidity. Sailors have often declared that, when it is chased, it hurls a shower of stones at its pursuers. But this, of course, is quite involuntary, the stones being those kicked up by the hind flippers as the animal shuffles hastily along.

There are many different kinds of seals, one of the largest of which is the walrus. This gigantic creature often measures sixteen or eighteen feet in length, and has two great tusks projecting from the upper jaw. These tusks are really the canine or "eye" teeth, and the ivory of which they are composed is of so fine a quality that it is highly valued by the manufacturers of fancy goods.

To the Esquimaux the walrus is indeed a necessity of life. There is no part of its body which he does not utilize for some purpose. Of its hide, for example, he makes the "kajak", or light boat in which he paddles himsclf about when the sea is not frozen over. Of the sinews and muscles, after drying and splitting them, he constructs nets and fishing-lines.

Fish-hooks, arrow-heads, and harpoon-heads he cuts out of the tusks. The oil which he presses from the blubber supplies his lamps, upon which he is obliged entirely to depend for light during the six months in which the sun never appears above the horizon. The fur serves him for clothing; while the flippers can be made into warm and comfortable boots, and the membrane which lines the body into an excellent waterproof cloak.

The animals from which seal-skin cloaks and jackets are obtained are called Fur Seals. About five different kinds of these valuable creatures are known, the most important being the 


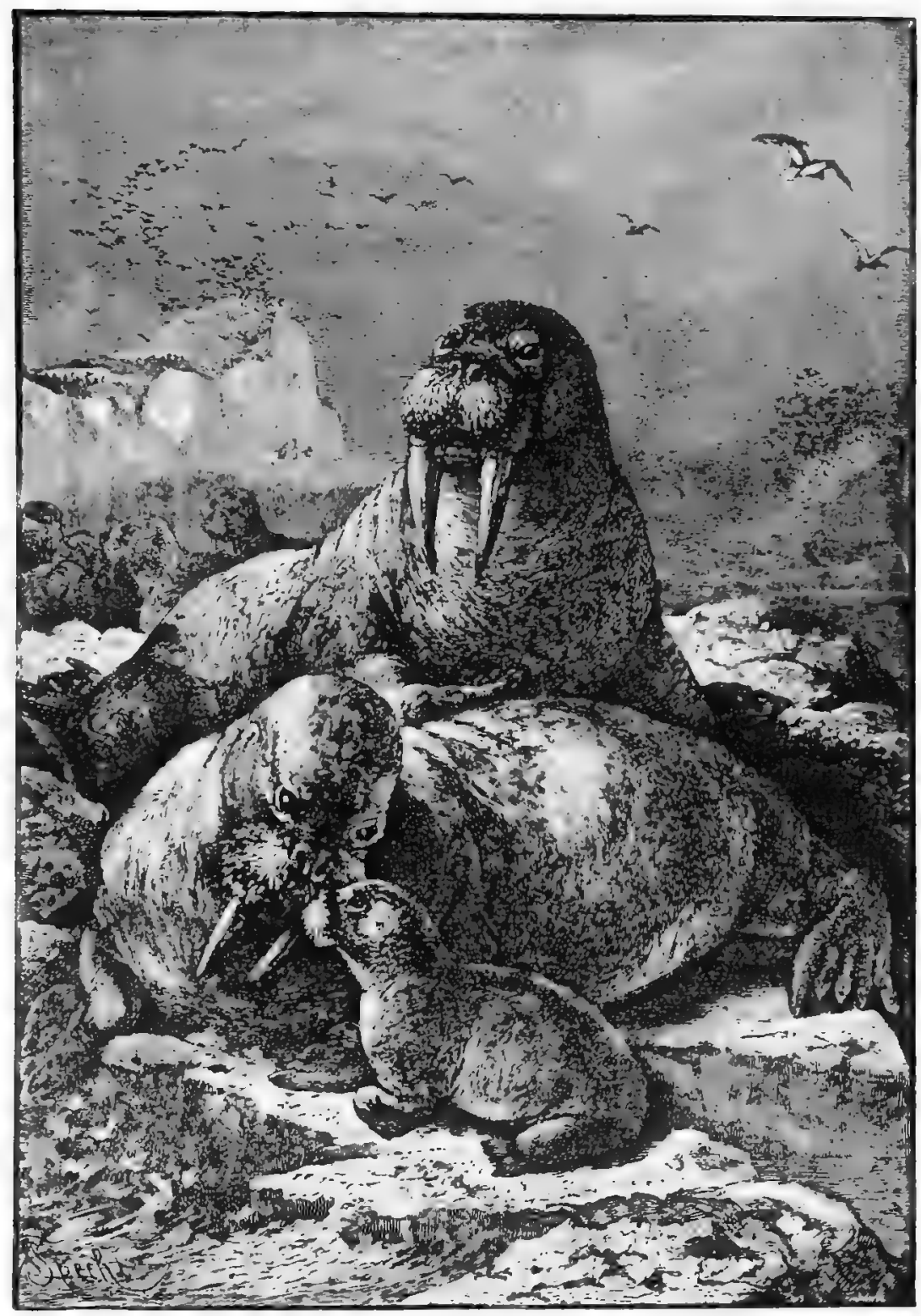

WALRUS

(M 868 ) 
Northern Fur Seal, which is found on some of the northern coasts of America.

On the Pribyloff Islands alone no fewer than one hundred thousand of these seals used to be killed every year. This seems a very large number; but a few years ago more than twice as many were annually slain, and the United States government was obliged to regulate the slaughter.

It is estimated that the "rookerics", as they are called, in which these seals live consist of between four and five million individuals, and that about a million young are born every year. But a very large number of these are destroyed by other enemies than man.

The hunting of the fur seal-or stal-fishing, as it is called-is much prosecuted in Alaska and the Aleutian Islands. The hunters, armed with wooden clubs, make their way to the rookeries, and, getting between the seals and the sea, drive the animals inland, and then kill them in succession by heavy blows on the snout, which is the most sensitive part of the body. The skins are then stripped from the bodies, "salted" to prevent decomposition, and shipped to the merchants.

Upon arrival, each skin undergoes very careful cleansing, after which a flat knife is passed through the skin itself, about midway between the upper and lower surfaces. This severs the roots of the long stiff bristles which form the outer covering of the fur, and which can then be removed without difficulty. Next follows a series of processes by which the warm close fur, or "pelt", is softened and preserved. Lastly, the fur is very carefully dyed, and thus becomes the familiar "seal-skin" of commerce.

\section{UNGULATES, OR HOOFED ANIMALS}

\section{THE OX}

The Ungulates, or hoofed animals, are perhaps the most important of the eleven orders into which the Mammals are divided. 
They include a large number of families, and differ quite as widely from one another as the various kinds of flesh-eating animals. To the ungulates, for instance, belong the horse, ox, sheep, pig, goat, deer, rhinoceros, hippopotamus, and elephant, together with a host of other animals the mere list of whose names would fill several pages of this book.

It will be seen, however, that the Ungulates form the order of

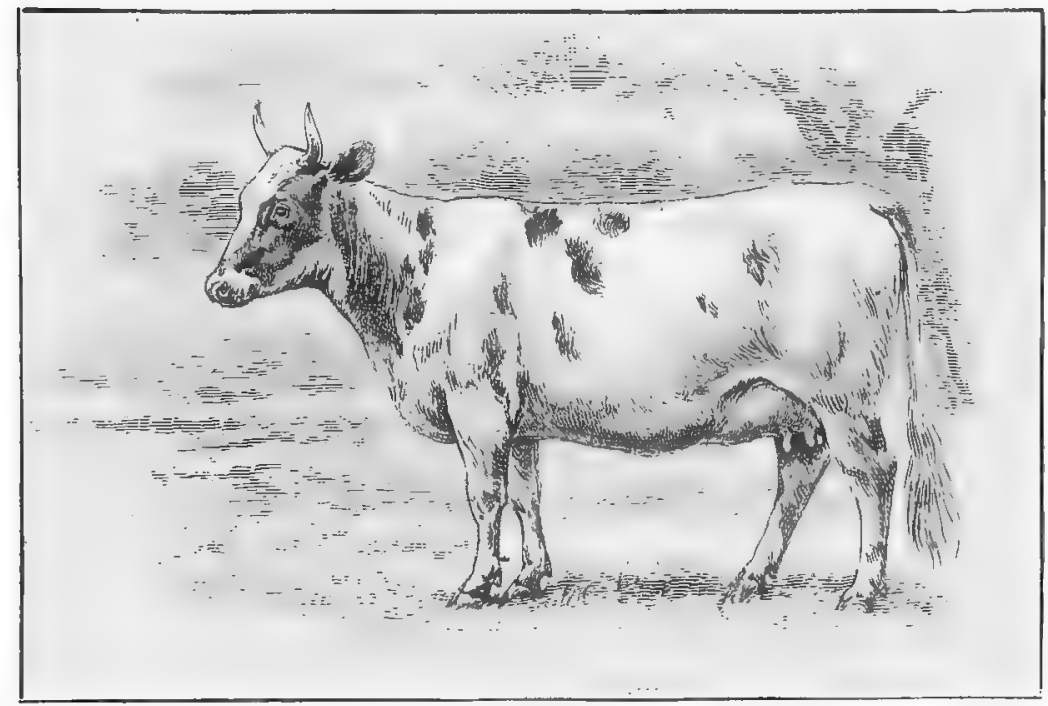

Ayrshire Cow

Mammals that is of most importance to man. We can scarcely imagine the straits to which mankind would be put if all the Ungulates were suddenly to disappear from off the face of the earth. It is from them that we obtain the greater part of our animal food, and a large amount of our clothing, while they supply us, in addition to what may be called the necessaries of life, with innumerable luxuries which we should now find it hard to dispense with.

The Ungulates obtain their name from the peculiar structure of their feet. In most of the animals with which we have dealt up to the present, the fingers or toes are provided either with claws or 
nails. The Ungulates have no claws, and, except in a few cases, are without nails, but the toes of their fore and hind feet are encased in a horny covering which we call the hoof. We shall learn more about this hoof when we come to study the horse.

Another peculiarity of the Ungulates is the fact that as a general rule the fore-limbs can only move backwards and forwards; they are not capable of a circular movement, as, for instance, in the case of a man's arms.

They are, as a rule, but poorly provided with means of offence and defence. Their bodies are often unwieldy and not built for speed, so that they are unable to escape from their enemies among the Carnivores by mere fleetness of foot. Nature has therefore provided them in many cases with formidable horns, with which they are able to beat off the attacks of all but the most powerful foes.

The Ungulates are, as we have said, divided by naturalists into a large number of families. One of these families, and certainly not the least important, is that formed by the oxen, sheep, antelopes, and goats. They are all closely related to one another, and are known as the hollow-horned ruminants. The word ruminant is another name for "chewing the cud".

We should find it a very difficult matter to do without the cow and the ox; for there is scarcely any part of their bodies which we do not put to some useful purpose.

The cow supplies us with milk; and out of the milk we make butter and cheese, and get curds and whey. In some parts of the world, too, people make sour mills their principal food. As soon as the milk is taken from the cow it is put into a skin bag, and kept there until it turns sour. It is then found to be so thick and hard that it can be cut with a knife, just lilie butter. Before it is eaten it is mixed with meal, and although people seldom like it at first, they soon come to prefer it to almost any other food.

The flesh of the ox, which we call beef, is a very important article of diet. By soaking beef in brine, it can be kept for a long time. The flesh of the calf is called veal, and is very delicate and tender. 
The hair of the cow is not spun into yarn, and then woven into cloth, like that of the sheep. But we do not waste it, for it is carefully stripped from the skin and mixed with plaster, in order to make it "bind".

The skin we turn into leather, and use for making boots and shoes, and all sorts of useful articles. Out of the horns we make cups, spoons, and combs, while we boil down the hoofs, and turn them into glue. Even the bones are cut up, and made into handles for knives.

If you look at the hoof of a cow or ox, you at once notice that it is not like that of a horse, but is split in two, or "cloven" as we generally say.

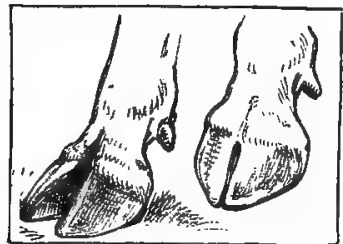

Cloven Hoof of Cow

The teeth, too, are quite different from those of a horse. There is no gap between the front and back teeth, like that in which a horse's bit is placed, and there are no teeth at all in the front of the upper jaw. When an ox eats grass, therefore, it does not really bite it, as a horse does, but only presses it against the teeth of the lower jaw, and then tears it away.

Strange to say, the ox does not chew its food before swallowing it, but waits until it can lie down and rest, Then it passes it back into its mouth, a little at a time, grinds it between its teeth, and swallows it once more. This is called "chewing the cud", or ruminat-

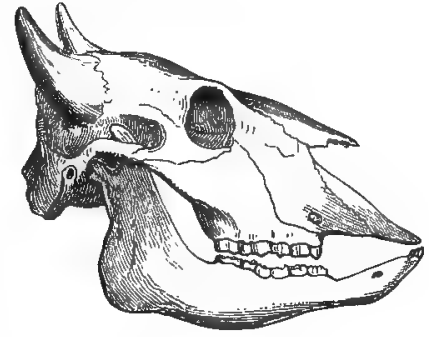

Skull of Cow ing, and many other animals treat their food in the same odd way.

The ox has many near relations both in the Old and New Worlds. The Yak of Central Asia, the Bisons of Europe and America, and the Buffaloes of Africa, are all more or less closely allied to the domestic oxen which we see in this country. Formerly the bison roamed in enormous herds over the whole territory of the United States as far as the Rocky Mountains. But at the present day it has nearly disappeared, owing to the ceaseless attacks of Indians and white hunters. In the old days when they had the prairies 


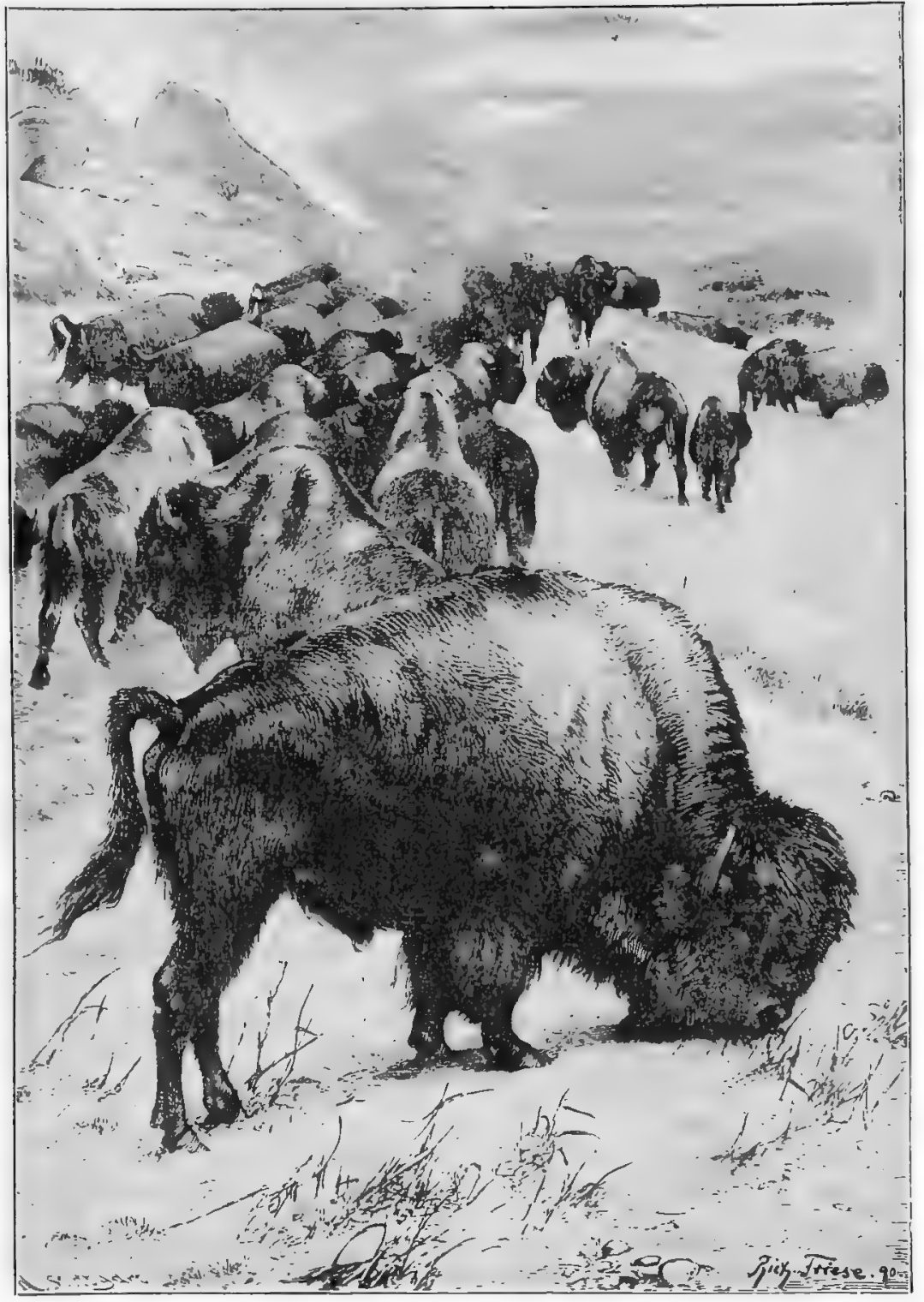


almost to themselves, they moved about in herds of several thousand head, and in their long migrations were accustomed to suim across the largest streams. They were, as a rule, exceedingly timid, and when once they began to run would plunge on like sheep in dense crowds. Nothing could then stop them. If a precipice lay in their path they would dash over its edge, the rear ranks pressing the front ranks forward to their death. The skeletons of thousands of bisons destroyed in this way have been found at the foot of steep declivities in Western America.

\section{THE SHEEP}

The sheep shares with the ox the distinction of being among the most useful of all domestic animals.

Let us see what we obtain from it. First, there is its wool, or "fleece", which we spin into yarn, and then make into cloth or flannel. This fleece becomes very thick in winter, and makes a warm coat for the sheep. In the spring, when the animal does not need its thick garment, we cut off the fleece close to the body with large scissors, or "shears", and send it away to be spun into cloth.

But it must first be cleaned, for there is a kind of oil in it which helps to keep out the rain when the shcep is alive, but which would render it quite useless for manufacturing purposes. If you were to rub your hands upon a sheep's back, you would find that they were quite greasy afterwards. All this grease must be thoroughly removed before the wool can be made into clothing.

Then there is the flesh of the sheep, which we call mutton, and which we use so largely for food. The fatty parts we use as suet, and the rest forms tallow.

Even the skin of the sheep is not without its value. We make the thinner parts into gloves, and use the thicker parts for binding books. The skin of lambs, too, is made into parchment, and used for writing upon. As this cannot be torn like paper, and is not easily burnt, it is generally employed for writings that we wish to preserve.

The wild sheep is intelligent, and when full-grown very 
courageous. It climbs and leaps well, and is an untiring runner. No mountain slope is too steep for it, no peak is beyond its reach. The Rocky Mountain sheep, for instance, is so active, and shows so much cunning in dodging his pursuers, that it is almost impossible to capture a specimen alive.

The flat-tailed sheep are a remarkable type found in some parts

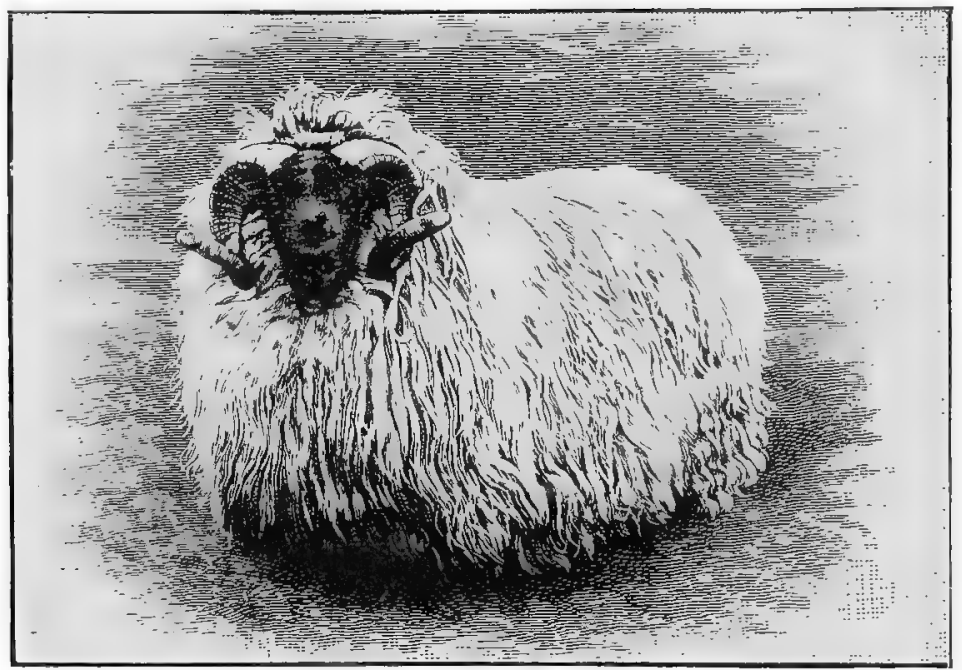

Blackface Ram

of Eastern Asia. The tails of these sheep are so long and fat that they drag upon the ground. In order to prevent them from being injured, their owners make little carriages of wood, and fasten the tails of the sheep upon them. Each carriage has two wheels, so that the sheep can draw it along without any trouble.

\section{THE GOAT}

In some respects the goat is very similar to the sheep, to which it is closely related. Its shape is much the same; its hoofs are cloven in the same way; and its teeth are formed in the same manner. But the goat has straight hair on its body, instead of fleecy wool; and on its head are two long and sharp horns, which 
are rough in front, and are always curved backwards. The male goat, besides, has a long beard underneath his chin.

In this country we do not keep goats in flocks, as we do sheep, for we make less use of them, and they are not nearly so easy to manage. But still they are useful creatures; and, as they can find

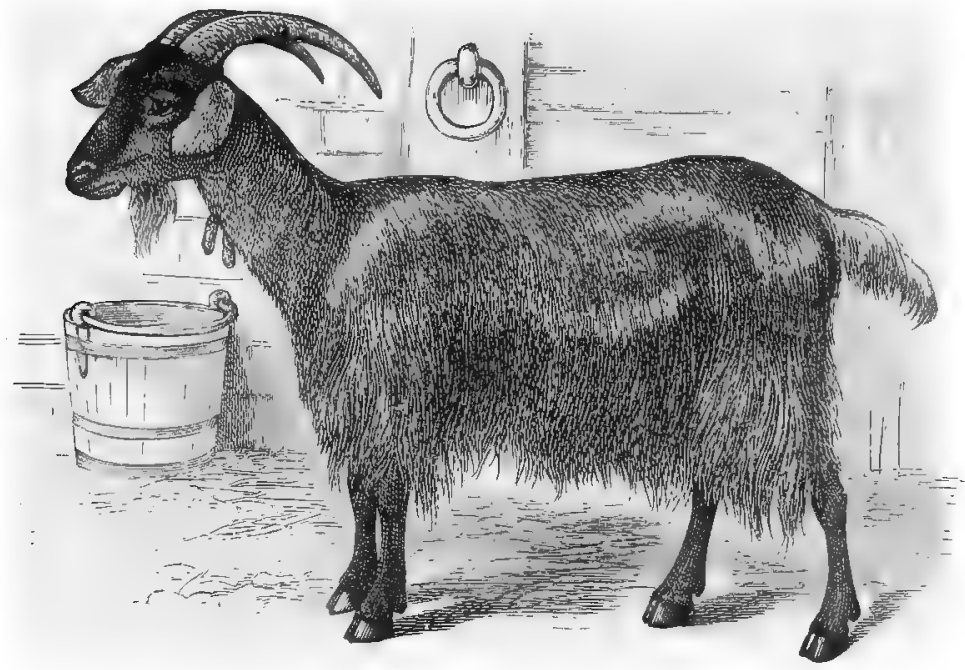

Pyrenean Milking Goat

food for themselves almost anywhere, they do not cost very much to keep.

Sheep have to be fed in winter with turnips, or other food, and so cost the farmer a great deal. But a goat is quite satisfied with the dry grass on a common or roadside, and thrives upon it just as well as if it were fed like the sheep. In some countries, where the ground is very rocky and grass does not grow well, people keep goats instead of cows. For goats give plenty of milk, find their own food, and climb about among the rocks where a cow could find neither food nor foothold.

The milk of the goat is very rich, but has a rather strong flavour, so that many people do not like it. In some parts of the world a kind of cheese is made from it, which is considered very palatable. 
We do not make much use of the hair of the goat in England. But in some countries, such as Turkey and Persia, it is made into carpets, which are esteemed of very great value.

There is a kind of goat which lives in Thibet, from whose hair very beautiful shawls are made. This is called the Cashmir goat, and as it lives in a very cold country, it has two coats of hair instead of only one. Next to the skin is a warm garment of woolly fleece, and outside this is a covering of long, silken hairs. It is from the soft inner fleece that the shawls are made, and in order to make one small shawl no fewer than ten goats have to be shorn.

The largest member of the goat tribe is the Ibex, an animal to be found only in the loftiest mountains of Europe and Asia. The ibex differs from the ordinary goat in the character of its horns, which are of enormous size.

$V^{\top}$ e do not often eat the goat's flesh; it is tough and hard. But that of the kid is naturally more tender, and in some parts of the world it is almost the only meat to be procured. Those who have tasted it say that it is like very delicate mutton.

The male goat is sometimes very quarrelsome, and will butt with his horns at any stranger. But if his beard be seized, he at once loses all his courage, and begins to bleat in a very pitiful way.

\section{THE ANTELOPES}

Midway between the oxen and the goats come the Antelopes. Some members of the family can scarcely be distinguished from oxen, others, as we shall see, are as closely related to the goats.

One of the prettiest of the antelopes is the African Kudu, an animal whose habits closely resemble those of the deer. It is to be found throughout the greater part of Central and Southern Africa, but is extremely shy, and makes its home only in the most inaccessible districts.

Among the steep precipices of the European mountains, from the Pyrenees to the Caucasus, dwells the Chamois, another member of the antelope tribe, an active and graceful little animal, which in general appearance is not at all unlike a small goat. 


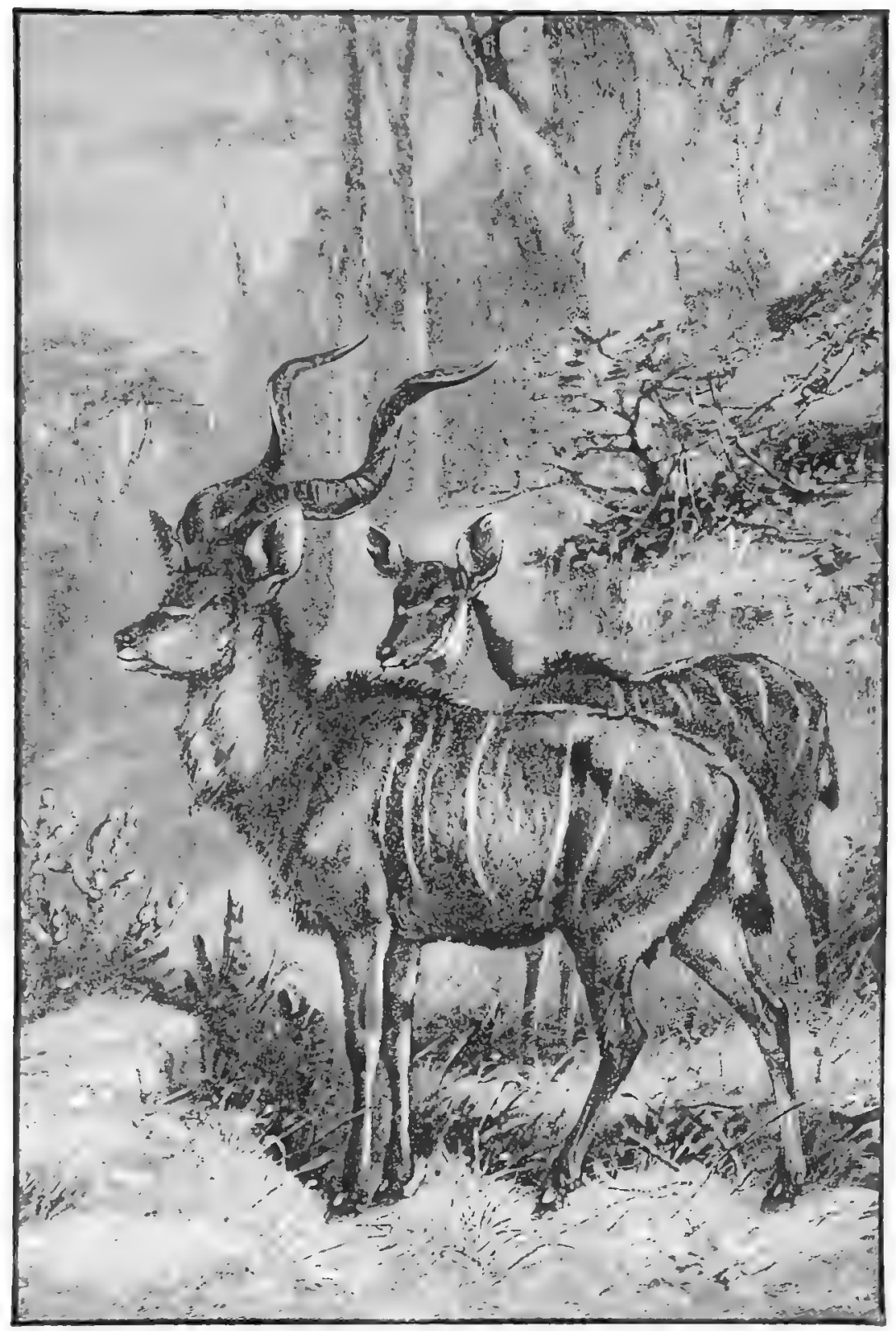


Many of these animals, like the kudu, bear a close resemblance to deer, with which they are frequently confounded. They can always be distinguished, however, by the character of their horns.

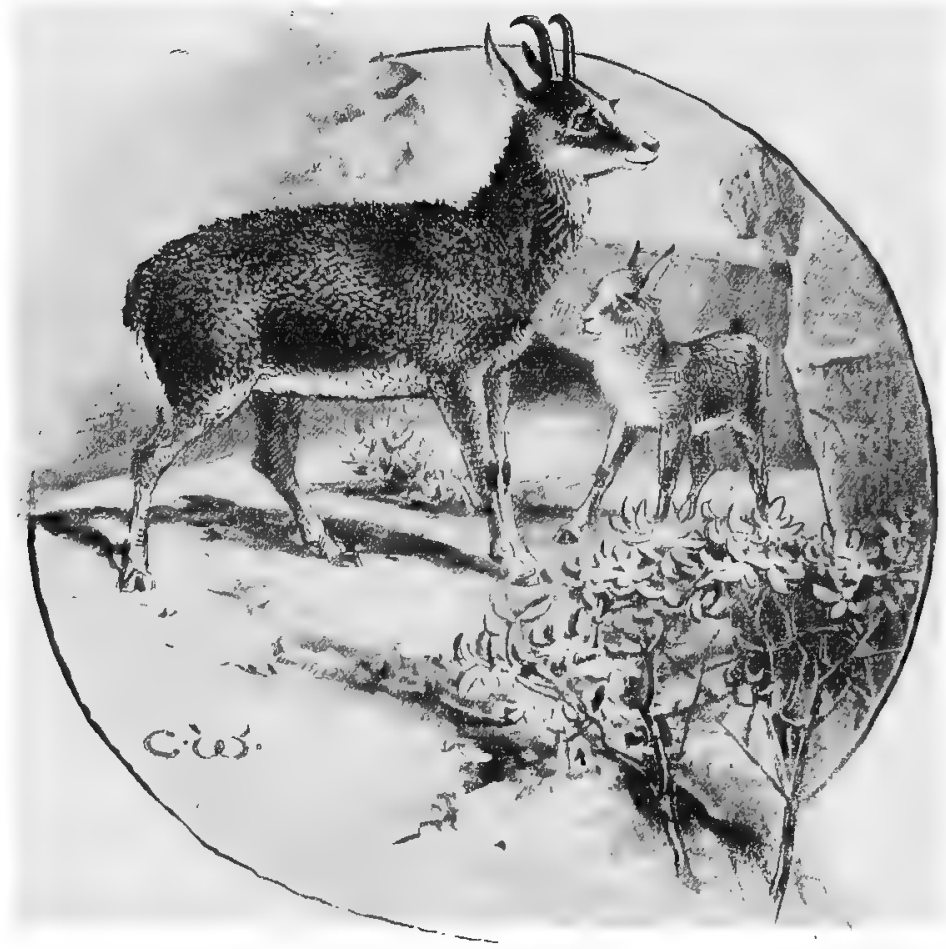

Chamois and Kid

These appendages, in a deer, are solid, and are renewed year by year, being generally thrown off in the winter, and beginning to grow again a week or two later. The horns of an antclope, however, are hollow, and are set upon a bony core, like those of the oxen, while they are not annually discarded, but are retained throughout the life of the animal. 
In the chamois the horns are about seven inches long, and are curved backwards at the tip into a hook-like form. It was formerly supposed by naturalists that these horns were employed in climbing, and that the animal was able by their help to raise itself to ledges which would otherwise be out of its reach. But it has now been proved that such is not the case.

The chamois, indeed, is so wonderfully sure-footed that it does not require any assistance from its horns. It can travel with amazing speed along rocky ledges which no feet but its own may tread, and can leap from crag to crag, or descend a precipitous cliff, with the most perfect agility and ease. Its hinder limbs, which are considerably longer than the front pair, assist it greatly in climbing, while it can slide down the face of a rock, and check its course whenever necessary, by the "false hoofs" of the hinder feet.

In summer time, the chamois, which cannot endure great heat, retreats to the upper heights of its mountainous home, and there enjoys the cooler atmosphere. But when autumn begins to give place to winter, it finds that its food-supply is running short, and so descends again to lower levels.

The chamois feeds upon many of the low shrubs and herbs which grow in mountainous regions. It is very fond, too, of the buds of trees, more particularly those of pines, firs, and juniper. In such quantities, indeed, does it devour these, that its flesh becomes so strongly tainted with their peculiar flavour that to many people it is extremely unpalatable.

As we may readily imagine from the character of its home, the hunting of the chamois is a pursuit of the greatest difficulty, only to be attempted by those of clear head and steady nerves, who have been accustomed to face danger in various forms, and are capable of enduring great hardships and privations. For the chamois hunter may follow his quarry for days without success, whilc a single false step may cause him to be dashed in pieces on the rocks below.

Few animals are more wary and cautious than the chamois. Its senses are unusually keen, and it can detect a man both by sight and by scent at a really astonishing distance. In order to guard against the possibility of a surprise, it always places sentinels 
whose duty it is to keep constant watch, and acquaint the rest of the herd with the first signs of approaching danger. When one of these sentinels detects a foe he utters a peculiar warning whistle. This is at once understood by his companions, and in a very few moments not a chamois is to be seen.

But the chamois has another enemy from which it cannot escape so easily as from man. This is the eagle, whose broad wings will carry it into fastnesses where no human hunter can penetrate. It seldom attacks an adult chamois, but will follow a herd about from place to place, and watch its opportunity to carry off one of the kids.

Like many other animals, the coat of that of this graceful little antelope varies in colour at different seasons of the year. Thus, in the summer the colour of the body is brownish yellow, with a darker stripe running along the back. In winter this hue is replaced by a dark blackish brown. The head is pale yellow, becoming darker upon the nose and between the eyes. The skin of the chamois is greatly valued, as it can be converted into a very strong and yet soft and pliable leather. Hence the name of "chamois-leather", which is now given, however, to various kinds of wash-leather made from the skins of other animals.

\section{THE GIRAFFE}

The Giraffe is possibly the sole survivor of what was once a large family. Skeletons of various kinds of giraffes that are unknown nowadays are dug up from time to time, shoving that the family was in past ages larger and more important than at the present day.

Owing chiefly to the remarkable length of its neck, the giraffe is by far the tallest animal known to inhabit the earth. It towers, indeed, even above the elephant, for a female giraffe frequently attains to a height of thirteen or fourteen feet, while a male sixteen feet high is by no means uncommon.

It is interesting to find that, notwithstanding its extraordinary length, the neck of the giraffe is formed upon just the same principles as that of other mammals. In all the other animals 


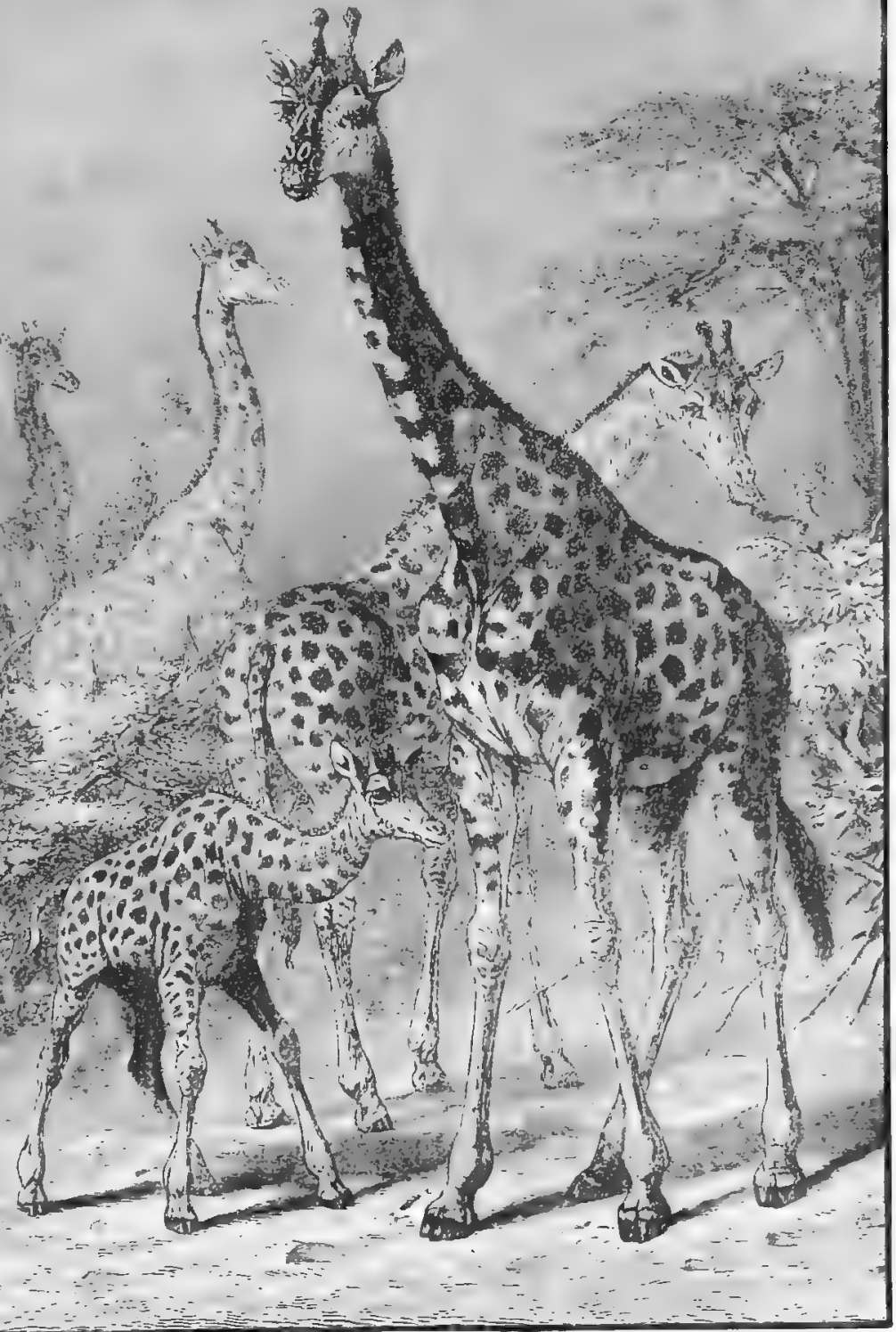


which belong to the mammalian class, seven of the vertebræ, or small bones of which the spine is made up, are found in the neck. To judge by appearances, one would imagine that in the neck of the giraffe there must be many more than this. Yet such is not the case, for there are still seven vertebræ only. But these are all grcatly prolonged, and so the length of the neck is attained.

The height of the giraffe is of great assistance to it in procuring food, for it feeds almost entirely upon the leaves of certain trees, very few of which put forth foliage near the ground. In order to enable it to pluck the leaves, its tongue is formed in a very singular manner. It has great prehensile power, like the tail of a spider monkey, and can be coiled round the stem of a branch which its owner desires to strip; and it can be lengthened at will. So greatly, indeed, can a giraffe attenuate its tongue, that it is said that it could pass that organ into the barrel of an ordinary latch-key.

The giraffe, as might be expected, does not find it at all easy to graze upon low-growing herbage, and only does so when it cannot obtain its ordinary food. In order to bring its head down to the level of the ground, it is obliged to separate its forelegs as widely as possible, and to bend down its long neck between them.

On the head of the giraffe are two prominences, which are often mistaken for horns. They remind one comically of common hatpegs. No one has suggested that they are of any service to the animal. These are situated between the ears. They are not in reality horns, however, but simply bony projections from the skull, not unlike those upon which the hollow horns of cattle and antelopes are set. They are covered with skin, and are ornamented by a tuft of long hair.

The giraffe is not quite so swift of foot as one might imagine from the length of its legs. It can travel, however, with no little speed, and on rocky and broken ground can easily outdistance a horse.

The traveller who first brought examples of the animal to England from Africa, in which continent it is alone found, speaks of it in these words:- "The first run of the giraffe is cxceedingly rapid. The swiftest horse, if unaccustomed to the desert, could not come up with it except with extreme difficulty. If the giraffe 
reaches a mountain, it passes the heights with rapidity; its feet, which are like those of a goat, endow it with the dexterity of that animal. It bounds over ravines with incredible power; horses cannot, in such situations, compete with it."

The action of this animal when running at speed is exceedingly awkward and ungraceful. Strictly speaking, indeed, it cannot be said to run, but proceeds by means of a series of galloping leaps, not unlike those of a frog, while its long neck rocks to and fro at every movement, just as thuugh it were balanced upon a pivot.

The giraffe is a very timid creature, and always endeavours, if alarmed, to seek safety in flight. When brought to bay, however, it will fight with great determination, delivering a series of terrific kicks with its powerful forelegs, and not uncommonly disabling its pursuer. Even the lion is afraid to attack a giraffe openly, and prefers to creep up silently behind it, spring upon its flanks, and bear it to the ground.

One would imagine that so tall and brightly-coloured an animal as the giraffe would be most conspicuous, even when standing among thick trees. Experienced hunters, however, tell us that very few animals are more difficult to detect, since its long neck looks at a Jittle distance just like a slender tree-trunk, while its colouring harmonizes exactly with that of the tropical foliage.

The most usual method of capturing the giraffe employed by the natives is by means of pitfalls, across the middle of which a narrow bank of earth, six feet or so in height, is left remaining. When the alimal falls into one of these pits its body is balanced across this wall, so that it can find no foothold, and is quite unable to escape.

\section{THE DEER}

Unlike the giraffes, the Deer Family are widely distributed over the face of the earth, and include a great number of species. They are to be found in most parts of the World, except in desert regions, where they seem unable to pick up a living as do some of their cousins, the antelopes.

The most striking feature of the deer family is the magnificent pair of antlers with which the male deer are as a rule provided during 


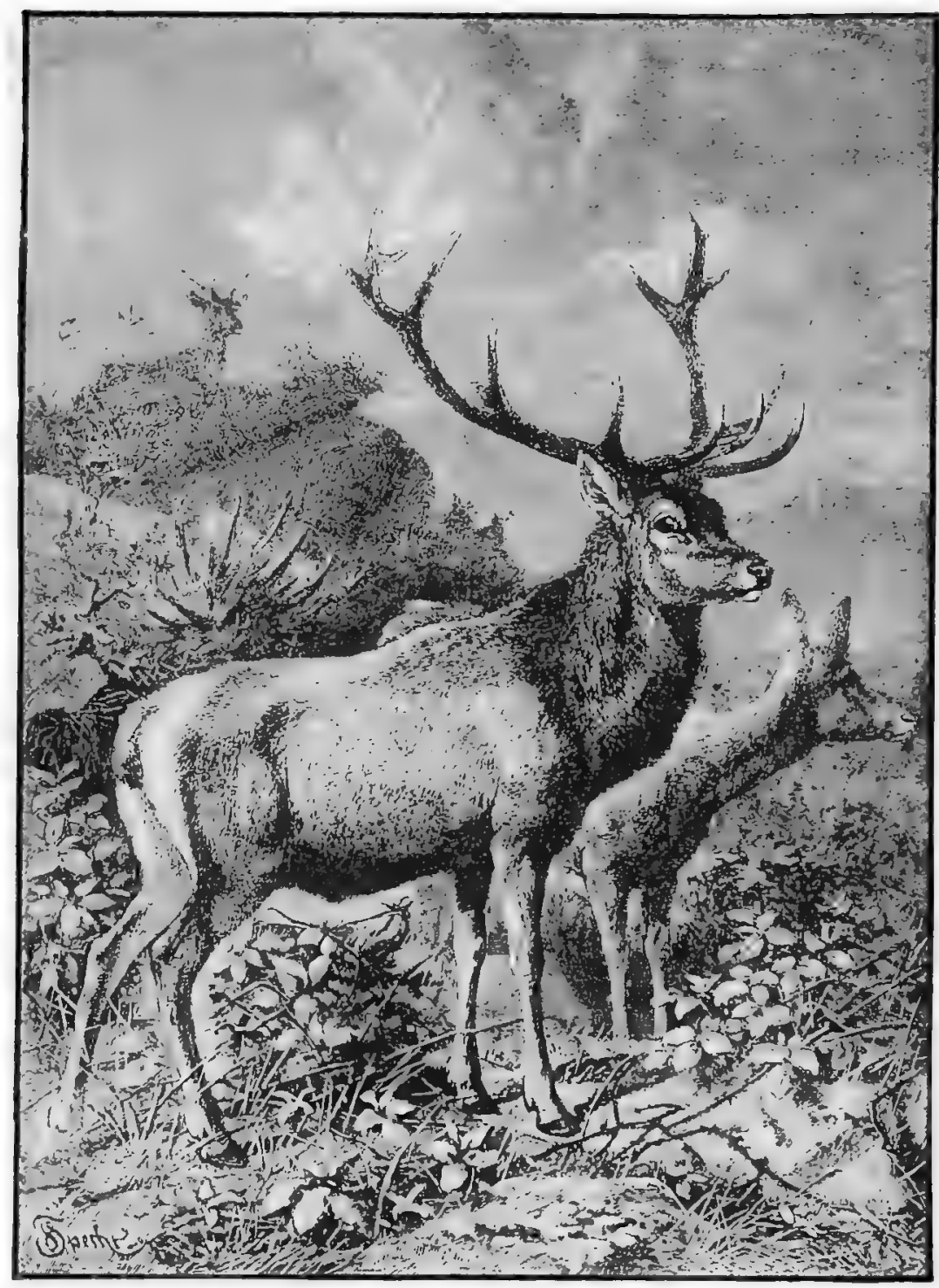


part of the year. The fawns are without these beautiful ornaments, which render the full-grown deer one of the most graceful and impressive of all four-footed animals. The long thin legs of the deer are admirably adapted for rapid movement, and with the exception perhaps of some of the antelopes there is no animal that, making allowance for its size, can be compared with it for speed.

In most European countries the hunting of the deer has for an indefinite period been regarded as the sport of kings. So carefully, indeed, were they protected in England, that anyone killing a stag in the king's forests without permission was liable to be put to death.

At the present time there are very few deer left in this country. Red and Fallow Deer are, however, still to be found in the Highlands of Scotland and in a few districts in England and Ireland, but if they were not carefully protected they would soon die out. Their favourite home is in dense forests or on wild moorlands as far removed as possible from human habitation.

\section{THE REINDEER}

We cannot find a better representative of the Deer Family than the Reindeer, which is by far the most interesting, as well as the most useful of this group of animals. It is still found in some abundance in the northern parts of the European and Asiatic continents; but wild herds are few, the greater number having been captured and placed under domestication.

For the reindeer is used for a great many purposes. It can be employed, for example, as a beast of burden and draught, and so takes the place of the horse. When harnessed to a light sledge, or bearing a rider upon its back, it can travel at a good speed for thirty or forty miles. Its driver guides it, not by means of reins and a bit, but by a cord fastened to its horns. By gently tapping this cord against the side of the animal, he shows it in which direction he wishes it to go.

A fully-grown reindeer can thus draw, if required, a load of three hundred pounds, and carry on its back a burden of about two hundredweight. In order to prevent its strength from being 
overtaxed, however, a law has been passed which limits the load to one hundred and ninety pounds, if drawn in a sledge, and to one hundred and thirty if carried upon the back.

The reindeer also furnishes its owner with excellent meat, as

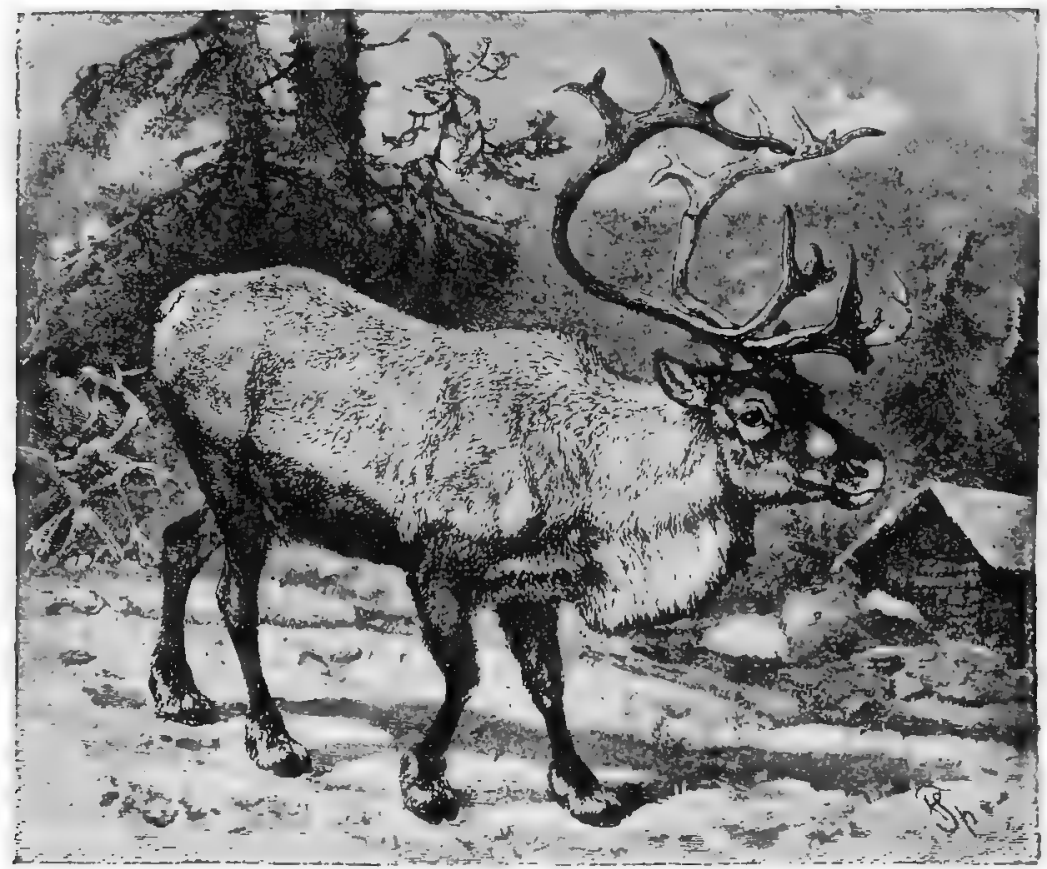

Reindeer

well as with rich, creamy milk, from which very good butter and cheese can be made. Thus it takes the place of the ox and cow as well as that of the horse. Again, its hair can be spun into warm winter clothing, so very necessary to those who dwell in the chilly climate of the far north. In this respect it takes the place of the sheep.

Quite recently, a new use has been discovered for the cloth spun from the hair of the reindeer; for it has been found that it is so light, that if a swimmer be clothed in a dress made from it, he finds it quite impossible to dive. A mat, too, of the size of an ordinary 


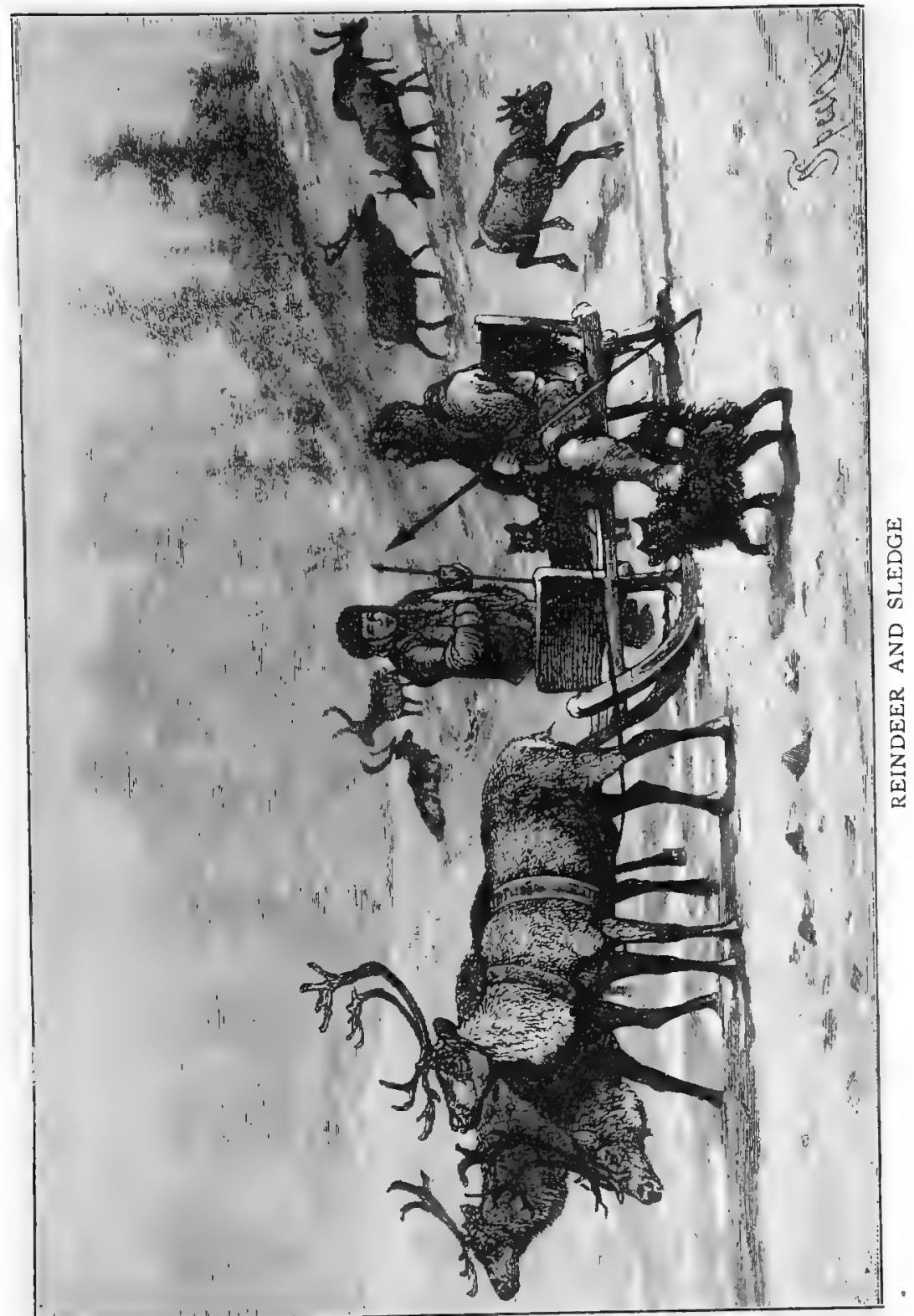


hearth-rug is so buoyant, that it will sustain the weight of a fullgrown man. It has been suggested, therefore, that the crews of life-boats should always be dressed in suits made of this hair when they venture upon their perilous journeys.

So valuable, indeed, is this interesting animal, that among the Lapps a man's riches are always estimated by the number of reindeer which he possesses. If he owns a thousand or more, he is considered rich. If his herd numbers only a few hundreds, he is still regarded as being in easy circumstances. But if his deer are less than fifty in number, then he is a poor man, and as a rule enters the service of one richer than he, with whose herds he combines his own.

In a state of freedom the reindeer always leaves its native forests at the beginning of summer, and travels northwards to a colder region. This it does principally perhaps to escape the flies and other insects which abound in the forest land.

One of its principal tormentors is a kind of gad-fly, which lays a number of eggs in its slin. Out of these soon hatch small white grubs, which burrow into the flesh of the deer and cause large and painful swellings, similar to those which we may sometimes see upon the back of a bullock or cow. The reindeer dreads this insect greatly, and even the humming sound which it makes as it flies is sufficient to drive a herd of these animals almost wild with terror.

All through the summer, therefore, the reindeer lives in the hills, returning in the autumn. Even when placed under domestication the animal is still obliged to make this annual journey, and every year, quite early in the summer, vast herds of reindeer may be seen travelling northwards, not to return until the hot weather has come to an end.

The principal food of the reindeer consists of a kind of lichen, which grows upon the ground in the large otherwise barren districts which these anima.s inhabit. In the winter, of course, their food is often covered by three or four feet of snow; but, guided by instinct, the deer scrape this away with their horns and hoofs, and thus contrive to satisfy their hunger. Sometimes, however, the surface of the snow is frozen into a solid sheet of ice, and then many of the animals perish from starvation. 
Now let us examine three important parts of the bodily structure of the reindeer; namely, its horns, its coat, and its feet.

You will probably recollect that, in speaking of the antelopes, I said that those animals are distinguished by possessing hollow horns set upon a bony core, which are retained throughout life, while the horns of deer are solid, and are cast off and renewed every year. We will now see how the horns of these latter animals are produced.

If we could see a reindeer towards the end of the winter, we should find him a very timid animal, hiding away in the deepest recesses of the forest. A few weeks ago he was bold and quarrelsome, quite ready to fight with others of his own kind, and, indeed, to encounter almost any foe. Now, however, his courage and pugnacity have quite deserted him. For his large, spreading horns have fallen off, and he is quite conscious that he has lost his natural weapons, and must live in retirement until they have been renewed.

At this time, if we could examine his head, we should find, just where the antlers had been, two small bony prominences, covered with a soft, velvety skin. If we placed our hand upon these we should find them quite hot to the touch. These are the new horns, which are quite small and soft as yet, and the warm blood which is coursing so rapidly through them is constantly depositing small particles of bony matter, and so causing them gradually to increase in size.

In a week's time the horns have grown considerably, and are beginning to throw out a number of "tines" or branches. A week later still they have grown a great deal more; and before very long they have attained to their full size, and are rather larger than those of the previous year. The age of a male deer, indeed, may always be calculated from the number of tines upon his antlers.

When the horns have quite completed their growth, the velvety skin which clothes them, and through which the blood-vessels passed, now loses its softness, and becomes hard and dry; and the deer, by constantly rubbing his newly-grown ornaments against the. branches of trees, soon scrapes it all away. Thus at last the horns assume the appearance in which they are so familiar to us.

We may imagine that the spreading antlers of a deer must 
prove a great obstacle to its progress when it is travelling through the thicker parts of the forest. But by throwing back the head they can be laid upon the neck, so that they are little hindrance.

The coat, too, of the reindeer is somewhat remarkable, for it is formed upon exactly the same principle as that of a seal. You will remember that the fur of the latter animal is twofold in character, an outer layer of thick, glossy bristles lying upon an inner coating of soft, warm hair. Just the same is the case in the coat of a reindeer, and the animal is thus protected from the keen frosts and biting winds of its northern home.

The feet of a reindeer are admirably suited to the life which their owner is required to lead. If they were formed like those of other deer, with small, firm hoofs, they would penetrate at almost every step through the frozen snow over which they so frequently have to travel.

But the ligament or tendon by which the toes are connected is extremely elastic, so that when the foot is placed upon the ground it spreads out, much like that of a camel, and the hoofs do not readily penetrate the frozen snow. When the foot is lifted from the ground, the toes spring together with a curious clattering sound, which is distinctly audible at some little distance.

\section{THE CAMEL}

The Camel differs widely from the ruminants with which we have become acquainted in the preceding pages.

In the East, where journeys lasting for several weeks have often to be made through sandy desert wastes, it takes the place which the horse naturally occupies in this country.

Horses, indeed, would be of little use in the desert. Their small, hard hoofs would sink deeply into the loose sand at every step; and after travelling for a mile or two, they would be unable to go any farther. Grass and water, too, might not be met with for two or three days together, and so they would suffer terribly from hunger and thirst. Thus, it is quite evident that horses would be useless in many parts of the desert. 


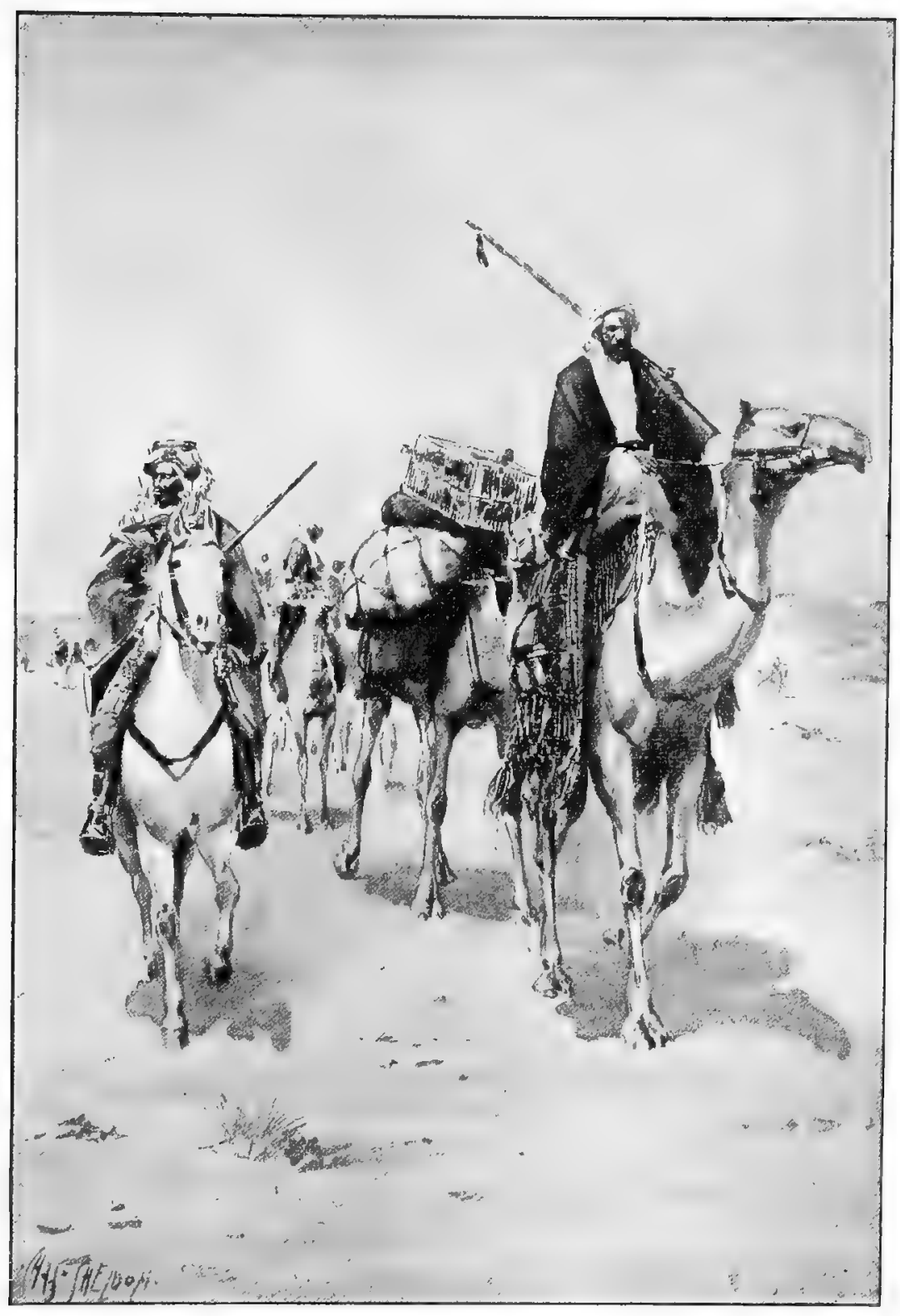


But Nature seems to have made the camel on purpose for desert work. For, instead of possessing hoofs like those of the horse, it has large, broad feet, with cushion-like pads beneath them. These feet do not sink into the sand like the hoofs of a horse, but allow the camel to walk along as easily as if it were upon firm ground. It cannot run or gallop as fast as a horse, it is true; but it can travel nearly all day long for several weeks at a time, when there is the necessity to so use it.

Although grass does not grow in the desert-except in the small fertile spots which we call "oases", and which are generally many miles apart-a kind of dwarf thorn-bush is sometimes found. This is quite sufficient for the camel, which browses upon it as it walks along.

It does not live entirely upon this dry food, however, and on the handful or two of dates which its master gives to it at the end of the day.

For the camel often lives throughout its long journeys principally upon its own hump! For the hump of the camel consists almost wholly of fat. And, although it may be large and firm at the beginning of a desert journey, the hump is found to have almost disappeared at the end. But this hump of fat is renewed again when the camel is able to indulge in plenty of food and water.

It is quite natural for the hump of fat to be absorbed into the body, and to serve the purpose of food. Just in the same way as you, if you went without food for several days, would feed, so to speak, upon the fat of your own body.

The camel can go for several days without water, which is a great natural provision, as, in the desert, wells are often three or four days' journey apart.

For the camel, like all animals which chew the cud, has no less than four stomachs, into each of which the food passes in turn. One of these stomachs is lined with cells, which can be opened or closed as the camel wishes. And each of these cells is large enough to hold a small quantity of water.

These cells serve the following purpose. When a camel drinks, it swallows much more water than it really requires at the time. 
All that it does not then need passes into these cells, where it is tightly fastened up. Each of these cells, as has already been said, can be opened or closed as the animal wishes. By this means it is able to travel for several days at a time without being obliged to drink.

The nostrils of the camel are formed in a rather curious way, for they can be tightly closed at will. The reason is this. In the desert country through which the animal has to travel, there are sometimes very violent "sand-storms".

Now, if the nostrils of the camel were formed like those of other animals, it would be in danger of suffocation by such a storm. But as it can close them tightly at will, all that the camel has to do is to wait quietly until the storm has passed by.

Still, we have not mentioned all the different ways in which Nature has fitted the camel for the peculiar life which it has to lead.

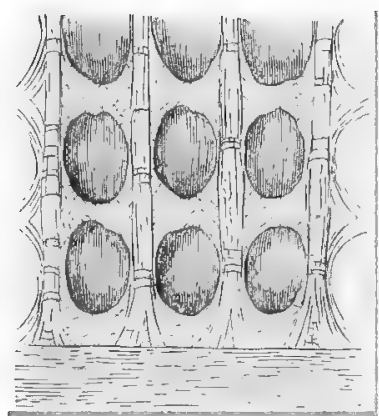

Water-cells in the Stomach of a Camel

It is a very tall animal, as no doubt most of you know; so that it cannot be loaded as we load a horse, but must be made to kneel down. Every morning, therefore, when it is travelling, it has to kneel while its burden is being fastened upon its back, and every night it has to kneel again, in order that this may be taken off.

The camel is not very swift of foot, and seldom travels at a speed of more than three miles an hour, when it is carrying a load. There is a special kind of camel, however, called the dromedary, which is a much faster animal, and is used principally for riding.

Many people think that the dromedary has two humps upon its back instead of one. But that is not the case. It is only a swift-footed breed of the common camel,-just as a racer belongs to a swift-footed breed of the common horse. The camel with two humps is quite a different animal, and is called the Bactrian camel, from the ancient name of the country in Asia in which it is found.

The camel is a very useful animal to its owner, apart from its 


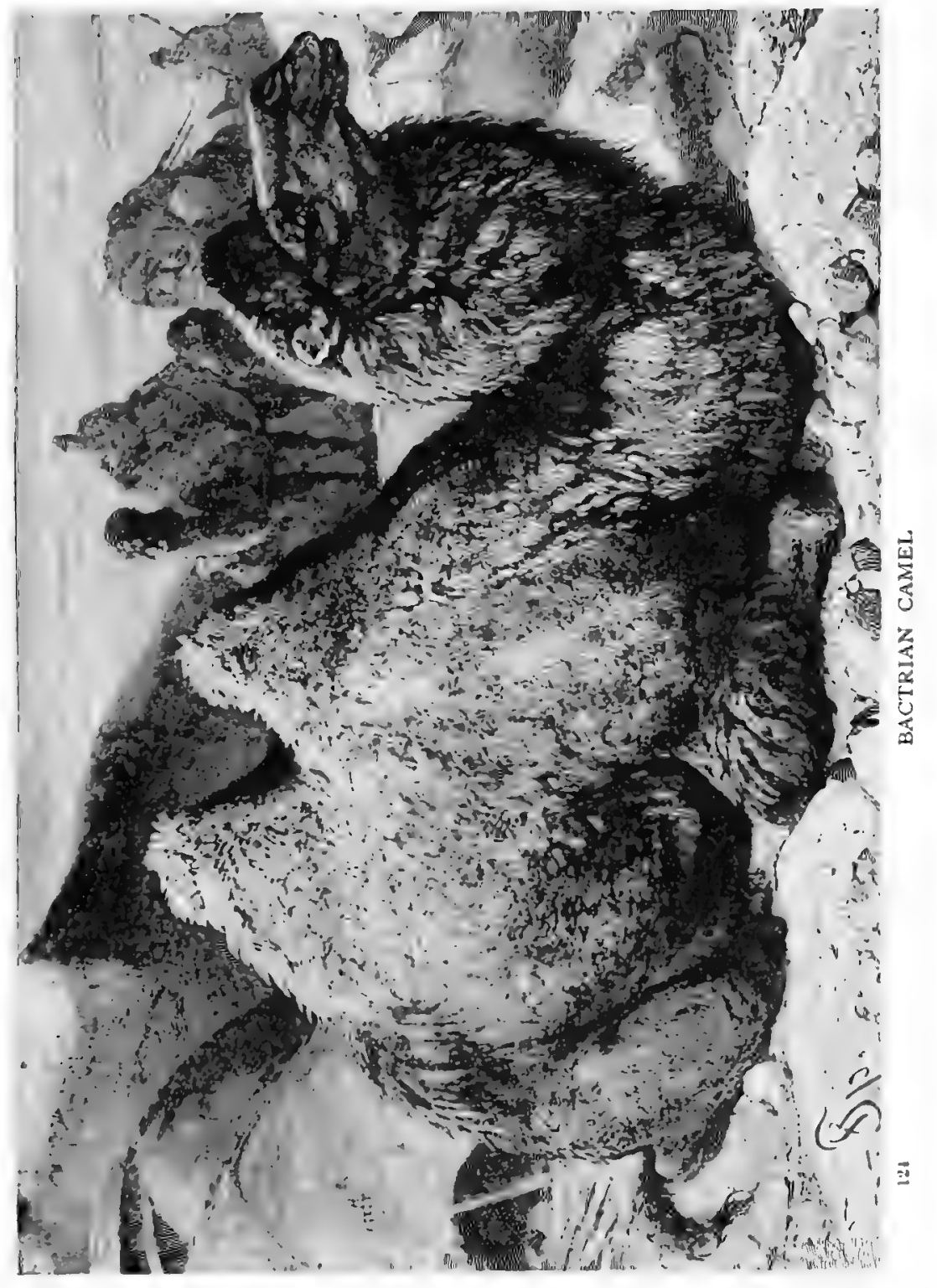


power of travelling through the desert. From its milk he makes a kind of cheese, which is very largely used for food in many parts of the East. Its hair, too, is carefully collected, and spun into cloth, while some is brought to European countries, and made into paint-brushes for artists, and a variety of things. The hide makes very strong and stout leather; and the flesh is very good to eat. But the camel is so valuable an animal, that only a very rich man can afford to kill one for food.

In Persia the Bactrian camel is used for a very remarkable purpose. A large and strong saddle is fastened upon its back, between the two humps, and upon this two heavy guns are fixed. Each of these guns is set upon a pivot, so that the rider, who sits behind them, can turn them in any direction.

The camels which are thus armed are formed into several regiments, known as the Camel Artillery, and more than once they have proved very useful in time of war.

Camels are surly, obstinate, and sometimes vicious, and cry angrily when receiving their loads. When passing a mounted man on a narrow path, they will sometimes suddenly turn their heads round and try to bite his arm or shoulder.

\section{THE HORSE}

We do not know when the horse was first tamed and trained to be useful to man, but we do know that when Julius Cæsar first invaded our own country of Britain, horses were in use, and were even used in warfare. Their fossil remains are found in the river gravels of England. Horses were here many thousands of years ago. Now we find them so valuable that we should not know how to do without them. Think how much they do for us. They draw our carts and carriages along the roads. They drag our ploughs and harrows over the fields. They help us to sow our corn, and to roll it when it is growing up; and, when it is ripe, they help us to cut and gather it in. If we go into a wood to cut timber, they help us to carry it away. If we dig a coal-mine, they work underground for us, and help to bring the coal to the 
surface. If we wish to ride, they will carry us on their backs, and take us wherever we want to go.

In looking at a horse, we can hardly help feeling that it was made to be the servant of man. Look at its back; does it not really seem as if it were meant to carry a saddle? Look at its mouth; does it not seem as if it were intended to hold a bit?

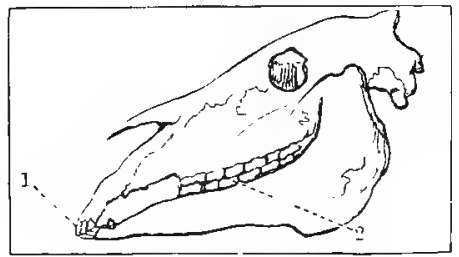

Skull of Horse

1, Cutting teeth; 2, Grinding teeth For you will see that there is a gap between its front, or cutting teeth, and its back, or grinding teeth. It is in this gap that the bit is placed.

Look at its limbs; do they not seem to be made for strength, as well as for speed of foot? And look at its hoofs; do they not seem to be meant for all kinds of hard work? Certainly Nature scems to have done her best to make the horse as useful to us as possible.

Its docility, too, is a most valuable characteristic. If the horse were a stubborn and obstinate animal like the zebra, which has hardly ever been tamed, it would be of very little use to us, notwithstanding its great strength. But, with very rare exceptions, horses are as gentle and tractable as could be wished.

And further, does not the very size of a horse suggest that it was intended for the service of man as a rider. Horses were probably first used for carrying their owners from place to place. Only treat them well, they willingly work for us. All that they ask in return is a dry stable, and plenty of good oats, hay, and clean water.

The Arabs are so fond of their horses that they do not put them in stables at all, but allow them to live in their own tents, just as though they were members of the family.

If you could look into an Arab's tent, you might even see the little children playing between the legs of the horse. It is very careful not to hurt them, and sometimes even joins in their fun. If its master enters, the horse goes to him, rubs its nose against him, and follows him about like a pet dog. 
Let us look for a few moments at a very important part of a horse's frame; namely, its hoof. Suppose that a horse is lifting up one of its fore-feet for us, so that we can examine it easily.

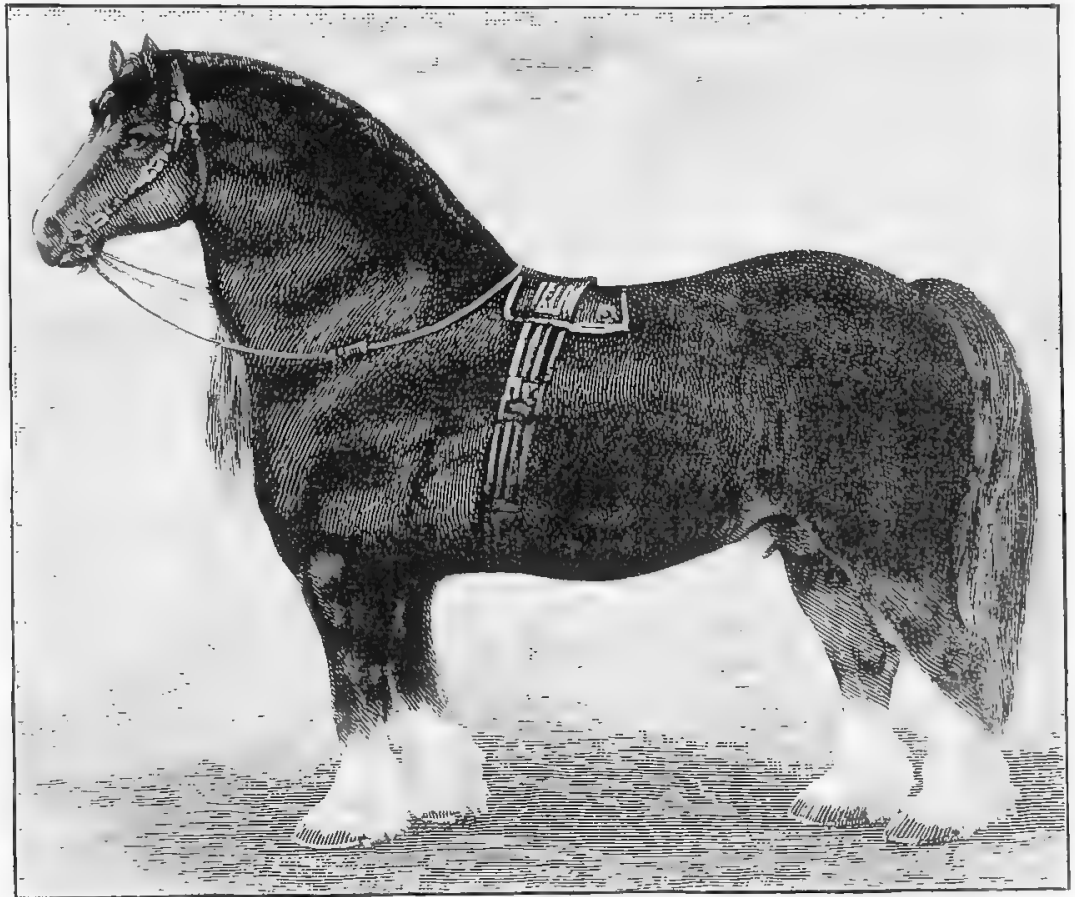

Clydesdale Horse

The hoof looks like a piece of hard horn, which seems to cover the whole sole of the foot.

In a state of freedom, the horse has no iron shoes to protect its hoofs, which in consequence are always being worn down by friction against the hard ground. We might suppose that they would soon be destroyed altogether, but they grow again just as fast as they are rubbed away, and so are never much the worse for wear.

The hoof of a horse, in fact, is very much like our own finger- 
nails, or the claws of a cat. We are obliged to cut our nails every now and then; and yet very soon they are as long as before. The cat's claws, too, grow so fast that she is frequently obliged to rub them down, as you may often see, by scratching the bark of a tree, or the leg of a table.

So it is with the horse's hoofs. They are constantly being worn away, but they are constantly growing. Thus, a wild horse's

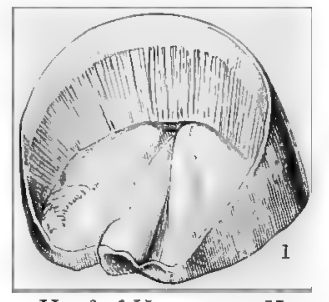

Hoof of Horse. I, Horn.

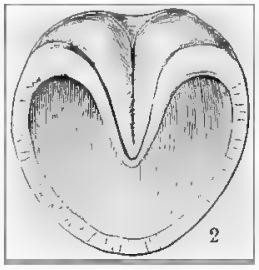

2, Sole, showing Frog hoofs are always in sound condition. In Canada the horses are shod for the summer months, but as soon as the snow appears the shoes are taken off again, because there will then be so little wear for the horses' hoofs that they will not require the protection of the iron.

Being made of a kind of horn like our finger-nails, the horse's hoof is not hurt by contact with rough stones or by nails being driven through it to hold the "horse-shoes" on. This absence of feeling in the hoof is of course a great advantage to the horse, since it can work and trot upon hard roads without being pained.

But though it is only horn, the hoof of the horse is wonderfully constructed so as to protect such a heavy animal from shaking and jolting itself when it gallops. The under-part of the hoof is formed of layers of horn that are folded and wrinkled, so that, when the foot comes down heavily on the ground, the folds and wrinkles act as springs, in the same way as springs in a carriage; namely, by preventing jarring and jolting.

The horny foldings are casily seen on the under-side of a horse's hoof when it is being shod. The most wrinkled portion is something like a frog in shape, and is therefore called "the frog". To horses in a wild state this springy structure is a wonderful provision for their protection.

A wild horse, indeed, can climb the side of a steep mountain, or even gallop over ice, without slipping. And the "frog", like 
the outside ring of horn, is so formed that it grows again just as fast as it is worn away.

You will remember that, when reading about the "animal army", and the way in which their bodily frames may be regarded as their uniforms, we pointed out how very careful Nature is to suit every part of an animal's body to the life which that animal is intended to lead. We can find no better example of this creative care than in the hoof of a horse.

\section{THE ASS}

Those who have spent a holiday at the sea-side will know well the Ass, or Donkey as it is more commonly called, for they will, of course, have enjoyed the fun of a donkey-ride on the sands. This animal, though less in size, is in many ways as useful as the horse. In fact it was used by man as a beast of burden many hundred years before the horse was subjugated, and held quite an important position as a domestic animal. But nowadays, in our own country, it has to be content with a very humble station, for it is mostly the servant of the poorer classes, who, unfortunately, very often try its patience severely.

In its wild state the ass is a swift and spirited animal, but it is easily tamed, though when domesticated it seems to lose much of its brightness, which perhaps is mainly owing to bad treatment. A poor depressed donkey is a pitiful sight. It hangs its head, and we might imagine it to be thinking of its more lively and happier freedom.

As a domestic animal it is given to fits of obstinacy. At such times it stands stock-still in the middle of the road, and is only brought back to the reality of life by heavy blows with a stick, just as a boy who has been dreaming in school of football or cricket is brought to his senses by a sharp stroke across his knuckles from the master.

A story is told of a donkey that was so stubborn that it would not move, till at last its master tied a wisp of hay to the shaft in front of it and just beyond its reach. Then there was not a (M 868) 
smarter donkey in the town, for it moved forward to get the tempting bite, and, as the hay moved with the cart, it ran on till its master wanted it to stop.

The braying of a donkey is a noisy, boisterous, and utterly unmusical sound, which most of us must have heard. If the animal were in a wild state its cry would probably mean a great deal

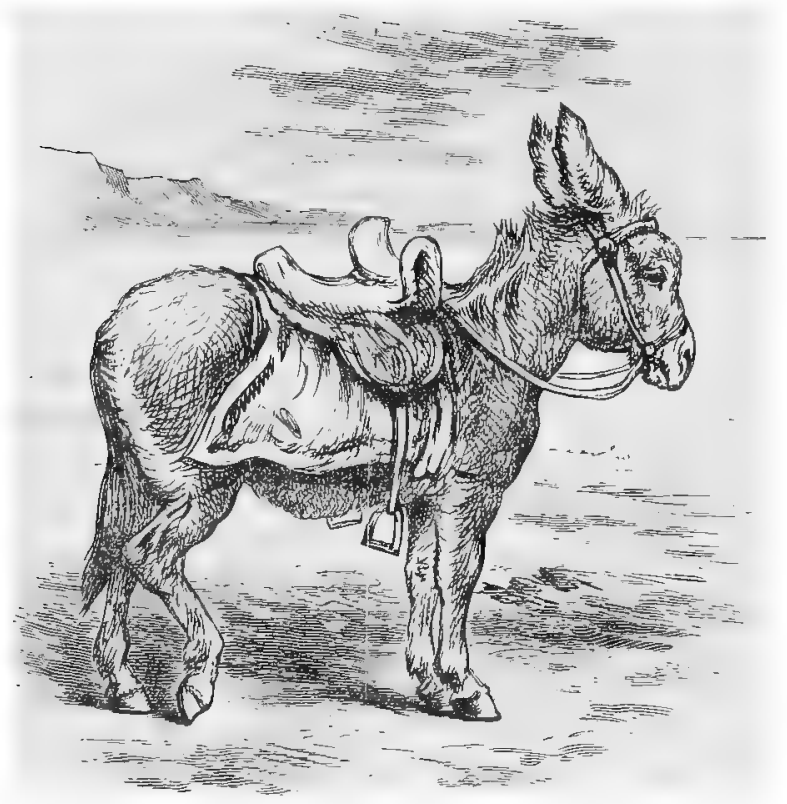

Donkey

to other donkeys; but as we don't understand donkey language, it is difficult for us to say what object the donkey has in thus expressing itself.

In form the donkey is very like the horse. It differs chiefly in lacking the flowing mane and tail, and in having much longer ears. Its mouth is equally well adapted for the bit. In colour it is commonly of a mouse-gray, but the shade varies, and while some may be found almost white, others are brown or nearly black. There is a dark stripe on its back from head to tail, and another 
across its shoulders, forming a cross, on account of which the donkey is in some countries regarded as a sacred animal, and is in consequence not ill-treated.

The donkey is a sturdy animal and very sure-footed, and, if well cared for, a good worker. In mountainous districts it is much used as a pack animal, that is, not to drag loads, but to carry heavy packages slung across its back. But for this work the mule, a cross between the horse and the ass, having the good qualities of both, is coming more into use.

\section{Bureau. 1'at:}

\section{THE ZEBRAC TTNVERSTTY}

One of the most beautiful creatures in the world is the Zebra. * It is like a graceful little pony wonderfully marked almost all over the body with black stripes on a white ground.

Several species of the zebra are found in different parts of South Africa. It is a very shy animal, and lives in small herds far from the abode of man. It likes to roam and graze among the hills, and when startled scampers off to a place of safety among the rocks. It seems to be able to scent danger a long way off, for it is very difficult to get near a herd. Those who have studied its habits say that one of the number is always posted at some point where it can see the country on all sides and so give warning in plenty of time.

The zebra is a near relation of the ass, the cross on the back of the latter showing their common origin. It is also believed by some to be the representative of the animal from which the modern horse has been developed. Often strange markings, similar to the stripes of the zebra, are found on the shoulders and fore-legs of horses whose parents were perfectly uniform in colour. And yet the zebra, which is swift, strong, and sure-footed, is so shy and full of spirit that it has never yet been successfully tamed. It is said that if it could be well trained it would make the best pony in the world.

Like the horse and the ass, the zebra defends itself at close quarters with its hind-legs. It never waits for the approach of an 


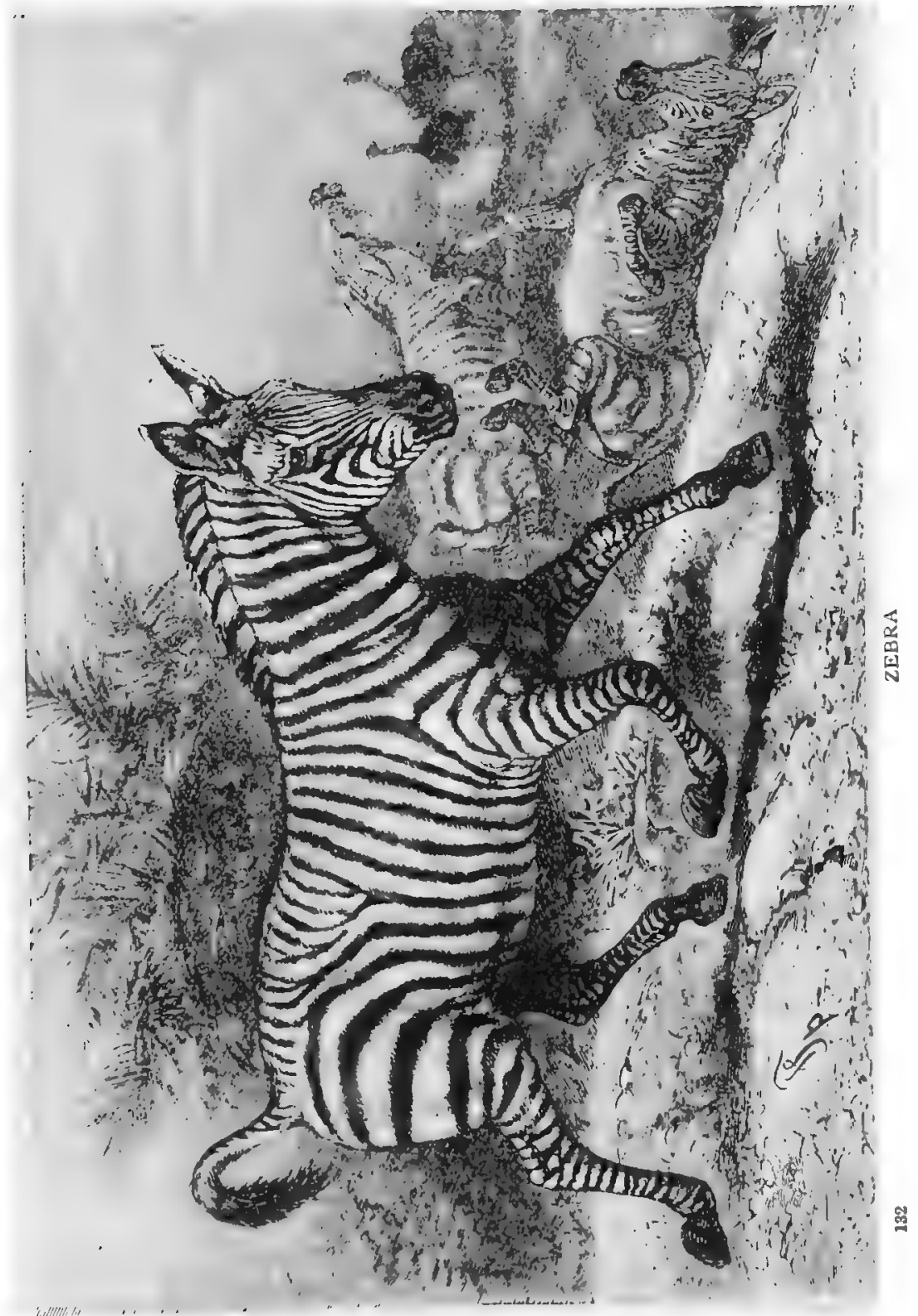


enemy, but travellers say of one species which lives on the plains, that, if overtaken, the herd forms into a compact body, with their heads in the centre, and presents a dangerous array of kicking heels to the foe.

These plain-dwelling zebras are seemingly not quite so timid as their hill-loving cousins. Though they avoid man, they like company, and, strangely enough, their favourite companions are ostriches.

\section{THE ELEPHANT}

If you have ever seen an elephant you must have noticed its trunk. What a wonderful organ it is! So strong that it can lift a heavy man from the ground and raise him high in the air, or tear down a stout branch from a tree; and yet so delicate of touch that it can pluck a single leaf or blade of grass, or pick up a pin from the floor. With the trunk, too, the elephant carries its food to its mouth; draws up water and squirts it down its throat when it is thirsty, or over its back and sides when it is hot. The trunk, indeed, is very much to an elephant what our arms and hands are to us; and without it the animal could not live. For the long tusks would prevent it from reaching the foliage of bushes and trees, while the short, thick neck would not allow it to stoop down and drink-so that it would very soon perish of hunger and thirst.

This curious and wonderful trunk is formed partly out of the upper lip, and partly out of the nose. If you could examine an elephant's mouth as it was opened, you would see that it possesses a lower lip, but not an upper; and this, with the fact that the nostrils run all the way through the trunk, would at once tell you that that organ is formed partly of the nose and partly of the upper lip; that is, that it is a prolongation of both. The upper lip and nose of an elephant, in fact, are so joined together as to form but one organ; and in that organ there are no fewer than fifty thousand separate muscles!

That is why an elephant's trunk is so strong, and why it can be put to so many different uses. One set of muscles enables it 


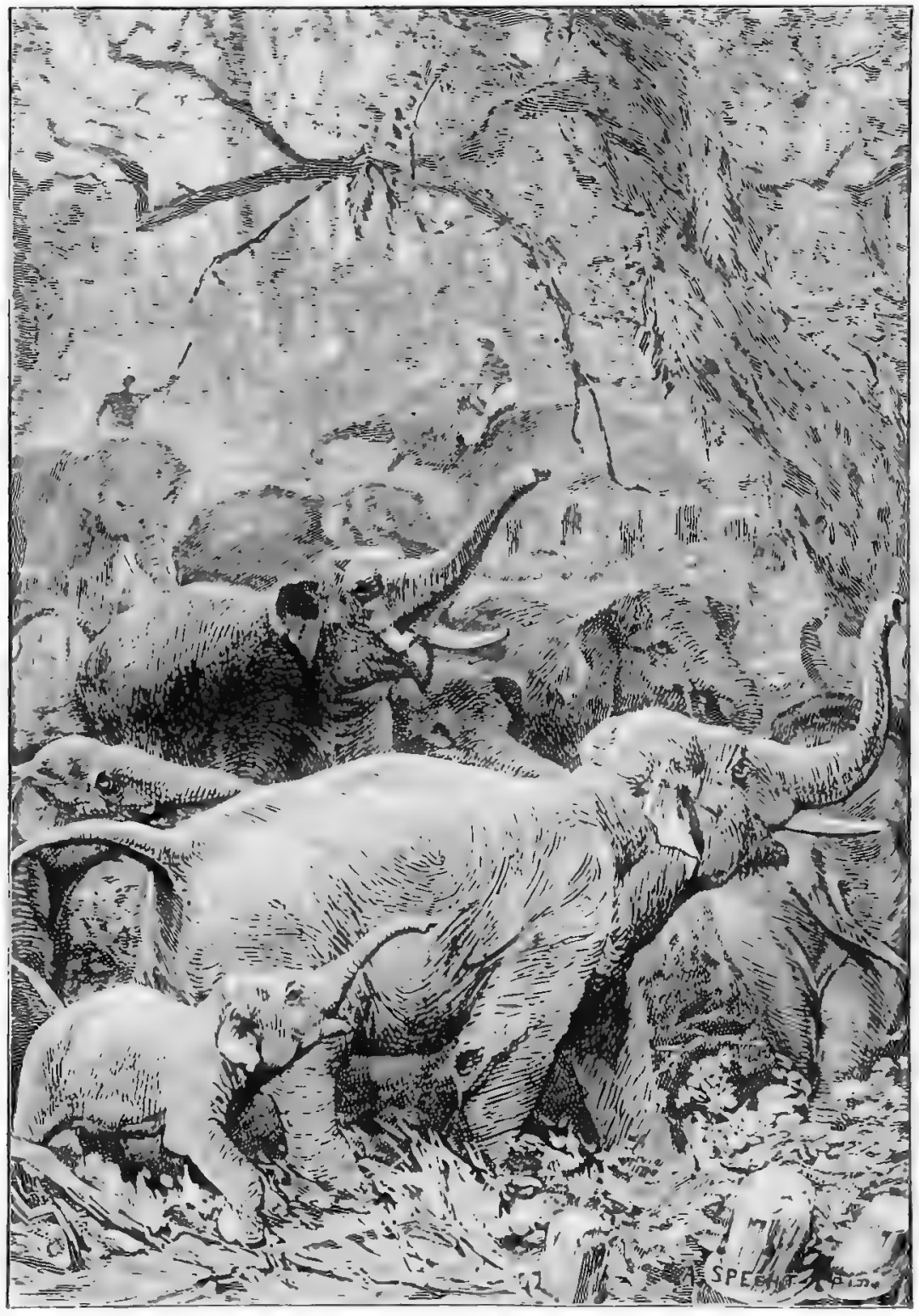


to lift the trunk, another to move it sideways, and another to coil it up. A fourth set allows it to make use of the little finger-like member, which you may have noticed at the tip, and to pick up even tiny objects with it.

The elephant can even throw with its trunk, and can take very good aim too, as the following anecdote will show.

Some years ago a man, wishing to play a trick upon an elephant, procured a number of nuts, some of which were very good, but others were so hot as to burn the throat of any who swallowed them. Having given the good nuts to the animal he then gave it the hot ones, which the elephant swallowed, thinking they were like the first. As soon as it had eaten them it drank a whole pailful of water, which happened to be standing by, in order to cool its burning throat. It then picked up the empty pail, and flung it at the head of the foolish joker, with so true an aim that the man only just contrived to avoid serious injury.

There are two different kinds of elephant. One of these, which lives in the dense forests of Africa, is called the African elephant. The other, which is found in certain parts of India, is known as the Indiar, elephant.

It is easy to tell to which of these two kinds an elephant belongs by looking at its ears. If these are small, so as not to cover the sides of the head, it is an Indian elephant. But if the ears hang down far below the neck, and are almost broad enough to allow a man to hide himself behind them, then you may be quite sure that the elephant comes from Africa.

Again, only a few Indian elephants have tusks, and these are never so long as those of the African elephant.

Indian elephants are often caught and tamed, and they are so intelligent and clever that they very soon learn to perform all kinds of work. In many a town in India we might see elephants building walls. They would have a bricklayer with them, of course, who would spread the mortar. But all the bricks would be arranged in their places by the elephants, who know exactly where to lay them, and how to place them in position. Or we might see another elephant making a road over a piece of marshy ground by laying down a row of stout logs. 


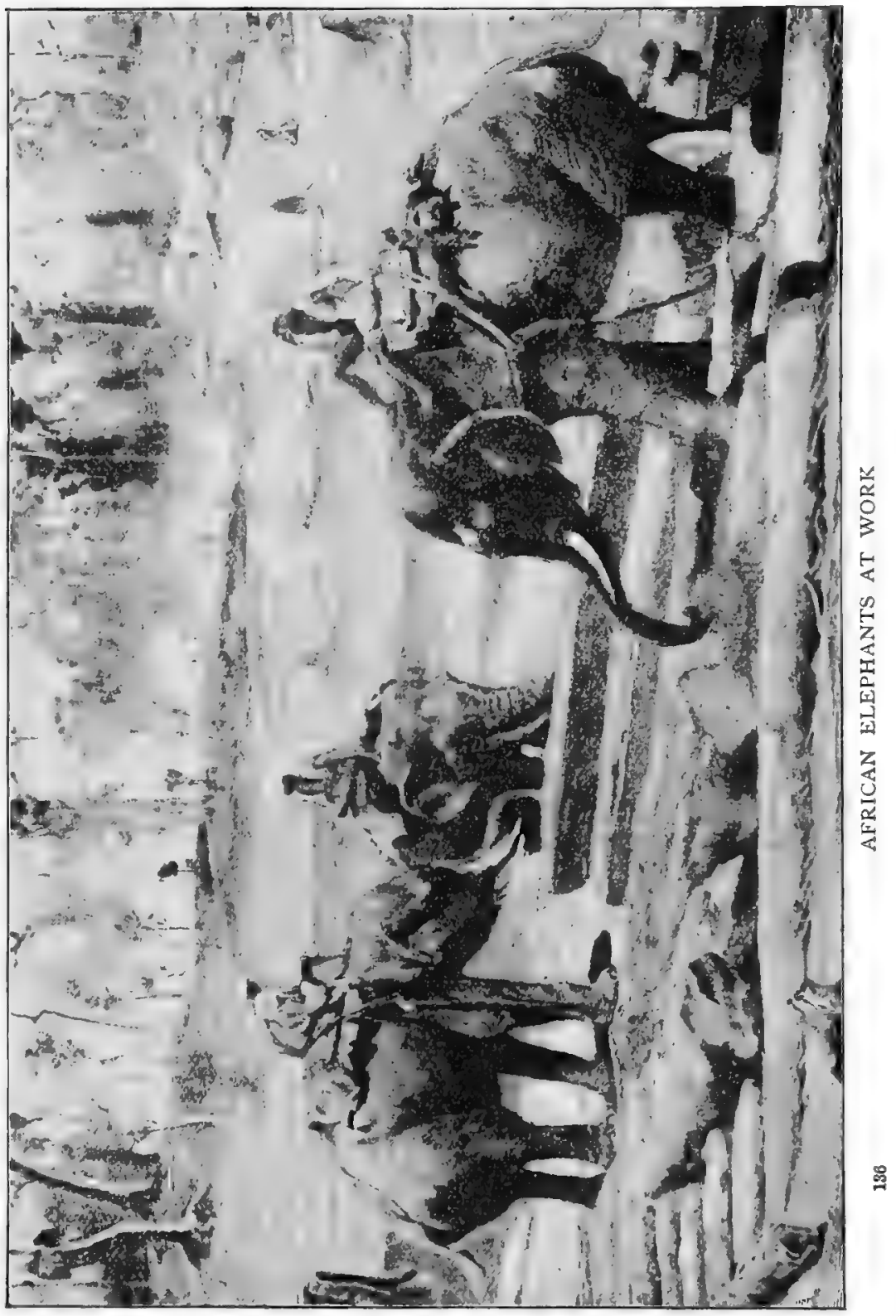


But the Indian elephant is chiefly used for riding; and we should be sure to see several elephants in the streets, each with a load of riders upon its back. These riders would be sitting in a large basket-work seat, called a "howdah", which is fastened upon the elephant's back, while the animal is guided by a "mahout", or driver, who sits astride upon its neck. The mahout carries a long iron spike, with a hook at the end, called a "haunkus", and this he presses against the elephant's head, to show in which direction it is to go.

The elephant is often trained to hunt the tiger; but this is not at all an easy task, for it is very much afraid of that animal. At first the skin of a tiger is given to it, and it is encouraged to toss it about, and trample

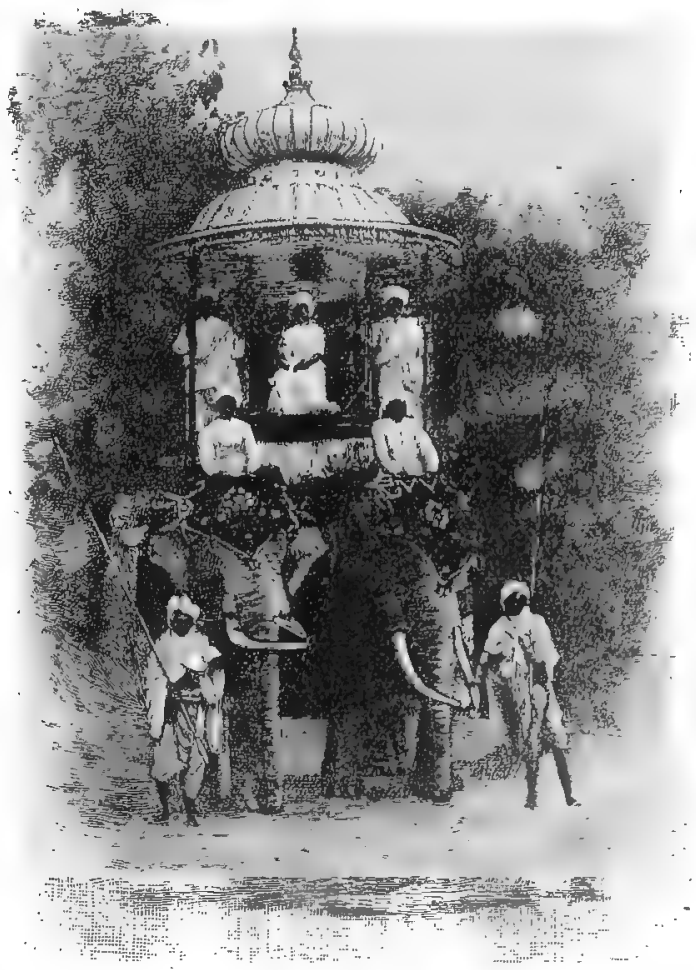

Elephants with Howdah upon it. Then the skin is stuffed, and given to it again, that it may treat it in the same way. Lastly, the elephant is securely fastened up, while a boy gets into the skin and runs about upon his hands and feet, in order that the elephant may be accustomed to seeing what it takes to be a tiger in motion. After this the elephant is considered to be $\mathrm{ft}$ for employment in the tiger chase. But, even after all this care, it often happens that when an angry 
tiger springs upon it with flaming eyes and a loud roar, the elephant runs away.

In olden days there were wild elephants in Great Britain, and their fossil bones are often found by those who work in sand and gravel pits.

\section{THE TAPIR}

On seeing a Tapir for the first time we might imagine it to be a near relation of the elephant. True, it is not nearly so large and bulky as that animal, for an adult tapir stands only about four feet high at the shoulder. In other words, it is no taller than an ordinary donkey. But it is very stoutly and heavily built; it has an extremely thick and leather-like hide, and, above all, its upper lip is prolonged into a short trunk, or proboscis, at the extremity of which are placed the nostrils. With this trunk the animal can pluck herbage and convey it to its mouth, although the finger-like tip is wanting which is so serviceable in the trunk of the elephant.

Thus, as far as its outward appearance is concerned, the tapir undoubtedly bears a considerable resemblance to the elephant. But when we come to examine it more carefully we find that in reality it is related to the swine. Its feet, for instance, are not at all like those of an elephant; neither are its teeth. And if we wish to place it in its proper position in the "animal army", we must look upon it as a creature which comes somewhere between the horse and the pig, but cannot be classed with either.

Three different kinds of tapir have been discovered, one of which is so rare that very little is known about its habits. The commonest of the three lives in the warmer parts of South America, and in some districts is very abundant. Yet, in spite of its numbers, it is not very often seen, for it is nocturnal in its habits, and hides during the day in the densest thickets, through which scarcely any animal but itself can force a path. Soon after sunset, however, it comes out from its retreat to feed, and also to bathe in some pool or river; and a hunter who wishes 
to shoot a tapir has only to lie in wait in a convenient hidingplace near the water's edge.

Unless it is driven to bay the tapir is a very timid animal, and is far more ready to run away than to fight. Trusting to its great weight, and the thickness and toughness of its skin, its first idea when attacked is to make for the densest part of the

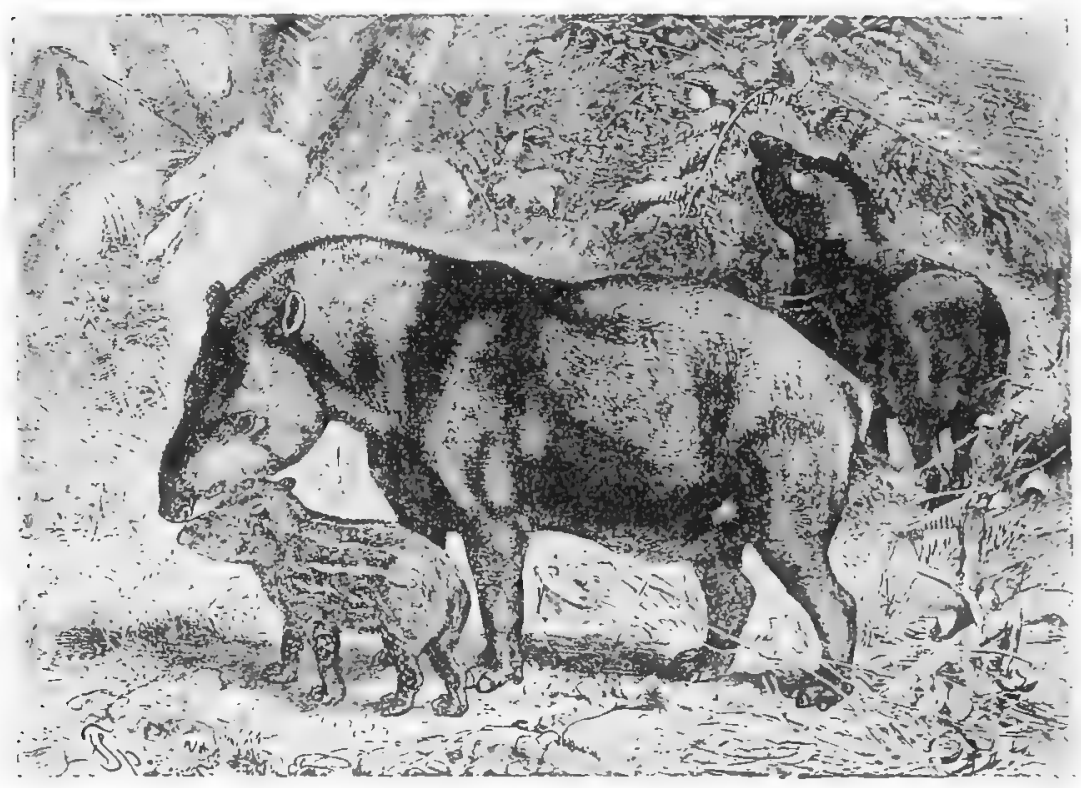

Brazilian Tapir

forest, through which it forces its way as easily as if the creepers were made of packthread and the bushes of straw. To follow it when once it has entered a thicket is quite impossible, so the hunter has to be very careful to kill it, or at any rate to wound it severely, with his first bullet.

If it should find flight impossible, however, the animal will fight fiercely, and sometimes inflicts most severe wounds with its sharp and powerful teeth.

The natives of South America sometimes capture the tapir 
with their curious lasso; but the animal is so heavy, and dashes away with such speed when it feels the noose upon its shoulders, that it will often snap a rope by which a powerful horse would be safely held. The Indians prefer, therefore, to shoot the animal with poisoned arrows, and entice it within range by imitating its peculiar whistling call. The arrows which they use are very

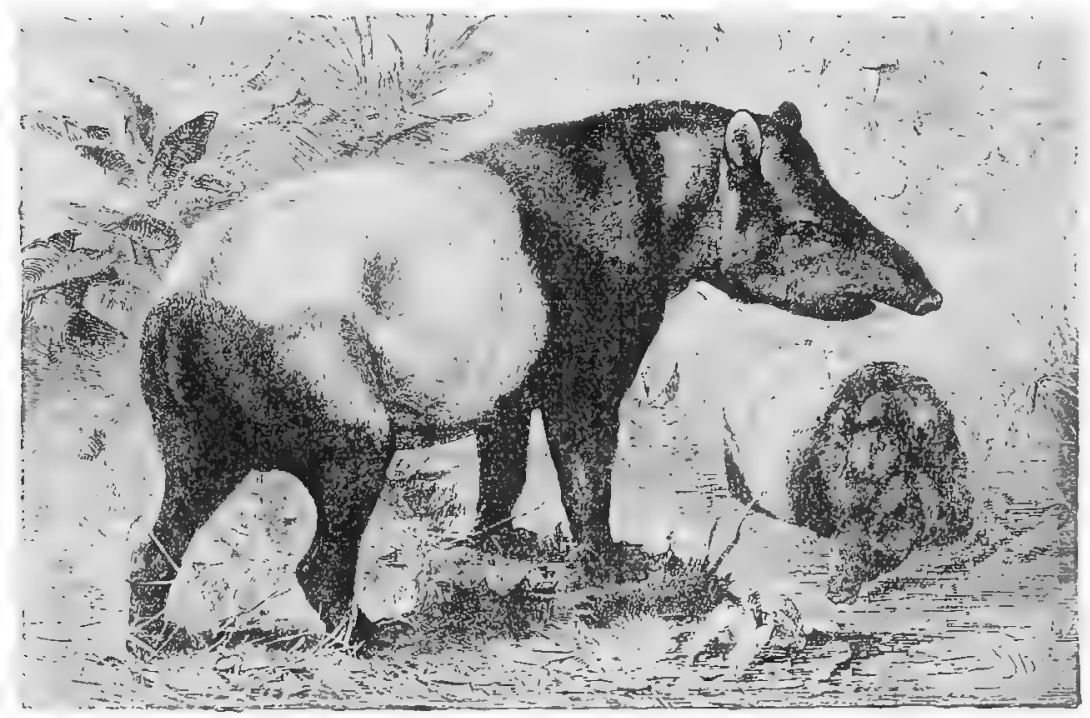

Malayan Tapir

small, not much larger than an ordinary knitting-needle. But the poison with which they are tipped is so deadly, and acts so rapidly when once it is introduced into the system, that the wounded tapir is sure to fall down and die before it has travelled very far.

When a tapir is taken alive it is often domesticated, and tame tapirs are said to be quite common in some of the villages and towns of Guiana. After a time they appear to lose all desire for a wild life, and are permitted to wander where they will. They alter their habits, too, and take to feeding by day instead of by 
night. And every day they roam into the forest in search of food, returning in the evening to the shed in which they sleep.

The Malayan tapir, which lives in several of the larger islands of the Malay Archipelago, as well as in the south-western provinces of China, is very easily distinguished from its relation in America, for its back and hind-quarters are almost white. Those who are familiar with it in a state of freedom say that in the distance it looks just as if it were wrapped in a white sheet. It has no bristly mane, like the American tapir, and is rather larger, with a longer trunk. The young animal, strange to say, is not marked in the least like its parents, but is spotted and streaked all over with yellowish fawn.

\section{THE RHINOCEROS}

No fewer than eight distinct kinds of Rhinoceros are known to exist in different parts of the world. Four of these are found in Southern Africa, and the remainder in Asia and the larger islands of the Malay Archipelago. They are all very much alike - great, bulky animals, smaller, it is true, than the elephant, but very much larger than the tapir; with short, stout, pillar-like legs; clothed in a thick, leather-like hide, so hard and tough that it will flatten an ordinary leaden bullet; and with either one or two stout horns upon the front part of the head.

These, however, are scarcely " horns" in the true sense of the term. The horns of antelopes and deer, for instance, are formed of a bony substance, and are connected with the skull. But those of the rhinoceros are composed, not of bone, but of a hair-like substance, so closely compressed as to form a solid mass. The tip of the horn is always quite smooth and polished, but at the base the hair-like structure can be easily seen. And if we were to remove one of these horns and examine it by means of a microscope, we should find that the fibres of which it is made up are true hairs, although in an altered form.

And these "horns", as we must call them for want of a better name, are not connected with the skull, but are merely a growth 


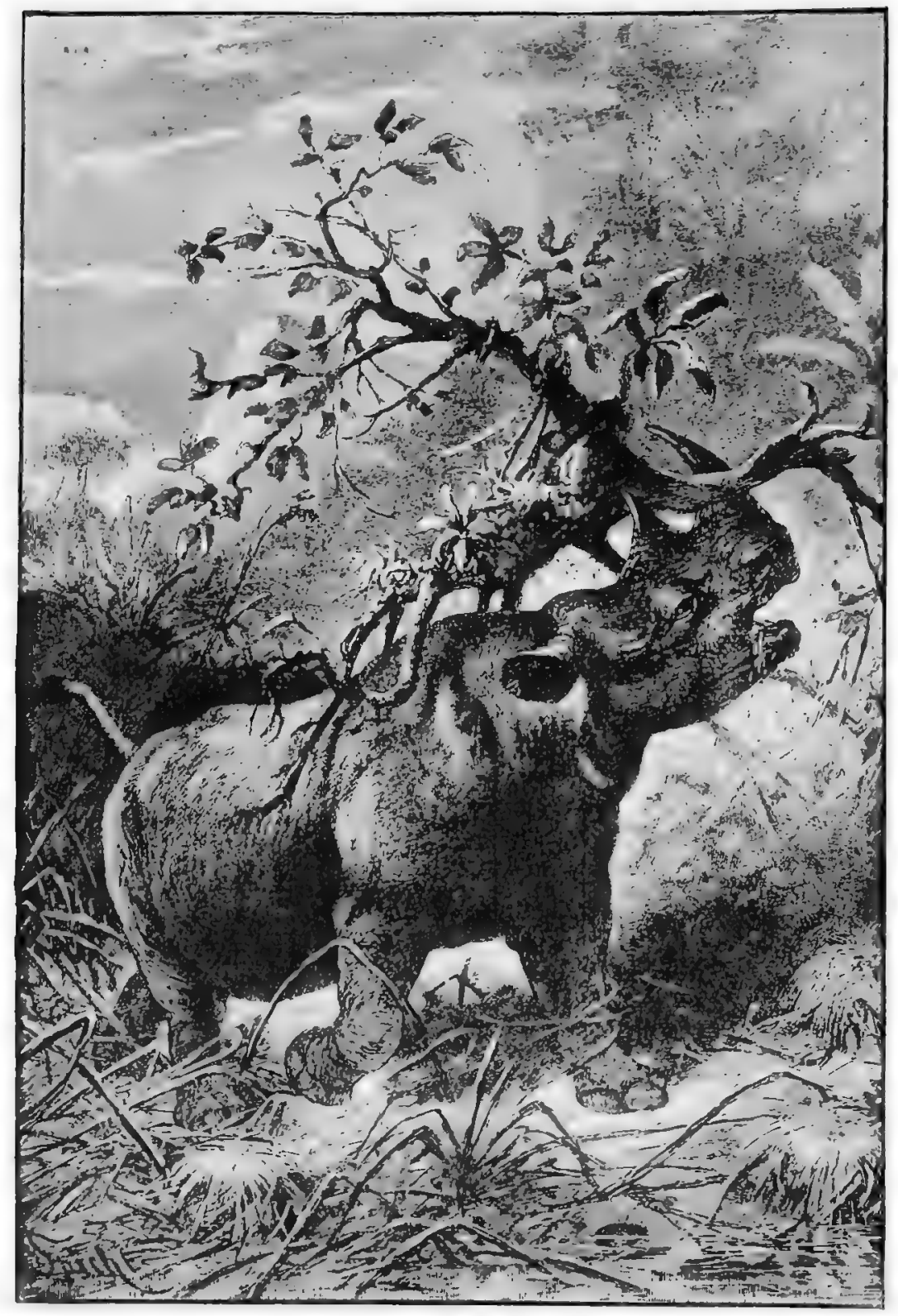


from the skin, and can be easily removed by passing a sharp knife round their roots, and so separating them from the hide. Beneath them, however, is a very strong arch of bone, with one end free, so that it may be as elastic as possible. This arch furnishes the horns with a firm support, and at the same time prevents the brain from being injured by the shock of the blows which they so often have to deliver.

A rhinoceros uses its horns for various purposes. With them, for instance, it digs in the ground in search of the roots which form a considerable portion of its diet. It uses them as weapons, and very formidable weapons they must be. The Indian rhinoceros is said to kill even the elephant, by dashing between its legs and ripping open its body. A well-known traveller tells us that a rhinoceros and an elephant were once found lying dead together, the horn of the former having been so firmly fixed in the elephant's ribs that its unfortunate owner could not withdraw it. And another traveller was once flung out of his saddle by the horn of a rhinoceros, which was struck completely through the body of his horse from below, and yet retained sufficient force to inflict a severe wound upon his thigh.

In olden days there was a curious superstition with regard to the horn of a rhinoceros, which was thought to be a sure test of liquid poison. Kings and other great men, indeed, often had a drinking-cup made of the horn and set with gold and jewels, and it was supposed that if poisoned wine were poured into such a cup it would at once begin to froth and bubble, and so give evidence of its deadly nature.

The horns of the rhinoceros vary rery much in length. In the Indian species, about which we have just been speaking, they are quite small, and are almost as broad as they are long. On the other hand, a rlinoceros found in Africa has a horn so long that a ramrod nearly four feet in length can sometimes be cut from it.

Very remarkable, too, is the skin of the rhinoceros. It has already been mentioned that it is so hard and tough as to flatten an ordinary leaden bullet, and the hunters, when they attack a rhinoceros, always harden their bullets with solder or tin. The 


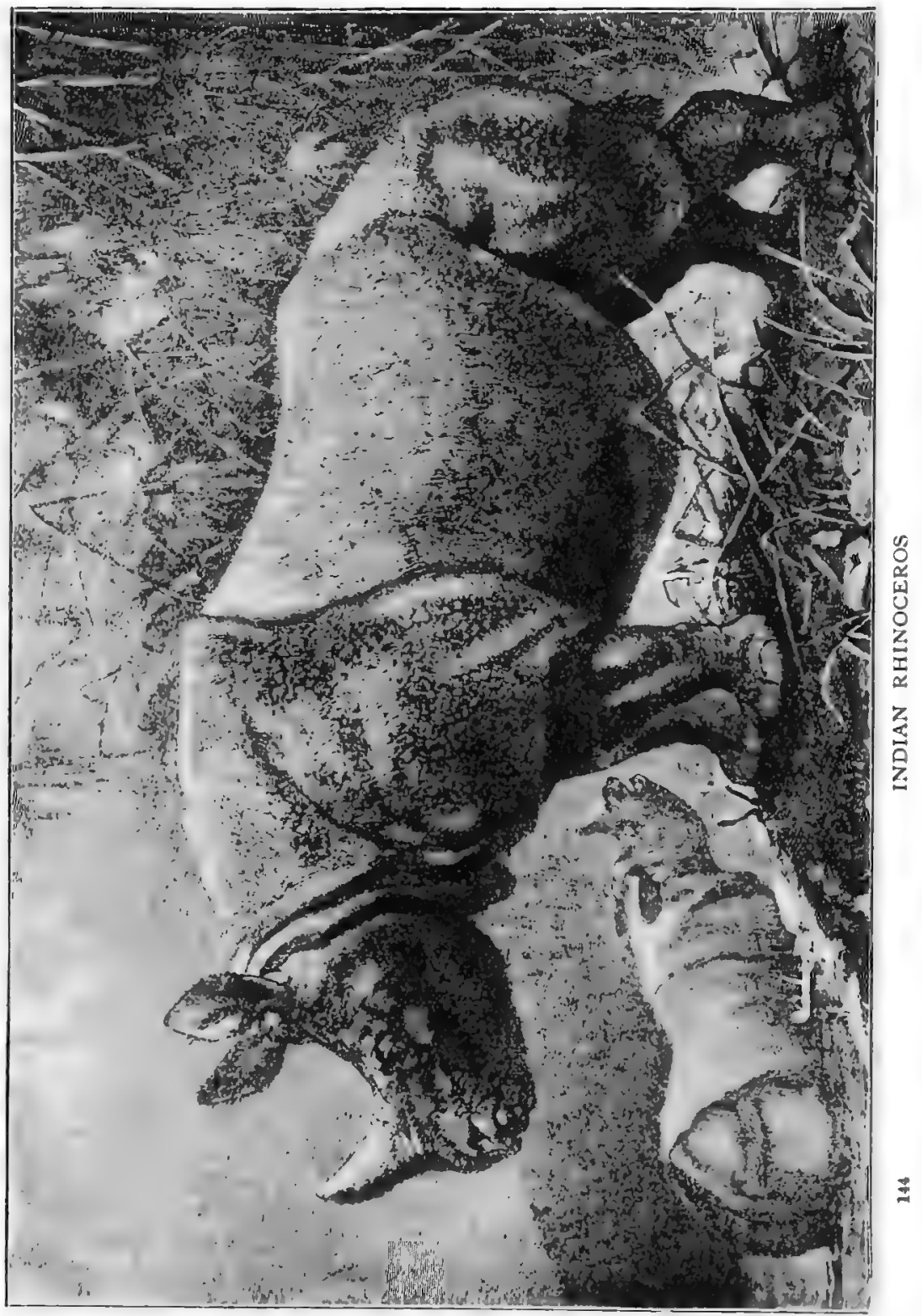


African savages, when they kill one of these animals, strip off its hide and make shields of it. These shields will turn even a rifle-bullet, unless it should happen to strike them quite full and true. A curious cattle-whip, called a "sjambok", is also made from the hide, and is so strong that it will cut a deep groove in a deal board.

In the Asiatic species of rhinoceros the skin is very loose, and lies in great folds upon the neck, shoulders, and hind-quarters. These folds can easily be lifted up by the hand. The skin beneath them is much softer and thinner than the rest, and flies and other parasites creep under them and greatly torment the animal. In order to destroy these tiny foes the rhinoceros wallows in the bed of a river, and so covers its whole body with a thick coating of mud.

Although the rhinoceros is so big and heavy, and so very clumsy in appearance, it can run with such speed as to outstrip any but a very fast horse. When attacked or irritated it becomes a most formidable enemy, seeming to lose all sense of fear, and caring nothing for the wounds which it receives. So fierce and savage does it become, indeed, that a very experienced hunter says that he would rather face fifty lions than one angry rhinoceros.

\section{THE PIG}

The Pig is an animal which most of us think rather disgusting. We say that it is always dirty, and smells very nasty, and we think that it is a very greedy, lazy creature, doing nothing but eat, drink, and sleep. But we forget that we often shut it up in a small sty, in which it can do nothing but feed and sleep, and where it cannot keep itself clean, even if it would. When it is living a free life, out in its native woods, it never eats so much as to become fat and lazy. And it is then as cleanly as any other animal.

Not very long ago pigs were found wild in England, and men used to hunt boars, just as they hunt foxes now. When the boars (II 868) 


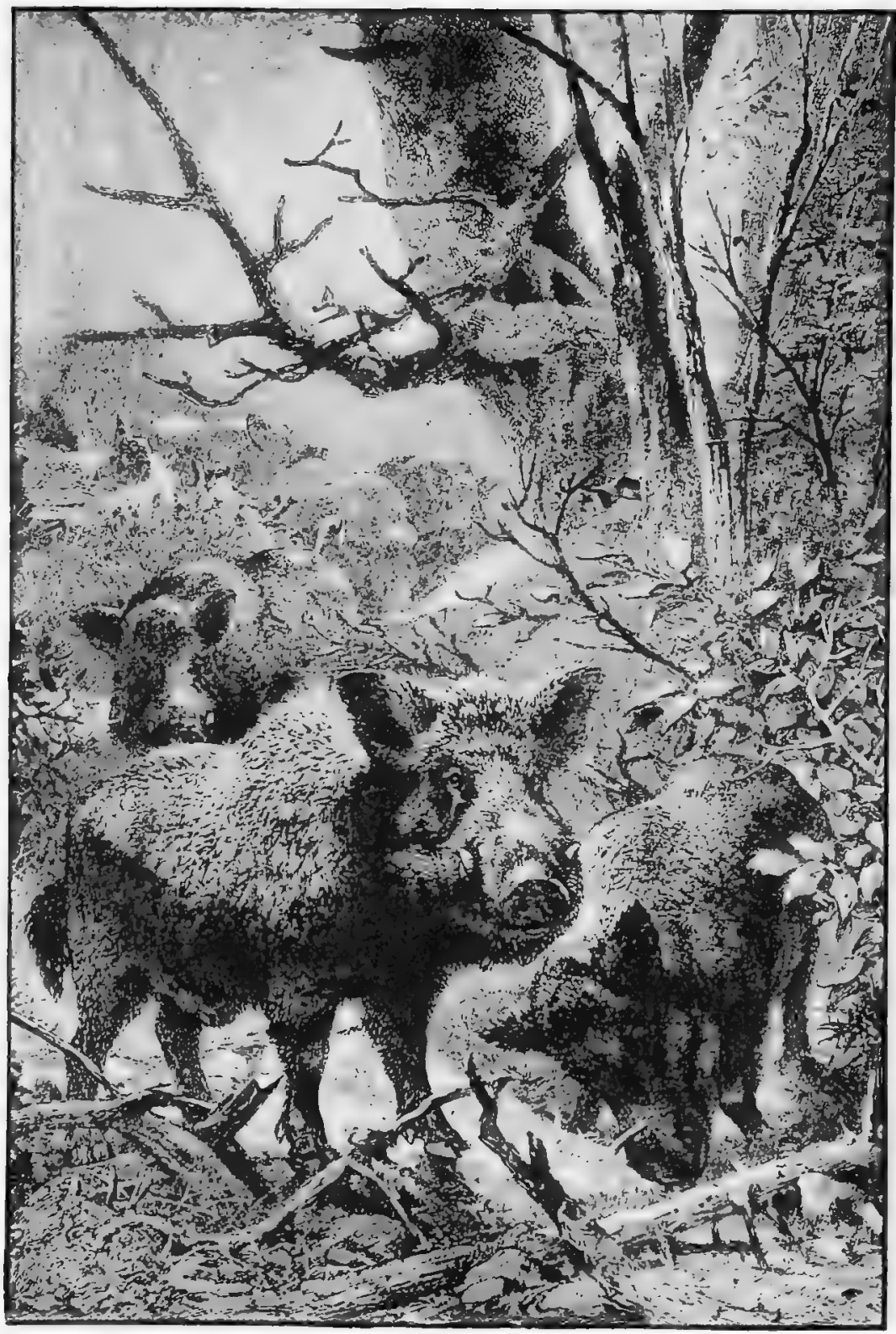


were not being hunted, no one was allowed to meddle with them, and anyone who did so was severely punished.

Although we may not like the pig, we cannot deny that it is very serviceable to us in many different ways. It is not only useful as an article of food, but many parts of its body can be used for other purposes. We melt a certain fat portion down, and so get lard, which we find useful in cooking. We soak the hide in hot water, so as to loosen the bristles, and then it is "tanned" into leather. This is so good and hard that the best saddles are made from it. And we do not throw away even the bristles, but make them into many kinds of brushes.

A steel ring is often passed through a pig's nose. This is done in order to prevent the aninal from burrowing in the ground. When it is wild it feeds partly upon roots, which it digs up with its snout. But when we keep it in our fields, we do not want it to burrow, and so we put this ring through the snout. The ring has sharp points upon it, which do not hurt the pig unless it begins to dig.

In some countries pigs are kept in large herds, and are let out every day into the woods to feed. All day long they wander where they like, and feed on acorns, beech-nuts, and anything else they can find. When evening comes, the swine-herd blows a horn, and soon all the pigs come running back, eager to get to the good supper and warm bed which they know await them.

\section{THE HIPPOPOTAMUS}

One of the largest of living animals is the well-known Hippopotamus, or River Horse, of Africa. It is not very tall, for it seldom attains to a height of more than five feet. But its body is often eleven or twelve feet in length; and it is so heavily built that in bulk it is little inferior to the elephant.

This enormous quadruped is never found very far from water, and is abundant in many of the African rivers. It is not entirely confined to fresh water, however, but is occasionally seen in the sea. It lives in herds, consisting of from five or six to thirty or 
forty individuals, which may be seen splashing and wallowing in shallow water together, now sinking for a while beneath the surface, and now coming ashore for an hour or two to feed.

The huge tush-like teeth of the hippopotamus give it a most formidable appearance. But it is by no means of a savage disposition, and will rarely fight unless attacked. When wounded, however, it becomes a terrible foe. Dr. Livingstone, the great traveller, tells us that a furious onslaught was made upon a boat, in which he himself was sitting, by a hippopotamus whose calf had been killed on the previous day. So determined was the charge of the infuriated animal that the fore part of the boat was lifted completely out of the water, one of the oarsmen thrown into the river, and the rest of the crew compelled to leap hurriedly ashore. Some years ago, too, a boat in which four men were seated was capsized by a wounded hippopotamus, and three of the four were drowned.

The hippopotamus feeds exclusively on vegetables, and its great teeth enable it to shear away stems and branches almost as stout as a man's arm. It is excecdingly mischievous in cultivated ground, for, besides eating some five or six bushels of produce at a single meal, it tramples down a broad pathway among the crops, so that it destroys far more than it actually devours.

When the track of a hippopotamus is found in a plantation, the grower, knowing that the animal will almost certainly return, suspends over its pathway a heavy block of wood, in the centre of which is fastened a poisoned spear-head. This is held in position by a cord made of twisted creepers, which is brought down and fastened across the path in such a manner that the pressure of the animal's body may release it. As soon as the hippopotamus presses against the cord, the wooden block falls and drives the poisoned blade deeply into its back, with the result that in the course of a few hours the animal dies.

Sometimes, too, the hippopotamus is taken in a pitfall not unlike that in which the giraffe is trapped, but with a sharp stake planted upright in the middle instead of the narrow wall of earth. When a hippopotamus falls into one of these pits it is, of course, impaled upon the stake, and very soon dies of its wound. 


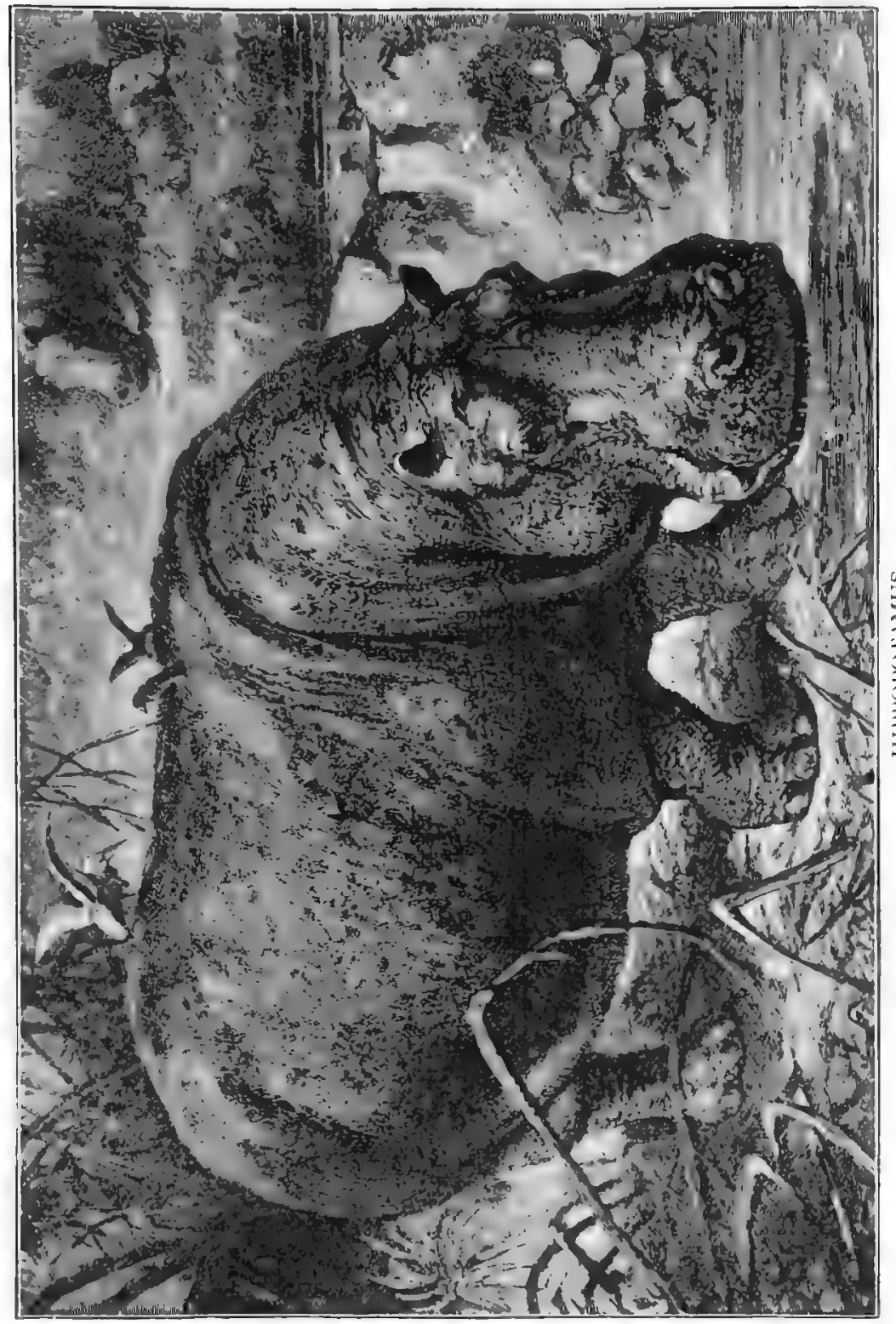


The animal is often destroyed by the natives, who arm themselves with a harpoon, to which a long and stout rope is attached, and with a number of sharp spears. When a hippopotamus is seen wallowing in a river, one of the most experienced of the hunters rows to the spot and plunges the harpoon deeply into its body. The end of the rope is then made fast to a tree, and the other hunters surround the wounded animal and hurl spear after spear at him as often as he rises to the surface, until he perishes from exhaustion and loss of blood.

The death of a hippopotamus is always hailed by the natives with great delight. In the first place, his flesh furnishes them with an abundant supply of food, on which they can feast heartily for several days. Out of his hide, which is no less than an inch and a half in thickness upon his back, they make long whips, which are used in driving cattle; while, thirdly, his tusks furnish a supply of excellent ivory, which can be sold at a high price to the traders. Of this ivory artificial teeth are often made.

The hide of a hippopotamus is always covered with a kind of natural oil, which exudes through the pores in the skin, and appears to preserve the animal from the injurious effects of longcontinued immersion in the water. The ears and nostrils, like those of the seal, are closed as soon as the head is plunged beneath the surface.

\section{THE CETACEA}

The Cetacea, which include the whale, the dolphin, the porpoise, etc., are mammals that live entirely in the sea, and are therefore thought by many to be fishes. They are warmblooded animals and breathe air and not water like the fishes. Yet in form they are very like fish. This fish form is necessary to enable them to move quickly through the water in order that they may overtake their prey, and also for their own safety. As ordinary limbs would be very much in their way, they are not provided 
with legs at all. Instead they have a flat fish-like tail set crossways, and not up and down like that of a fish. This tail they use as a propeller. In place of fore-legs they have a couple of fin-like limbs. Like fishes they have no neck, as that also would retard their swimming.

Some of these animals are valued by man for the oil which is to be got from their "blubber", and also for their hide, which makes very tough leather. The blubber is a thick layer of fat beneath the skin, and protects the animal from the cold like a very warm great-coat.

\section{THE WHALE}

The largest of the Cetaceans is the Whale. This gigantic animal lives chiefly in the cold Arctic seas, but is found in other parts of the world, and sometimes visits our own seas and estuaries. On account of its icy home the whale is protected by a very thick coat of blubber, which contains a vast quantity of oil enclosed in a great number of cells. This oil is the chief reason why the whale is so valuable an animal.

But this coating of blubber has another use as well as that of keeping out the cold. The whale is a good diver, and often descends to a very great depth. The pressure of the water at a few hundred feet beneath the surface would quickly kill the animal if it were not in some way protected. And this protection it obtains from its coat of blubber, which is so elastic that it quite prevents the pressure from injuring it.

The whale is a grand diver, and can remain under water for more than an hour at a time. When it can do without air no longer, it rises to the surface, and takes fifty or sixty deep breaths. The so-called "spoutings" are the expiration of its breath, which throws up the water like a fountain as it passes from the blow-holes, i.e. its nostrils, which are placed in the top of its head. This water is mainly condensed vapour from the whale's lungs. People have therefore sometimes thought that the whale breathes not air, but water.

The whale has two paddles on the fore part of its body, but 


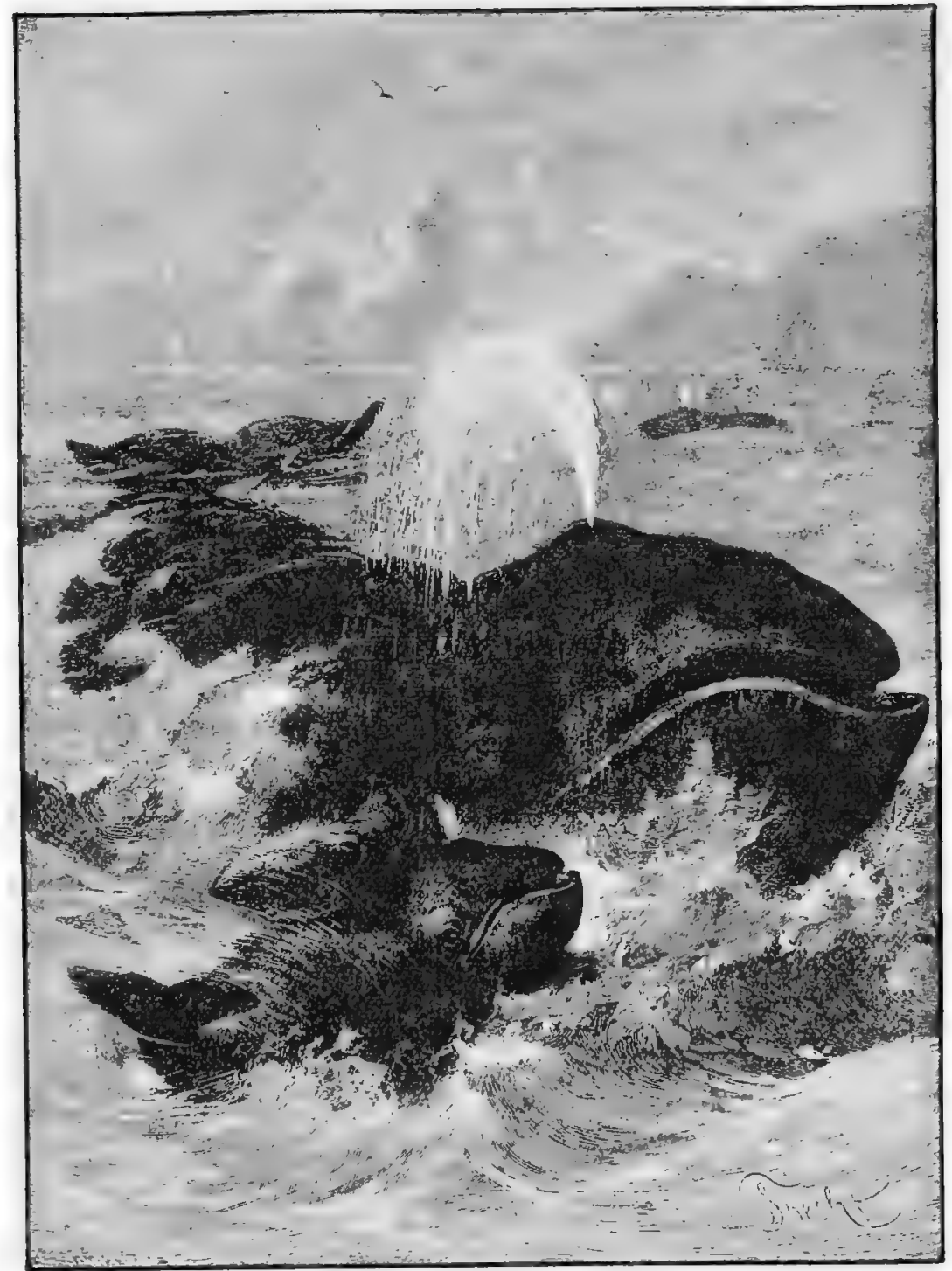


none on the part where the hind-legs of the ordinary quadruped and most other mammals are placed. But it has a large and powerful tail with great lobes placed horizontally, and that is of much more use to the whale as an aquatic animal than hind paddles would be. The lobes of this tail are often from 20 to 25 feet in breadth. The tail in fishes is the real swimming instrument, and so it is with the whale, whose tail is so immensely powerful that with a single blow it has been known to dash a boat in pieces.

We read just now of the "blow-holes" of the whale, how the animal forces out its breath through them when it rises to the surface, and how it sometimes drives a column of spray into

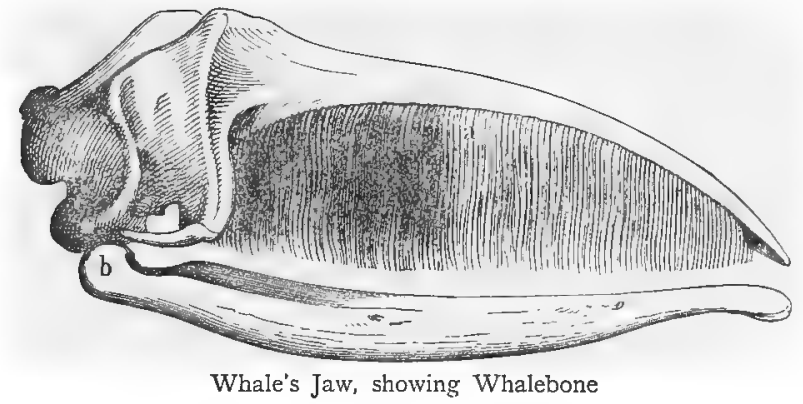

the air as well. We may wonder how it is that the water does not flow down these blow-holes when the whale dives. The reason is, that its nostrils are made in such a way as to close as soon as the whale sinks under water, and open again only when the animal returns to the surface.

As in fishes, the whale's organs of hearing have no external prominence, but are very small apertures behind the eyes.

Besides oil there is another valuable product which we get from the whale, namely, whalebone.

If we could examine a whale's mouth, we should see the whalehnne hanging down from the upper jaw in large plates, which are sometimes as murch as eleven feet in length. Each of these plates terminates in a kind of fringe, so that the whole forms a close mesh-work all round the mouth. 
These fringed plates are used for catching their prey. The whales from which whalebone is obtained have very narrow throats; and, although they are such enormous animals, they cannot swallow anything larger than such creatures as shrimps, small jelly-fish, and the young of crabs and lobsters.

These small creatures always live in large shoals, and are caught by the whale in a very remarkable way. Opening its great jaws as widely as possible, it swims rapidly through the shoal, the water rushing through its mouth the while, and the fringed whalcbone sifting out the tiny victims; until, the animal's mouth being full, it closes its jaws and swallows them at leisure.

The whalebone, therefore, forms a kind of sieve, which sifts the whale's food from the water.

We must not think, however, that all whales have such narrow throats, and feed upon such tiny prey; for some catch and sivallow quite large fishes. These have no whalcbone, as it is not required by them. Instead they have a number of stout, strong teeth, with which to seize and hold their slippery victims.

Some savage tribes set a great value upon these teeth. One chicf, indecd, has been known even to make war upon another, in order to obtain possession of a single whale's tooth!

The spermaceti whale is one of the toothed whales. It is called the "spermaceti" or "sperm" whale because we obtain from it the spermaceti "wax" which is so much used for making candles.

This spermaceti is mainly found in two large cavities in the upper part of the whale's head; not in the form in which we know it, but as a kind of thick, oily liquid, which can be baled out in buckets. The sailors procure it by cutting a hole in the top of the whale's head, and letting down a bucket, just as if they were drawing water from a well. A single whale will sometimes yield as much as twenty large barrels of this valuable oil from the head, and from seventy to a hundred barrels of oil altogether.

When this oily liquid has been drawn off, it is allowed to stand for a time. Before long the spermaceti separates from the oil, and is soon firm enough to be taken out and put into a separate vessel. 


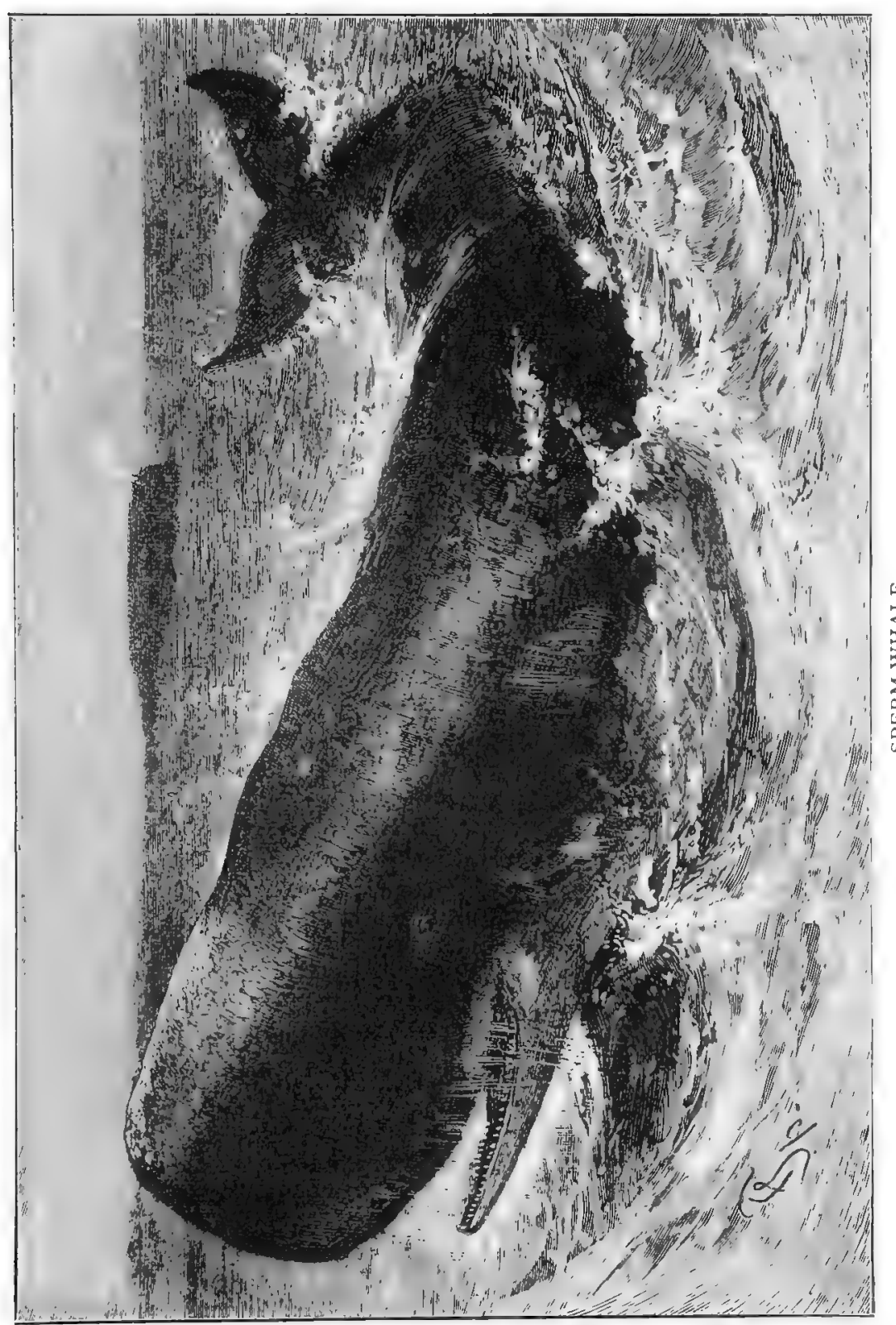


Still, however, as a good deal of oil clings to it, it has to be melted two or three times, and carefully purified, and then passed through very close hair-sieves, before it is fit for use. The oil itself is very valuable, and is much prized for the clear, white light which it gives when burnt in lamps.

Whales are killed with a harpoon-a stout barbed spearwith a long rope-line fastened to it. The aim of the hunters is always to exhaust the whale, by preventing it from breathing, after it has been struck by the harpoon. As soon as it rises to the surface and begins to "spout", they row to the spot as quickly as possible, and cause it to dive again beneath the surface. They then wait for it to rise, and do the same again and again, until the poor animal is so spent as to fall an easy prey. A long and very sharp lance is then driven into some vital part of the body; and in a short time the animal is floating dead at the surface of the water.

Whales are the largest animals now known, being sometimes more than a hundred feet in length. One, which was killed off the British coasts some years ago, measured ninety-five feet in length, and weighed two hundred and forty-nine tons! But they are so much persecuted that they now very seldom grow to their full size before meeting with some whaling-vessel, and falling victims to the harpoon and lance.

\section{THE PORPOISE}

It is a pretty sight to see the Porpoise at play. It rolls and tumbles about in the water as if it were the happiest of beings. The porpoise is perhaps the most familiar of the cetaceans. It is to be seen any day during the herring season in our bays, lochs, and river-mouths. This is because it lives on herring, mackerel, and other small fish. As herring are always found in very large shoals, the porpoise has a very happy time during the season, and it seems to roll about for very joy.

Porpoises are generally seen in companies or "schools" of from six to twelve, and often more, and as they always travel in 
single file, their rolling motion makes one think of a huge serpent swimming along the surface of the water. In this way they have possibly given rise to many stories of the sea-serpent.

The porpoise is usually from four to six feet in length. Its head and the fore part of its body are broad and heavily built.

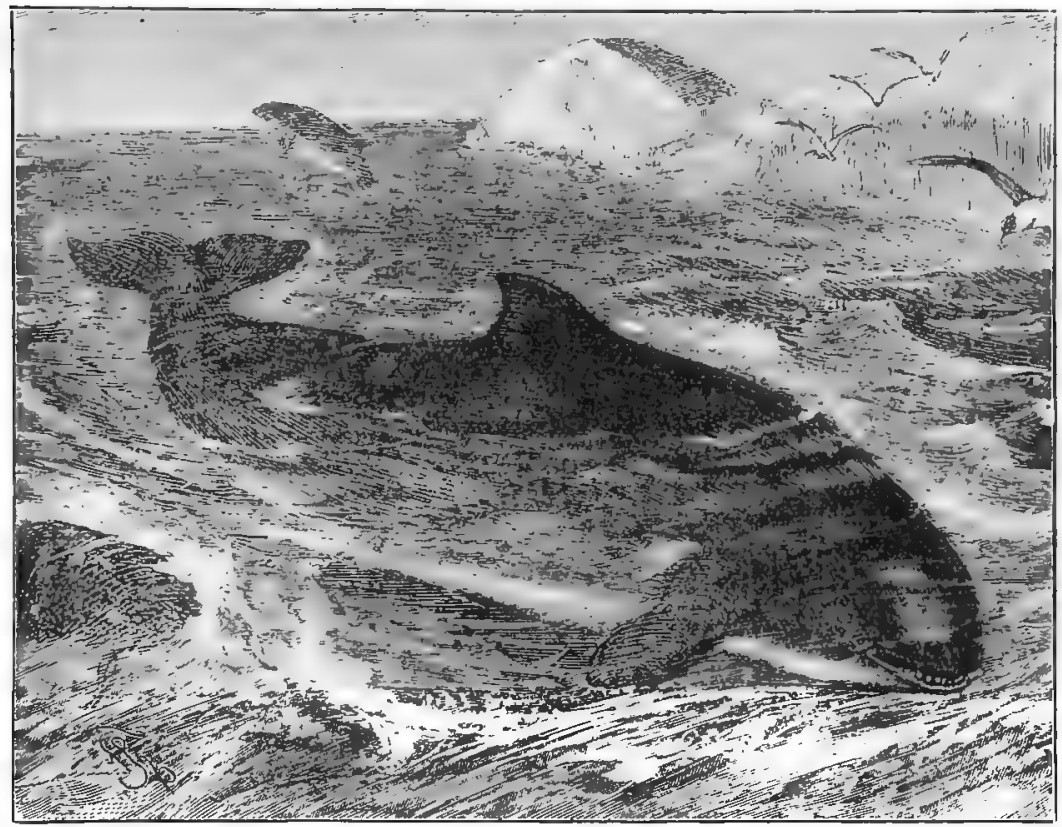

Porpoise

It is black on the back but white underneath. Like the whale it is guarded from the cold by a coat of blubber about an inch thick, covered by a very tough hide. It has a broadly lobed tail like that of the whale, two paddles or flippers in the fore part of its body, and a well-defined fin on its back.

The porpoise was formerly killed for food, and is still eaten by some. Those who have tasted porpoise steaks pronounce them very good. 


\section{RODENTS}

This is a very large group of animals. So large is it, indeed, that about one-third of all the mammals in the world belong to it. The name "Rodent" is given to the class because they all nibble

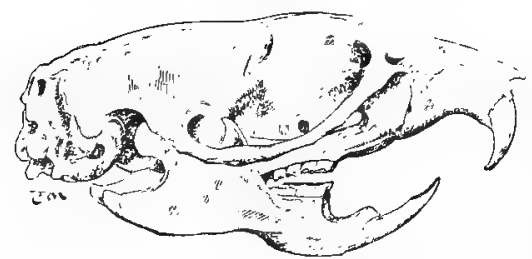

Skull of Rodent, or Gnawing Animal (Rat) Natural Size) or gnaw their food instead of biting it.

A Rodent animal may always be known by its front teeth. If we look at a hare, a rabbit, a rat, or a mouse, for example, we shall see that the front teeth are very much longer than the rest, and that they project quite out of the mouth. As the constant gnawing wears them away, they are continually growing again, so that they are always kept at just the right length.

These teeth are specially formed for nibbling hard substances. They are faced with a thin plate of extremely hard enamel, which is not worn away so rapidly as the softer bone behind it, and thus a sharp cutting edge is always preserved.

\section{THE SQUIRREL}

No one who has seen it can help admiring the Squirrel-that pretty, graceful little animal, with a big bushy tail, which runs so quickly up the trees, and scampers so nimbly along the branches.

In almost any wood it may be seen at play, skipping about amons the dead leaves upon the ground, or gaily chasing and gambolling with its companions. Up one tree it goes, along a branch, and down another, seeming to be as merry as the day is long.

But one must stand quite still while watching it; for the slightest 


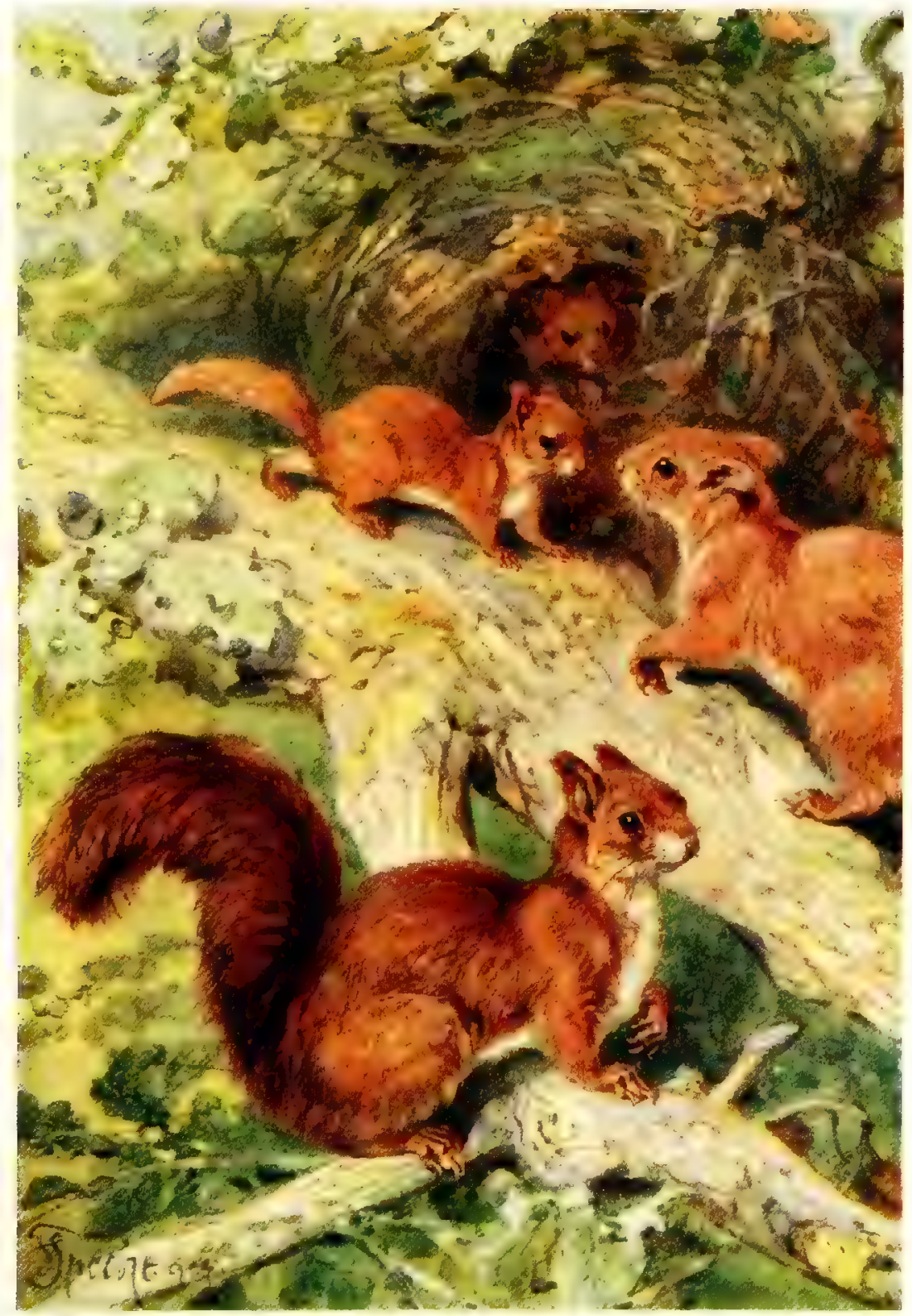

TAMIT.V OF ( ONMITIN GOTTTPTITC 

sound or movement alarms it, and it is so agile that when it is disturbed it seems almost to fly from branch to branch, and from tree to tree, and is soon lost to sight.

The squirrel finds its "rodent" teeth very useful when it has to eat a nut. It takes the nut in its paws, and nibbles away the point. Then it can get its teeth in to break the shell, which it continues to do till the kernel is released. It then cleverly peels off the brown husk and enjoys its dainty meal.

The squirrel is very fond of nuts, and early in the autumn it gathers a quantity together, and hides them away in some place of safety, to be a provision when a milder day than usual may rouse it up from its long winter sleep, or when the spring has come and it is not an easy matter to find food.

Unlike most mam-

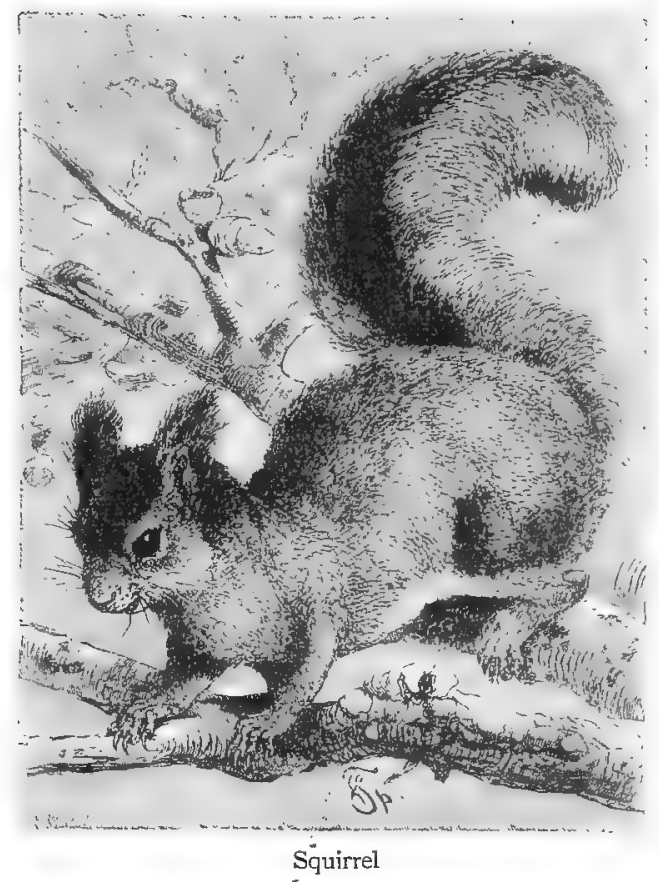
mals, the squirrel lives in a nest, placed high up in a fork of a tree. And a very clever builder the little animal is! Although it has nothing but leaves, grass, and moss of- which to make its dwelling, it weaves these together so closely and well that even the rain cannot find its way through.

In this nest it sleeps during the night; and also for two or three hours in the heat of the day. During the winter months it hardly ever leaves it at all, for it is most of the time asleep. 


\section{THE BEAVER}

The Beaver is one of the animals which in olden days abounded in Great Britain, but have now for several centuries been extinct in that country. A few small colonies yet remain on the Elbe, in Sweden, and in various parts of Northern Europe and Asia. In North America, however, beavers are still plentiful, and frequent the smaller streams and rivers in considerable numbers.

These wonderful animals have long been famed for their sagacity and architectural skill. Taught by some marvellous instinct, they seem to know that the waters in which they live will be greatly lowercd during the heat and drought of summer. In order to prevent this, therefore, they construct an immense dam, which spans the river from side to side, and forms with the banks a reservoir, which is at all times full of water.

In order to obtain the logs of which this dam is principally composed, a company of beavers set to work together and cut down a number of trees, always selecting those which grow near to the river bank. This they do by gnawing a deep groove round the trunk until the weight of the tree causes it to snap off. It is said that the beavers are sufficiently intelligent to cut their groove deepest on the side of the tree nearest the water, in order that it may fall in the direction most convenient for their purposes.

When the tree has fallen, the beavers proceed to cut it up into logs of from three to six feet in length, still by gnawing through the wood with their strong rodent teeth. Having done this, they carefully strip off the bark and store it away to serve as food during the winter months. Finally, the logs are dragged one by one to the edge of the water, and then floated down to the spot where the dam is to be made.

These logs are not forced upright into the bed of the stream, as is sometimes imagined, which would be a quite impossible task for such creatures; but they are laid down at the bottom in regular order, and prevented from floating up again to the surface by mud and stones piled upon them.

The dams constructed in this manner are sometimes of enor- 
inous dimensions. It is not at all unusual for a single dam to be two hundred yards in length, fifteen or sixteen feet wide at the bottom, five feet in width at the top, and from ten to twelve feet in height. Such a dam as this, of course, is the work of several years, and the beavers are always busy both in adding to it, and in repairing any damage which it may chance to have sustained.

When the current of the stream is rapid, the beavers appear to know that a straight dam will almost certainly be washed

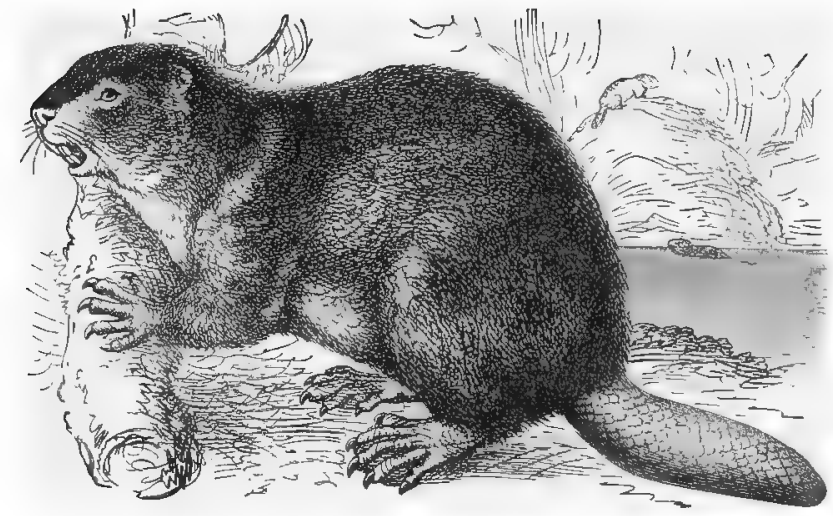

Beaver

away. They therefore build the barrier in the torm of a curve, with the convex side presented to the current, the force of which is thus broken, and diverted to either side.

As time goes on, the completed dam becomes greatly enlarged by the fallen trees, branches, \&c., which float up against it. After a time earth is deposited upon it, and vegetation springs up, until a broad bank of herbage extends from side to side of the river.

The dams greatly change the appearance, not only of the river itself, but also of the surrounding country; for the constant labours of the busy little animals of course result in the formation of clearings in forest-land, which are often of many acres in extent. On these, which are partially flooded during a considerable portion (M 888) 
of the year, peat soon begins to form; and this spreads year after year, until in place of the old forest ground is a peat marsh, mostly known as a "beaver meadow". Traces of these peat marshes have even been found in countries from which the beaver has for many years disappeared. In some parts of North America "beaver meadow's" extend throughout nearly the entire course of a stream, and a broad opening is cut through the forest upon either bank.

After the dam is completed, the beavers still continue to fell trees and cut them up into logs, which are used for necessary repairs, and the bark of which supplies food during the winter months. When required for this latter purpose they are sunk under water, and piled carefully together in the neighbourhood of one of the beaver habitations, about which we shall presently read.

In close proximity to their dams the beavers always construct a number of "lodges", as they are generally called, in each of which five or six animals live together. These lodges are built in the same way as the dam itself, a number of logs and branches being carefully laid in position, and fastened in their place by means of stones, while the interstices are filled in with smaller sticks and earth. The whole is then plastered over with a thick coating of mud.

On the average, these lodges, which are nearly circular, are about seven feet in diameter, and from two to three feet in height, measured internally. But the walls are so thick that the external diameter is seldom less than fifteen feet, and the height tluan seven. In the winter these walls freeze into a solid mass, and bid defiance to even the sharp claws of the wolverene, a predacious weasel-like animal, which otherwise might dig its way into the lodge and feast upon the inmates.

The beavers are most painstaking in the construction of these habitations, and repair them carefully if they should be in any way damaged. A lodge is never situated far from the watcr's edge, and round each is dug a ditch which communicates with the stream, and is of sufficient depth to prevent the water in it from ever being completely frozen. Into this ditch the entrance opens, so that the inmates of the lodge can make their way to 
the stream and back again without being obliged to walk over dry land.

The floor of a beaver's lodge is always warmly carpeted with dry grasses or the soft fibrous substance which lies between the

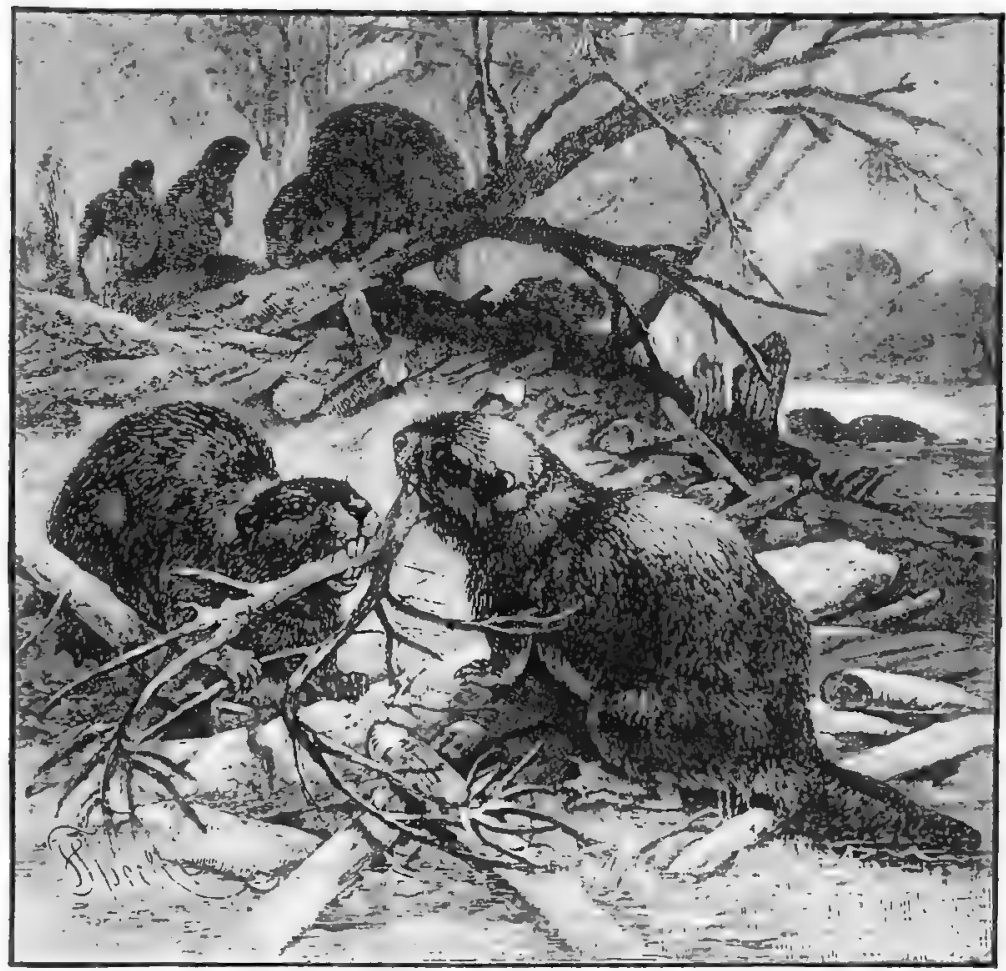

Beavers at Work

bark of trees and the wood, and the chips which the builders have made in the course of their labours. Round the sides of the chamber are arranged the beds, made of similar materials, of which each beaver is said to have one to himself. The space in the middle is always left unoccupied.

It is a somewhat singular fact that in almost every colony 
of these busy little creatures there are two or three which will not work like their companions, but prefer to spend their time in idleness. These are not allowed to live in the lodges with the rest, and are driven away if they venture to show themselves. They therefore live in holes in the banks of the stream, which they excavate with their sharp claws. They are generally called "terricrs" by the hunters.

A mere glance at a beaver would be sufficient to show us that the animal is intended to spend a considerable portion of its life in the water. Its fur is formed like that of the seal, a layer of thick bristly hairs covering a warm coating of softer fur which lies beneath them. That this provision is necessary we can easily understand, when we remember that during some six months in the year the watery home of the beaver is frozen over.

We should note, too, that both the nostrils and ears are firmly closed by the pressure of water upon them, so that nothing can enter while the animal is swimming beneath the surface. This is a sure sign of an aquatic animal.

And we should notice that the toes of the hinder feet are united by stout membrane like those of the ducks and swans, so that they can be employed as paddles. With these the beaver rows itsclf, so to speak, through the water, as though its body were a boat, and the legs the oars. Every boat, howerer, requires a rudder by which its course can be directed, and this the beaver possesses in its tail, which is broad and flattened, and admirably fulfils that purpose.

This broad, flat tail is sometimes employed in quite a different way. If a beaver, when swimming at the surface of a river, be suddenly alarmed, he raises his tail and brings it down with astonishing force upon the water, causing a shower of spray to fly up into the air, while the sound of the concussion can be heard at a distance of more than a quarter of a mile. By this singular trick warning is probably given to other beavers.

The fore-paws of the beaver are not employed in swimming, but are used for building, carrying, and conveying food to the mouth. In the manipulation of small objects the animal displays much tact, and will peel a potato by merely turning it round and 
round against its sharp incisor teeth, just as our common English squirrel will do with the kernel of a nut.

\section{THE RAT}

Many of the animals about which we have hitherto been reading are very useful to us. Now we come to one which often does a very great deal of damage, and is of no appreciable use to us, namely, the Rat. In our barns, granaries, corn-stacks,

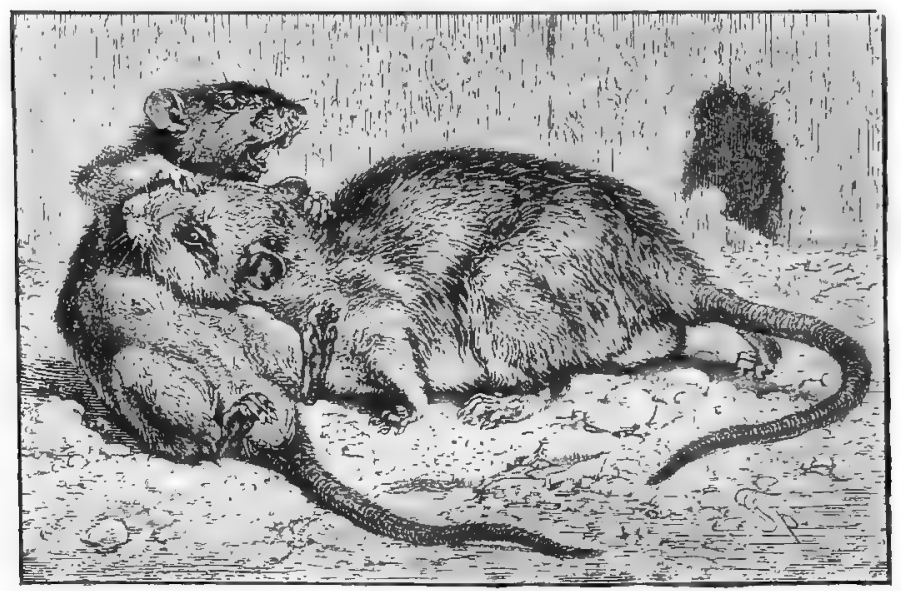

Brown Rat attacking Black Rat

poultry-yards, and even in our gardens and houses, it is very troublesome. And it increases in numbers so fast as to defy all our efforts to keep it down.

We have often seen in a farm-yard a stack of corn built, not upon the ground, but upon supports, which are shaped much like mushrooms. These are called "staddles", and are used to prevent rats from climbing up into the stacks.

Sometimes, however, a rat is brought from the fields in a sheaf of corn, and so gets into the stack. But he cannot stay there very long, for he soon becomes thirsty, and is obliged to leap 
down to the ground in order to go and look for water; and when he is once down he cannot get back again.

In the summer-time the rat prefers to live out in the open country. So, as soon as the days begin to grow warm, he leaves the house or barn where he has been living during the winter, and goes out into the fields for a few months.

Sometimes he makes his hole in a hedgerow, near which plenty of good food is to be found. Or he will go down to the river bank, and live upon dead fish or any other edible thing that may turn up. When autumn comes, and the days draw in, he goes back to his winter dwelling.

We must not think that all rats are altogether mischievous, for many live in drains and eat all sorts of substances that would otherwise decay and poison the air by their bad odour. These rats are much larger than those which live in barns, and are so fierce and strong that one of them is almost a match for a dog. Sometimes a number of them will join in an attack, and then even a man armed with a stick would find it very difficult to beat them off.

The front teeth of a rat are so sharp and strong that one of these animals has been known to gnaw a hole quite through a hard brick. Of course its teeth must have been very much worn down in doing so; but then, like the incisors or "cutting" teeth of all rodent animals, they would always be growing, and the wear would be constantly remedied.

\section{THE HARVEST MOUSE}

When sitting quietly in a field one may catch sight of a mouse of so small a size that it is hard to believe that it can be a fullgrown one. It is of a reddish-brown colour, except underneath, where it is white. It is so small that, without counting its tail, it measures only a little more than two inches in length. This is the Harvest Mouse, and we shall find it well worth our while to watch it for a few moments.

While we are looking at it, and admiring its graceful move- 
ments, it runs up a stout grass stem as nimbly as a squirrel runs up a tree, and begins to eat the ripe seed at the top. We notice, also, that it grasps the stem, not only with its little paws, but also with the tip of its tail, which it coils tightly round it.

We have already read about the spider-monkeys of South America-those curious monkeys with long, strong tails, which they can coil tightly round the branches as they pass along through the trees. Now the tail of a harvest mouse is very much

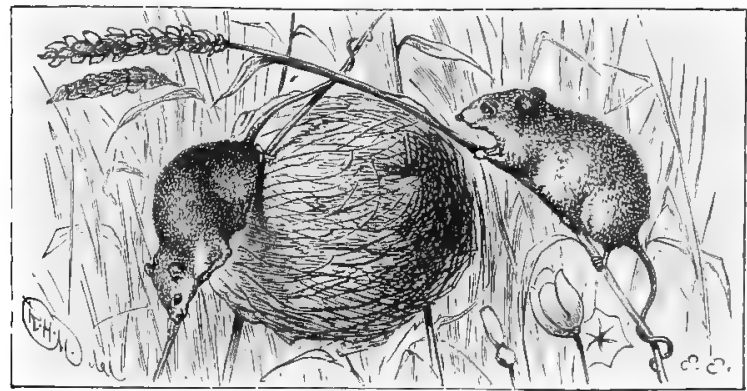

Harvest Mice and Nest

like that of a spider-monkey, and the little animal uses it in just the same way. So that it has not only four useful, handlike paws, but also a tail which serves as a sort of fifth hand.

The harvest mouse builds an odd little nest, which is always fastened to three or four stems of grass or corn, about a foot from the ground, and is about as large as a cricket-ball. It is made of long strips of dry grass, which the clever little animal weaves into a kind of close basket-work. Strange to say, the mouse does not make any entrance-hole, but pulls the sides of the nest carefully together when it comes out, so as not to leave the smallest opening. Thus it looks as if there were no way of entering or leaving it.

In this remarkable nest the harvest mouse brings up her family of eight or nine little ones. They grow so rapidly that one would think they would soon become too big for their home. But the walls of the nest are so elastic that they stretch just as much as is needed. It thus affords plenty of room for 
the little animals until they are able to take care of themselves.

Although the harvest mouse is so pretty and interesting, the farmer does not like it, for it eats his corn, and often gets carried with the sheaves into his stacks. It is not obliged to leave these after a day or two, like the rat, when they are placed upon "staddles", for it can obtain quite as much moisture as it needs from the rain and dew which fall upon the tops and sides of the stacks. And it does so much mischief that the farmer is obliged to kill it without mercy.

\section{THE PORCUPINE}

One of the strangest of living animals is the Porcupine, famous for its formidable array of long, sharp spines, which are ringed alternately with black and yellowish white. It is an inhabitant of several countries of Southern Europe, and also of Northern Africa and many parts of Asia. But as it is strictly nocturnal in its habits it is not very frequently seen, even in those districts in which it is most abundant.

This singular creature is another member of the great family of Rodents or "gnawing animals". Its rodent teeth are remarkably sharp and strong, and are capable of inflicting a very severe bite. Yet the animal appears never to employ them as weapons. When it is attacked its first impulse is to seek safety in flight. But if it finds that its pursuer is gaining upon it it suddenly runs backwards upon him, and endeavours to wound him with its spincs.

It was formerly supposed that the porcupine possessed the power of casting these spines to some little distance, and of so wounding an enemy. But this is not the case. It is quite true that the quills are not strongly inserted into the skin, and that they sometimes fall out by accident. But beyond the power of raising and depressing them at will, the animal has no control over them, and is quite unable to launch them like spears into the air. 
These quills vary considerably in length. Those upon the back sometimes measure as much as fifteen or sixteen inches, but are not so formidable as the shorter and straighter spines which grow among them. At the tip of the tail are about twenty short, flattened spines. These, of course, are useless as weapons,

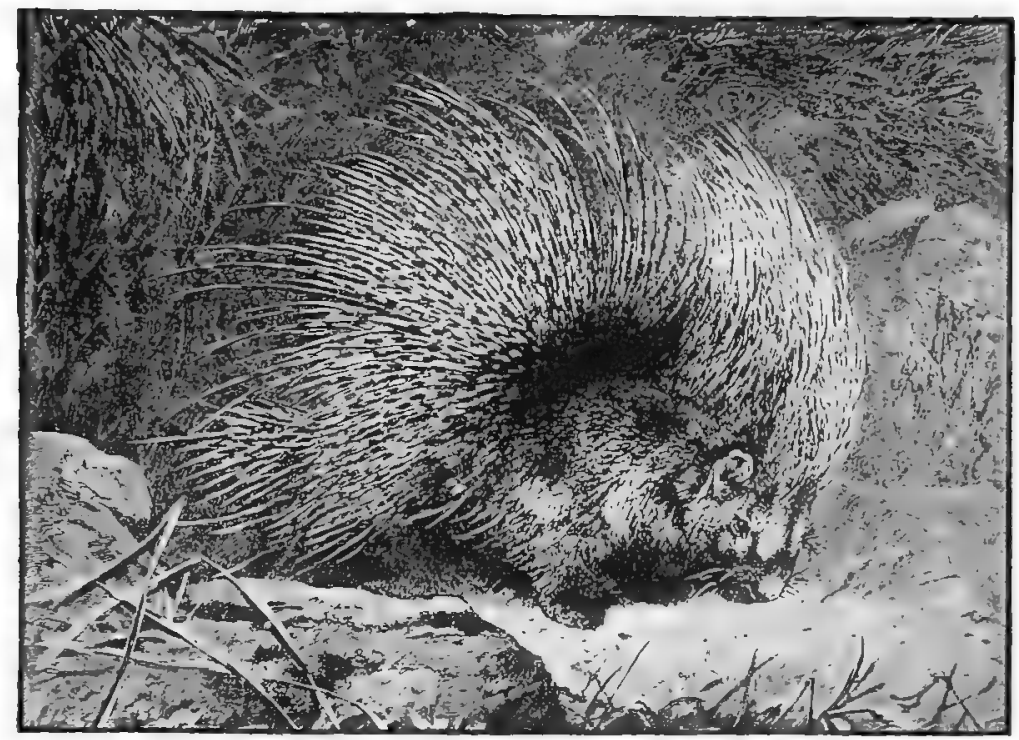

Porcupine

but can be clattered together with a loud and peculiar noise, which proves very alarming to horses and other animals.

The head, shoulders, limbs, and under parts of the body are riothed only with short spines, intermixed with stiff, bristle-like hairs. Upon the neck is a crest of long, curved bristles, from twelve to fifteen inches in length.

During the daytime the porcupine conceals itself in a crevice among the rocks, or in a burrow which it has dug with its sharp, strong claws. Its food is entirely of a vegetable character, and principally consists of herbage, fruit, roots, and the bark of various trees and shrubs. It is said that the animal is never known to 
drink, but obtains such moisture as it requires from certain succulent roots.

Towards the middle of spring the mother porcupine busies herself in constructing a nursery, in which to nourish and bring up her young. This she does by making at the bottom of her burrow a warm nest, lined with leaves, grasses, and other vegetable substances. The young porcupines, when first born, are very unlike their parents, for their quills, which are quite white, are almost transparent, and are pressed closely against the body. They grow very rapidly, and are soon able to leave the burrow and find food for themselves.

For commercial purposes the porcupine is valuable only for its spines, which are largely employed for penholders. Its flesh, however, is frequently eaten, and in flavour is said greatly to resemble that of a sucking pig.

\section{THE HARE}

Perhaps the most remarkable feature in the Hare is her wonderful speed. The animal dashes along almost like a flash of light. Even the swift-footed greyhound, which is so much larger, can scarcely overtake her. And the strange thing is that she is able to run uphill almost as fast as upon level ground.

That is because of the curious way in which her limbs are formed. The hinder legs are much longer than the front ones, so much longer, indeed, that the animal does not really run, but travels by a succession of long leaps. She can ascend a hill therefore with much greater ease than an animal whose front and hind legs are of the same length. But, on the other hand, when she tries to run dow'nhill, her long hind-legs are very apt to overbalance her; and therefore she always takes the side of the hill in a slanting direction, so as to reduce the danger of falling head over heels to the bottom.

The eyes of the hare are set in a curious way. They are situated quite upon the sides of the head, so that the animal can scarcely see an object exactly in front. The writer was once 
standing quietly in a field watching some fox-hounds that were just entering a little copse about a hundred yards away, when a hare started up and came straight towards him. Hu did not move, and she came quietly hopping along, without seeing him, till she was not more than a dozen feet distant. He then gave

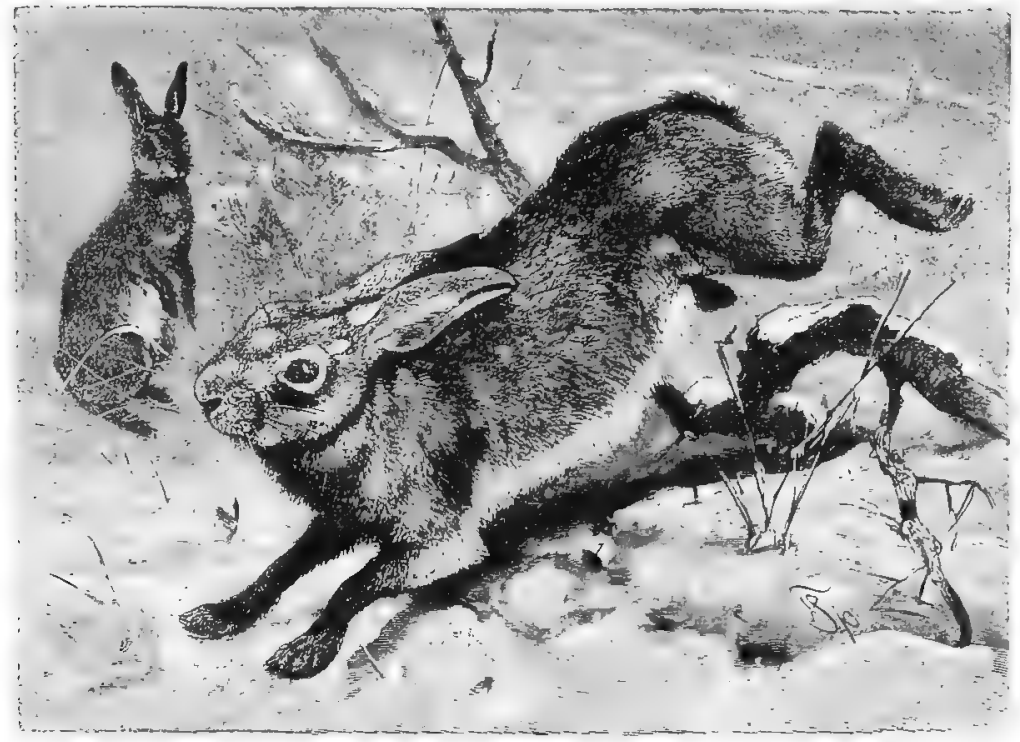

Hare

a low whistle, at which she turned her head, caught sight of him, and in a couple of seconds had disappeared.

We often think that the hare is a very timid animal, and in a certain sense she is. But she will sometimes show a quite unexpected courage. Tame hares, for example, have been known repeatedly to chase and drive away cats that ventured into their feeding-ground. Hares fight fiercely among themselves too; and in defence of her young the mother hare will fight to the death.

The young of the hare are called "leverets". There are usually from four to six in a litter, and the little animals remain with their mother for rather more than a month. Unlike the 
young of the rabbit, they are born with their eyes open, and are able to run about on the very day of their birth.

The hare does not burrow in the ground like the rabbit, but lies during the day in a small hollow or depression. This is called her "form". As soon as the darkness begins to fall she goes out to feed, and often wanders to a considerable distance before dawn. But soon after daylight she is sure to be back in her "form", to which she seems just as much attached as if it were a carefullymade dwelling.

But she does not live in the same "form" all the year round. During the summer and early autumn, when the weather is warm and there are no chilly winds to be feared, she generally lies out in the fields. But as soon as the leaves begin to fall and the frosts come, she seeks a more sheltered situation.

Her behaviour during a heavy snow-storm is very remarkable. She does not leave her "form" in order to look for a place to which the flakes cannot penetrate, but just moves slightly backwards and forwards as the snow falls, so as to press it into a kind of wall all round her body. This she continues to do until she is completely covered over, and lies in a little oval chamber, with just a small breathing-hole communicating with the outer air. By this hole she is frequently discovered, for a well-trained dog will detect the scent through the snow, and lead his master to the spot where she is lying.

The hare seems to know perfectly woll that she possesses this powerful odour, and when she is hunted with hounds will resort to all manner of devices to break the line of scent. One very favourite plan is to run back on her own course for a little distance, leap as far as possible to one side, and make off in another direction. Sometimes, too, she will boldly leap into a stream, swim for some way, and then land on the opposite bank. A hunted harc has even been known to swim boldly out to sea, and make her way to an island more than a mile from the shore. 


\section{THE RABBIT}

The common rabbit lives in holes which it digs in the ground. These holes are known as burrows; and, when there are a number of burrows close together, the place is called a warren.

In order to see the rabbits in a warren, it is best to go either quite early in the morning, or else a little after sunset, for then they come out of their burrows, and do not seem to suspect any danger. And what games they have! Such romping, and scampering, and chasing one another; such running in and out of their holes, and even playing a sort of hide-and-seek! So full of fun are they that they are almost like so many kittens. And they will gambol away merrily until it is too dark to watch them any longer.

If you move while

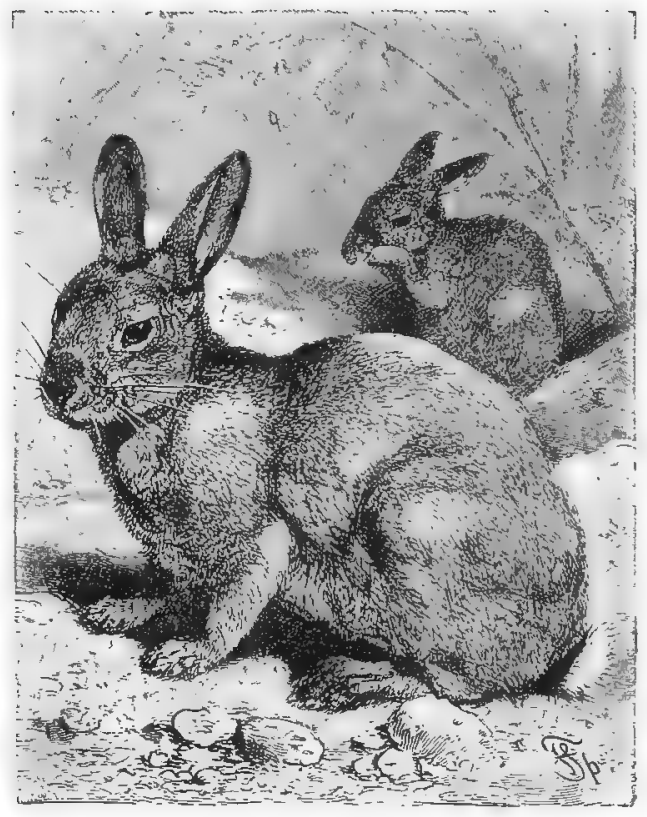

Wild Rabbit you are looking at them, or make the slightest sound, they will at once disappear into their burrows. But you have only to wait quietly, and you will see first one pair of long ears poked out of a hole, and then another, and very soon the pretty little creatures will be playing about as merrily as before.

In order that it may be able to dig its burrows, the fore-legs of the rabbit are very strong, and the claws are large and stout, 
so that it can scratch away the soil easily. The burrow generally runs for some distance under the ground, and has an entrance at each end. So if a stoat or a weasel should come in at one end and try to catch it, the rabbit can run out at the other.

When the mother rabbit wants to bring up her family, she leaves her own burrow and digs another, with a kind of chamber at the end of it. This chamber is her nursery, and here sle makes a bed for her little ones of dry grass and leaves, which she collects and arranges with much care. Lest it should not prove sufficiently warm for the delicate little creatures, which have no fur when they are born, she lines it with soft down plucked from her own body.

Like kittens and puppies, young rabbits are not able to open their eyes until they are nearly a fortnight old. But they grow so fast that after about four or five weeks they are quite big and strong enough to take care of themselves.

\section{THE EDENTATES}

This is a very strange class of animals. The name given to the group means "toothless". They are not altogether without teeth, but they have none in the front of the mouth, and those at the back are few and small. They are in this respect the opposite of the class (the Rodcnts) which we read about last. Another characteristic of these animals is that they are all provided with great claws, which are so prominent as almost to seem a deformity. The Sloth finds its claws very much in its way if it tries to walk on the ground, which it very seldom does, and eien those members of the group which live on the ground move slowly and awkwardly.

The Edentates comprise only a few species, the principal of which are the Sloth, the Armadillo, and the Ant-eater. They all differ very widely from one another in form and appearance. They are to be found only in the tropics, and the three mentioned 
only in South America. The remains of huge monsters, which formerly belonged to the group, but are now extinct, have also been found in the fossil state, that is, buried in ancient deposits, in Scuth America.

\section{THE SLOTH}

When told that an animal exists which spends almost the whole of its life in a state of suspension, with its head hanging down and its feet in the air, we may fancy the assertion difficult to believe. Yet it is perfectly true, for this is the attitude adopted by that most remarkable animal, the Sloth, during the whole of the night and the greater part of the day.

This creature, in fact, eats suspended, walks suspended, and sleeps suspended; for it lives entirely among the branches of trees, from which it hangs by means of the enormous claws with which its feet are furnished. These claws are curved, so that they can be hooked over a bough, and the muscles of the limbs never seem to be fatigued by the weight of the body.

This they have to sustain day and night; for a sloth never lies down like other animals, even when sleeping, but remains still hanging from a bough, with all its feet placed closely together. When in this position it hardly looks like an animal at all, and might very easily be mistaken for a loose bundle of hay.

If a sloth be taken down from its leafy home and placed upon level ground, it can only travel in a very awkward and ungainly manner. So ill adapted are the limbs for walking that in this position they cannot even bear the weight of the body, which drags upon the ground like that of a reptile.

The feet, too, have no soles, and are naturally turned inwards, so that the animal is obliged to balance itself as well as it can upon their outer edges; and it can only drag itself painfully along by hitching the great claws of the fore-feet into some inequality in the ground, and pulling its body a few inches forward. It was in consequence of this slow method of progression that the animal was originally named the "sloth".

When placed amid its natural surroundings, however, it is 
very far from being "slothful". Hanging beneath the branches by its great curved claws, it travels along quite easily, and with some speed, insomuch that a famous traveller tells us that, when he found a sloth upon the ground and replaced it in a tree, it was

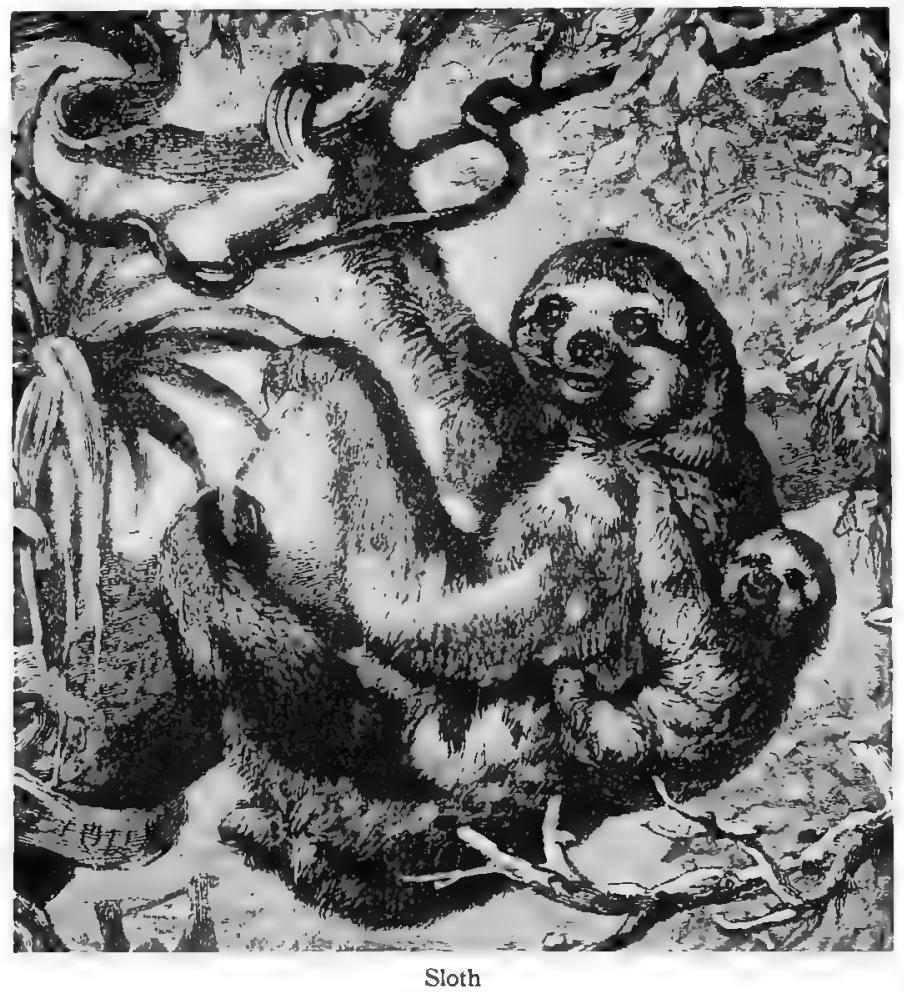

"speedily lost to sight". The animal always prefers to travel when the wind is high, for then the branches are blown together, so that it can pass from tree to tree without difficulty.

The sloth is also remarkable for the structure of its teeth. It has no incisors, or "cutting teeth", neither does it possess the canincs, or "eye-teeth", which in most mammals are so sharp and strong. Even the molars, or "grinding teeth", are small, and they 
are also few in number. But, as it feeds entirely upon leaves and tender shoots, it does not require so many teeth as most other animals, and scarcely masticates its food at all before swallowing it.

One naturally wonders how the sloth manages to drink. It can only walk upon the ground, as we have already seen, with very great difficulty. For this purpose, however, it never requires to do so, for as dew falls heavily almost every night in the South American forests in which it makes its home, it can obtain as much moisture as it needs from the foliage which surrounds it.

When a sloth is engaged in feeding, or in drawing leaves together in order to

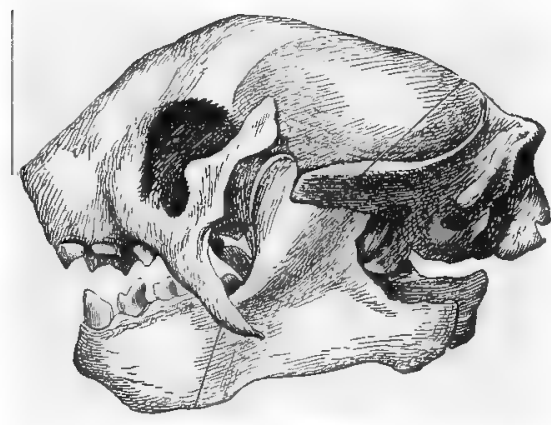

Skull of Sloth obtain the moisture which has been deposited upon them, it makes use of its clumsy-looking fore-paws in a very dexterous manner. It hooks them round a leaf or branch, and so draws the moisture into its mouth.

These claws vary in number, some sloths possessing three upon each foot, and others only two.

For some little time after the young of the sloth are born, they are not sufficiently strong to travel along beneath the branches and obtain food for themselves. For several weeks, therefore, they cling firmly to the body of their mother, and are carried about by her wherever she goes.

$A$ very singular sloth is that called the $A i$. It has three great claws upon each foot. On its back is a long blackish mark, which looks as if it had been produced by the pressure of a heated iron. The flesh of this animal is a favourite dainty with the native hunters, and many an unfortunate $\mathrm{Ai}$ falls a victim to their poisoned arrows, which they shoot through blow-pipes. 


\section{THE ARMADILLO}

It is remarkable how Nature has in many cases forestalled the inventions of man. There is a kind of fish which can give electric shocks to any animal it may come in contact with, and the bee knew how to make a perfect hexagon long before man understood geometry. Now most readers will know what a coat

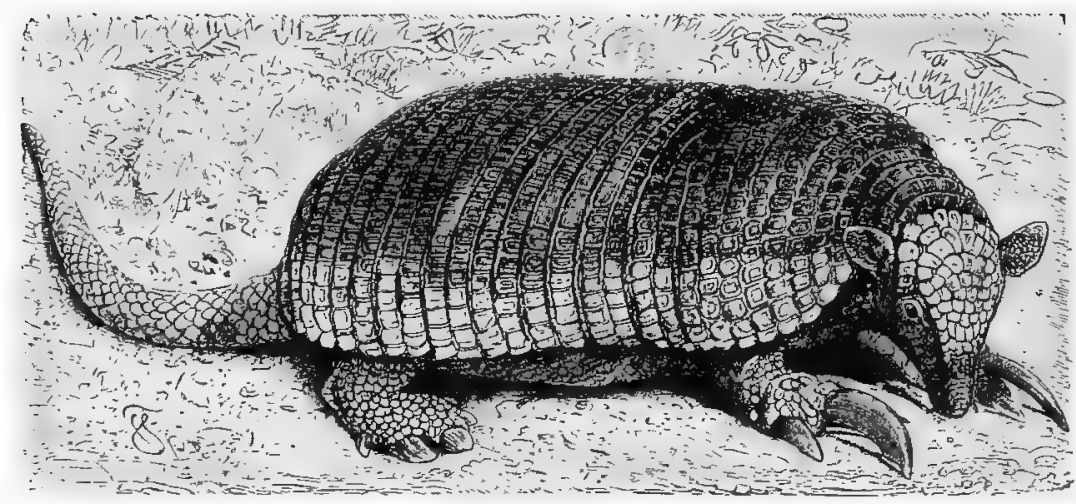

Giant Armadillo

of mail is. They will have seen either a real one in a museum, or a picture of one in some book of the old chivalric days. It was a shirt of leather, covered with a close net-work of steel rings, or with a great many small overlapping steel plates, which was worn by soldiers to protect them from the arrows and spears of the enemy. But long before such a thing was thought of by man there was a little animal which Nature had furnished with a complete suit of mail to protect it against its foes. On account of this wonderful armour this animal has been called the Armadillo.

The armour, which is formed of thin bony plates, consists of a headpiece and a shield for the fore part of the body and another for the hind portion. These are solid, and are connected by bands of plates joined by flexible skin, which allow the animal to bend its body, and even to roll itself up into a ball like the hedgehog. 
On the under side the body is covered with coarse hair, which sometimes finds its way out between the plates and almost hides them. The tail and legs are also armour-protected.

The armadillo is a burrowing animal, like the mole, and in shape it is well suited for this purpose, while its legs are short and powerful, and are armed with very strong claws with which it digs out the earth in a wonderful way. It burrows so quickly that it is very difficult to catch, and the natives, who are very fond of its flesh when roasted, are obliged to smoke it out of its nest, as is sometimes done with rats in this country. Its food consists of roots, worms, snails, etc.

There are several kinds of armadillo. The largest, known as the giant armadillo, is about three feet long. The smallest is only a few inches in length, and is a pretty little white-furred creature with a pink shell-like armour.

\section{THE ANT-EATER}

The Ant-eater, which, as its name implies, lives on ants, is a pure Edentate-that is to say, it has absolutely no teeth. It is an awkward-looking animal, gray and black in colour, with a very large bushy tail, a narrow head with a long, pointed snout and small mouth. On its fore-feet it has great claws which seem to be very much in its way, and its movements are slow.

Now one naturally asks how it is that such a creature is able to catch lively insects like the ant. If any reader has seen in his garden at home a toad sitting on the ground and "spitting poison", as it is said, he has really seen it catching flies with its tongue, which is very sticky. In this way also the ant-eater feeds. It has a very long tongue like a whip, which it thrusts out of its small mouth, and draws back again by a very rapid movement. This tongue is covered with sticky matter, so that each time it is put out it draws back with it a supply of ants, and, on account of its lightning-like motion, the ants have very little chance against it.

Some reader may wonder now why it requires such large 
claws, as of course it does not use them in order to kill prey. In South America, where it lives, ants are very plentiful, and they build as their homes huge heaps of mud often twice as high as a man. To break into these, therefore, the ant-eater uses its claws.

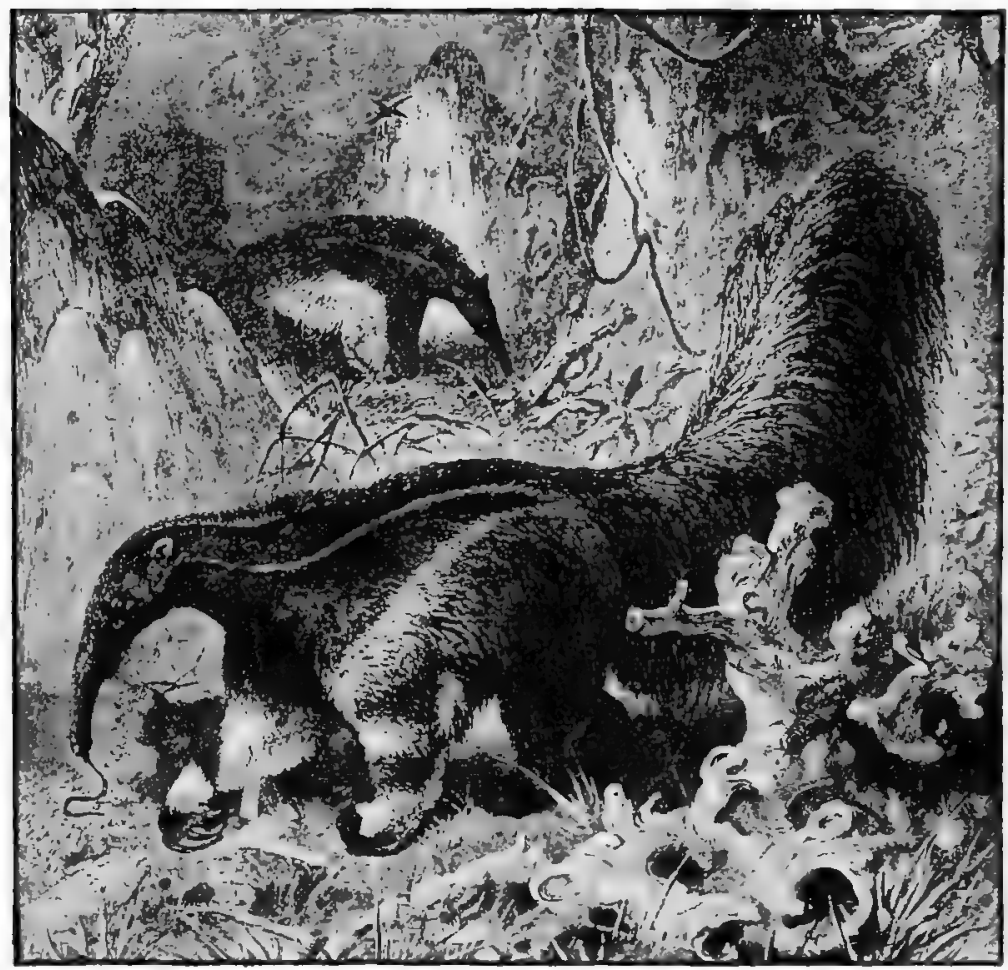

Ant-Eater

In this way it gets its ants crowded together, and does not depend upon stray ones to be found upon the ground.

When the ant-eater is attacked its claws prove very formidable weapons of defence. One has been known to rip open a jaguar with a stroke of its claws.

Some species of ant-eater live almost entirely among the trees, 
and in these the form is of course modified to suit their habits. The snout is not so long, while the claws are suited for clinging to branches, for which purpose the tail, which is long and pliable, is also used, in the manner of some monkeys.

The ant-eater, like most of the Edentates, sleeps during the day and moves about at night. It makes no den or nest into which it may retire, but when it wishes to rest it covers its body with its large bushy tail. The thick skin with which nature has provided it sufficiently protects against attacks of ants.

\section{MARSUPIALS}

This is a large class of mammals which differs from those we have already read about in the fact that its members produce their young at a very immature stage, and in order to protect them until they are more fully developed, the female is provided with a pouch in which she carries them for several months. It is from this pouch that the group receives its name of "Marsupials" or "Pouched Animals", the Latin word marsupium signifying a pouch or purse.

\section{THE KANGAROO}

The Kangaroo is a very strange-looking animal. When it is sitting upright, which is its more usual position, it looks like a greatly overgrown hare. It has very small and short fore-legs; but its hind-legs, and especially the thighs, are very large.

In consequence it does not run, like almost all other animals, but hops along, in a nearly upright position, like a dog when "begging".

Its big hind-legs are so powerful that at every bound it springs over about fifteen feet of ground. If it be alarmed it can travel so fast that even a swift dog can scarcely overtake it.

Each hind foot of a kangaroo is armed with a very large 
and sharp claw. This is so terrible a weapon that it has often been known to rip up the body of a large dog at a single stroke of the kangaroo's leg.

A kangaroo is always ready to run away, but, if brought to bay, it will fight with great ferocity. It makes, if possible, for a big tree, against which it sets its back, so that it cannot be attacked from behind. And as soon as a man or a dog ventures within reach it kicks out fiercely, and its aim is so true that it very seldom misses its mark.

So well is this habit known that those who hunt the kangaroo put collars made of strong chain on their dogs, so as to prevent them from being ripped up.

But sometimes the kangaroo will kill the dogs in quite a different manner; for, if it can find a pond or a stream, it will leap boldly in, and, seizing the first of its pursuers, will hold it under water until it is drowned.

Kangaroos are only found in Australia and Tasmania, where they live in large flocks. As their skins can be made into very excellent leather they are much sought after, and many thousands are destroyed every year. So great, indeed, has been the annual slaughter of these remarkable animals that in many parts of Australia they are now protected by law during several months in the year, just as pheasants, partridges, and other game birds are protected in our own country.

When kangaroos are first born they are only about an inch long; not much bigger, indeed, than newly-born rats. But the mother has the curious pouch in her body, in which she carries her young until they are eight or nine months old.

By chance the little ones may be seen poking their heads out of the pouch, as though to see what the world is like. After a time they are allowed to come out for a little while, and hop about on the ground. But if any danger appears, their mother quickly puts them back into her pouch, and keeps them there until the danger is past. 


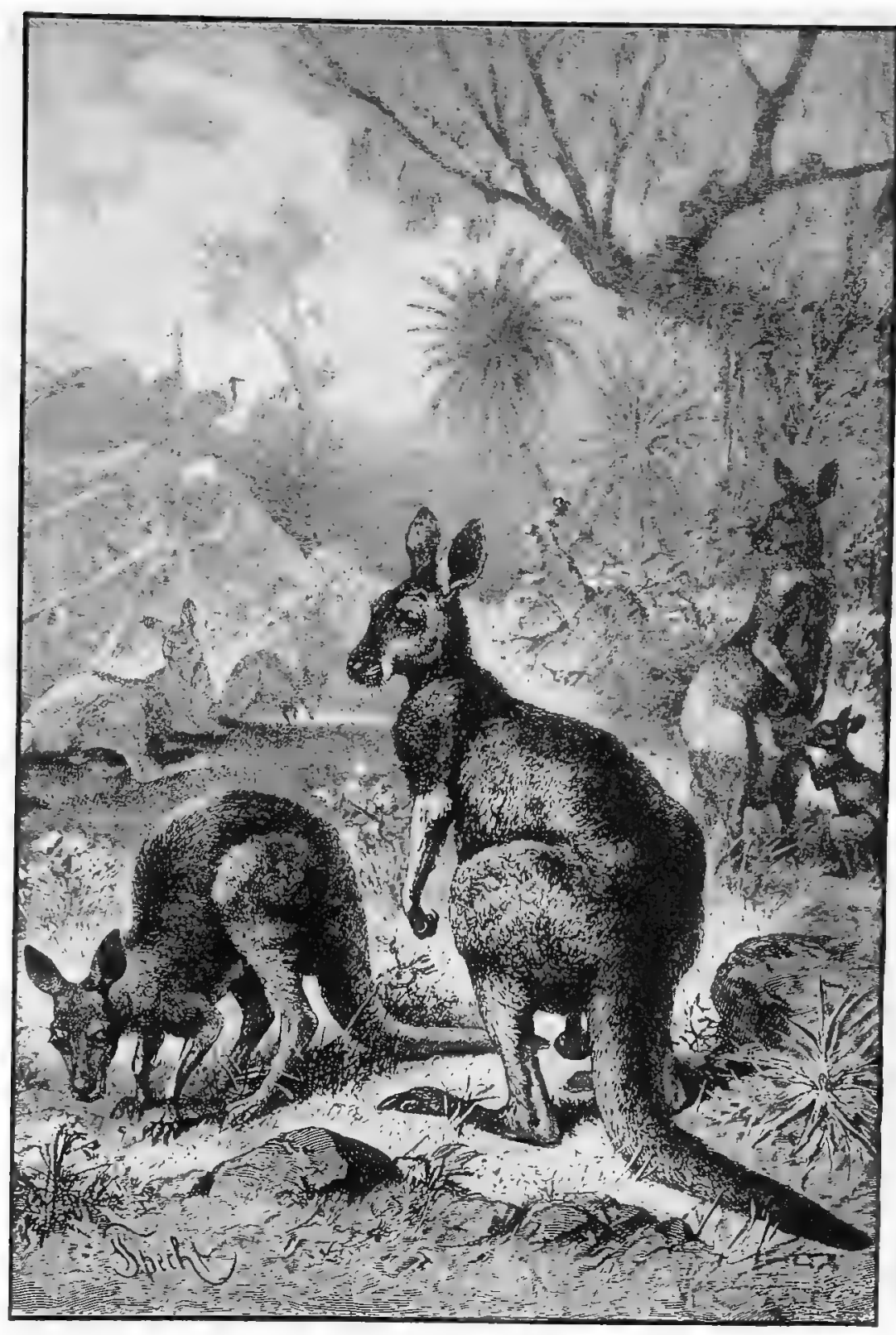




\section{THE OPOSSUM}

Almost all the Marsupials, or pouch-bearing animais, such as the kangaroo, live in Australia and the neighbouring islands. The group, however, is divided into several families, and the members of one family, strange to say, live, not in Australia, but in different parts of North and South America.

These are the Opossums, and very curious creatures they are. In one respect they are very much like the famous spidermonkeys, which also live in America; for they have long prehensile tails, which can be twisted tightly round a branch, and so are very useful in climbing. These tails are covered, not with hair, but with scales, like those of rats and mice; and they are so strong that an opossum will often suspend itself from a bough by its tail alone, and hang quietly for several minutes while busily occupied in gathering and eating the fruit which is growing below.

But opossums do not live on fruit alone. Indeed, there is scarcely any kind of food which they will not eat. Birds, small mammals, reptiles, frogs, and insects-none of these come amiss to their voracious appetites. To poultry-keepers they are especially troublesome, for they make their way into the hen-roosts night after night, and devour both the fowls and their eggs. And they are so wary and clever that it is almost impossible to keep them out.

Fruit-growers and farmers in the southern parts of North America find them a terrible pest, for scarcely a night passes in which numbers of the mischievous little animals do not rob their orchards and fields. Every few weeks, therefore, a grand "possum hunt" is arranged. All the negroes who work on the plantation are allowed to come, and soon after sunset a number of men and dogs set out in search of the marauders.

A moonlight night is always chosen for the sport, as then the animals can easily be seen when they take to the trees. Before long the dogs, which are carefully trained to the work, find an opossum, which at once seeks refuge in the nearest tree, while its pursuers stand barking below. The hunters hurry to the spot, 
and a negro is ordered to climb the tree and shake the opossum down. As fast as he climbs, the opossum climbs higher, until the top of the tree is nearly reached. The poor opossum is driven to the end of a branch, and there hangs on by paws and tail. The negro follows as far as possible, shaking the bough violently. For a time the poor animal maintains its hold, but at last it falls headlong to the ground, and is pounced upon by the eager dogs below.

In order to make a nursery for her young ones, the mother opossum builds a warm and cosy nest of grass and moss and leaves. She usually places this nest in a hollow tree, where it is sheltered from wind and rain, and is not likely to be found. The young are very queer little creatures, scarcely an inch long when first born, and blind. Yet their tails are prehensile

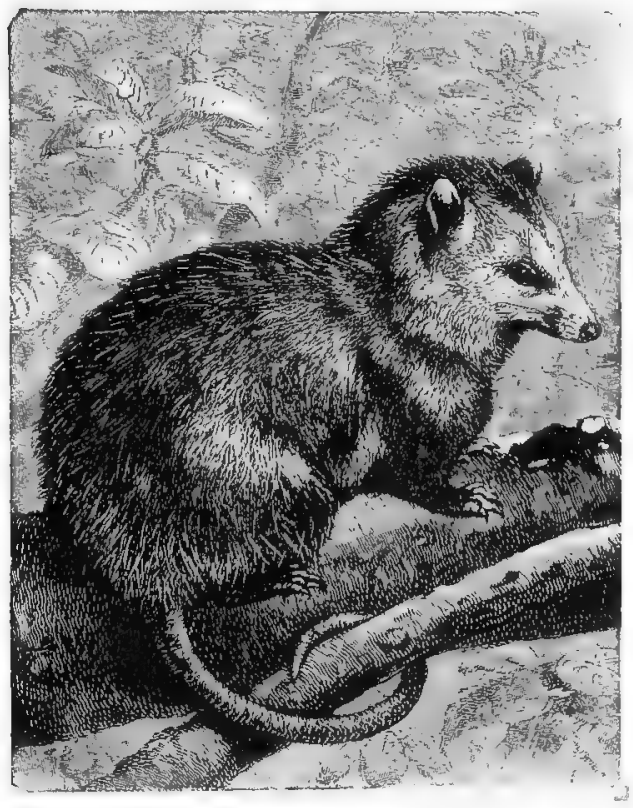

Common Opossum from the very first, and are generally coiled round one another's bodies.

For some time the little animals are kept in their mother's pouch, often poking out their tiny heads to look about them, just like young kangaroos, but when they are about five weeks old they are big and strong enough to leave their protecting shelter and run about by themselves.

Even after the young opossums have grown to some little size, however, they travel about with their mother. And very odd they look, for they climb up on her back, and, in order to avoid 
falling, twist their little tails tightly round hers, as if it were a branch of a tree.

Nearly all the opossums live in the trees, and are very active among the branches, although they are rather clumsy and awkward upon level ground. One species of these animals, however, never seems to climb a tree at all, but spends a great part of its life in the water! This is the Yapock Opossum, which is found in Brazil, and makes its home in holes in the banks of rivers and streams. It can swim and dive well, for its toes are webbed like those of a beaver or a duck, so that they can be used as paddles. The food of this animal consists of fish, tadpoles, water insects, and various aquatic molluscs, and its mouth is furnished with cheek-pouches like those of many monkeys, so that it is not obliged to rise to the surface every time it catches a victim.

\section{MONOTREMES \\ ORNITHORHYNCHUS}

Ornithorhynchus is the name of a very strange animal, which is otherwise known as the Duck-bill, from the peculiar shape of its beak. It is indeed a creature that might well be described as halfmammal and half-bird. The shape of its body is like that of the otter, and the habits of the two animals are somewhat similar. Like the otter also, its feet are webbed, the web on the fore-feet extending a little beyond the claws. It is well clothed with fur, which is brown on the back and white underneath. But its most remarkable feature is its snout, which is hard and shaped like the bill of a duck, and serves much the same purpose. The jaw of the ornithorhynchus, however, differs from that of a duck in that it is furnished with teeth at the back.

Another and more remarkable point in which the ornithorhynchus resembles a bird is that it lays eggs from which its young are hatched.

The ornithorhynchus lives in freshwater streams, and is to be 
found in numbers in the broad pools of the rivers of Tasmania and the south of Australia. Insects, worms, etc., which it finds in the mud at the bottom of the water, are its staple food.

The nest of this animal is made in a burrow in the bank of the river. There are generally two entrances to the nest, one opening below the surface of the water, and the other in the bank above.

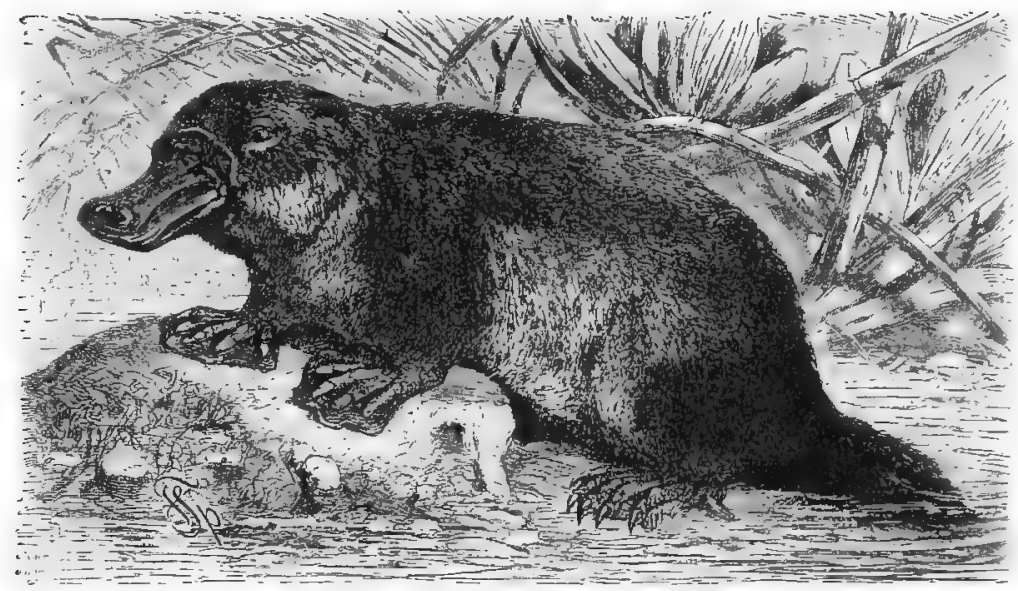

Ornithorhynchus (Water-mole or Duck-mole)

These passages lead into a chamber which contains the nest, at some distance from the water.

The body of the ornithorhynchus is specially built for life in the water. The animal is therefore a splendid swimmer, and, as might be expected, it is not very active on land.

The ornithorhynchus is a very shy animal, and does not often expose itself, except when it is getting dark. 


\section{BIRDS}

The creatures which are most familiar and most interesting to observers in this country are undoubtedly the Birds. This is, of course, because they are as a rule harmless, and, being allowed to live pretty much as they please, have become very numerous, and frequent our woods, fields, and even our gardens, with little or no fear of us. Much, indeed, of the delight of a country life is due to the birds. Their constant flittings about, their chirping and chattering in hedgerow and thicket, and the wonderful power of song with which many of them are gifted would be sadly missed were we to lose them. When spring is drawing near, many people in the country listen eagerly for the songs of the birds, and some know the different species by their voices, and could almost tell the time of year without a calendar, simply by the birds they hear singing and the manner in which they sing.

The habits of birds make a very interesting study. If you look out of your window almost any morning of the year you are sure to see several different species taking their breakfast on the lawn. If you care you can, by kindness, make friends with them, and you will find that a knowledge of their ways and the pleasure of their company will more than repay you for your trouble and the crumbs you may throw to them. They quickly get to know you, and after the first shyness wears off will come to your call. In winter especially, when the ground is frozen or covered with snow, some of them, and especially the robins, become quite fearless, will alight on your window-sill and pick crumbs from your hand, and even venture into your room.

It has been observed that birds are very faithful to one another. In the early spring, when they are pairing, you may often see two cock birds, which are both courting the same hen, fighting a very fierce duel, just as champions used to do in olden times. The object of their affections watches the fight from a tree hard by, and invariably flies off with the victor. But this happens chiefly among the young birds, for it is found that in many cases, when 
once paired, a cock and hen are faithful to each other, even till death, the one not long surviving the other.

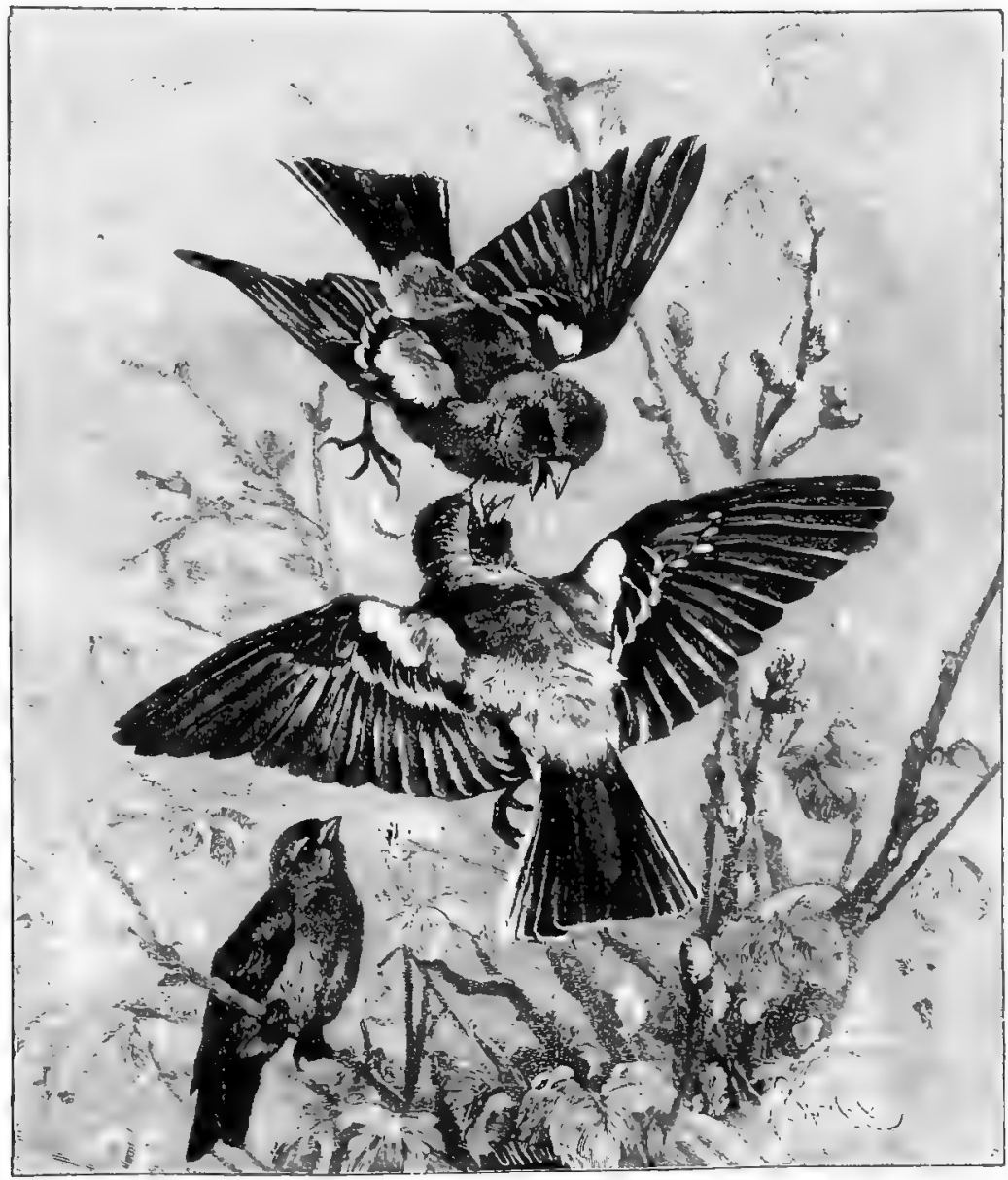

Cock Ghaffinches Fighting

On account of the change of temperature in the different seasons, some birds find that, for the safe rearing of their young and to save themselves from starvation, it is impossible for them 
to stay all the year round in one locality. They therefore migrate, many of them travelling very long distances, and even crossing very wide seas. Many of the birds we see in this country in spring and summer leave for other lands in autumn. When it is time for them to go you may see the different species gathering in large flocks in your own district. As they cross the country these are joined by other flocks until they look almost like black clouds passing through the air. Other birds, which do not leave the country, migrate from the fields and moors to the shore, or seek shelter in woods and gardens.

At first it seems very wonderful how birds, which are usually such small creatures, should be able to cross wide seas in safety. One would naturally expect them to fall into the water exhausted long before they reached the other side. But the reader has perhaps noticed, when travelling on a train that was running at a high speed, that many birds are able to fly as quickly as the train, and apparently with very little trouble. This is because the body of a bird is so wonderfully shaped that the air offers very little resistance to it, while the muscles with which it works its wings are very powerful, and can drive it along swiftly for a long time without getting exhausted. So strong are these muscles that a swan has been known to break the oar of a boat with a blow from its wing. It is by their great muscular wing-power, therefore, that birds are able to travel such long distances.

If you put your hand out of the window of a railway-carriage you will find that the swift motion through the air makes it very cold in a short time. How is it, then, that the rapid flight of birds does not benumb their bodies, especially when they fly high up, where the air is much colder than it is nearer the ground? It is because they are so perfectly clothed with feathers, which keep in the heat and keep out the cold. These feathers are the characteristic distinction between birds and mammals. There is, of course, the fact that they fly; but then all birds do not fly, while some mammals do. There is also the distinction that they produce their young from eggs; but, as we have seen, there is a mammal in Australia which, besides having a bill like a duck, lays eggs from which its young are hatched. But all birds have feathers, while no 


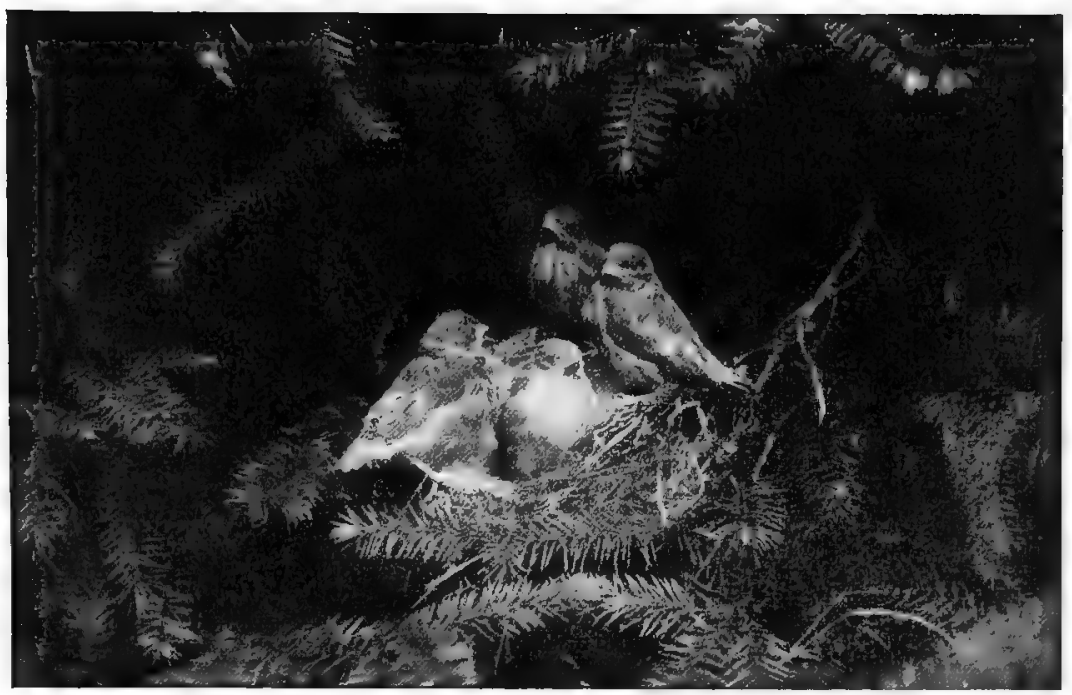

Linnets and Nest

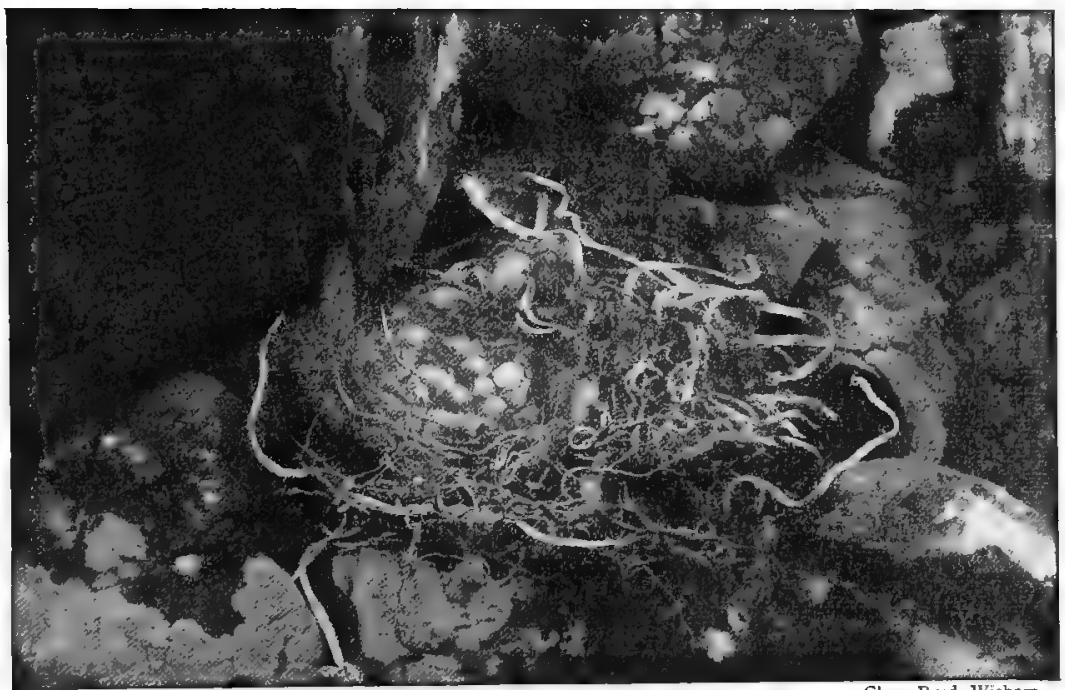

Photographs by

Kestrel's Nest

Chas, Reld, Wishaw 
other kind of animal has. These are placed very close to the body, and are so smooth on the surface as not to impede the bird in flight. The tail-feathers are used for steering, like the rudder of a boat.

The plumage of birds, especially in the warmer climes, is often very beautiful. That of the cock bird is usually more brilliant than that of the hen. In many cases it is difficult at first to believe that the two birds are of the same species.

Once every year birds "moult", that is, shed their feathers. During this period they are very dull; but as new feathers quickly grow in place of the old ones, they are soon as lively as ever again.

The eggs of birds exhibit great variety in shape and colouring, and the latter is often very beautiful. Birds that build in holes often lay white eggs, or nearly white-white with a few brown

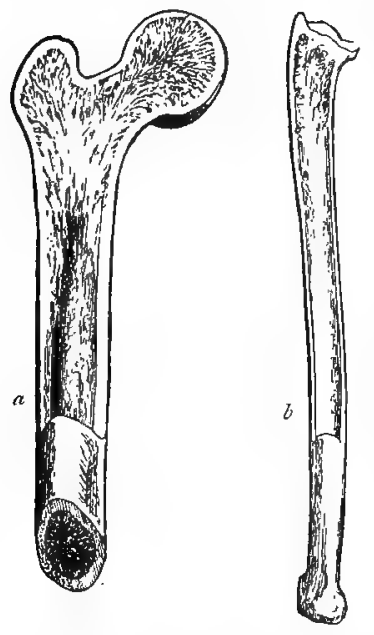

$u$, Section of bone of mammal showing marrow; $b$, section of bone of bird. specks at the broad end. Those which nest on the ground as a rule lay eggs which closely resemble their surroundings in colour, and are thus often difficult to find.

In the case of the larger birds the young are hatched almost fully fledged, and are at once able to run about. The eggs are therefore generally laid in a very rough - and-ready nest, and sometimes simply on the bare ground. But in the case of the small birds the young are produced in a more helpless condition, and have to be carefully protected until they are able to fly.

Birds show wonderful ingenuity in the building of their nests. Some build with mud, others with hay, straw, or sticks; others again weave moss, horse-hair, and wool into a very cosy nest; and some even stitch large leaves together. All succeed in making very snug homes for the young birds, usually well hidden from the eyes of a possible enemy.

It may seem strange that a bird does not fall off a tree when 
it goes to sleep. But it is really in no danger of falling, for the tendon which governs the movements of its toes is so constructed that when the bird sits down they catch a firm hold of the perch, from which they cannot be loosened till it stands up again. So while it is asleep a bird is actually fixed to its support.

Birds, like mammals, have a four-chambered heart, and are warm-blooded. The skeleton is very lightly constructed, the bones being generally hollow; and many birds are able to pass air to various parts of the body, and even into their bones. Their digestive powers are marvellous, as no doubt some have thought when they have seen them swallowing small pebbles. It is said that the ostrich considers nails a special dainty. But birds do not take these things as food, neither do they digest them. They know, however, that such hard substances will help to prepare for digestion their ordinary food, which often consists of corn and other hard seeds.

Most birds are gifted with very good memories. Those that migrate are known to come back to the same nesting-place year after year, while many can be taught to speak and even to whistle a whole melody.

\section{THE CLASSIFICATION OF BIRDS}

Naturalists have found it so exceedingly difficult to classify birds that even up to this day no perfectly satisfactory arrangement of the birds has been fixed upon.

The great difficulty of arranging the birds into natural orders, families, genera, and species, arises out of the one fact that they are as a class, i.e. as a whole group of animals, so very much alike. They are all covered with feathers, all have wings, more or less developed, and two legs. They are all without teeth, all have beaks, all lay eggs, none suckle their young, and almost all of them fly. So while it is easy to know a bird from a mammal or from a reptile, it is not easy to make distinctive divisions among the birds themselves, not nearly so easy as it has been to so divide (M 868) 
the great class of Mammals into their various groups or natural orders.

We may mention the fact that the various attempted classifications are generally founded upon variations in the instruments by which the birds mainly obtain their food, i.e. their beaks and feet, or upon some internal differences. But we need not attempt to consider these points of variation; that would be quite a labour, as we can imagine, when we understand that over ten thousand species of birds exist in the world.

If we follow, so far as is necessary, the ORDERS which seem to the revising editor of this little work most simply and naturally suggested, we shall do very well; and we shall have the satisfaction of knowing that we are not led astray.

Birds, as we have already learned, belong to the great division or Sub-KInGDom in the animal world of the Vertebrata, so that they are as much animals as horses or dogs, notwithstanding vulgar opinion, and the advertisements of so-called naturalists, who are "animal and bird stuffers"! The following list of Orders may be regarded as the most successful classification of birds that has been devised. It will help us to understand the true relationship of the birds which we shall consider. Before proceeding we may draw attention to the fact that some of the groups included in the list are now extinct.

\section{ORDERS OF BIRDS}

I. Passeres-Perching Birds.

2. Picarie-Woodpeckers, Cuckoos, Hornbills, \&c.

3. Psittaci-Parrots.

4. Striges-Owls.

5. Pandiones-Ospreys.

6. Accipitres-Eagles, Falcons, Vultures, \&c.

7. Steganopodes-Pelicans, Cormorants, and Gannets.

8. HERODIONES-Herons and Storks.

9. Odontoglosse-Flamingoes.

10. Anseres-Ducks, Geese, and Swans.

II. PaLAMedex-Screamers. 
I2. Columbe-Pigeons, Dodo, and Sand-Grouse.

13. Galline-Fowls and Game-Birds.

14. Fulicarise--Rails and Coots.

15. AleCtorides-Cranes and Bustards.

16. Limicole-Plovers, Curlews, Snipe, \&c.

I 7. GAvı\&-Gulls and Terns.

I8. Tubinares-Petrels and Albatrosses.

19. Pygopodes-Divers, Auks, and Grebes.

22. IMPENnES-Penguins.

23. Stereornithes - Wingless, and therefore flightless, birds of Patagonia (extinct).

24. Ratite-Ostriches, Emus, Cassowaries, \&c.

25. SAURURA-Long-tailed Birds (extinct).

\section{PASSERES}

The Passeres include more than half of all the existing birds, the typical form being none other than our friend the Sparrow, "Passeres" being derived from Latin passer, a sparrow. Among the members of the group are the highest of the birds, both in structure and attainments. This great order is of course divided into a large number of families, and to these we shall refer as we have occasion.

\section{THE CROWS (Family CORVID $x$ )}

It may surprise some to learn that the family of the Crows takes the lead in the bird world. But that they are said to do so by the most prominent men of science should be enough for us. This family includes many very intelligent and beautiful birds, among them being the Rook, the Raven, the Jackdaws, the Jays, the Magpies, Choughs, \&c. 


\section{THE ROOK}

The Rook is one of the most useful birds that we have in this country. Almost all through the year it helps us. Although it undoubtedly steals some of our corn in spring and autumn, and sometimes takes a few walnuts and young potatoes as well, yet we ought to consider these as the payment for the work which it does. And a very small payment it is for the valuable assistance which it is constantly giving us.

It helps us by killing the grubs which live upon the roots of our crops. One grub of which it is very fond is that of the cockchafer. This is one of the most mischievous of all insects. For three years at least it lives under the ground, eating the roots of our corn, turnips, and cabbages, and indeed of almost every plant that we grow.

If it were not for the rook, we should at times find it very difficult to grow any crops at all. But the bird can do what we cannot. It seems to know at once exactly where a grub is lying, and, driving its stout, strong beak into the ground, drags out the insect and devours it. As the rook lives chiefly on such grubs, we can imagine how very useful it is.

Those who live in the country must have seen rooks following the plough. These birds know perfectly well that when the earth is turned up, many of the grubs will be turned up too. They, therefore, hop along in the furrows, a few yards behind the ploughman, and snap up great numbers of these troublesome creatures.

Yet in some places the farmers believe that the rook is among their greatest enemies. Once in a certain part of England all the farmers thought so, and they had all the rooks killed. But in the following year they found that they were wrong, for they had to pay women and children to collect the grubs, which the rooks would have killed for nothing. In some districts on the Continent, and particularly in France, these birds and others had to be reintroduced and encouraged; for the farmers, who had ignorantly slaughtered them, found that without their aid their crops would not pay for the growing. 
Quite early in spring the rooks visit their old nests, in order to see what repairs are required. Then, if the winter storms have not damaged them too severely, they gather together a few sticks

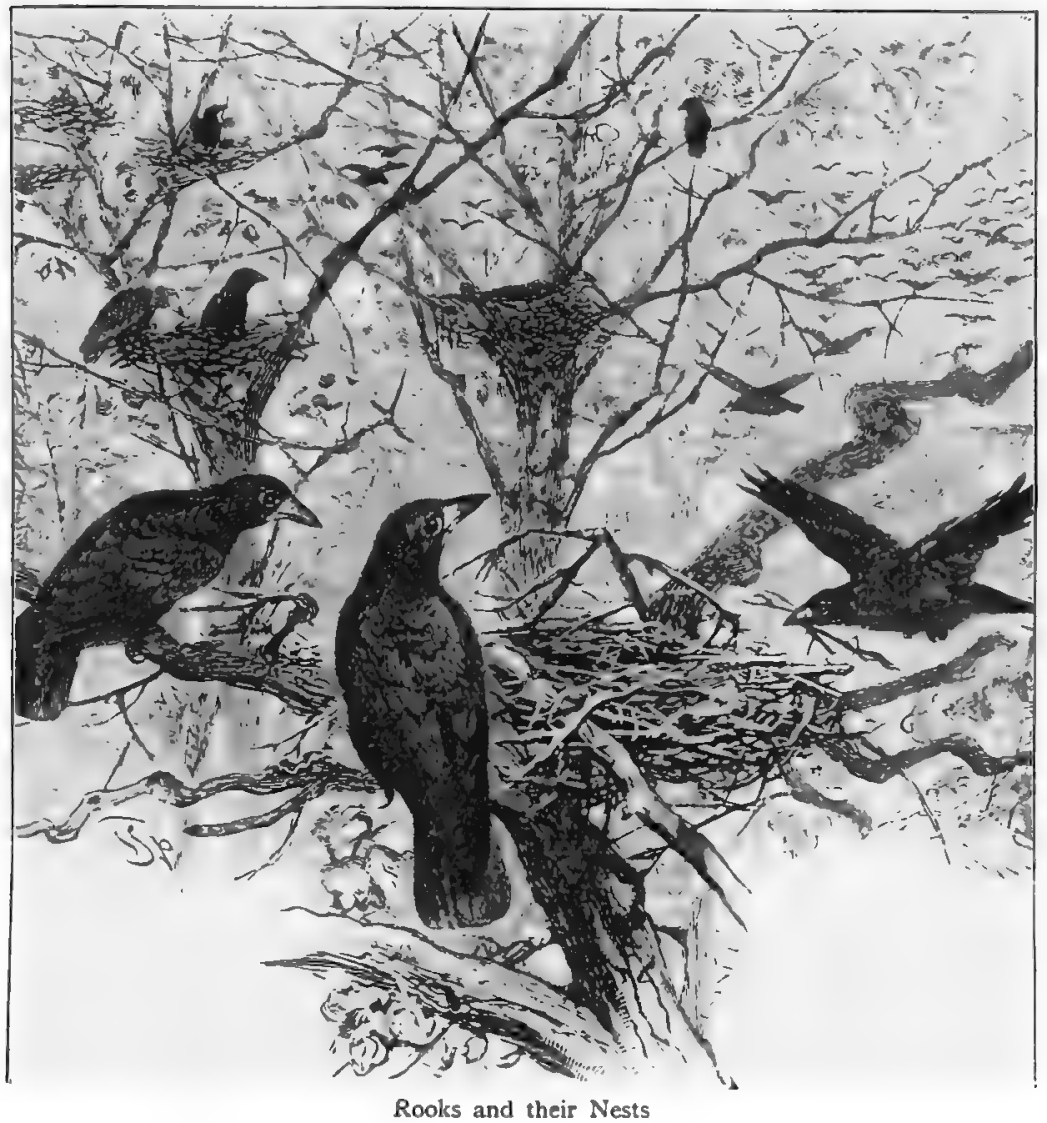

and twigs, and very soon make them as good as new. The nests are always built in the topmost branches of very high trees, where even a good climber cannot easily get at them.

Rooks evidently have laws of their own, and punish all who break them. They will not allow young rooks, for instance, to 
build their nests in a tree by themselves. If they try to do so, the old rooks go and pull the nests to pieces.

No rook is allowed to steal sticks from another's nest. This rule is very strictly kept, and a rook who breaks it is at once set upon and punished by all its fellows, sometimes even with death.

More than once a "rook parliament" has been seen. A number of the birds were assembled in a circle, in the middle of which was the culprit, guarded by three or four jailers. The case was tried, sentence pronounced, and the offending rook executed, after which the others flew away.

\section{THE RAVEN AND CARRION-CROW}

Closely related to the rook are the Raven and the Crow. Unlike the rook, however, they are both solitary in their habits. The former, which is the largest of the family in Europe, lives apart, building in very high trees or on ledges of precipitous rocks. The latter usually builds its nest in some high tree in a wood. Both feed on carrion, and a dead sheep provides them with a feast. But the raven will carry off chickens and rabbits, and will even kill lambs, and if it sees a sick sheep it will attack it and tear out its eyes before it is dead.

\section{THE BIRDS OF PARADISE (Family PARADISÆIDE)}

The Birds of Paradise come next to the crows, to which, notwithstanding their gorgeous and elaborate plumage, they are nearly related. The Bower-birds follow, and then the friendly and well-known Starling.

The Bird of Paradise is found only in New Guinea and the neighbouring islands, and it receives its name from its beautiful plumage. Its back and wings are a rich brown, and the breast a deep violet or purple. The head, which is like velvet, is pale yellow; and the throat, bright green; while round the base of the bill, which is greenish, is a broad ring of velvety black. The bird 
is about the size of a thrush, but from its sides thick tufts of yellow plumes, tipped with brown, grow and stretch out far beyond the tail, and may be expanded in such a way as almost to hide the

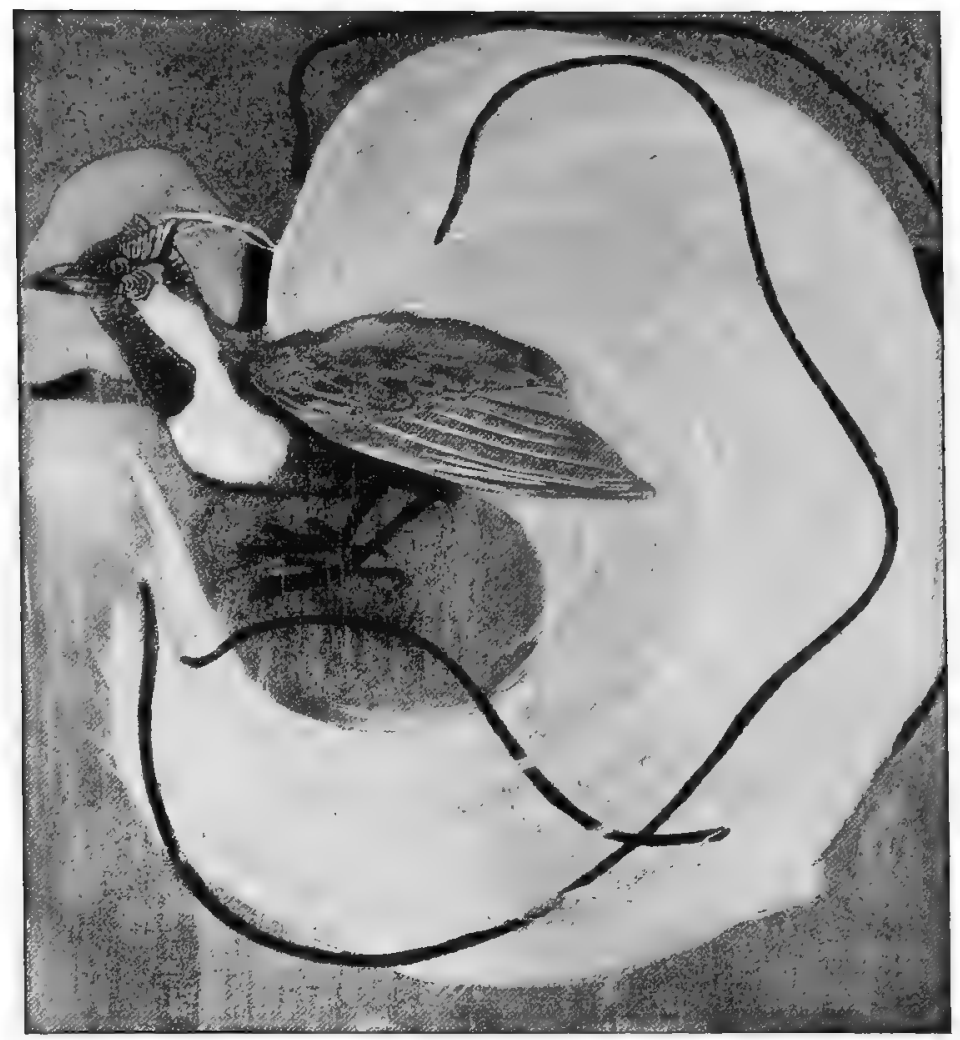

Bird of Paradise

body. Two long wire-like appendages also stretch out behind. The bird thus looks considerably larger than it really is.

As with most birds, it is the male that is so beautifully plumed. It is said that he is so proud of his fine feathers that he delights to gather his friends together for the sake of showing them off. 
Before much was known about this bird it was thought that it had no legs and never alighted on trees. People believed that it was always on the wing, only occasionally resting by hanging to a branch by its wiry tail-feathers. This belief originated in the fact that the bird was only known from the skins which the natives of New Guinea used for ornament, and from which the legs had been removed. It has, of course, legs like every other bird.

The Bird of Paradise lives chiefly upon insects, and as it darts about in the sun after its prey it makes a very wonderful spectacle. It lives in large flocks, and builds high up in the forest trees. Very little, however, is known of its habits, for it is an extremely shy bird.

The bright colours and beautiful plumage of the Bird of Paradise may be said to be its glory and its curse; for they have made it much sought after for purposes of adornment. But this may be said of many exquisitely beautiful birds, some of which have even been exterminated.

We must take this as a description of a typical "Bird of Paradise", for there are a good many different species, which have a wide distribution.

\section{THE STARLINGS (Family STURNIDA)}

This family comprises a large number of species, which are scattered over the world. Of these the common Starling is a good type.

Is the starling a friend of the farmer, or not? Undoubtedly it is, and one of the very best friends that he has. If it were not for the starling his pastures would soon be spoilt, and a great deal of his corn destroyed. And in a very few years' time he would find it hardly possible to grow either corn or grass.

If we were to get up very early in the morning and go down to the meadows, we should find the starlings hard at work. Quite a large number of them would be there, walking about briskly on the grass, and every now and then plunging their beaks into the ground and dragging something out. This is a worm or sone mischievous grub, which was causing a great deal of damage. If 
we look out of the window soon after sunrise, we may see these birds doing the same work on our lawns.

The grub of which they catch the greatest number is that of the daddy-long-legs. The farmers call this grub the "leather-jacket", because its skin is so tough that it almost seems as though it were made of leather.

This is a very mischicvous insect, for it eats the roots of corn and grass, and of many other crops, and so kills them. And therefore the farmer, when he notices a flock of starlings hard at work in his fields, ought to feel thankful that he has a band of such good friends to help him.

As the starling is one of those birds which can be taught to talk, it is sometimes caught and kept in a cage as a

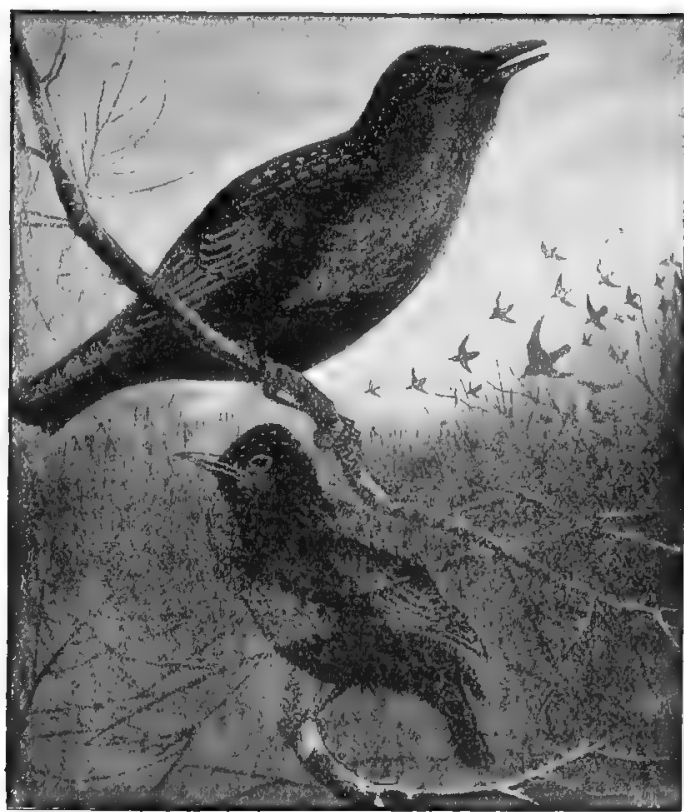

Starlings pet. Some cruel people slit its tongue with a sixpence, because they think that it will talk better afterwards. But this is, of course, a mistake, and the poor bird suffers a great deal of needless pain, and sometimes even dies from the injury.

We do not often see a solitary starling, for it is one of those birds which likes to live in large flocks. Thousands and thousands of starlings may often be seen together, all seeming to be under one leader. When he turns, they turn. When he rests, they rest. And in some wonderful way he gives the word of command to them, so 
that they can obey his slightest movement, and even break up into smaller flocks, and afterwards join together again in one. A flock of starlings in the air, indeed, is like a band of well-trained soldiers, so exactly do they keep time with one another in all their movements.

The mother starling is very fond of her young ones, and will even risk her life to save them. Once a barn took fire, and it seemed as if five little starlings, which were in a nest in the thatch, would be burned alive. But the mother bird, after flying to and fro in great trouble for a while, suddenly dashed through the flames to her nest, took out one of her young ones, and carried it away to a place of safety. Then she returned to the nest and rescued another. And very soon the brave bird had placed all her five little ones beyond the reach of the fire.

\section{FINCHES (Family FRINGILLIDAs)}

Missing the Orioles, Cow-birds, Weaver-birds, and their allies we come to the great group of the Finches.

This family embraces many well-known birds. We have only to mention Linnet, Greenfinch, Chaffinch, Hawfinch, Brambling, Redpole, and Siskin, to show this. And when we add our daily friends the Sparrows - House-Sparrow, Tree-Sparrow, RockSparrow, Canary, and Bullfinch-we at once feel that we are among old friends.

\section{THE SPARROW}

In town or in country, who does not know the Sparrow? This bold, saucy little bird may be seen almost everywhere, in lane and street, in park and garden, in field and meadow. It follows man wherever he goes, and never seems to live very far from human dwellings, for it knows full well that wherever he is it will be able to find sufficient food. It stays with us all through the year, too, instead of going away to other countries, as so many other birds do, for the summer or the winter. And so of all our British birds, perhaps, we know the sparrow best. 


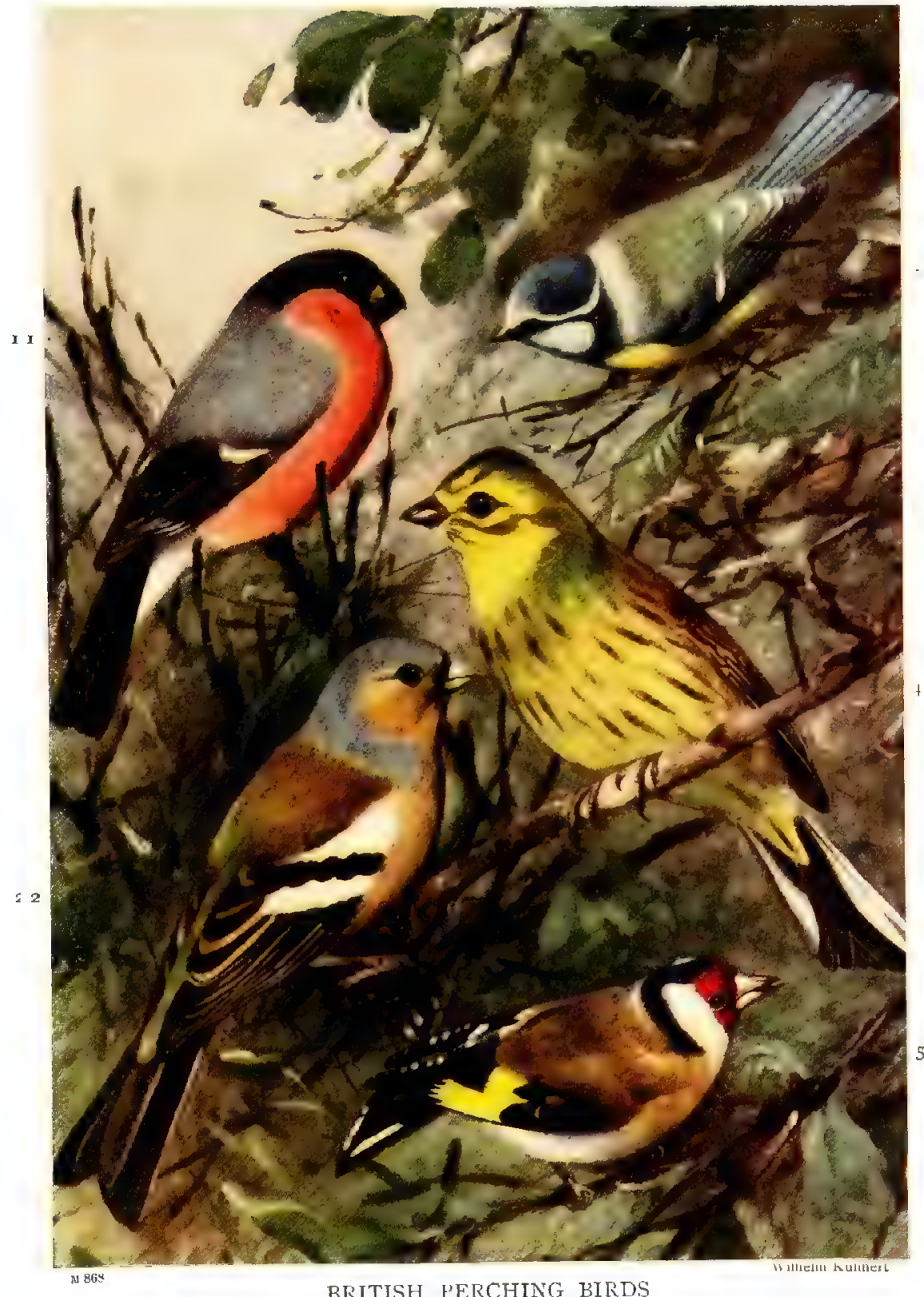
1. Bullfiuh.
c. Chaffiuch.
3, Bluc-Tit. 4, Yellow-Hammer.
5, Goldfinch. 

Some people do not like the sparrow. The farmer, for instance, declares that the bird is very troublesome in his corn-fields. It comes in great numbers, he says, when the grain is nearly ripe, and quite strips hundreds or even thousands of ears round the edges of the fields. And when the corn is gathered it goes off, he tells us, to the stacks, and continues its mischief there.

Not content even with this, it follows the drills when the fields are being sown, and picks up a great deal of the seed before the

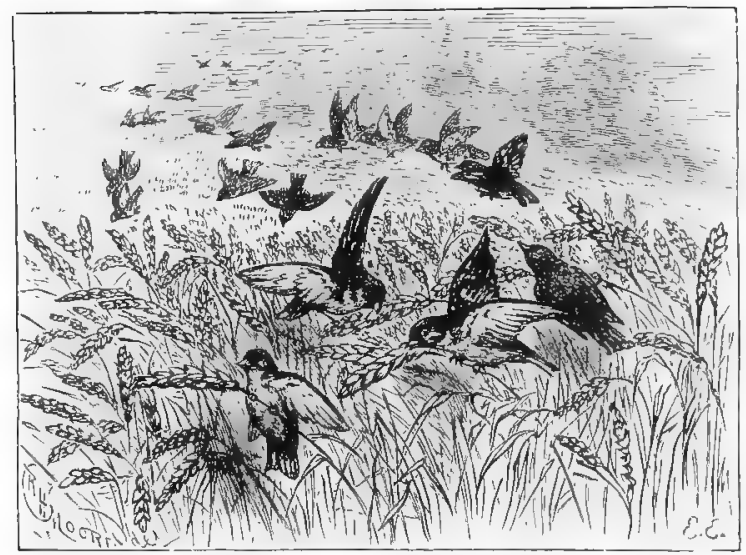

Group of Sparrows among the Grain

harrow can cover it in. It makes holes in the thatch, too, to sleep in at night during the cold months of winter. And, lastly, it steals the straw when it wants to make a nest in the spring.

Then the gardener says that it does all kinds of mischief to his flowers and vegetables. In the spring, he tells us, it picks all the crocus flowers, and lays them down on the ground by the side of the plants; and later it treats the pinks in the same way. It pulls primroses to pieces, too, and scatters the petals all over the flower-beds. Then it goes into the kitchen-garden, destroys the young cabbages and lettuces, picks the peas, and damages the fruit. And if he sows a little grass seed on the lawn, it scratches it up as soon as he has covered it in. 
The poultry-keeper, again, does not like the sparrow because it devours the corn which he has scattered for his fowls and chickens. It is so bold, he says, that it will not be frightened away for more than a minute or two, but comes again and again, as long as there is any grain left to steal. It knows just when the fowls are going to be fed, and is always waiting to come and take its share of thcir feast.

Lastly, we are told, it turns swallows and martins out of their nests and drives them away, and so prevents these useful birds from killing the insects which often do so much harm.

The sparrow, then, is accused of doing a great deal of mischief; and there is no doubt that much that is said against it is truc. But let us see if there is not something to be said in its favour as well.

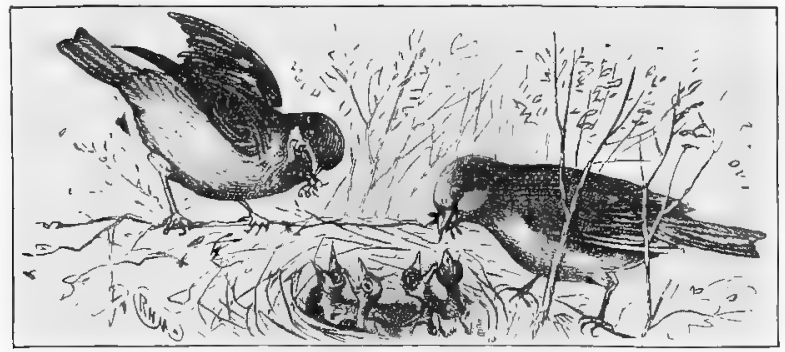

Sparrows feeding their Young

There is one way in which it is certainly very useful to us; for its young ones cannot eat grain like their parents, but have to be fed on caterpillars and grubs. These little sparrows, like all young birds, are very hungry creatures, and all day long one or other of the parents is seeking for insects for them, and bringing these to the nest. And so, in order to feed their five or six little ones, they catch and destroy nearly three thousand insects every week!

A great many of these insects are very mischievous in our fields and gardens. Day and night they are busily devouring our crops, and, if the sparrows did not destroy them, they would do a great deal of harm. By and by, too, they would lay hundreds or even thousands of eggs, and from every one of these another grub might hatch out to carry on the mischief. By killing them, therefore, the 
sparrow helps us very much, and partly pays, as it were, for the damage which it causes at other times of the year.

There is another way in which it is useful. There is no doubt that it is very fond of grain, and will steal it, whenever it can, from our corn-fields, our stacks, and our poultry-yards. But when it cannot get grain, it eats the seeds of wild plants instead; and among these are some of the weeds which give the farmer so much trouble when they get into his fields.

In two ways at least, then, the sparrow is useful to us, and we must not think of it as being altogether an enemy, even if it does sometimes commit so much mischief.

Although it is quite a small bird, the sparrow is very quarrelsome, and will attack other birds much larger than itself. Once a starling was seen hopping about on a small lawn, and every now and then pulling a worm out of its hole. Just behind it, however, came a sparrow; and as soon as the starling caught a worm, the sparrow snatched it out of its beak, flew away, and swallowed it. The starling was much the bigger bird of the two, but it seemed quite afraid to fight with the sparrow, and did not attempt to pursue it and take the worms away again.

The sparrow makes a very untidy nest of straw, grass, and feathers; sometimes in a hole in a tree, sometimes in the branches, sometimes under the eaves of a house, and sometimes even in the nest of another bird. Indeed, there is scarcely any place in which it does not sometimes build. It lays from four to six gray eggs, spotted and speckled with brown, and sometimes brings up as many as three families in a single year.

\section{LARKS (Family ALAUDIDE)}

After the Finches comes the delightful sub-family of BuntingsReed-Bunting, Common Bunting, Yellow Bunting, etc., and then follows the Lark family, which includes over a hundred species.

\section{THE SKY-LARK}

When crossing the fields on a spring day you have no doubt often noticed a little bird rise from almost under your feet, and, 
after flying for a short distance, begin to soar and to sing. This is the Sky-lark, which, although it is not in appearance a beautiful bird, is one of the sweetest songsters in this country. You may watch it soaring until it actually goes out of sight, and yet it continues to sing as it rises, and as it descends again, until it almost reaches the ground, when it suddenly swoops down and disappears among the grass.

It is, of course, the male bird that sings, but, close to where it flew up, the female was probably sitting on her nest, which you might possibly have found hidden at the foot of a tuft of grass. The sky-lark in colour is much like the ground on which it builds, and when sitting on its nest it is not easily discovered, so that it feels quite secure and will not move until it is almost trodden upon. It generally lays four or five eggs, which are white, closely marked with dark and light-brown spots. Sometimes two broods are hatched in a season.

In the autumn these birds collect in large flocks, and they keep together in this way all the winter. In spring they again pair off, and so spend the whole summer. They are so plentiful in some parts that large numbers of them are killed and sold to the gamedealer, which we must feel to be a great scandal. On the Continent this beautiful songster has been almost annihilated in various districts in order to satisfy a barbarous animal appetite.

The young birds are often caught and kept in cages. If well taken care of a lark will sing almost all day when spring comes round, especially if its cage is hung outside the window where it may enjoy the fresh air and sunshine. But its song in confinement is not to be compared with that of the "bird of the wilderness" as it "at heaven's gate sings".

\section{TITMICE (Family PARIDÆ)}

Following close upon the Larks come the Wagtails, Pipits, Creepers, Tits, Shrikes, Waxwings, and one or two less-known groups. Let us look more carefully at the familiar Tits, of which such names as Great Tit, Crested Tit, Marsh Tit, Blue Tit, and Coal Tit must be known to us. 


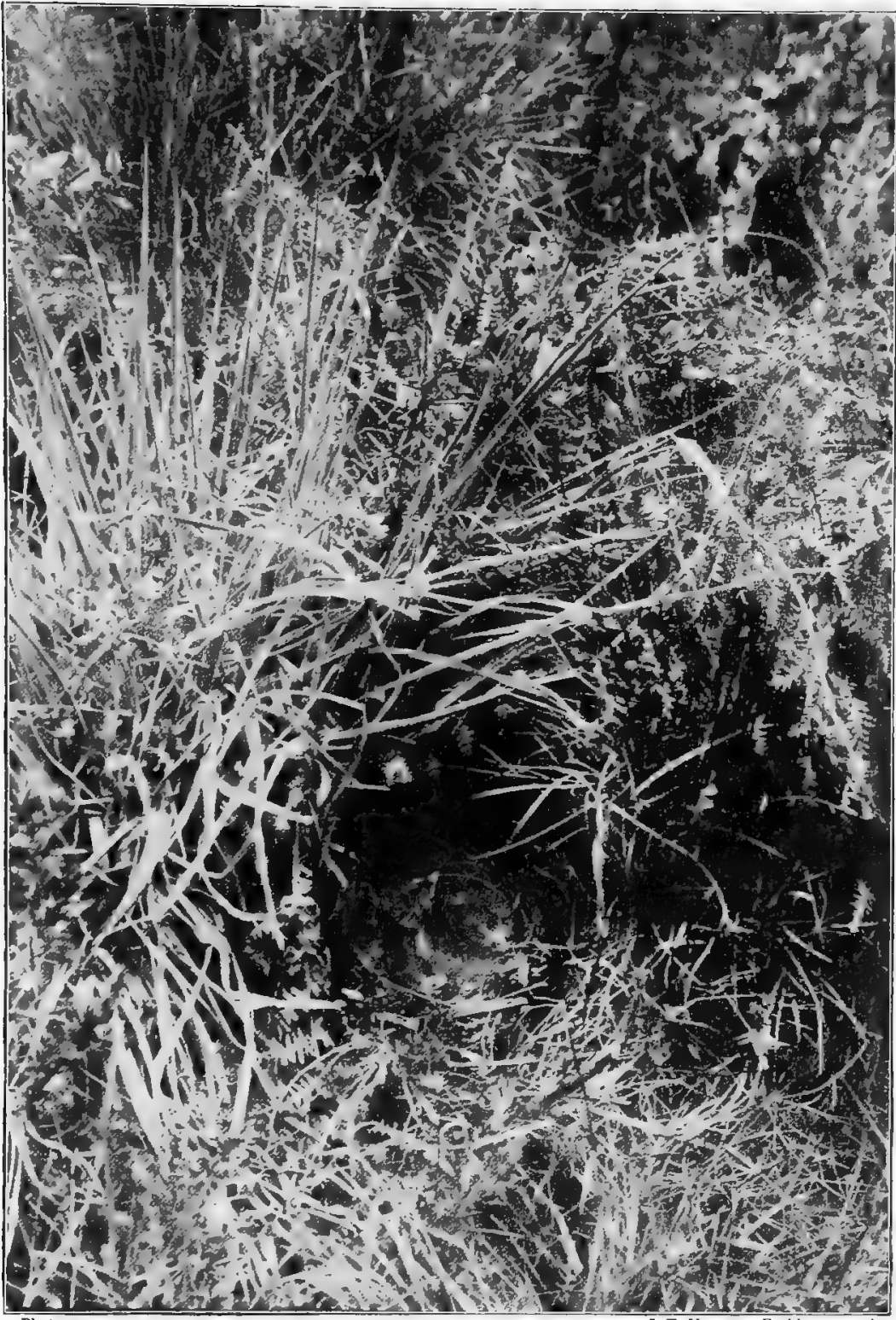


Very odd little birds are the Titmice, which are so well known to almost every resident in the country. We do not meet with them out in the open fields. We never see them digging in the ground for worms and grubs, like the starling; or catching moths and beetles in the air, like the nightjar; or stealing corn, like the

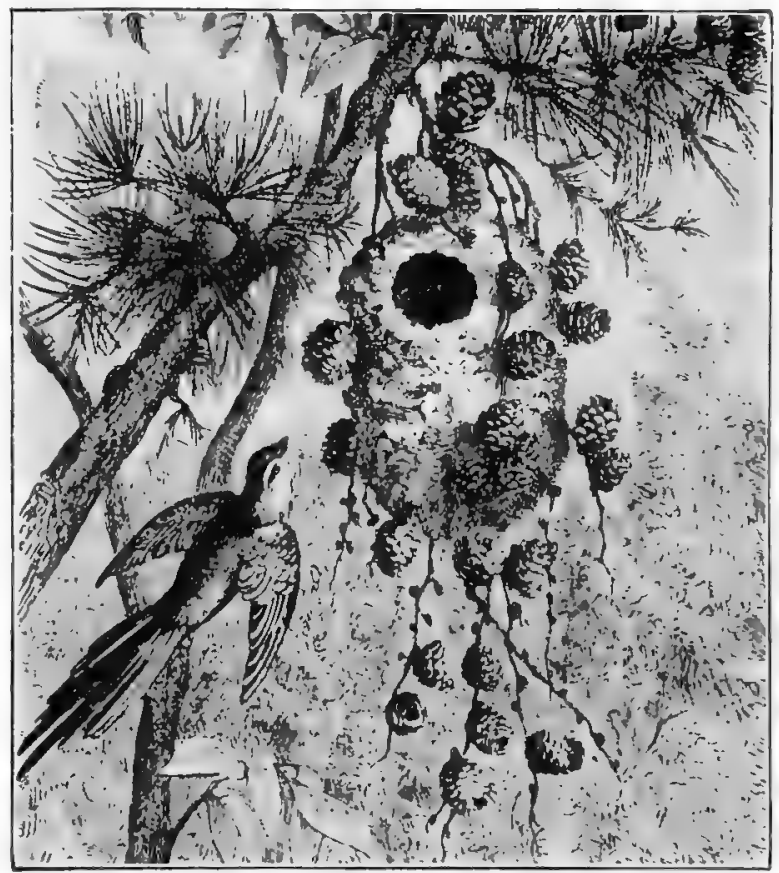

Long-tailed Titmouse and Nest

sparrow. Unless we look for them, indeed, we shall scarcely notice them at all. For their work is in the trees. There they hunt for the little insects which feed upon the leaves or the young shoots, or which hide themselves in the chinks and crannies, and under pieces of loose bark.

Their fcet are so formed that they can perch upon a branch, or on the side of a branch, or even underneath a branch, with perfect 
ease. Thus an insect cannot hide in any part of a tree where they are unable to follow and find it out.

These titmice are useful little birds, for many of the insects which they kill are very mischievous, and would do a great deal of harm if they were not destroyed.

One of these insects we call the "woolly blight". We have perhaps seen on the trunk and branches of an apple-tree a number of what look like little white tufts of cotton-wool. These tufts are the covering of this little blight insect, which drives its sharp beak into the bark, and sucks up the sap. It is a small insect, it is true, and cannot do much harm singly。 But it increases in numbers so very fast that soon the trunk and branches are almost covered with tufts of the white cottony substance, and the tree is weakened and cannot bear its proper crop of fruit. And at last it may even die from the injury which it receives.

Now the titmice are very fond of these troublesome little creatures, and destroy great numbers of them every year. We may see them running up and down the trees, and busily pecking away at the tufts of "wool". As they kill many other mischievous insects also, they are true friends to us; and we may well forgive them the little harm they do to our fruit-blossoms in spring, and to our ripe pears in autumn.

Most of the titmice build their nests in holes in trees, so small that there is only just room for the birds to pass in and out. Very warm little nests they are, made of wool, moss, and feathers; and in them the mother bird lays a number of little white eggs, prettily spotted with red.

If the mother bird is disturbed while sitting on her eggs she utters a hiss, just like a snake. And she will fiercely peck the fingers of any one who tries to interfere with her or take her eggs.

The long-tailed titmouse builds its nest on a branch or in a bush, and covers it all over with spiders' webs and bits of lichen, so that it may not be noticed. It is a very beautiful nest; and, as it is made in the shape of a bottle without a neck, the bird is often called the "bottle-tit". 


\section{THRUSHES (Family TURDIDE)}

The Thrushes embrace the Missel, Song, and other thrushes, Blackbirds, Redwings, Fieldfares, and Ring-Ouzels. The true thrushes are much more South American birds than European. There are twenty-four species known in South America, and only five in Europe.

\section{THE SONG THRUSH}

Walking in a garden or a field, we may often notice a stone with a number of broken snail-shells scattered all round it. On examination we see that the snails to which these shells belonged must have been broken upon it, for it is quite covered with slime and with fragments of shell. What can be the meaning of this? How came the shells there? And what has become of the snails themselves?

If we hide close at hand for a short time we may find out. In a few minutes a Thrush flies towards us with a snail in his beak. He goes straight up to the stone and begins to hammer the snail upon it, turning it this way and that, as the shell becomes cracked and broken.

When he has finished his task, he picks off and scatters the broken shell with his beak, and in brief space the poor snail, being thus deprived of its home and protection, is gulped down whole, and the thrush flies away to search for another.

So the puzzle is explained. All the shell fragments are the remains of snails which the thrush has found, brought here, and killed and eaten. He has been helping the gardener, by destroying creatures which do much harm to his flowers and vegetables.

Sad to say, however, the bird himself is a thief at times. He likes nothing better than a little ripe garden fruit, and he naturally helps himself. So the gardener is not always glad to see him, even though he does kill so many snails.

The gardener forgets that for at least nine months in the year, thrushes and blackbirds are his best friends; for during that time they are engaged wholly in destroying things which he calls "pests". 
Everyone who lives in the country knows the song of the thrush, which is so full, so rich, and so delightful that many people prefer it even to that of the nightingale. From early morning until late in the evening he sings, and there are very few days in spring, summer, and autumn when we may not hear him. And

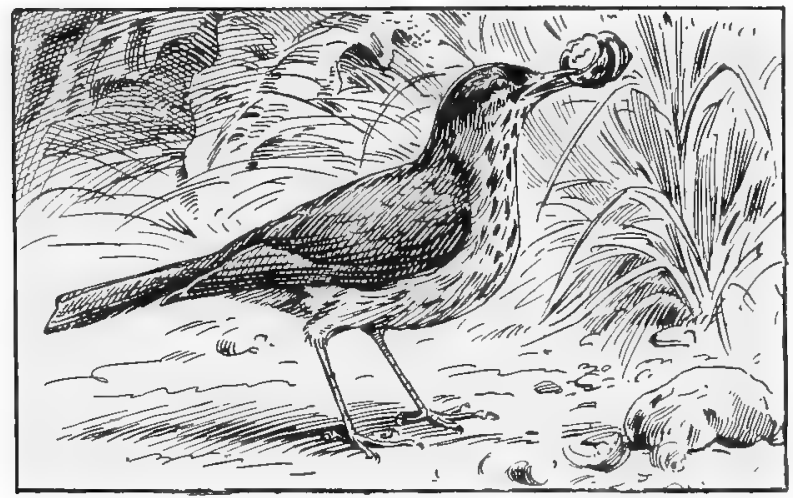

Thrush breaking the Shell of a Snail

he is so cheery and happy, and seems to enjoy his life so much, that it is a very cruel thing to take him away from his woodland home, and imprison him, as is often done, for the rest of his days in a close and narrow cage.

The thrush is a very early builder, and begins nest-making long before the leaves are on the trees. After making the framework of grass and straw and roots, he lines the inside with a kind of plaster, and smooths it down very carefully. Then the female lays her four or five pretty pale-blue eggs, each with a few small black spots at the larger end.

\section{THE ROBINS AND NIGHTINGALES (Sub-family of the Turdidæ)}

Immediately after the Thrushes come the Chats-Whinchat, Stonechat, Blackchat, and Redstarts, and next to them our pets the Robins and the magnificent singers the Nightingales. 


\section{THE REDBREAST}

Who does not know the brisk little brown bird with the brightred breast, that comes to the window on cold frosty mornings when snow is lying deep? This bird will even fly into our room if we only generously court his friendship, and make friends with us in such a way that his visits will be repeated year after year. Because of

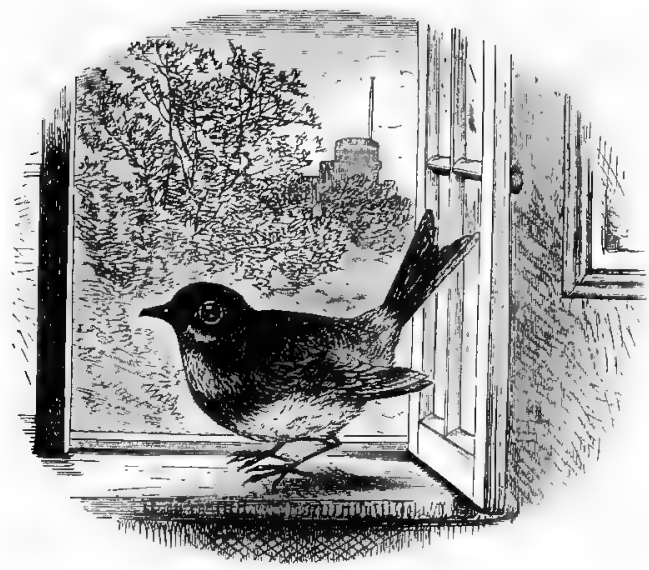

Robin Redbreast

this friendly disposition the Redbreast, or Robin, as he is more commonly called, is one of our prime favourites among the birds. Hehas domestic business in the fields and woods of the country all the spring and summer, though he sometimes builds his nest and rears his offspring in our gardens. But he is sure to return in the late autumn, and during the winter to demand our generosity and attention. He sings, too, in autumn, and even in winter on a fine day when most other birds are mute, but this is no doubt his expression of gratitude to his human friends.

The Redbreast builds at the root of an old tree or in a bank or old wall, often near a stream. Sometimes, too, he selects strange sites for his home-an old plant-pot or can, for instance, or any such cosy receptacle. The nest is very cleverly made of dead leaves and moss, and lined with hair and feathers. The female lays five or six eggs, which are white, prettily spotted with reddish-brown, and sits on the nest carefully till the young are hatched. The male meanwhile occupies a branch close by, and sings sweetly to her, or busies himself by fetching food for her. 
This charming little bird is no milk-sop, for in the early spring we may see violent combats going on between two robins. They fight fiercely, and feathers fly right and left. But this is pure jealousy, and generally happens when one robin comes too near the nest of another, or when two males are fighting for one female.

The robin is always a lonely bird. Most other birds live in flocks during the winter, and some even all the year round. But it is seldom that more than one or two robins are seen together, or among the birds to which crumbs are thrown on a cold morning.

\section{THE NIGHTINGALE}

About the middle of April-in some years a few days earlier, and in some a few days later-there comes to us from over the sea one of the most famous songsters of the feathered race. This is the Nightingale, a plain and unattractive little bird to the eye, but one which charms all ears with its floods of liquid melody. During the latter part of April and all through May it sings, and one never tires of listening to its wonderful song.

Two mistakes are very commonly made about the nightingale. The first is the supposition that it sings only by night. Truly we usually hear its song distinctly after nightfall; but that is because the air is so much quieter at night than in the day, when myriads of other birds are singing, and we notice the song more. But we may hear the nightingale's song at any hour of the day if we listen carefully. So incessantly does he sing, indeed, that we cannot help wondering when during the twenty-four hours he contrives to take any rest!

The second mistake is to suppose that it is the hen nightingale that sings. This is quite an error. The hen does not sing; so of course it is the voice of the cock-bird that we hear, as is the case with all other songsters.

The cock-nightingale sings cheerily to his mate, while she sits in silence, brooding over her five little olive-green eggs, and thinking, no doubt, of the five little nestlings which will soon be hatched out. 
The nightingale is very proud of his powers of song, and becomes very jealous if he thinks that he has a rival. The writer often amuses himself on a spring evening by whistling to the bird as soon as his song is ended, and pretending to be another nightingale. First he whistles a few notes. The bird answers, and then waits to see if the whistling is repeated. If it is, he becomes quite excited, sings louder and louder, and comes nearer and nearer, until at last he is only a few yards away. When he finds that he has been taken in, and that it is not another nightingale that has been whistling, he gets very angry and begins to scold and chatter.

The nightingale's song does not continue all through the year. The bird only sings for about six weeks, for he does not begin until he reaches this country, about the middle of April; and as soon as the eggs are hatched at the end of May he loses his voice, and does not recover it again until the following spring.

Nightingales feed upon worms, almost all kinds of insects, and sometimes upon fruit. In the summer, for instance, they have been seen pecking away busily at "black-heart" cherries; possibly because the weather was hot and dry, and they could find no water to drink. But if there is one dainty which they prefer to another, it is the grub of that curious flat beetle which bakers call the "meal-worm".

This they seem quite unable to resist; and bird-catchers, when they want to catch a nightingale, always bait their trap with a meal-worm. If the bird has once been caught, however, and allowed to escape, not even a meal-worm will tempt him again; and, knowing this, residents in neighbourhoods where nightingales build have sometimes employed a man to capture as many of the birds as possible, and then set them free again, knowing that the professional bird-catchers might then come and set their traps in rain.

The nightingale is a very affectionate bird, and becomes so much attached to his mate that if he is separated from her he is almost sure to pine to death. 


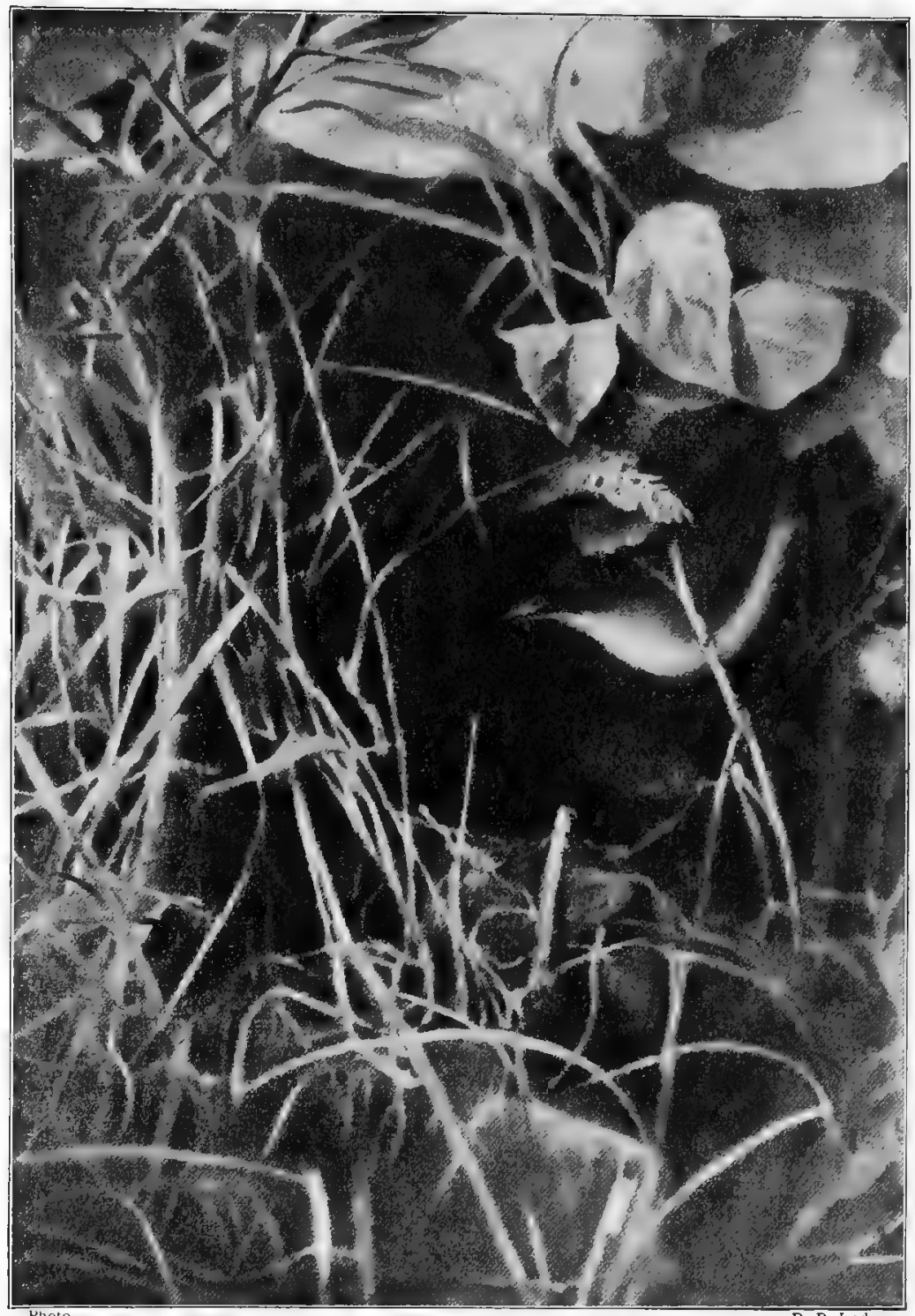

Photo.

NIGHTINGALE AND NEST

R, B. Lodge 


\section{THE WRENS (Family TrogLodytide)}

According to some the big group of Warblers is another subfamily of the Turdidæ. In any case they lead us directly into the family of the Wrens. These are almost all very small birds, but over one hundred species are known.

\section{THE COMMON WREN}

The pretty little Wren is almost the least of all our British birds, for only the gold-crest is smaller. What dweller in the country is not familiar with it? As you walk along the lanes, you may see it flitting in and out of the hedge beside you, never flying very far off, and often allowing you to approach very closely to it. You may often hear its shrill little cry, and sometimes, no doubt, you have listened to its song.

The wren builds in a bank or in the hole of a tree, or among the ivy on a wall. The nest seems very big for the size of the bird, but then the wren brings up quite a large family, and may soon be the mother of eight or ten little ones, and possibly even more. And when all these little birds begin to grow, they will want a large nursery to live in.

Everyone who has seen a wren's nest must agree that it is a very wonderful piece of work. It is remarkable that a little bird, with only its beak to help it, can weave the walls so closely, and that it should be able to line the inside so warmly with moss and feathers.

The wren always covers the outside of its nest with dried leaves, moss and fungus, and bits of twig, and makes its home match so well with the surrounding objects that one might almost look straight at it and yet never see that it is a nest.

This is an instinctive and skilful precaution which the wren always takes. It seems to know that it has many enemies ready to destroy its home, and so it covers it very carefully with the same objects with which it is surrounded. 
If the nest is built among dry leaves, it covers it with leaves; if it is placed among moss, it covers it with moss; and so on. And so, very often, the nest of the wren is passed by, when that of any other bird would be seen at once.

The mother wren seems to make the framework of the nest, while her mate sits close by and sings to her. This part of the

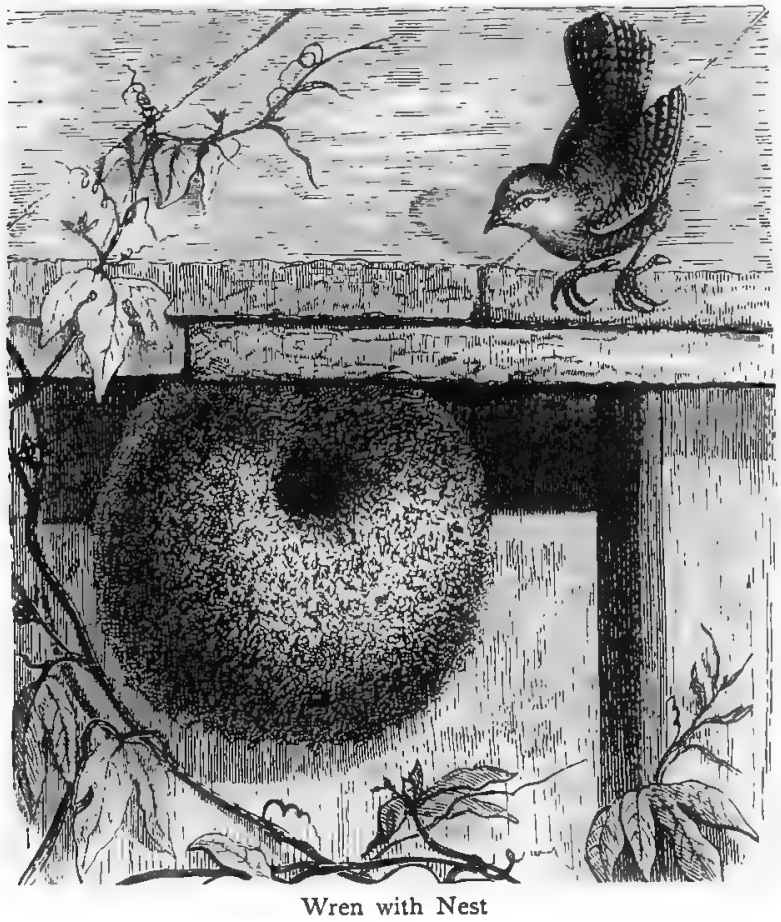

task occupies about a day, and after it is done the two birds go to work together.

They are so neat and careful, and take so much pains, that the nest is not finished for eight or nine days. When it is quite completed, the mother wren lays from six to fourteen little white eggs, prettily spotted and speckled with pink. And very soon a family of little wrens is hatched out into the world. 
The wren feeds on small caterpillars and other tiny insects. We may see it on our rose-bushes, busily picking off the little "blight" insects which damage them so much; so that, tiny little bird as it is, it is really of service to us.

\section{THE SWALLOW (Family Hirundinid E)}

After the Wrens come the Mocking-birds and their relatives, a group known as Babblers, and then through the Fly-catchers we are introduced to the Swallows.

The true swallows are well illustrated by the common Chimney species. But there are Sand-Martins, Purple Martins, and others of the same family which are placed in different genera.

The chief home of the swallow family is Africa.

Although the Swallow is only with us during a part of the year, it is one of the birds which we know best. The reason is, that it always lives so very near to our houses, and has such peculiar ways and such wonderful powers of flight. The swallow, indeed, cannot bear to be far away from human habitations. It never goes out into the fields or the woods to make its nest and bring up its young, but builds in a barn, an outhouse, a chimney, or even in an empty room, from which we may see it constantly passing in and out. All day long it is flying to and fro in search of flies, around the house and about our windows.

Like the martin and the swift, the swallow cannot bear cold; neither can it endure great heat. When wirter is coming on in this country it flies away over the sea to warmer countries in the south, and escapes the frost and cold. By and by it finds the weather there becoming too hot for it, and is obliged to fly northwards again.

One of the reasons why the swallow leaves us in the autumn is that its natural food is beginning to fail, and it goes to a climate where flies are common again. As soon as the insect-world is again on the wing in our northern regions, the swallow returns.

Every year of its life, therefore, it has to make two long journeys across the sea. And although it has nothing to guide it, it finds its 


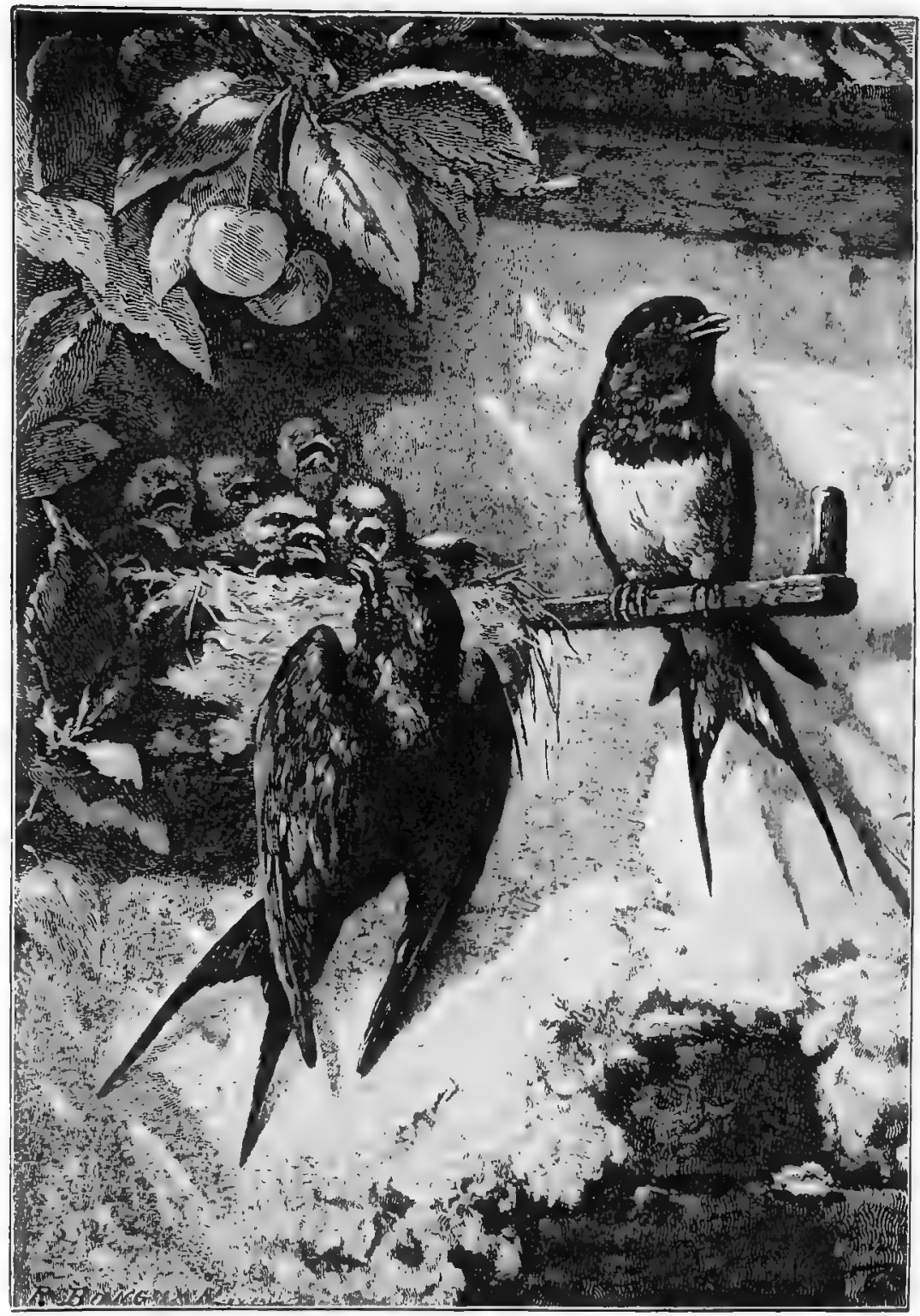


way quite well. A pair of marked swallows have been known to come back to the same place year after year, and to make their nest in exactly the same spot.

In one way the swallow is very like the nightjar. That bird, you will recollect, has a very large and wide beak, and a very sticky tongue, so that even a large insect, when once it is seized, has no chance of escaping. The beak of the swallow is made in just the same way, and as it dashes along through the air it catches numbers of little insects. These stick to its gummy tongue, and are held firmly until it is ready to swallow them.

Many people find a difficulty in distinguishing the swallow from a martin or a swift. But you may easily know the swallow by its long forked tail, which is more than twice as long as that of either of the other birds. The martin has a broad bar of white across the lower part of its back, and is white underneath; while the swift is a very much larger bird, and has long, narrow, sickle-shaped wings.

The swallow builds its nest in a very curious way. It makes the walls of mud, which it brings in little pellets from the nearest puddle or pond. These it kneads carefully together, and so makes the outer shell of the nest.

If the mud does not "bind" well, it procures a few short pieces of straw, and works them in with it. Then it gathers together soft feathers, and makes a lining with them. And so it has a warm dry nest in which to bring up its little ones.

\section{PICARI $Æ$}

With the American Fly-catchers, Chatterers (the latter including the Bell-birds), Wood-hewers, and the Lyre-birds, we come to the end of the great order of the PASSERES or the Perching Birds.

Then we enter upon another great order of birds, which includes some families with which we are more or less acquainted. The order PICARIÆ introduces us at once to the VIoodpeckers, and from them we pass almost straight to the Cuckoos, which lead us 
through one or two less-known families to the highly-interesting Humming-birds. The Swifts follow, as they show an actual relationship to the Humming-birds, which in turn are connected with the Nightjars, and so introduce us to them.

From the Nightjars we pass through West Indian Todies and American Motmots and Bee-eaters, to the Hoopoes; and then through the Hornbills we come to the beautiful group of Kingfishers and the peculiar Madagascar Frog-mouths.

\section{THE WOODPECKERS (Family PICIDE)}

The Woodpeckers form a connecting link between the Passeres and the Picariæ. There arc a good many species distributed over both the Old and the New World.

Probably few of us have ever seen a Woodpecker alive. We may pass again and again through a wood in which the bird is quite common, and possibly not catch sight of it. For it is a very shy bird indeed, and is always very careful to keep well hidden from view.

But if we sit down under a bush, or against a tree-trunk, and remain for a few minutes motionless, a woodpecker may come quite near, and we may be able to watch it at work.

What is its work? Catching insects. Not butterflies, moths, and bees, which it might find flying about; it does not care for these. The insects for which it searches are those which bore into the bark and the wood of trees.

If you could examine a woodpecker you would see how well it is able to seek for and capture the insects.

You would notice, in the first place, its strong, sharp beak. This beak is a kind of natural chisel; and when the woodpecker finds an insect in its burrow, it can quickly chip and cut away the wood round it by a few strokes of its bill.

Being made of horn, however, and not of steel, it is not brittle like a chisel; and if an insect should have taken refuge underneath the bark, the bird can prise up the bark, just as a carpenter would do with a strong screw-driver. 
You would find, too, that the woodpecker's tongue is extremely long, and also very slender; so that it can be passed into a very narrow hole. This tongue is very sticky, like that of the toad, and there is a kind of little brush at the tip. And so, if it were only to touch an insect in its burrow, it could easily drag it out.

Then you would notice that the feet of the bird are very curiously made; for two of the long toes are directed forwards and

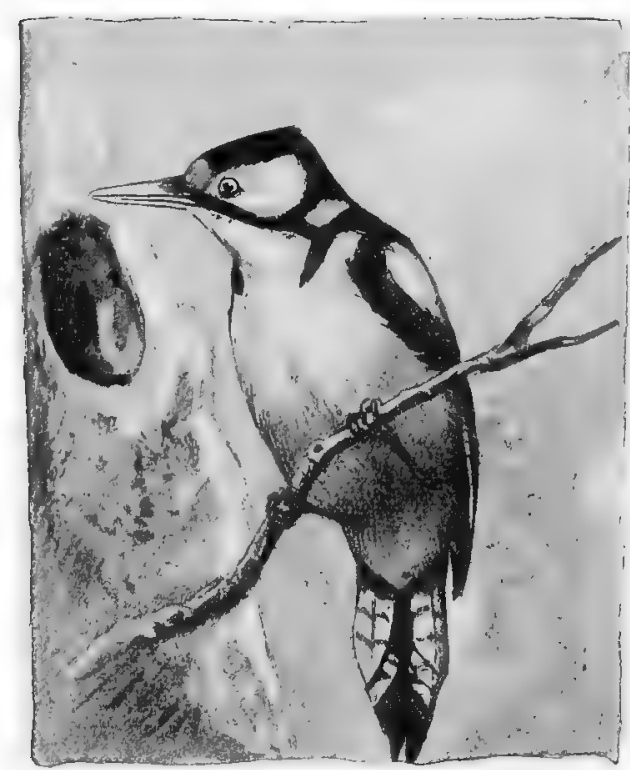

Woodpecker two backwards, while each has a sharp, curved claw. This is to enable the bird to cling easily to the upright trunk of a trec.

But, in order to help it in doing so, its tail, which is very short and stiff, is set at such an angle with the body that the bird can rest upon it when it is clinging to a tree-trunk. When, therefore, a woodpecker is engaged in digging out an insect from a tree, it really sits upon its tail, which serves as a kind of stool. Thus we see that nature, besides giving the woodpecker a special work to do, has also furnished it with special tools, as it were, with which to do it.

Once a pair of woodpeckers made a very ridiculous mistake. Some telegraph wires had been put up, and the birds, hearing the humming sound which these wires make when there is a slight breeze, thought that it was caused by insects which were burrowing in the posts. So they set to work to dig them out, and chipped away so diligently that they made a big hole in the post, and very nearly cut their way out at the other side! 


\section{THE CUCKOO (Family CUCULIDE)}

The Cuckoos are a large and widely-distributed family, being found well-nigh everywhere in the world. They have not all the same habits as our own cuckoo, for some build nests and rear their own young; but we may take our familiar visitant as a type of the family.

The oldest of English songs thus begins:-

$$
\begin{aligned}
& \text { "Summer is a-coming in, } \\
& \text { Loud sings Cuckoo". }
\end{aligned}
$$

And to this day one of the first sounds for which we listen in spring is the note of the cuckoo. We never feel that winter has really gone until we hear it. For the cuckoo is a very delicate bird, and flies away over the sea quite early in the autumn, in order to avoid the frost and snow.

It always seems to know, in its warm winter home, when our cold weather is over; and then it comes back again to spend the spring and summer with us.

Another old rhyme tells about the short visit of the cuckoo to this country:-

$$
\begin{aligned}
& \text { "In April } \\
& \text { Come he will. } \\
& \text { In May } \\
& \text { He sings all day. } \\
& \text { In June } \\
& \text { He alters his tune. } \\
& \text { In July } \\
& \text { He prepares to fly. } \\
& \text { In August } \\
& \text { Go he must." }
\end{aligned}
$$

Now this is quite true. The cuckoo always comes to us in April, when the frosty days are over and the trees are putting out their leaves. In May you may hear him calling, "Cuckoo, cuckoo!" from dawn to dusk.

But in June his note alters, and then he cries, "Cuck, cuck, cuck-oo!" instead of "Cuckoo!" as before. In July he is not heard 
at all, for his voice is said to "break", and he sings no longer. In August he takes flight across the sea, and leaves us until the following spring.

One of the strangest facts in the life of the cuckoo is, that it

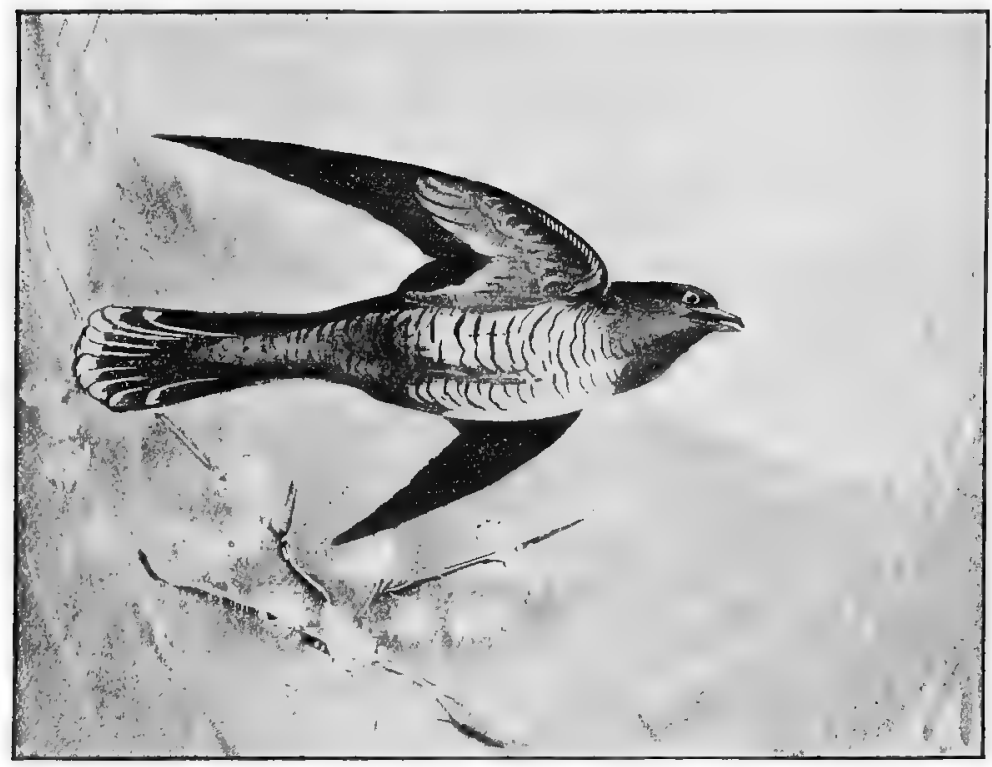

Cuckoo

does not make any nest, but always lays its eggs, one at a time, in the nests of other birds.

The nest of the hedge-sparrow is mostly chosen for this purpose, where the egg of the cuckoo is occasionally found among its four or five pale-blue eggs. It also frequently deposits its egg in the lark's, the meadow pipit's, the water wagtail's, the chaffinch's, and more rarely in the blackbird's nest. Naturalists are still doubtful whether the cuckoo actually lays its egg (for it seldom deposits more than one in any nest) in the other bird's nest, or lays it on the ground first and then places it among the other eggs with its beak or claws. Cuckoo's eggs have been found 
in nests in positions where, it would seem, the birds could only have placed them by the aid of the beak.

The cuckoo's egg is very small for the size of the bird, and so the duped foster-parents have never, so far as is known, been concerned about the strange egg, which is hatched with the rest. All is well till the young cuckoo, which grows very fast, claims most of the attention of the foster birds, and therefore most of the food which they so assiduously bring. Ere long, either by design or by accident, it shoulders the other young birds out of the nest; and then it has usurped the home and the whole attention of the old birds as well. It grows apace, and after about five weeks' board and lodging under these false pretences, flies away, leaving, one would imagine, the devoted foster-parents in a dazed state of mind as to the character and development of their fancied progeny.

If all accounts be true, the young cuckoo seems to exercise some sort of fascination upon other birds, as it is said that before it is fully fledged other birds will sometimes come and feed it; and they have been known to do so even when the young cuckoo was captured and kept in a cage.

It is possible to mistake a flying cuckoo for a hawk, which it very much resembles. Indeed, even the smaller birds sometimes make just the same mistake, and "mob" a cuckoo in the air, just as they mob a sparrow-hawk.

The cuckoo gets the credit in the popular mind of living upon the eggs of other birds. But it does not rob as well as deceive other birds; its food consists of moths, dragon-flies, various beetles, and caterpillars, and the young cuckoos are vegetarians so far as to eat different kinds of berries as well.

\section{HUMMING-BIRDS (Family TROCHILID $A$ )}

Humming-birds have well been termed the "gems of the feathered race". Nearly five hundred different kinds of these tiny creatures have been discovered, and nearly all are remarkable for their exquisite colouring, the beauty of their form, and (M 868) 
the elegance and grace of their movements. They are found only in America and some of the adjacent islands, and are most plentiful in Mexico and the countries bordering upon the equator.

The flight of these little birds is very remarkable. Perhaps we can best describe it by comparing it to that of a certain moth which is not at all uncommon in England, and may be noticed on almost any sunny summer day.

While looking at the blossom of a honeysuckle or geranium, or some other plant, we may have seen hovering in front of it a shadowy form, which vanishes as soon as we move. But if we remain motionless again it reappears, and begins hovering as before. By using very great caution we see that it is a stoutbodied, brownish moth, which, with its long slender trunk extended, is sucking the nectar out of the flowers.

This is a Humming-bird Hawk-moth, so called from its marked resemblance to the beautiful little birds of which we are speaking. So decided is the likeness, indeed, that many a resident in America or the West Indies, on visiting this country, has written to the newspapers to say that he has seen a humming-bird hovering in front of a flower, and has afterwards been quite astonished to find that it was only a moth.

Now humming-birds hover in front of flowers in exactly the same manner as this moth, and for just the same reason: they plunge their long beaks into the blossoms, and suck the nectar which gathers in them. Many of these birds appear to frequent one particular kind of flower only, and have their beaks specially formed to allow them to penetrate into its recesses. Some humming-birds, for example, have long and perfectly straight beaks. The beaks of others are curved upwards; those of others, again, are curved downwards. And there is one humming-bird which visits flowers of a very peculiar shape, and in consequence has a beak with a double curve.

But we must not allow ourselves to think that humming-birds feed entirely upon nectar, for this would be a great mistake. The principal part of their food, indeed, consists of small insects which they find in the very flowers that they visit in quest of nectar; so that these flowers supply them with both food and drink. They 


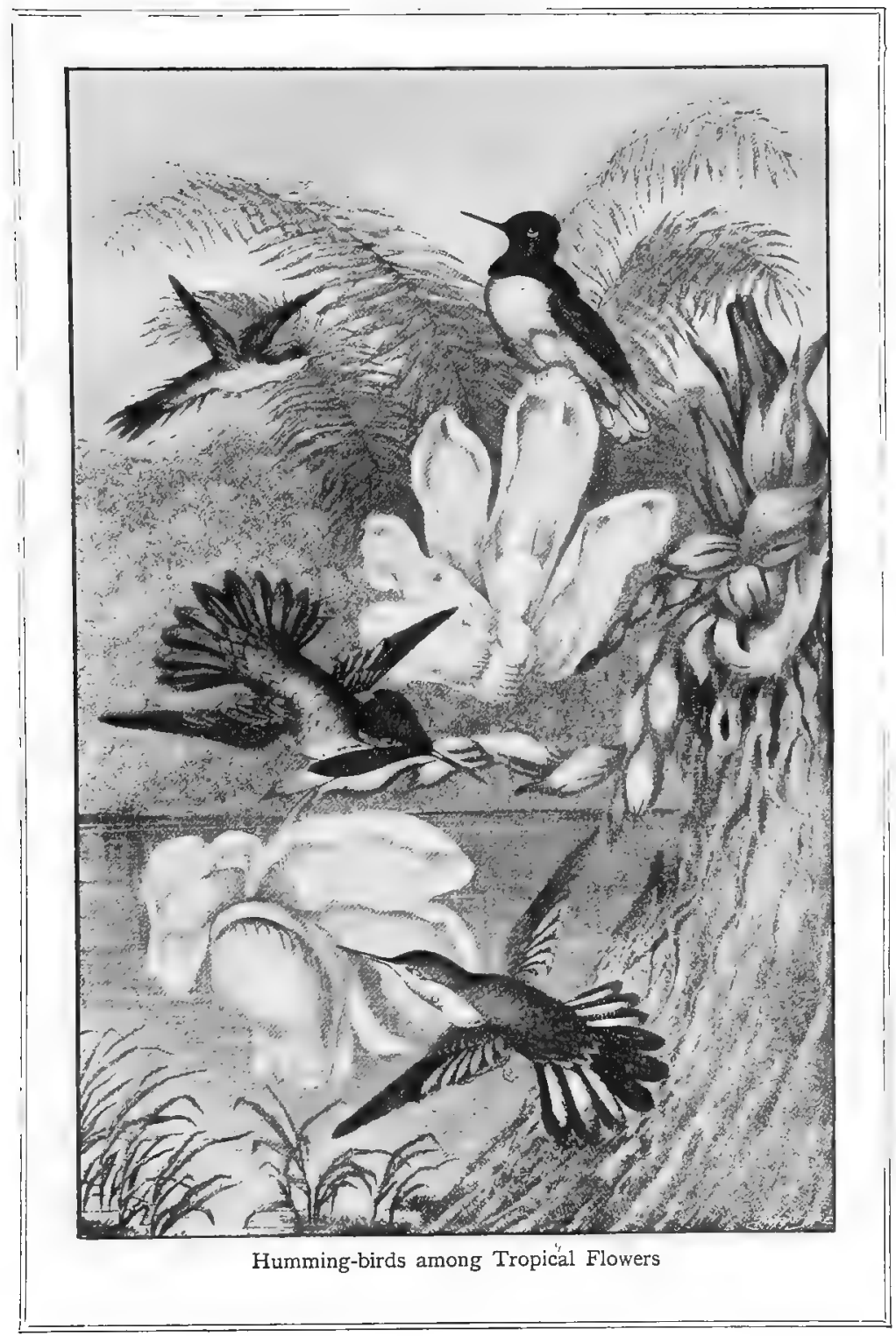


are also fond of small spiders, which they pick out from the centre of their webs. And some humming-birds will poise themselves in front of a leaf or twig, and pick off, one after another, the tiny insects that are feeding upon it.

In order to enable these birds to extract both insects and nectar from flowers, their tongues are very curiously made. Instead of being short, thick, and fleshy, like those of very many birds, they are very long, and so slender as to be almost hair-like, and are double in structure, so that they can be passed far down into the interior of the flower, and can lick out every insect and every particle of nectar that it contains.

As is the case with many birds whose powers of flight are greatly developed, the legs of humming-birds are small and weak. In this respect these birds resemble our own swallows and swifts, which can dash to and fro all day long upon untiring wing, but cannot walk, or even stand, upon the ground without difficulty. But a humming-bird seldom perches except at night, and then not upon the ground, so that its marvellous powers of flight more than compensate for the weakness of its limbs.

These birds are called "humming"-birds because of the humming or buzzing sound which is made by the rapid vibration of their wings as they hover in front of a flower. We may hear a similar sound when watching one of the humming-bird hawk-moths, of which we have already spoken.

Travellers tell us that different kinds of these birds produce different sounds, and that it is often possible to detect the species to which a humming-bird belongs by simply listening to the buzzing of its wings. One bird is said to produce a sound just like that of a blue-bottle fly, while the hum of another is compared to the whizzing of a wheel driven by machinery.

\section{THE NIGHTJAR (Family CAPRIMULGIDE)}

On a warm summer evening, when the air is still, you may hear a very strange and curious sound. It is not at all easy to describe, but is something like the whirring of a wheel in rapid motion, or 
like the sound of the word "churr", with the last two letters very much rolled out.

This sound may continue without a break for several minutes at a time, and you wonder what it can possibly be. It may seem to proceed from a clump of trees at a little distance, up to which you walk, when you may see an oddly-shaped bird, with a large

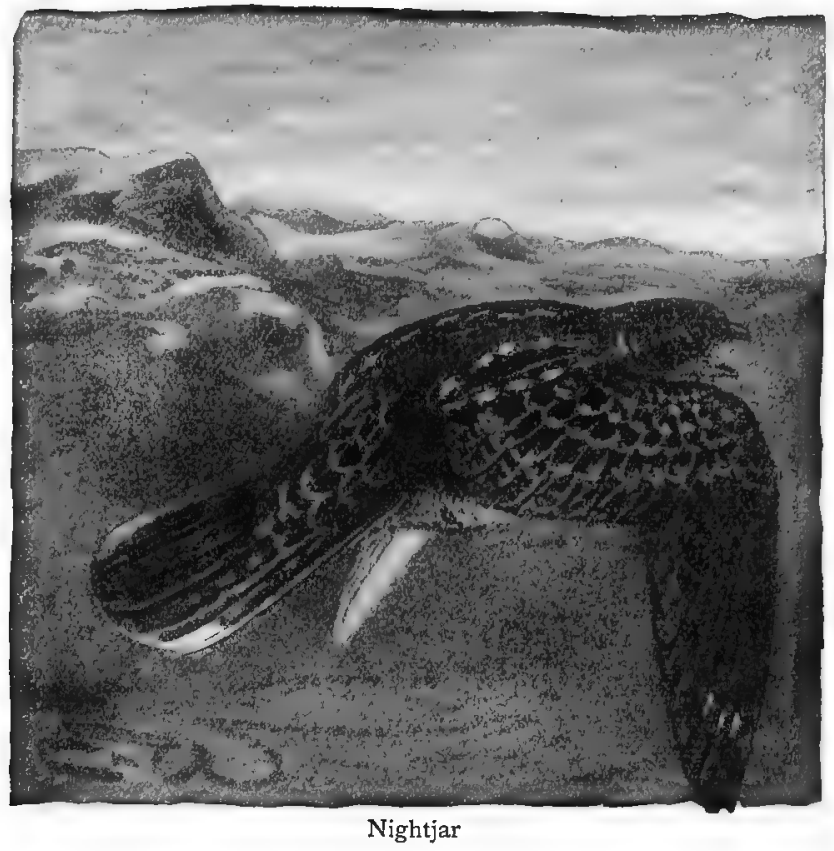

round head and hardly any neck, sitting along a branch, instead of across it.

This is a Nightjar, one of the most singular birds in this country. Sometimes it is called the goatsucker, because people used to think that it sucked the milk of goats. But this is a pure fable, for it lives on insects; and, so far from being mischievous, is really a very useful bird.

It is quite true that a nightjar has been seen leaping up towards the udders of cows, as though it were trying to steal milk from 
them. But it is really catching flies, which annoy cattle by night as well as by day, so that it is performing a useful act, and not a mischievous one.

In another way, too, it is of great service. In the early summer you may have seen a great number of yellowish-brown, hairy beetles flying round the tops of small trees at dusk. At times they are in such numbers that they look like a swarm of bees; and if you catch one you find that it is not unlike a small cockchafer.

It not only looks like a cockchafer, but is quite as mischievous; for the fat white grub which produces this beetle lives for three long years under the ground, and eats the roots of our crops. Now the nightjar is very fond of this beetle, and destroys it in great numbers, besides killing many other insects which are troublesome in our fields. So it is a very good friend to us, and we ought to protect it, instead of trying to destroy it.

In order to enable it to catch these large insects, the beak of the nightjar is formed in a very singular way. It is so very wide that when the bird opens it its head seems almost to be divided in two. Then its tongue is very sticky, like that of the toad and the frog, so that, if an insect once touches it, it is actually caught.

Besides this, at either side of the beak are a number of stout bristles, which make a kind of fence, and quite prevent a prisoner from passing through them. Thus even a large strong beetle like the cockchafer, when once it is seized by the nightjar, has no chance of escaping.

The nightjar does not make a nest like most birds, but lays two white eggs, mottled with brown, on the bare ground, underneath a bush or a clump of ferns. It does not stay in this country all through the year, for it cannot find any food during our cold winter. Early in autumn, therefore, it flies away over the sea to a warmer country, and does not come back again until late in the following spring.

\section{THE KINGFISHER (Family ALCEDINID e)}

To see a Kingfisher in his native haunt and engaged in his daily fishing is a sight not easily forgotten. He flits rapidly hither 


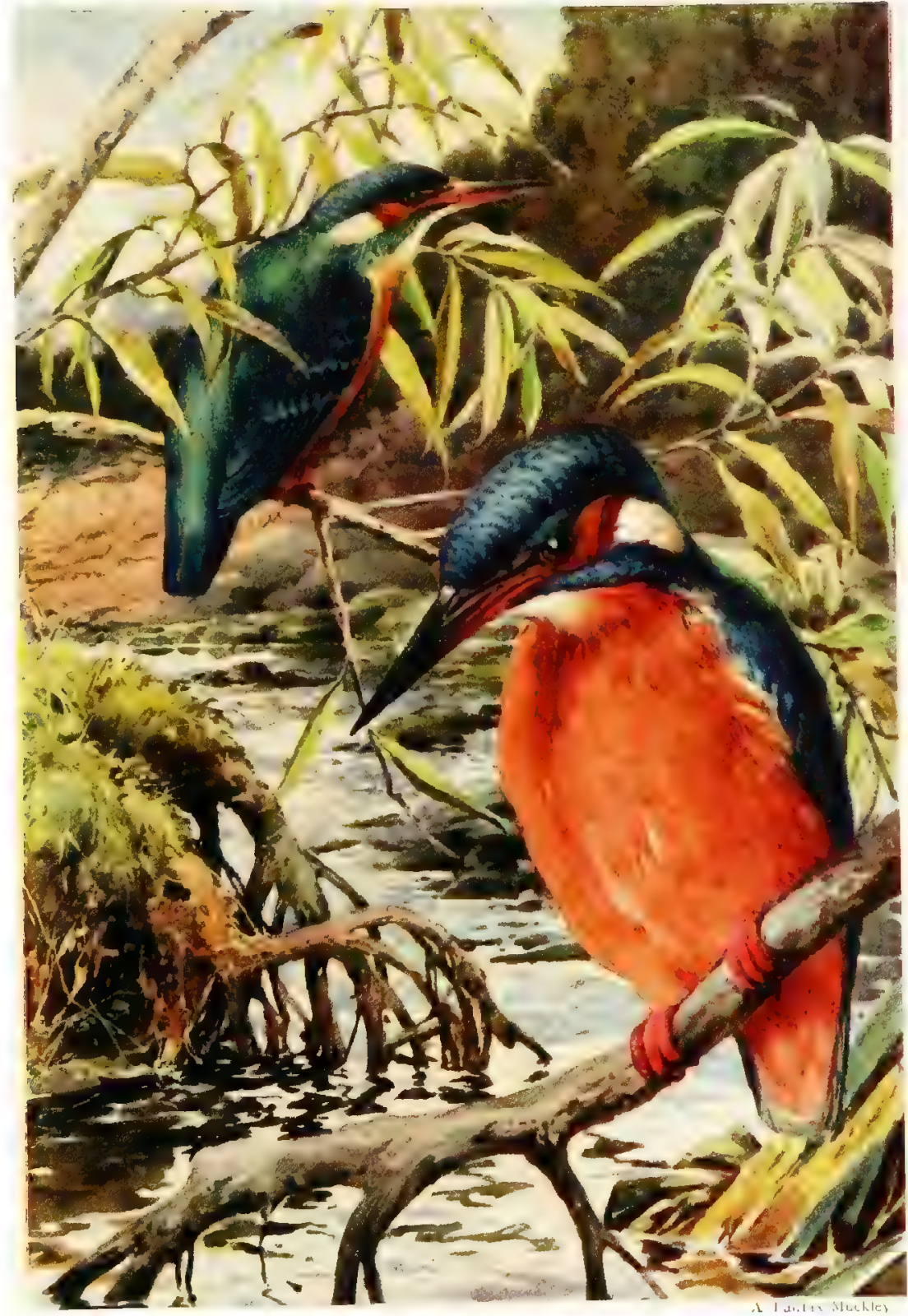

KINGFISHERS 

and thither like a living gem or a flash of greeny-blue light. If we are fortunate we may see him select a perch-always over a running stream,- and in the sunlight he is perfectly gorgeous. But ere

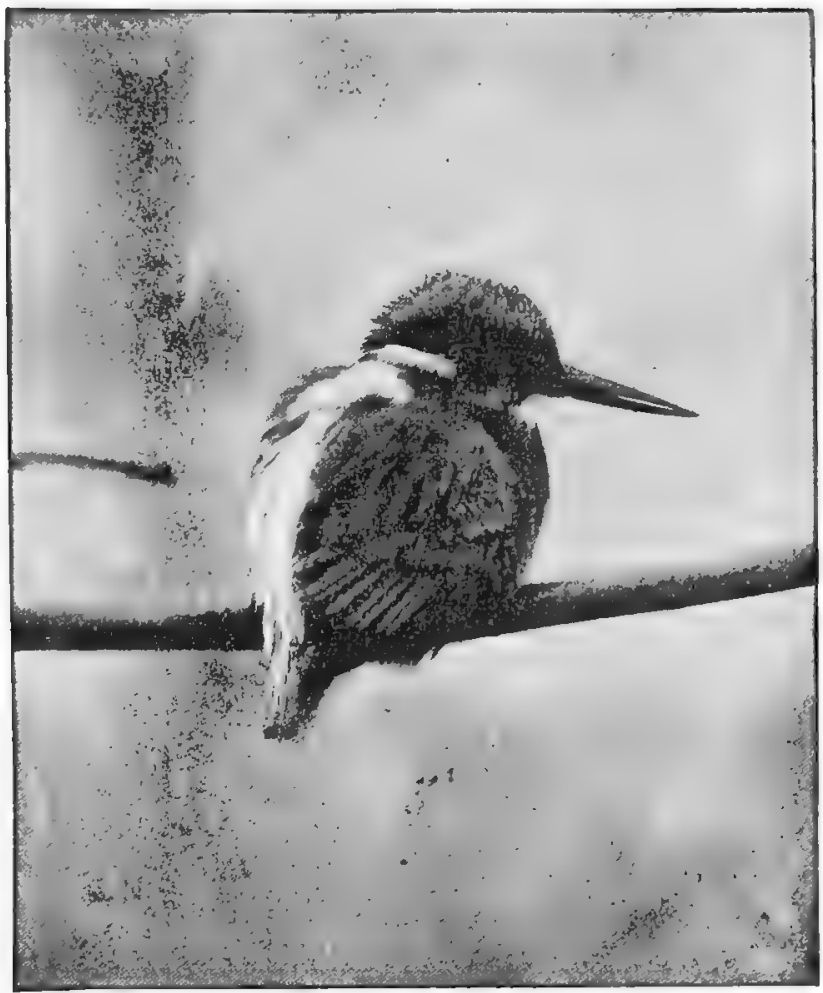

Kingfisher

we have realized his beauty he has shot down into the water, risen again with a fish in his mouth, and is out of our sight-a vision of a beautiful being, as wonderful in its activity as in its brilliant adornings. The first sight of a kingfisher is a revelation of how exquisite in its motion and power and glory of colour a living creature in its own wild life may be. 
He has gone off to his nest, no doubt, to feed his hungry little ones. But he is sure to be back in a few minutes, and we shall again see him select his perch, watch for and obtain fresh victims.

What a very beautiful bird he is! We cannot see him well as he flies past; but while he is perched we have just time to realize and to admire his bright plumage.

The feathers on his head and the upper part of his back are rich, dark green, sometimes tipped with light blue. The lower part of his back is a light violet, which glitters in the sunshine; his tail is deep blue, and his throat and chin are white; while the under part of his body is of a pretty chestnut-brown. His eyes are crimson, and his long bill is black. A white streak passes from each eye to the back of his neck.

The kingfisher does not build in a bush or in a tree, like so many other birds, but always makes his nest in a hole in a bank, usually quite close to the water's edge. He generally chooses the burrow of the water-rat for this purpose, and scoops out a chamber at the end sufficiently large to hold the nest.

The nest is a very wonderful thing. It is built, not of sticks, nor grass, nor hay; not of dead leaves, wool, moss, nor feathers, but of fish-bones. For the kingfisher cannot digest the bones of the fishes which he captures, any more than can the owl the bones of its mice. So he passes them back through his mouth, collects them together, and makes his nest of them.

The kingfisher is a very rapacious bird, and his appetite is seldom satisfied; but every now and then he contrives to catch more fish than he can eat at the time. In such cases he searches for a crevice in the bank of the stream, or for a convenient nook among the roots of a tree. This he turns into a larder, into which he puts his victims as fast as he catches them, and comes back somewhat later in order to eat them.

Sometimes he catches quite large fishes, and finds no little difficulty in getting them out of the water. $\mathrm{He}$ is said to carry these to the nearest stone, and strike their heads against it until they are dead. 


\section{PSITTACI}

The Parrots as a group of birds are much more satisfactory than most of the feathered natural orders, because it is not easy to misplace any of the tribe. The group is a very large one, as at least five hundred species of true parrots are known. It also inciudes the families of the Macaws, the Love-Birds, the Lories, the Cockatoos, and others.

\section{THE PARROT (Family NESTORIDÆ)}

The Parrot is a well-known bird, and many readers will no doubt have heard one speak and whistle airs. It is easily tamed, and its extraordinary capacity for picking up and mimicking the sounds it hears never fails to make it a great favourite. It has a wonderful memory, and may be taught to repeat words or sentences or even to whistle a tune.

If you watch a parrot in its cage you will notice that it climbs about from point to point with its claws and its strangely-curved beak. This will give you an idea of its habits in its wild state. It lives chiefly on fruits, and its ability to climb enables it to get into the necessary positions for securing its food. When feeding, flocks of parrots gather on the trees, clambering about as you see tame ones in their cages, and chattering noisily.

The parrot builds generally in a hole in a tree, and lays two or three white eggs. When the young are newly hatched, the parents give them food which they have previously softened in their own crops, just as you may have seen pigeons doing at home.

The parrot is beautifully coloured. Some species are bright green, some gray touched with red, some white. Indeed there are as many different varieties of colour as there are species, and as they fly about in flocks in the bright sun of the tropical countries where they live they present a very wonderful sight. They move through the air quickly and gracefully, but as they fly they utter shrill screams. If you go into the parrot house at the Zoo you 
will get a good idea of the noise they make, and you will then no doubt wonder how it is that they can be taught to whistle so sweetly.

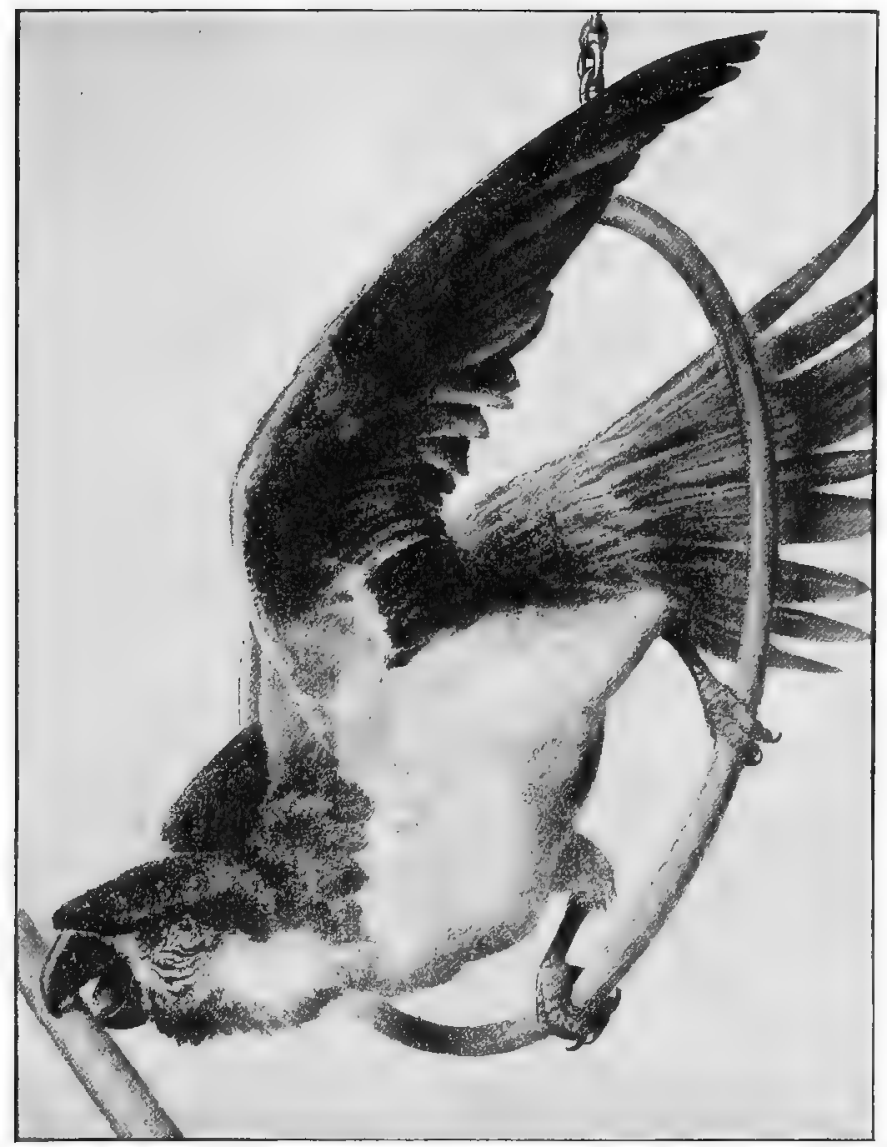

Parrot

The parrot is found in largest numbers in the forests of South America and Australia, where fruits and nuts are most plentiful; it also abounds in India and Africa. Though it is not found in Europe in its wild state, it is well known as a cage-bird. It thrives 
in captivity, and often lives to a great age under what must be very unnatural conditions.

\section{STRIGES}

Owls are to be found the wide world over. But as their habits are almost without exception nocturnal - that is to say, as they are abroad by night and hidden away by day-they are not readily seen. About 200 species are known, but they are so much alike that our Common Barn-owl is a very good type of the group.

\section{THE BARN-OWL}

Asleep all day and awake all night, the barn-owl is a strange bird, as well as a very useful one. In some respects it is like the kestrel. It has the same strong sharp talons, and the same way of killing its prey. And, like the kestrel, it feeds chiefly on mice. It is, indeed, a kind of night-hazw, and is just as useful after sunset as the kestrel is during the day.

If we think it wonderful of the kestrel hawk that it should see a mouse from high up in the air in the daytime, what are we to think of the owl, which does the same even after the sun has set, and it is what we call dark? Many animals, such as cats, foxes, and stoats, hunt for their prey at night. So do the different species of field mice; they hunt for sleeping butterflies and moths and beetles, as well as for corn and seeds; but while they are hunting, they are hunted in turn, for the owls are out flitting about with their noiseless wings, and many a prowling mouse and sleeping sparrow is pounced upon, and either swallowed whole, there and then, or taken to feed the young in the owl's nest.

That owls and other animals, such as the cat, can see at night may perhaps astonish us; but their eyes are so constructed as to catch even the faintest rays of light. And as they are so very sensitive to light, they actually suffer when it is very bright. The 
irises in the eyes of such animals almost close when the light is strong, as we must have seen in those of the cat. But when there

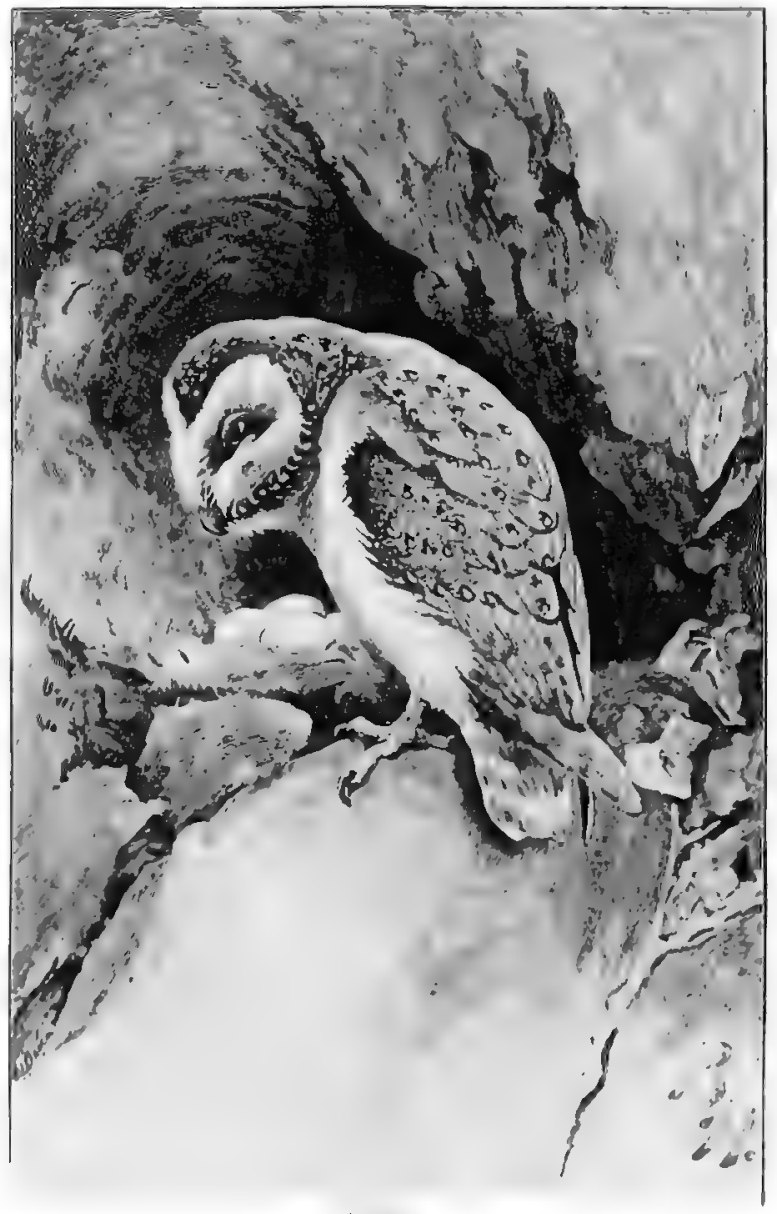

Barn-owl and Nest

is little light the iris opens very wide, so that all rays freely enter the eye. 
But neither cats nor owls could see in the dark: that is to say if it were actually dark. No night, however, is ever perfectly. dark, and most nights, but not all, are sufficiently light for owls to see their prey.

Like the other Raptores or "seizers" the owl catches its prey in its talons, and probably with one squeeze ends its little life. But it does not, as most of that group of birds do, tear the mouse or small bird to pieces in eating it, it swallows it whole, and as it cannot digest the bones and fur or feathers, these are expelled again through the mouth in the form of balls or pellets. As many of these balls as would fill a bushel measure have been found near the dwelling-place of a pair of owis.

The owl is the only British bird that feeds at night. But inasmuch as it kills mice and other small animals, and even young rats, it is particularly useful to farmers, who encourage its residence in or near their farms.

Even the barn-owl can be brave on occasion. It will defend itself from the attacks of a much larger animal than itself. In its defence it throws itself on to its back, and fights with its talons. A poor dog, which was merely inquisitive in approaching an owl, lost both its eyes before it could realize that there was any danger in the talons of such a creature.

The owl makes no real nest, but lays and hatches its eggs in a hollow tree or in some hole in a barn roof, where it will remain all day, and will arouse itself to action when all the other birds have retired for the night.

\section{ACCIPITRES}

While the great group of Owls may be described as the nocturnal or night birds of prey, the greater tribe of Falcons, Hawks, Kites, Buzzards, Eagles, and Vultures may be designated the diurnal or day birds of prey.

This great group is known by the name of Accipitres. 
All these birds are nearly related to the Owls, their connecting link being the Ospreys, one species of which was formerly common in Scotland and in some parts of England, but is there now almost exterminated.

The whole of the Accipitres come under the general name of "Hawks" as their name implies-accipiter, a hawk, from accipeo, to take by force. They are all birds that take their prey by force. The terms falcons, kites, eagles, \&c., are family and sub-family names for smaller groups of the great hawk tribe.

\section{THE KESTREL HAWK (Family FALCONIDE)}

This bird may be taken as a good type of the Falcons, which is the first family in the order Accipitres, although it is not one of the actual family of the Falconidx, but of a sub-family, the Falconinx.

Some of us have possibly seen a fairly large bird suspended motionless, that is "hovering", in the air. This is the Kestrel Hawk seeking its prey, which is mainly mice. It will remain apparently motionless for several minutes, and if it sees no mouse, with a whirl of its wings it takes up another position, watching the earth below while it hovers as before. Now it sees a likely victim, drops down from its great height like a stone, the poor little mouse is caught in its powerful talons, which close with a terrible grip, and the mouse has breathed its last.

All the great hawk family have wonderful sight, which is well exemplified in this "kestrel", for it sees its victim from such a great height that were we placed in a similar position we should probably be unable to distinguish a much greater animal than a mouse in the grass and herbage below. It is said to catch even beetles as they fly in the air; and to snatch from water, with its claws, a fish or a newt upon which it has swooped down from its watching-place in the air.

These birds of prey-hawks, owls, eagles, and vultures-all possess powerful hooked beaks. Yet these beaks are seldom used in the act of killing; the equally powerful claws are sufficient, and are used for that purpose. 
There is a reason for this, for the bird's eyes would be in the greatest danger every time a victim was approached were the beaks used in the attack; and further, the bird would lose the advantage of fully seeing its victim. So it is more natural for birds of prey to kill with their talons than with their beaks. Their beaks are hooked for the purpose of rending their victims when they are killed.

The kestrel prefers mice to any other food, and is so quick in catching sight of them, and so clever in seizing them, that every day it kills a

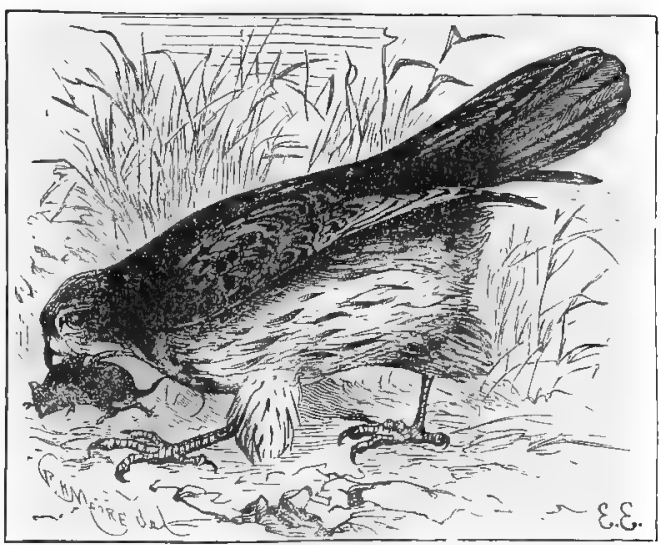

Kestrel with Mouse great many.

The bird is, therefore, a very good friend to the farmer, who would lose his corn if the mice were not destroyed. Of all our British birds there is scarcely one which is more valuable than the kestrel. It has been calculated that every kestrel, during the ten months of the year which it spends in England, destroys the enormous number of ten thousand mice!

\section{THE EAGLE (Sub-family AQUILINæ)}

From the Kestrels we pass naturally to the Eagle family, the Aquilinæ, which includes the Honey-buzzards, Kites, Eagles proper, and certain of the Hawks and Harriers, with some less well-known genera.

The eagle is sometimes called the King of Birds, just as the lion is called the King of Beasts. And, in fact, the eagle among birds is very much what the lion is among mammals. It is a 
creature of prey, for instance, and always prefers to catch and kill victims for itself; and it kills them with its long, sharp claws, or "talons". The beak is employed to tear the flesh of the victims after they are dead. The talons alone are used in the killing.

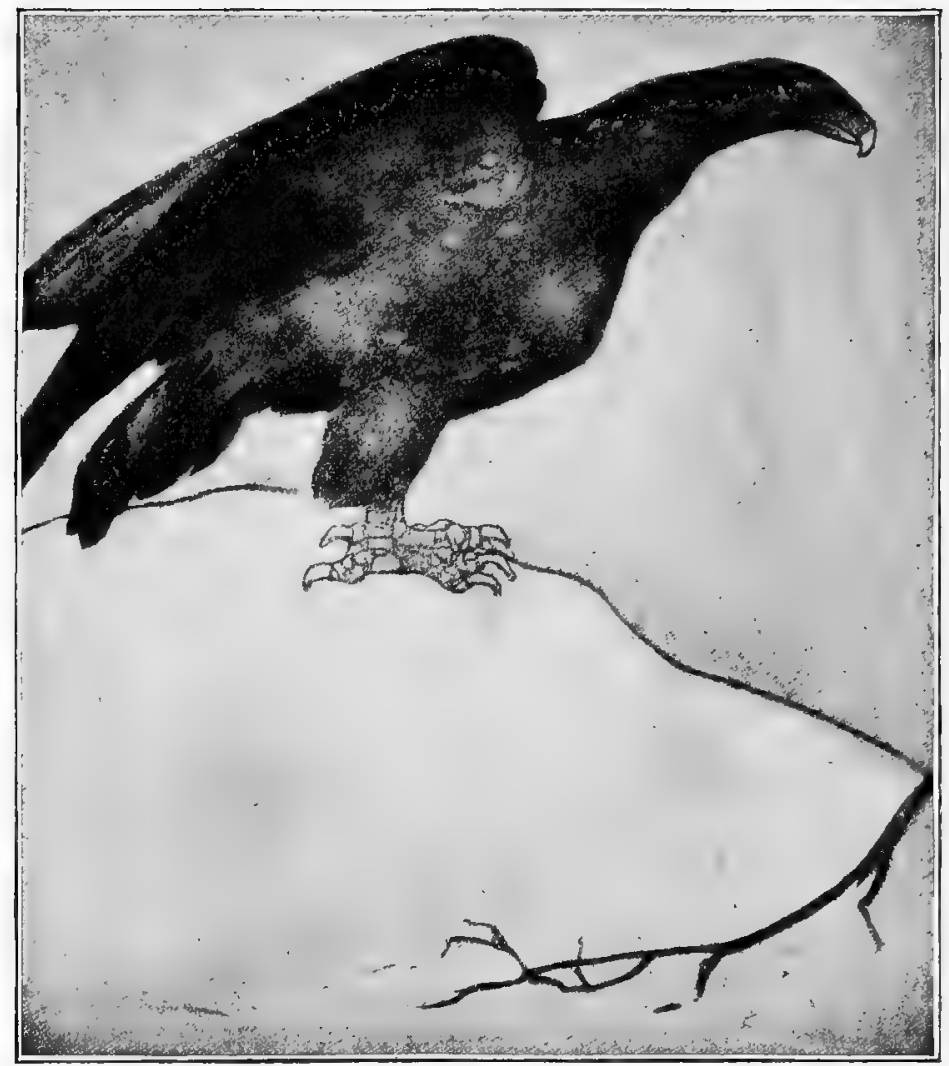

Eagle

Many years ago eagles were plentiful in many parts of Great Britain. But they did so much mischief to flocks and to game that it was found necessary to destroy them; and now they are hardly ever to be seen except in the wilder parts of Scotland. 
The eagle's nest, which is sometimes as much as nine feet high, is called an "eyrie", and is nearly always placed very far up on the side of a steep cliff or rock, where nobody is likely to be able to get at it. It is always made of sticks, which the eagle heaps loosely together upon a ledge of rock.

The young eaglets are very hungry little creatures. All day long they are clamouring for food; and you may see the parent birds constantly engaged in satisfying their wants. Now a plump hare is brought home, and now a rabbit. Or a partridge or a grouse will be divided among the occupants of the nest. Or even a lamb will be carried away from a flock. No wonder that the gamekeeper and the shepherd do not like to see an eagle near their charges.

Eagles were of old occasionally known to carry off children. Once an eagle snatched up a little baby, which had been wrapped in a shawl by its mother and laid down to sleep in a corner of the harvest field, while she was at work, and carried it off to its eyrie.

In her despair the mother ran to the foot of the cliff on which the eyrie was built, and climbed up it, although it was so steep that not even a man had ever succeeded in scaling it before. In the nest she found her child alive and unhurt; for the shawl in which it was wrapped had prevented the eagle's claws from hurting it. Catching it up in her arms, the brave woman began to descend the cliff, and succeeded in reaching the ground in safety.

\section{VULTURES (Family VULTURIDÆ)}

The Vultures are the last great family of the order Accipitres.

In many respects they are very much like eagles. They have the same broad and mighty wings, the same powerful talons, and the same strong and sharply-hooked beak. But the shape of the beak is not quite the same, the middle toe is much longer than the others, and the feathery fringe that eagles have over the eye is wanting.

These are differences of structure; but there are also differences of habit, the chief of which is that vultures seldom kill their own (M 868 ) 
prey, as eagles do, but prefer to feed upon the carcasses of animals which they find lying dead.

How the birds discover these carcasses it is not at all easy to say. For a great many years naturalists thought that their powers of scent were so keen that they could detect the odour of putrefying flesh at a very great distance, and so were attracted to the spot where their repulsive banquet was lying. But then it was found that if the body of a dead animal were covered over, so that it could be smelt without being seen, the vultures would fly past it over and over again without discovering it. On one occasion a vulture actually perched upon the carcass of a horse which had been covered with sacking, and never found out that the material for a hearty mcal was lying beneath its feet. So it seems very certain that vultures do not find their food by means of their powers of scent.

They have doubtless very sharp eyes, like all birds of prey. But then they will come to a carcass from miles away, when it must be completely hidden from their sight. In the Crimean war, for instance, vultures were attracted to the battle-fields from a distance of hundreds of miles. So it would seem that they do not find their food by their sense of sight alone.

The real explanation of the mystery seems to be this. A vulture, when he is looking for food, always rises to a great height in the air-so high, indeed, that, great bird though he is, he looks but the merest speck-and there he hovers motionless, just as a kestrel does in our own country. Now, while he is thus poised aloft, he not only scans every yard of the country beneath him, but also probably keeps a careful watch upon every other vulture within sight. If one or other of these swoops down to the ground, the presence of food is suggested, and he flies off to partake of the feast. Other vultures have observed lim ; and they naturally follow. Others follow in their turn; and so before very long quite a number of the great birds have collected together, all pushing and jostling one another in order to obtain a share of the feast.

Knowing how quickly these birds are attracted by the carcass of a dead animal, the natives of Africa sometimes trap them in a very ingenious manner. 
Having killed a buffalo, a rhinoceros, or an elephant, they open the body and take out the contents (viscera). A young Kaffir lad then creeps inside the carcass and pulls the skin together, so

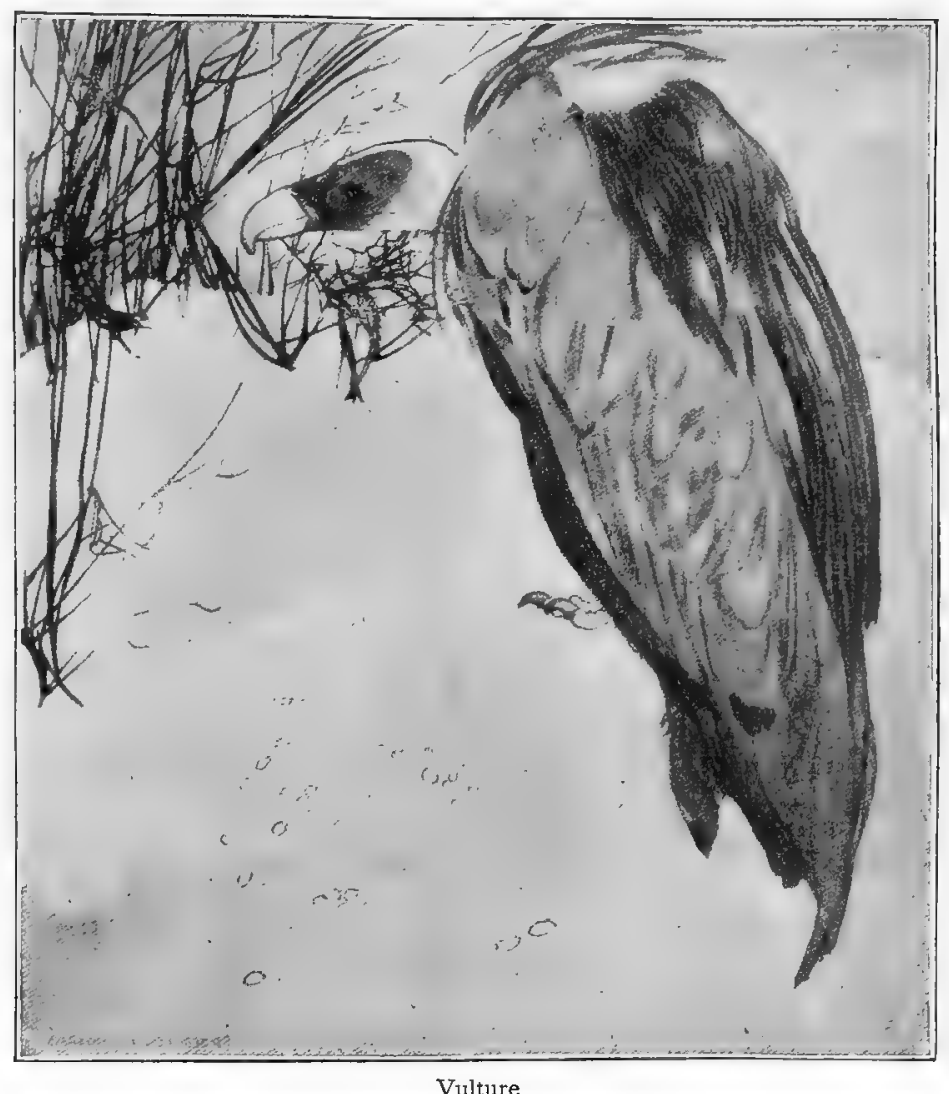

as to leave only a small aperture. Before long the vultures detect the carcass, wing their way to the spot, and settle upon it. The Kaffir watches his opportunity, thrusts out his arm, seizes one of the birds by the legs, and jerks him inside. Almost before the bird knows what has happened to him his wings and legs are 
firmly bound, his beak is tied up, and he is packed away in a corner. Then another bird is captured and treated in the same way, and so on until a sufficient number has been obtained.

Although vultures can go for a long time without food they have enormous appetites, and, having found the body of an animal, will go on eating until they cannot swallow any more. To such an extent do they gorge themselves that, when their disgusting meal is over, they are often quite unable to fly.

In Egypt vultures are protected by law and no one is allowed to interfere with them. This is very sensible, for they are most useful in the towns and villages in devouring the offal which is thrown out from the houses, and so preventing it from decaying and poisoning the air. They also destroy numbers of rats and mice and so are of great service to the farmers.

\section{HERODIONES}

Passing by the Cormorants-Order STEGANOPODES-which in some ways are connected with the Eagles and Falcons, and which include the Cormorants proper, the Darters, Gannets, Frigate- and Tropic-birds, we come to the group of Herons, Storks, and Ibises.

\section{THE HERONS (Family ARDEIDE)}

The Heron family include the Herons proper and the Bitterns. Some seventy species are known, and their range is almost worldwide. They are mostly sub-tropical, and their chief homes are semi-marshy tracts.

Some of us, when in the early morning or in the evening we have strolled beside a river or lake, have probably seen a large, long-legged bird, standing motionless in the water, which, as soon as it catches sight of us, stretches out its long neck, rises into the air, and flies swiftly away, with its long limbs spread out behind it, and in a few minutes is out of sight. 
This is a heron, one of the largest birds now found wild in England. In olden days it was very plentiful, and was hunted by means of falcons, being "preserved" for the chase very much as game birds are preserved now. But when the fens and marshes were drained it became much less abundant, and in most inland districts is now but seldom seen.

Several "heronries", however, still exist, and in one of these, which is situated only a few miles from London, between thirty

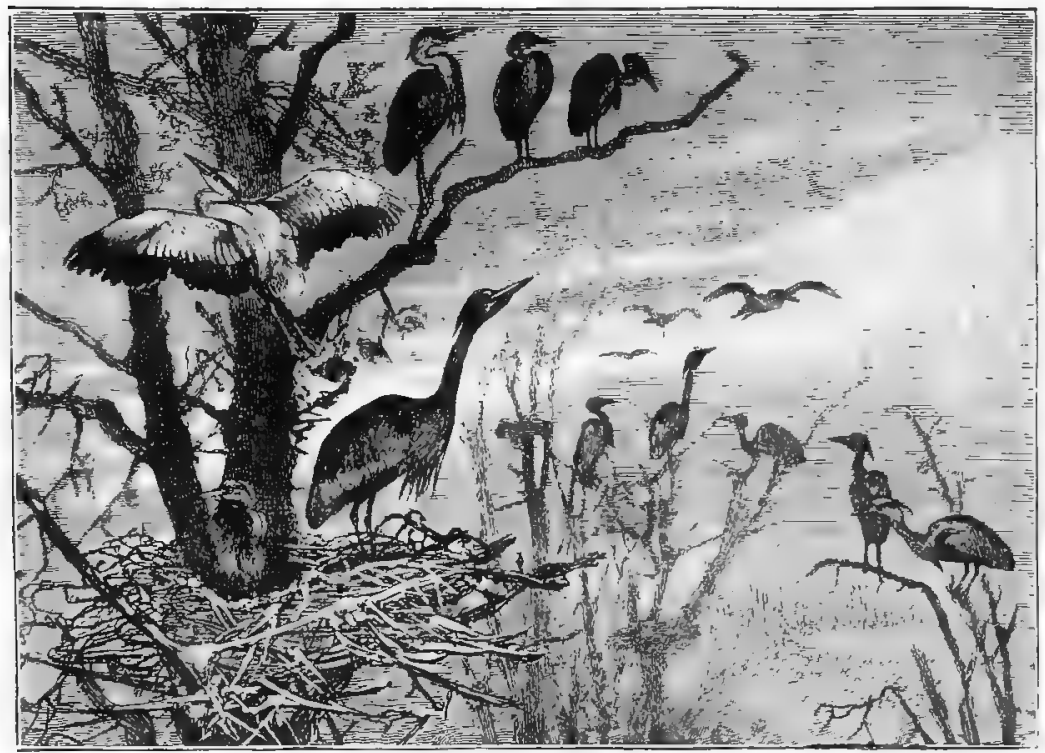

Herons and Nests

and forty pairs of these great birds breed every year. They travel for long distances in search of food, and may be seen flying homewards towards evening many miles away from their nesting-place. On our wilder coasts they are not at all uncommon, and at low water may often be noticed standing in the pools which the retreating tide has left among the rocks, keeping diligent watch for any fish that may come sufficiently near. When the heron is watching for prey it generally stands upon one leg only, the other 
being drawn closely up underneath its body, while the head is sunk between the shoulders.

When a fish is captured by a heron, it is usually swallowed immediately. An eel, however, wriggles and twists about so much that the bird is obliged to take it out of the water, and to beat it upon the ground until it is dead. Frogs, toads, and newts are also devoured in great numbers by these birds, which have even been known to swallow water-rats, after first killing them by a sharp squeeze across the head or neck.

Even to larger animals a heron is a formidable antagonist, for its beak is both long and exceedingly sharp, and is directed with wonderful accuracy of aim. The bird always seems to strike first at the eye of its adversary, apparently knowing that when it is blinded it can be much more easily despatched.

Herons have been known to unite together in order to attack a foe. A very remarkable battle of this kind was once witnessed near London. A pair of swans were swimming on an artificial lake, when seven herons flew down and began to attack them. For some little time it seemed that the fierce blows which the assailants delivered with their long beaks would ensure for them the victory; but the swans defended themselves gallantly with their wings, until the herons were wearied out and flew away.

Herons nest in company, as a rule, selecting for the purpose a copse of very tall trees. They are by no means accomplished builders, for all that they attempt to do is to make a platform of sticks about a yard across, with just sufficient depression in the middle to prevent the eggs from rolling out when the trees are swayed by the wind. The same nests are used year after year, any necessary repairs being made in the early spring just before the eggs are laid.

The eggs are four or five in number, and are pale-green in hue, like those of a duck. It is sometimes thought that, when the bird is sitting upon them, its long legs must hang down upon either side of the nest. This, however, is not the case. When a heron sits it draws its legs under its body, by bending them at the joint which we wrongly term the "knee", and which is, in reality, the 
ankle. Thus it can sit upon its eggs just as comfortably as any other bird.

The heron measures about three feet in length from the point of the beak to the end of the tail, while the wings, when spread, are four feet and a half from tip to tip. From the back of the head projects a crest of elongated feathers, the colour of which is a beautiful slaty blue.

\section{THE STORK (Family CICONIDA)}

The Stork forms the second family in the Herodiones. It is a European bird, and one species is occasionally a visitor in England. It extends to Turkey, Persia, and Central Asia, and spends its winter (or some species do) in Northern Africa.

The Ibises and Spoon-bills close the Herodiones, and then we come to several Orders in which are some familiar forms.

In some parts of Europe it is quite common to see a large pile of sticks on the top of a house or a chimney. This is the nest of the stork. The people in those countries think so much of this bird that they even put boxes, old wheels, and so forth, on their chimneys and other parts of their houses to induce it to build there. The stork returns to the same nest year after year, and the people welcome it as we do the swallows in this country. It builds its nest of sticks, and, as it adds something to it every year, the bundle gradually gets larger and larger.

The stork is a large bird, standing more than three feet high. In colour it is pure white, with the exception of the wings, which are black, and the long, straight bill, and the legs, which are red.

This bird feeds upon small animals, such as frogs, lizards, insects, \&c.; and its flesh is not edible, so there is no reason for killing it. In fact, in Egypt it is looked upon as a sacred bird, and none of the natives will destroy it.

The eggs of the stork are large and white. When the young are hatched the parents are very attentive to them, and will risk their own lives to preserve those of their offspring. There is a 
story of the noble action of a stork whose nest was on a house which caught fire. The bird did everything in her power to save her young, but when she found she could not carry them off she

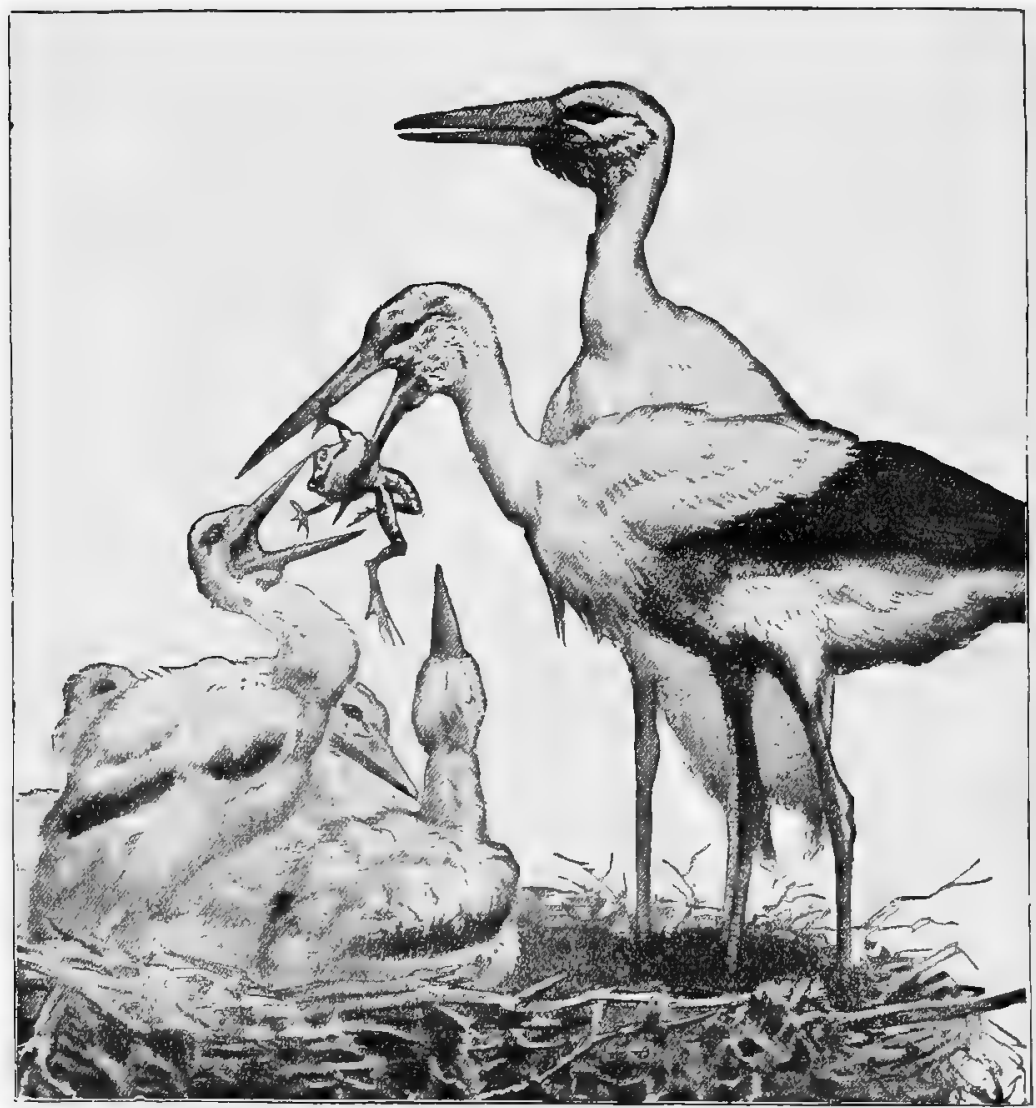

Family of Storks

remained and died with them. Storks, too, when once paired, seldom separate except during the migratory season. They nest together year after year in the same place.

The stork has no natural and particular cry like most other 
birds. But instead it makes a loud clicking noise with its bill, which may be heard at a great distance, even when it is flying high in the air and out of sight. It is a bird which very seldom visits this country. But during the summer it is to be found in most parts of Europe except where it is very cold. In winter it flies away to the south, and visits Egypt in very large numbers.

\section{ODONTOGLOSS $Æ$}

We should at first sight certainly be inclined to place the Flamingoes with the Herons, and Storks, and Ibises, but in reality they are more nearly related to the Ducks and Geese. So they are grouped into a family by themselves.

\section{FLAMINGOES}

Let us suppose that we stand upon the borders of one of the great swamps of Northern Africa. It is not a very attractive spot, neither is it a very healthy one; for if we remain there long we should certainly fall victims to fever and ague. But for a few weeks in every year there is a most remarkable sight to be witnessed there.

The swamp is a great sheet of shallow water, stretching away as far as the eye can see. There is not much vegetation, for the water is salt. No trees, no bushes, no reed-beds or banks of rushes; nothing but here and there a thin patch of some strange plant which thrives in the brackish water. But what is that thin crimson line in the distance?

That is just what we have come to see. If we go a little nearer we shall find that it consists of nothing but thousands upon thousands of great rosy-red birds from five to six feet high. What long, stilt-like legs they have! How slender and flexible their long 
necks are, and how they twist and turn them about! Now they have caught sight of us, and are rising into the air.

These are Flamingoes, and those earthen hillocks on which many of them seem to have been resting are their nests. Let us wait quietly until they settle down again, and then learn what we can of their habits. Seeing that we do not move, or attempt to interfere with them, they soon begin to descend, and in a few minutes are wading about as before. Their long legs enable them to walk where they will, for the water is not deep. Some of them seem to be looking about for food.

But why is one bird at each end of the line standing quite still, and not moving about like the rest? And why do so many of them plunge their heads down into the water, and appear to be splashing about in the mud at the bottom?

These questions are easily answered. The solitary bird at either end of the long line is a sentinel, who is keeping a careful watch for the approach of danger. If he notices any sign of an enemy, he will at once alarm the rest of the flock, and all the birds will fly away.

Those who have their heads plunged beneath the water are engaged in feeding. Their beaks are formed like that of the duck, with a number of small channels upon either side. When they have taken a beakful of mud and water, these channels act as a filter, allowing the mud to be washed out, while all the tiny creatures that were living in it are retained and swallowed. While a flamingo is thus engaged, its head is thrust between its legs and is therefore upside down, so that the upper mandible can scoop up the mud.

Standing among the rest are some flamingoes that are busy, not in feeding, but in preening their plumage. So flexible are their necks, that the beak can reach to any part of the body. The long legs, too, are more under control than we should have imagined, for here is a bird scratching its head with its claws, as easily as if it were a robin or a sparrow.

The nests are little mounds of mud and earth standing about eighteen inches above the level of the surrounding water, with a shallow depression at the top to contain the eggs. When the 


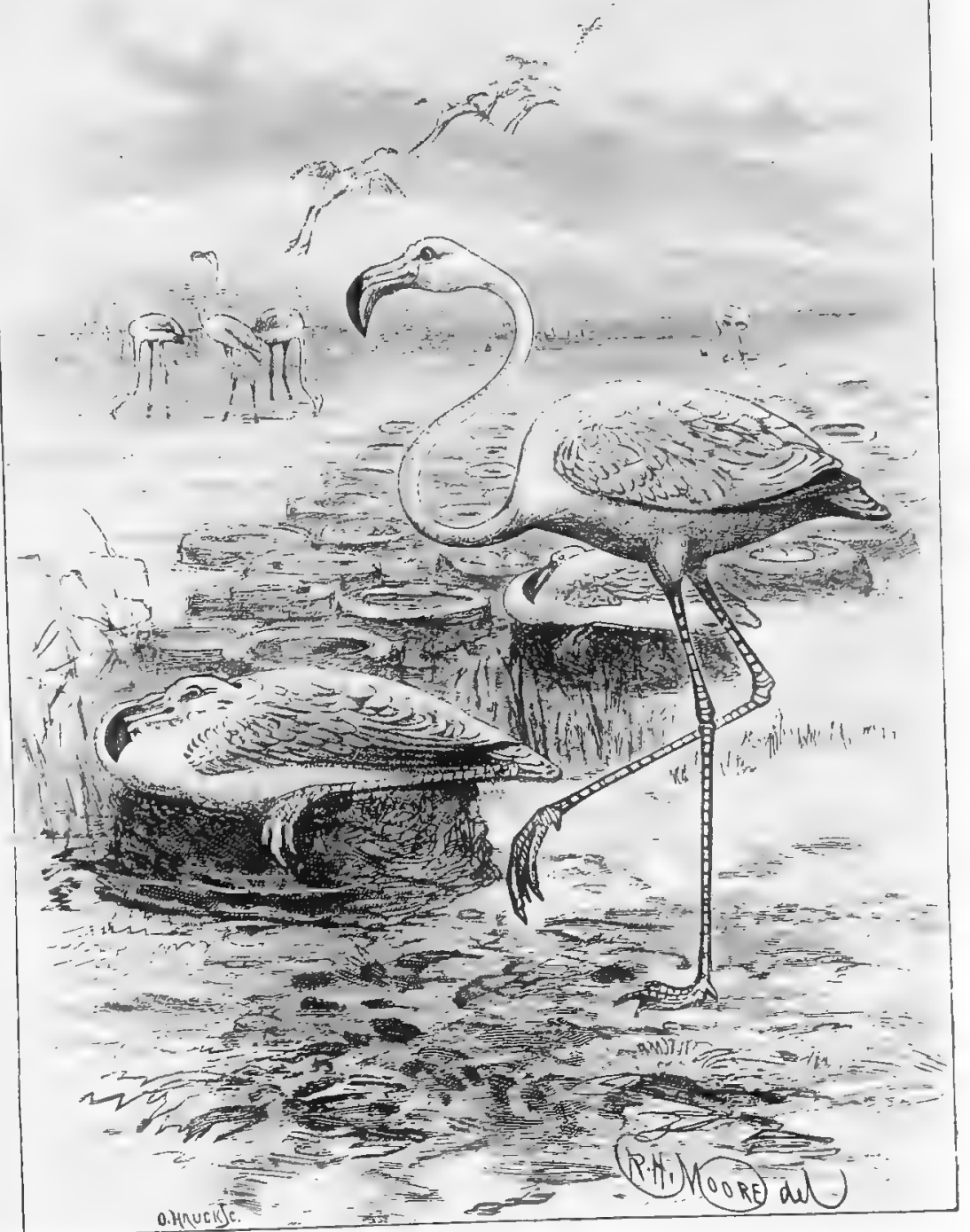


bird is sitting, it doubles its long legs under its body, after the manner of a heron.

These beautiful birds will not remain in this locality very much longer. Before many days have passed, the eggs will all have been hatched, and a few weeks later the young will be fledged and ready to $\mathrm{fly}$. By that time the heat of the summer will be coming on, and, in order to escape it, the whole flock will take flight for Southern Europe, where they will remain until late in the autumn.

\section{ANSERES}

The familiar birds Ducks, Geese, and Swans are all embraced under the family name Anseres. It is an extensive group as we all know, and some of its members are found in almost every country in the world.

\section{THE DUCK}

If we had never before seen a Duck, and knew nothing at all about it, we should still be able to tell, just by looking at it, that it was intended to spend a great part of its life in the water.

This we should know by its broad, webbed feet, the toes being quite joined together by a connecting membrane. Webbed feet are always a sign that the animal which possesses them is able to swim. The otter, the beaver, the swan, and the frog, as well as the duck, all have webbed feet. And these they use as paddles with which to row themselves through the water.

Then we should notice that the body of the duck is not balanced like the bodies of other birds, its legs being set very far back. That is why it cannot walk so steadily as a fowl or a turkey, and waddles along in such an awkward way. What the bird loses, however, in its progression on land it gains in the water. When a man is rowing, you will notice that his oars are always rather behind the middle of the boat, because then it is much more easy 
for him to row. For the same reason the oar-like legs of the duck are set rather behind the middle of its body.

Further, it is remarkable that although the duck spends so

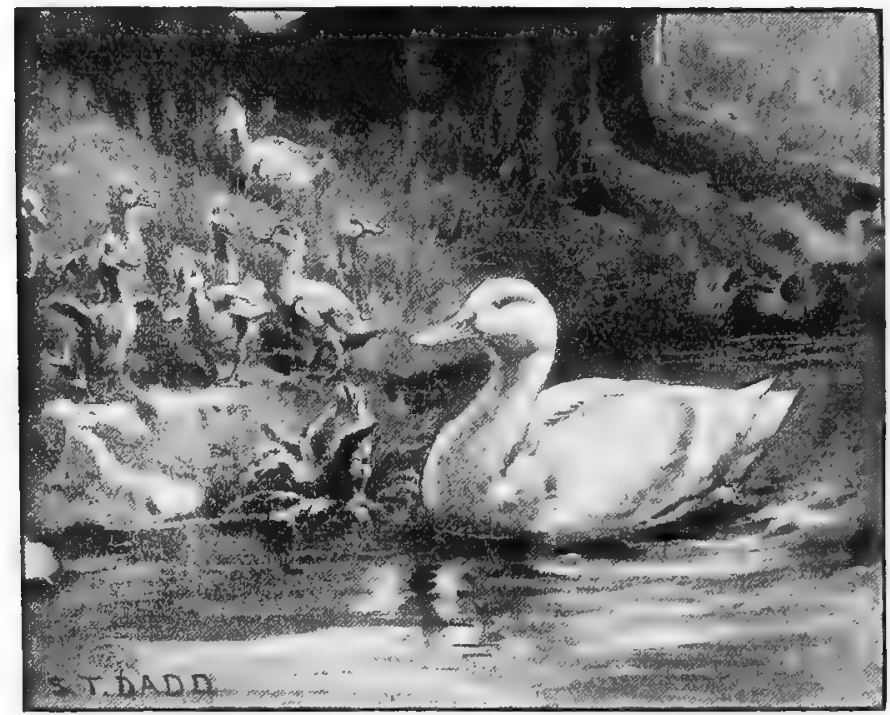

Duck and Ducklings

much of its time in the water, it never seems to get wet. This is due to the fact that a kind of oil oozes through a great number
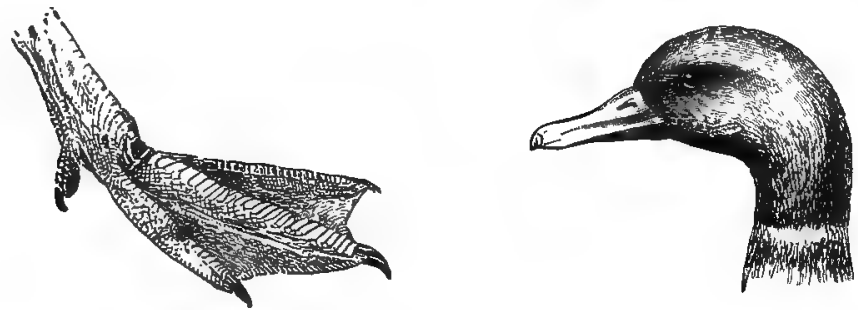

Foot and Head of Duck

of very tiny holes in the skin, and spreads all over the feathers. This oil prevents the water from really touching the feathers, and keeps the bird perfectly dry. 
In order that it may swim well, therefore, the duck has broad, webbed feet, which make very useful oars; a body balanced just like a boat; and a thick warm coat of feathers, which keeps the water from contact with its body.

But there is still its beak to which we must pay attention. The duck feeds chiefly on worms and other small creatures which it finds in the mud. It gathers up this mud, and presses its beak very closely together. The result is that all the mud is squeezed out of groove-like holes along the sides of the beak, while worms and other creatures are left behind to be swallowed. The beak is a kind of natural sieve, and with it the bird sifts its food out of the mud.

\section{COLUMBÆ}

Pigeons are a large and widely distributed group of the feathered race, almost all the members of which, from their general likeness to our well-known and beautiful domestic pigeons and doves, could be recognized as such without trouble.

All the existing pigeon group are pretty, graceful creatures, but the extinct Dodo and Solitaire, although they belonged to the Columbæ, were flightless and very ungraceful in build.

There are several distinct families of pigeons. The Columbidæ is the typical one, and that is best represented by our domestic pets. Ring-, and Turtle-, and other "doves" are placed in a different family, and these, with the extremely pretty Sand-grouse, lead us into the order of our Game Birds.

\section{THE PIGEON (FAmily Columbid $Æ$ )}

All readers must know what a pigeon is. There are a great number of different kinds of tame pigeons, some with tails like fans, others that can blow themselves up like balloons, others that tumble heels over head as they fly, and others still that may be taken to places hundreds of miles from home and yet will fly almost straight back to their own nests. 
In all parts of the world many varieties of wild pigeons are to be found. If you are near a pine wood you may often hear the gentle coo-cooing of the pigeons among the trees, and if you take a walk through the wood you will every now and then be surprised by a loud flapping overhead as pigeons, startled by your

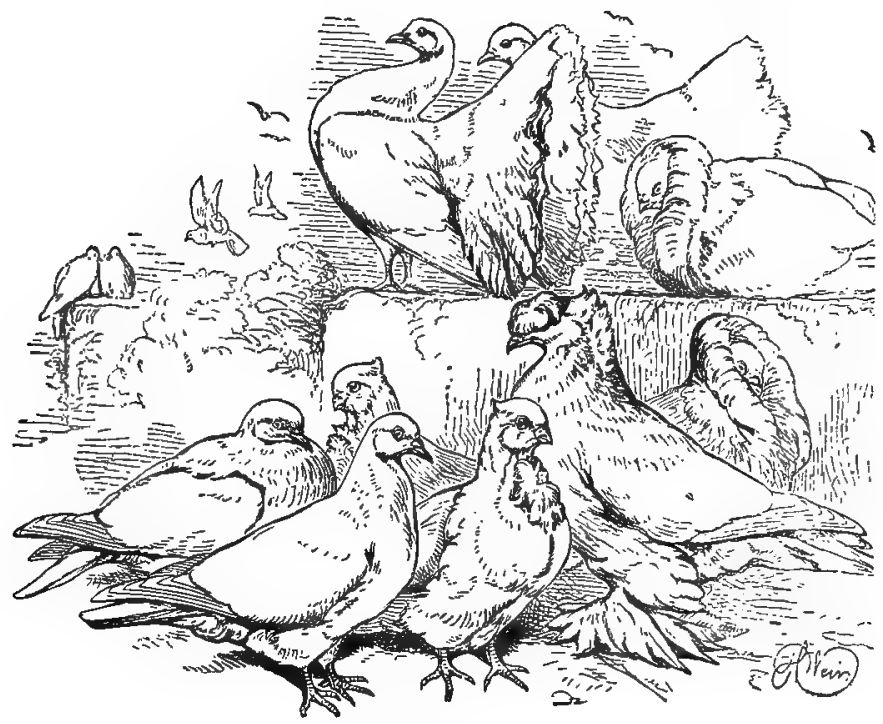

Pigeons

steps, fly away from their roosting-places. Looking up you will see here and there among the branches little bundles of sticks. These are the pigeons' nests. If you climb up a tree and look at one you will find that it is made of sticks loosely put together, and just sufficiently hollowed in the centre to keep the two glossy white eggs from falling over.

Pigeons never lay more than two eggs at a time, but they sometimes rear several broods in a season, and in every case one of the young birds is a cock and the other a hen. The young, when first hatched, are very strange little things. They have no feathers, are quite blind and very helpless, and they have larger beaks than their parents. But this last peculiarity enables the old birds to get 
their bills inside those of their young, and so feed them with a milky food from their own crops. The young pigeons, however, grow very quickly, and are soon able to fly into the fields to find food for themselves.

Though pigeons usually build in separate trees they are nevertheless fond of company. They feed in flocks, and as their food consists chiefly of fruits and seeds they are said to do a great deal of damage in the corn-fields.

In one thing the pigeon differs from almost all other birds. Most birds, when drinking, take a mouthful of water and let it slip down the throat by throwing back the head, and repeat this till their thirst is quenched. But the pigeon swallows water just as we do, so that when it puts its bill into the water it does not take it out again till it has had quite sufficient. The manner in which the pigeon feeds its young, by softening the food in its crop first instead of giving it raw, is also different from that of other birds.

Tame pigeons become very much attached to their home, but their attachment is like that of the cat and not that of the dog. A dog will follow his master wherever he may go, but though the cat does not do that it will return again and again to the old house. So pigeons, when taken to a new home, have to be confined for many days in order that they may become used to their new quarters, otherwise they would fly away back to the place from which they came. This habit has been utilized in the case of one species, called the carrier pigeon, which is thus made to carry lutters from distant places.

\section{GALLIN $\approx$}

This group of birds is very large and is divided into several families, which include about sixty generc. We lead off in this great group with a family which embraces the Grouse and Ptarmigan, and then come to the Pheasant tribe, which include many wellknown species, and of which we may take our Barn-door fowls as the type. 
They are all much alike in general build and structure; all are handsome birds, and some, such as the Argus and Golden Pheasants, are exceedingly beautiful in form and colouring. And when we come to the Peacock, which crowns the Phasianidæ, i.e. the Pheasants proper, we may well be lost in wonder as we gaze upon its gorgeous plumage.

Among the other families of the order are the British Turkeys, Curassows, Guans, Quails, \&c.

\section{PHEASANTS (Family PhasIanidæ)}

This family includes Partridges, Pheasants proper (which genus embraces our domestic fowls and the Peacock), Guinea-fowls, and Turkeys.

\section{THE PARTRIDGE}

One of the most familiar of our game-birds is the common Partridge. This bird is about the size of a small hen, and is beautifully coloured with brown, black, gray, and red.

The Partridge is found very often in the corn-fields, where it may run about among the grain without being scen. It makes its nest of dead leaves and grass, generally hidden away at the foot of a hedge or among the corn. There it may sit securely on its eggs, which are usually about twenty in number and are greenish-yellow in colour. As soon as the young birds are hatched they are able to run about, and the parents take them out into the fields to look for food. They make a pretty sight as they move about.

The old birds take great care of their young, and the henpartridge will play a clever trick to allure an unsuspecting enemy away from her brood. If anyone approaches them the young birds scatter in all directions and disappear among the grass. But the mother runs away from them, pretending she is wounded and unable to fly. In this way she probably induces the intruder to try and catch her; but she never allows herself to be caught. She always keeps just a little way in front of her pursuer, until she is 
sure that her young are safe, and then she flies over a hedge with a loud whirring of her wings and is not seen again. After a

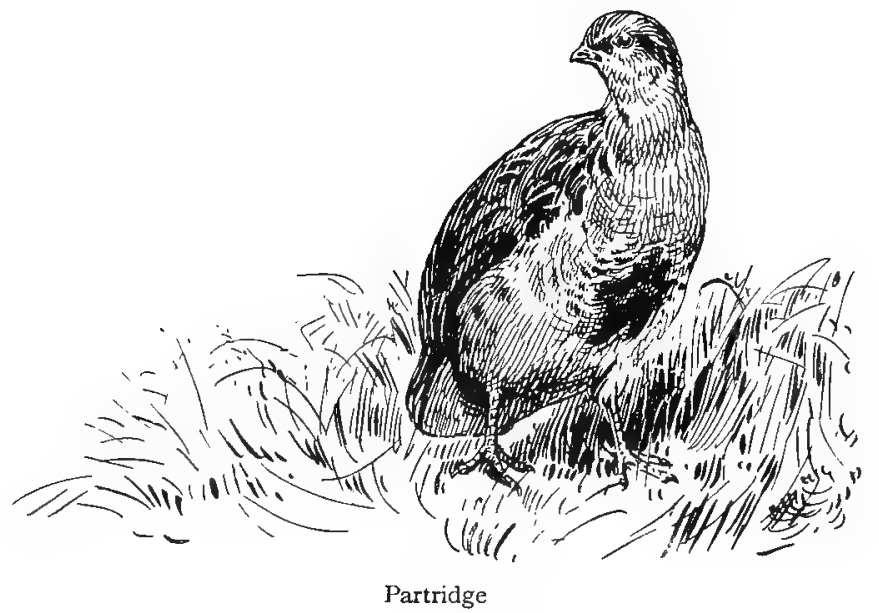

time she will return to where she left her family, and bring them to her at once with a call.

When young the partridge lives chiefly on insects, and considers ants' eggs a special dainty. As it grows older it also eats grain and other seeds and herbage.

\section{THE PHEASANT}

The Pheasant is a foreigner and was brought to this country from the East. Though it has become pretty well used to our climate, it might not be able to live here if the woods in some parts were not specially laid out for it. But as the pheasant is "preserved" for the sportsman it is very well looked after. Branches are laid on the ground to offer it good nesting-places, or what is called "cover", and in very cold seasons it is fed. But its eggs are often taken from it and put under a hen to hatch. When brought up in this way the young birds are very tame and will feed in the yard along with the other fowls. But when spring 


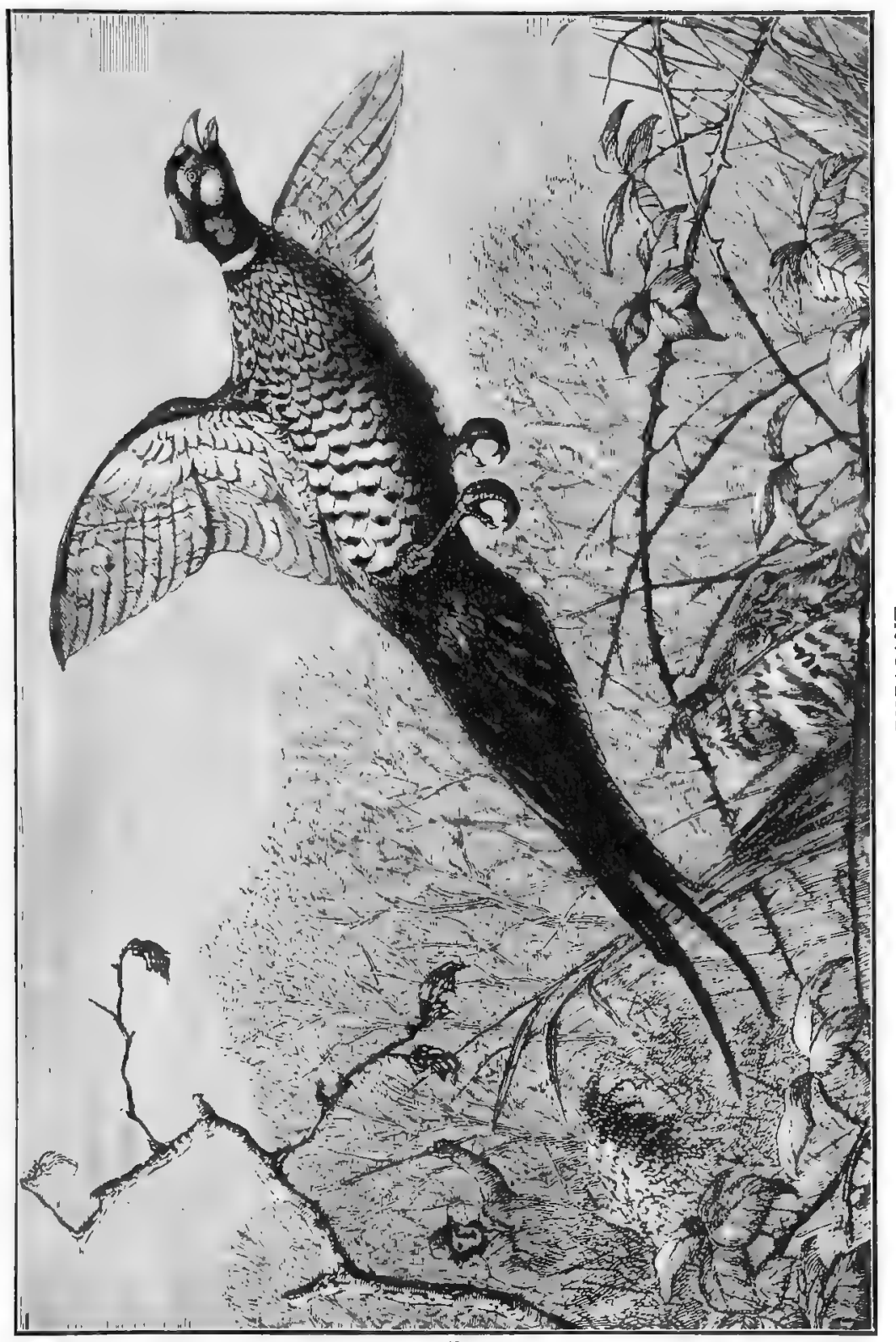


comes round again they generally fly off to the woods for the nesting season.

The pheasant is one of the most beautiful wild birds in this country; its feathers are tinted with green, yellow, red, purple, and black. The splendid long tail-feathers are much used for decoration. As in most other species, however, the hen-pheasant has not such fine clothes as her husband.

The nest is made on the ground, usually hidden by some overhanging plants. Dried leaves and feathers are the materials used in its construction, and as the eggs are of a light-brown colour, one might pass very close to them and never see them. From ten to twenty eggs may be found in a pheasant's nest.

If you pass along a country road in the evening, or in quiet spots any time during the day, you may see the pheasants feeding, generally near a wood. They are very shy birds, and do not go far from their covert. If you clap your hands or shout you will sec them all running away to hide in the thicket, or flying away among the trees with a loud whirring noise. But if you keep quiet you may hear the cock-pheasants crowing. Their call is not a proud crow like that of the barn-door cock, but a shrill double cry as if the bird were startled.

\section{PEA-FOWL}

The Peacock is a familiar inmate of many English farmyards. We may see him strutting to and fro, with his beautiful train spread out to its widest extent. Very proud indeed he is of this train, with its numerous eye-like spots of metallic green, gold, bronze, purple, and blue. And if he thinks that we do not admire it sufficiently, he will rattle his long quills loudly together in order to attract our attention to it.

This train is often called the "tail" of the peacock. In reality, however, it is not the tail at all, but consists of the feathers which lie above the tail, and are usually termed the tail-coverts. The true tail is quite small, and is nearly always overlooked, for the feathers which compose it are only about seven or eight inches 


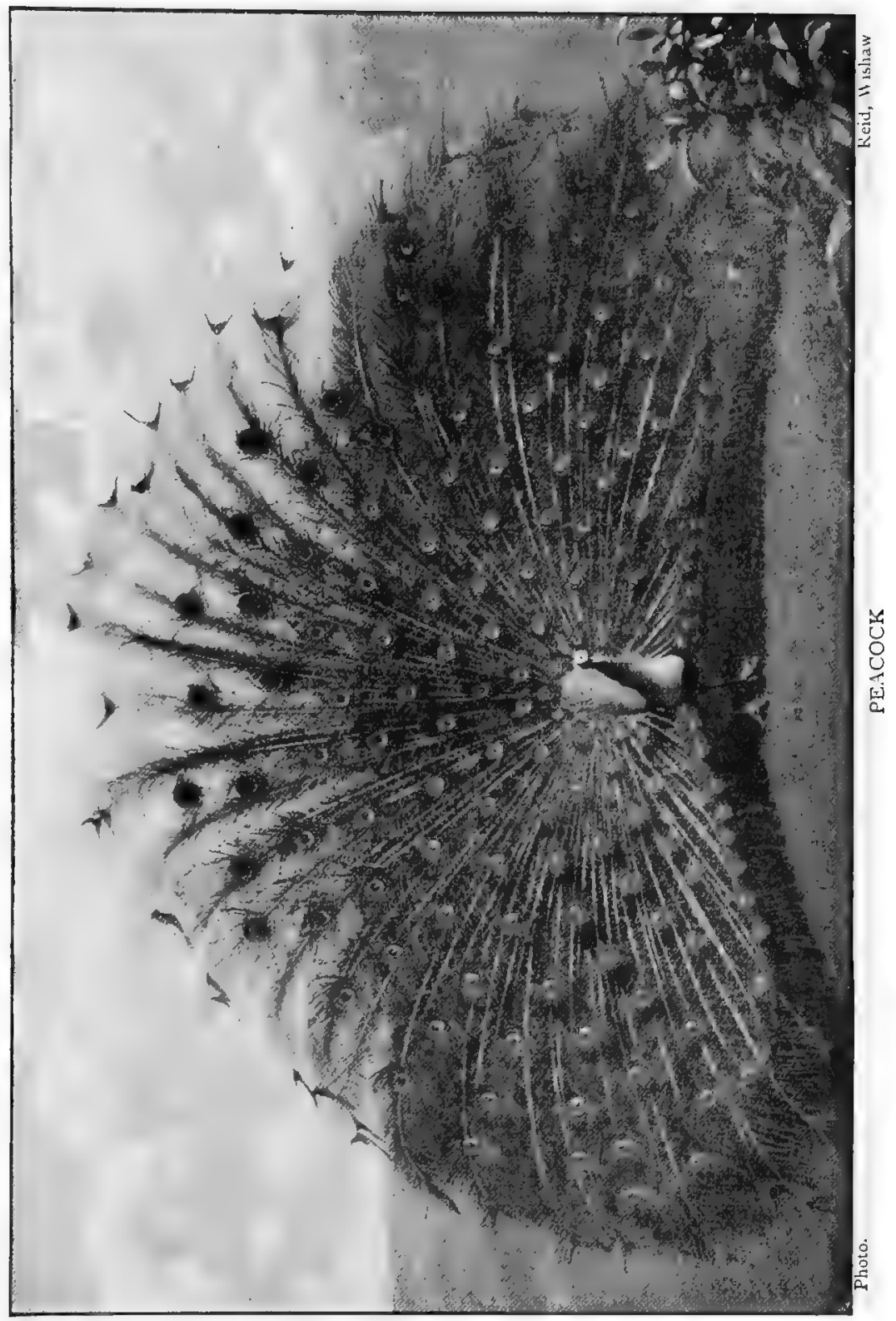


long. These feathers, which are very stout and stiff, serve to support the train when it is spread out.

This handsome bird in a state of freedom is an inhabitant of the thick forests of India, and in some parts of that country is very common. To us it would seem strange to meet with thirty or forty wild pea-fowl, all busily engaged in feeding. Yet such a sight is often seen by the traveller as he passes through an Indian jungle. A well-known hunter tells us that he once saw more than twelve hundred of these birds in one enormous flock.

One reason why they are so abundant is, that in many parts of India the natives look upon them as sacred, treating them with great reverence, and not allowing them to be in any way molested. The pea-fowl soon discover that they are never interfered with, and become quite tame, entering the villages without showing any signs of fear, and even roosting upon the roofs of the houses.

In other districts, however, they are regularly hunted, and sometimes in a very singular manner. Although the peacock can fly very well, its heavy body and long train prevent it from rising into the air very quickly. The hunter, therefore, mounting a swift horse, arms himself only with a whip to which a very long lash is attached. When he catches sight of a peacock, he gallops towards it at full speed, and strikes at the bird with his whip as it rises into the air. The long lash, of course, curls round its neck like a noose, and before the bird can break away the hunter has hauled it down and secured it.

Another way of hunting the peacock is to shoot it as it is roosting at night, or during the heat of the day. But the hunter is obliged to approach it with the greatest caution, as, if one of the birds be alarmed, it utters a loud warning cry, which is at once understood by its companions; and the whole flock instantly take to flight.

Peacock-hunting, too, is a somewhat dangerous sport, as the thick jungle to which the bird retreats at night is also the favourite hiding-place of the tiger. Peacocks, however, are greatly afraid of this animal, and often warn the hunter of its proximity by the loud frightened screams which they utter as they hastily make their 
way to the higher branches of the trees. An experienced hunter, when he hears this cry, is always on his guard, for he knows that a tiger is not very far away.

The jackal, too, is an enemy to the peacock, and is much dreaded by the bird. The presence of a dog also, which it no doubt mistakes for a jackal, always alarms it. At the sight of one it manifests the greatest uneasiness, mounting as far out of reach as possible, and continually uttering its loud cry of warning.

The pea-hen, which is not nearly so handsome a bird as her gaily-bedecked mate, makes her nest upon the ground, and usually lays from twelve to fifteen eggs. These are hatched about the end of November, and the chicks feed upon the standing corn until about the end of March. While quite young their flesh is considered a great delicacy, and old birds can be made into excellent soup. In ancient times the peacock formed one of the principal dishes at a Roman banquet, and was commonly eaten on great occasions in England.

\section{FULICARI 死}

This order includes the Rails and the Water-hens. The Common Coot, the well-known Water-hen, may be taken as a typical species.

\section{THE COOT}

On many a large inland piece of water we may see a number of dark brown birds, not quite so large as ducks, which swim well, and occasionally disappear by diving under the water.

These are Coots. In some respects they are much like moorhens; but we can always tell a coot from a moor-hen by looking at the horny plate just above the base of the beak. In the moor-hen this plate is of a ruddy orange colour. But in the coot it is pure, shining white. 
If we could examine the two birds closely, we should find that there is another very well-marked difference between them. The moor-hen, although it can swim well, has its toes quite simple, like those of a wading bird, and not joined together by webbing. The coot, however, although its toes are not exactly joined, has a broad web upon each, which spreads out when the bird is in the water, and so converts the foot, as it were, into a broad and powerful paddle.

It is not very easy to watch the habits of the coot, for it is a shy bird. If it is alarmed it either dives beneath the surface and disappears, or swims into a bed of reeds, and defies all attempts to dislodge it. Even a clever water-dog is often baffled by a coot, which in some mysterious way hides itself so well that a dog is quite unable to find it.

The nest of the coot is a very curious structure. It is made of reeds and rushes in the form of a broad, almost circular pillar, the eggs being placed in a slight hollow upon the top. It is easily seen, for it stands well out of the water, and is usually placed at some little distance from the bank, generally, but not always, among low reeds or other water herbage.

It is said that the bird always seems to know when a flood is coming, and carefully raises the level of its nest so that the water may not injure the eggs. But it sometimes happens that the rush of water is stronger than it expects-so strong, indeed, as to wash the nest from its moorings, and carry it floating away. When such an accident happens, however, the bird is said to remain quietly sitting upon its eggs until the nest is stranded, when it fastens it down in its new situation.

Although coots are not quarrelsome birds as a rule, they will fight fiercely at times, and drive away birds much larger and stronger than themselves. A few years ago a curious combat was witnessed between a pair of coots and a swan. The coots had been laying the foundations of their nest, and were just beginning to build the structure, when the swan trampled down all their careful work, and began to make her own nest in the same spot. Early next morning the coots began their task over again, and again the swan came and destroyed the results of their labours. Suddenly, 


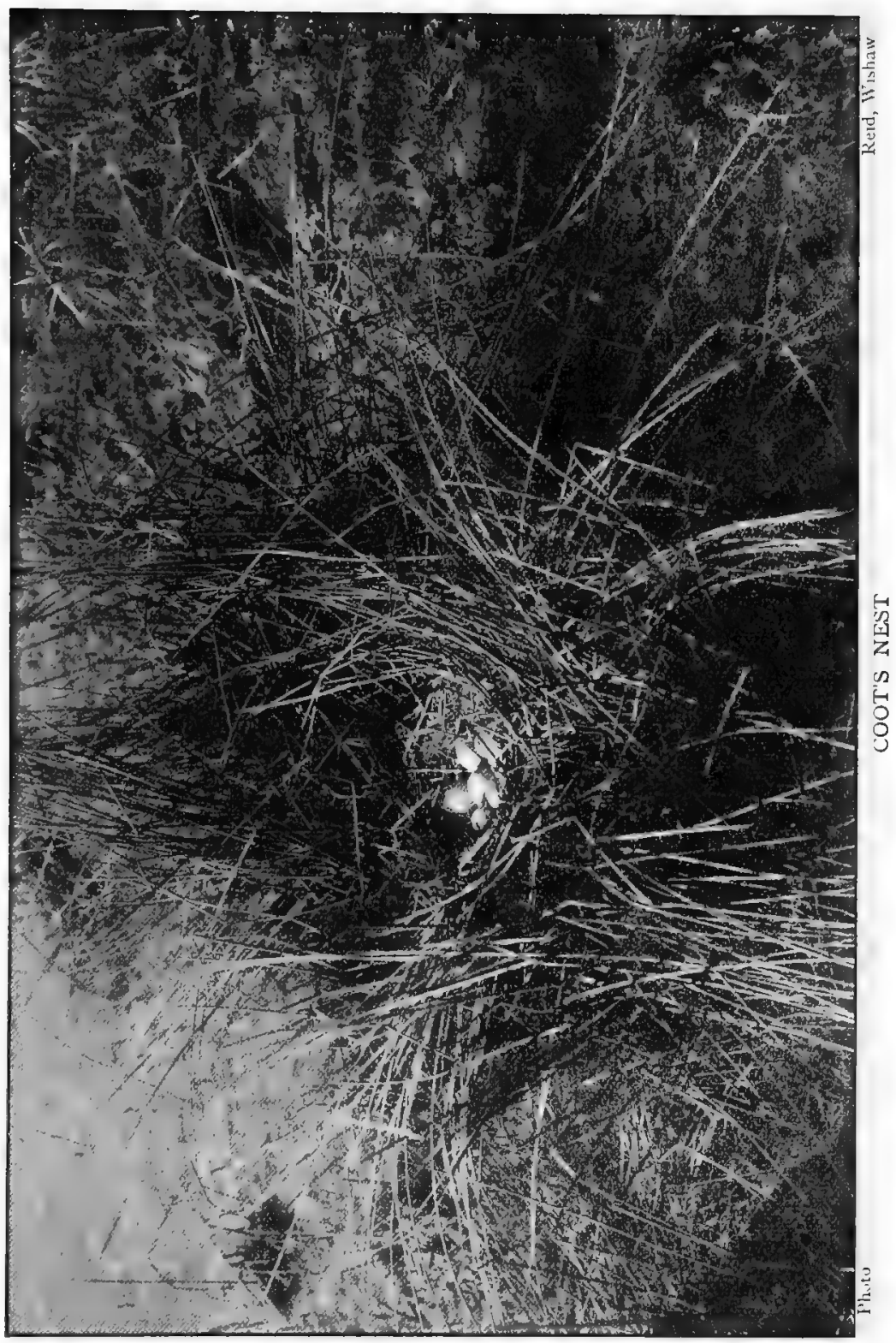


however, the two little birds came up and gave battle. One alighted on her back and pluckily attacked her neck, while the other flew into her face, beat her head with its wings, and so frightened and bewildered her that at last she retreated, leaving the plucky little coots masters of the situation. They then began for the third time to build their nest, and this time completed it without molestation.

The coot feeds on water insects, water snails, and tiny fish, and may often be seen diving bencath the surface to seek for them. Sometimes it leaves the water and pokes about among the herbage on land, in search of caterpillars, worms, \&c. When the frosts come, and the ponds and lakes are frozen over, it flies away to the sea-shore, and there remains until warmer weather melts the ice, and it can return to its former haunts.

\section{GAVI $\AA$ \\ THE GULLS}

Through the Water-hens we are introduced by a perceptible relationship to the Bustards, Cranes, and others which form the order Alectorides, and these in turn lead us to the Plovers, Sandpipers, Snipe, \&c., i.e. the order Limicolæ. Through that order we reach the great and well-known Gull tribe.

Everyone who has ever paid a visit to the sea-side must have noticed the Sea-gulls. And very few people can see them without admiring them.

They are such beautiful birds, with their long, narrow wings and bright plumage! Some are almost entirely white, with just a tinge, perhaps, of gray; others have black heads or black backs. And they are so wonderfully graceful, too, as they sweep quietly to and fro over the water. Now they soar upwards, so easily that there seems no effort in their flight; now they sweep downwards, with the same silent, gliding motion; or they will hover almost motionless for a moment or two, like a kestrel over a stubble field. 
And all the time their keen, bright eyes are eagerly scanning the water below in search of food.

Now one of them dashes down to the surface of the water, and rises again an instant later into the air. He has caught a fish or a floating titbit, and is ready for more. Now the whole flock have

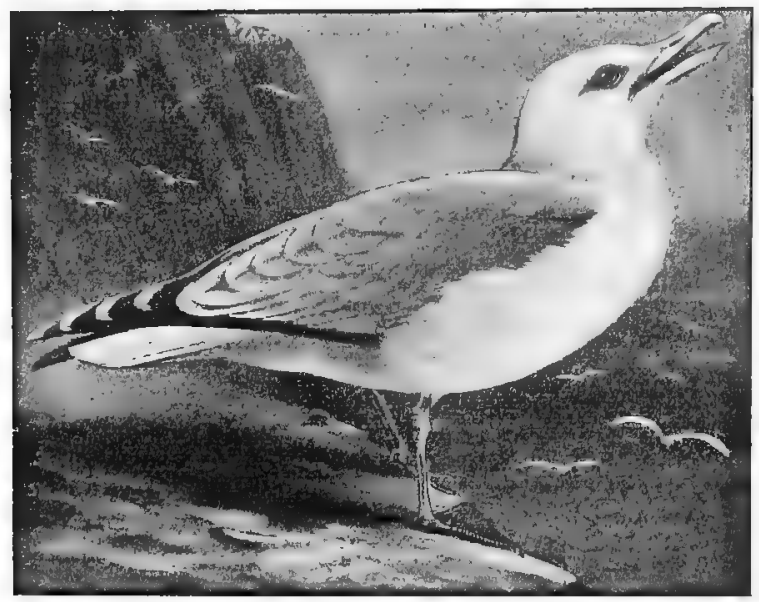

Herring Gull

descended and are sitting on the water, bobbing up and down with the motion of the waves. A shoal of fish fry is passing, and a hundred heads are under water in a moment, and play havoc with the infant fishes. Very soon all the pretty white birds are in the air again, sweeping as before to and fro over the sea.

We see them again when the tide is down, and the retreating waves have left many a dead crab, and star-fish, and shell-bearing mollusc behind. How busy they are as they traverse the water's edge, and search every inch of the mud for sundry dainty morsels! They are still busy when the water comes in again. They retreat slowly before it, keeping sharp watch for anything eatable as they go. And so for hours we may watch their ways and doings until, when the shore is fully flooded, they rise into the air once more and take to feeding on the crest of the waves. 
But some of them do not spend the whole of their time on the shore, or in flying over the sea. Hundreds upon hundreds of them may often be seen in a newly-ploughed field, sometimes many miles from sea. The rich brown soil is dotted all over with their white and gray bodies. Among them are a number of glossy black rooks, so that the field has quite a chequered and lively appearance. And all of them, white birds and black alike, are busily hunting for the worms and grubs that have been turned up by the plough.

Near the coast, indeed, the gulls are among the farmers' best friends. To the newly-turned soil they come, day after day, in search of the destructive creatures that feed on the roots of our crops; and many a wire-worm, and "leather-jacket", and fat white cockchafer grub do they devour before his mischief is half completed. So useful are they, indeed, that it is scarcely too much to say that, if it were not for the gulls and the rooks, the sea-side farmer would scarcely be able to grow any crops.

It may be asked why a gull's nest is never found by the seaside? It is because the gulls fly far away just before the nesting season begins. Some make their way to inland marshes, and lay their eggs in the reed-beds, trampling down the grass and rushes into a kind of rough platform on which to place them. But the greater number go to the high rocky islands on our northern coasts; and there, on the ledges of the lofty cliffs, their eggs are laid in hundreds of thousands.

It is a wonderful sight when something alarms the gulls on one of these islands; for up they fly, in countless multitudes, even darkening the sky with their dense masses, and almost deafening one with the rush of their hurrying wings. And they come swooping down again with almost equal turmoil, each by some wonderful instinct finding its way to its own little cluster of eggs, which lie quite unprotected on the ledges of the high rocky cliffs.

Those who take gulls' eggs have to be lowered by long ropes from above; and there are men who make it their profession to rob the ledges twice in the season of all the eggs, which they sell, as they are a valued article of human food. Once more, however, the despoiled birds will lay; and this time they are allowed to hatch their eggs and bring up their little ones in peace. 


\section{IMPENNES}

\section{THE PENGUINS}

From the preceding order we come, through the Skuas, the Albatrosses, the Petrels, the Auks, the Divers, and the Grebes, to the Penguins. These birds are so much alike that they are all included in one family, which is made up of only some twenty species. They have nevertheless a wide distribution, being found among the Antarctic ice, and about the coasts of South America, South Africa, and Australasia. They are limited to the southern hemisphere.

The Penguins are strange white-breasted birds, about three feet high, and in their native haunts may be seen drawn up in great multitudes on the beach, bearing a curious resemblance to row upon row of well-drilled soldiers. There they stand side by side, perfectly upright, and looking just as if they were listening for the word of command. Some are swimming about close by; others are just leaving the water, and waddling clumsily over the rocks in order to join their companions; others, again, are making their way down to the sea.

The Penguin is a very interesting and curious bird. Its wings, for instance, cannot be used for flight. They are very tiny and peculiarly shaped, and, indeed, remind one of the flippers of a seal.

Nevertheless these wings are not useless even upon land. If the penguin is alarmed or pursued upon dry land, it will fall upon allfours, as it were, and scramble along upon its wings and feet after the manner of a quadruped. But in the water they are the means of rapid progression, so that it can dive and compete with the swimming powers of fish, which it overtakes and captures for its food. Indeed in activity and power of swimming the penguin is said to equal the dolphin. These birds, indeed, have often been mistaken for fish or small active cetaceans, that is, the family to which porpoises and dolphins belong.

Another peculiarity of these odd birds is that when they are on shore they do not all stand together, but separate themselves into 
several companies. One company consists of the young birds that have not long been fledged; another, of those that are changing their feathers; a third, of those whose moulting is completed; and a

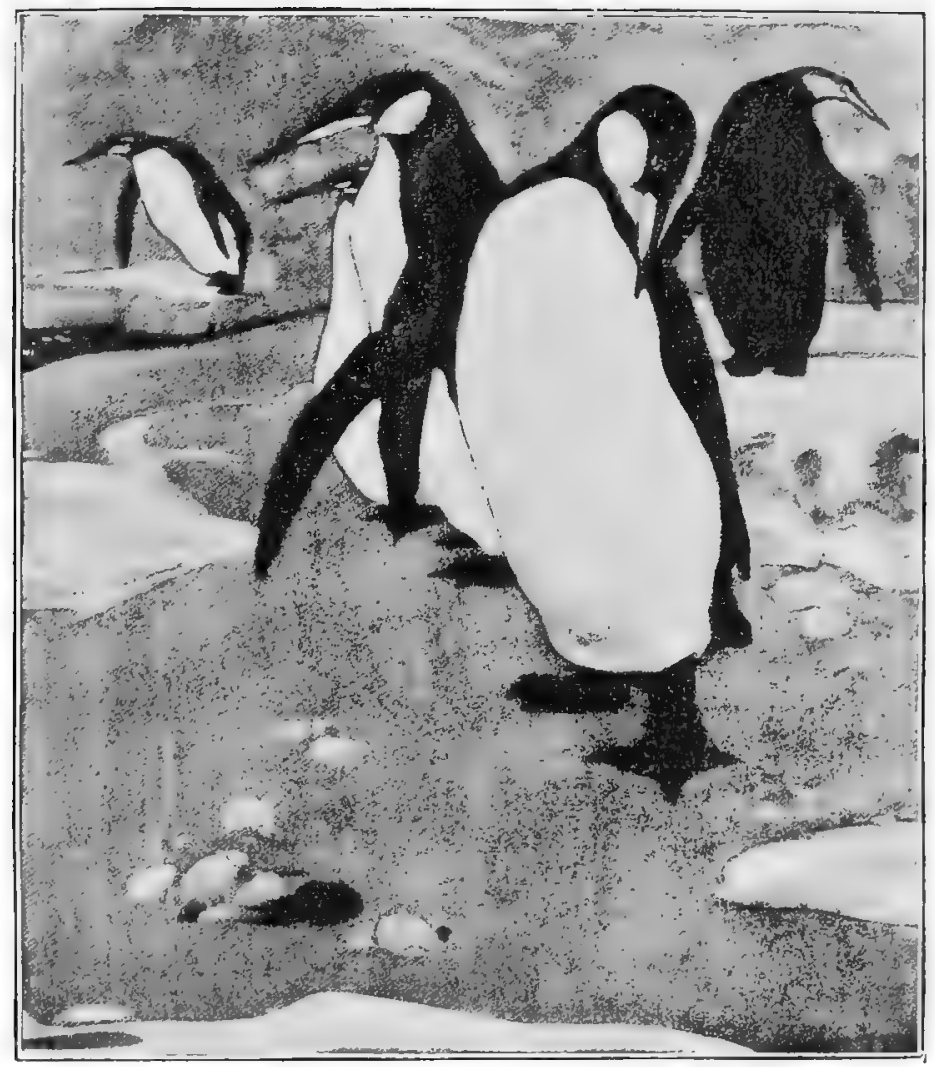

Penguins

fourth, perhaps, of those that are building their nests. If a bird should find its way into a group to which it does not belong, the others all become exceedingly angry and drive it away.

The Penguin lays two eggs, one of which is often larger than the other. When the time approaches for these to be hatched, 
the cock birds, which have hitherto been in attendance upon the hens, leave them and go out to sea. There they remain for about a week, no doubt enjoying themselves, for when they come back they are exceedingly fat.

After the young are hatched out, the cocks take charge of them for a time, while the hens in their turn go out to sea. They do not stay for so long as their partners, and are soon back at their nests, bearing in their beaks and throats a large supply of food for their hungry little ones. When the young penguin wishes to eat, it places its beak within that of its mother, and takes as much as it needs of the nourishment which she has provided for it.

On Macquarie's Island, in the South Pacific Ocean, penguins are very numerous, although a great many are captured and killed and boiled down into soup. A well-known traveller estimated that in one settlement alone there could scarcely be less than eighty thousand of these birds, about one-half of which were always at sea. On their way to and from the water they always travel by the same narrow paths, which in time are worn quite smooth by the constant traffic of so many feet.

A traveller who was shipwrecked upon an island in the South Seas tells us that a penguin, when sitting upon her eggs, is not allowed by her companions to leave them, even for a few minutes. "Woe betide any unfortunate hen", he says, "who dared to leave its own nest to go a short walk; for no sooner was it noticed, than all the neighbours raised a cry of anger and horror, and prepared to give the delinquent an unmerciful pecking as it wended its way through the thick ranks of its comrades. If it returned to its lord and master, the tune was immediately changed from discordant howls and croaks to a more musical tone of thanksgiving and rejoicing." 


\section{RATIT $Æ$}

This order includes such extraordinary birds as the Ostriches, Cassowaries, Emeus, and the peculiar Kiwis of New Zealand. Many of the relatives of these birds are extinct. The Ostrich is the largest bird that is known to exist at the present time.

\section{THE OSTRICH}

We are accustomed to think of turkeys, geese, and swans as large birds; but any one of these would look like the merest chicken by the side of an ostrich. Even a small ostrich is quite as tall as a tall man; while the head of a large one is as high above the ground as that of a camel.

Yet, possibly within a few hundred years ago, much larger birds than even the ostrich were alive; birds which must have been equal in height to an elephant, or even to a small giraffe! And, although these are not found now, their skeletons may be seen in several museums.

Although the ostrich is a bird, it is not able to fly, for its wings are so small and feeble that they cannot raise its great weight into the air. All that an ostrich can do with its wings is to use them as balancers when it is running. When speeding across its native deserts, it holds its wings straight out from its body.

But, though the ostrich cannot fly, it can run so remarkably fast that it has no need of strong wings. Even a swift horse cannot overtake an ostrich in fair chase; and the bird would never be caught at all if the hunters did not know that it always runs in a curve. When the hunter is pursuing an ostrich, therefore, he waits until he sees to which side the bird is turning; and then he gallops across at full speed, and intercepts it as it passes him.

The natives, however, have a far better plan for killing the ostrich than merely pursuing it on horseback. Knowing that, 


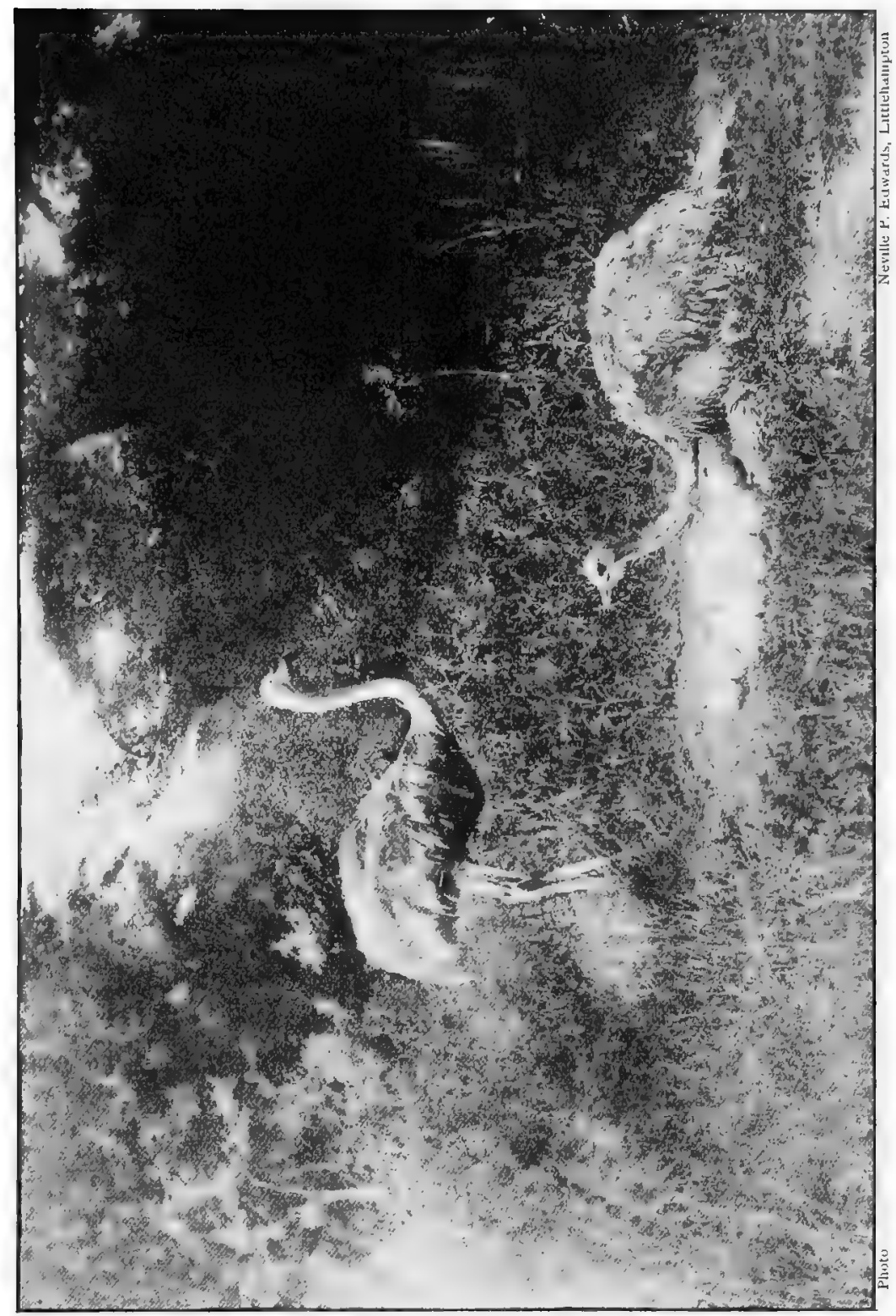


although it is a wary bird, it is not very clever, a native hunter takes the skin of a dead ostrich, and puts it over his own body. He holds the head up in the air by means of a stick, and then, bow and arrows in hands, begins to walk slowly up to the ostriches he wishes to kill.

Every now and then he stops, bends the head of the dead bird down to the ground as though it were feeding, and then moves on as before. The ostriches, of course, see their enemy approaching, but are deceived, by the skin which he wears, into thinking that he is one of themselves. As soon as he is sufficiently close, the hunter fits an arrow carefully into his bow, and discharges it into the body of the nearest ostrich. The arrow is so small that it would scarcely inflict a deadly wound upon a great bird like the ostrich; but it is dipped into a most deadly poison, and the ostrich which has been struck by it soon falls down dead. The others, according to accounts, do not seem at all alarmed by the death of their comrades, and go on feeding. Thus the hunter is able to kill as many ostriches as he wishes.

The ostrich lives in the hot, sandy deserts of Africa, and is among birds very much what the camel is among mammals. So strong is the likeness, indeed, that the ancients used to call the ostrich the "camel-bird"

It has large, broad feet, like those of the camel, and for the same purpose. Both the camel and the ostrich are obliged to travel over loose, sandy soil, into which their feet would sink if they were formed like those of other animals. But these large, broad feet sink only slightly; and so the birds can travel upon the sand as easily as upon a road.

Over the breast-bone of the ostrich is a hard, horny pad, like the pads on the knees and chest of the camel. In both cases the reason for their presence is the same. When the camel kneels down upon the sand, its knees and breast would be chafed and cut, if it were not for the pads which protect them. In the same way, when the ostrich sits down-as upon its eggs, for exampleits breast rests upon the sand. So that is protected in just the same manner.

In this way, again, therefore, there is a likeness between the 
ostrich and the camel. Travellers tell us, moreover, that in the distance the two are really so much alike, that it is not at all easy to distinguish one from the other.

The ostrich has only two toes upon its foot, one of which is a good deal larger than the other. This toe is armed with a sharp and powerful claw, which the bird uses very much after the manner of the kangaroo-kicking out at its enemies as soon as they draw sufficiently near. So fierce is its stroke, and so sharp is the claw, that one of these birds has been known with a single blow to kill a hyæna, and to rip up the body of a large dog.

The eggs of the ostrich are very large; so large, indeed, that one will furnish a hearty meal for six or eight men; a single ostrich's egg is said to be equal to twenty-eight hen's eggs. The bird lays its eggs in a hollow scooped out in the sand, and they are principally hatched by the heat of the sun.

The parent birds never wander

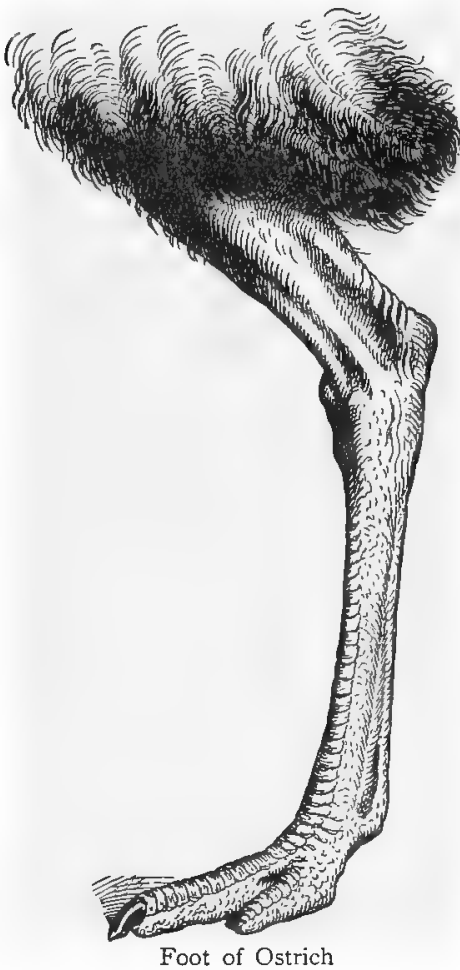

Foot of Ostrich very far away from their eggs, and will fiercely attack any enemy that may happen to approach them. All round the nest are laid a number of other eggs, which are not sat upon, even at night, and therefore do not hatch. When the little ostriches are hatched, these eggs seem to be broken, and given to them as food.

The natives of Africa put the ostrich egg to a rather curious use. After extracting the contents through a small hole at one end, they employ it as a water vessel. Sometimes, too, the shell is broken up into pieces, which are then carefully chipped into spoons and ladles. 


\section{REPTILES}

In former periods of the world's history Reptiles occupied a leading position so far as numbers, and size, and power were concerned, and Birds and Mammals an inferior one. Now the positions are reversed. Mammals and birds are much more numerous in the world than reptiles, and are much more imposing and powerful groups of animals.

We need not therefore be surprised to learn that more groups of reptiles have ceased to exist than are living to-day. It may interest us even to see the names of the groups of the Reptilia which have died out, as well as the names of the orders which still exist.

\section{ORDERS OF REPTILES STILL REPRESENTED}

I. Crocodiles-Crocodilta.

2. Tortoises and Turtles-Chelonia.

3. Lizards and Snakes-Squanata,

4. Tuateras (Beaked Lizards)-Rhynchocephalia.

\section{ORDERS OF REPTILES WITH NO LIVING REPRESENTATIVES}

I. Dinosaurs-Dinosauria.

2. Flying Dragons-Ornithosauria.

3. Plesiosaurians-Plestosauria.

4. Fish-lizards-Ichthyosauria.

5. Mammal-like Reptiles-Anomodontia.

The characters of the living reptiles are:-(r) They are all cold-blooded; (2) they all lay eggs, and never suckle their young; (3) they are never covered with hair, or fur, or feathers, but with scutes, or scales, or, as in the turtles, with a bony carapace or external shield.

We must not forget that they belong to the great kingdom of the Vertebrata; all have a spinal column, although all have not 
necessarily attached limbs, such as legs or paddles. The Snakes proper have no limbs.

Reptiles, especially in their past history, show considerable relationship to birds, although at the present time, with the indications of their relationship, birds and reptiles show stronglymarked differences - for instance, in the feathers and warm blood of the former and the scales and cold blood of the latter.

\section{CROCODILIA \\ THE CROCODILES (Family CROCODILIDA)}

The huge creatures which we call Crocodiles are among the largest and fiercest of the reptiles that now exist. Some of them, when fully grown, attain to the surprising length of twenty-five feet; and they do not hesitate to attack a man, if he should venture too near the water where they lie in hiding. They are not found in this country, nor, indeed, in any other part of Europe. But in many of the rivers and lakes of Asia, Africa, and America they are very common.

The crocodile has a very odd way of killing its prey. Let us suppose that a deer, for example, has come down to the river-side to drink. The animal does not notice its enemy; for the crocodile, when lying quite still in the water, looks so much like a floating $\log$, that even the sharpest eye would often be deceived.

But the great reptile, sluggish as it seems, is on the alert; and as soon as it catches sight of the deer, it dives quietly under water, and swims cautiously up to the place where the animal is drinking. If the deer be not on the alert, with a sweep of its mighty tail the crocodile knocks the poor creature into the water, and, seizing it, holds it underneath the surface until it is drowned.

The jaws of the crocodile are exceedingly strong, so that when once a victim is seized, it has little chance of escape. Each jaw is furnished with a long row of sharply-pointed teeth, which fall 
out, and are replaced by others, as often as their points are worn away. But though the jaws of the crocodile are so hideous there is a little bird which is not afraid to enter its mouth. It seems to do so in search of food, and it probably picks up leeches and other parasites that have been irritating the great reptile, for the latter never seeks to interfere with its intrepid little visitor.

If we were to examine the crocodile, we should see at once that its feet are not nearly large and broad enough to serve as

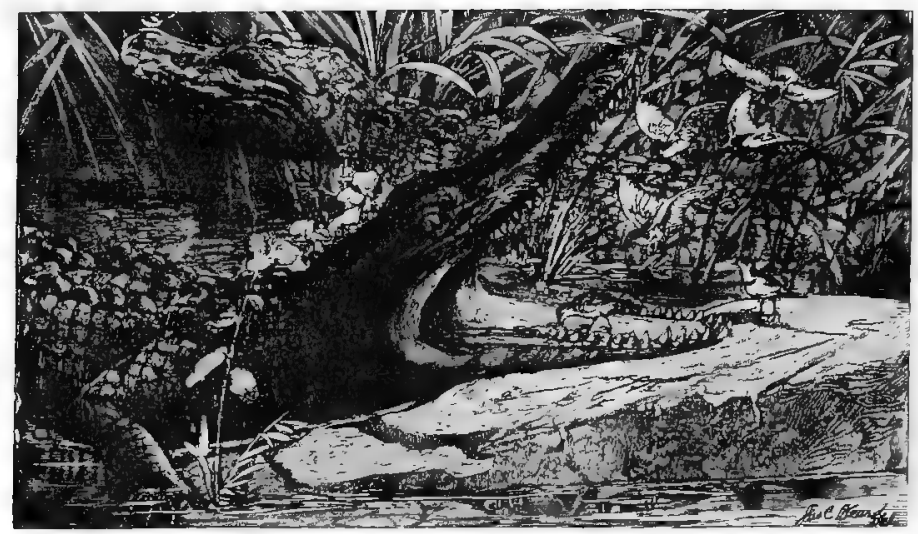

Crocodile and Crocodile-birds

paddles, like those of the duck or the swan. Even if they were so, indeed, the short and feeble limbs would not be strong enough to drive them with sufficient force through the water. In their place, however, it employs its long, broad tail, one sweep of which will propel it for a distance of many yards. The crocodile, in fact, swims just like the common newts, or "efts" as they are sometimes called, which we may find in great numbers in almost any weedy pond.

If you catch a newt, and put it into a basin of clear water, you quickly notice that it does not use its feet at all in swimming; but that it simply waves its tail from side to side as it glides along.

This is exactly what the crocodile does. Only, as it is so very 


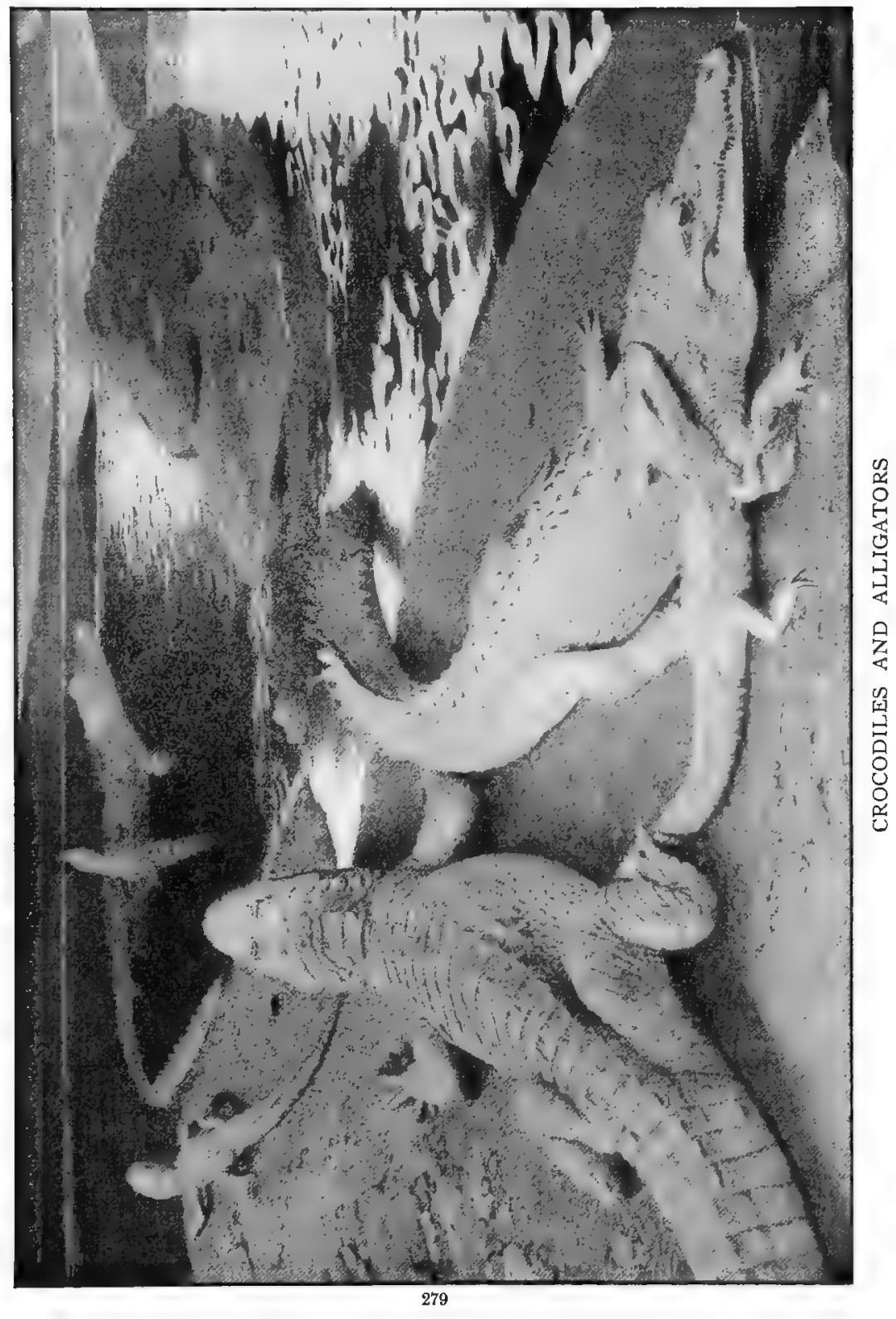


much larger and stronger than the newt, it can swim with much greater speed.

Upon dry land the crocodile is not at all at its ease, and is slow and clumsy in its movements. Its neck is formed in such a manner that it cannot turn its head to either side; while its short, feeble legs can only drag the long, heavy body along at a very slow rate. But the animal does not often come on shore. It much prefers to enjoy the warm sunshine while basking upon the surface of the water.

The hide of the crocodile is extremely hard; so hard, indeed, that even a rifle bullet will often glance off from it, if it should happen to strike it at an angle.

Knowing how tough the hide is, the natives of the countries in which it lives often strip off the skin of a dead crocodile, and make it into suits of armour. And in these they are quite protected from the swords and spears of their foes.

Like nearly all reptiles, the crocodile lays eggs, which it buries in the sand, and leaves to be hatched by the heat of the sun. These eggs are about as large as a turkey's, and are of a dirty white colour. One crocodile lays from twenty to sixty eggs.

A little animal called the mongoose is very fond of these eggs, and digs up and eats so many that it helps to keep the numbers of the crocodiles within due bounds.

The Alligator, a near relation of the crocodile, is to be found only in America. In form it is very like the crocodile, but it is never quite so large. Its length is usually from fifteen to eighteen feet. The habits of the two animals are similar. Other members of this family are the Cayman and the Gavial.

\section{CHELONIA}

This order is divided into four families-the Tortoises and Terrapins (family Testudinidæ), a smaller family of the AlligatorTerrapins, the Turtles (family Chelonidæ), and the Soft Tortoises (family Trionychidæ). 


\section{THE TORTOISES (Family TESTUDINIDE)}

Most of us have seen a Tortoise, and have wondered at its hard, horny shell, its small, weak legs, and the odd little head which it can draw back quite out of sight into its shell.

A number of tortoises may sometimes be seen for sale upon a truck in the street. These have probably just been brought

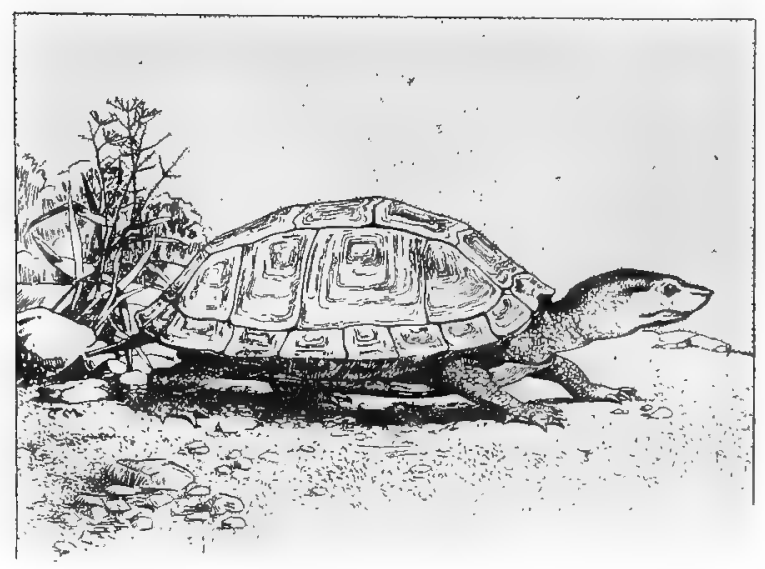

Tortoise

over here in some ship. For in certain countries they are so extremely plentiful that they are actually collected and put into ships to serve as ballast!

Now, the shell of a tortoise is not a covering, like that of a snail or a periwinkle. Properly speaking, indeed, we ought not to call it a "shell" at all; for it is externally made of horn, and internally of what in mammals are parts of their bony skeleton. Strange as it may seem, the upper part consists of the ribs, and the lower part of the breast-bone! These grow on the outside instead of inside the body, and are greatly widened out and flattened. If the upper shell is taken off, the course of the ribs may be traced on its under surface. The ribs are covered with 
large bony plates, which are joined to one another in just the same way as the bones in our own skulls.

Tortoises have no teeth, but the edges of their mouths are horny, and so sharp that they easily cut away the herbage upon which they feed. In some of the larger tortoises these jaws are so strong, and so keenly edged, that they have been known to snap off the fingers of a man's hand at a single bite.

If you look at a tortoise while it is walking, you will see that its body is not well supported by its legs, but drags along the ground. This is the case with most reptiles. They may be said to only waddle along; while almost the whole weight of their bodies often rests upon the ground. As has been said, snakes have no legs at all.

The feet of the tortoise are armed with stout, strong claws. With these the animal is able to dig into the ground.

Those who have kept a tortoise as a pet must have noticed that it disappears about the end of September, and is not seen again until April or May. The explanation is, that the tortoise in this country, like the hedgehog and the bat, falls into a deep sleep at the approach of winter, and does not awake again until the warm days of spring come round once more.

\section{TURTLES (Family CHELONIDE)}

In many respects Turtles are very much like tortoises. They have the same curious "shells" enclosing their bodies, and the same sharp, horny jaws. But their legs are longer than those of tortoises, and are flattened and widened out so as to serve as paddles. If we could strip off the shell, we should find that the ribs are more free than in the tortoises.

Turtles are capital swimmers, and spend the greater part of their lives in the sea. Indeed, they hardly ever leave the water except for the purpose of laying their eggs. Most of them feed upon sea-weed, but one or two are carnivorous, and eat starfishes, small crabs, and the various creatures which we generally —although wrongly—call "shell-fish". 
That beautiful substance commonly called "tortoise-shell", which is so largely used for making combs, the handles of pocketknives, and other fancy articles, is the horny covering of the bony shell of the turtle.

These plates are generally taken from the Hawksbill Turtle, in which they are very large, and of fine quality. Each turtle

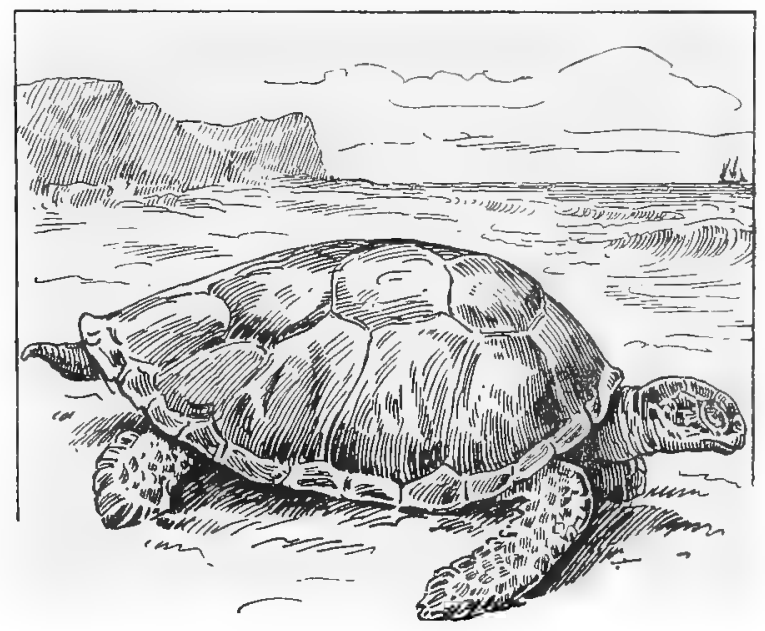

Green Turtle

yields thirteen. When they are first stripped off the plates are dry and brittle, and of no use at all for purposes of commerce. But after they have been steeped in boiling water they become quite soft, and can then be cleaned, and pressed flat between blocks of wood. If they are not thick enough, two or more plates can be firmly fastened together by laying a heavy weight upon them while they are still hot and wet. And by applying suitable pressure they can be moulded into any required shape.

Some turtles are very good to eat. From the flesh of the Green Turtle, for instance, the famous "turtle-soup" is madc. This turtle grows to a very large size, for specimens have often been found measuring more than four feet in length, and nearly 
three feet from side to side. A turtle of this size would weigh six or seven hundred pounds.

These creatures are captured in two ways.

Sometimes they are taken by means of a long spear, called a "harpoon". The head of this weapon is not fixed to the handle, but merely slips into a socket at one end; and the two are fastened together only by a cord. The hunters row out in a small boat, and, when they catch sight of a turtle, give chase, and plunge the harpoon into its shell. The frightened animal dashes swiftly away, and tries hard to shake itself free of the weapon. If the harpoon were just an ordinary spear it would probably succeed, but as it is barbed that is almost impossible. The turtle swims rapidly away from its pursuers; but the handle of the harpoon floats and hinders its movements and prevents it from diving. And before long the exhausted animal is overtaken and lifted into the boat.

But more often the turtles are captured at night, when they leave the sea and crawl up to the shore above high-water mark to lay their eggs. The hunters are on the watch, and, as soon as a turtle is far enough away from the water, they run up to it and turn it over upon its back. Sometimes the animal is so big that they cannot do this with their hands alone, but are obliged to use long poles as levers. Now when once it is overturned a turtle cannot escape, for its legs are not long enough even to touch the ground, and there it has to lie until the hunters come and carry it off to their boat.

When a turtle lays her eggs she scrapes a hole in the sand with her hind flippers. When she has dug down to a depth of from eighteen inches to two feet, she drops in her eggs, which are often nearly two hundred in number, and carefully arranges them side by side in regular rows. As soon as all are in position she collects the scattered sand, fills in the hole, and smooths the surface so neatly that it is not casy to see that it has been disturbed. And then she leaves them to be hatched out by the heat of the sun.

In about three weeks the little turtles appear, and at once make their way towards the sea. But numbers of enemies (birds 
and others) are on the watch for such dainty morsels, and many of them are snapped up before they can gain the friendly shelter

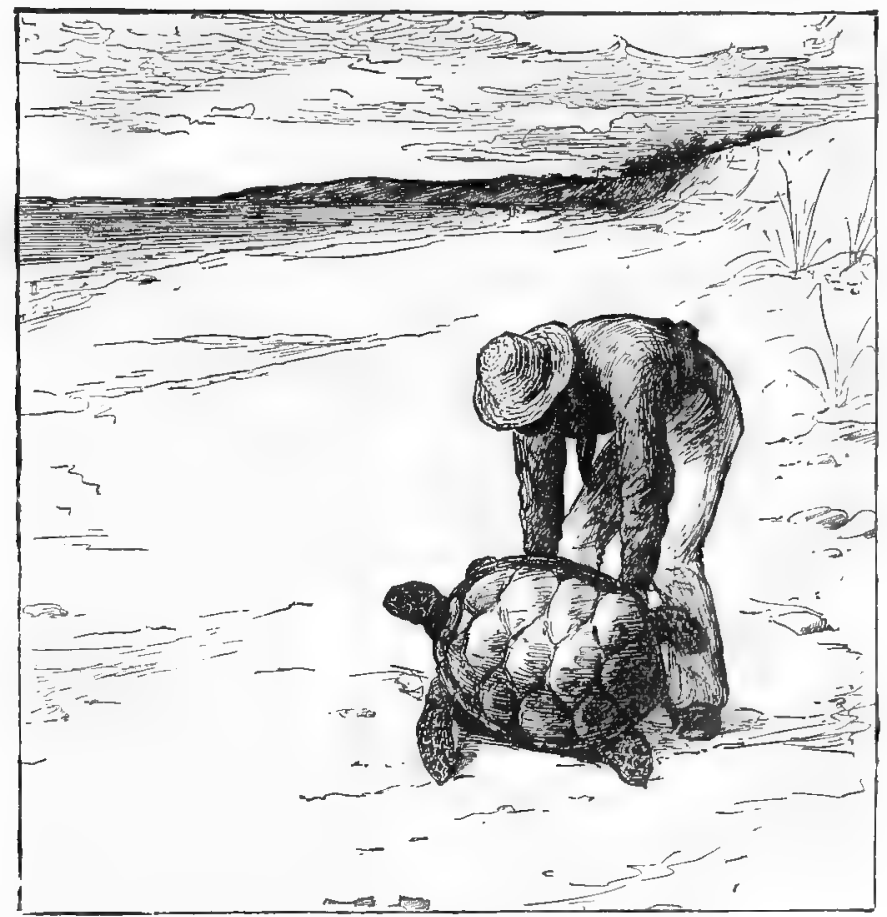

Capturing a Turtle

of the waves. But these animals multiply so rapidly that it is probably necessary that their numbers should be kept under.

\section{SQUAMATA}

While Lizards, Chameleons, and Snakes come under the one order Squamata, the two latter are separated from the former as sub-orders. They are all, however, part of the great Lizard group, 
which is further divided into some few families, as we may well suppose when we learn that the snake-like blind-worm and its allies are placed among the Lizards proper and not among the Snakes. The presence or absence of legs must not be taken as showing what is and what is not a lizard. While most "lizards" have well-defined legs and feet, some have only two, and these often so small as to be of little use, while others have none at all, and so at first sight might be taken for snakes.

It is this gradation of four-footed lizards into snakes that has probably more than anything else decided naturalists to associate this wide range of reptiles into the one order of the Squamata or Lizard group. All the lizards of to-day are comparatively small; for their larger representatives we have to look back to former ages in the world's history.

\section{LIZARDS}

Lizards are to be found in almost all parts of the world, but are most plentiful in the warm countries. Only two species are found in Britain, viz.: the sand-lizard and the viviparous lizard. The former is greenish, and the latter brownish, both being very prettily marked with dark spots. The one frequents sandy heaths, while the other prefers a bank near water, in which it may sometimes be seen swimming.

Like all reptiles, the lizard is protected by scales. Its head and body are flat and narrow, and its tail is very long, sometimes twice as long as the rest of the body. The tongue of the lizard is peculiar. One might almost think that the animal had two tongues; but it has only one, which is slit at the point, and also on each side a little farther back.

The young are produced from eggs, which are generally left to be hatched by the heat of the sun. But one species, the viviparous lizard, produces its young alive. These are able to run about as soon as they are born, but the parents take care of them till they have gained some experience. 
Lizards, when alarmed, will often cast off their tails, which they have the power of reproducing.

There are a great many different species of lizards, and some

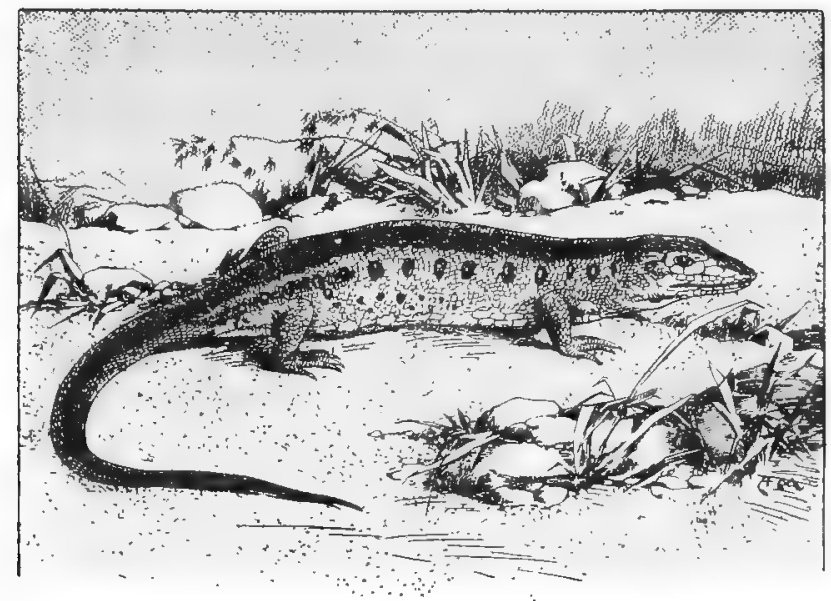

Lizard

of them are very beautiful and varied in colour. Others, too, change their colours like the chameleon.

These animals are sometimes caught and kept as pets, and they become quite tame.

\section{THE IGUANA (Family IGUANIDE)}

This family of lizards may be taken as a typical group. It is a large family, embracing at least 300 species, and these are placed in about fifty genera; which shows us that the study of lizards proper might alone occupy a lifetime. The Iguanas, whose chief home is South America and the West Indies, like most true lizards, are mainly either insect or vegetable feeders.

The Iguana is not a handsome animal. Its body is large and rather clumsy-looking, and is much too heavy for its limbs to support in ordinary fashion. A row of spines, too, that runs along 
its back gives it a very formidable appearance; and the curious hanging pouch underneath its chin makes it look more uncouth still.

If you approach it, it does not attempt to run away, but tries to make itself look more fierce than ever, by puffing out its pouch, and lashing its long tail from side to side. Indeed the animal is

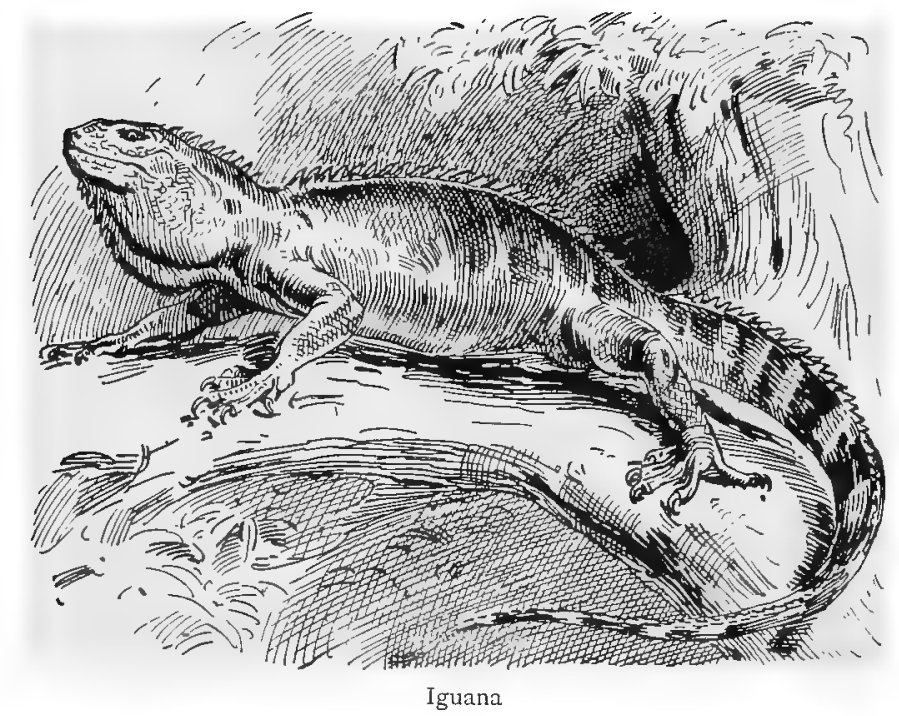

very easily caught; for you can get so close to it that you simply have to make a noose at the end of a long cord, and slip it over its head.

That is the way in which the hunters generally capture an iguana; and then, with a sharp jerk, they bring it to the ground. If they want to take it away alive, they tie up its mouth, for its teeth are very sharp, and it well knows how to use them.

One would naturally think that if kept for weeks without food it would starve to death, but, like a great many other reptiles, it can live for a long time without food. The green turtles, to which we have already referred, are often kept in the hold of a ship for several weeks without food; and the iguana can live 
quite as long with nothing to eat, and seem none the worse for its long fast.

After they have caught them and taken them home, the hunters sell the iguanas for food. One would scarcely think that that ugly, fierce-looking reptile would be very good to eat; yet its flesh is very delicate, and is said to be quite as good as the breast of a spring chicken. Iguana cutlets, too, are considered a great dainty; so when an iguana is caught there is not much difficulty in selling it.

When the iguana finds that it cannot frighten away intruders, it begins to think of moving away itself. If it only thought of this in time it would not be so easily caught, for it climbs well in spite of its clumsy-looking frame, passing briskly from branch to branch, and moving along quite easily and quickly.

When it is alarmed an iguana will often jump into a river or other water, for it can swim well and swiftly. With fore-legs stretched out in front, and hind-legs pressed closely against its body, it propels itself by means of its long tail, which it waves to and fro in the water just as a crocodile does. And it need be in no fear of drowning, for it can hold its breath so long that, if it were plunged under water, and held there for a time, it would not be much the worse when it was released.

\section{THE BLIND-WORM}

Crawling through the grass in a meadow, or on a heath, we sometimes see a brown, slender animal, about a foot long, which looks like a snake. It has no yellow patches behind its head, however, like a common snake, and no chain of black markings down its back, like a viper. We thus know that it is not a snake at all, but only a lizard without legs. It is called the Blind-worm, and it cannot bite us or hurt us in any way.

Perhaps we think that we should like to look at it more closely: and we stoop to pick it up; and then probably a most curious thing will happen. Instead of gliding away, the blind-worm begins to jump up and down in the air! 
This takes us quite by surprise, and for a minute or two we only look at it and wonder what it can possibly be doing. When at last we seize it we find that we have caught, not the blind-worm at all, but only its tail, and that the head and body are now nowhere to be seen.

The fact is, that when the blind-worm thinks that it is in any danger, it has the power of snapping off its tail just where it joins the body. Stranger still, the tail at once begins to twist

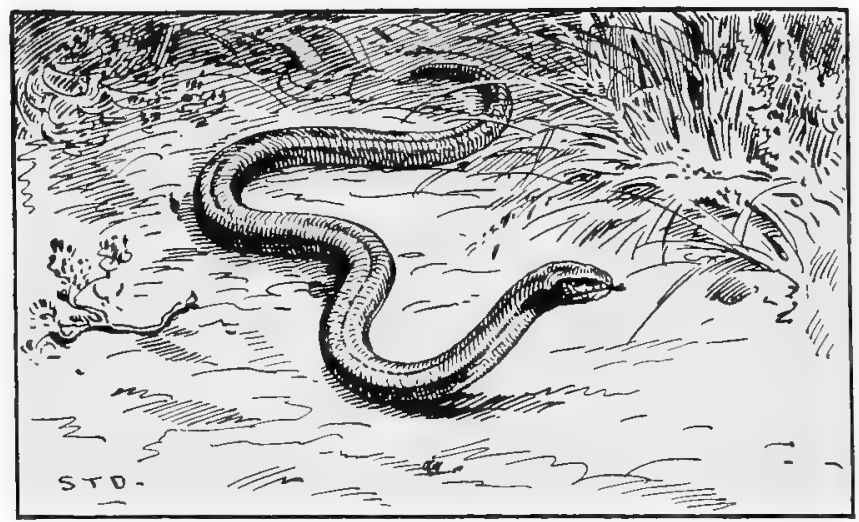

Blind-worm

and spring about as described above, and continues to do so for some little time. The attention of the blind-worm's enemy is quite taken off by this; and while he is watching it the blindworm itself creeps quietly away.

But, it may be asked, does the blind-worm not die after receiving such an injury? No! on the contrary, the wound heals over at once, and very soon a new tail grows in the place of the old. This power of throwing away certain parts of the body is possessed by many animals. Several species of lizards, crabs, and lobsters, and some star-fishes, are known to do the same thing. You may frequently find a blind-worm which has a rather short and blunt tail. You may be quite sure that this is a second tail, and that the first one was snapped off. 
Why this pretty little lizard should be called a blind-worm it is not easy to say, for it is not blind, but has a pair of sharp though very small eyes. As you watch it you will see that it keeps darting its little black tongue in and out. Many people think that this tongue, which is forked like that of a serpent, has a poisonous sting. But that is a mistake; the blind-worm could not hurt us in any way.

We never see a blind-worm in the winter, for then it falls into a long deep sleep, in which it feels neither hunger nor thirst. As soon as the warm spring evenings arrive, however, and the slugs come out to feed, the blind-worm wakes up and comes out too.

The blind-worm is really useful, and ought to be encouraged rather than destroyed, as is too often the case.

\section{THE CHAMELEONS (Sub-order RHIPTOGLOSSA)}

The Chameleons form a sub-order by themselves, being distinguished from the true lizards by several characteristic features. But these do not destroy their relationship to the lizards, nor to the snakes which follow.

Nearly fifty species of chameleons are known, and they are found chiefly in Africa, Madagascar, and the neighbouring islands. We shall consider one as a type.

This singular little lizard is one of the strangest animals in all the world. Not on account of its size-for it is only a small creature, never more than a few inches in length-but because of the wonderful power which it possesses of changing the colour of its body.

Generally its colour is bright green, like that of the foliage among which it lives. But often, even while one is watching, it will turn to blue, or to dull brown, or to a dirty yellow! or a number of dark spots may appear upon it; and by and by these spots will run into one another, and become stripes. Then by degrees the colour will change back into the original green. But stranger than all this is the fact that no one has been able to find out how this wonderful change of colour is produced. 
All who see the chameleon are much interested by its curious eyes. These are very large, and project from the head in a very singular way. They are almost entirely covered with skin, and the animal can only see out of a small round hole in the centre.

But these eyes can be moved at the same time in different directions! One eye perhaps is looking upwards or forwards, while the other is looking downwards or backwards. Thus the animal can really see before and behind it at once.

The tongue of the chameleon is very curious. It is very long and slender, with a cup-shaped tip, and is extremely sticky, like that of the frog or the toad.

This tongue can be darted out with

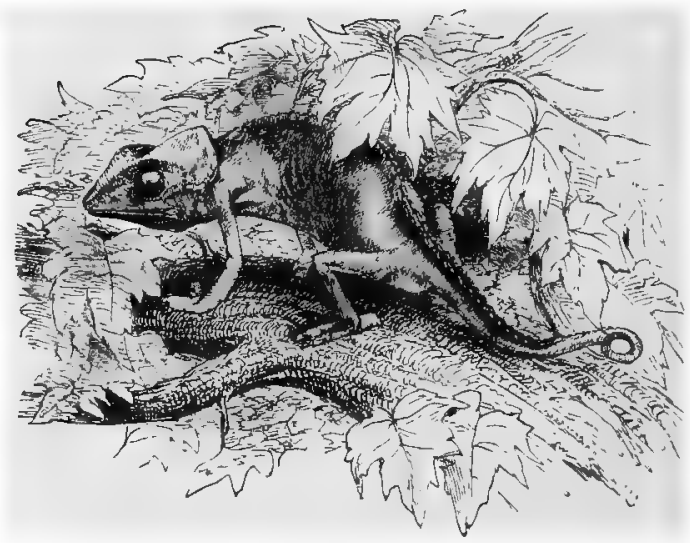

Chameleon

lightning-like speed; and the animal takes such good aim with it, that it hardly ever misses a fly or other insect which has settled anywhere near it.

The chameleon always lives in trees; and its little paws with their sharp claws are very useful for climbing and grasping the branches. Its tail, too, can be coiled tightly round a branch, just like that of a spider-monkey or an opossum; it forms a kind of fifth hand, as it were, and is of very great assistance.

When a chameleon is climbing about in a tree, it hardly ever moves a single step until it has curled this useful little tail tightly round some convenient branch, in order to make sure of a firm hold.

It is very leisurely in its movements; indeed, the chameleon is never in a hurry. If it lifts a paw into the air in order to make a step forward, it will very often wait for ten minutes or a quarter of an hour before putting it down again. 


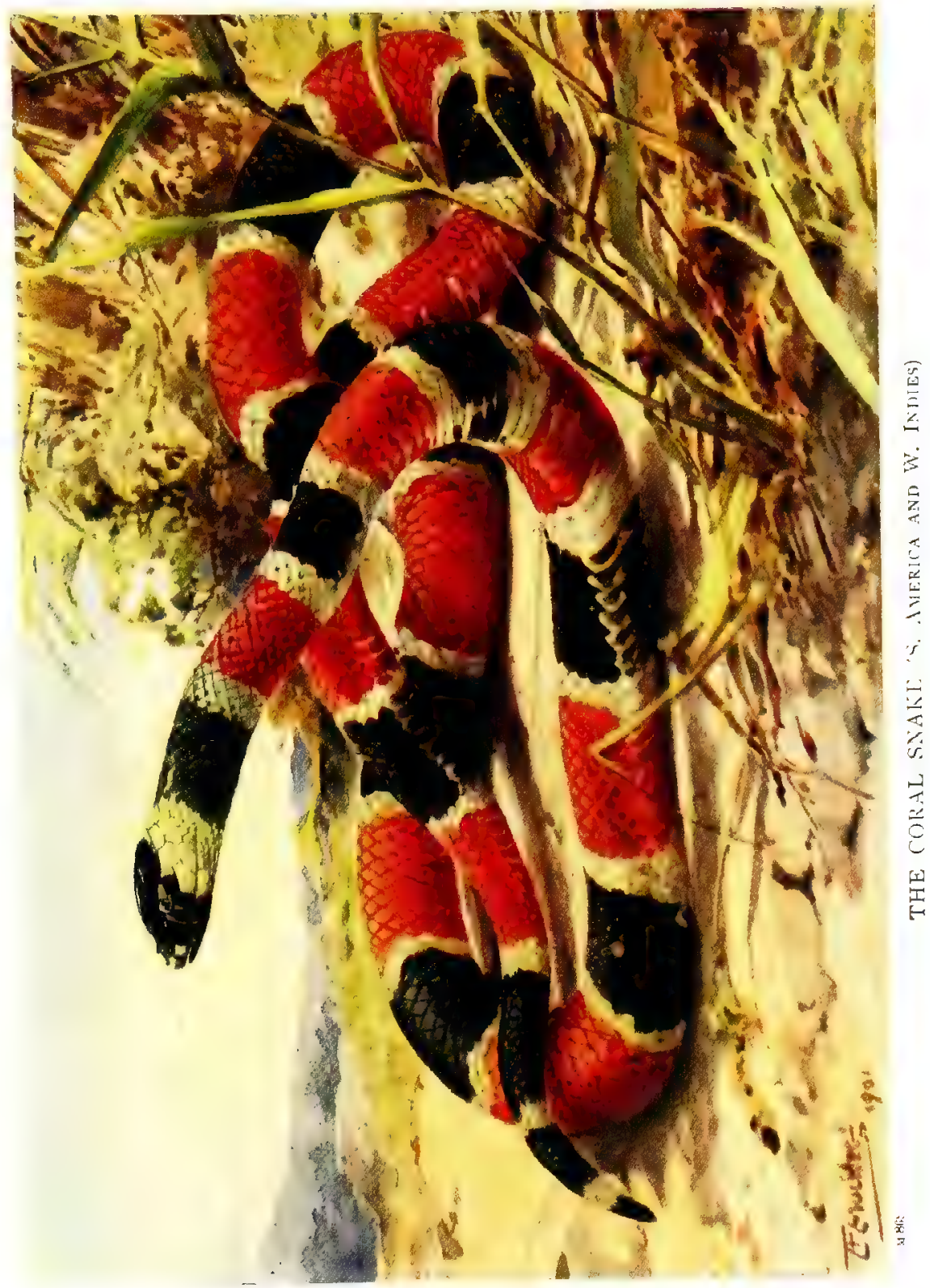



In the course of a whole day it may possibly not move a yard from the spot where it spent the previous night. Nothing excites it, and nothing alarms it; and even when it sees an insect, it hesitates about catching it for so long that very often it loses its expected victim.

\section{THE SNAKES (Sub-order OPHIDIA)}

While we are still among the great order of Reptiles, the Squamata, we have reached the Ophidians, the true snakes. This sub-order contains a very large number of species. About fifteen hundred species are known, but they are scattered the whole world over, except in New Zealand, and in places, as in parts of Asia and tropical America, they occur in great abundance.

This sub-order is divided into several families.

\section{PYTHONS, BOAS, ANACONDAS (Family BOIDE)}

Passing by one or two families of small Ophidians, called Blindsnakes, we come to the most formidable family among them all. This includes the largest of the snakes.

\section{THE BOA CONSTRICTOR}

The serpent which we call the Boa Constrictor is, with the exception of the anaconda and the python, the largest and most powerful snake in the world. It lives in the swampy forests of tropical America and Madagascar, and sometimes grows to a length of twelve or fourteen feet. In girth of body it is equal to the thigh of a man. It is so strong, moreover, that it can crush a deer or dog to death in a few minutes.

When the boa constrictor is watching for prey, it usually conceals itself in a tree, with its tail coiled tightly round a stout branch. When an animal passes within reach, the snake darts at it, seizes it with its jaws, and then, with the speed of lightning, folds it in the coils of its body, and proceeds to crush it to death. 
It does not merely tighten the folds, as many people think, but places one coil upon another. This it does in order to be

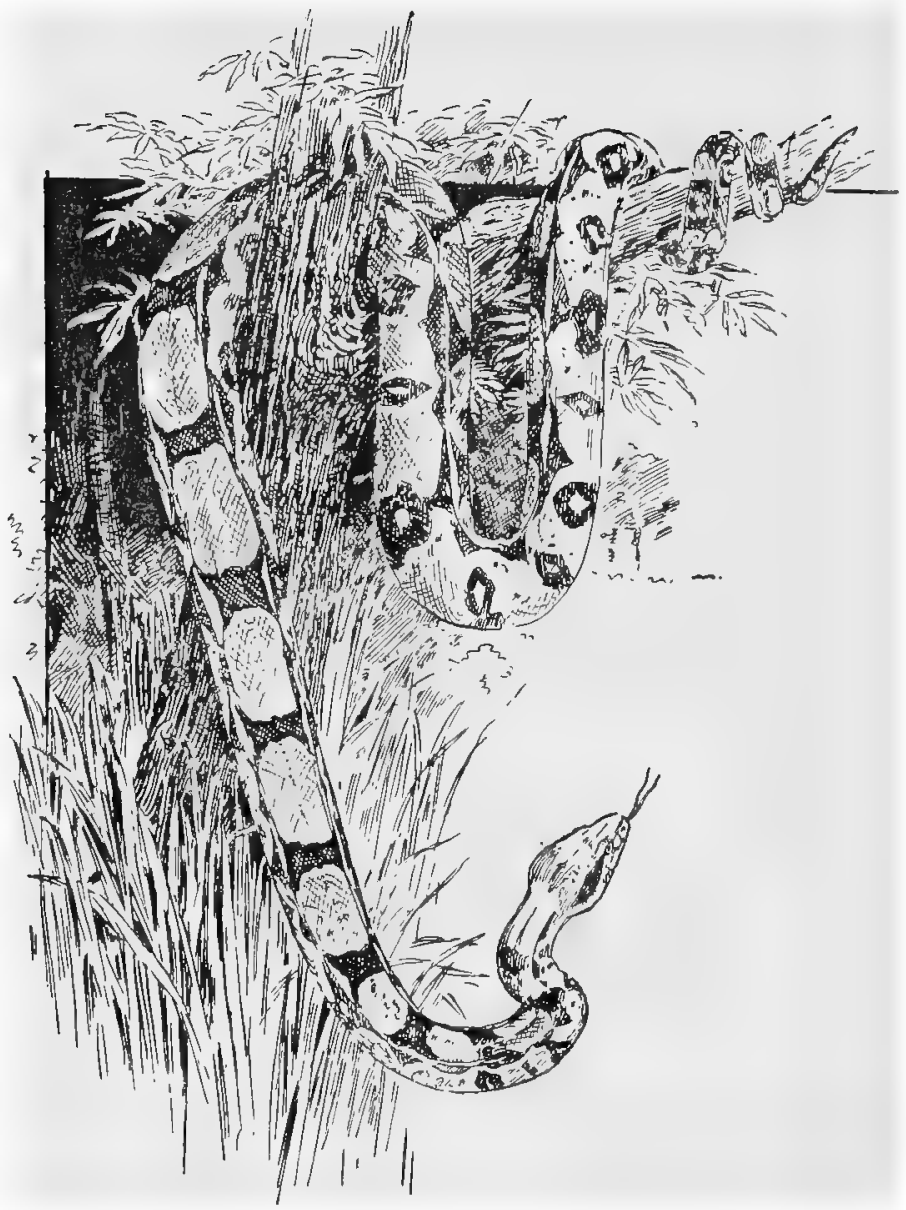

Boa Constrictor

able to press the harder; just as we ourselves enclose one hand within the other when we want to squeeze some object very hard indeed. 
So great is the strength of the boa, that in a few seconds the victim is not only dead, but crushed into a shapeless mass; and then the snake proceeds to eat it.

At first sight this would seem a very difficult task, for snakes cannot tear their victims into pizces, as many creatures of prey do. They are obliged to swallow them whole; and the animals killed by the boa constrictor are often larger in diameter than its own body. How, then, is it to swallow them?

Both the jaws, and the throat and body of the boa constrictor, are formed in a very curious way; for the former can separate one from the other when necessary, while the latter can be stretched almost indefinitely. And by slow degrees the boa swallows its victim, whose outline may often be clearly traced through the highly-stretched skin of the snake's body.

After such a feast it does not require any more food for some time, and generally goes to sleep for several days, while its meal is being digested. It can always fast for several weeks, if necessary, without seeming to suffer from hunger.

The boa constrictor is not one of the venomous snakes, and has no poison fangs in its mouth. Its palate, however, is lined with several rows of curved teeth, which all point towards the throat. These help it very much in swallowing its prey; for they hold it firmly in position, and do not allow it to be forced back by the pressure of the muscles of the neck.

The Anaconda is so much like the boa constrictor that it is often mistaken for it. This snake seldom attacks man; but the natives are very much afraid of it, and will never go near the pools in which it is so fond of lurking.

The anaconda is larger than the boa constrictor, being sometimes upwards of thirty feet in length.

The Python, which has been known also to attain the length of thirty feet, is confined to the tropical countries of the Old World. It has no poison fangs, but crushes its victims like the boa. One peculiarity of this snake is that it coils itself round its eggs, and protects them until the young are hatched. 


\section{THE COBRAS (Family COLUBRID}

The Cobras are by no means the only snakes in this family, but they are the best-known. The family is larger, so far as the number of species is concerned, than the preceding one, but in the size of its individual members it is, as a rule, considerably smaller.

\section{THE COBRA-DI-CAPELLO}

This is a capital type of the family. It is one of the most deadly of the venomous snakes, and is found only too plentifully throughout almost the whole of India. So poisonous is its bite, that when once its fangs have pierced the skin no remedies are of any avail, and death invariably follows in from one to two hours after the wound is received. And, although a reward is paid by the government for every cobra's head that is brought in, many thousands of people are killed every year in India by this snake alone.

A man was once killed in the Zoological Gardens of London by the bite of a cobra. He was in charge of the serpents, and was quite aware of their dangerous character. One day, however, in a fit of intoxication, he seized a cobra by the tail, and began to swing it round and round his head. As quick as thought the angry reptile made a dart at his forehead, and just pricked him with its fangs between the eyes. The wound was only a slight one, but in little more than an hour he was dead.

There are certain men in India who do not appear to be at all afraid of these terrible serpents. These are the famous "snakecharmers", who will handle cobras quite freely, and scarcely ever seem to receive a wound from their poisonous fangs. It is said that the snakes with which these men perform their startling tricks have been carefully deprived of their fangs, and so are perfectly harmless. But although this is no doubt true in many cases, it is not true in all.

In one respect the cobra differs from all other snakes, for 


$$
1
$$


it can dilate its neck at will, so that it looks like a kind of broad hood. In order to allow it to do this the upper ribs are flattened, and are so formed that they can be considerably raised or lowered. This "hood" is always spread when the reptile rears up to strike, and gives it an unusually formidable appearance.

The food of the cobra consists chiefly of small animals, frogs, and insects; but it is fond of birds' eggs, and will often rob a nest of its contents. If it finds a hen-roost, too, it will creep inside and search for eggs.

Like many serpents, the cobra is very fond of milk, which it laps up with its long forked tongue. Once a man's life was saved by a knowledge of this fact. A party of officers were sitting round a table in India, engaged in a game of cards, when one of them felt something gliding up his leg. Looking down, he was horrified to find that it was a cobra, and gave himself up for lost. One of his brother officers, however, ran quickly into the kitchen, fetched a saucer of milk, put it down upon the ground; and almost directly the cobra came down to it, began to drink, and was killed.

Another kind of cobra, called the Haje, is found in Africa. It is very venomous, and is said to possess the power of spitting its poison to a distance. For this reason it is often known as the "spitting snake". A well-known traveller tells us that on one
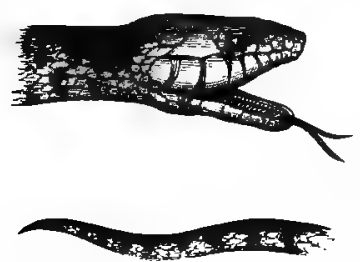

Head and Tail of Common Snake occasion a haje spat a drop of this poison into his eye, which became very much inflamed, and pained him greatly for several hours.

Two of the three British snakes are included in this family, namely, the Ringed or Grass Snake and the very rare Coronella.

We may recognize the former at a glance by the bright yellow patch on either side of the neck, just behind the head, and also by the double chain of small dark spots which run along the back. On either side of the body, too, is a single row of somewhat larger spots. This snake is quite harmless. 
It is not advisable, however, to handle it without taking the precaution of first putting on a pair of thick gloves, for it can pour out a powerful and most disagreeable odour, which clings to the fingers for hours, and can scarcely be removed even by repeated washings. When the snake is kept in captivity it soon

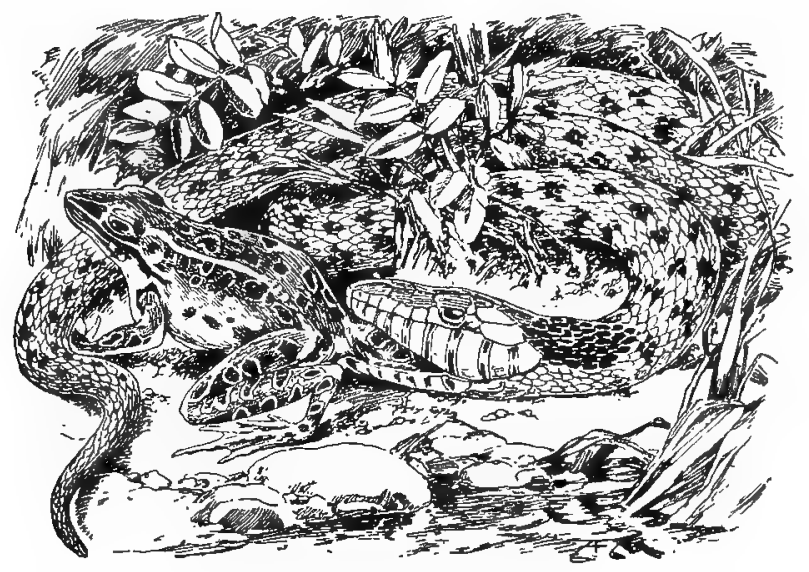

Grass Snake swallowing a Frog

learns to know its owner, and will submit to be handled without making use of this singular means of defence.

The grass snake delights in hedgerows, and we may often hear its peculiar rustle as we walk along a country lane. If we can contrive to watch it for a moment or two we shall notice that it continually darts its slender forked tongue in and out of its mouth. Many people imagine that the tongue is poisonous, and are very much afraid of the snake in consequence. It is not so, however, and the tongue of even a venomous snake is perfectly harmless.

Next comes the Coronella, which is so scarce in this country that we are not at all likely ever to meet with it. It is also quite a harmless snake, and may be known by the dark patches upon the head and neck, and also by the black streak under each eye. Along the back runs a double row of black markings, similar to those of the grass snake. 


\section{VIPERS (Family VIPERIDÆ)}

The Adder, which is the third British snake, is a good type of the Viper family. It may easily be distinguished from the two alrcady mentioned by the zigzag chain of lozenge-shaped black markings which runs along the spine.

This snake lives chiefly upon heaths and sandy commons, and is fond of lying coiled up in the sun, in which position it bears so strong a resemblance to a piece of twisted stick, that a passer-by might easily tread upon it before discover-

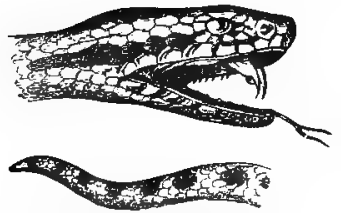

Head and Tajl of Common Viper ing its real nature. It is a venomous snake, and a wound from its poison-charged fangs is sufficient to cause serious illness, and has occasionally been known to result even in death.

The fangs of a viper are very curiously formed. They are situated in the upper jaw, one upon either side, and lie back upon the roof of the mouth when they are not required for use. Were it not for this provision, the snake would experience great difficulty in swallowing its food. Each fang, however, is surrounded by strong muscles, which throw it forward when the head is raised to strike, and hold it firmly in position until after the blow has been delivered.

Just behind the sharp point of each fang is a tiny hole, shaped somewhat like the eye of a needle. This hole opens into a channel which runs through the tooth, and communicates at its base with a small sac, or vessel, in which the poison is contained. It will thus be seen that, when the stroke is delivered, the pressure upon the tooth forces a small drop of poison out of the sac and through the channel, and so into the flesh of the victim.

The poison fangs of a viper are nearly transparent, and are almost as brittle as glass. If one of them should be broken, however, there is always a new one lying beneath it in readiness to take its place. If the head of a viper be carefully dissected, 
as many as four pairs of these fangs can be seen, each in a more undeveloped state than the last.

Like almost all venomous snakes, the viper is a timid creature, and will always attempt to make its escape if danger should threaten it. If it be brought to bay, however, it becomes a very formidable antagonist, for its stroke is made with such lightninglike rapidity that it can with difficulty be avoidied.

The young of the viper are from ten to fifteen in number, and look like worms with very large broad heads. For some little time after they are born they travel about with their mother. It has sometimes been said that, in times of danger, the little vipers crawl into the mother's mouth, and take refuge within her body. But whether this is really the case is a matter of considerable doubt.

\section{AMPHIBIANS OR BATRACHIANS (Class Amphibia)}

A careful study of Frogs, Toads, Newts, and Salamanders has shown us that we can no longer consider these creatures to be "Reptiles", although they are unquestionably related to them. Neither can we as a whole describe them as "Batrachians", as this term can only correctly be applied to frogs and toads, and thus the newts and salamanders would be incorrectly included.

But inasmuch as the whole of the animals of this group are amphibious their comprehension under the new class-name of Amphibla is an excellent one.

These amphibians are separated from the reptiles because of certain characteristics in their life-history and in their structure, some of which characteristics suggest a relationship to much lower animal forms; for instance, the metamorphoses (i.e. changes of form) through which many of them pass between the egg and the adult stages.

Before the adult stage is reached many show a distinct relation- 
ship to fishes, and so they form a kind of connecting-link between the fishes and the reptiles. As an example of this, in their younger stages they breathe by means of gills and live entirely in the water; when the adult stage is reached they breathe by means of lungs, although they still live largely in the water, and they are then more closely allicd to reptiles. In a fow instances gill-like appendages
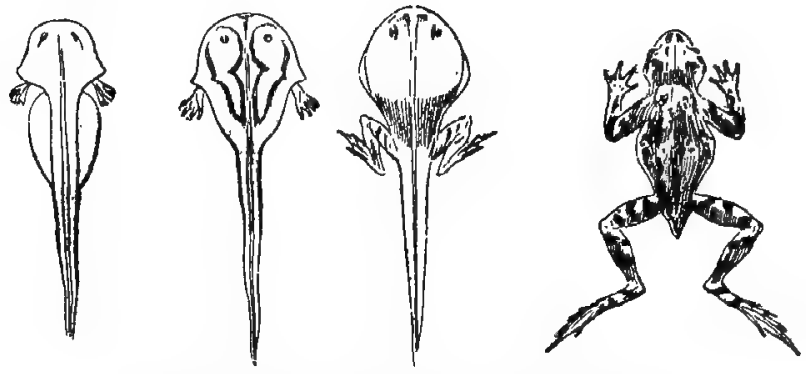

Different Stages in the Development of the Frog

remain with them through life, so that they to some extent respire water as well as ordinary air.

In former ages giant amphibians existed. The whole group is now, however, made up of small animals. They have a worldwide distribution, if we except the frigid zones and dry deserts, but they are most common in moist tropical and sub-tropical regions.

A distinction is made in the animals of this great class by its division into separate orders, the frogs and toads forming the order Ecaudata, the newts and salamanders the order Caudata, and a few worm-like amphibians the order Apoda.

These orders are divided into a good many families, which embrace a great number of species. 


\section{ECAUDATA}

\section{THE FROGS (Family RANIDæ)}

While it is quite young the Frog lives in the water altogether. At that time of its life we call it a tadpole, and we may see it swimming about in almost any pond during the spring.

Tadpoles come from the jelly-like eggs which we often see floating in great masses upon the surface of ponds. If we look at one of these eggs we see that there is a round black spot in the middle. This is the future tadpole, and by and by the egg bursts, and it comes out into the water. It is an odd-looking little creature. Just a round black head with a tail coming out of it, and no body or legs at all. That, indeed, is why it is called a tadpole, for the word is really "tailedpoll" or "tailed-head".

All day the little tadpole swims about in the pond, eating as much as it can. Before long two little legs begin to show themselves behind the head. By and by another pair of legs appears

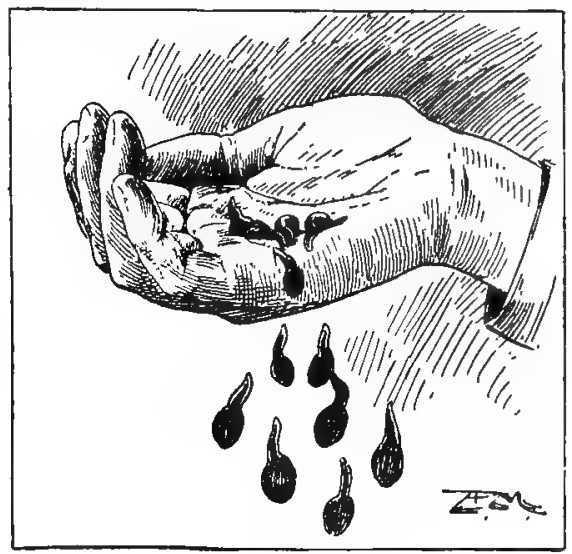

Tadpoles in front of these, and then we see that the tadpole is fast getting a body, as well as a head and tail. Strange to say, however, the tail, instead of growing, now becomes smaller and smaller, until at last it disappears altogether.

Another change has been taking place in its body. All this time the tadpole has been breathing water, like a fish, by means of gills, which we could easily see on either side of its neck. But now these have vanished, like the tail, and a pair of lungs have taken their place. Thus our tadpole, which used to live in the 
water only, has become a frog, which can live either in the water or on land.

The frog catches a fly in a very curious way. Its tongue, instead of being formed like ours, is reversed, as it were, with the root just inside the lips, and the tip down the throat. This tongue

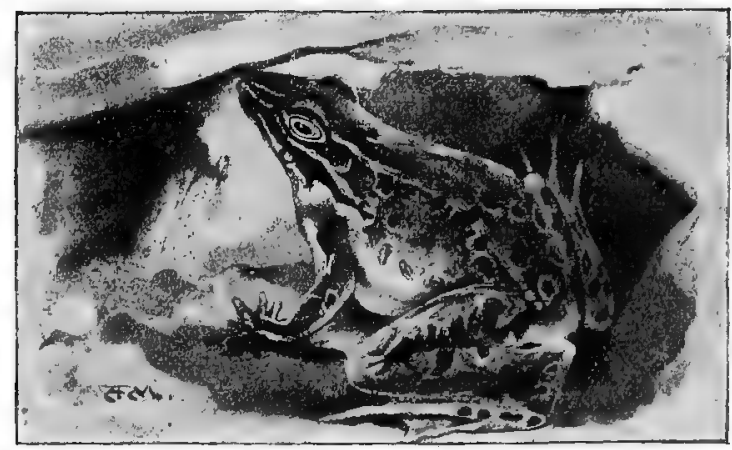

Frog

is very sticky, like that of the night-jar, so that if it once touches an insect it holds it quite firmly.

When the frog sees a fly within reach, it takes careful aim, darts out its tongue, just touches its victim with it, and draws it back. The fly sticks to the tongue, and is carried into the frog's mouth; and so quickly is it caught and swallowed that you can harrdly see the operation.

Frogs are very useful to us, for they destroy all kinds of mischievous insects. Good gardeners, therefore, are very glad to have them in the garden, and will sometimes even purchase them if they do not find a sufficient number there already.

Most of the frogs and toads are nocturnal in habit, as they cannot bear dry air; a few exist in shrubs and trees, but always in moist situations.

\section{THE TOADS (Family BUFONIDÆ)}

Toads vary from the typical frog so far as to be placed in a family by themselves. Their differences to the common observer 
are, however, not in build, but in the way in which they use their limbs, and in variations in their coats or skins. Toads usually have rough and "warty" skins, and they never hop like frogs but crawl about in a more or less laboured fashion. Their hind-limbs are much shorter than are those of the frogs.

The eggs of the toad are laid later in the spring than those of the frog, and the little tadpoles, when they hatch out, are smaller and darker in colour.

All through the summer these tadpoles grow, but very slowly; for, when their tails disappear and they become perfect toads, they

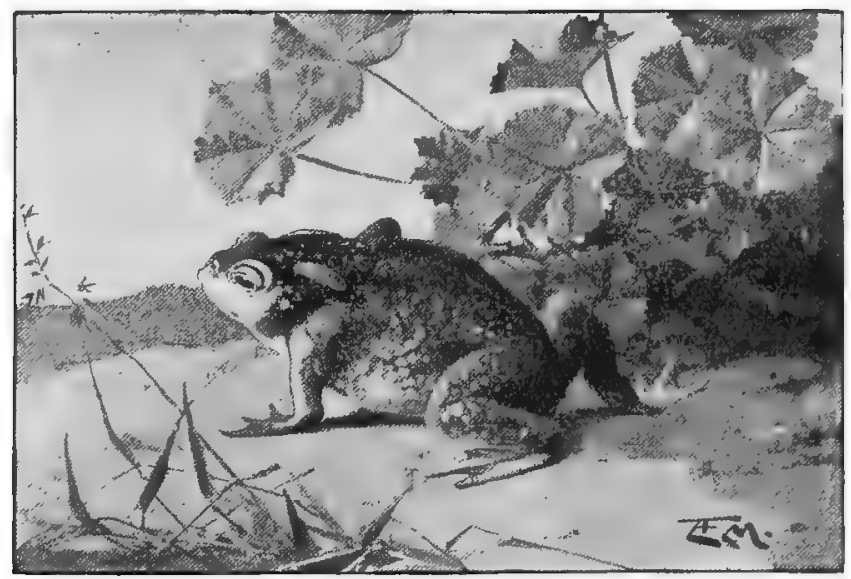

Toad

are only about as big as blue-bottle flies. About the end of August these tiny toads are sometimes very plentiful in damp situations, and one sees them scrambling about in all directions. But so many of them are captured and devoured by their foes that it is said that only about one in a thousand lives to grow up.

If you examine a toad carefully, you will see that just behind nis head are two large glands. If these are pressed, a thick oily liquid oozes out. This liquid is strongly acrid, and will make a delicate skin smart if it falls upon it. A dog, too, if he picks up a toad and happens to squeeze one of these glands, will drop the 
animal immediately, and begin to foam at the mouth. And in such a case he can very seldom be induced to take up a toad again.

Perhaps it was the possession of this liquid that gave rise to the old idea that toads are poisonous. In some parts of the country, even now, these animals are dreaded far more than adders, while

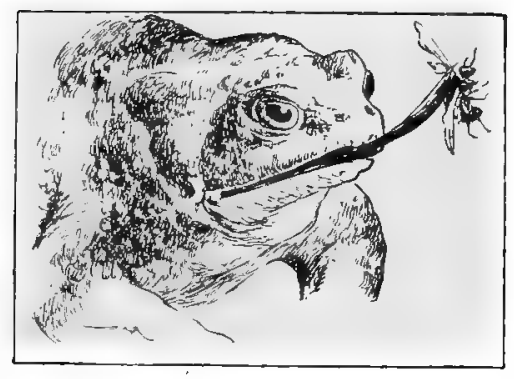

Toad catching its Prey they are even said to spit fire into the wounds which they inflict!

That many of these animals do secrete a virulent substance in certain cells in their skins is well exemplified in the fact, that in some parts of the world matter obtained from their skins is used by the natives for poisoning their arrows.

Another curious legend concerning the toad is, that it carries a very valuable jewel in its head, which disappears as soon as it dies. And it was said that the only way to obtain this gem was to place the animal on a piece of scarlet cloth. The toad, in its delight at the brilliant colour, would then drop its precious treasure for a moment, so that a quick hand might gain possession of it!

Toads, like frogs, live chiefly on insects, and have tongues formed in the same curious way. Sometimes, too, a toad will eat a worm. It is very amusing to watch him doing this, for the worm, which he always seizes by the middle, twists and wriggles about, and for some little time prevents him from swallowing it. But at last he seizes it with his fore paws and crams it into his mouth; and then, with a sudden gulp, it is gone.

At times, too, the toad swallows a still more singular article of diet. This is his own skin! Every few months he casts his skin, like a snake; and as soon as he has thrown it off, he seizes it with his paws, rolls it up into a ball, and swallows it! 


\section{CAUDATA}

\section{NEWTS AND SALAMANDERS}

Although Newts ana Salamanders are nearly related to the Frogs and Toads, there is a marked difference in their adult forms. The latter are then, as we have seen, without tails, while the

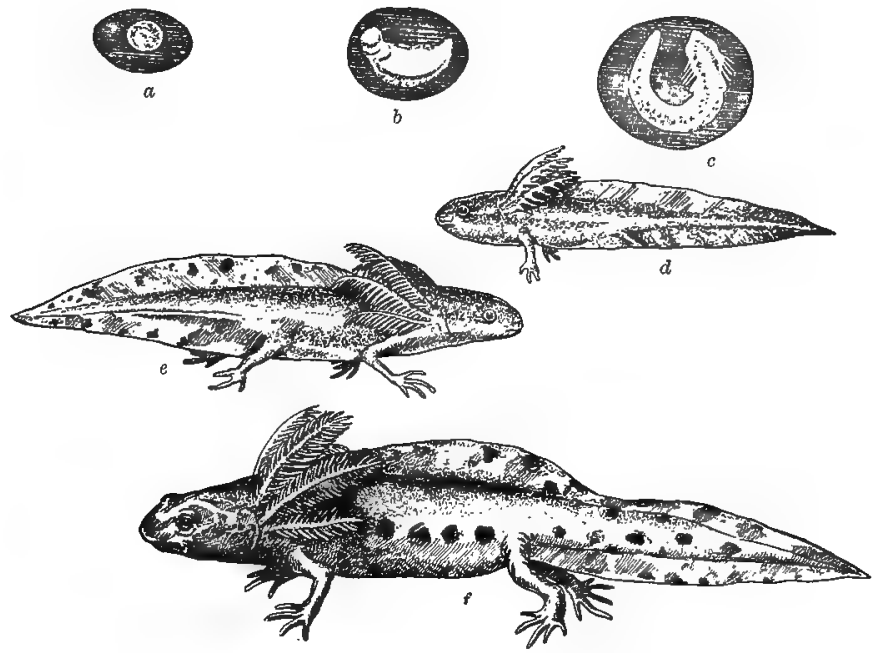

How the Newt Grows

$a-c$, Change within the egg; $d$, with gills and front pair of feet; $e, f$, with both pairs of feet.

former possess tails of great development which serve the purpose of propellers in the water.

A few of the newts and salamanders have no hind-legs, and one group has no legs at all. These form the order Apoda to which we have referred above, apoda meaning simply without feet.

The newts and salamanders are more devoted to an aquatic life than the frogs and toads; but they are almost all lungbreathers, and so have to come to the surface of the water for air. 
This group of animals is almost confined to the northern hemisphere of the world. About one hundred and twenty species are known.

The common newt is as good a type of the group as one could wish.

The best way to catch newts is to fish for them with a small net, pushing it backwards and forwards among the weeds at the side of a pond.

But they may sometimes be caught in a simpler way still. All that is required is to tie a strong thread round the middle of a worm, and drop it into the water where a newt is likely to be hiding. The hungry little animal is almost sure to seize the vorm, and then, by a quick jerk, it can be brought out of the water before it has time to loose its hold.

Where newts are very plentiful, two are sometimes caught at once in this way, each having seized an end of the same worm.

Newts feed upon worms and the various small insects which they find swimming about in the water. They even eat tadpoles, too, their first cousins, soon after they come out of the egg, and before they are too big to be swallowed.

To see a newt eating a worm is a very curious sight. It does not seize it by one end, as we might expect, and then slowly devour it; but takes it by the middle, and swallows it in a succession of gulps.

The newt is a perfectly harmless creature. Its teeth are so small and feeble that it could not possibly bite us, and it is not poisonous in any way.

If we catch a number of newts, and keep them for a time in a vessel of clear water, we are sure before very long to see pieces of empty skin floating at the surface. The reason is that the newt, just like the snakes, toads, and frogs, throws off its skin every now and then, a fresh one having been formed underneath it. Even the toes of the tiny little paws are drawn out from their old covering, and we may often notice the empty skin of one of the feet floating by itself, and looking like a delicate fairy glove.

The eggs of a newt are laid in a very curious manner. They are not fastened together into a large, jelly-like mass, like those 
of the frog, or into long strings, like those of the toad, but are laid singly.

Such being the case, we might think that they would be in great danger of being devoured by fish or other water creatures. But the clever newt guards against such a misadventure, by twisting each egg carefully up into the narrow leaf of some water-

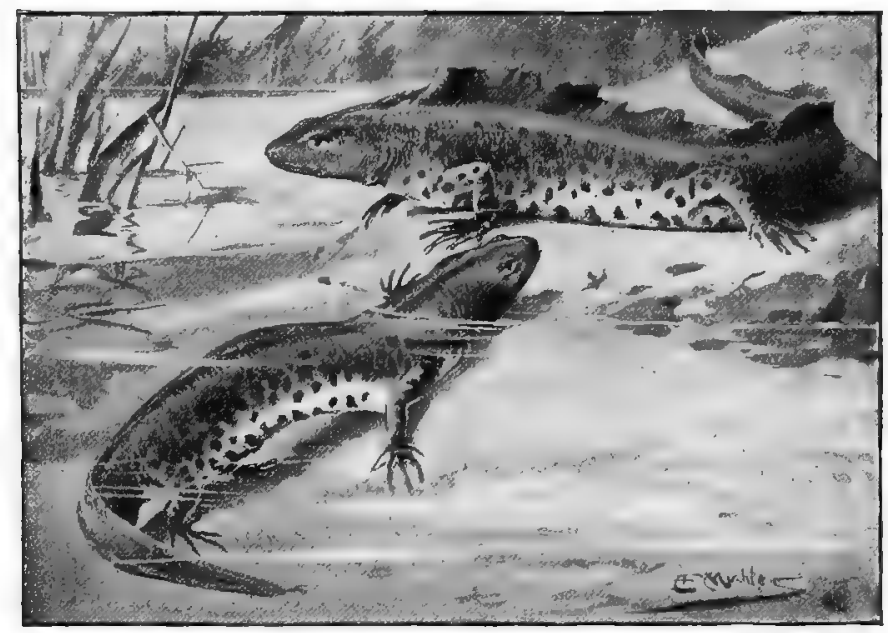

Male and Female Newts

plant. She doubles a leaf over, places the egg in the bend, and finally, with one twist of her deft little paws, she fastens it in its place, and quite conceals it from sight.

When winter draws near, the newt leaves the pond, and seeks for some underground refuge in which to live during the months of frost and snow. Often it will bury itself in the loose earth at the foot of a tree; and there it sleeps all through the winter, requiring no food, and scarcely breathing. No sooner do the warm days of spring come round, however, than it awakes from its slumbers, and leaves its hiding-place, and soon it is back again in its native ponds, hunting for worms and insects with which to satisfy its hunger after its long fast. 


\section{FISHES}

While Fishes as a class are easily distinguished from all other animals, they show their relationship to certain of the amphibians in the fact that a few of their members possess lungs as well as gills. These are styled Lung-Fishes; and they are not only allied to the newts and salamanders by the possession of lungs, but they are also somewhat like them in build. As a rule, however, fishes breathe by means of gills.

Instead of legs and arms, fishes are provided with fins, thin filmy webs stretched on a number of little bones. Sometimes these fins

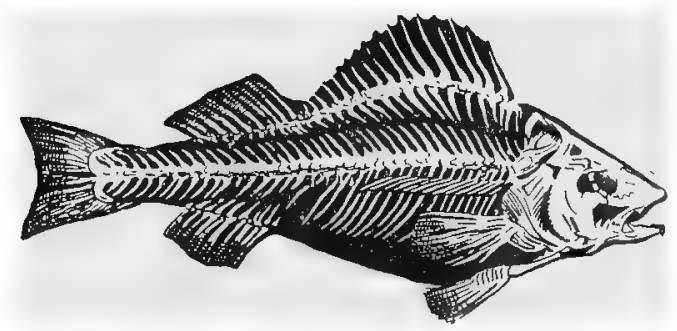

Skeleton of a Fish are very small, and sometimes they are developed to a wonderful extent, as in the case of the flyingfish.

The fishes are all cold-blooded, and as a rule possess hearts of only two chambers.

The heart of the lung-fishes, however, is a three-chambered organ.

Like the reptiles, the fishes are usually clothed with scales, but in some cases the skin is quite unprotected. Some few species are covered with bony plates.

Just as birds are specially built for flying through the air, so the form of a fish is perfectly adapted for moving through the water. The head is sharp, and the body is oval in form and narrow. The scales are placed somewhat like the slates on the roof of a house, but fixed towards the head, and directed backwards so that the water slips over them easily.

Perhaps the most interesting part of a fish is its breathing apparatus. If you open the gill-covers of a fish you will see a number of reddish arches. These are the gills; and they are red because all the blood is sent there from the heart, in order that 


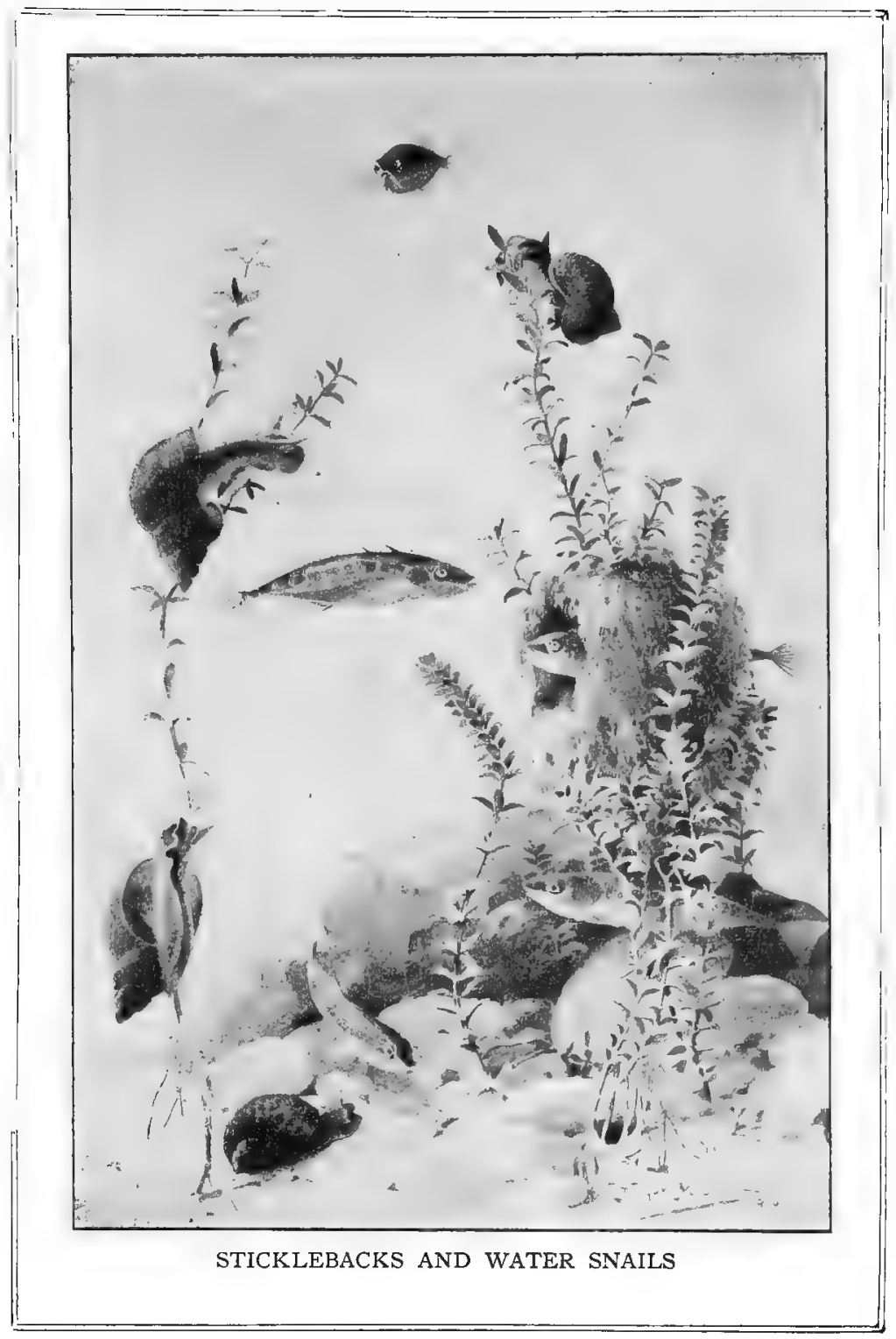


it may get a supply of oxygen before it is distributed through the body. Instead, then, of inhaling air as other animals do, the fish passes water through its gills, which absorb a great part of the oxygen which it contains. And this action is repeated incessantly.

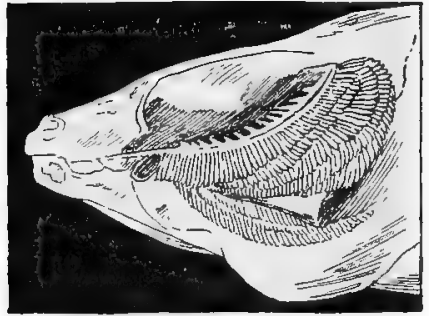

Gills of Fish

Most fish produce their young from spawn, as the jelly-like eggs of fish are called, and one female will lay thousands of eggs in a season.

While many fish deposit their eggs and leave the hatching to chance, some are very careful of their young. They build nests in which they lay their eggs, and guard them faithfully until the young can take care of themselves. The common stickleback of our ditches and ponds is a good example of the nest-building fish.

The forms of fishes are indescribably varied. While some are, from our view, intensely ugly, many are extremely beautiful in form as well as in colour. Some are as gorgeously coloured as the most brilliant of birds.

Many fishes are, like birds, migratory. They spend the winter in the deeper parts of the ocean, and in the spawning season they come to the shallower water near land. Some, for example the salmon, migrate from the freshwater rivers to the salt sea for a part of the year and return to their streams for the other part.

It is believed that fishes, in proportion to their size, have much longer lives than most other animals. Indeed it is thought that, if not destroyed by their enemies, they attain to a very great age. Pike and other fish have been known to attain ages varying from fifty to eighty years.

It will be enough for us, so far as classification is concerned, if we try to understand that the great class of fishes is divided into four sub-classes, as follows-

I. The Lung-Fishes-DipnoI.

II. The Chimæroids-Holocephall.

III. The Bony Fishes and Ganoids-Teleostomi.

IV. The Sharks or Rays-ElasmobranchII. 
The only fishes of which we shall have occasion to speak belong to the last two sub-classes; not many species are included in the first and second. But almost all the fishes with which we are, or are likely to be, acquainted belong to the third sub-class-the Teleostomi. There are not nearly so many of the sharks and rays.

\section{TELEOSTOMI}

\section{THE SWORD-FISH (Family ZIPHIID E)}

In the days of wooden ships it was occasionally found, when a vessel was brought into dock to be scraped and cleaned, that a long

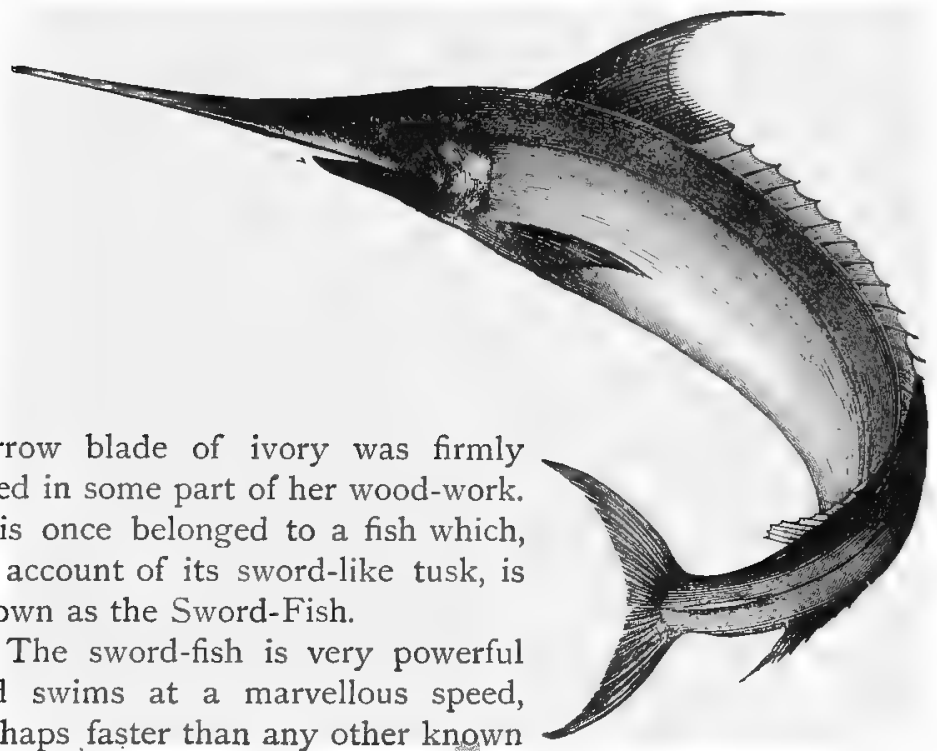

narrow blade of ivory was firmly fixed in some part of her wood-work. This once belonged to a fish which, on account of its sword-like tusk, is known as the Sword-Fish.

The sword-fish is very powerful and swims at a marvellous speed, perhaps faster than any other known fish. Its upper jaw is elongated into a sharp sword-like beak. Armed with Common Sword-fish this formidable weapon it goes in search of its prey, and when it sees a likely victim, rushes at it and transfixes it. A shoal of 
sword-fish have been known to attack a whale, and succeed in stabbing it to death.

But nothing could show the strength of the sword-fish better than the way in which it drives its sword into the bottom of a ship. In the British Museum you may see a plank taken from the side of a ship in which is embedded the sword of one of these fish. The weapon has been driven through twenty-two inches of the wood. Think now what force it would require to put a bolt through a plank of the same thickness. It is surmised that sword-fish in attacking ships mistake them for whales.

The sword-fish is sometimes caught in nets set for other fish, but in some countries the capturing of these creatures is quite an industry. The fishermen go out in boats which have a little platform at the bow. On this platform a man stands with a harpoon in his hand, which he throws at any sword-fish that may come near enough. The fish is thus killed by its own method.

Sword-fishes are not a numerous family, but they attain to a large size, reaching fifteen feet in length.

\section{FLYING-FISH (Family SCOMBRESOCID}

When a ship is sailing through tropical or sub-tropical seas its occupants may suddenly see a whole shoal of fish rise out of the sea, and travel through the air for a considerable distance, glistening in the sun like burnished silver. These little creatures are known as Flying-Fish, although they do not really fly. They leap from the sea, and skim over the waves by the aid of the very long winglike fins with which they are provided. In one single leap the flying-fish is said to travel a distance of three hundred yards, only touching the water occasionally to wet its fins, and to bound forward with a fresh impetus. It does not, however, fly in this way for the sake of amusement, but probably in order to escape from fishes or dolphins, which prey upon it. Often, however, its attempts to escape are in vain; while it may gain a short respite from its enemies in the water, it is often pounced upon by sea-birds as it flies through the air, but it doubtless often baffles both the sea- 


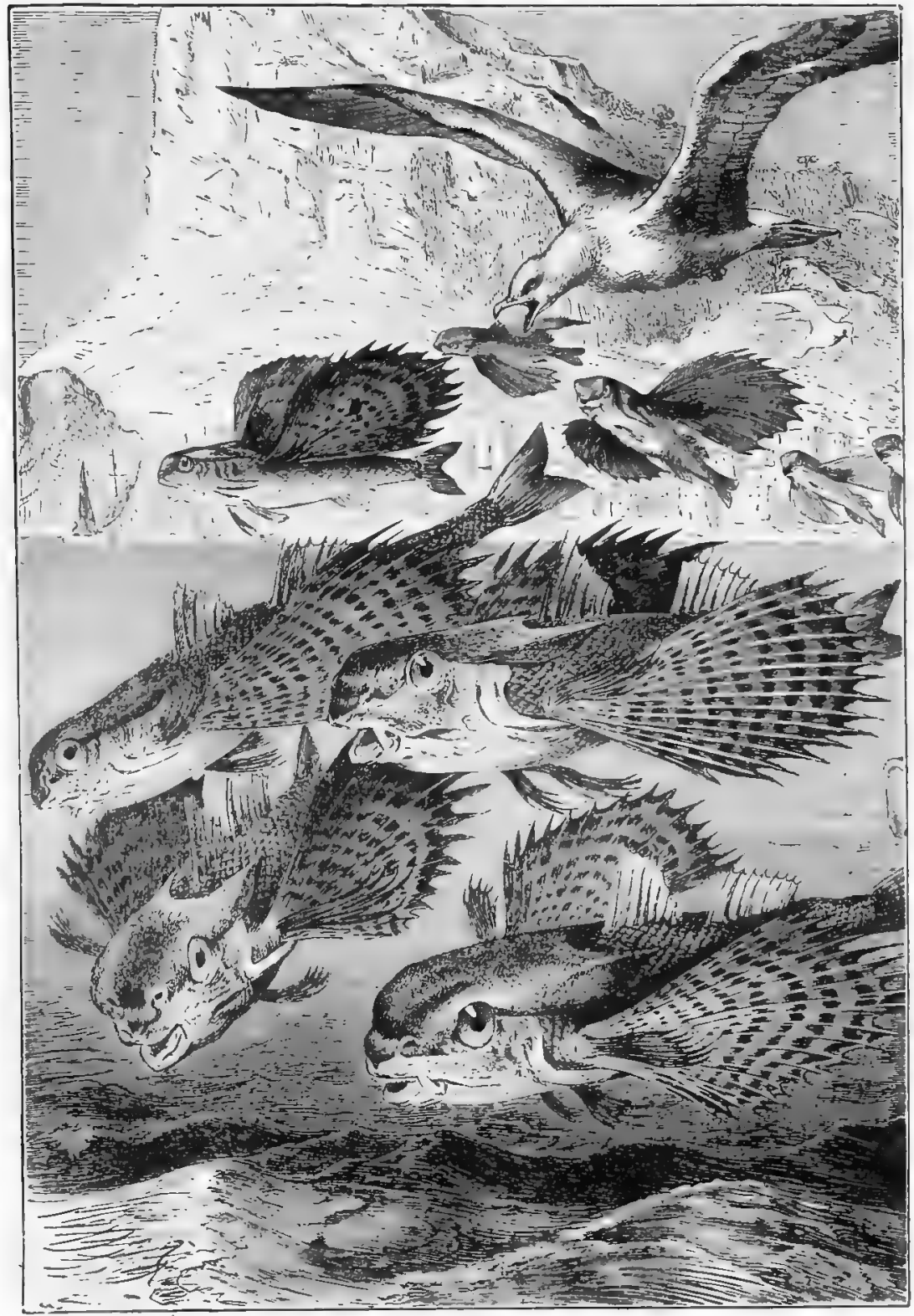


birds and the dolphins. Occasionally these flying-fish rise so many feet above the surface of the water as to fall on the deck of a ship. But this is generally due to their being caught in a gust of wind, or happens at night when the ship is not seen. Over forty species of this genus are known.

\section{THE COD (Family GADID}

One of the most familiar fishes in this country is the Cod. It is caught in large numbers on our own coasts, and furnishes food and employment for many people. The cod fishery is indeed a large and valuable industry.

The cod is usually some three or four feet in length, but occasionally individuals have been caught over five feet long, and weighing over a hundred pounds. In colour it is greenish on the back, spotted freely with yellowish brown, while underneath it is silvery. Its head is large, and it has strong jaws which are armed with very sharp teeth. One may always know it by the beard, or rather the single barbel (as it is called) which is attached to its lower lip, and which possibly serves as a feeler, like the whiskers of a cat.

The cod makes its home in the North Atlantic and the North Sea, and lives chiefly in large shoals on the great sand-banks off Britain, Norway, Iceland, and especially off Newfoundland, where the creatures on which it preys are very abundant. It seems to swallow the smaller shell-fish whole and, after it has digested them, to throw up the shells. In this way the cod was very useful to naturalists before they were able to dredge the bed of the ocean, for they often found in its stomach shells of the creatures that inhabit the bottom of the sea, which they were unable to get in any other way.

Besides being sold fresh, the cod is cured and dried in large quantities; and an oil which is extracted from its liver is much used for various purposes, but chiefly medicinally. As it is entirely a deep-sea fish it is caught by means of a line and hook instead of by a net.

Though it is taken in such large numbers, the cod is not likely 


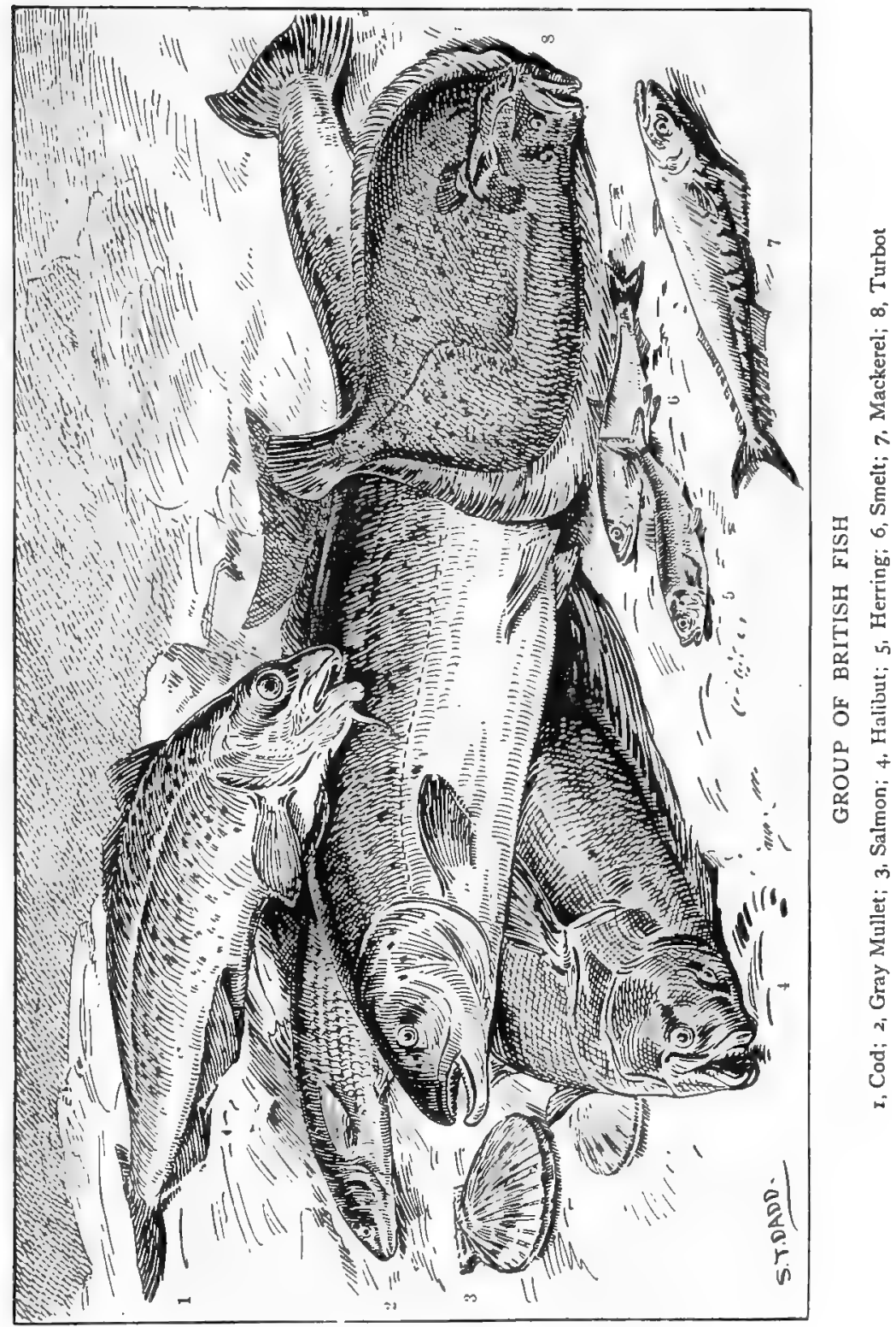


to become extinct, for the number of young it produces is extraordinary. It has been estimated that one female cod will deposit some millions of eggs in a season.

The whiting and the haddock are close relatives of this fish.

\section{FLAT-FISH (Family Plueronectida)}

The Flounder, the Plaice, and the Sole are among the bestknown of what we generally call "flat" fish.

But instead of calling them "flat", it would be more correct to describe them as "narrow" or "thin" fish. For what we call the "back" is really one of the sides, while the lower part of the body is the other side!

When a flounder is quite young it swims, not in the position in which we are accustomed to see it, but upright in the water; so that the thin edge of its body, instead of the flat surface, is uppermost. And that thin edge, of course, is its back.

But after a few days a great desire comes upon it to lie down upon its side in the mud at the bottom of the water. This it does; and then a very strange thing happens, for the side which is uppermost becomes dark in colour, while the side upon which it rests remains light. Thus the flounder assumes the appearance in which we are accustomed to see it.

When once a flounder lies down upon its side it never again swims as it did before, but adopts an entirely different kind of movement.

If you were to look at one in an aquarium, or vessel for keeping fish, you would at first be unable to see it. Its brown back is so exactly like the mud or sand upon which it rests that only a practised eye can detect it. But when it rises you would see that it waves its whole body in the water, instead of swimming with its tail like other fishes.

A much more remarkable change than that of colour takes place in its body soon after it lies down. One of its eyes is now rendered useless to it; for, as this eye rests in the mud underneath, the fish cannot of course see with it. 
So this eye begins to move; and, little by little, it travels on until it has gone round the head and reached a spot by the side of the eye upon what is now its upper side! There it stops; and so, during the rest of the flounder's life, it has both its eyes upon one side of its head, instead of one upon each side as before.

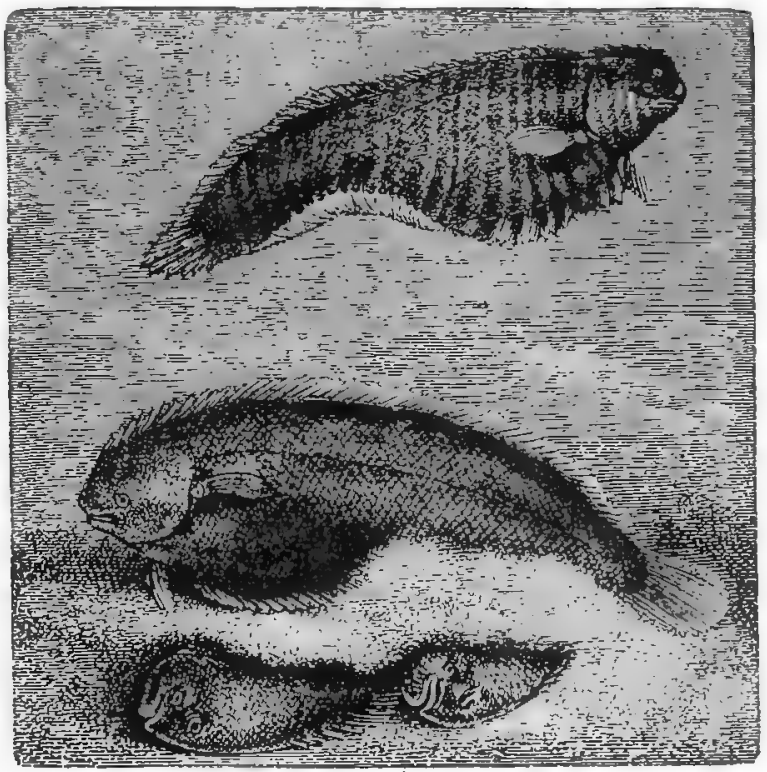

Soles

These "fiat" fishes are among the most curious of all the curious fishes that are found in the sea.

This family is a remarkably valuable one from a food point of view, as we may see when we name some of them-turbot, halibut, sole, plaice, flounder.

\section{EELS}

It is somewhat difficult to believe that an Eel is indeed a fish, and not an aquatic snake. Its long slender body, its narrow, pointed tail, and the activity with which it twists and wriggles about 
when handled, give it a very snake-like appearance; and the people of some parts of our country so firmly believe that it is a snake, that they refuse to eat its flesh. It is, however, a true fish, for it is provided with gills, is covered with very minute scales, possesses true fins, and has a two-chambered heart.

In most parts of Great Britain eels are very abundant, living in rivers, streams, lakes, ponds, and even ditches. We do not very often see them, for during the greater part of the year they lie

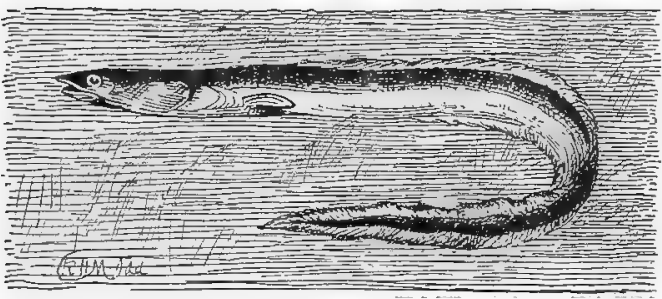

Eel principally in the mud at the bottom of the water, and appear to travel chiefly by night. But on warm, still days in June and July they are fond of rising to the surface in weedy spots, and basking in the rays of the sun. While so engaged we may frequently see them suapping at the various small insects which fly near the surface of the water.

Eels occasionally leave the water, and travel some distance over dry land. In this way they pass from one pond or ditch to another. Their gills are modified in such a way that a quantity of water is stored up in a little reservoir, by which the gills can be moistened from time to time, so that respiration can be freely carried on even when the animal has left the water. Nevertheless, they carefully select a damp night for their terrestrial migrations.

Towards the end of summer, eels which live in rivers migrate towards the sea. Many reasons for this proceeding have been suggested; but the true explanation seems to be that they know by instinct that the brackish water at the mouth of a river is warmer during winter than that of either the sea or the river itself. While thus travelling they are captured in enormous quantities, chiefly by means of "eel-pots", which allow them freely to enter, but prevent them from making their escape.

Another way of catching eels is by "bobbing". A number of worms are tied together with worsted, which is twisted in and 
out between them in such a way as to form a tangled ball. This is then fastened to the end of a strong line, and dropped into the water. When an eel tries to swallow the worms its teeth are caught in the worsted, and before it can disengage itself it can be dragged out of the water.

Eels are more commonly taken, however, by "spearing". The spear consists of a long-handled fork with four prongs, each of which is barbed at the tip. This is plunged into the mud at the bottom of a pond or stream, and an eel, when caught between the prongs, is securely held by the barbs.

Eels which live in ponds and streams whence they cannot travel down to the sea in autumn, either hide under stones or bury themselves in the mud, and there remain in a condition of torpor until the first warm days of spring.

Like other fish the young of eels are produced from eggs, an enormous number of which are deposited by a single fish. They are so exceedingly tiny that it is by no means easy to count them. By the aid of a powerful microscope, however, this task has been successfully accomplished, and it has been found that a large eel, of some six pounds in weight, produces no fewer than nine million eggs annually.

While very young the little eels are called "elvers", and are then quite unlike their parents. When they have grown to a length of about three inches they are almost transparent, and look like strips of vermicelli, with a little round black dot on either side of one end. These dots are the eyes. So small and thin are the elvers at this stage that eighty only weigh one ounce.

In olden days, before it had been discovered that eels lay eggs like other fish, and that these little elvers are their young, it was commonly supposed that they were produced from horse-hairs which fell into the water as the horses were drinking, and after long soaking were converted into eels!

The food of eels is very varied; indeed, they will devour almost any substance of an animal nature. They are fond of worms, and of the different insects which fall into the water; and they will also eat frogs, toads, tadpoles, newts, small fish, and even the young of aquatic birds. Mice, rats, and water-voles, too, are (M 868) 
occasionally devoured by them, and once an eel was found dead, having been choked by a rat which it had captured, but which had proved too large for it to swallow.

Eels are very tenacious of life. Not only can they live for a very long time when removed from the water, but they will sustain injuries that to almost all other animals would prove immediately fatal. Fishermen generally kill them by grasping their necks, and slapping their tails sharply two or three times against a post, or across the side of the boat.

Two different kinds of eels inhabit the fresh waters of Great Britain, one being called the Sharp-nosed, and the other the Bluntnosed Eel. A third kind, however, known as the Conger-Eel, is marine, and is very plentiful off our English and Irish coasts; and, as this is a most interesting creature, we must not pass it by without learning something about it.

This eel is much larger than either of the freshwater varieties, for it sometimes attains to a length of ten feet, and a weight of one hundred and thirty pounds. A conger-eel of this size is equal in circumference to a man's thigh. It cannot be captured without some little difficulty, for it is immensely strong, and struggles with such determination when it is hooked that only a very powerful man can lift it from the water. Even when it is placed in the boat it continues its efforts to escape, and writhes and twists about with the greatest activity. Its teeth, too, are long and sharp, and if it should seize the foot or arm of one of the fishermen, nothing but death will induce it to loose its hold.

The tail of the conger-eel, besides possessing great muscular power, is prehensile, like that of a spider-monkey or an opossum. More than once, one of these curious fishes, after having been hooked and drawn into a boat, has been known to seize the gunwale with its tail, and by means of the "purchase" thus obtained, to jerk itself over the side and back into the sea.

The line by means of which conger-eels are captured is usually about four hundred feet long, and to it are fastened a number of "snoods", or shorter lines at regular distances apart. Each of these snoods is furnished with a hook, so that a number of eels can be captured upon the same line. 


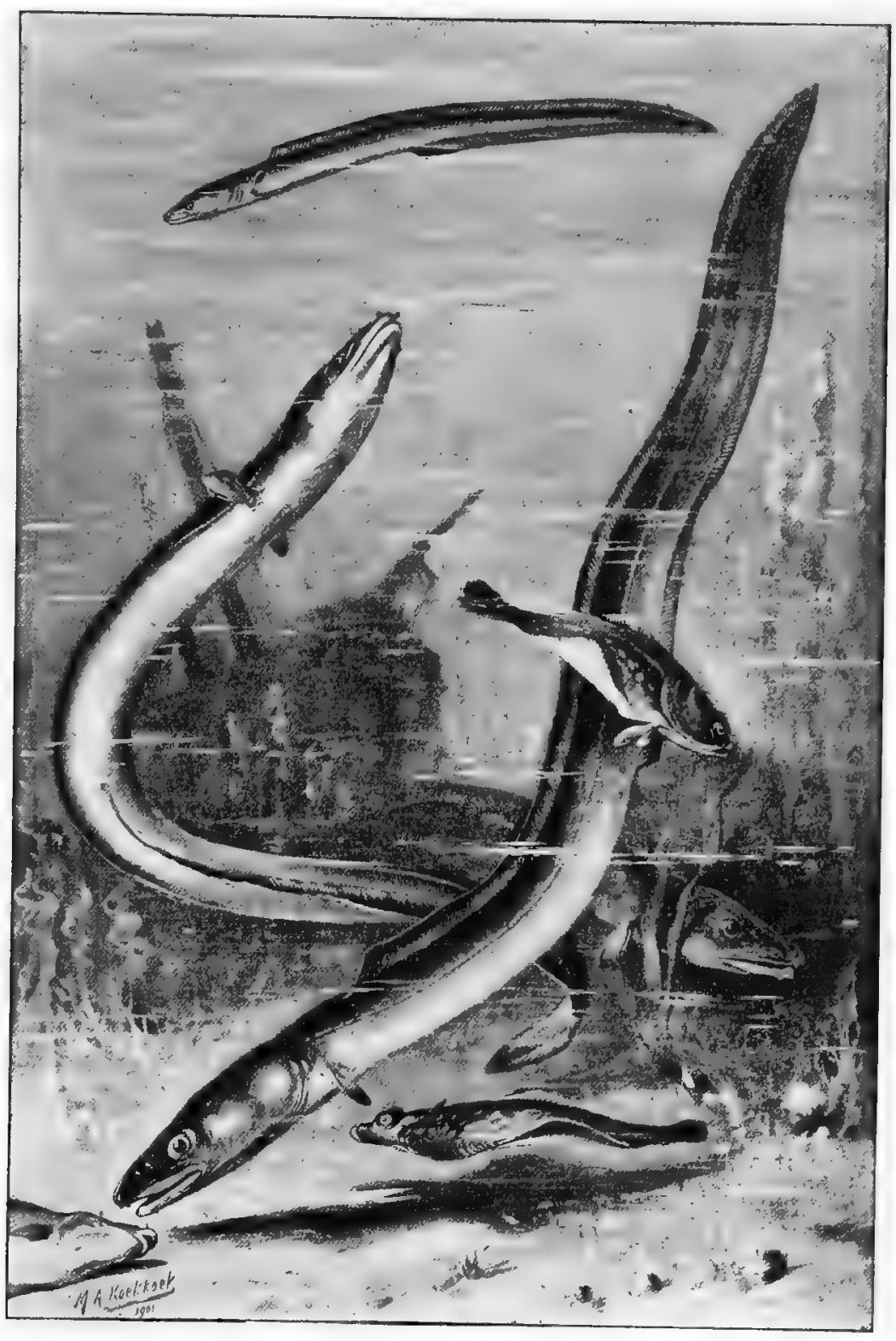


Most extraordinary of all the eel family is the Electric Eel, which is found in many of the pools and rivers of South America. As its name implies, this animal is capable of administering an electric shock to any creature which comes into contact with it; and it can even project its invisible discharge to some little distance, and kill a fish that is swimming several feet away.

The manner in which the electricity is produced still remains a mystery. Along the body run two organs, one lying upon the other, from which the shock evidently proceeds; but how it is generated and stored up, and how the eel employs it, no one has as yet been able to discover. Yet the discharge is sometimes very severe, for a native boatman, when dragging his boat up some rapids, once received a shock from one of these animals, and was obliged to go ashore and rub his leg for some time before he could again make use of the limb.

These eels are said to be captured by the Indians in a very curious manner. A number of horses are driven into the pool which the eels are known to inhabit. Disturbed by the splashing, they bring themselves into contact with the horses, and deliver a severe shock of electricity. The terrified horses plunge wildly about, and thus provoke the eels to continue to give shocks until their store of electricity is quite exhausted, when they can be lifted out of the water without danger.

\section{THE PIKE (Family ESOCIDæ)}

Though the Pike is caught in large numbers for food it is perhaps better known through the many wonderful tales that are told of its fierceness and voracity. Nothing seems to come amiss to it. It preys very largely upon other fish, but if it cannot get these it will swallow frogs, insects, or young water-birds, and it will even attack and devour water-rats and other animals that may come in its way. It has a habit of lying at the surface of the water and basking in the sun, and stories are told of pike that have at such times been attacked by a hawk, and either managed to drive off the bird, or actually succeeded in drowning it. 
The pike is altogether a freshwater fish, and is to be found in most lakes and rivers in the temperate regions in Europe and America. You may spy one lying like a log in the water, and by stealthily watching may suddenly see it make a dart at some

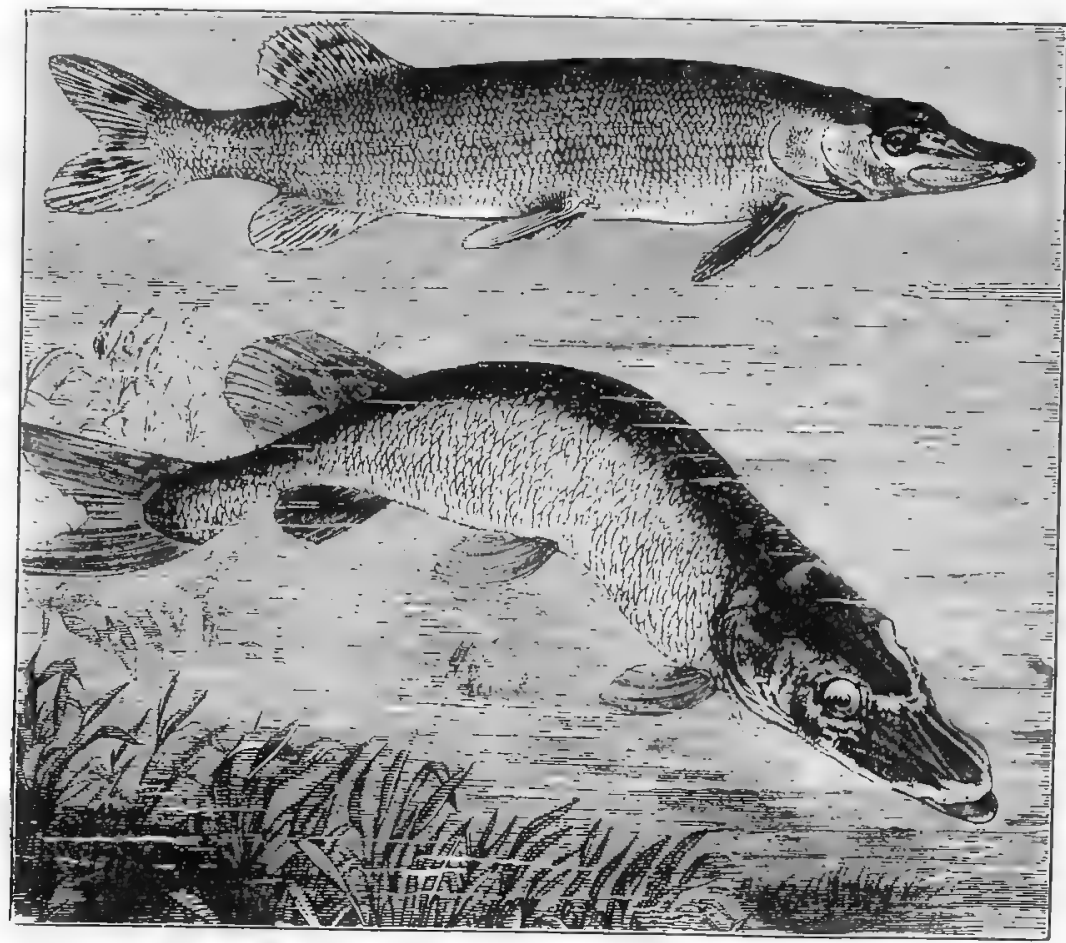

Pike

animal that has been unfortunate enough to come near it. When pursuing its prey the pike proves itself a very powerful swimmer. So strong indeed is it that unless taken by net it can only be caught by a very stout line and hook.

We often hear strange stories of the size to which a pike may attain, as well as of its strength and voracity. It certainly grows to between three and four feet in length, and sometimes weighs more than thirty pounds. 
The Pike is not so rounded in form as most other fish, its head being extended into a long flattened snout. Its jaws are furnished with very formidable teeth. In colour it is green and yellow on the back, and white underneath.

\section{THE HERRING (Family CLUPEId $Æ$ )}

The Herring is unquestionably nearly related to the Salmon proper, and it was formerly included in the Salmonidæ, but now the various species of herring have been placed in a separate family.

It is a most interesting sight to see the herring-fleet sail out of the harbour of one of our coast towns before sundown. The herring,

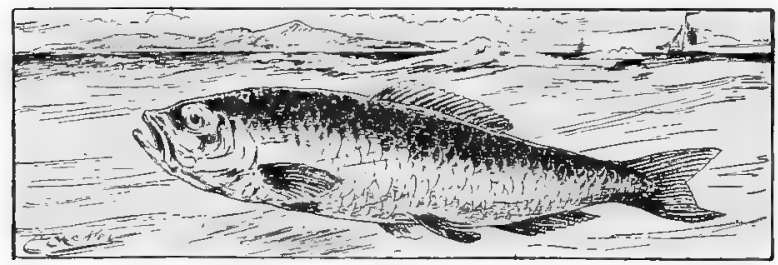

Herring

with which all must be familiar, can only be caught at night, and as it lives in immense shoals it is taken by means of drift nets attached to bladders, which you may see stretched in long lines in the water. The fishermen set their nets when they go out at night, and early in the morning they take them in again. The fish are often collected from the different boats by steamers, and carried off straight to the markets. As the herring is very erratic in its movements, a boat may be very lucky one night and get nothing at all the next, while the fishing at a station may be very successful one season and a complete failure the following year.

The herring, which is a migratory fish, spends the winter in the deeper parts of the ocean, where its food is most abundant; but when the warmer weather returns it comes in in great shoals to the shallower water of bays and river-mouths for the purpose of deposit- 


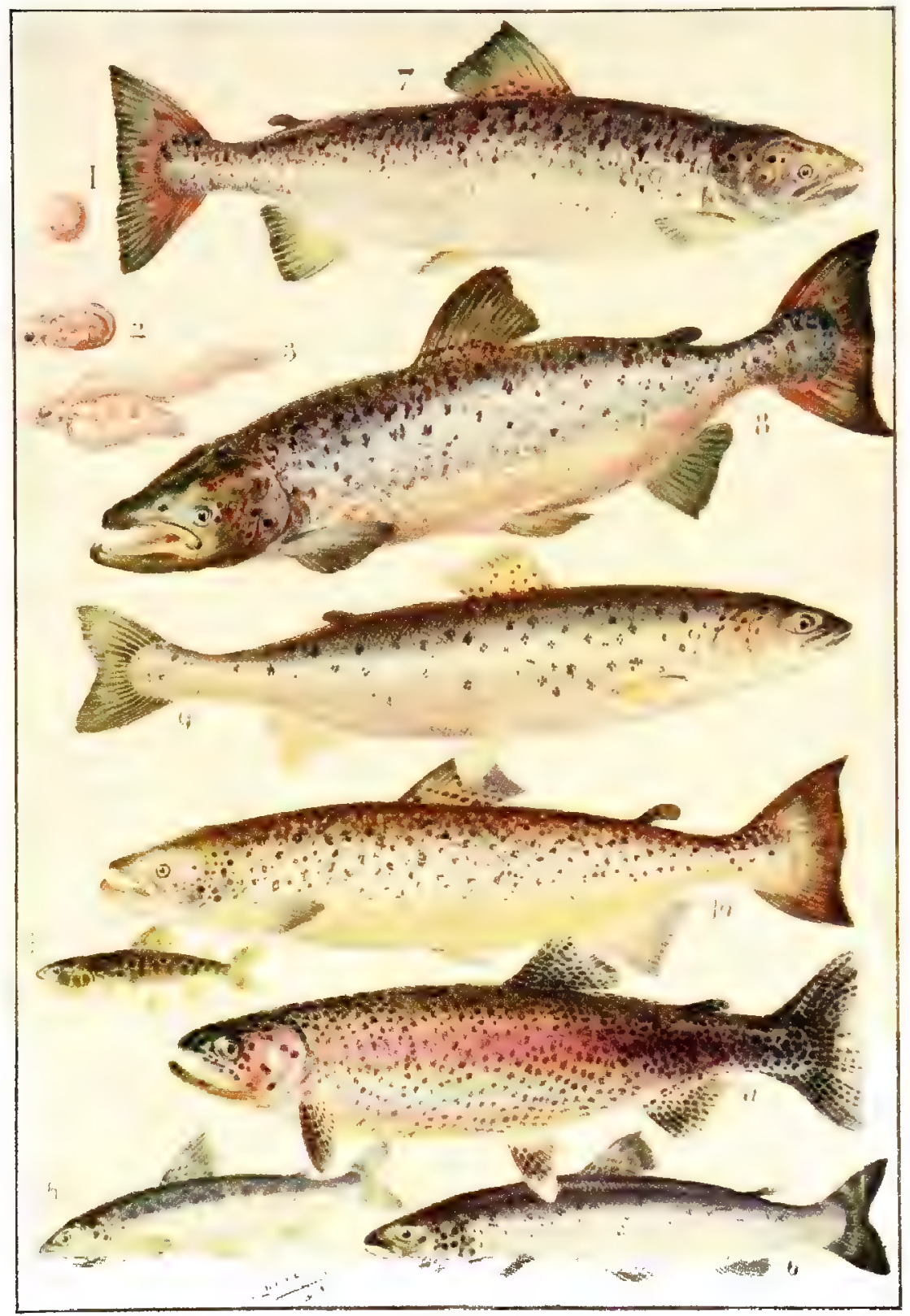

r, Salmon Egg magnified. 2, Shell of the Egg burst, showing head of fish protruding. 3, Young fish after escape from egg. 4, Parr. 5, Simólt. 6, Grilse, 7, Commor Salmon, female. 8, Common Salmon, male. 9, Salmon Trout, or Sea Trout. so, Bull Trout. II, Rainbow Trout. 

ing its spawn. When approaching the coast the shoals may be seen stretching for miles, for they often swim close to the surface and their motion through the water causes an unusual ripple. When the young herring, or herring fry as they are called, are hatched, they keep for a time in shoals so densely crowded together that they appear to be in almost solid masses. Thus they fall an easy prey to porpoises and whales, and, when they come to the surface, to sea-birds. So many are destroyed in this way that it is surprising that such large numbers survive to be caught in the nets.

As the herring is so plentiful, and so excellent a fish, it forms a very important article of food. Many thousands of people are engaged in preparing it for the market. If so many are caught that all cannot be disposed of fresh, they are salted or smoked, and transformed into "bloaters" or "red herring".

The herring, which is usually about a foot in length, is greenishblue on the back and sides, while underneath it is a very bright silver. Its lower jaw protrudes slightly beyond its upper one.

Some sixty species of herring are known, but they are distributed over the world. Some are, however, rather poisonous than edible. A freshwater species is found in Australia.

\section{THE SALMON (Family Salmonid E)}

The Salmon has well been called "the king of freshwater fishes". It grows to a considerable size, attaining in Britain occasionally a weight of 70 lbs.; in Canada, often of over $80 \mathrm{lbs}$. It is possessed of wonderful strength and activity, so that it affords capital sport for the angler, and its flesh forms a great dainty for the table. Certainly there is no other fish in our rivers and lakes that can be said to equal it in any of these three respects.

In former days this valuable fish abounded in almost all the larger streams of Great Britain. It can only live, however, in perfectly pure water, and, now that so many of our rivers are polluted by sewage, and by refuse which escapes from various manufactories, it is found in very few English streams. But in Scotland it is still fairly plentiful, and many thousands of fine salmon are taken every year by rod and net. 
The life-history of the salmon is a very remarkable one. Like all other fishes, it comes from an egg. This egg, with a great number of others, is placed by the mother salmon in a furrow in the sandy bed of a river. How this furrow is made is not ascertained, some observers saying that both parents dig it out

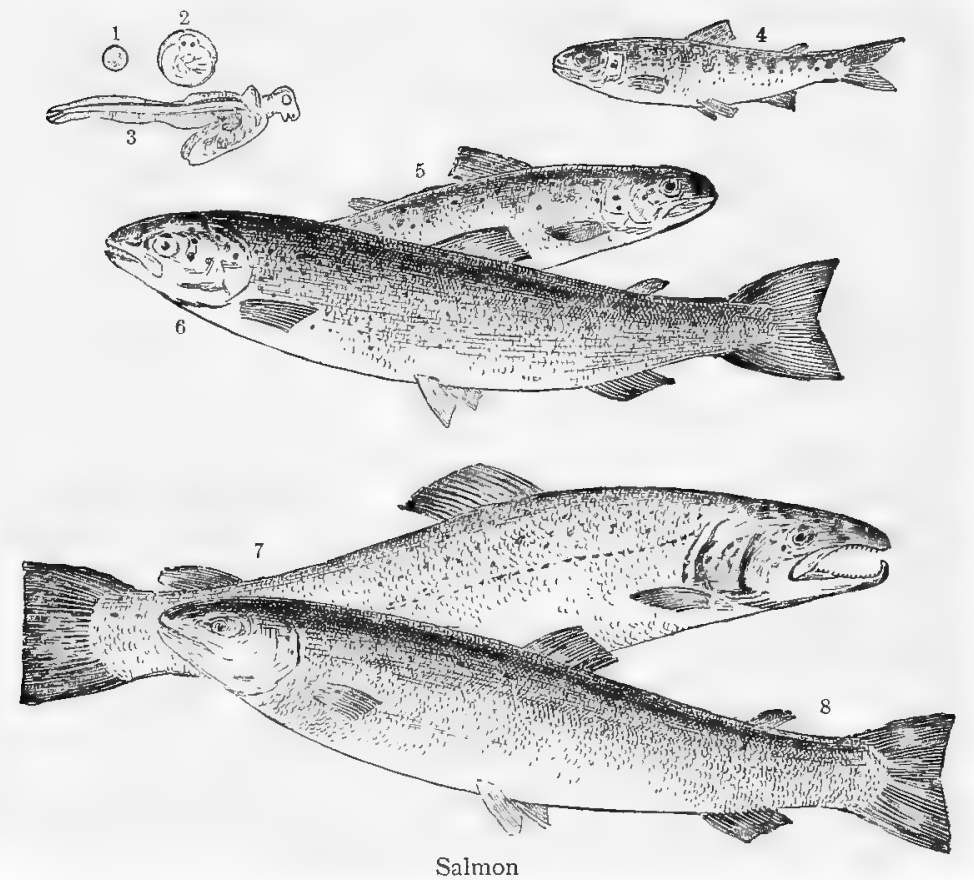

I, Egg; 2, Egg (magnified); 3, Fry (magnified); 4, Parr; 5, Smolt ; 6, Grilse ; 7. Common Salmon (male); 8, Common Salmon (female).

with their snouts, and others that it is produced by the tail of the mother only. After the eggs are laid-an operation which takes ten or twelve days-the parent leaves them, and rests quietly for a time to recover strength.

In due time the eggs hatch. At first the little fish is not at all like its parents, having no scales, and being quite transparent. For some time it does not eat, its mouth not being properly 
developed. But by way of sustenance it carries part of the material of its own egg about with it, a kind of bright reddish bag beneath its body; and upon the contents of this bag it lives until it can find food for itself.

From this period it grows very fast. At this stage of its life the little salmon is called a "parr", and this title it retains until it is about a year old. Its colour is now a pale brown, and upon its sides are several dusky stripes.

At the end of either the first or the second year of its life, the appearance of the little "parr" begins to alter. Shining silvery scales grow all over its body, so that the dark bands upon the sides are hidden; and now it is called a "smolt". With this change it seems to become tired of the fresh water, and makes its way down stream until it comes to the sea. There it lives for three or four months, feeding upon small shrimps, the young of crabs, \&c., and growing very fast. It then returns to its river, and makes its way up the stream until it reaches its former haunts. This curious journey to the sea and back is undertaken every year.

Having visited the sea, the "smolt" becomes a "grilse", or a "salmon peal"; and the name of "salmon" is not given to it until after it has completed its second journey.

In walking along the banks of some of our salmon streams, we should probably wonder how the salmon are able to return after once they have travelled down to the sea. For in the course of the stream are many waterfalls, up which it would seem quite impossible for a fish to pass.

But the salmon do pass up quite great falls, which they ascend more by leaping than by swimming. If we were to watch a waterfall while the fish are ascending the river, we should probably see salmon after salmon swim swiftly up to the foot of the fall, and, with a sudden stroke of its tail, leap out of the water high into the air. The first time, and the second time, perhaps, the fish fails to clear the fall, but, not discouraged, it takes another and another leap; and so on until the obstacle is safely passed.

When a waterfall is a very difficult one, landing-places are sometimes made for the fish, so that they may ascend it in two or three leaps instead of only one. A careful observer, who planted 
high poles in the water at the sides of a fall in order to measure the fishes' leaps, tells us that on several occasions he has seen a salmon: spring out of the water to a height of no less than sixteen feet.

The Salmon is a northern hemisphere family. Strangely

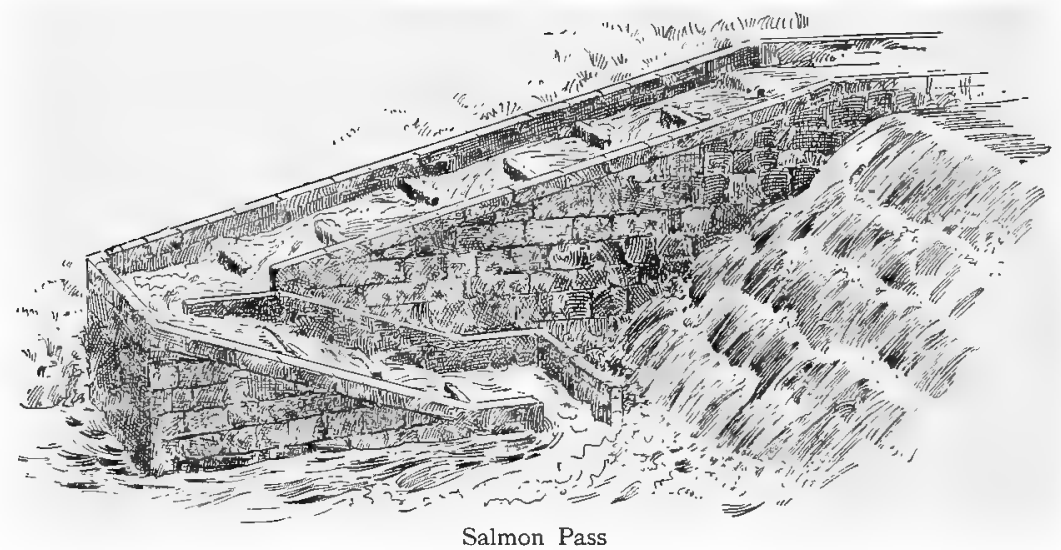

enough, it seems to prefer rivers that run north or west. On some of the N. American rivers it attains a large size, and at times exists in such numbers as to clog the wheels of steamboats.

\section{ELASMOBRANCHII}

\section{SHARKS}

There are a great many different kinds of Shark. One, for instance, the Little Dog-fish, is only about eighteen inches long. It is very common off our British shores; and sometimes, after a very severe storm, we may find it lying dead upon the shore.

The eggs of this shark are very curious objects, and are sometimes called "mermaids' purses". They are hard and horny, oblong in shape, and black in colour. At each of the four corners there is a long, slender "tendril", very much like those which we see on the pea and many other climbing plants. 


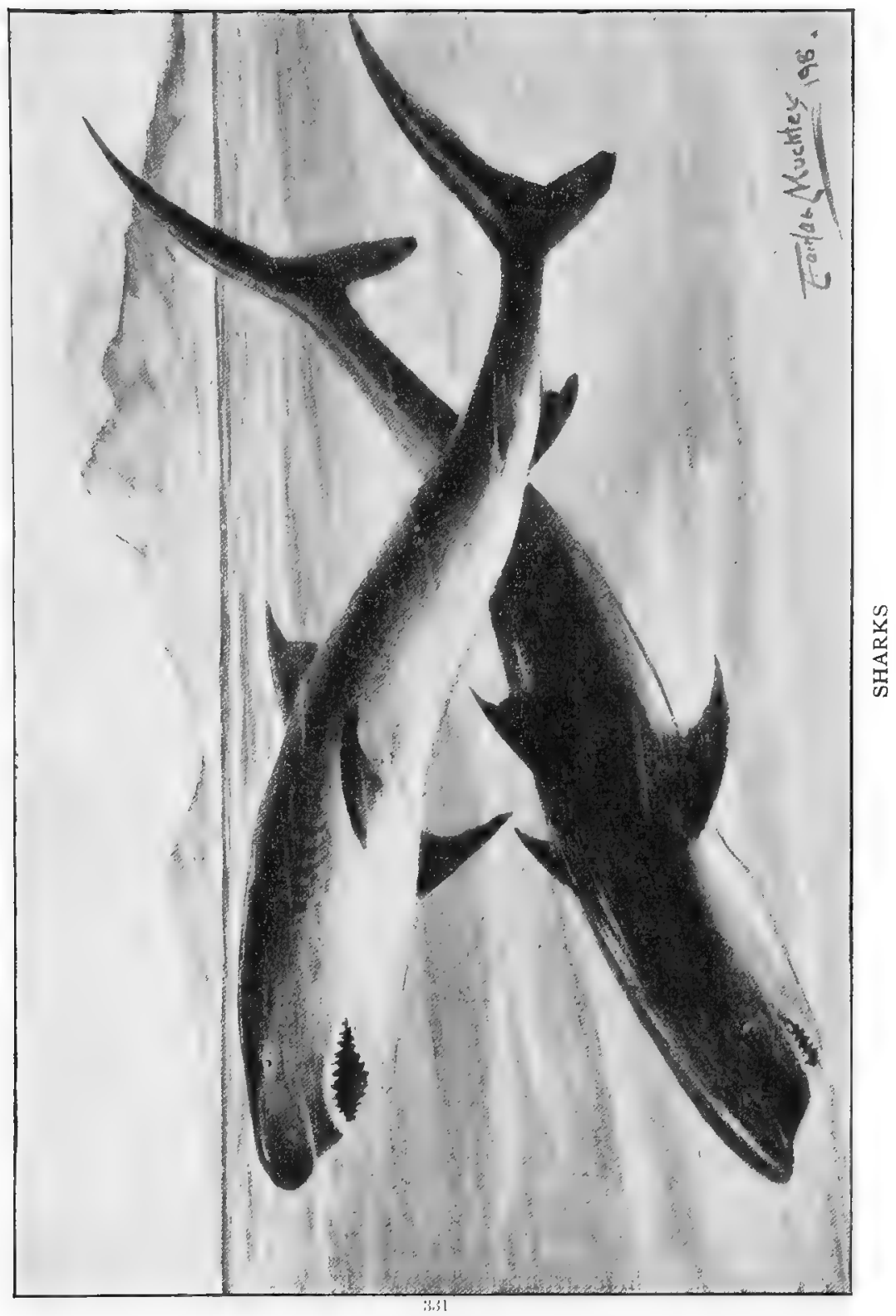


These tendrils, when the egg is laid, coil tightly around seaweeds at the bottom of the water, and prevent the egg from being thrown up upon the shore, until the little shark is hatched out.

A great contrast in size to the little dog-fish is the formidable White Shark, one of the fiercest fishes that roam the ocean. This shark is said sometimes to attain a length of thirty-five feet, or even more; while its jaws are so powerful, and its teeth so sharp, that it has been known to sever a human body at a single bite.

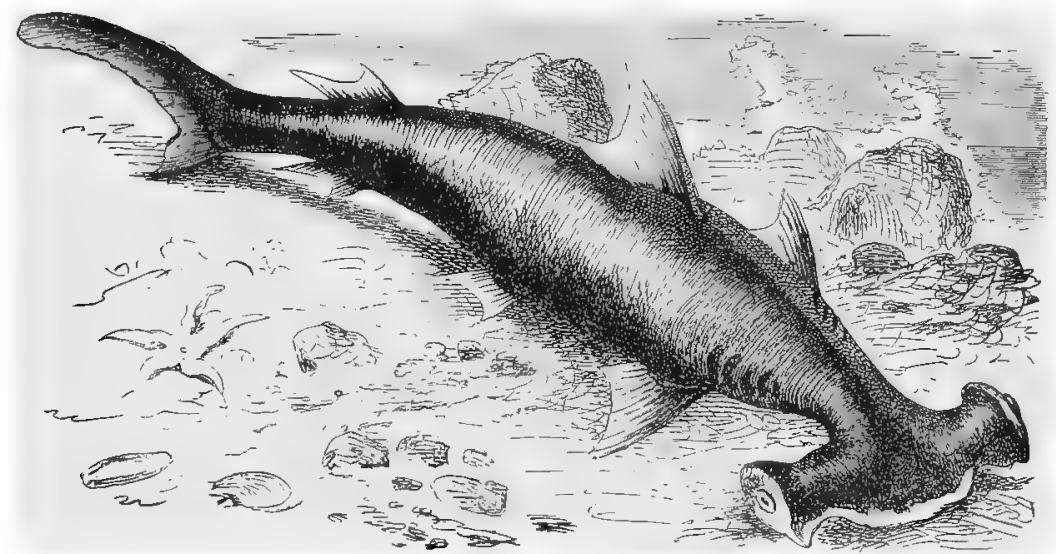

Hammer-headed Shark

The white shark is very common in the Pacific Ocean, and the islanders capture it in a simple but curious way. All that they do is to tie a rope round a big $\log$, so that it may hang down in the water, with a noose at the lower end.

A shark is almost sure to come and examine the log, and, somehow or other, it nearly always manages to put its head through the noose. As soon as the natives see, by the movements of the $\log$, that the shark is caught, they put off in boats, and, having caught it, batter its head with clubs until it is dead.

The strangest of all these great fish is the Hammer-headed Shark. The head of this shark is shaped like a hammer, and projects to some distance from either side of the neck. At the ends of these extremities the eyes are placed. This shark is sometimes found in the British seas, and is from eight to twelve feet long. 


\section{THE INVERTEBRATES}

To classify all the animal world into Vertebrates and Invertebrates, that is, into two groups which should be distinguished by either the presence or absence of a spinal column, would seem to us to be a very simple matter.

But the more the animal world is studied the more difficult classification becomes. With every further step in our acquaintance with the structure and nature of animal forms the less easy is it to say where the Vertebrates should end and where the Invertebrates should begin; for with some animals it is difficult to say whether the spinal column should be considered to be absent or present.

The following table of Invertebrates gives us the most modern view of correct classification. This should help us to understand the true positions of the various greater groups of this vast kingdom of animal forms.

The kingdom of the Invertebrates is divided into the following sub-kingdoms:-

I. The Arthropoda-Insects, Spiders, Crustaceans.

II. The Echinodermata-Star-fish, Sea-urchins, \&c.

III. The Mollusca-Cuttle-fish, Whelks, Oysters, Mussels, \&c.

IV. Molluscoida-Lamp-shells, Corallines.

V. Vermes-Worms and their relatives.

VI. Ccelenterata--Jelly-fish, Sea-anemones, Corals.

VII. PORIfERA-Sponges.

VIII. ProtozoA-The microscopic Foraminifera (single-celled animals).

Most of us are probably acquainted with certain representatives of all these sub-kingdoms except the last, and that fact alone 
should make the table interesting to us. In any case the table will help us to classify the animals which we are about to discuss.

\section{N S E C T S}

As we have seen in the preceding table, Insects are only a part of the sub-kingdom Arthropoda, which includes spiders, scorpions, centipedes, millipedes, crabs, and shrimps.

Now the term "insect" (from Latin insectum, divided) originally embraced all the groups of creatures which make up this subkingdom. For all these animals are "divided" in the sense

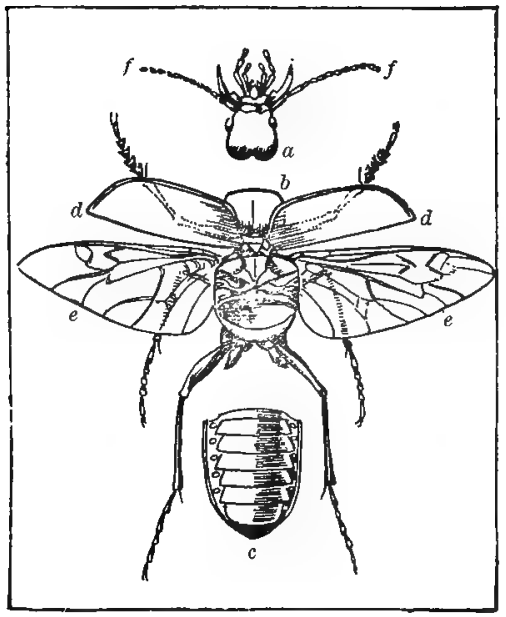

Diagran showing the parts of Insects $a$, Head ; $b$, chest: $c$, abdomen ; $d d$, wing-cases; $e e$, wings; $f f$, feelers. originally meant, and that was that they were jointed animals, some more and some less, but all jointed in their bodies like a lobster or a beetle.

But true insects are distinct from lobsters, and spiders, and scorpions in many important points; and so, when it was seen that all the members of the great group which are now known as insects possess six, and only six, legs, that was thought to be a better mark of distinction; and therefore the true insects are by some now styled the Hexapoda (i.e. the six-footed), which fact we may at least bear in mind, as the other groups in the Arthropoda are characterized by their members possessing more than six legs.

A further distinction of the true insects exists in the fact of their bodies being divided into three easily-recognized portions, 
namely, the head, thorax (or chest), and the abdomen. The rest of the Arthropoda are not so consistently divided.

Other general characteristics of the group are, that their muscles are attached to the inside of their external covering, which, being firm, is their main support; that they do not breathe by means of gills or lungs, but through breathing-holes placed along the sides of the abdomen, by which air is conveyed to all parts of their bodies; and that their heads are furnished with very sensitive feelers.

Insects as they grow pass through a number of changes in form before they reach maturity. When they are hatched from the egg they are tiny caterpillars or grubs. While in this form they have voracious appetites, for they are continually eating. This is necessary, for they grow very quickly, so quickly, indeed, that their skin several times becomes too small for them, and they cast it off and appear in a nice new coat. When they have grown to their full size, some of them make a nest called a cocoon, into which they retire for a longer or shorter period. Here they change their form completely, and become what is known as a chrysalis. You would scarcely believe by the appearance alone that the caterpillar and the chrysalis were the same creature; for the latter has no legs and no apparent head. It is just a something within a stiff shell. But as the days pass a new form is shaping itself inside; and one morning you will find that a beautiful moth or butterfly has broken its way out of the shell. At first the wings are not fully formed, but they soon stretch to their full size and their owner flies away. It is difficult to realize that this is the same creature as the little worm-like caterpillar you saw hatched from the egg.

It seems hard that, after taking so much trouble to get wings and be able to fly, it should only have a very short time to live. But most insects when they reach maturity only live a few days, although some live for several weeks, and occasionally hibernate through the winter. They lay their eggs in a place of safety, and where there will be plenty of food for the young caterpillars, and then they die.

Some insects pass the first part of their lives in water, and the latter part in the air; while others spend most of their time in the water. 
It is very difficult to catch a fly, as most of us know from experience. The reason of this is that insects have very remarkable eyes. These are situated on the sides of the head, and are large and compound (i.e. each is divided into a great many different lenses), and so enable their owner to see in all directions. Besides these, some insects have three single eyes on the top of the head.

For self-protection some are armed with nippers, others with formidable stings, while yet others depend entirely on their power of flight. But some of the more defenceless present a remarkable peculiarity. As they are more preyed upon than those that can defend themselves, they require some means of preserving their species, and they are, therefore, often coloured and shaped like leaves or sticks, the resemblance being very striking when they are at rest.

The number of species of insects is greater than that of any other class, though very many are not yet known to us. In variety of form and colouring also, the insects are very remarkable, and often exceedingly beautiful.

\section{H Y M E N O P T E R A}

The order HymenopterA (that is, membrane-winged) is a group of well-known, highly intelligent, and certainly most interesting insects. It is a very large group, containing sub-orders and a good many families, some of which we shall recognize as old acquaintances if we run through a few representative names, as follows:-Saw-flies, Wood-borers; Ants, Wasps, and Bees. Several of these names are certainly quite familiar, and the creatures themselves are no doubt known to many of us.

If we consider typical specimens of ants, wasps, and bees, and one of the parasitic wasps (the Ichneumon) as an illustration of what the word parasitic means, we shall have a good idea of the general characters of the Hymenoptera. 


\section{ANTS (Family FORMICID $E$ )}

It may sound absurd to say that there is an insect which has disciplined armies, keeps slaves to do its work, and has cows which it milks. But all this in some sort may be said of the Ant, which is certainly one of the most wonderful creatures that we

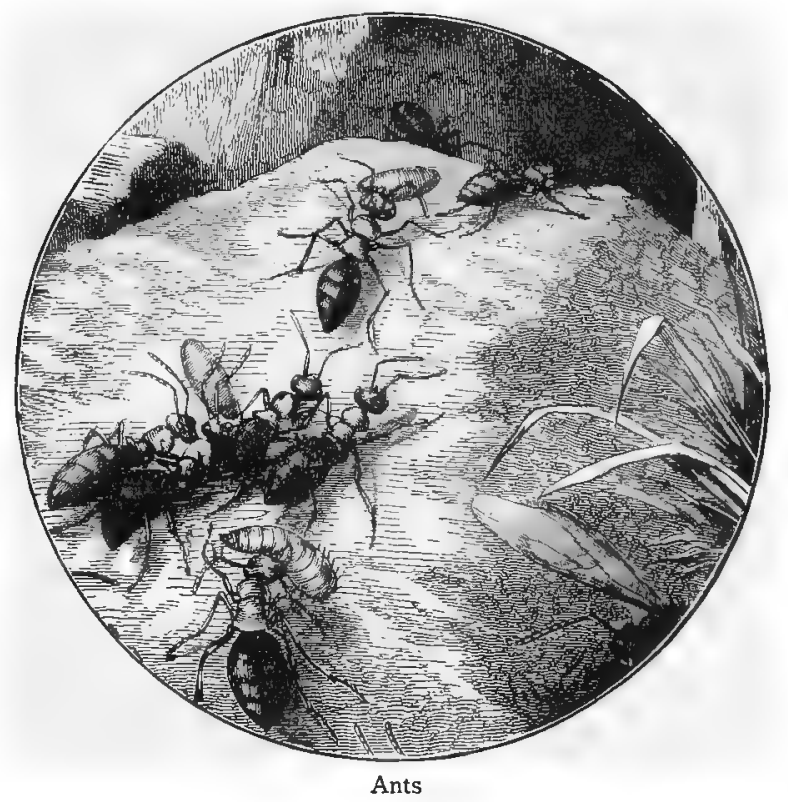

know. It is a plain-looking little insect, black or red in colour. But it possesses keen black eyes, jaws armed with little teeth, and a formidable sting, and its six legs are each furnished with two iittle claws, which help it in climbing.

One may often disturb a colony of ants by turning over a stone, and then see the little creatures running about wildly with white bundles in their fore-legs sometimes as large as themselves. These bundles which they are so anxious to preserve, are commonly known as ants' eggs, but their correct name is pupæ. They are ( 4868 ) 
really cocoons, from which full-grown ants will shortly eat their way out.

The active little ants which carry the cocoons about are called "workers". Their duties are to go out and forage for food, protect the home, and nurse the young. They never have wings.

Both males and females, however, have wings when they break from their cocoons, and escape from the nest. The workers are said to do their best to keep them within bounds, and even catch and bring back many that have got out. Those that do make their escape fly off into the world. The male seems to die shortly afterwards, but the female looks about for a suitable place for a nest of its own. When it has fixed on a good situation it seems then to lose its wings, and starts to prepare a nest for its young.

Some species of ant carry off the workers of other species and make slaves of them. They send out an army to attack a neighbouring nest. Scouts are sent on in advance, who bring in reports to the main body, which, when all is ready, rushes upon the nest of their intended victims. A fierce battle is waged, and many are killed on both sides. But the result is generally in favour of the attacking party, who, when they have driven back their opponents, enter the nest and carry off the pupæ of the workers. These, when hatched in their new nest, have no desire to run away, for they cannot remember their old home, and they work, of course, quite contentedly.

Besides keeping slaves, ants rear "cows" and milk them, only their "cows" are the little insects called aphides, which live on plants and trees, and the "milk" is a sweet fluid called honeydew, which they secrete. The ants induce their "cows" to drop this fluid by stroking them gently.

The ant-hill is generally a very interesting structure. It is built of mud and other materials, and is in foreign countries sometimes twelve feet high. Inside, it is divided into a number of chambers, which are joined by many galleries. Passages also lead from them to main thoroughfares, and so to the entrance. The eggs, larva, and pupæ are kept in these rooms arranged in rows and fed and attended by the workers, and are removed from one part to another as they grow towards maturity. 


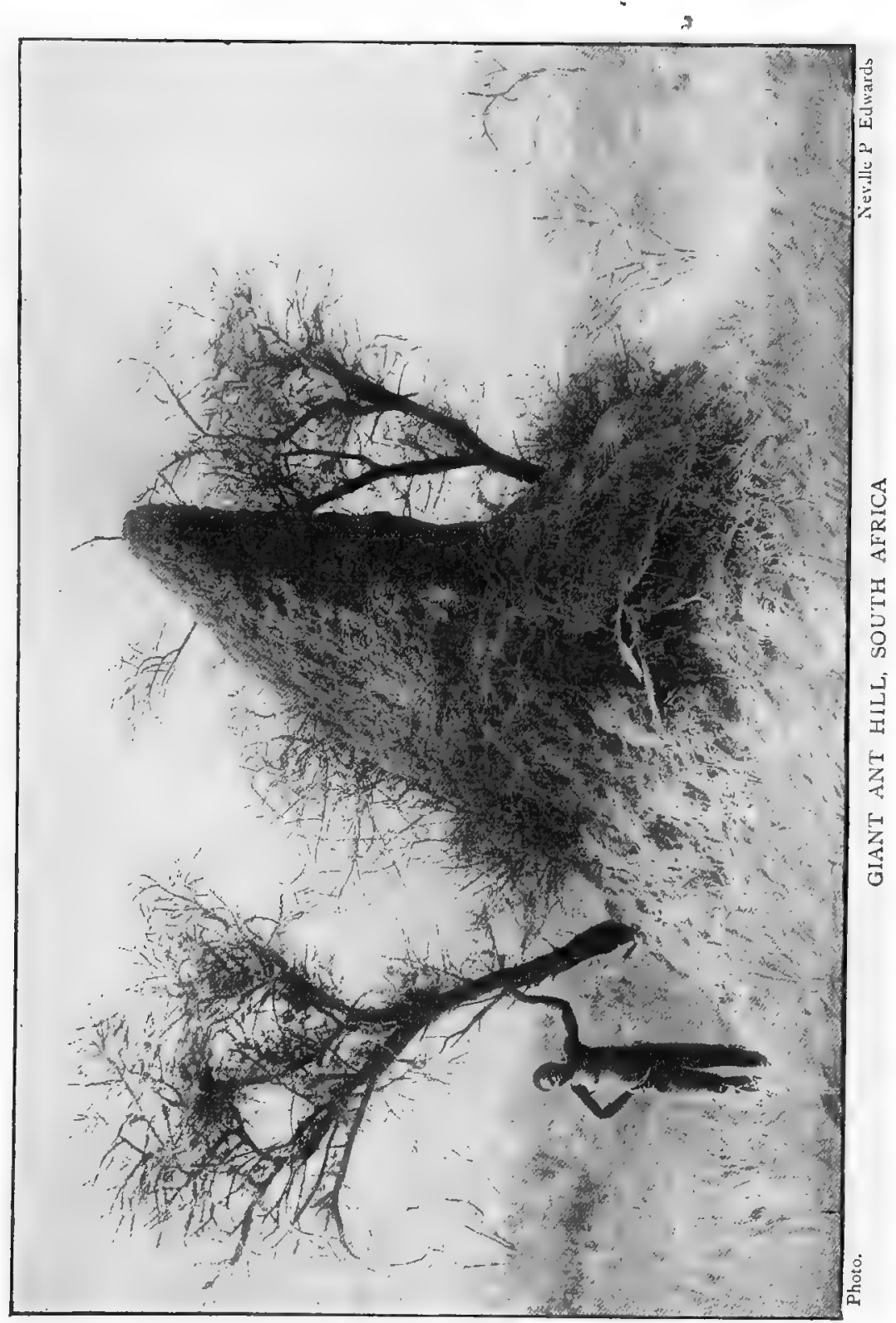


Besides being skilful builders, ants are clever road and tunnel makers. Sometimes they make a tunnel from their nest to a tree, where they get a large supply of honey-dew from the aphides.

Roads are to be seen starting from their nest and leading in all directions. If you watch these roads you will see ants coming and going on them bringing in food, generally insects they have captured and killed, to the nest. You may see them meeting and apparently talking to one another. It is supposed that they give one another information about anything they may have seen, and even directions how to find it; for after being stopped in this way those going from the nest often change their direction and make off towards the place whence their friend has come.

Ants are very courageous, and will sometimes attack insects much larger than themselves. If their victim is too large for them to carry, they tear it to pieces, or get their friends to help to carry it off, to feed the young and the stay-at-homes. Some ants are furnished with stings, which they use with effect on any animal that assaults them or damages their nest.

\section{WASPS (Family VESPIDE)}

Wasps, like their cousins the bees, are divided into three classes, namely, queens, drones, and workers.

In the early summer the queen wasp, which has lived all winter in some snug retreat, comes out and looks for a suitable place to make a nest. She perhaps chooses to suspend her nest from the branch of a tree, but usually she decides to occupy some deserted mouse-hole, and having taken possession, she sets to work to enlarge it and to hollow out the interior into quite a large chamber. Then she starts to build. She has taken care that the chamber is in such a position that one of the small roots of a neighbouring tree will run across the roof, and to this she fastens a small perpendicular column of a curious, paper-like substance, which she obtains by scraping from old posts and fences a quantity of decaying wood, and then kneading it up with her jaws. 
When this column is finished, she makes three small cup-shaped cells beneath it and lays a single egg in each. This done, she proceeds to make a kind of umbrella-shaped covering above, of the same curious material, and then forms more cells and covers them in the same way.

Before long, the eggs that were first laid begin to hatch, and three little grubs make their appearance in the cells. The queen now becomes busier than ever, for she has to supply the grubs with food, and enlarge their cells as they increase in size. This they do very rapidly, for they have enormous appetites, and never seem to be satisfied.

At first she feeds them with the juice she procures from flowers, or from some over-ripe fruit which she has chanced to find, or perhaps with some

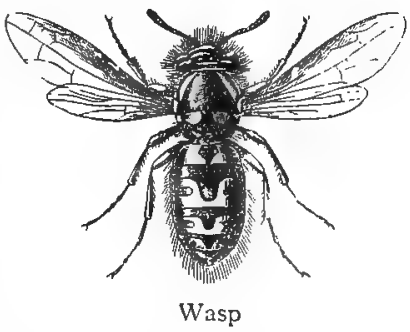
honey which she has stolen from a bee-hive. As they grow bigger, however, and require more solid nourishment, she supplies them with small pieces of fruit, instead of only the juices, while now and again she will take home a nice fat caterpillar, or a bluebottle fly, and divide it amongst them.

Every day, too, she has to add to the walls of the cells, and make new ones, so that from dawn to night she is always hard at work, unlike the queen bee, who does nothing but lay her eggs.

As time goes on, the grubs reach their full size. Then they retire into their cells, close the opening with a kind of silk which they spin, and turn into pupæ. In this state they remain for several days, after which they break their way out into the nest in the form of full-grown wasps.

At once they begin to help the queen, and, directed by her, carry on the work of building the cells, covering in the nest with a casing of paper, and building strong pillars to support the weight of the different tiers of cells. The workers, also, besides searching the whole country round about for food, act as sentinels, and fight, if need be, in defence of the home. 
The drones are not idle, like the drone bees, but take their share in the work of the nest, and make themselves very useful in clearing out the galleries. It is their duty, also, to remove the body of any wasp or grub that may chance to die. The drones, however, do not make their appearance until late in the summer.

We get an idea of how hard a wasp has to work when we learn that a large nest will contain nearly sixteen thousand cells, the inhabitants of which have to be fed several times a day. And wasps have not learned the art of storing up food, like the bees, but are obliged to depend entirely upon what they can contrive to pick up from day to day.

The cells, too, are used several times, an egg being laid in each almost directly its tenant has left it. An important part of a wasp's duty, therefore, is to thoroughly clean out each cell as soon as it is empty, in order that the queen when she comes round may find it quite ready to receive her and her egg.

As soon as the chilly days of autumn arrive, all the grubs are taken out from the cells, carried to a little distance, and put to death. This seems a very cruel proceeding; but it is not actually so. For, if the grubs were left in their cells, they would slowly starve to death for want of the food which the workers could no longer procure for them.

Before this slaughter takes place, however, there is great excitement in the nest, for hundreds of queens and drones have been born, and these fly away to seek their fortunes. The drones die in a short time; but the queens, hiding under loose bark, in hollow trees, or in moss, live through the winter and form nests of their own in the following summer. As for the workers, the first frosty night kills them.

\section{ICHNEUMON FLIES (Family ICHNEUMONIDÆ)}

While watching a caterpillar nibbling we may sometimes see a little black fly perch upon its back. She reminds one, as she sits upon the caterpillar, of a starling sitting on the back of a sheep. 


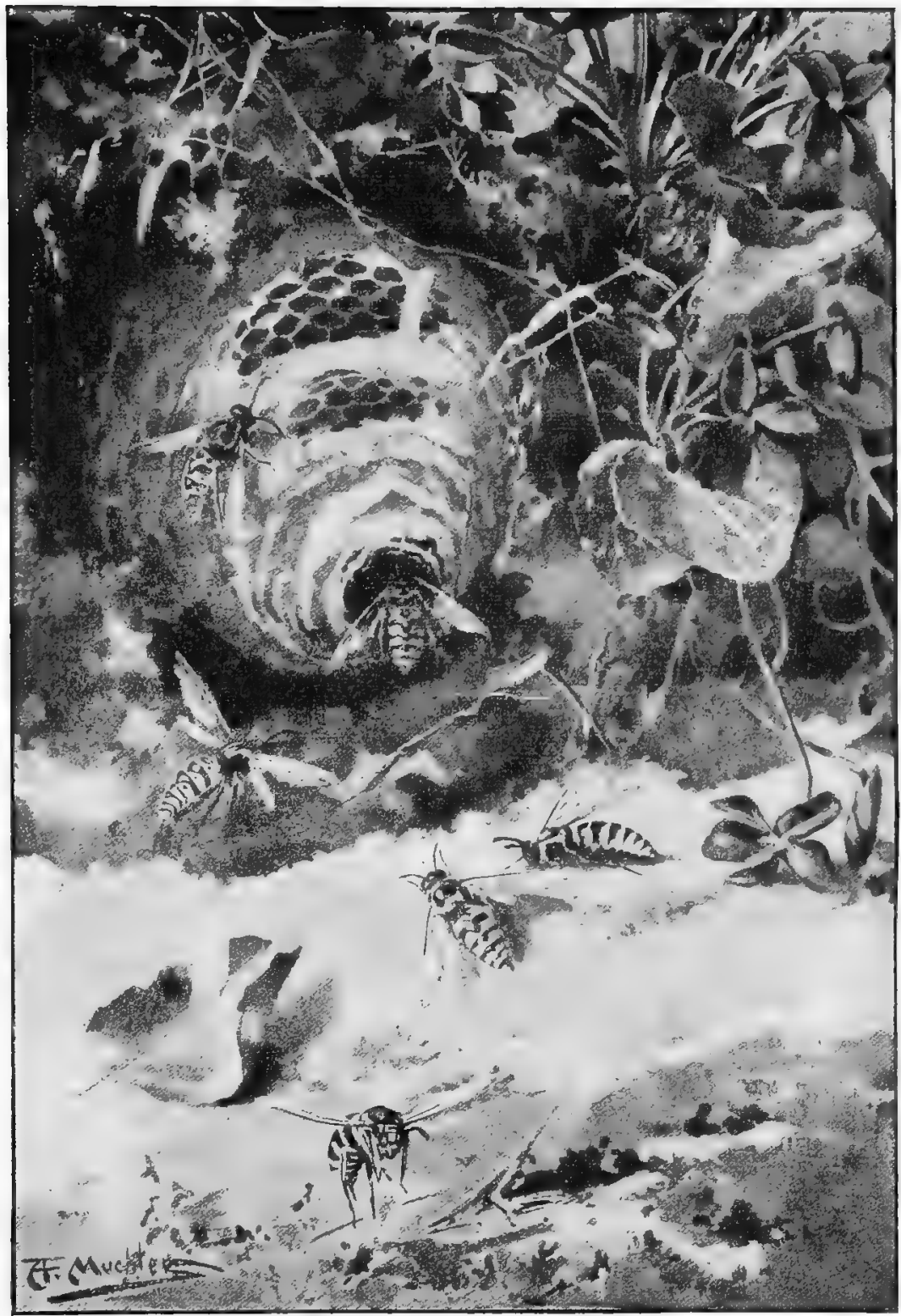


That little fly possesses an instrument at the end of her body with which she immediately begins to pierce the caterpillar's skin. Each time she does so she deposits an egg in her victim's body, and as this operation is repeated fifty or sixty times in the same caterpillar we can have full sympathy with all its

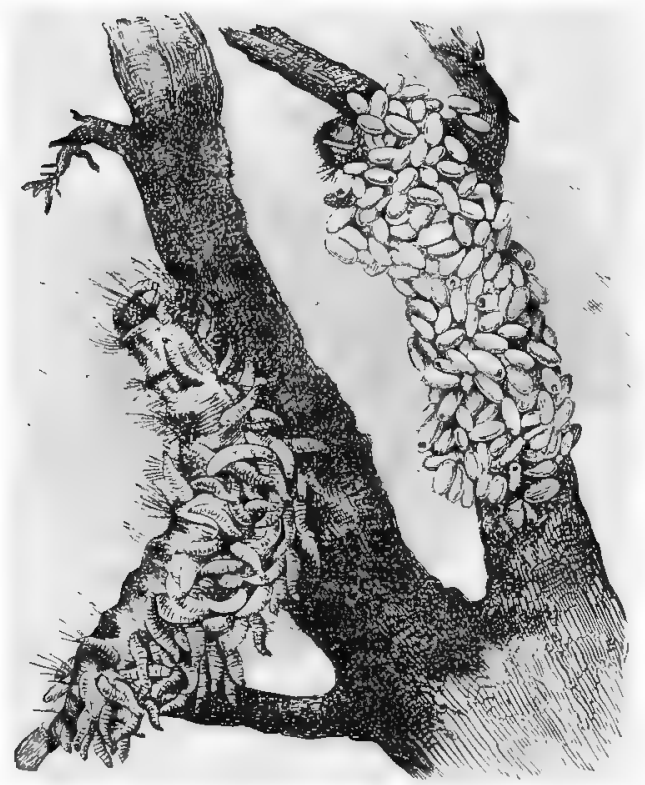

Caterpillar devoured by the Larvæ of Ichneumons, and Caterpillar covered with their Cocoons expressed objections to so awful a visitor.

The caterpillar has received its death-stroke. For that little visitor is the Ichneumon Fly, and every time the little black instrument was poked into the flesh of the caterpillar it left an egg behind it which in a few hours' time, with all the other fifty or sixty eggs, will hatch. Out of each egg will come a hungry little grub, and those fifty or sixty grubs will feed internally upon the flesh of the caterpillar!

This is their only diet throughout their existence. Morning, noon, and night those hungry little mouths gnaw away at the caterpillar's flesh. Fortunately the caterpillar seems to suffer no pain, and to be unconscious that so many deadly foes are slowly devouring it. Even its appetite does not suffer, and it goes on eating just as before, changing its skin at intervals, and appearing to be in perfect health.

At first the little grubs, led by a wonderful instinct, avoid the vital organs of their victim, and feed only upon the fat, of which a great deal is stored up within its body. When this is exhausted, 
however, they turn their attention to the more vital parts of its frame. And now it ceases from feeding, sickens, and finally dies.

Meanwhile, the grubs within it have completed their development, and are about to become chrysalids. So they bore their way out of the now empty and shrivelled skin, and spin for themselves tiny silken cocoons, which they usually fasten upon it. In these they undergo their transformation, only to become, in the course of a few weeks or months, according to the weather, little black flies just like that which laid her eggs in the back of the caterpillar.

The number of caterpillars destroyed by these extraordinary insects is almost incredible; for of the caterpillars of the common large white butterfly, which are so destructive to our cabbages and cauliflowers, no fewer than ninety-five out of every hundred are said to perish through their attacks.

Very few insects escape persecution from these flies, of which there are a very great number of different kinds, some 5000 species being already known. Some of them lay their eggs, not only in the flesh of caterpillars, but in chrysalids or pupæ, and even in eggs. So that an insect is not really safe from them until it has attained its perfect state.

The number of eggs which these remarkable flies deposit in the bodies of their victims varies very considerably. Some ichneumons lay one egg only, and the grub, when at last it kills its victim, is nearly as big as the caterpillar itself. Others place several hundred eggs in the flesh of each victim; and one instance is known in which more than a thousand ichneumon flies were hatched out from the body of a single caterpillar!

\section{THE HIVE BEE (Family APID}

As much might be said about the Bee as would fill a whole book. We may have noticed that all the bees are not quite alike. Some are much stouter than others, and have their bodies rounded instead of pointed, while their eyes are almost as large as all the rest of the head. These are the male bees, or drones as they are 
called. They have no stings, and although they live on honey, they do not bring any home. After the time for swarming is past, they are all put to death by the other bees, and then no more drones appear until the following spring.

The smaller and more slender-bodied bees are the workers, or neuters, as they are often called. These are the labourers of the hive, whose business it is to collect honey, make wax, construct cells,
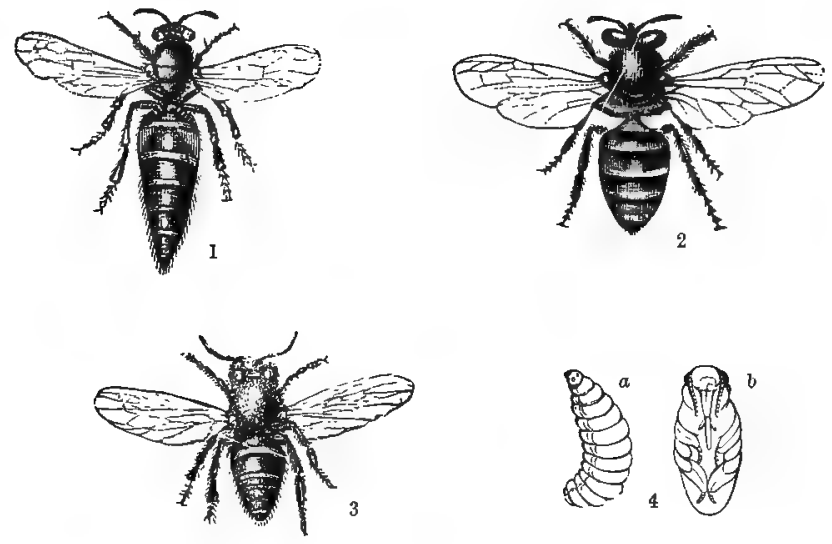

i, Queen Bee. 2, Male Bee or Drone. 3, Worker Bee. 4, $a$, Grub; b, Pupa.

take care of the eggs, and nurse and feed the grubs. As there are always a very great number of these in the hive, they are kept hard at work all through their lives.

Besides the drones and the workers, there is a third kind of bee in the hive, and that is the queen. Her body is rather longer than that of a worker, but her wings are rather smaller. If we watch the bees in the hive we may know her at once by the great respect which is paid to her by all the other bees. Some of them always surround and take care of her. They follow her wherever she goes, and keep an open space for her to walk in. So anxious are they to honour her, indeed, that they never turn their backs upon her, but walk before her backwards, just as a courtier does before a real queen.

The great business of the queen is to lay eggs. She does not 
attempt to procure honey, like the workers; nor does she build cells, guard the hive, or take care of the young. And, except just before swarming time, there is never more than one queen in a hive. In a large hive there will be one queen, perhaps two thousand drones, and from ten to twenty thousand workers. But these numbers vary at different seasons of the year.

So completely is the time of the queen bee occupied in laying eggs, that she is not expected even to feed herself, but is carefully

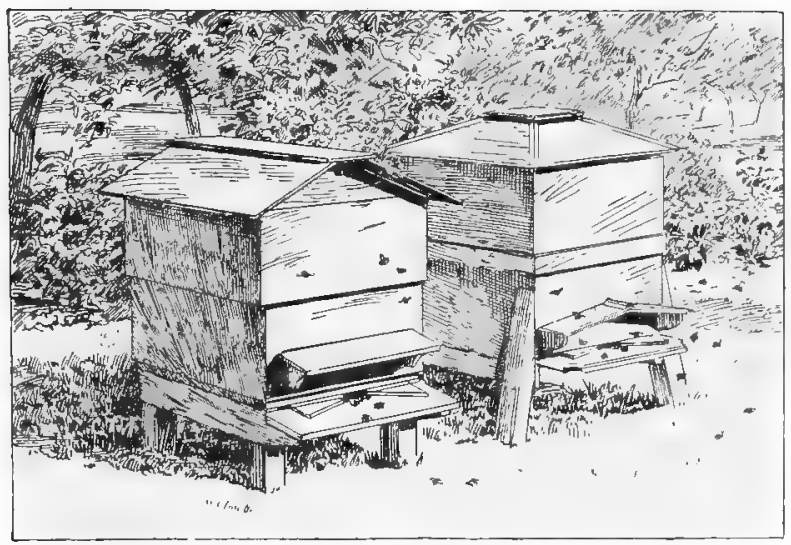

Bee-hives

fed by some of the workers, who bring her food as she may require it.

If we could examine a worker bee we should notice six little flaps, like very small pockets, on the lower surface of its body. These flaps are called the "wax-pockets", and it is from them that the wax exudes with which the "combs" are made.

When the bees want to make a comb, a number of them hang themselves together in a long string, holding on by one another's feet, and then remain quite still for some hours. At the end of that time from each of the little pockets a very small plate of wax has exuded. With this the bees set to work to build.

They knead the wax-plates with their jaws until they have made them quite soft, like so much clay; then, with a great deal 
of care, they build the foundation of a double set of cells, each of which always has six sides. All the time that it is working, the bee keeps feeling the walls of the cell with its horns, and so

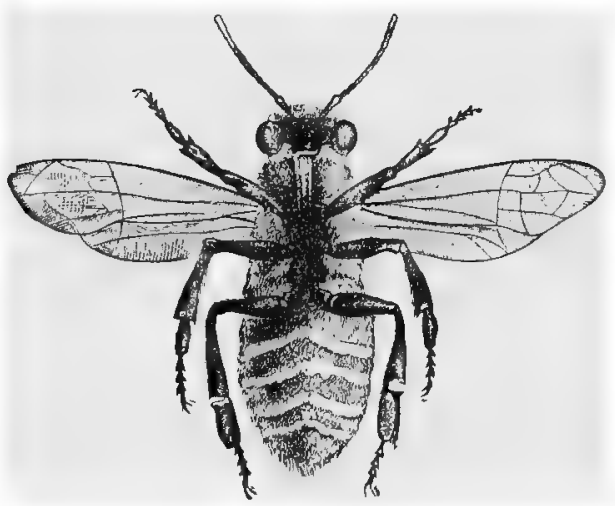

Wax-worker, seen from below (magnified) discovers if they are not exactly of the right size and shape.

If we examine a newlymade comb we may see that the edges of the cells are rather darker and redder than the rest. This is because the bee covers them with a thick gum, which it obtains chiefly from the buds of the horse-chestnut tree, or from pines. And you may often notice the bees scraping this gum off, and carrying it away to their hives to help them in building their combs. The bees also use it for several other purposes.

The cells are not always quite alike. Some are intended for nurseries, in which the worker grubs are to live; and these are

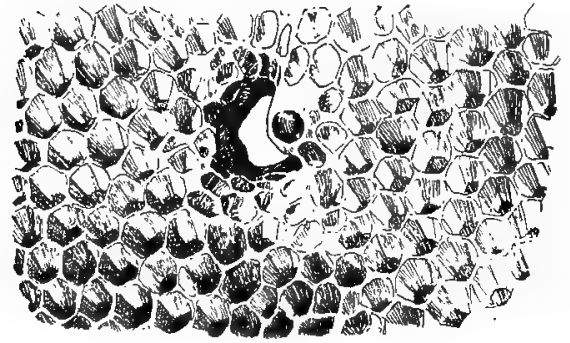

Portion of Honey-comb-showing cells rather small. Others are meant for the drone grubs; and these are a little larger. But others still are simply built as store-rooms for honey; and these are the largest of all. Between every two combs the bees leave a passage about half an inch in width.

As soon as the nursery cells are completed, the queen bee comes and lays an egg in each. She carefully examines every cell first, to ascertain whether it is properly built and prepared. In order that she may not feel hungry 
while she is at work, a number of neuter bees accompany her with food.

We may think that the queen bee, who is so anxious to see that the cells for her eggs are properly constructed, would be very careful of the little grubs when they hatch out. But she

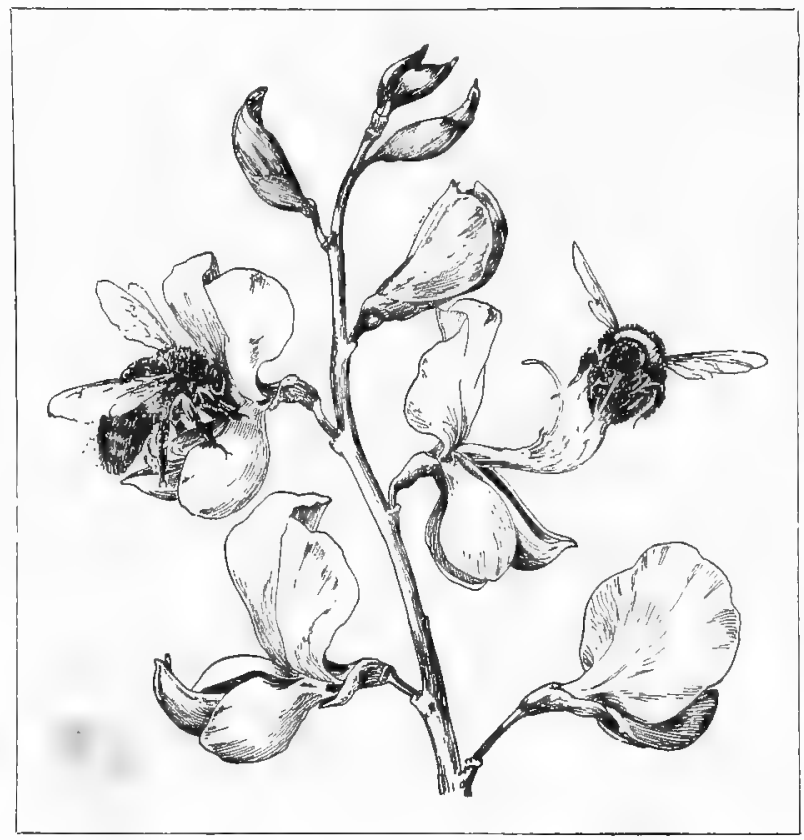

Bees in quest of Honey

does not seem to care about them in the least. When once the eggs are laid, she never goes near the cells any more, but leaves the workers to feed her little ones, and see that they do not come to any harm. All that she seems to think about is to lay still more eggs. This is not to be wondered at, as the whole future progeny of the hive depends upon that one queen.

The workers are so attentive to the grubs, however, that they quite make up for her neglect. As soon as the queen bee lays an egg in its cell, a worker bee puts in with it a small quantity of a 
kind of jelly, which is made by mixing honey with the pollen of flowers.

On the fourth day after the egg is laid, the little grub makes its appearance, and begins to eat this jelly. As soon as it has consumed this, the workers bring it some "bee-bread", which is made of pollen pressed very firmly together. And on this it feeds for the remainder of its grub life.

In about seven days from its birth, the grub has grown to its full size, when the workers, seeing that it will not want any more food, cover in its cell with a waxen lid. The grub

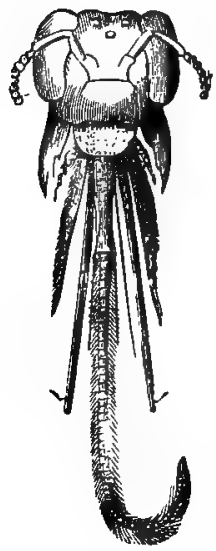

Head of Bee (much enlarged), showing the brushlike Tongue. then spins a silken cocoon, and turns to a pupa, or chrysalis, inside it. Ten days later the skin of this pupa bursts, and out comes the perfect bee.

The drone grubs take a little longer to grow into bees. These feed for eight instead of seven days, and remain in their cocoons two days longer than the worker grubs. But, on the other hand, the queen grubs grow rather faster, for they only feed for six days, and become perfect bees in a little more than a fortnight from the time when they spin their cocoons.

It is an astonishing fact that the bees, if they choose, can actually turn a worker grub into a queen. This they do by feeding it with the jelly all through its life, instead of giving it "bee-bread" as soon as the first supply is exhausted.

So if any of the queen grubs should happen to be killed, a number more can easily be obtained by simply changing the food of some of the young worker grubs.

The queen bee will never allow a second queen in the hive if she can help it, but other queens are often protected from her; so, when these queen grubs hatch, there is a great commotion. Before long the old queen, or one of the new ones, flies out of the hive with a great number of workers. These, after flying about for a time, gather themselves into a ball with their queen in the midst. This is called swarming, and if the cluster of bees is put into a new hive they will make it their home. If not, they 
will find a home elsewhere. After this swarming all the superfluous queens are put to death.

Contrary to common opinion it is found that bees really make the honey which they store; it is therefore not the simple product of flowers. The juices of the flowers, when swallowed, do not pass into the stomach of the bee, but into what is called the honey-bag. There they remain for some little time; and when the bee pours them out again they have become true honey.

The pollen, when it is collected, is placed on the bee's

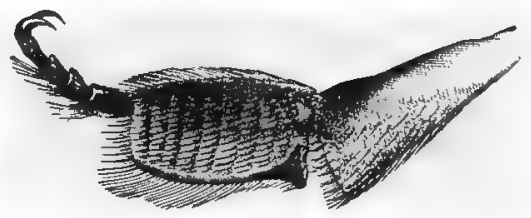

Brush and Pincers of Worker Bee hind-legs, and the long hairs prevent it from falling off as the bee flies home.

There is still a part of the bee which we ought to notice, and that is its sting. Drones have none at all. But the queen bees and the workers possess stings, which are connected, inside the body, with two little thread-like bags of poison. When the insect uses its sting it is pressed upon these bags, and a tiny drop of poison, as the sting is hollow, passes into the wound.

Enough has been said to show what very wonderful insects bees are, and how much there is to admire and marvel at, both in their bodies and in their work.

\section{DIPTERA}

The order Diptera ("two-winged" flies) contains a vast number of species, but is represented by many well-known forms. If we mention gnats, daddy-long-legs, house-flies, horse-flies, blowflies, blue-bottle-flies, hover-flies, midges, and the common flea we shall have an excellent idea of the kind of creatures which the group contains.

We can only find space, however, for consideration of two of these, namely, the Gnats and the Daddy-long-legs. 


\section{GNATS (Family CULICIDAs)}

The Gnat is not a very great favourite with us. We know too much of the powers of its beak, and the irritating nature of its bite, to be very fond of it. We have, however, one great consolation

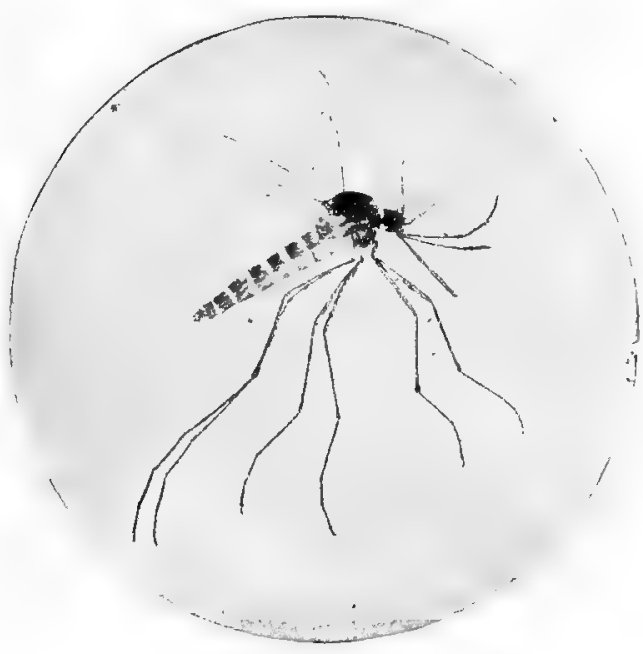

Gnat: much enlarged in the fact that our British gnats are comparatively harmless in comparison with their first cousins the mosquitoes; for mosquitoes belong to the same family as our gnats, in fact, no real distinction is to be made between them. But nevertheless the gnat is a most interesting insect.

When the mother gnat is about to lay her eggs she flies off in search of some pond or stagnant pool, or ditch of standing water. Even a rain-water butt will answer her purpose, if she can find nothing better. For the future grubs, when they hatch out, will only be able to live in the water; and therefore she must so place her eggs that, when they appear, they may find themselves in their native element.

But she does not merely drop her eggs into the water and leave them. That would never do; for unless they are in contact with the air as well as with the water they will not hatch. So the clever little gnat, as she lays them, fastens them together into a kind of boat or raft.

It is very interesting to watch a gnat laying her eggs. She rests on some small floating object, such as a bit of leaf or twig, 
and holds her long hind-legs crossed behind her. With these she takes each egg in turn, and places it just in the right position in the boat which she is forming, fastening it to those next it with a kind of natural glue. Before long her task is completed, and she flies away; and the egg-boat is left floating on the surface of the water.

Numbers of these egg-boats may be found in the summer-time in almost any rain-water butt. They are not very large, and you might think at first that they were only floating smuts. But if

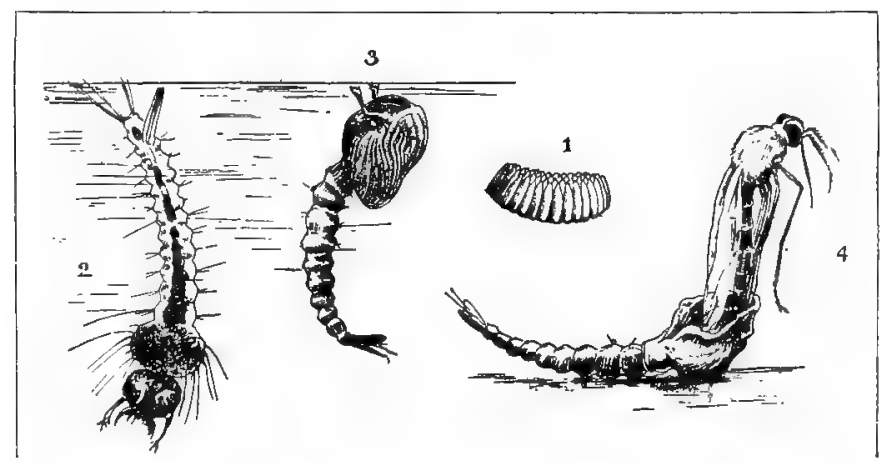

Gnat. 1, Eggs; 2, Larva; 3, Pupa; 4, Perfect Insect emerging from case

you take one out and look at it carefully you will see that it is made up of two or three hundred eggs, shaped like tiny skittles, and fastened closely together, side by side.

If one of these little boats is plunged under water it floats up to the surface again. If it is turned over it rights itself immediately. It is a kind of self-righting life-boat, and long before we ever thought of building such boats, nature had given us the pattern in the egg-boat of the gnat.

After this little boat has been floating on the surface of the water for a few days a tiny door opens at the bottom of each egg, and out come the grubs into the water. They are very odd little creatures, with large heads and long slender bodies, and curious tufts of hair near the end of their tails.

These tufts of hair indicate breathing organs. A gnat grub, ( $\mathrm{M} 868$ ) 
although it lives in the water, does not breathe water, as the fishes do, but respires air, just like almost all other insects. When it wants to breathe it rises to the top of the water, and there floats, head downwards, with its little feathery tuft just poked above the surface.

Gnat grubs feed upon all sorts of fragments of animal and vegetable substance.

After a week or two, when they have changed their skins several times, as all grubs do, and grown to some little size, they become

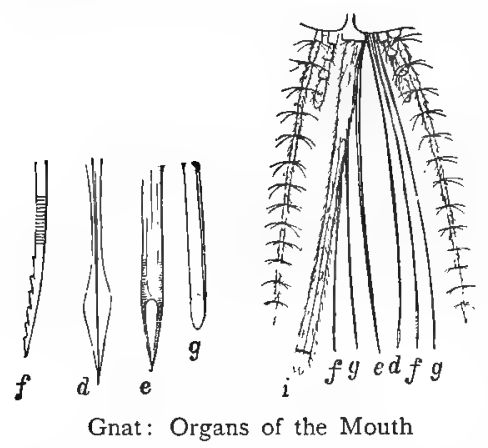
chrysalids or pupæ. Their shape is greatly altered now, for the front part of their bodies is swollen into a large mass, in which the future legs and wings are slowly developing. The tufted breathing-tube at the end of their tails is gone, too, and now they breathe through two short tubes that project from the upper part of the body. They spend a good deal of their time floating quietly at the surface of the water, but they can swim about, when they please, almost as easily as before. But during this period they take no food, for their mouths are covered over with skin.

For a few days the gnat pupae rest quietly at the surface of the water, or swim gently to and fro. Then the last change takes place. The skin of the pupa splits along the back and opens, the perfect gnat creeps out, and, standing upon its own castoff covering, which serves as a kind of raft, proceeds to dry its wings. And before long the insect is able to spread them and fly away.

When we examine the beak of a gnat through a microscope, we find that that delicate little instrument is made up of no fewer than seven different parts! First there is a kind of sheath (i), in which all the other parts are packed away when they are not in use; then there are five very sharp lancets $(d f g)$, which are employed in piercing the skin; and lastly, there is the tongue $(e)$, 
by means of which blood is sucked from the wound. As soon as the hole is pierced the gnat injects a minute drop of a clear whitish fluid, in order to make the blood flow more freely; and it is this fluid that gives rise to the swelling and irritation that always follow the bite.

But all gnats are not armed with this formidable weapon. Only the females, indeed, can bite, for the beaks of the males are not fully developed.

When we look at a gnat through a microscope we find that it is a very beautiful insect; its beak, head, body, and wings are all covered with tiny scales, very much like those upon the wings of a butterfly or moth. When the light falls upon these they glisten with many exquisite tints, all the colours of the rainbow playing over them. Thus we may fairly say that the gnat, though a troublesome insect, is a very interesting and beautiful one.

\section{THE DADDY-LONG-LEGS (Family TIPULID $Æ$ )}

The Daddy-long-legs is in many respects only a large gnat.

For a long time the grub of the daddy-long-legs lives under the ground, like the wire-worm, and feeds upon the roots of grass and corn. At times it does so much harm that a great part of the corn in the fields is quite killed by it. And whenever we see a meadow with patches of grass that look dead and withered, we shall probably not be wrong in saying that the daddy-long-legs grub is lying hidden below.

Farmers call this grub the "leather-jacket", because its skin is so very tough and strong. It is of a dirty-white colour, and is so wrinkled that it looks as if its skin were too big for it.

When this grub is fully grown it is about an inch and a half long, and as thick as a drawing-pencil. It has a pair of strong black jaws, which cut through the roots of the corn and grass almost like scissors.

In the autumn we may possibly see a daddy-long-legs laying her eggs; and a very interesting sight it is. She walks about over the grass until she has found a spot where the ground is soft, 
and so suitable for her purpose. Then she stands almost upright on her long hind-legs, and begins to bore a hole with the sharp spike at the end of her tail, turning her body from side

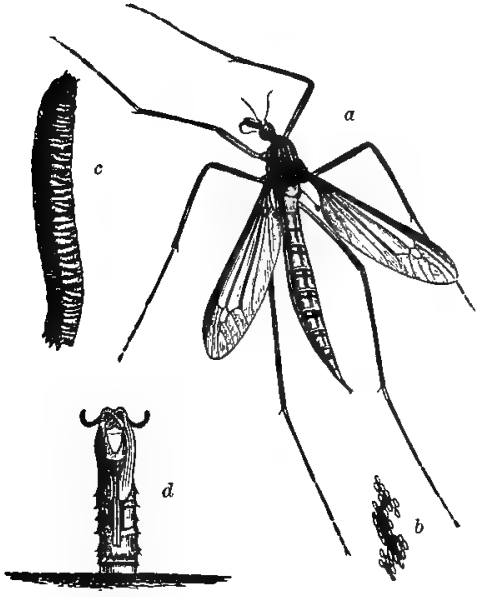

$a$, Daddy-long-legs; $b$, Eggs of do.; $c$, the Grub or "Leather-jacket"; $d$, Empty case of do.

rise from the ground, but flutters about just as though the wings themselves were injured. Blue-bottles, house-flies, gnats, and many other insects have these balancers instead of hind-wings.

\section{LEPIDOPTERA}

This beautiful group of insects, as the name of the order (Lepidoptera) implies, have their wings covered with minute scales, to the presence of which they owe their wonderful colouring and often gorgeous appearance.

Butterflies and Moths are so much alike in general build, and in their life-histories, that it is difficult to draw an exact line 
between the two sets of creatures. A butterfly, however, usually flies by day and the moths at night; but even this rule is not hard and fast. When at rest butterflies generally carry their wings straight up over their heads, moths usually bear them folded at their sides. The antennæ in butterflies usually terminate in a little knob. In moths this knob is absent, and the antennæ are often "plumed".

There are many families and genera in this great group. Members of this order are so well known that a general discussion of one will be all that we need here.

\section{THE PEACOCK BUTTERFLY (Family VANESSA)}

The Peacock Butterfly is so called because of the beautiful blue spots upon its wings, which are very much like the "eyes" upon a peacock's tail.

During summer it is a caterpillar, and is busily eating the nettle leaves upon which it feeds. About the end of July, however, it is fully grown and becomes a chrysalis or pupa, hanging itself up by the tail to a leaf or a twig. Two or three weeks later its skin splits open, and the perfect butterfly comes out; that is some time in August.

While we are watching the peacock butterfly and admiring its beautiful wings, it suddenly closes them over its back. How different they look now! There are no bright-blue eye-spots upon their lower surface; and they look, indeed, almost as if they had been charred.

So black are they that if the butterfly were sitting upon a treetrunk we should hardly see it; and no doubt its enemies often pass it by without noticing it.

If we catch it gently by the wings and release it again, we shall find that our fingers are covered with a kind of mealy dust.

When we place a little of this mealy dust beneath the microscope, we find that it is made up of thousands upon thousands of very tiny scales, of all shapes, but most of them cut and chiselled in a very beautiful manner. 
The scales are arranged in rows upon the wings, and overlap one another just like the slates on the roof of a house.

If we place one of the eyes of this butterfly under the microscope, we find that it is made up of a very great number of small eyes, set very closely together, and each with six sides, like the cells of a bee's honey-comb.

Nearly all insects have similar eye-masses; and very often there are a most astonishing number of separate eyes in each mass. In those of the common house-fly, for instance, there are four

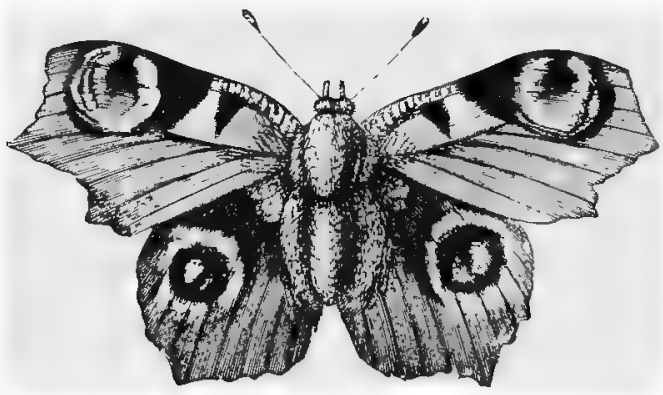

Peacock Butterfly thousand. That is a great number; but the dragon-fly has twelve thousand, or three times as many. There is a butterfly, however, which has still more, for in each eye-mass it has seventeen thousand three hundred and fifty-five separate eyes. But, more amazing still, a certain small beetle possesses no fewer than twenty-five thousand and eighty-eight!

On the head of the butterfly are two long and slender horns, each with a little knob at the tip. Underneath the head is the trunk or proboscis, coiled up tightly, as it always is when it is not being used. The butterfly can uncoil it in a moment, however, and always does so when it wants to suck up the juices of a flower.

The caterpillar of the peacock butterfly is not nearly so pretty as the butterfly itself. Its whole body is of a dull black colour, with only a few small white spots; while it is covered all over with black spine-like hairs.

It feeds upon the leaves of the stinging nettle, on which we may often find it in June and July. Not uncommonly we see peacock butterflies early in the spring; such specimens have hibernated through the winter in some sheltered spot. But on 
the first warm spring day they awake, and are soon out enjoying the sunshine.

\section{LOOPER CATERPILLARS (Family GEOMETRIDE)}

The term "looper" is applied to a large class of caterpillars, which walk in a very peculiar manner-namely, by drawing themselves up into a kind of loop, then straightening their bodies, and drawing them up into a loop again. For this reason they are called "Geometers" (earth-measurers).

Besides its six true legs, the caterpillar of a moth or a saw-fly is furnished with a number of "claspers", or false legs, which are also employed in walking.

These claspers are not legs, strictly speaking, and are quite unlike the true limbs in their structure. They are, indeed, merely fleshy

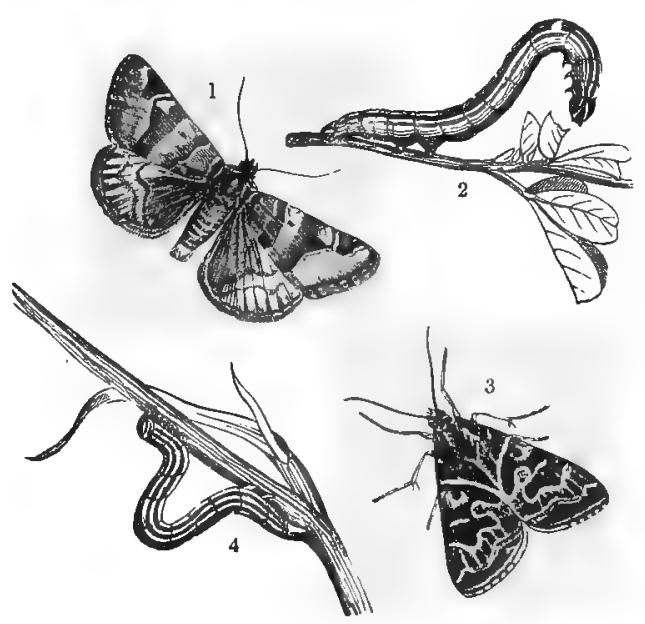

1, Burnet Moth. 2, Caterpillar ("looper") of do. 3, Shipton Moth. 4, Caterpillar ("looper") of do.

pads, surrounded with a row of very small hooks, by means of which a firm foothold can be obtained. So powerful are these claspers that when a caterpillar has once taken its hold it is quite difficult to remove it.

Now most caterpillars have ten of these claspers, set at intervals upon the lower surface of the body. Some, indeed, possess as many as sixteen. "Looper" caterpillars, however, have only four, which are placed at the extreme tail-end of the body; the consequence is that they are quite unable to walk in the same way as their fellows. 
When a looper caterpillar wishes to move, it takes a firm hold with the six true legs, which are situated close to its head, and draws up its body until it has assumed the loop-like form already referred to. Then gripping its support with the claspers at the tail-end, it straightens out its body, and takes fresh hold with its legs, drawing its body up after it as before, and the process is re-
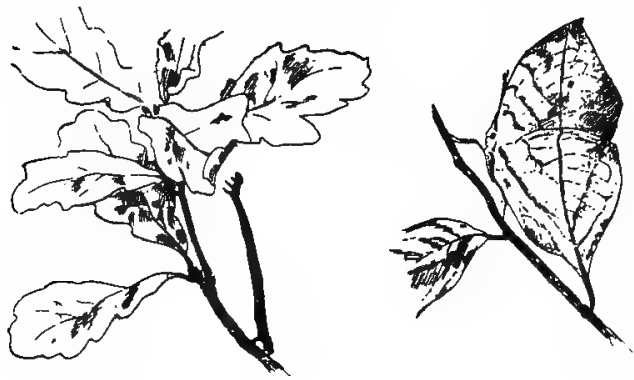

Caterpillar resembling twig

Butterfly resembling leaf

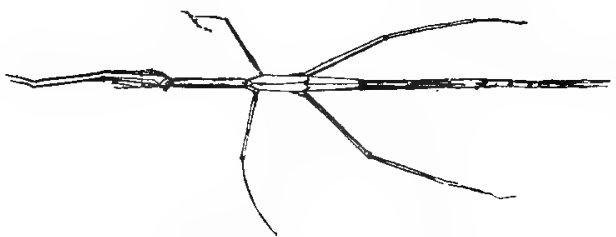

Insect resembling piece of stick

Some Instances of Insect Mimicry peated again and again.

Some species of looper caterpillar are remarkable for their wonderful resemblance to twigs and pieces of stick, which is much increased by their habit of clinging to a small branch with the claspers only, and stretching out their bodies, rigid and motionless, as though they were growing out of it. As if to add to the deception, too, their bodies are swollen out at intervals into small lumps and knobs, that look just like those which mark the spot on a twig where the new leaves are about to appear. In one or two caterpillars these knobs are tipped with light green, which causes them to look as if the buds were opening. Doubtless this strange power of mimicry, which they possess in common with many other insects, often preserves these caterpillars from the attacks of birds, and perhaps from other enemies as well. Nature has taken care, too, to colour their bodies in accordance with the hues of their food-plants, so that even the sharpest eye has difficulty in detecting them unless they move.

These caterpillars possess silk-glands somewhat like those of the spiders, but with this difference, that while the thread 
of the spider is spun by a special organ at the end of the body, that of a caterpillar proceeds from the mouth. By this thread the caterpillar suspends itself from its food-plant, or lowers itself to the ground, and the thread also provides material for those loopers that make a cocoon. This silk hardens upon coming in contact with the air, just like that of the spiders.

\section{COLEOPTERA}

The great order COLEOPTERA, that is, the "sheath-winged" insects, is well defined from almost all other insects by its characteristic marks. The members of this group undergo a complete metamorphosis, like the Diptera and the Lepidoptera, from grub to pupa, and from pupa to the perfect insect. But they are easily distinguished from these by the fact that their "fore" or upper wings are modified into wing-cases, or "sheaths", as their general name implies.

These sheaths are hard or horny, and are styled elytra; while the inferior or under wings are their true wings, and their only means of flight. As a rule these insects fly well, the wing-cases being held up while the two wings are in use. When they alight they fold their wings, and tuck them away under their protecting "sheaths".

We have only to mention the name "beetles" to realize what our Coleoptera are like. We know them already when we see them, and we know that many of them are magnificently coloured. And when we speak of tiger-beetles, stag-beetles, water-beetles, weevils, musk-beetles, and the beautiful little lady-birds we begin to feel at home with them.

This is a very great group as to families, and genera, and species - the lady-birds alone number about a thousand speciesbut none of them can be said to be very large. Some foreign species that reach the size of the palm of a large hand are considered to be gigantic. On the other hand, many of the beetles are exceedingly small. 


\section{THE GREAT WATER-BEETLE (Family DytiscidÆ)}

It is a warm, sunny morning in autumn, and we are standing on the bank of a small weedy pond, in readiness to see whatever there is to be seen. No breath of wind is stirring, and there is not a ripple upon the water. Suddenly we notice a disturbance. A small black object appears above the surface, a curious popping sound is heard, and then with a kick and a struggle the small black object disappears.

This is a Great Water-Beetle, which has been diving, and has just come up to obtain $a^{*}$ fresh supply of air. Let us see what there is to learn about him.

His two hindmost legs are broadened and strengthence into oars, and they are fringed with stiff hairs to make them more serviceable.

These oar-like limbs are naturally of very little use to the beetle on dry land. If he is taken from the water and placed upon the ground, he can only shuffle awkwardly along, like a seal or a walrus in similar circumstances. But as he is very seldom obliged to travel upon land, this defect is of little importance.

Although they live in water these beetles are true air-breathers. They keep a supply of air underneath their hard wing-cases, or elytra.

Experiments have been made for the purpose of ascertaining how long one of these beetles could remain beneath the surface of the water. One has been kept under water for an hour and twenty-seven minutes without being killed, that is, stifled for want of air.

The breathing-holes of the water-beetles are placed upon the back instead of along the sides of the body as in most insects, so that respiration can be carried on while the insect is under water.

These beetles often leave the water, and at night they climb out and set off for a journey in the air. Their wings are large and broad, and carry them swiftly and easily along; and in this way they travel from one pond to another.

If we take a beetle from a pond, allow him to become dry, 
and then pour water upon him, it runs off the polished surface of his body just as it does from a duck's back. If we lay him gently on the surface of the water, he will struggle hard to dive, but will not succeed, because his shiny body repels the water. By dropping from a height, however, as he does after a flight, the

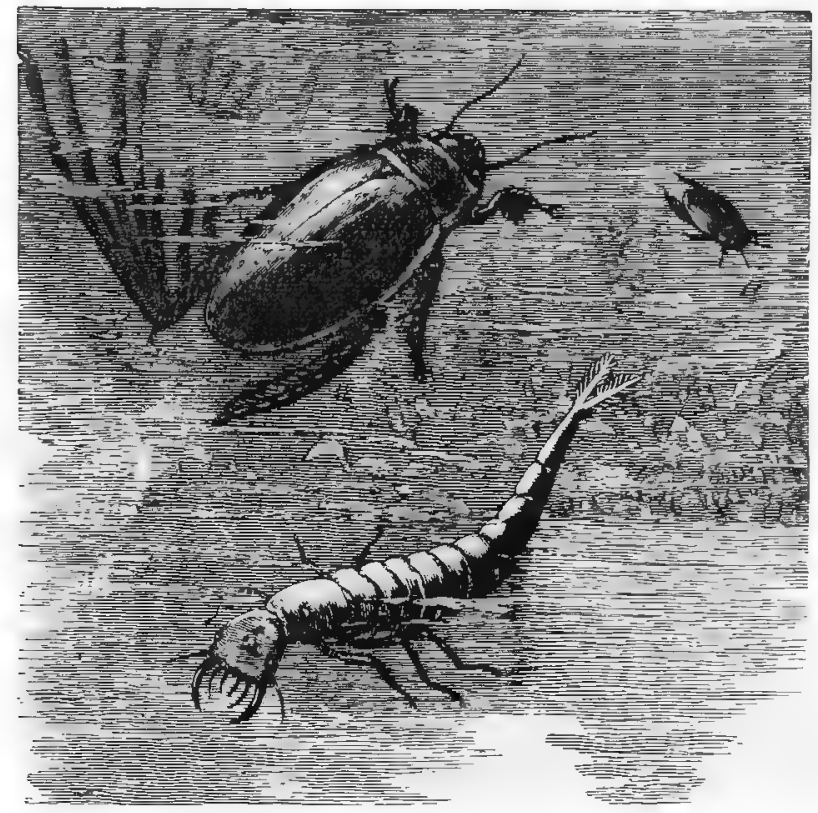

Great Water-Beetle and Grub

impetus of his fall carries him beneath the surface; and then, of course, he can swim and dive without difficulty.

Sometimes, however, he makes a very curious error; for, mistaking the glass of a greenhouse for the surface of a pond, he lets himself fall upon it. Water-beetles are often quite stunned in this way, and are found in the morning in the gutters, or on the ground below.

The eyes of the great water-beetle are very large, and project considerably from the head. Thus the insect is enabled to see in 
every direction, and to keep a careful watch for both enemies and victims.

We must be careful in handling this curious beetle, for between the hinder legs is a short, sharp spike. If it can, it will force its body backwards between our fingers, and drive this spike into our flesh.

Now let us learn something about the life and habits of our Great Water-Beetle. Being an insect, it of course begins life as an egg. This soon hatches, and produces a little grub with a long, slender body, a pair of big sickle-shaped jaws, and a curious tufted appendage at the end of its tail.

Almost as soon as this little grub makes its appearance in the world it begins to eat; and in eating it spends almost the whole of its life, until it is a grub no longer. It feeds upon living victims, which it contrives to capture in almost incredible numbers. Yet it cannot swim very fast. It has no paddles, like the perfect insect, with which to row itself through the water; neither can it drive its body along by forcibly ejecting a jet of water, like the cuttle-fish, the piddock, and the grub of the dragon-fly. But it secures its prey by cunning.

It hides among rubbish, and patiently waits until a tadpole, a grub, or other small creature comes within reach, when it seizes it, and having reduced its victim to a mere shell, throws it away.

The grub of the water-beetle has a curious, tufted appendage at the end of its body. This is the breathing organ, and communicates with the air-tubes, which in this grub, just as in every other insect, run throughout the whole of the body, even to the tips of the "antennæ", or horns, and the claws. In order to breathe freely, the grub has only to keep the tip of this organ just above the surface; and so it always lies in wait for its prey in shallow water, where it can lie at the bottom, or in weeds and leaves, and yet keep the end of its breathing organ protruding from the water.

When this larva is fully grown it leaves the water, burrows into the muddy bank, and there makes an oval cocoon. In this it changes to a chrysalis, or pupa, from which, in due course of time, the perfect beetle emerges. 


\section{WIRE-WORMS (Family ELATERIDE)}

If you have ever walked through a corn-field early in spring, when the corn is coming up, you will probably have seen here and there a patch of bare ground with hardly any green blades upon it. Wire-worms are probably lying underneath, and have devoured the roots of the young plants just as they were sprouting.

This grub lives underground for no less than three years, and all that time nibbles away at the roots of our crops. It does not eat much of each, but, after gnawing away just enough to kill the plant, it forces its way through the earth, very much as a worm does, until it comes to another plant, which it attacks in like manner.

Even a single wireworm can do a great deal of harm in the course of its life. If it were not for such birds as the starling and the rook, indeed, which find out
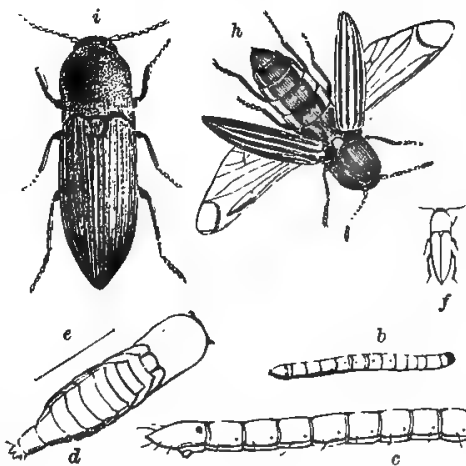

$\frac{a}{a}$

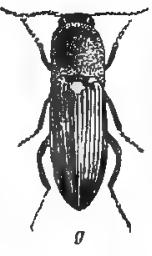

8

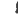


short, so that it cannot get up again like other beetles. But suddenly one hears a "click", the beetle springs up into the air, and, turning half round as it falls, comes down on its feet. Sometimes it turns a little too far, and rolls over again. And then it gives another "click", and springs into the air a second time; and so on until it meets with success.

The click-beetles have very large wings, and you may often see them flying in the sunshine, and then settling on some sweetsmelling flower. Most of them are dull brown and black in colour; but sometimes one finds a very beautiful one, with wing-cases of a bright scarlet.

\section{THE GLOW-WORM (Family LAMPIRID $A$ )}

One of the prettiest of the many pretty sights to be seen in the country is the light of the Glow-worm. In the evening, about the end of June or the beginning of July, we may see here and there on banks, or by the edges of a path through the woods, a little shining point of pale green light. If we stoop to see what causes it, we find that the light proceeds from a small, soft-bodied, grublike creature of a dull grayish-brown colour, about half an inch long, with six short legs. When we pick it up it feels cold to the touch, and as soon as we handle it the light goes out.

This is a glow-worm; which, although it looks so much like a grub, is a perfect beetle. It has no wings and no wing-cases that we can see, for they are so very small and undeveloped that we do not notice them. Yet it has quite completed its growth, and is as perfect as the great water-beetle about which we have already spoken.

It is only the female glow-worm that is so like a grub. The male has large wing-cases and a pair of powerful wings beneath them, with which he can fly well. But, on the other hand, his lantern is a very faint one, and he does not shine nearly so brightly as his humble little mate.

We do not know how this strange light is caused. Many people have tried to find out, but no one has as yet succeeded in solving 
the mystery. All we know is, that it comes from a thick fluid which lies just beneath the skin, and that it shines through a kind of little window upon the lower surface of the body. But what the fluid is, or why it shines, no one can say.

Some people have thought that the light enables the beetle to find its mate; but then thousands upon thousands of other beetles

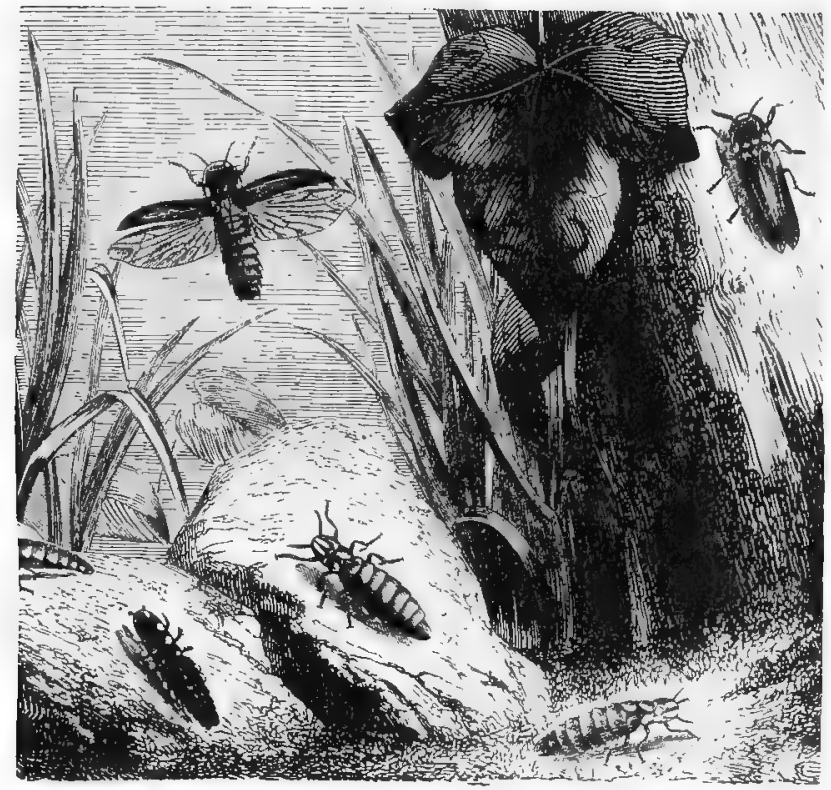

Glow-worms-Male and Fenale

find their mates without any help of the kind. Others have supposed that it serves as a means of protection from birds and other insect-eating creatures; but it certainly attracts toads, for the writer once caught about sixty glow-worms and put them in a fernery, and the toads ate them all in a couple of nights. The true explanation of the light itself, and the means by which the insect controls it, has therefore yet to be discovered. Indeed, the glowworm is a living puzzle, and not even the wisest and most learned of naturalists is able to tell us very much about it. 
The life-history of the glow-worm is rather a curious one. It begins life, of course, as an egg; and out of the egg comes a little black grub, resembling, in everything but size, the mother beetle. It is even luminous, in some degree, and people who have seen it shining among the grass late in the autumn, or early in the spring, have often mistaken it for a perfect glow-worm.

This grub lives on most curious food, namely, snails. Almost as soon as it hatches out of the egg, it sets off in search of these molluscs. When it finds one, it burrows into the shell, and begins to eat the flesh of its victim. And before very long it has killed and devoured it, and is ready to seek for another.

The grub of the glow-worm passes the winter in a state of torpor, neither eating nor drinking. But as soon as the warm days of spring come round it wakes up from its slumbers, and resumes its long-interrupted meal. By about the middle of May it is fully fed, and then, burrowing into the ground, it becomes a pupa, or chrysalis. From this the perfect beetle emerges about six weeks later.

\section{LADY-BIRDS (Family COCCINELLIDE)}

We have already seen how a small and harmless-looking insect, such as the wire-worm, can do us a great deal of mischief. Now let us see how another small insect can do us a great deal of good.

Most of us know what a Lady-bird is. Everyone who lives in the country must have seen it often, for it is very abundant, and sometimes appears in such numbers that it seems to be everywhere.

The lady-bird feeds upon the aphis, or "green-fly", and follows it wherever it goes. So, whenever a swarm of the troublesome little blight insect appears, a swarm of lady-birds is almost sure to follow before very long.

Sometimes these lady-birds come even from across the sea. Near the coast of Kent, for instance, hops are grown very largely, and every now and then the aphis comes to the hop-gardens, and begins its work of destruction. Before long, however, the 
lady-birds are almost certain to arrive, and one may see them flying in vast multitudes from over the sea. At such times the shore and the cliffs upon which they alight are quite reddened with them. They cover every rock as the tide goes out; and still they come, more, and more, and more, as though they would never cease.

A great many of these lady-birds are not strong enough for such a long flight, and become exhausted before they can reach the land. Many, too, are blown into the water by the wind; while a great number are overtaken by the waves as they crawl upon the shore. When one of these swarms visits us, thousands upon thousands are drowned; and when the tide goes
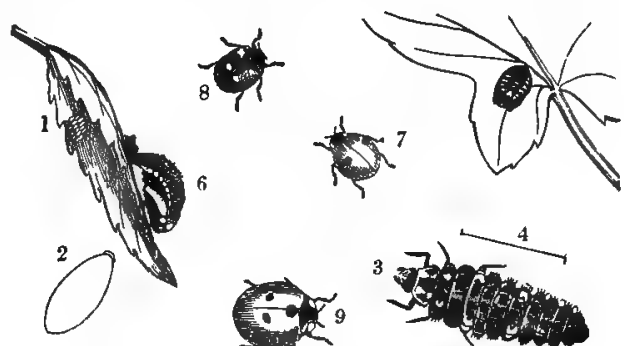
back it leaves quite a bank of dead bodies, magnified; 4, Natural length of larva; 5, 6, Pupæ; stretching in a long scar- 7,8, 9, Lady-birds

let line for many miles.

Soon, however, we see the results of their work. The ladybirds seem to know just where their assistance is required, and go off straight to the hop-gardens. And there they set to work and eat every aphis they can find.

They lay their eggs, too, and very soon the little grubs are hatched, and begin to feed upon the aphides with as good an appetite as their parents. It has been calculated that each perfect lady-bird, and each grub, will destroy the mischievous little insects at about the rate of one aphis for every minute of the day!

The lady-bird, then, is one of the most useful insects that we know, for it does us no harm at all, and is always searching for and killing some of our worst enemies. If the lady-bird were to cease from its work the aphis would increase in numbers so rapidly that it would soon destroy all our crops, and leave us neither corn nor vegetables to eat. 


\section{NEUROPTERA}

This order is the last great group of insects whose life-history embraces the three conditions of metamorphosis, namely, larval, pupal, and "perfect" forms. This group includes the caddis-flies, the scorpion-fly, the alder-fly, the ant-lion, and the lace-wings. But the caddis-flies, of which a considerable number of species are known, are made into a sub-order termed Trichoptera, while the rest are grouped together as the flat-winged sub-order Planipennia.

\section{CADDIS-FLIES}

It is a bright, sunny afternoon in early summer, and we are walking along the bank of a small stream. Suddenly, from the long herbage just in front of us, there rises a little brown-winged insect, which looks very much like a moth. Its flight, however, is not at all like that of a moth. Let us follow it and try to find out what it is. Now it has settled upon a blade of grass, and we walk cautiously up to it, when we find that it is not a moth but a Caddis-Fly.

It again rises into the air and flies off in the direction of the stream, where it alights upon the water, and runs along the surface as if it were on dry land, leaving a track behind, like the "wake" made by a boat. Suddenly it disappears from sight; but, on looking more closely, we can see it creeping down the stem of one of the water plants. It has gone under the water to lay its eggs.

There is a little pale-green object at the end of its body. That is its egg-bag, which it is about to fasten to some leaf near the bottom of the water.

In a few days' time the eggs hatch, and out come a number of very small grubs. Now these grubs are somewhat like the hermit crab. The front part of their body is encased in a coat of shelly armour, while the hinder part is soft and quite unprotected. The little creatures seem quite aware of this, and also of the fact that 
numbers of hungry foes are always on the watch to devour them. So they set to work to protect themselves from assault.

This they do by making a little "case" in which to live. The material of which it is constructed varies greatly. Some caddis grubs simply fasten two dead leaves together and live between them. Some make a case of little stones, or grains of sand; others will have nothing but grass blades, or bits of reed, which they carefully cut up into suitable lengths. Others, again, prefer the shells of minute water snails, and do not seem to care in the least whether their inmates are alive or not; so that, when the case is finished, one sometimes sees the inhabitants of the shells pulling in one direction, while the caddis grub is dragging them in another!

In order that the grub may be able to retain its position within this case, the end of its body is furnished with two strong hooks, with which it clings so firmly that the

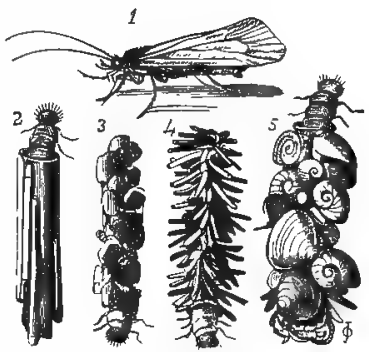

Caddis-Fly and Grubs

r, Caddis-Fly; 2, Grub in case formed of straw and dry grass stalks; 3 , in case formed of small stones; 4 , in case formed of grass roots; 5 , in case formed of shells. body may be torn in two without causing them to loose their hold.

When it has finished growing, the caddis grub retreats altogether into its case and spins a close silken net-work over the entrance. It then turns into a pupa, and can rest secure in its artificial protection.

When it leaves the chrysalis state and becomes a perfect insect it does not eat, for it has no mouth! But it never seems hungry. Its life in this stage is very short, and after a few days it lays its eggs and dies.

\section{ORTHOPTERA}

This order includes, with others, some groups, such as the true May-flies, dragon-flies, and white ants, which used to be placed in the Neuroptera. But as none of these undergo the complete 
metamorphoses which characterize the foregoing order they are rightly separated from it. The Orthoptera embraces many interesting and beautiful forms, among which we may mention the dragon-flies as being exceptionally beautiful. Their development is from a small form not unlike the perfect insect.

\section{THE DRAGON-FLY (Family Odonata)}

The Dragon-fly is one of the very fiercest of all insects. It is a kind of tiger in the insect-world.

All day long it is seeking for prey. It flies backwards and forwards, backwards and forwards, here, there, and everywhere; and every now and then it seizes some hapless insect and devours it. And immediately after it has finished eating its victim, it flies off in search of another.

The dragon-fly has large wings, and can overtake almost any other insect.

A gentleman, wishing to find the true speed of the dragon-fly's flight, caught one of these insects, and put it into a very long greenhouse, in which he had also let loose a swallow.

The bird very soon caught sight of the dragon-fly, and pursued it backwards and forwards several times. But each time the two passed him, the gentleman noticed that the dragon-fly was at least six feet in front of the swallow.

The dragon-fly does not always live its active life in the air. For many long months it is only a grub, living in the water, with nothing to show how different it is afterwards to become. But it is just as fierce and voracious as a grub, and all day long is on the watch for prey.

Underneath its head the grub has a curious organ called the mask, which is made up of several joints, with a pair of large, strong jaws at the tip. It can unfold this mask when it pleases, and is accustomed to catch its victims with it, hiding away and catching them as they pass, or gliding quietly beneath them, and seizing them with the horny jaws.

This dragon-fly grub swims in a very remarkable way. A 


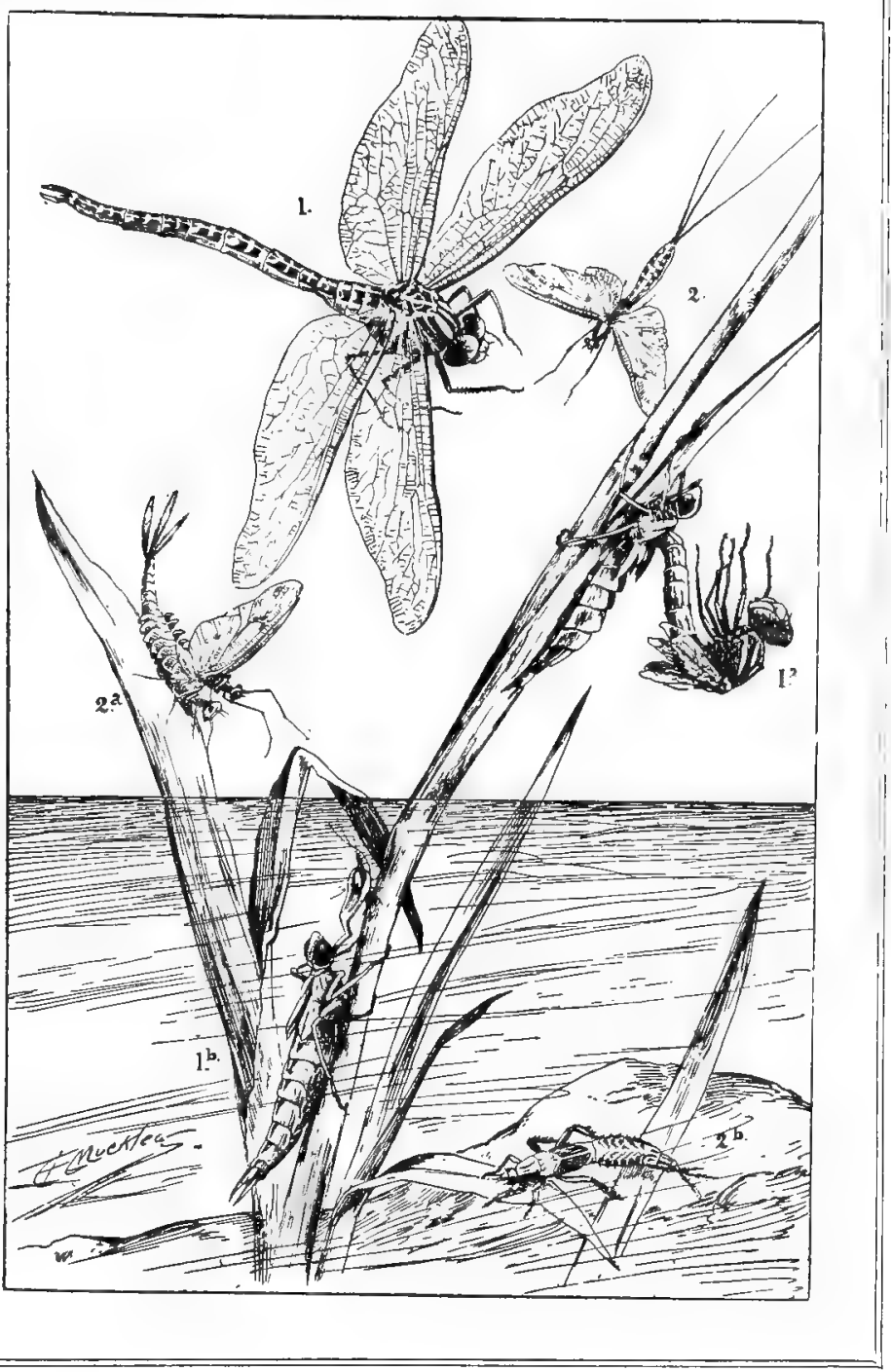

I, Dragon-fly; $1 a$, Dragon-fly escaping from chrysalis; $1 b$, Larva of Dragon-fly 2, May-fly; $2 a$, May-fly escaping from chrysalis; $2 b$, Larva of May-fly 
rocket ascends into the air because, when it is fired, a great quantity of gas rushes out from it, and pushes against the air with such force that the rocket is driven upwards. Now the dragon-fly grub is a kind of water-rocket. Through the centre of its body runs a narrow tube. Water is taken into this, and squirted out with great force. The result is, that it pushes against the surrounding water, just as the gas from the rocket pushes against the surrounding air. The insect grub is thus driven sharply forwards.

\section{THE EARWIG (Family FORFICULIDÆ)}

The Earwig is not the dangerous insect we have imagined it to be. It has no desire to enter our ears, nor are its tail-pincers alarming, as their chief use is said to be the folding up of its wings.

An earwig's wings are large, but the covers under which they have to be packed, when they are not being used, are small.
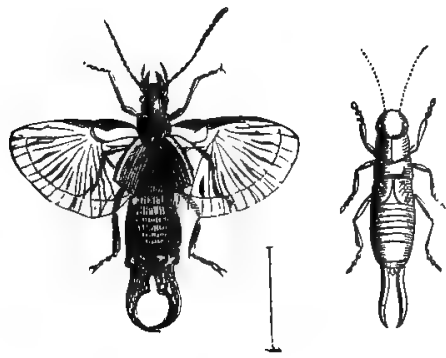

Earwig-Adult, Pupa, and Larva

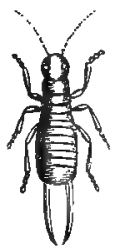

So the earwig, as soon as it settles, turns its tail up over its back, takes hold of one of its wings with its pincers, and folds it neatly across. Then it folds it again, and again, and again, until it is small enough to go under the wing-cover.

Having done this, it

treats the other wing in the same manner, and packs both wings away in a very few seconds.

The earwig is almost the only insect that takes any care of its eggs.

If you turn over a big stone in the early spring, you may sometimes find an earwig standing closely over its pile of little white eggs. It does not attempt to hatch them by the warmth 
of its body, but simply remains near them, and protects them from enemies.

Even though the earwig does damage our flowers, we must at least admit that it is a good and faithful mother. And, perhaps, now that we have learnt something about it, we shall look at it with a little less fear and more interest than we have felt before.

\section{RHYNCHOTA}

This order contains many beautifully-coloured insects, and a great number of well-known forms. It includes bugs, the waterboatman, the pond-skater, the water-scorpion, the cochineal insect, the destructive vine pest (the phylloxera), and others.

\section{THE APHIS (Family APHIDIDE)}

If we examine a rose-bush at almost any time in the spring or summer, we may find on the buds and the young shoots a great number of very small insects. These often exist in such vast numbers that they completely hide the younger portions of the plant.

They are of different sizes and of different colours. Some are nearly as large as grains of corn; some are so small that you can scarcely see them. Some are light-green, others dark-green; some pink, and others almost red. But they all have long horns, soft bodies, and very long, slender legs. And some, but not all, have transparent gauzy wings as well, over which all the colours of the rainbow seem to play in turn.

Although these tiny insects look so very different, they are really all the same, some being more "grown up", so to speak, than others. They are known by several names. Farmers, for example, mostly call them the "green fly", and dislike them because they do so much harm to hops, corn, turnips, beans, and many other plants which are grown for food. 
Gardeners often call these insects the "green blight", and dislike them because of the great damage which they do to roses, and to many of the plants in gardens and in greenhouses. But another and more correct name for this green fly, or green blight insect, is the "Aphis".

By the appearance of a single aphis, we find it very hard to understand how it can do so much mischief. What a small creature it is, and how feeble and helpless it seems!

Yet farmers tell us that it sometimes destroys whole fields of corn and beans, while it is hardly possible to describe the injury
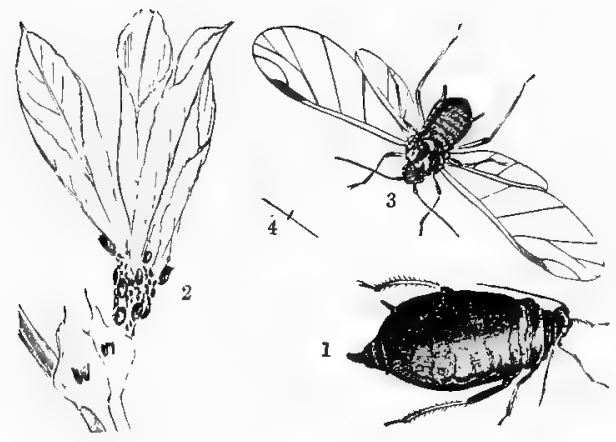

I, Aphis (highly magnifed); 2, Same on plant leaves; 3. Winged Aphis (highly magnified); 4, Natural size

which it causes to hops. A hop-garden may be full of strong, healthy plants, all twining round and round the poles, and covered with blossoms. But a week later one may see nothing but withered stems and dry and dead leaves. That is the work of the aphis!

It increases in numbers so fast, that where there is one aphis to-day, there will be two or three hundred in a day or two's time; and a few days later there will be three hundred times three hundred, and in very brief time, countless millions. It has been found that a single aphis, before it dies, may have more than six thousand million descendants-four times as many as there are people in the whole world!

This seems very marvellous, but it is quite true. Indeed, if vast numbers of these mischievous creatures were not killed by other insects, and by birds, they would very soon prevent us from cultivating any crops at all.

The aphis has no jaws, but it has a beak which it drives into the leaves or the bark of its food-plants, and so sucks up their sap.

One or two, or a dozen, or twenty aphides could do little harm; 
but when thousands upon thousands of the little insects are incessantly sucking away, we can well understand how easily they weaken, and even kill, large and strong plants.

One kind of aphis has a very remarkable beak. This insect lives on the young shoots of larch-trees, and comes out early in the spring, when there is no foliage on the branches to shelter it from the fierce winds. If it had to trust to its slender limbs for a hold, it would be blown away, and would die. So Nature, instead of giving it a straight beak, has provided it with one shaped like a corkscrew. This, when driven deeply into the bark, gives a very firm hold; and thus the aphis is anchored down, as it were, by its own beak.

It is not only by taking their sap that the aphis weakens the plants on which it feeds. If you examine its back you will see two tiny tubes projecting, one upon either side. The sap, as it passes through the body of the aphis, is turned into sugar, and comes out through these little tubes.

This sugar falls upon the leaves below, and makes them as sticky as if they had been smeared with treacle. Now a plant breathes through its leaves, in which there are numbers of little holes for the air to pass in and out. And as the sugar chokes up these holes, it prevents the plant from breathing, and so helps to weaken it.

This sugar is called "honey-dew". It is this that the ants are said to extract from the aphis, much as we obtain milk from cows. Owing to this curious habit, the aphis is sometimes known as the "ant-cow".

\section{MYRIOPODA}

It is perhaps difficult to realize that "centipedes" and "millipedes", which form the great class of the MYRIOPODA (the "manyfooted"), should be the near relatives of insects, and so come next in order to them. But naturalists now place them in this position, and make the centipedes a class by themselves under 
the name of CHILOPODA, and the millipedes into another class entitled the DiplopoDA. Through these forms we arrive at the class ARACHNIDA.

\section{ARACHNIDA}

Most people, if they were asked what a Spider is, would reply that it is a kind of insect. But this would be a mistake, for spiders are not insects according to scientific classification.

The frame of an insect, as we have seen, is divided into three parts, which we have called the head, the chest, and the body. The frame of a spider, however, is divided into two parts only,

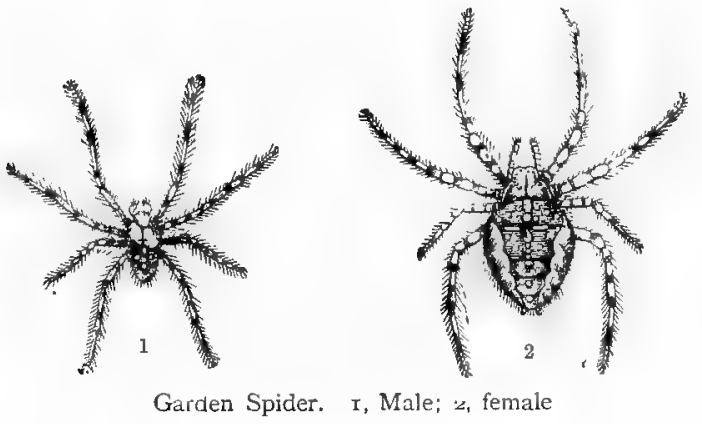
the head and chest being united.

All insects have six legs, although two of these are sometimes not fully developed. Spiders, however, always have eight legs. Sometimes these legs are very long, sometimes very short; but as a rule we can see and count them quite easily. Spiders, moreover, never have wings.

There is a great difference, also, between the eyes of spiders and those of insects. Insects, as we know, have two great eye-masses, one upon either side of the head. Each of these is composed of a great number of separate eyes, which are mostly six-sided in form, like the cells of a honey-comb. A common house-fly has no fewer than four thousand of these eyes, while a well-known English butterfly has between seventeen and eighteen thousand!

But a spider has only eight eyes at the most, and these are situated, not at the sides of the head, but upon its upper surface. By examining the head of a spider we can easily see these eyes, 
which are set in different directions, so as to command a wide field of vision.

On the head of an insect, too, are two horns, or antenne, as they are more properly termed. These may be long and slender, short and stout, plumed, knobbed, clubbed, or saw-like; but in some form or other they are always present. Spiders, however, do not possess them.

Once more, an insect passes through three transformations before it attains to its perfect state.

Spiders, however, undergo no such changes of form. When hatched they are as perfect as

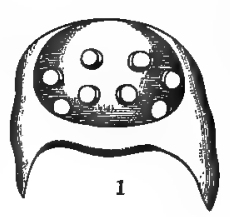

1, Eyes of Spider.

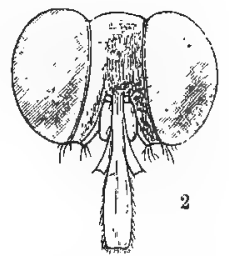

2, Compound Eyes of Common Fly their parents in all but size. As they grow, these little spiders, like the grubs of insects, throw off their skins at intervals; but the change of raiment brings with it no corresponding change of form.

Many insects and many spiders spin silken webs. The insects do so to provide themselves a habitation, or as a means of protection from their enemies; but spiders make their nets in order to entrap their prey.

In spring and summer we may find spiders' webs everywhere; in the trees, in the bushes, in the grass, in greenhouses, outhouses, and sheds. Everywhere the silken nets are hanging. If we examine them we shall probably find that they contain the remains of insects which have been entangled in them, and partly devoured by the spiders that set them.

The spider's threads are spun from a thick, glutinous liquid of a pale yellowish colour. This is the silk, in its original form. Until it leaves the body of the spider it is nothing more than a gummy fluid. But it possesses the property of hardening as soon as it comes into contact with the air, and thus assumes the form in which we know it.

At the end of the spider's body are minute organs called spinnerets, and each of them communicates with one of the silkproducing glands. When the spider spins a net, it touches with 
the tip of this organ the object to which the end of the line is to be fastened, and drawing its body rapidly away, a delicate thread is formed, which hardens as it is made.

This thread is wonderfully strong, and will support a much heavier weight than one would imagine. The secret of its strength

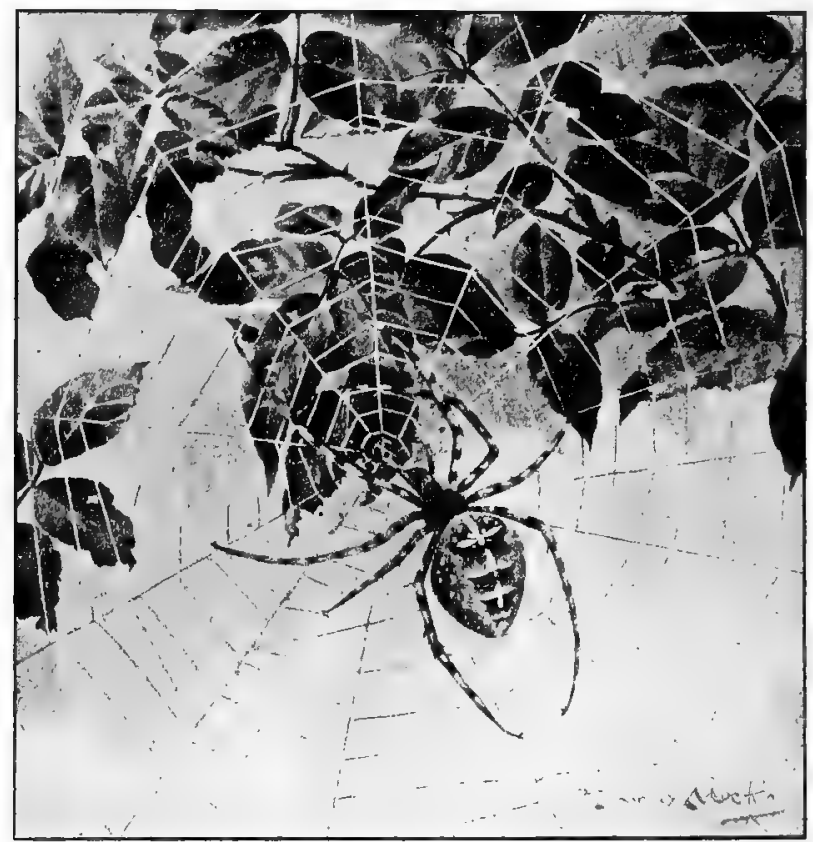

Spider gand Webpra

is, that it consists, not of a single line, but of a number of slender strands all closely twisted together. Each spinneret is pierced, not by one large hole, but by a multitude of small ones. The silk is forced simultaneously through all these holes, so that a large number of exceedingly delicate threads are formed. And as the body is drawn away, these are all twisted together into a single strong line, just as is done in the manufacture of ropes.

Taken individually, these threads have but little strength, but 
when twisted together they illustrate the truth of the old saying that "union is strength", for a great force, comparatively speaking, is required to break them.

We must remember that we are still in the vast world of "jointed animals" (the Arthropoda), and in that respect all the insects are related to those which we are now considering; but the true insects were left behind as soon as the Myriopoda came into view. Our present class, Arachnida, comprises no fewer than eight orders, which are made up of a host of variously-formed scorpions, spiders, ticks, and mites. Of scorpions there is a vast number of species in the world, but of spiders the host is well-nigh illimitable.
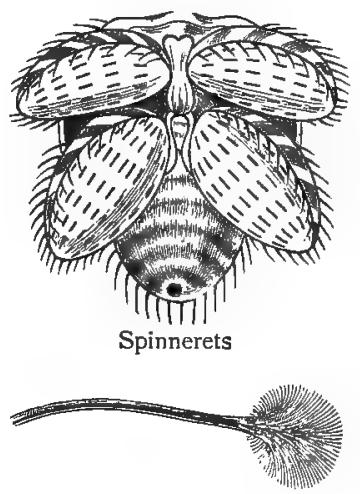

Attached End of Spider's Thread

\section{ARANEÆ}

We all know what a spider is like. It has usually a plump body, with its head, as we have already mentioned, buried in its chest. It has eight legs; but the two front "claws" often look so like legs that it seems to have ten of these organs. The characteristic number, however, is eight.

\section{THE GARDEN SPIDERS (Family ARgIopid $\approx$ )}

On examining the web of a Common Garden Spider, we see that it is composed of a number of threads radiating from a centre like the spokes of a wheel, and that upon these another thread is coiled round and round. The framework, of course, is made first.

We also see that while the spokes of the net are perfectly smooth and simple, the spiral thread is covered with tiny drops of a very sticky liquid. Unlike the silk itself, this liquid does not 
harden when it comes in contact with the air. Days after it has been deposited, it remains just as sticky as ever. It is to these little glutinous drops that an insect adheres when it flies against the net.

The number of these sticky drops in a single web is almost incredible. A careful observer, who has paid much attention to the subject, tells us that in every

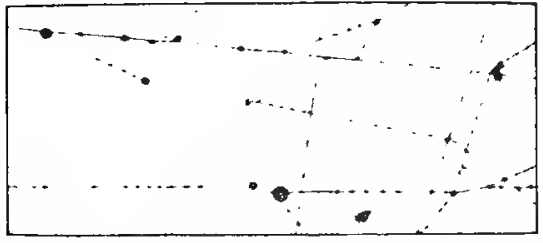

Spider's Web with drops of sticky matter inch of the spiral thread are no fewer than two hundred globules. Now, in an ordinary web of the common garden spider, the spiral thread upon an average is thirty-six feet in length. And so, by a simple calculation, we find that in that single web there must be very nearly eighty-seven thousand of the tiny drops of gum!

The spider itself can run about over its web without becoming entangled in it, while an insect which once touches it seldom succeeds in breaking away.

This is not altogether due, however, to the globules of sticky fluid; for the silken threads themselves are highly elastic, so that they yield as the insect struggles, and do not break.

When a large insect is captured, the spider never allows it to struggle for long, for it knows by instinct that its victim may break away or damage the net. So, no sooner does a large insect fly against the net and begin to struggle, than it runs quickly to the spot and seizes the prisoner.

If it is a wasp or a bee it does not attempt to touch it, but cuts three or four of the threads which hold it, and allows it to escape. As soon as the prisoner has flown away, the spider carefully repairs the damage, and then retires to its hiding-place to wait for another victim.

Should the captive, however, be destitute of offensive weapons, the spider seizes it with its long legs, places the spinnerets for a moment against its body, and then begins to turn it rapidly round and round. As it does so it pours out silk, which now issues from 
the spinnerets, not in a single thread like that of which the web is composed, but in a broad, ribbon-like band. In a very few minutes the prisoner is completely swathed like a mummy in this silken band, and of course can struggle no more. The spider then bites it with its venomed jaws, and leaves it, still rolled up, until it is hungry and requires a meal. At times one may see five or six of these insect mummies in the web of a single spider.

Spiders employ their silk for other purposes than that of spinning a web wherein to entangle their prey. If they wish to descend from a height, for instance, they easily lower themselves by a single stout thread; and, if alarmed, they can ascend this line again to the place whence they started. Some spiders, too, travel for long distances through the air by simply spinning a loose thread, to which they cling,

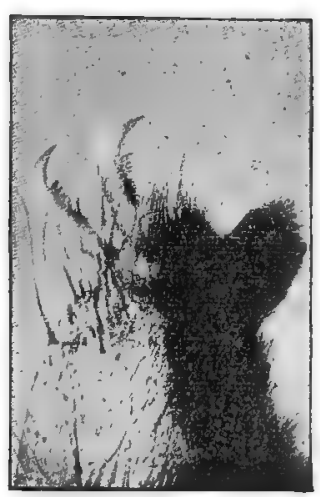

Spider's Foot and allowing the wind to bear them whither it will. These are generally known as Gossamer Spiders.

The eggs of a spider are always encased in a silken bag, which is either put carefully away in some place of security, or carried about by the mother until the little ones are hatched. We may often find these egg-bags on fences and walls, or under the loose bark of trees.

Many spiders make dwelling-places of silk, and some of these habitations are very remarkable. Among long grass, or in tangled herbage, we may often find a spider's retreat, in the form of a conical or a four-sided silken case, in the centre of which the spider sits watching for prey. So closely woven are the walls of this little dwelling that we cannot see the spider through them. Directly we touch her home, however, she comes hastily out and runs away with great rapidity. 


\section{THE TRAP-DOOR SPIDERS (Family CTENIZIDÆ)}

The home of the Trap-door Spider is very curious and interesting. It is made in a hole carefully excavated in the ground. This hole, from one inch to several inches in depth, is neatly lined with silk, and the entrance, which is nearly circular, is closed by a silken pad, which forms the "trap-door". The spider is always very careful to cover the upper part of this door with fragments of earth, so that, as it exactly fits the entrance, it can hardly be detected when closed, even by the most experienced eye.

To open this door when the occupant is within is extremely difficult, for, as soon as the spider finds that such an attempt is being made, she runs up to the top of her burrow, and clings with all her strength to the silken pad. When she is out, however, she leaves the door open; and then, by the exercise of a little care, the silken lining can be taken out uninjured from the burrow. After the earth which clings to it has been removed, it looks like a small silken stocking.

One kind of trap-door spider is even more ingenious, for, besides closing the entrance to her home with a silken pad, she makes a small additional burrow at right angles to the other, a couple of inches or so from the surface of the ground. Into this, the mouth of which is carefully covered with a silken curtain, she retires when threatened by danger, so that, even if the door of the principal burrow be forced open, the dwelling appears to be empty.

Only one spider of the trap-door group is found in Great Britain. This, however, does not make a true trap-door, but continues the silken lining of the burrow above the surface of the ground, so that the upper part falls over and closes the entrance. This spider is also remarkable for having its eyes set upon little turrets, which project above the level of the rest of the body, and enable it to command a wide field of vision.

Trap-door spiders very seldom leave their burrows by day, evidently fearing that the open door may attract the notice of 
some enemy. At night, however, they sally forth in search of prey. They spin no web in which to entangle their victims, but carefully search for insects and other small creatures in the retreats to which they have retired for the night.

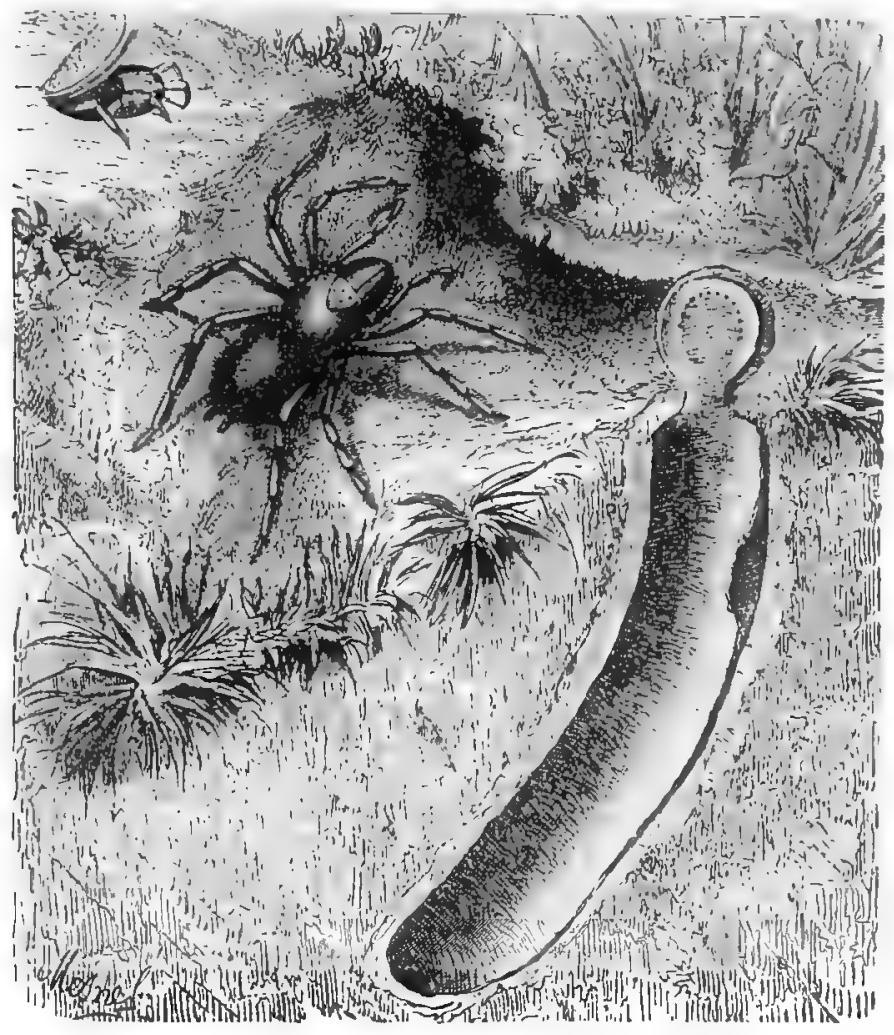

Trap-door Spider, and Interior of its Dwelling

The great Crab Spider of Surinam is a near relation of these remarkable creatures. This is the largest and most formidable of all known spiders, for it is more than two and a half inches in length when fully grown, while its limbs cover a surface larger than that of a man's hand.

This huge spider does not limit its diet to insects, but some( $(\underline{M} 868$ ) 
times preys upon young birds, which it takes from their nests at night. In confinement, too, it has been known to kill and devour frogs and even mice. The poison with which its jaws are charged is almost as potent as that of some snakes, and a victim, when bitten, succumbs to its deadly influence in the course of a very few minutes.

\section{THE HUNTING SPIDER (Family ATTIDÆ)}

There are still two very interesting spiders, both of them natives of Great Britain, which we ought to notice. The first of these is the pretty and active little Hunting Spider, which is also
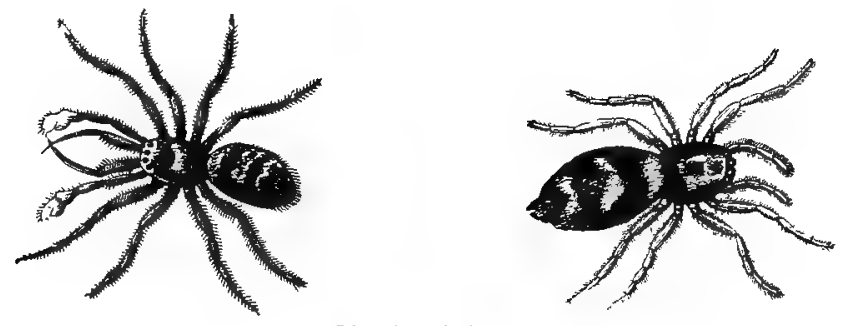

Hunting Spiders

known as the Zebra Spider, on account of the black and white stripes upon its body. In all parts of the kingdom it is very plentiful, and on a sunny day may be seen running briskly about on almost every tree-trunk, window-ledge, fence, and wall.

This is one of the spiders that spin no web. It possesses silk-glands, however, and makes incessant use of them, for it never moves, even for a single step, without leaving a silken thread behind it. Sometimes this thread proves very useful, for in leaping upon its prey the spider occasionally misses its footing. If it should meet with such a mischance, however, it is prevented from falling by its line, which checks its descent and serves as a ladder up which it can climb.

The hunting spider is gifted with wonderful craft and agility, and contrives to approach its victims so silently that they are not aware of its presence until it leaps upon them and secures them. 
It is very interesting to watch one of these spiders when it is making its way towards a fly upon a wall or railing. The unsuspecting fly is sitting upon the edge or the upper surface of the railing. The spider creeps along below, travelling for a few inches with great caution, and then peering round a corner in order to see whether its quarry has taken alarm, it gradually approaches a little closer, and so on until, with a sudden spring, it pounces upon its victim and inflicts the fatal wound.

\section{THE WATER SPIDER (Family Argyronetide)}

Our next spider lives in the water, and is therefore called the Water Spider. It is especially fond of clear, weedy ponds, in which it is sometimes found in the greatest abundance. Like water insects, moreover, it can remain submerged for some time.

It breathes air, but it has no air-cistern, like the water beetles, for it possesses no wing-cases beneath which a supply of fresh air might be stored up. It has, however, a body thickly clothed with long hairs; and when it dives, a number of little air-bubbles are entangled among these, so that the spider can breathe with perfect freedom.

By means of these hairs, too, it brings the air-supply to the odd little silken cell which serves as its nursery. This cell is always placed beneath the surface of the water, and is fastened by a number of threads, or "guy-ropes", to the stems and leaves of aquatic plants. In shape it is like a thimble, the mouth being always below.

Having constructed its nursery, the spider next proceeds to fill it with air. This it does by ascending to the surface, and then diving below with a quantity of air entangled, partly among its long hairs, and partly between its hinder legs. Creeping beneath the cell, it gives itself a shake, and so dislodges the air, which floats up through the wide mouth, but cannot pass through the closely-woven walls. A second supply is then brought in like manner, and the process is repeated until the cell is full. 
When this important operation is completed, the spider lays her eggs, which she places in a saucer-shaped cocoon, fastened to the inner 'wall of her nursery. About one hundred eggs are encased in this silken covering. She then mounts guard over them, by resting just inside the mouth of the cell, with her head downwards.

Every now and then the parent spider seems to think that a fresh supply of air is necessary. She therefore gives her nest

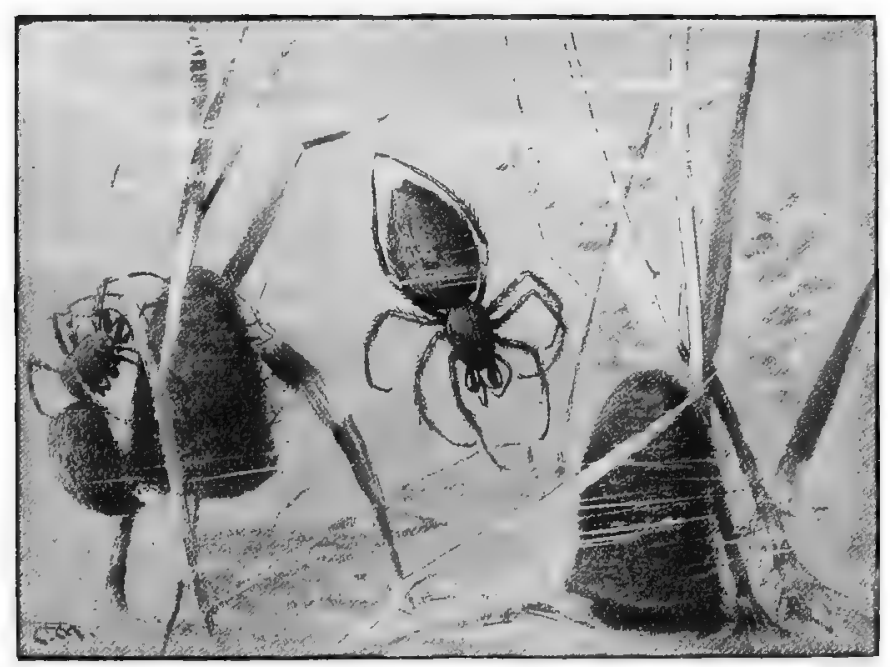

Water Spiders

a sudden tilt to one side, so that the exhausted air is turned out, and floats up in a large bubble to the surface. Then, replacing the little nursery in its former position, she quickly refills it in the same manner as at first. This nursery also serves as a diningroom; for, whenever the spider catches a victim, she brings it down to the cell before beginning to devour it.

This is the only species of water spider known in the British Isles, or indeed in Europe. Other species occur in other parts of the world, and some few marine spiders are known. 


\section{CRUSTACEA}

The Sea-spiders and the King-crabs form connecting links between the previous group and the Crustacea. The Crustaceans of course belong to the kingdom of the Invertebrates, and to the sub-kingdom of the Arthropoda. The class is named Crustacea, because the species which it comprises are almost invariably encased in a hard unyielding "crust" or shell, which covers body and limbs alike, with the exception of the Hermit-crab group, whose soft bodies have to be protected by the adoption, in place of armour, of any mollusc shell that happens to be handy. They have generally ten well-developed limbs, sometimes more; but as these are variably feet, or feeders, or jaws, or claws, it is difficult at times to say how many feet, or how many limbs or organs a Crustacean possesses.

It is easy, however, to follow one characteristic feature of classification, and that is as regards their tails. Some have long tails, as, for instance, the lobsters; and some have tails scarcely worth mentioning, as in our sea-side friends the crabs. So there is a short-tailed group and a long-tailed group.

The crabs proper include many species-the edible crab, landcrabs, and a great host of others which much resemble each other in general build. The lobster group embraces, besides true lobsters, prawns, shrimps, hermit-crabs, crayfish, \&c.

Crustacea are mainly inhabitants of seas; but some, as for instance crayfish, live in fresh water, while some have successfully assumed a terrestrial life and make forest-land their home. Besides those mentioned, common wood-lice, sand-hoppers, fresh-water shrimps are all included in this class; as are also barnacles, and the almost microscopic water-fleas.

We may take the common lobster as an excellent type of this bony-clad group. 


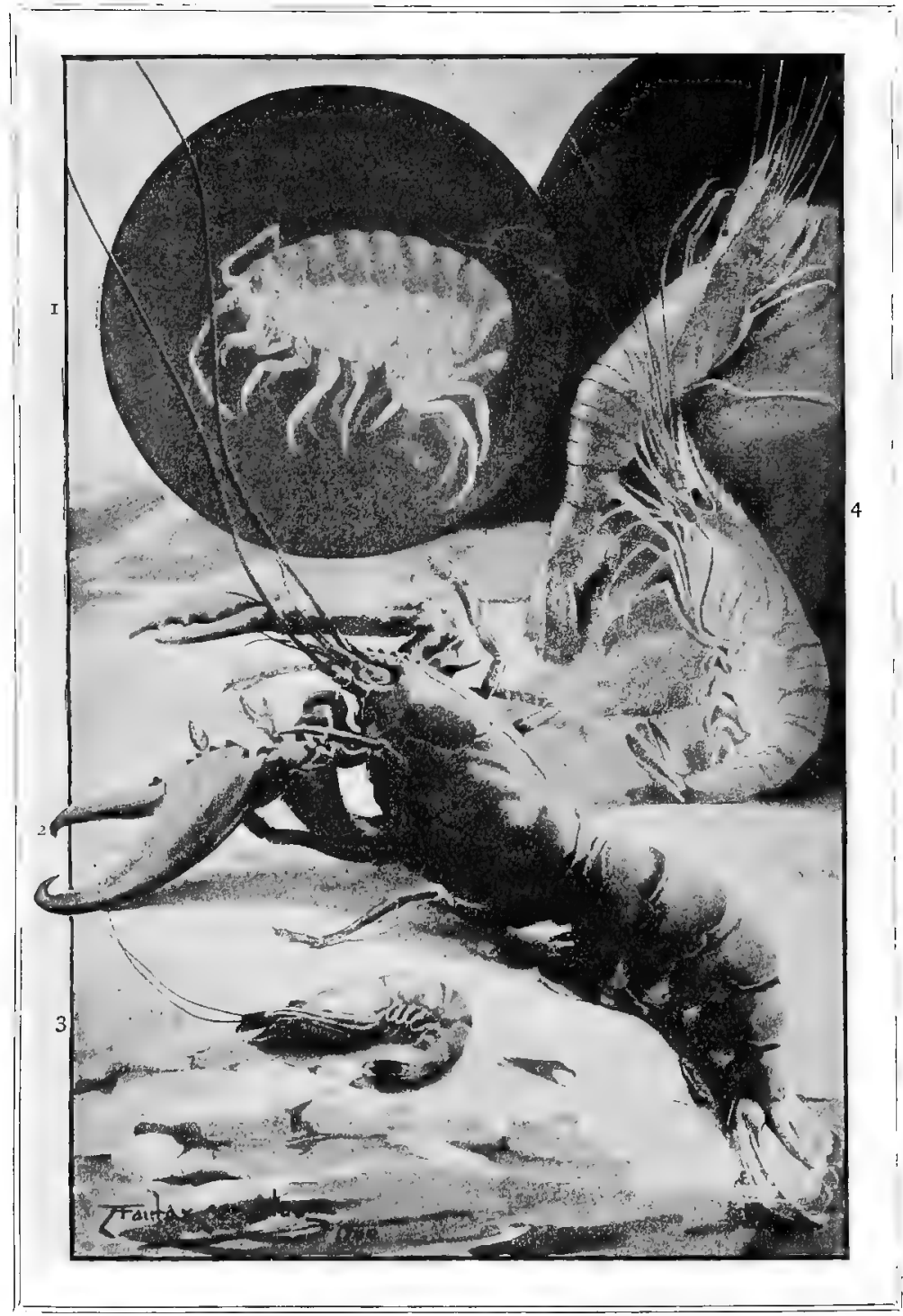

CRUSTACEANS

I, Sandhopper (magnified); 2, Lobster; 3, Shrimp; 4, Prawns 


\section{THE LOBSTER (Family NEPHROPSIDÆ)}

We must all have noticed that a lobster is characterized by its long horns, mail-clad body, and great claws.

The skin of a lobster may be considered as an external skeleton, enclosing the body in a kind of natural armour, with many joints and hinges. For, if we examine a lobster's body, we shall see that it is almost as flexible as that of a caterpillar. In spite of its casing of hard shell, it can be folded or doubled up so that the extremity of the tail lies almost underneath the head.

But the skeleton of a vertebrate animal has another function to fulfil besides that of supporting the body; it has to serve as an attachment for the muscles. All the different movements which we can make are due to the action of our muscles. Now the muscles of a lobster, which possesses no bones, are attached in just the same way to the inner surface of the shell. The larger and more powerful muscles, too, such as those that work the great claws, have a ridge provided for their attachment, just like some of the bones of our own bodies. So that the shell of a lobster really fulfils the office of a skeleton in both respects, as it gives the necessary support to the body, and also serves as an attachment for the muscles.

In the lobsters and crabs this shell is formed of three separate layers, and is so wonderfully hard that it is often employed for the purpose of sharpening knives.

At certain seasons of the year the lobster loses all inclination to eat. Taught by instinct, too, it conceals itself in some rocky crevice, in which its enemies are not likely to find it. Its flesh then loses its consistency, its muscles become flabby and powerless, and its body is reduced to the condition known as "watery".

After a short time the shell splits, and is gradually thrown off, together with the coating of the horns and the eyes, and even the membrane which lines the stomach. The animal, although already clothed in a new suit of mail, is now extremely soft, and increases rapidly in size, until, after a few hours, it is very much larger than 
it was before throwing off its shell. The new shell then quickly hardens, and at the end of three days the lobster is able to go out into the world again. This change of shell takes place several times in the life of the animal.

The principal difficulty in this process appears to lie in the withdrawal of the great claws; for the great mass of muscle of

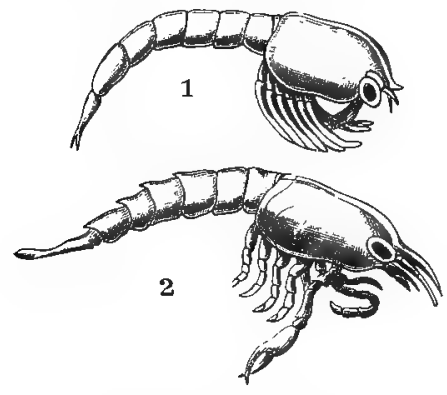

Young Lobsters

r, Just born. 2, After first month. which these chiefly consist has to be drawn through a very narrow opening. The sides of this opening, moreover, are very sharply edged, so that it would seem that the flesh must be greatly torn and wounded in the process. And so, indeed, it often is. But the animal appears to suffer no pain from its wounds, which rapidly heal, and by the time the new shell has hardened, it is quite able to use its powerful claws again.

The lobster, like many other crustaceans, possesses the singular power of reproducing a lost member. If one of its legs, for example, should be accidentally torn off, the wound rapidly closes, and before long a new limb is produced in place of the old. If a lobster be alarmed, it will often throw off its great claws of its own accord, and they are afterwards replaced by others. It is said that if a cannon is fired above the spot where a lobster is lying, the animal invariably casts off one or more of its members.

The lobster swims by doubling up its fan-like tail with a rapid movement under its body, by which action it is thrust backwards.

In this way a lobster can dart for eighteen or twenty feet at a single stroke, moving so rapidly that the eye can scarcely follow it. It is said, too, to be able to direct its course with perfect accuracy, even though travelling backwards, and at full speed to enter a crevice only just wide enough to allow its body to pass. Shrimps and prawns, which in many respects are very much like small lobsters, swim in exactly the same manner. 


\section{ECHINODERMATA}

This sub-kingdom of the Invertebrates comprises animals of peculiar interest, and often of wonderful beauty. They are also highly characterized by their almost universal assumption of the "star" form, which we shall at once recognize in such names as Stone-Lilies, Star-Fishes, Sea-Urchins, \&c. From this radiate character this great group used to be known, in association with jelly-fishes and sea-anemones, as the Radiata. But the creatures we have named, and their immediate relations, show something of an intestinal cavity and system, which the jelly-fishes and seaanemones do not have; and further, they are related to higher creatures by the possession of a vascular system (i.e. of bloodvessels). They are, therefore, separated from their old friends of the "Radiate" group, and are now known as the Echinodermata (i.e. "the hedgehog-skinned"); while the jelly-fishes, corals, seaanemones, and their allies are grouped into another sub-kingdom and are termed the Coelenterata.

\section{MOLLUSCA}

The Mollusca form a sub-kingdom in the animal world of no mean proportions. More than 50,000 living species are known, and the rocks are full of the fossil forms of species that once lived. As a rule they are small creatures, such as the mussel, oyster, periwinkle. But some, of a different style from these, such as cuttlefishes, reach to an enormous size.

They belong to the Invertebrates and are soft-bodied, as their name implies (Lat. mollis, soft). But they use lime in their life economy just as much as the Vertebrates do, only in a different way. Most of them build up limy external coverings, either in one piece, as in the garden snail or periwinkle; or in two pieces, as in the oyster and pecten; or in more than two pieces, as in the pholas and chitons. 
This great sub-kingdom of animal forms is divided into five classes as follows:-

I. Cephalopoda-Cuttle-Fishes, Squids, Nautilus, \&c.

II. Gasteropoda (the Univalves)-Snails, Whelks, Periwinkles, \&c.

III. Amphineura-Chitons, and certain of their relatives.

IV. SCAPHOPODA-The "tooth-shell" animals and their allies.

V. Pelecypoda (the Bivalves)-Mussels, Cockles, Oysters, \&c.

From our own knowledge we can see, by glancing at this classification, that the three important classes among the five are the Cephalopoda, the Gasteropoda, and the Pelecypoda. In comparison with these, the third and fourth classes are small in numbers, and unimportant.

Probably four-fifths of all the Mollusca are inhabitants of water. Many of them live in fresh water, but the greater number are found in the sea. They are also, however, widely distributed over the land surfaces of the world.

As may be supposed from the enormous number of species, the Mollusca are divided into a great number of orders, sub-orders, families, and genera, but we need not trouble ourselves about these, except to classify the few illustrative specimens which we shall consider.

\section{CEPHALOPODA}

The Cephalopoda are the most highly developed of the Mollusca. Except in very few instances they do not live in shells, as the larger number of the Mollusca do; they may therefore be styled a naked group. As a rule, however, they secrete a "shell" inside their bodies, which in many cases forms a support to them like the backbone among the Vertebrates. But it is a shell in all cases, and not a bone, although it is at times horny in its nature. It is generally of the material of which true shells are made, namely, carbonate of lime and animal matter, and in some of the 
cuttle-fishes it is chambered. In one species (the Spirula) the internal shell is a coiled tube of many chambers.

The family of the Nautilus (the Nautilidæ) is the only group of the Cephalopoda that lives in shells. These are also chambered

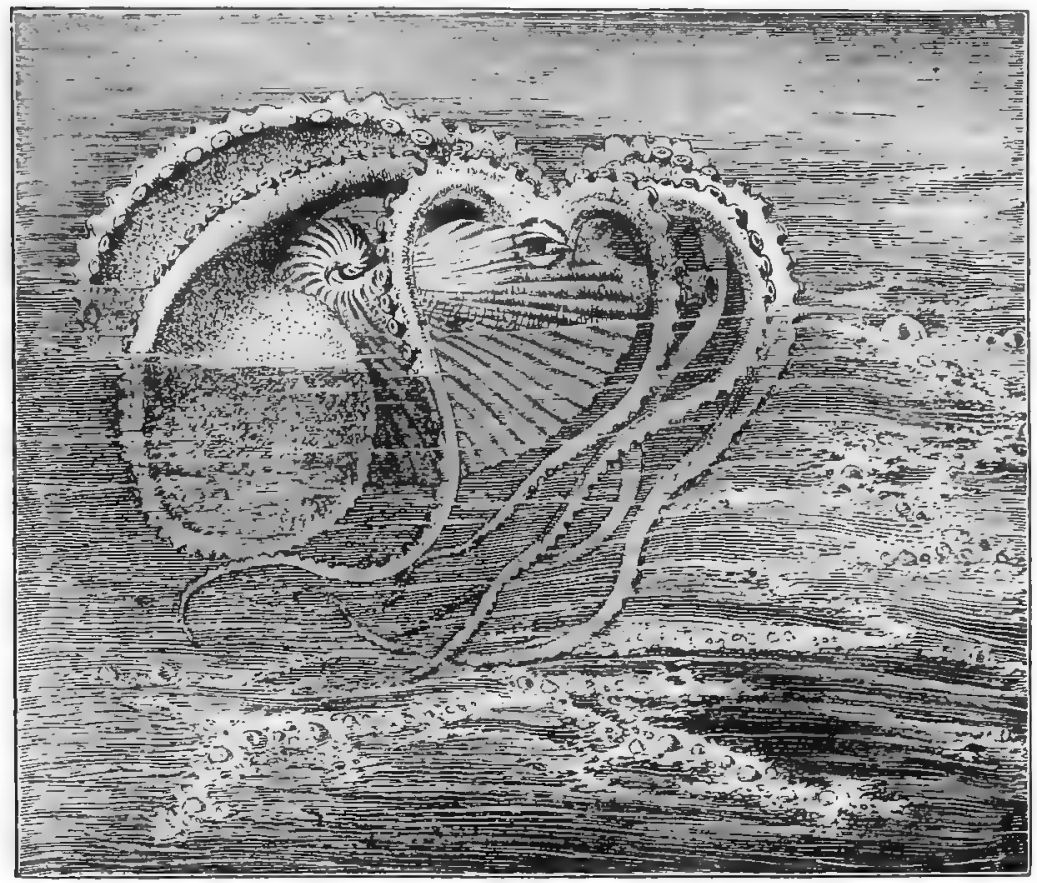

Nautilus

and exquisitely constructed, the animal occupying the mouth of the shell, which may be described as the open chamber, and that which was last formed.

Considerably over 400 species of living Cephalopoda are known.

\section{CUTTLE-FISHES (Family OCTOPODIDA)}

It may be enough for us here to know that the head-footed Molluscs are divided into two sub-orders-those with eight ten- 
tacles are called the Octopods, and those with ten tentacles the Decapods. When there are ten tentacles, two are usually much longer than the other eight, and are used for anchoring to stones or other objects.

If we have seen an Octopus, living or dead, we know what a Cuttle-fish is. It is, though unprotected externally, one of the most formidable creatures to be met with. It possesses two staring eyes, and its eight arms are always ready to coil around any object which it may desire to attack. As each arm is furnished with long arrays of cup-like discs that attach themselves to anything at the will of their owner, and as the animal itself is furnished with a hard parrot-like beak, it is more wonderfully endowed with terrible attacking forces than any monster of fable. And what is characteristic of the common Octopus is equally applicable to the group generally. The Sepia, the Loligo, the Argonaut, the Nautilus, all are armed in the same way. Let us consider the Octopus further as an illustration of the whole group.

The discs upon the long tentacles of the cuttle-fish are formed upon the principle of a "sucker". Each is a circular, fleshy cup, in the centre of which is a small piston formed of muscular substance, which can be withdrawn at the will of the animal. Thus, when several of these suckers are placed against a rock or a stone, and the muscular pistons withdrawn, a "vacuum", i.e. a chamber that is perfectly empty, is formed, and the discs adhere so strongly to their hold that the tentacle cannot be torn away.

The power of these suckers is extremely great. A few years ago a diver, when attempting to lift a submerged stone, was seized by two of the tentacles of a huge cuttle-fish which had been lurking beneath it. Thinking that he could easily disengage the suckers, he tried to tear the tentacles away, but found that it was quite impossible to do so. Had he not snatched up an iron bar which was fortunately lying close by, and probed its body into a shapeless mass, he would undoubtedly have fallen a victim to his strange antagonist.

"No fate", says a well-known writer, "could be more horrible than to be entwined in the embrace of those eight clammy, corpselike arms, and to feel their folds creeping and gliding around you, 


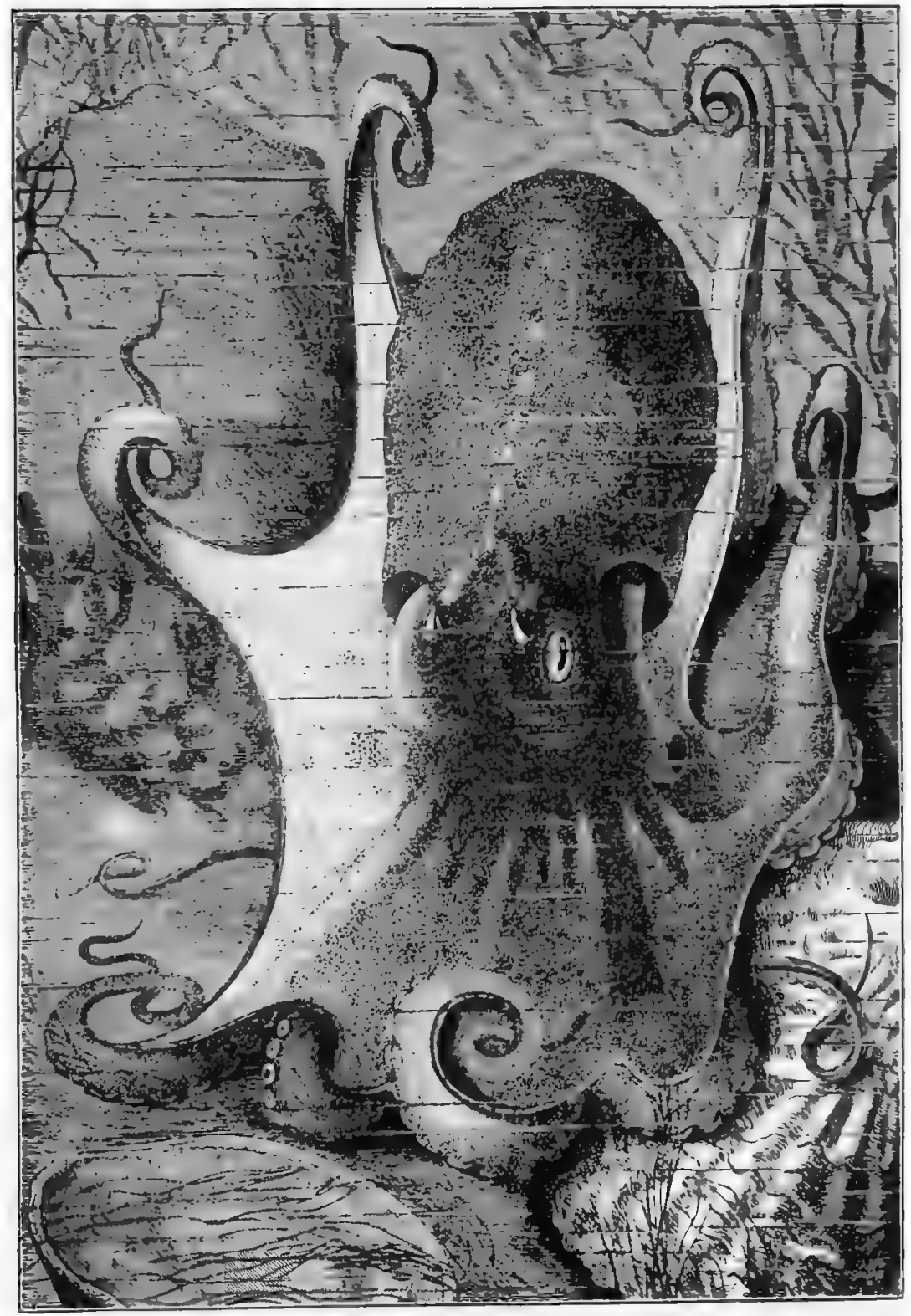


and the eight hundred discs, with their cold, adhesive touch, gluing themselves to you with a grasp which nothing could relax, and feeling like so many mouths devouring you at the same time."

These creatures frequently attain to a gigantic size. Occasionally specimens are cast ashore whose long tentacles, from tip to tip, measure more than thirty feet when fully spread; so, one may easily understand that a human being, if once seized in their terrible grip, would have no chance of escape.

The long arms, or tentacles, of a cuttle-fish, with their formidable array of suckers, are employed for purposes of locomotion as well as in capturing prey. For the animal walks upon its head by using its tentacles in place of feet.

But the cuttle-fish has another method of progression, which it adopts when alarmed or hurried. It breathes by means of gills, one of which lies upon either side. When the water has passed through these organs it is conducted out of the body by a short tube, which is directed towards the head, and is usually known as the "siphon".

Now the cuttle-fish is able both to regulate the passage of water through this siphon, and also to expel the liquid, if need be, with considerable force. When it wishes to swim, therefore, it gathers up its long arms, so that they may project straight from the body and offer no hindrance, and then sends out a jet of water sharply and suddenly. This jet, of course, acts upon the surrounding water just as the volume of gas which pours out from the mouth of a sky-rocket acts upon the surrounding atmosphere; and the animal is driven rapidly backwards by the recoil.

So swiftly can a cuttle-fish swim in this manner, that it is very difficult for the eye to follow its course. When alarmed, too, and anxious to escape from an enemy, the animal makes use of a most remarkable means of protection, which renders it for a time invisible.

Inside the body is a sac, or bag, which has the property of secreting a liquid of intense blackness. This liquid can be expelled through the siphon at the will of the animal. When a cuttle-fish is frightened, therefore, it swims rapidly backwards, and at the same time ejects its inky. liquid. The water through 
which it has passed is thus darkened, and the cuttle-fish is probably lost to sight.

It is from this inky fluid that the colour known as "sepia" is prepared. As soon as the cuttle-fish has been killed, the ink-bag is removed from its body, and the contents poured into a vessel and allowed to stand for a time. The liquid is afterwards poured off, and the sediment formed into cakes.

From some kinds of cuttle-fish, too, a very fine and pure chalk is procured, being found in the form of a "bone", as it is improperly termed, for it is the shell, which lies buried in the flesh. This so-called "bone" is easily detached, and may not uncommonly be found lying upon the sea-shore.

The beak of the cuttle-fish, which has already been mentioned, is hard, sharp, and strong, and shaped very much like that of a parrot. It consists also of two mandibles, like that of a bird. The tongue is closely set with a number of sharp, hook-like spines, all directed backwards.

Like lizards, star-fishes, and other creatures still lower in the scale, the cuttle-fish has the power of reproducing a severed member. The conger-eel is one of its most deadly foes, and likes nothing better than a tentacle torn from the body of a cuttle-fish. The injured animal, however, seems to suffer little from the mutilation, the wound rapidly heals, and in due course, it is said, the missing member is replaced by another.

The eggs of these singular animals are fastened to a seaplant in large clusters, and, being of a dark purple colour, bear a curious resemblance to a bunch of grapes. By fishermen and others, indeed, they are often called "sea-grapes".

\section{GASTEROPODA}

The stomach-footed Molluscs are well represented by the Snails and Whelks, the one being typical of the land group, the other of the aqueous group. 
As we should naturally suppose, the land group of Molluscs are almost without exception air-breathers, and are therefore formed into the order Pulmonata.

The marine group are almost entirely water-breathers, and so they form another order, the Pectinibranchiata, i.e. the "combgilled", because the plates of their gills are arranged like the teeth of a comb.

But many of the freshwater Molluscs are lung-breathers, like their friends on land; they have therefore to come to the surface of the water occasionally to renew the supply of oxygen. Some of the aqueous Mollusca have a lung and gills as well. Others have gills which grow on the outside of their bodies like small trees or shrubs; but we need not say more here on this head. Let us look at our friend the "snail".

\section{SNAILS (Family HELICIDE)}

Most of us think the Snail a very mischievous creature; and in our gardens no doubt it is. It eats our vegetables, flowers, and fruits, and does some harm; but in the woods and fields it is not mischievous, and there is no reason why we should destroy it.

It is a much more interesting creature than we might suppose; and there is a good deal for us to learn about it.

Let us suppose that we have a snail crawling upon the table in front of us. We shall see that the part of the animal outside the shell is long and shiny, and that it has a kind of head with four horns, two of which are much longer than the others.

The part of the body upon which it crawls is called the foot, because it makes progression by it. As it crawls along you will notice that it first stretches out the front part, and then draws up the rest after it; so that it really moves somewhat like a worm.

The two longer horns, or feelers, upon the head have each a little black speck at the tip. This speck is an eye, and the snail can push it out and withdraw it when it wishes, besides being able to draw the feelers themselves back into the head.

The snail cannot make its way upon a dry surface. As it 
crawls along it pours out its slime, and so obtains a moist footing. But in dry weather it goes to sleep inside its shell, and waits until there is a fall of rain or dew.

The skin or covering of the snail is called the mantle; and it is by this that the shell is made. As the snail grows, it adds more and more to the edge of the shell, so as to make it big enough for its body. If you look carefully at the shell, you will see that these little additions are marked by what are called "lines of growth".

The snail cannot bear cold, so it hides away in some snug hole as soon as winter begins. It closes up the mouth of its shell

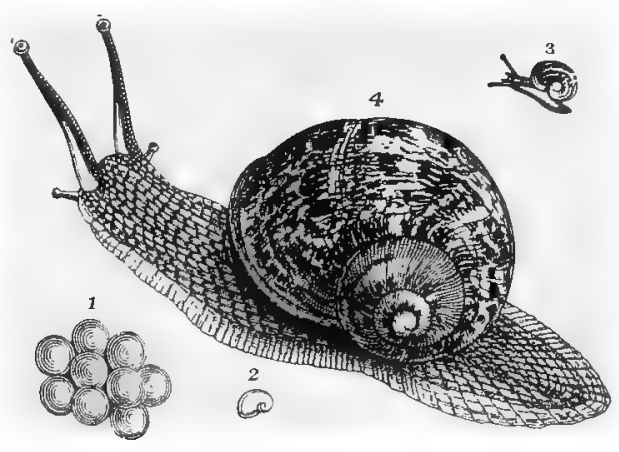

r, Eggs of Snail; 2, Shell taken from Egg; 3. Young Snail; 4, Full-grown Snail

by making two or even three horny doors, with just a tiny aperture in each to allow it to breathe.

In some parts of the world snails are used as food, and people even fatten them for the table. The Romans were fond of them; and in some of the old Roman camps we may still find a large species of snail which they introduced into this country.

\section{WHELKS (Family BUCCINIDÆ)}

Among the commonest shells that we find lying upon the seashore are those of the Whelks. We can scarcely help noticing them, for they lie about everywhere. Here, on the open sand, are two or three of larger size, with a pale yellow band running round them, like those that are sold for food in so many of our large towns. Behind this rock is another, quite white, but with a number of bold, wrinkled ridges winding spirally round it from top to bottom. And here, in this ridge of broken coal, small flints, and bits of (M868) 
chalk which the tide has washed together, are dozens and dozens more, very small, but very beautiful. Some are yellow, some gray, some pearly-white; some are slender, others are stoutly built; some are exquisitely carved and chiselled, others are almost smooth. Yet, different as they are, there is a strong family likeness between

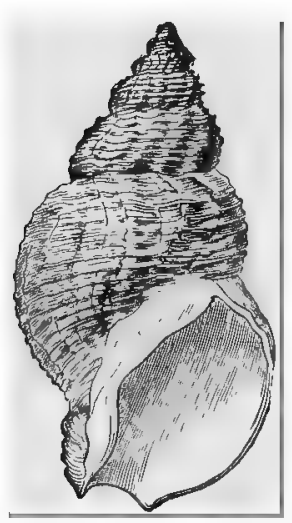

Whelk Shell them, so that it would hardly be possible to mistake the shell of a whelk for that of any other mollusc.

Wherever we find whelk-shells, we shall also find the empty eggs out of which they came. These are fastened together in large masses, each about as big as a cricket-ball; and we may see them lying in numbers upon the beach, or rolling along before the wind on a breezy day. They are yellowish in colour, and not unlike pieces of sponge.

If you look closely at one of these masses, you will see that each egg is about as large as a pea. When they were laid, however, each was only about the size of a small pin's head. But the membrane which encloses them, and corresponds with the shell of a bird's egg, has a very curious property. It allows water to soak inwards, but not to pass out again. As soon as the eggball is dropped into the sea, therefore, each egg begins to take in water and expand. Ere long each has greatly increased in size, and the ball, which was at first so small, has assumed the form in which we are accustomed to see it.

We have perhaps often noticed other kinds of shells that have a small round hole bored through them, about the size of that which would be drilled by a fine brad-awl. This hole is the work of a whelk, which first pierced the shell, and then devoured the animal inside it. It was done in this way:

The whelk's tongue is horny, and is set with very small but very sharp and strong teeth from one end to the other. It has several hundreds of these teeth in all, placed in three or four parallel rows. When we examine them by the help of a microscope we see that they are most beautiful objects, looking as if they 


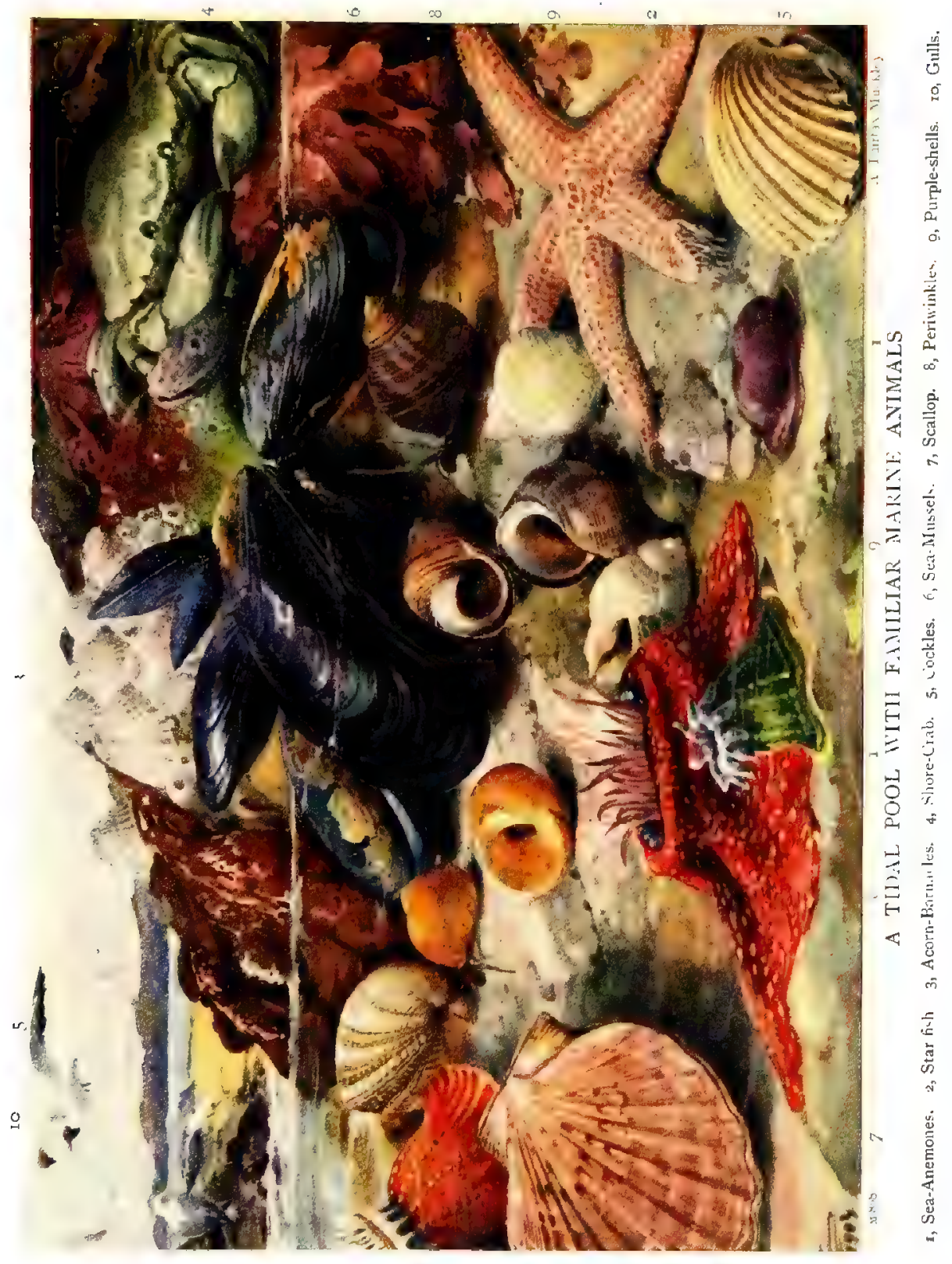



were made of mother-of-pearl. And they are so sharp that the whelk can bore through the shells of its victims with little difficulty.

But the hole having been made, the tongue now serves the purpose of extracting the body of the owner of the shell which has been pierced in this systematic, house-breaking sort of fashion.

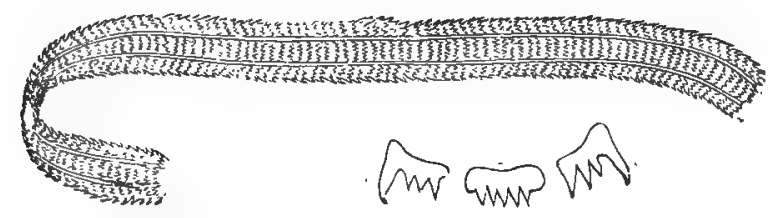

Tongue of Whelk; general view, and enlarged view of detached Teeth

Whelks are captured for the market in a very simple way. A large basket is partly filled with pieces of decaying fish, and then lowered by ropes to the bottom of the sea. The whelks soon detect the feast, and come flocking in numbers to the basket, which is then raised to the surface and its contents transferred to a tub. In this way great numbers of the molluscs are often taken in a short time.

\section{PELECYPODA}

This is the great group of bivalve creatures; that is, of animals whose shelly covering consists of two pieces. The Snails and Whelks are representatives of the much greater group of univalve creatures; that is, creatures whose shelly covering is of one piece.

These bivalves are all aqueous in habit. As we must know what an oyster and a mussel are like, let us consider one or more uncommon members of this great group.

\section{THE PIDDOCK OR PHOLAS (Family PHOLAdide)}

In one respect the Pholas is not a good representative of the bivalves, as its shell consists of one or more pieces, besides the typical two "valves". But it is a most interesting creature. 
Where our sea-coast cliffs are composed of limestone or chalk, we may have noticed that the rocks are perforated by a great number of tunnels, each of which is sufficiently large to admit a man's thumb. These are the burrows of the Piddock or Pholas, as we have called it.

Let us suppose that we have before us a piece of chalk which has been pierced by these creatures, and that we have carefully split it open with a mallet and chisel. There, lying in its tunnel,

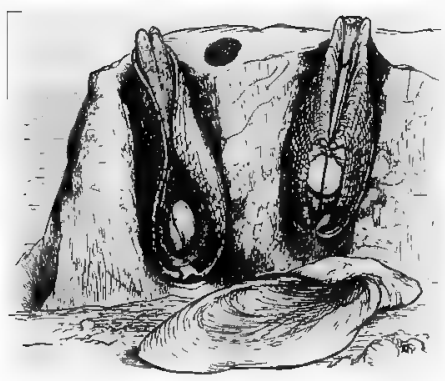

Piddocks is the piddock or pholas that made it - a mollusc with a double shell, hinged firmly together at the back. Its shell has a number of raised lines which cross and recross one another, causing its surface to resemble that of a rasp.

It is by means of this shell that the tunnels are made. When boring a hole in the chalk the pholas takes a firm hold with its "foot", or that part of the body which can be pushed out from between the shells and used in locomotion, and then begins to turn slowly from side to side. The sharp edges of the valves soon cut a hollow, which is quickly enlarged by the action of their rasp-like surfaces upon it. And before long the animal is buried in the rock.

The piddock has a siphon of the same character as that of the cuttle-fish, through which a jet of water can be expelled with no little force. So, when the burrow becomes clogged by the particles of stone or chalk, all that the animal has to do is to eject a jet of water. which washes out the tunnel, and removes the obstruction.

Upon some parts of our coasts the work of the pholas has been extraordinary.

That the piddock or pholas has helped the sea very materially to undermine and destroy the cliffs upon its margin is unquestionable. For it drives its tunnels through and through the rock, until it reduces them almost to the condition of a honey-comb. Then 
the sea beats into them, washes the dividing walls away, and the face of the whole cliff comes down. Sea and mollusc together succeed in accomplishing what the sea could but slowly perform alone; and peninsulas are slowly changed into islands by the combined action of the two.

Geologists tell us, indeed, that our own country was formerly a part of the continent of Europe, and that it would possibly still be joined to that continent if it had not been for the incessant labours of the piddock. This shell-bearing mollusc has at least helped to convert England into an island, and so to shape the course of modern European history.

\section{THE SHIP-WORM OR TEREDO (Family TEREDINIDE)}

The Teredo or "Ship-worm" is to wood and wooden constructions what the pholas is to limestone and other rocks. Indeed the ship-worm and the pholas are so nearly allied that the former may be described as only a long-drawn-out species of the latter. The ship-worm also possesses its bivalve shell, but reduced to what we might call a head-covering.

A very odd thing about the ship-worm is, that it changes its form as it increases in size. When first hatched out of the egg it does not look like a worm, but reminds one of a very small hedgehog; for its body is almost spherical, and is covered all over with projecting hairs, or spines. At this stage of its life it swims freely through the water. When it is about a day and a half old its skin splits open, and hardens into a kind of shell. Even this shell changes its form, however, for first it is oval in shape, then it becomes triangular, and then again it alters until it is nearly spherical once more. The animal has a projecting "foot", too, by means of which it can move about, after the manner of the snail. Before long, however, it ceases its travels, and fastens itself to some fixed object or floating log, after which it rapidly develops the worm-like shape, and quickly becomes a perfect ship-worm.

As has been suggested, this curious creature does not bore into 
limestone or chalk, like the piddock, but tunnels into solid timber, such as the submerged portions of wooden piers and the hulls of wooden ships. And in this way it is often the cause of very considerable mischief.

In one year only, at Plymouth, it caused damage to the extent of no less than eight thousand pounds; and many a good vessel

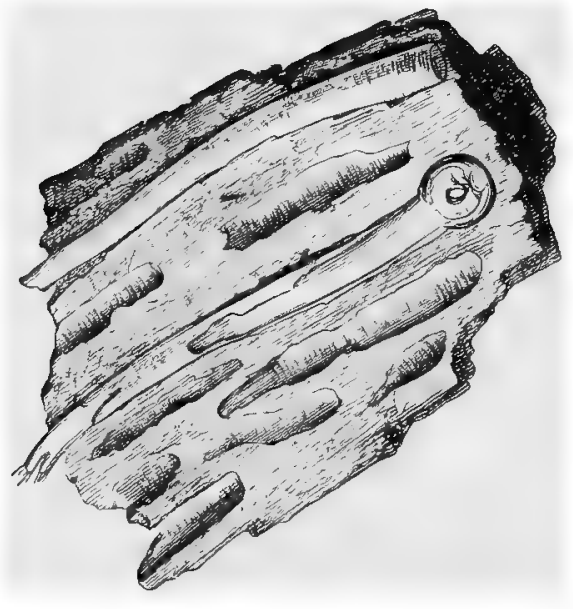

Teredo or Ship-worm, and Fragment of Wood bored by others has been rendered useless by its depre. dations. The ruin of the important dykes of Holland has often been threatened by its operations.

The ship-worm does not eat the wood which it cuts away, but obtains its entire nourishment from the sea-water which is continually passing through its system. It never seems to cease burrowing, and destroys the timber in which it lives so completely, that very often, in a large block of wood, there is scarcely a cubic inch of solid substance. The walls between the burrows are frequently no thicker than paper.

As the animal drives its tunnel along, it lines it with a thin coat of a shelly substance, just as engincers, when they are making a railway tunnel, line it with a coating of brick. And it is interesting to learn that Sir Isambard Brunel, to whose skill and ingenuity we owe the famous Thames Tunnel, first conceived this method of construction while examining the labours of the shipworm.

It is found that wood is protected from the ravages of the teredo by covering its surface with rows of broad-headed iron 
nails. These quickly rust, and the rust spreads to the adjoining wood, rendering it so distasteful to the molluscs that they will not attack it.

\section{VERMES}

Between the sub-kingdom of the Echinodermata and the alreadymentioned Coelenterata (the jelly-fish, corals, sea-anemones, \&c.) comes the sub-kingdom Vermes, which sufficiently explains itself as comprising the "worm-like" animals. Among the members of the group are the Annelids or true worms; the Leeches, the Rotifers, the Thread-worms, the Flat-worms, \&c.

As the common Earthworm is so often under our eyes, let us take him as a type of the Vermes.

\section{ANNELIDA \\ THE EARTHWORM (Family LUMBRICID E)}

Few creatures are more despised and misunderstood than the Earthworm; and yet few creatures are more valuable. It is one of Nature's great workers; and though, like so many of its fellowlabourers, it is small and insignificant, its vast numbers compensate for its want of size, and enable it to perform a task of the very highest utility, namely, the preparation of soils for the better growth of plants.

An earthworm has no distinct and separate head. But if we examine it we shall notice that one end of its body is much more pointed than the other, and that as it moves along it always travels with this pointed end first. We shall see, too, that it is continually feeling about with this pointed end.

This is the head, and to its conical shape the earthworm chiefly owes its power of forcing its way through the earth. Beneath the head is the mouth. 
If we examine it with a powerful magnifying glass we see that on each of the rings or "segments" of which its body is made up there are eight short, stiff bristles, four being placed in a row upon

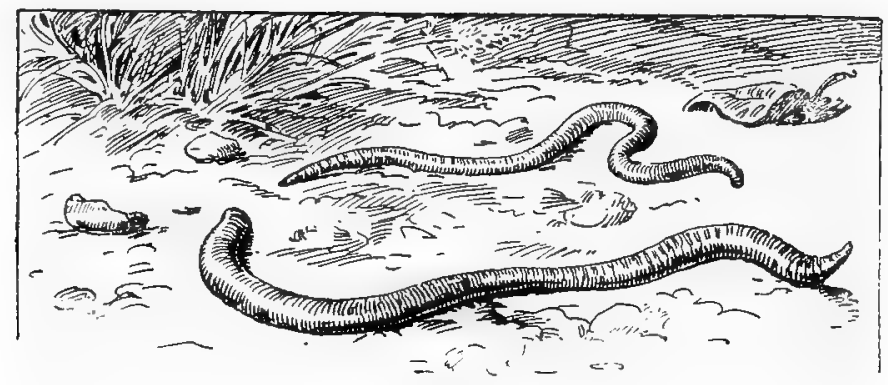

Earthworms

the lower surface, and two at either side, all having their points directed backwards. These bristles are sufficiently long and stiff to be felt by the fingers if we pass it between them from the head towards the tail.

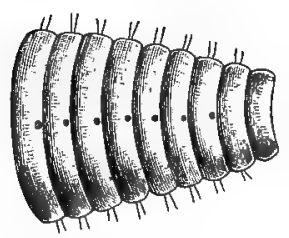

Section of Body of Earthworm, showing Bristles

It is by means of these bristles that the earthworm travels, for it can use them just as a snake uses the broad, sharp-edged scales upon the lower surface of its body, for the purpose of propelling itself along.

Earthworms are not very fond of travelling, however, and seldom leave their burrows altogether. If we go out with a lantern on a dark night we shall see numbers of them lying quietly upon the ground, or moving their pointed heads to and fro in search of leaves. If we touch them, however, or if they even feel the vibration caused by our footsteps, they will vanish as if by magic. Each had the end of its tail in its burrow, so that it could draw itself quickly back at the first intimation of danger.

In passing through the soil, carthworms are greatly assisted by the slime which is continually issuing from minute pores in the skin, and keeps the entire body constantly moist. This slime prevents the earth from adhering to them as they force their way 
through it. In dry weather they always burrow deeply beneath the surface in order to secure a constant supply of moisture. If they are placed in the sun, or on dusty ground, they very quickly die.

At night we may see the worms seize dead leaves and carry them partly underground. We must often have seen a number of these leaves partly projecting from their holes.

The worms feed upon the leaves which they thus secure. It is not easy to see the mouth of a worm, for it is completely covered by the lip when not actually in use. But it is quite large enough to nibble away at the edges of a leaf; and in this way the worm obtains a considerable proportion of its food.

But it also feeds in another and a perfectly different manner, and one that is very remarkable, for it swallows a quantity of earth, and, after digesting any particles of animal or vegetable matter which it contains, passes it out of its body again in the form of the "worm-casts" with which we must all be familiar.

This earth, when it issues from the body of the worm, has been transformed into a very powerful manure. So strong is it, indeed, that if a plant is placed in a flower-pot filled with nothing else, it will very quickly die. If a gardener uses it he always mixes it with a quantity of other earth. When spread over the surface of the ground, however, this natural manure is extremely useful, more especially in pasture land, which is seldom manured in the ordinary way. This is done by the wind and the rain. When the worm-casts are thrown up, the wind and rain quickly spread them over the ground, so that the vegetation is kept constantly nourished.

In fields wherein worms are numerous, nearly a fifth of an inch of rich manure is thus supplied and distributed over the whole surface in the course of a single year. And it is the more valuable for this reason, that the earth of which it is chiefly composed has been brought up by the worms from below.

Thus we see that the whole of the surface soil is continually passing through the bodies of worms, and continually being renewed. By earthworms, in fact, the soil is in a sense made, and by earthworms it is constantly kept in a condition which renders it suitable for agricultural purposes. 
There is another way, too, in which the earthworm is useful; for, by constantly tunnelling through the earth, it helps to bring air to the roots of the plants, and also promotes the drainage.

We may thus say that worms are useful in three ways, viz. by renewing the soil, by ventilating it, and by helping to drain it. So they are certainly the allies and assistants of the farmer.

\section{COELENTERATA}

As we have seen, the Cœlenterates are radiate in structure like the Echinoderms, but then they are of a distinctly lower organization. They might be described as the "all-stomach" animals. Many of these creatures are exceedingly beautiful in structure, and in colouring are often magnificent. Some of them, namely, the Corals, produce hard structures of most exquisite designs and texture. Those, however, of which we shall speak, viz. the Jellyfishes and the Sea-anemones, deposit no such structure whatever.

\section{JELLY-FISH}

We may have seen upon the sea-shore, when the tide is going down, a number of what seem to be lumps of white or yellow jelly lying motionless upon the sand. Or, as the tide comes in or goes out of some estuary, we may have seen great quantities of the same curious objects floating past, sometimes in such immense numbers that they almost seem to form a solid mass. These are Jelly-fish, and very remarkable creatures they are.

For their bodies are made up of hardly anything else but seawater. Yet they are beautiful and often exquisitely coloured, and when the animal is floating in the water with its disc expanded, its delicate tentacles hang down below, and give it the appearance of a wonderful fairy-like mushroom.

Round the edge of the disc are a number of much more slender threads, which also hang down in the water, and are often so 
delicate that it is almost impossible to see them. These are the fishing-lines with which the jelly-fish captures its prey; for it feeds on living victims, although it looks so harmless, and sometimes destroys them in considerable numbers. Yet the threads are so

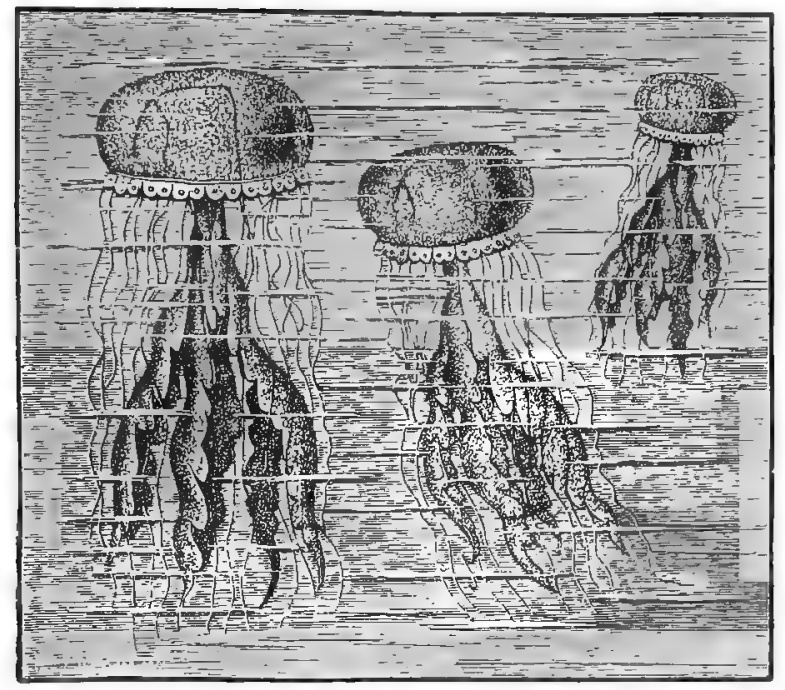

Jelly-fish

very slight that one wonders how they can ever hold their prisoners; much more how they can kill them.

But the mystery is easily explained. Each fishing-line, although it is so delicate, has some hundreds of minute oval cells running all along its length; and in each cell lies a slender, sharply-pointed dart tightly coiled up. As soon as a small animal comes into contact with the line, however, the cells open and the darts fly out, and in an instant their needle-like points have entered the flesh of the victim. In its struggles to escape it brushes against other fishing-lines, which fasten on to it in the same way; and, as the darts are all poisoned, the captive very soon dies.

Very few jelly-fish are able to injure a human being. But one, which is often found off our coasts towards the end of summer, 
is sufficiently poisonous even to kill a man, if three or four of its threads should come into contact with his body. It is about as large as a soup-plate, and of a tawny yellow colour; and the fishing-lines, which are very numerous, are often several feet in length.

Those who have been stung by this formidable animal, and have lived to tell the tale, say that the pain at first is merely like that caused by the sting of the nettle, but that it rapidly increases until it becomes almost unbearable, while both the heart and lungs are seriously affected. Indeed it is possible that many of those who are drowned while bathing, and are supposed to have been overcome by cramp, in reality fall victims to this terrible jelly-fish.

\section{SEA-ANEMONES}

In the pools among the rocks of the sea-shore one often notices a number of curious flower-like objects fastened to the rocks.

They look very much like asters. But they are soft and clammy, and when touched they fold themselves up. All their bright colours disappear, and the beautiful flowers of a moment ago have become shapeless lumps of dark-coloured jelly.

They are Sea-anemones, and the touch has frightened them. But they will soon unfold again. The "petals" will appear once more, and the bright colours begin to show. The anemones, perhaps, are hungry, and will quickly recover their fright.

What an exquisite creature an anemone is! it is for all the world like a living flower growing out of the rock.

But it is not growing out of the rock. It has only attached itself by the lower part of its body, which it uses as a sort of "sucker".

The radiating filaments which look so much like the petals of a flower are the tentacles or arms with which the anemone catches its prey. When they are expanded the animal has spread its net for victims. These tentacles are formed very much like the fishing lines of the jelly-fish, being armed with numbers of minute darts, which are coiled away in little cells when not in use. They are 
very strong, in spite of their small size; and one of these anemones would easily catch and hold a prawn or a shrimp, or even a small fish.

The mouth of the anemone is in the midst of the tentacles; and when a victim is caught they slowly turn inwards and hand it down into the mouth, whence it passes straight into the stomach.

An anemone is in fact a highly-endowed and highly-decorated stomach. It possesses the power of locomotion by means of its "sucker" foot; but as to animal parts and animal functions, these all seem to be merged in the stomach, its one important organ.

\section{PORIFERA}

\section{THE SPONGES}

After the sub-kingdom of the jelly-fish, the corals, and the seaanemones comes a yet lower sub-kingdom of the invertebratesthe Porifera (the animals of "pores" or holes), viz. the Sponges. Of these some 2000 are known, about 300 of which occur in the British seas. Some are very beautiful and highly coloured. Their skeletons-such as we know as "sponges"-are often formed of threads of flint, and look like glass; and some are of most wonderful form and construction. 


\section{PROTOZOA}

This is a kingdom of very small creatures, which have in fact only been revealed to us by the microscope, for they are all so minute that they cannot be studied by the naked eye. Yet they are as wonderful and as perfect as other living beings, and as well adapted for the functions which they are destined to perform as the Leviathan of the deep. 
Accipitres, 237.

Adder, 300.

$\mathrm{Ai}, 177$.

Alaudid $2,205$.

Alcedinida, $23^{\circ}$.

Alligator, 280.

Amphibians, 301.

Anaconda, 293.

Annelida, 407.

Anseres, 252.

Ant, 337 .

Ant-eater, 179.

Antelope, ro6.

Aphidida, 375.

Aphis, 375.

Apidze, 345.

Aquilinæ, 239.

Arachuida, 378.

Aranex, $38 \mathrm{r}$.

Ardeidx, 245.

Argiopida, 38I.

Argonaut, 396.

Argyronetidæ, 387 .

Armadillo, 178 .

Ass, 129.

Attidæ, 386 .

Aye-Aye, 29.

Baboon, 22.

Badger, 87.

Bat, 3 I.

Batrachians, 30r.

Bear, 77.

- Brown, 80.

- Polar, 78 .

- Sloth, 83.

Beaver, I60.

Bee, 345 .

Beetle, 362.

- Water, 362.

Birds, 188.

- Humming, 225.

- of Paradise, I98.

Bison, ror.

Boa-constrictor, 293.

Boar, I45.

Boidæe, 293.

Buccinidæ, 4or.

Buffalo, ror.

Bufonida, 304.

Butterfy, Peacock, 357 .

Caddis Fly, 370.

Camel, roo.

Caprimulgide, 228.

Carnivores, 44 .

Cat, 45 .

Caterpillar, Looper, 359.

Candata, 307.

Caymen, 280 .

Centipede, 377.

Cephalopoda, 394 .
Cetacea, 150.

Chacma, 26.

Chameleons, 29 r.

Chamois, 106.

Cheetah, 58.

Chelonia, 280 .

Chelonid $x, 282$.

Chimpanzee, 12.

Ciconidx, 247.

Clupeida, 326 .

Cobra, 296 .

- di Capello, 296

Cnccinellidx, 368 .

Cod, 316.

Coelenterata, 4 ro.

Coleoptera, $36 x$.

Collie Dog, 69 .

Colubridze, 296.

Columba, 254.

Columbidæ, 254 .

Conger Eel, 322 .

Coot, 263 .

Coronella, 299.

Cougar. (See Puma)

Corvidæ, 195 .

Crab, 389 .

- Hermit, ${ }^{8} 8$.

- King, $3^{89}$.

Crocodile, 277.

Crocodilia, 277 .

Crocodilid:e, 277.

Crow, 195.

- Carrion, 198.

Crustacea, $3^{80}$.

Ctenizidæ, $3^{8} 4$.

Cuckoo, 223 -

Cuculida, 223 .

Culicidae, 352 .

Cuttle-fish, 395 .

Daddy-long-legs, 355 .

Deer, Ir3.

Diptera, 35I.

Dog, 67 .

- Collie, 68.

Donkey. (See Ass.)

Dragon-fly, 372 .

Dromedary, I23.

Duck, 252.

Duck-bill, I86.

Dyticidz, 362 .

Eagle, 239.

Earthworms, 407.

Earwig, 374 .

Ecaudata, 303 .

Echinodermata, 393.

Edentates, 174 .

Eel, 319.

- Conger, 322.

- Electric, 324.

Elasmobranchii, 330.
Elateridx, 365.

Elephant, 133 .

Esocidæ, 324.

Falconidx, 238 ,

Finches, 202.

Fish, 310.

- Cuttle, 395.

- Flat, 318.

- Flying, 314

- Jelly, 4 Io.

- Star, 393.

- Sword, $3^{\text {I3 }}$.

Flamingo, 249 .

Flesh Eaters, 44.

Flounder. (See Fish, Flat)

Fly, Caddis, 370 .

- Dragon, 372.

- Ichueumon, 342.

Forficulidæ, 374 .

Formicidx, 337 .

Fox, 75 .

Fringillid $æ, 202$.

Frog, 303.

Fulicariæ, 263 .

Gadid $x, 326$.

Gallinæe, 256 .

Gasteropoda, 399.

Gaviæ, 256.

Gavial, 280.

Geometridz, 359.

Gibbon, I6.

Giraffe, 110.

Glowworm, 366 .

Gnat, 352.

Goat, 104.

Gorilla, 9.

Grass Snake. (See Ringed Snake.)

Gull, 266.

Haje, 297.

Hare, 170 .

Harvest Mouse, 166 .

Hawk, Kestrel, 238.

Hedgehog, 35.

Helicidæe, 400.

Herodiones, 244 .

Heron, 245 .

Herring, 326 .

Hippopotamus, 147 .

Hirundinid 2 , 218.

Hoofed Animals, 98.

Hoolock, 17 .

Horse, 125 .

Howler Mnnkey, 20.

Humming-bird, 225 .

Hyæna, 64 .

- Spotted or Laughing, 67.

Hymenoptera, 336 .

Ibex, so6.

Ichneumon Fly, 342 . 
Ichneumonidre, 342 .

Iguana, 287.

Jguanidæ, 287 .

Impenues, 269 .

Insect-eaters, 35 .

Insects, 334 .

Invertebrates, 333 .

Jackal, 73 .

Jaguar, 60.

Jelly-fish, $4 \pm 0$.

Kangaroo, $18 \mathrm{I}$.

Kestrel Hawk, 23o.

Kholah. (See Jackal.)

Kingfisher, 230.

Kudu, African, to6.

Lady-bird, $3^{68 .}$

Lammergeyer, 242 .

Lampyridze, $3^{66}$.

Larks, 205.

- Sky, 205.

Lemur, 27.

Leopard, 55 -

Lepidoptera, 356 .

Lion, 45.

Lizard, 286.

Lobster, $39 \mathrm{I}$

Loligo, 396.

Looper Caterpillar, 359.

Lumbricida, 407 .

Mammals, 7 .

Marsupials, I8r.

Millipede, 377 .

Mole, 37 .

- Water, 187.

Mollusca, 393.

Monotremes, 186.

Mouse, Harvest, 166.

Myriopoda. 377 .

Nautilus, 395 -

Nephropsidze, 39 r.

Nestoridz, 233.

Neuroptera, 370.

Newt, 307.

Nightingale, 213.

Nightjar, 228.

Octopodida, 395.

Octopus. (See Cuttle-fish.)

Odonata, 372 .

Odontoglossx, 249.

Ophidia, 293.

Opnssum, 184

- Yapock, 86

Orang-Utan, 14.

Ornithorhynchus, 186.

Orthoptera, 37 I.

Ostrich, 272.

Otter, 89.

Owl, Barn, 235.

Ox, 98 .

Panther. (See Leopard.)

Parida, 206.

Parrot, 233.
Partridge, 257.

Passeres, I95.

Peacock Butterfly, 357.

Pea-fowl, 259.

Pectinibranchiata, 400.

Pelecypoda, 403 .

Penguin, 26g.

Phasianida, $25^{8}$.

Pheasant, 258.

Pholadida, 403 .

Pholas. (See Piddock.)

Picarix, 220.

Picida, $22 \mathrm{I}$.

Piddock, 403 .

Pig, 145.

Pigeon, 254 .

Pike, 324.

Plaice. (See Fish, Flat)

Pleuronectida, $3^{1} 8$.

Polar Bear, 78.

Porcupine, 168.

Porifera, 4 ${ }^{\mathrm{I}} 3$.

Porpoise, 156.

Primates, 9 .

Protozoa, 414.

Pulmonata, 400.

Psittaci, 233.

Puma, 62.

Python, 293.

Rabbit, 173 .

Ranida, 303.

Rat, 165 .

Ratita, 272.

Raven, 198.

Redbreast, 212.

Reindeer, II5.

Reptiles, 276.

Rhinoceros, I4t.

Rhiptoglossa, $29 \mathbf{r}$.

Rhynchota, 375 .

Ringed Snake, 297.

Rodents, 758 .

Rook, 196 .

Salamander, 307.

Salmon, 327.

Salmonidaz, 327.

Sambresocida, 3I4.

Sea-anemones, 412.

Sea-urchin, 393 .

Seal, go.

Sepia, 396.

Shark, 330.

- Hammer-headed, 332.

- White, 332.

Sheep, 103.

Ship-worm, 405.

Shrew, 4I.

Sky-lark, 205.

Sloth, 175 .

Snail, 400 .

Snake, 293.

- Ringed or Grass, 297

Sole. (See Fish, Flat.)

Song Thrush. (See Thrush.)

Sparrow, 202.

Spider, $37^{8 .}$

- Crab, $3^{85}$.
Spider, Garden. $3^{8} \mathrm{x}$.

- Gossamer, $3^{8} 3$.

- Hunting or Zebra, 386.

- Sea, $3^{89}$.

- Trap-door, $3^{84}$.

- Water, 387 .

Spider Monkeys, Ig.

"Spitting Snake". (See Haje.)

Sponges, 4I3.

Squamata, 285 .

Squirrel, 158.

Star-fish, 393

Starling, 27o.

Stone-lily, 393.

Stork, 247

Striges, 235.

Sturnidze, 200 .

Swallow, 228 .

Sword-fish, 3I3.

Tadpole, $3 \circ 3$.

Tapir, $13^{8}$.

Teleostomi, 319 .

Teredinida, 405

Teredo. (See Ship-worm.)

I estudinida, $28 \mathrm{I}$.

Thrush, 2 Io.

Tiger, 52 .

Tipulidæ, 355 .

Titmice, 206.

Toad, 304 .

Tortoise, $28 \mathrm{r}$.

Trochilida, 225.

Troglodytidx, 2 I6.

Turdidæ, 2 Io.

Turtle, 282 .

Ungulates, 98 .

Vanessa, 357 .

Vermes, 407 .

Vertebrates, 7 .

Vespidx, 340.

Viper, 300 .

Viperida, 300 .

Vulture, 24I.

Vulturida, 24x.

Walrus, 96.

Wasp, 340 .

Water-beetle, 362 .

Weasel, 85 .

Whale, Greenland, 15 I.

- Sperm, 154

Whelk, 4 oI.

Wolf, 70 .

Woodpecker, 22 t.

Worm, Blind, 28 g.

- Earth, 407.

- Glow, $3^{66}$.

- Ship, 405.

- Wire, 365 .

Wren, 216.

Yak, ror.

Yapock Opossum, 186.

Zebra, I3I.

Ziphiidat, 3 I3. 



